UNITED STATES DEPARTMENT OF THE INTERIOR

GEOLOGICAL SURVEY

\title{
Analytical results from a geochemical survey of the U.S. Virgin Islands
}

by

R. T. Hopkins, R. E. Tucker, T. A. Roemer,

J. D. Sharkey, and H. V. Alminas

Open-File Report 86-86

This report supplants U.S. Geological Survey Open-File Report 0F-84-785. A part of the data from St. Thomas and St. John appeared in the earlier report. 


\section{CONTENTS}

Page

Introduction. .......................................... 1

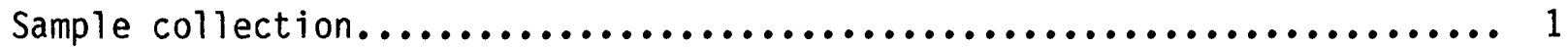

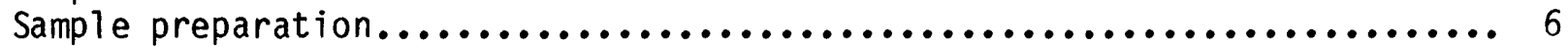

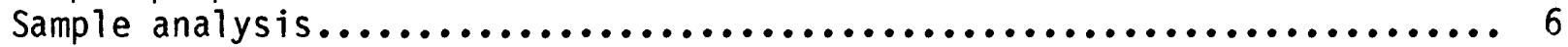

References cited.......................................... 10

Explanation of data tables................................... 10

\section{ILLUSTRATIONS}

Figure 1. Index map of the Virgin Islands and vicinity ............. 2

Figure 2. Sampling sites on $\mathrm{St}$. Thomas........................ 3

Figure 3. Sampling sites on St. John......................... 4

Figure 4. Sampling sites on St. Croix......................... 5

Figure 5. Sample preparation flow sheet for concentrates............. 7

\section{TABLES}

Table 1. Limits of determination for the spectrographic analys is of rocks, soils, and stream sediments, based on a 10 -mg sample........ 8

Table 2. Limits of determination for the spectrographic analysis of the nonmagnetic, magnetic, and hand-magnet fractions of panned concentrates and oxalic-acid leachates based on a 5 -mg sample.........

Table 3. Semiquantitative spectrographic analysis of outcrop samples

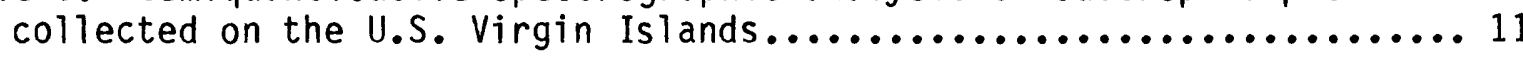

Table 4. Semiquantitative spectrographic analyses of soil samples collected on the U.S. Virgin Islands.

Table 5. Semiquantitative spectrographic analyses of stream-sediment samples collected on the U.S. Virgin Islands.

Table 6. Semiquantitative spectrographic analyses of the nonmagnetic fraction of heavy-mineral concentrates from the U.S. Virgin Islands...109

Table 7. Semiquantitative spectrographic analyses of the magnetic fraction of heavy-mineral concentrates from the U.S. Virgin Islands...142

Table 8. Semiquantitative spectrographic analyses of the hand-magnet fraction of heavy-mineral concentrates from the U.S. Virgin Islands...175

Table 9. Semiquantitative spectrographic analyses of oxalic-acid leachates derived from the bromoform-light fraction from the U.S. Virgin Is lands... 


\section{INTRODUCTION}

The U.S. Geological Survey began multidisciplinary studies of the U.S. Virgin Islands in 1983. These studies are being conducted to assist the Government of the Islands by providing necessary information for future planning and resource appraisal. The initial phase of the geochemical study was designed to examine the regional geochemical characteristics of the Islands.

The U.S. Virgin Islands are located in the Greater Antilles island arc some 40 miles east of Puerto Rico (figure 1). The major islands include St. Thomas, St. John, and St. Croix. There are about 50 smaller islands in the study area, concentrated near St. Thomas and St. John.

St. Thomas is 12 miles long by approximately 3 miles wide and contains some 19,000 acres. St. John is 7 miles long, on the average is 3 miles wide, and contains some 12,000 acres. The topography of both is lands is mountainous. The highest elevation on St. Thomas is 1556 feet (Crown Mountain) and 1277 feet on St. John (Bordeaux Mountain). The islands have very irregular coastlines with many bays and offshore islets. St Croix, the largest of the U.S. Virgin Islands, is $22 \mathrm{mi}$ long and some $6 \mathrm{mi}$ wide and incorporates approximately 54,000 acres. St. Croix is characterized by regular coast lines and has two adjacent islands. The topography here is more subdued. The highest areas on St. Croix occurs in the northwest (Mt. Eagle at $1,165 \mathrm{ft}$ ) and on the eastern end of the island. Streams on all these islands are intermittant and discharge into the sea.

The climate in the Virgin Islands is maritime tropical. The average annual rainfall at higher elevations is 50-60 in. and at lower elevations 20-30 in. There is no well-defined wet or dry season. The temperature is generally constant between 80 and $85^{\circ} \mathrm{F}$.

The vegetation is generally not native to the islands and consists of thorny brush and Hurricane grass in the formerly cleared areas. The uncleared portions of the more mountainous areas are covered by dense tropical forest with a few large trees and a dense undergrowth of brush and vines.

\section{Sample collection}

Rock, soil, and stream-sediment samples were collected during three field seasons. St. Thomas and St. John were sampled during June and November 1983, respectively. St. Croix was sampled in November/December of 1984 .

Stream-sediment samples were collected from third-order streams. If additional sampling detail was required, B-horizon soil samples were collected in the intervening areas. At stream-sediment and soil sites, a 10-15 $1 \mathrm{~b}$ composite sample was collected for panning and a 1-1b sample for sieving. In many instances, especially on St. Croix, a stream-sediment and an adjacent soil sample were collected. Outcrops were sampled whenever available near a stream-sediment or soil sample site as a composited 1-lb chip sample. Sample sites for St. Thomas, St. John, and St. Croix are shown on figures 2, 3, and 4 , respectively. 


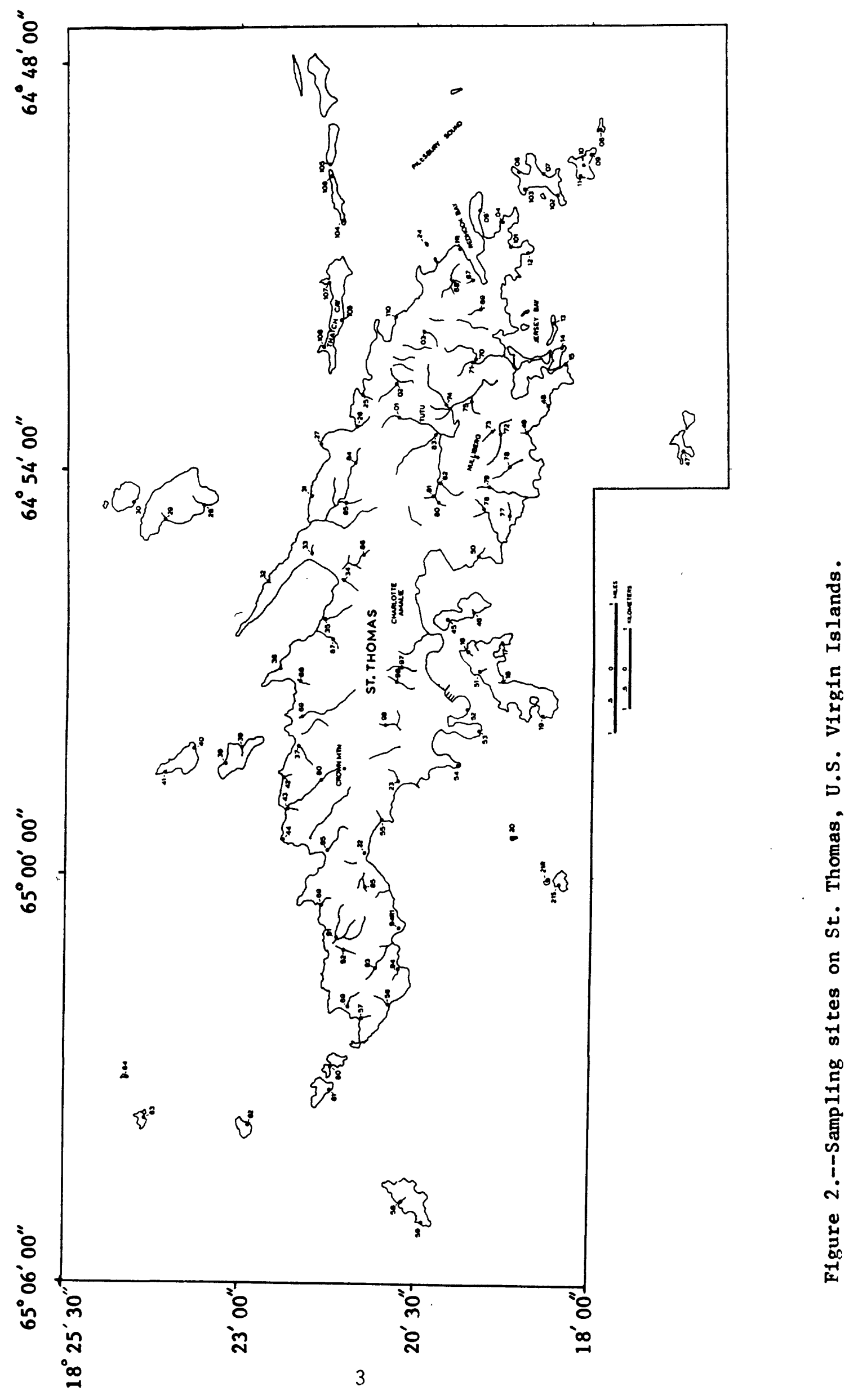




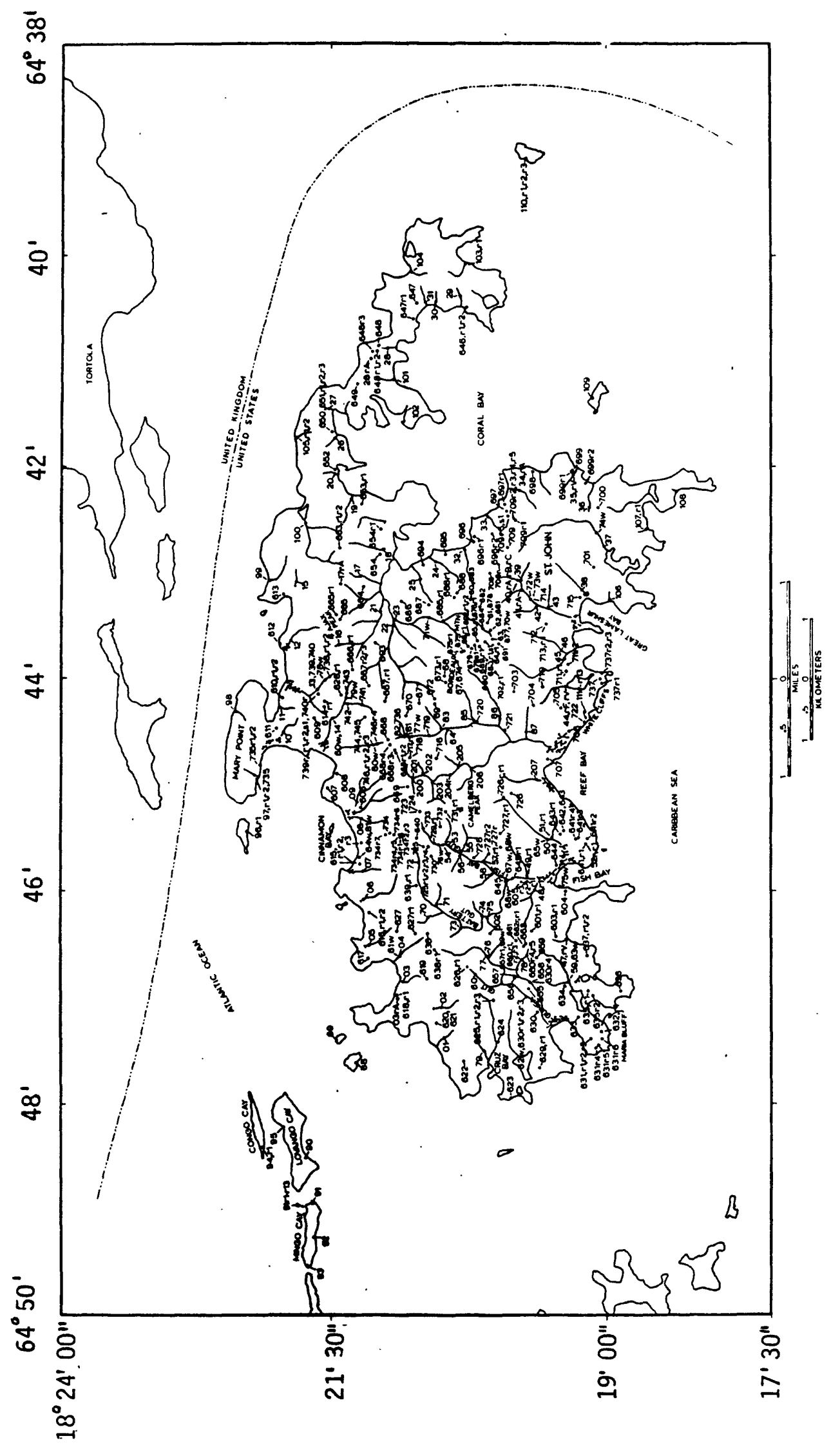

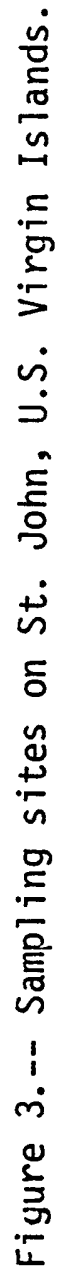




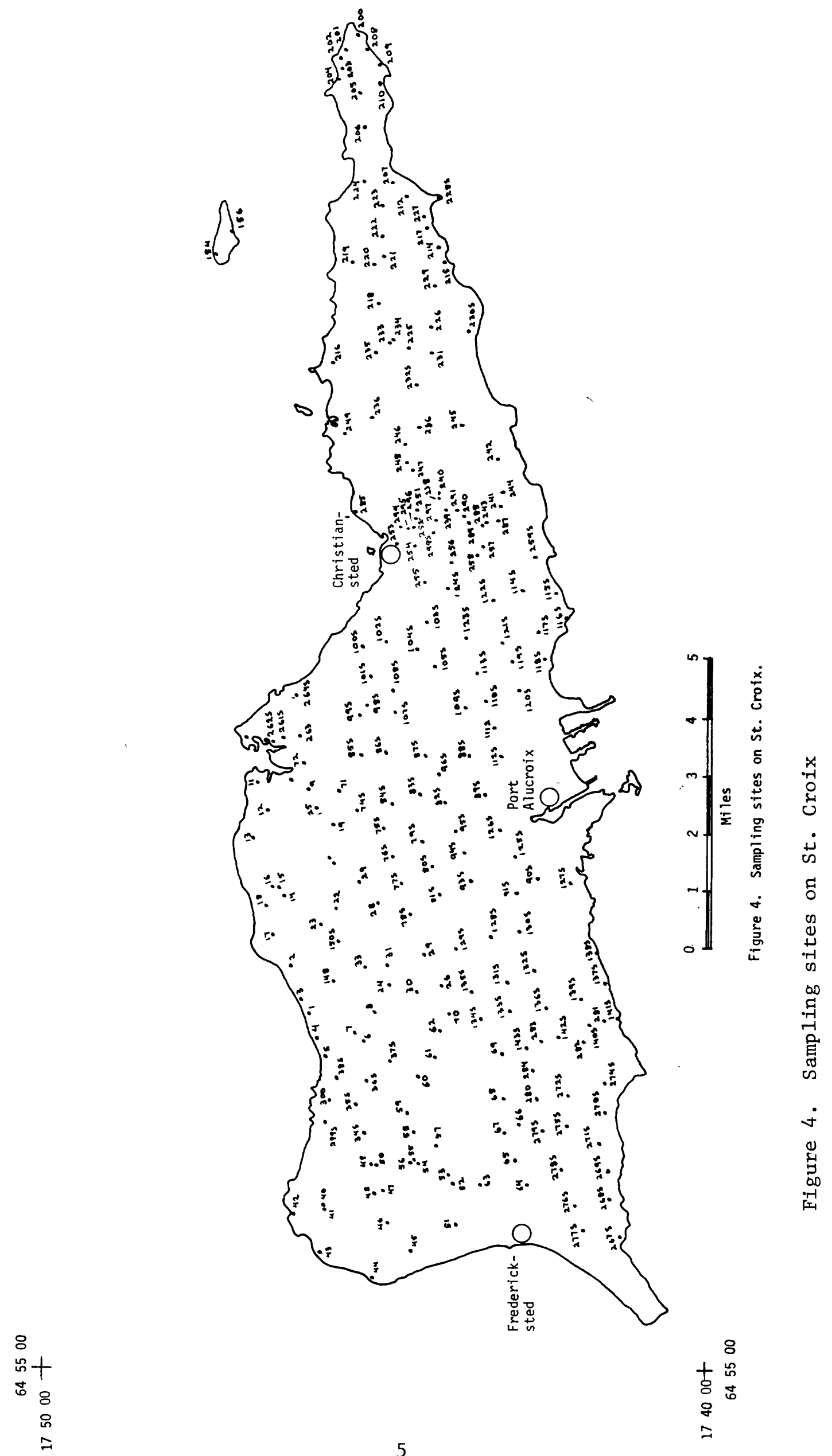




\section{Sample preparation}

Al1 samples were oven dried at $250^{\circ} \mathrm{F}$ for six hours as per U.S. Department of Agriculture regulations. The 1-1b soil samples were disaggregated, sieved, and the $<80$ mesh fraction analyzed. The stream sediments were sieved and the $<80$-mesh fraction analyzed. The rocks were crushed, pulverized using ceramic plates, and the resultant material was analyzed.

A sample preparation flow sheet for panned concentrates collected on St. Thomas and St. John is shown in figure 5. The St. Croix panned concentrates were treated in an identical way with the exception that the magnetic

separation was done with an S. G. Frantz Co. ${ }^{*}$ LB-1 model separator. A split equivalent to the 1.0 ampere $L-1$ model fraction was obtained using a .35 amp setting with a $15^{\circ}$ forward and $20^{\circ}$ side slope.

The oxalic-acid leachates were prepared by bringing $5 \mathrm{gm}$ of the bromoform-light fraction to a boil in $20 \mathrm{ml}$. of $5 \%$ oxalic acid. The solution was filtered hot through a No. 41 Whatman filter and the filtrate brought to dryness on a hot plate. The resultant material was then heated for 4.5 hours at $450^{\circ} \mathrm{C}$ in a muffle furnace to convert the oxalates to oxides. The oxides were homogenized with a mortar and pestle prior to analysis (Alminas and Mosier, 1975).

\section{Sample analysis}

A11 sample types were analyzed by the six-step D.C.-arc semiquantitative emission spectrographic method (Grimes and Marranzino, 1968) for 31

elements. All of the analytical values are reported as six steps per order of magnitude $(1,1.5,2,3,5,7$ or multiples of 10$)$. These values approximate the geometric midpoints of successive concentration ranges (Grimes and Marranzino, 1968).

This analytical method utilizes a series of elemental standards against which the elemental concentrations in the samples are compared. If a sample contains elemental concentrations above the highest standard used (table 1), the elemental concentration is represented by a "greater than" symbols ( $>$ ) before the upper standard. If a sample contains elemental concentrations below the lowest standard, two code designations can be assigned for the elemental concentration. If the sample concentration is slightly below the lowest standard, the elemental concentration is represented by a "less than" symbol (<) before the lower standard. If the sample concentration is not detected, the elemental concentration is given and " $N$ " code. The six-step D.C.-arc emission spectrographic method provides reproducibility within one geometric interval of the reported value approximately 86 percent of the time and within two geometric intervals of the reported value approximately 96 percent of the time (Motooka and Grimes, 1976). The limits of determination for the spectrographic analysis of rocks and sieved soil and stream-sediment samples are given in table 1. Limits for the concentrate fractions and the oxalic-acid leachates are given in table 2 .

* Any use of trade names is for descriptive purposes only and does not imply endorsement by the U.S. Geological Survey. 


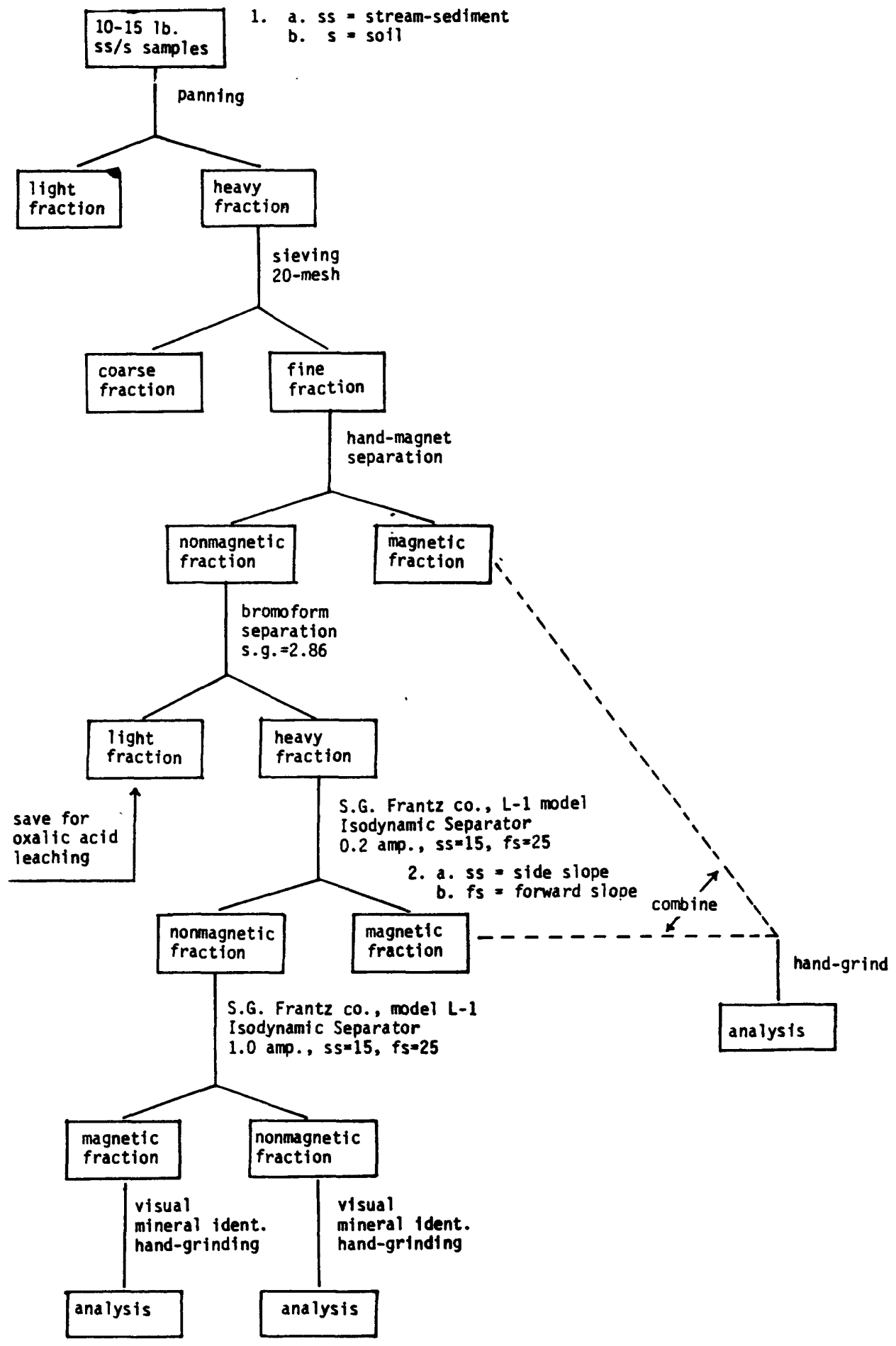

Figure 5.--Sample preparation flow sheet for concentrates. 
TABLE 1.--Limits of determination for the spectrographic analysis of rocks and stream sediments, based on a 10 -mg sample
Elements
Lower determination limit
Upper determination 1 imit

Percent

\begin{tabular}{lcc}
\hline Iron (Fe) & 0.05 & 20 \\
Magnesium (Mg) & .02 & 10 \\
Calcium (Ca) & .05 & 20 \\
Titanium ( $\mathrm{Ti})$ & .002 & 1 \\
\hline
\end{tabular}

Parts per million

\begin{tabular}{lrr}
\hline & 10 & 5,000 \\
Manganese (Mn) & 0.5 & 5,000 \\
Silver (Ag) & 200 & 10,000 \\
Arsenic (As) & 10 & 500 \\
Gold (Au) & 10 & 2,000 \\
Boron (B) & 20 & 5,000 \\
Barium (Ba) & 1 & 1,000 \\
Beryllium (Be) & 10 & 1,000 \\
Bismuth (Bi) & 20 & 500 \\
Cadmium (Cd) & 5 & 2,000 \\
Cobalt (Co) & 10 & 5,000 \\
Chromium (Cr) & 5 & 20,000 \\
Copper (Cu) & 20 & 1,000 \\
Lanthanum (La) & 5 & 2,000 \\
Molybdenum (Mo) & 20 & 2,000 \\
Niobium (Nb) & 5 & 5,000 \\
Nickel (Ni) & 10 & 20,000 \\
Lead (Pb) & 100 & 10,000 \\
Antimony (Sb) & 5 & 100 \\
Scandium (Sc) & 10 & 1,000 \\
Tin (Sn) & 100 & 5,000 \\
Strontium (Sr) & 10 & 10,000 \\
Vanadium (V) & 50 & 10,000 \\
Tungsten (W) & 10 & 2,000 \\
Yttrium (Y) & 200 & 10,000 \\
Zinc (Zn) & 10 & 1,000 \\
Zirconium ( $r r) ~$ & 100 & 2,000 \\
Thorium (Th) & & \\
\hline
\end{tabular}


TABLE 2.--Limits of determination for the spectrographic analysis of the nonmagnetic, magnetic, and hand-magnet fractions of panned concentrates and oxalic-acid leachates, based on a 5 -mg sample

Elements Lower determination limit Upper determination limit

Percent

\begin{tabular}{lcc}
\hline Iron (Fe) & 0.10 & 50 \\
Magnesium (Mg) & .05 & 20 \\
Calcium ( Ca) & .10 & 50 \\
Titanium (Ti) & .005 & 2 \\
\hline
\end{tabular}

Parts per million

\begin{tabular}{|c|c|c|}
\hline Manganese $(M n)$ & 20 & 10,000 \\
\hline Silver $(\mathrm{Ag})$ & .1 & 10,000 \\
\hline Arsenic (As) & 500 & 20,000 \\
\hline Gold $(A u)$ & 20 & 1,000 \\
\hline Boron (B) & 20 & 5,000 \\
\hline Barium ( $\mathrm{Ba}$ ) & 50 & 10,000 \\
\hline Beryllium (Be) & 2 & 2,000 \\
\hline Bismuth (Bi) & 20 & 2,000 \\
\hline Cadmi um (Cd) & 50 & 1,000 \\
\hline Cobalt (Co) & 10 & 5,000 \\
\hline Chromium (Cr) & 20 & 10,000 \\
\hline Copper (Cu) & 10 & 50,000 \\
\hline Lanthanum (La) & 50 & 2,000 \\
\hline Molybdenum (Mo) & 10 & 5,000 \\
\hline Ni obi um ( $\mathrm{Nb})$ & 50 & 5,000 \\
\hline Nickel (Ni) & 10 & 10,000 \\
\hline Lead $(\mathrm{Pb})$ & 20 & 50,000 \\
\hline Antimony (Sb) & 200 & 20,000 \\
\hline Scandium (Sc) & 10 & 200 \\
\hline $\operatorname{Tin}(\mathrm{Sn})$ & 20 & 2,000 \\
\hline Strontium (Sr) & 200 & 10,000 \\
\hline Vanadium (V) & 20 & 20,000 \\
\hline Tungsten (W) & 100 & 20,000 \\
\hline Yttrium $(Y)$ & 20 & 5,000 \\
\hline Zinc $(Z n)$ & 500 & 20,000 \\
\hline Zirconium $(Z r)$ & 20 & 2,000 \\
\hline Thorium (Th) & 200 & 5,000 \\
\hline
\end{tabular}




\section{REFERENCES CITED}

Alminas, H. V., and Mosier, E. L., 1975, 0xalic-acid leaching of rock, soil, and stream-sediment samples as an anomaly accentuation technique: U.S. Geological Survey Open-File Report 76-275, 24 p.

Grimes, D. J., and Marranzino, A. P., 1968, Direct-current arc and alternating-current arc spark emission spectrographic field methods for the semiquantitative analysis of geologic materials: U.S. Geological Survey Circular 591, 6 p.

Hopkins, R. T., et al, 1984, Analytical results from a geochemical survey of St. Thomas and St. John, U.S. Virgin Islands, using soil, rock, and panned-concentrate samples: U.S. Geological Survey Open-File Report $84-785,64 \mathrm{p}$.

Motooka, J. M., and Grimes, D. J., 1976, Analytical precision of one-sixth order semiquantitative spectrographic analyses: U.S. Geological Survey Circular 738, $25 \mathrm{p}$.

\section{Explanation of data tables}

The data in tables 3-9 are presented in the same sequence for all sample types: St. Thomas, St. John and St. Croix. The letters ST, SJ and SC in the field numbers identify the sites as originating on the islands of St. Thomas, St. John and St. Croix, respectively.

Latitudes and longitudes are not incorporated into table 3 . Here, field numbers like 84SJ001R, 84SJ001R1, 84SJ001R2 indicate that three separate outcrop samples were collected in the immediate vicinity of sample site 84SJ001. The latitude and longitude for each sample site are provided in the other data tables. 


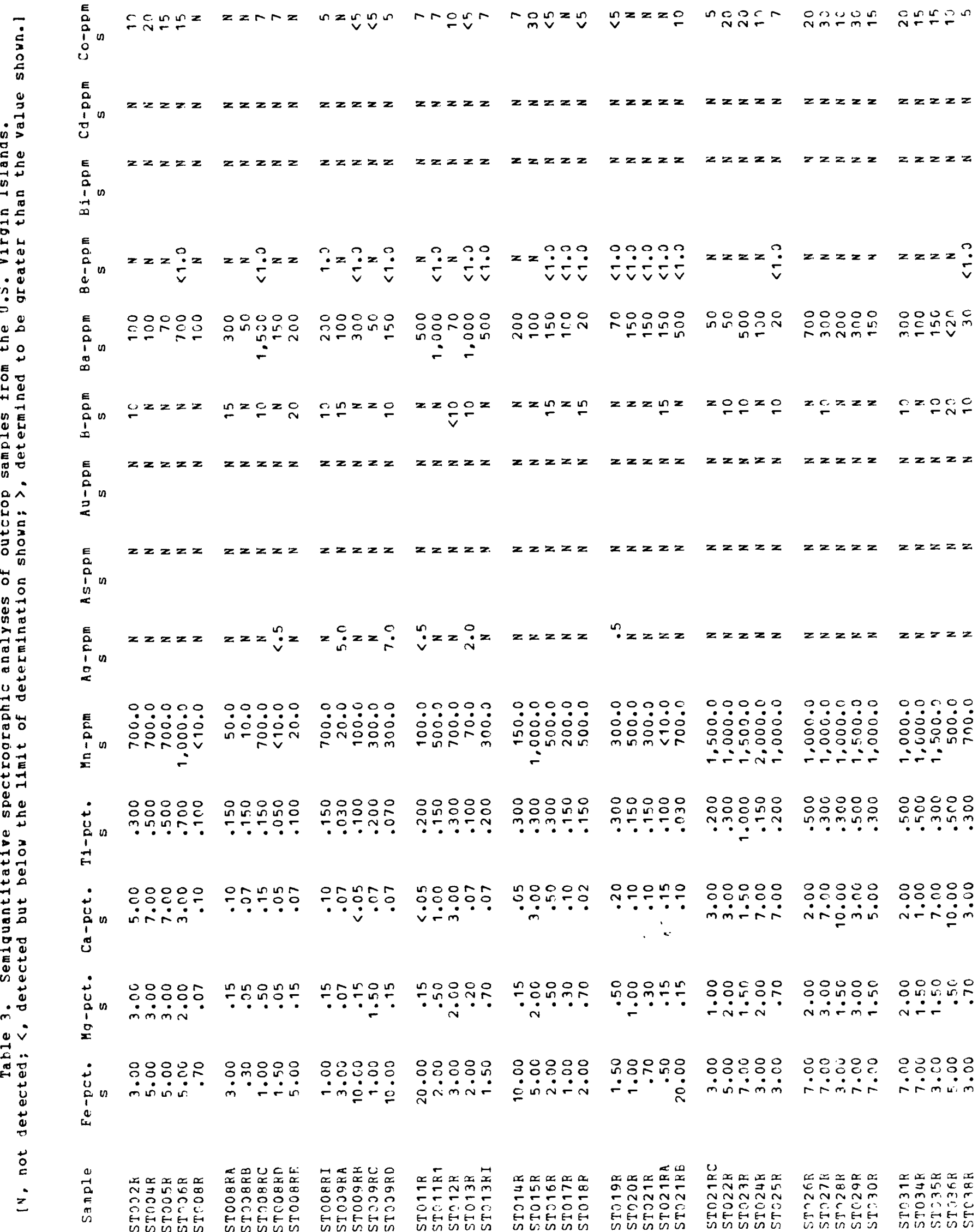




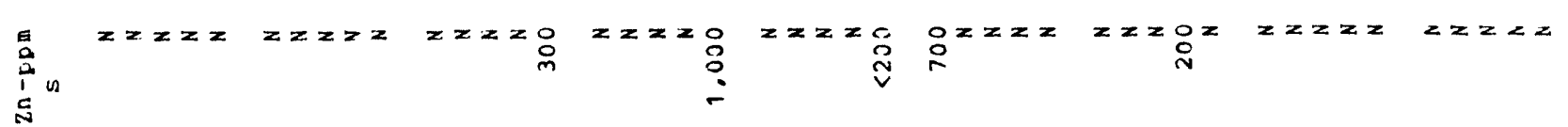

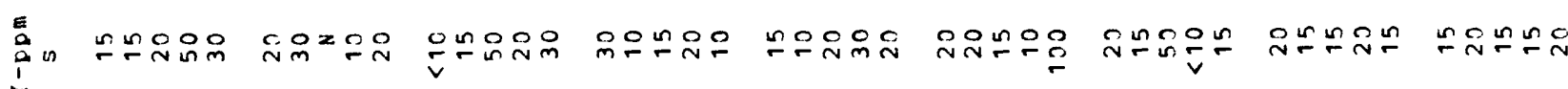

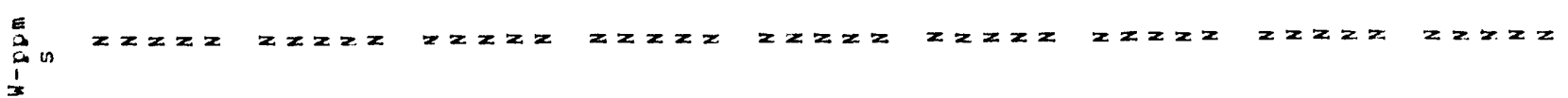

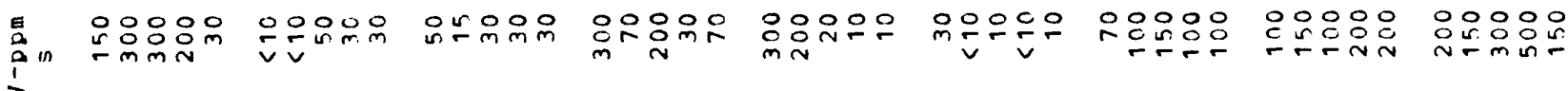

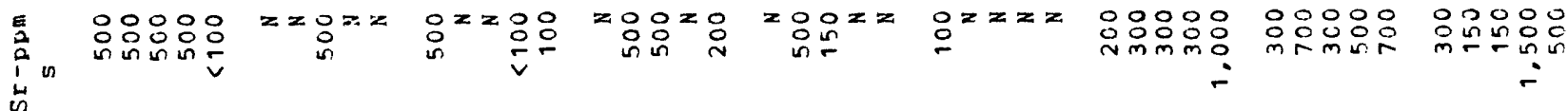

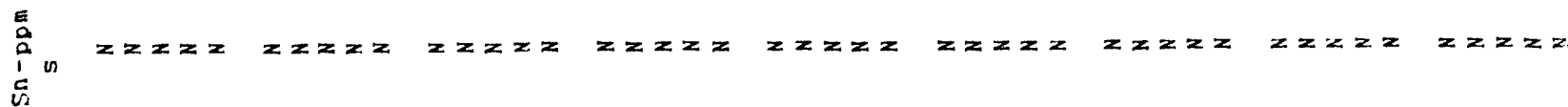
总

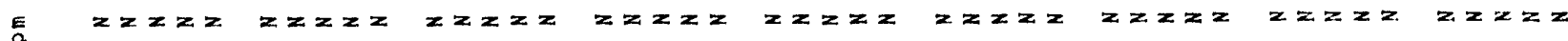
in

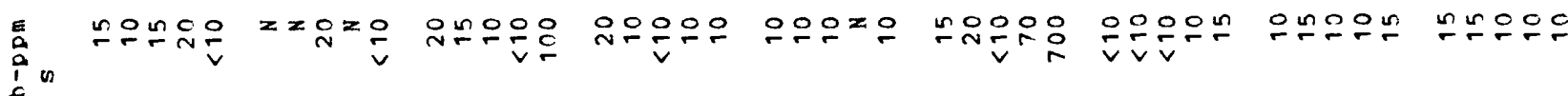

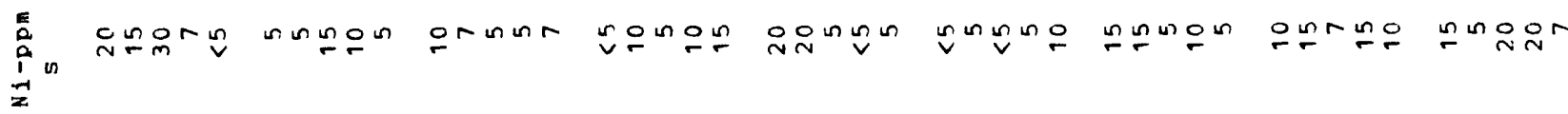

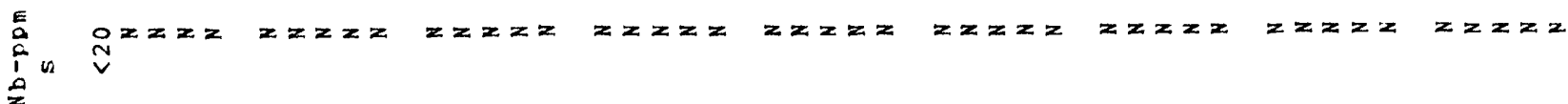

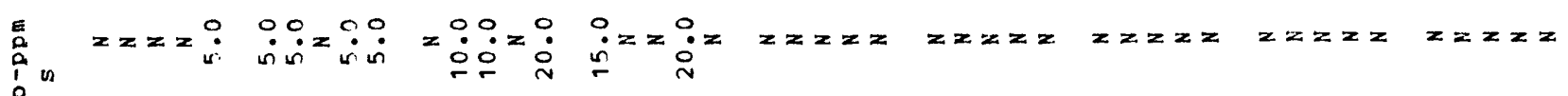

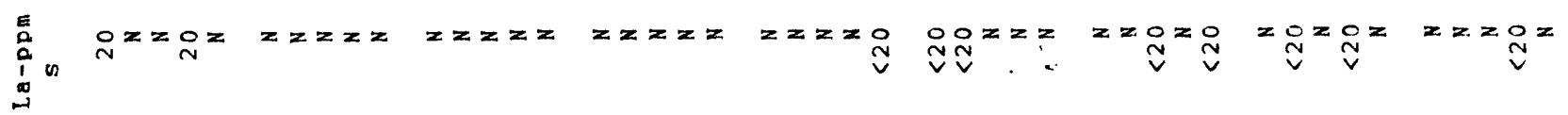
E 융윰

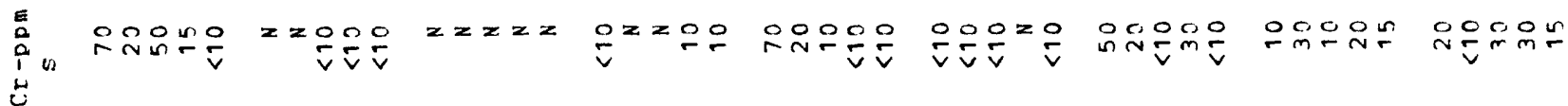

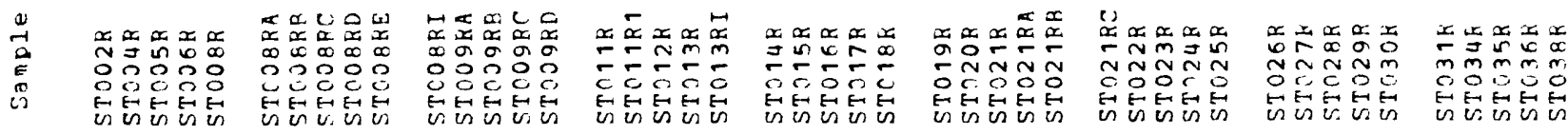




$$
\text { 嶎 }
$$$$
x z z z
$$$$
2
$$

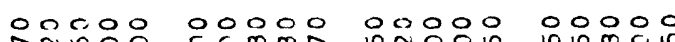

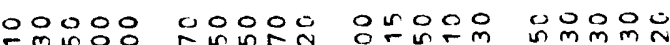

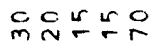
N

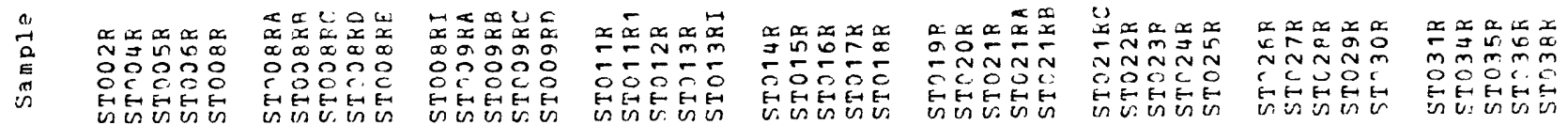




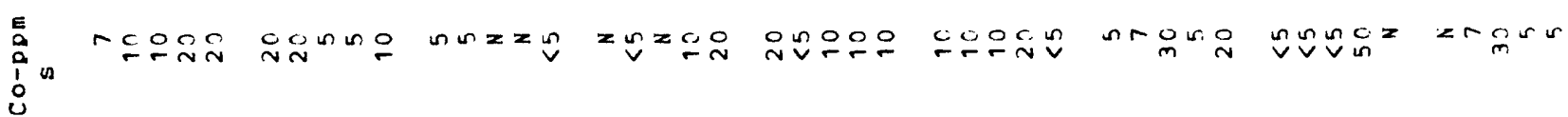

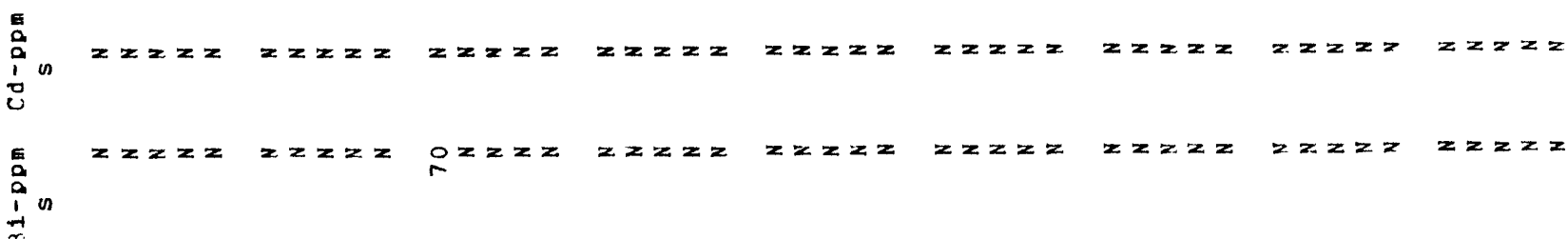

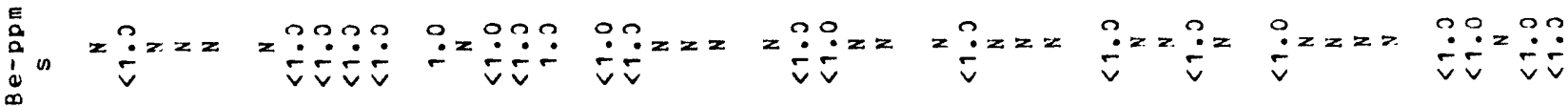

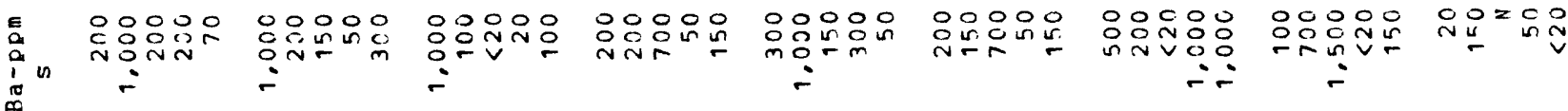
良

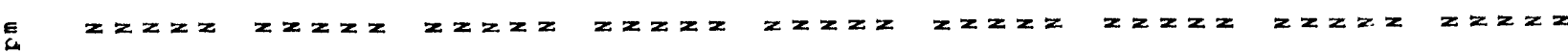
$i^{2}$ in

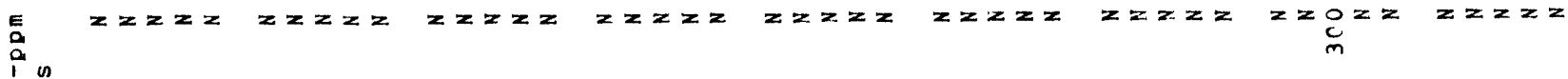

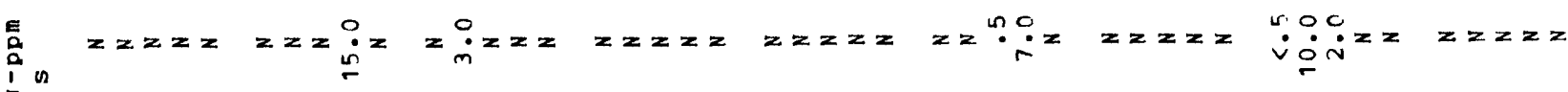
000000000000000000000000000000000000000000000

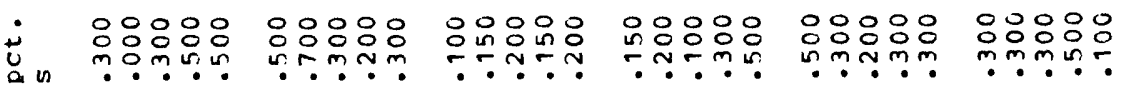

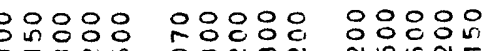
-1

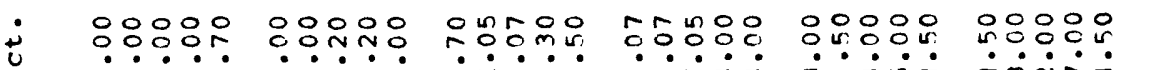

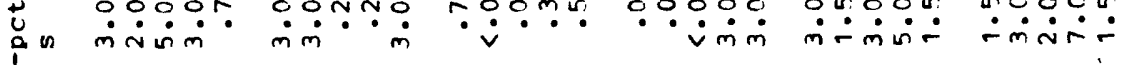

응ㅇㅇ은 i

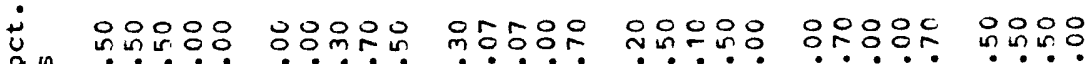

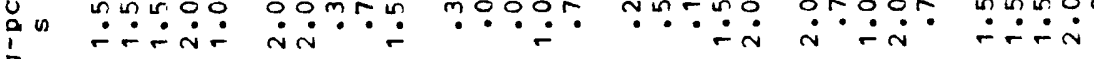

\section{응ㅇㅇㅇㅇㅇㅇㅛ

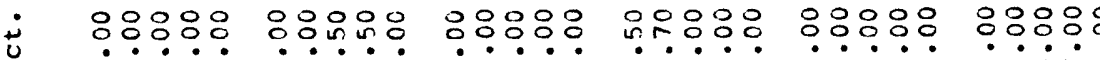

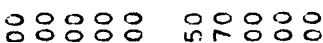 \\ 00000 \\ 000}

$\dot{m}$

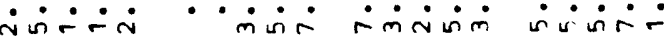

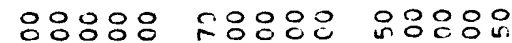
i

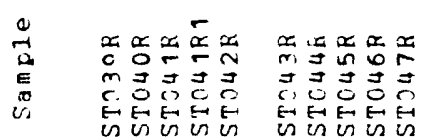

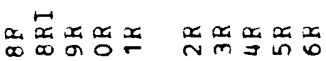

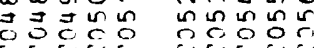

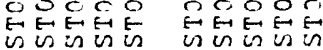

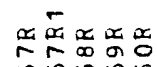
in nn

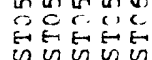

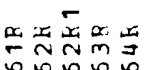

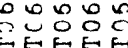

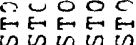

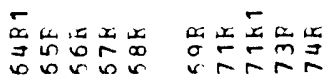

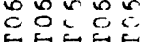

旨出出兒昆

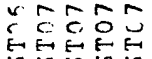

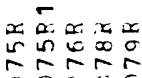
OORE 


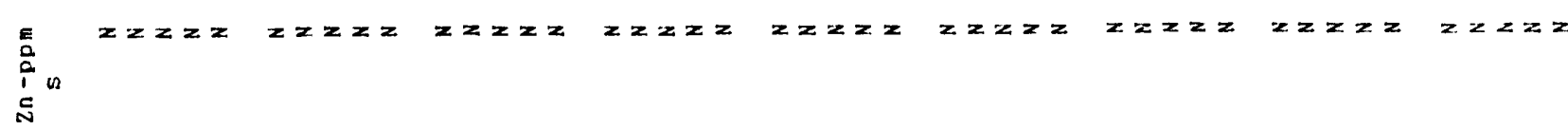

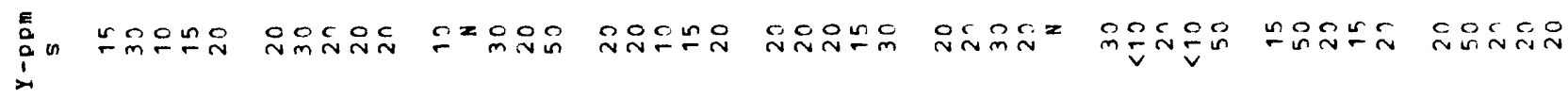

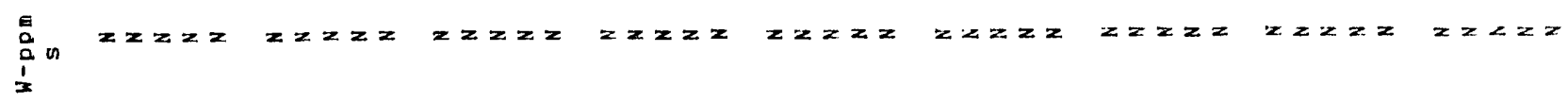

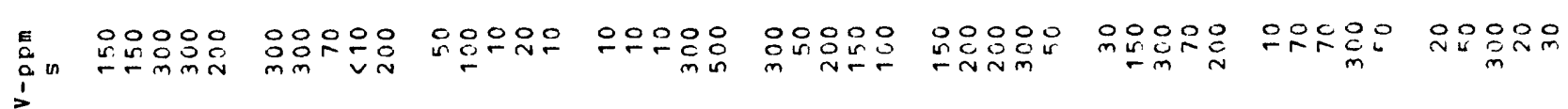

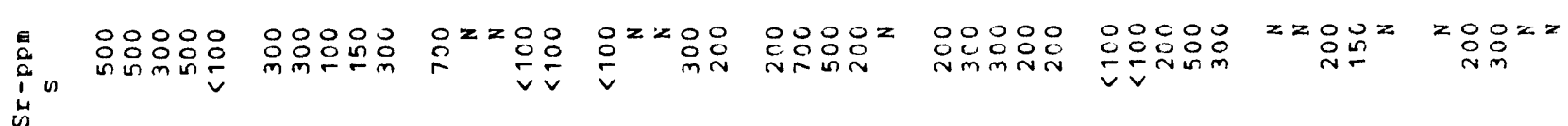

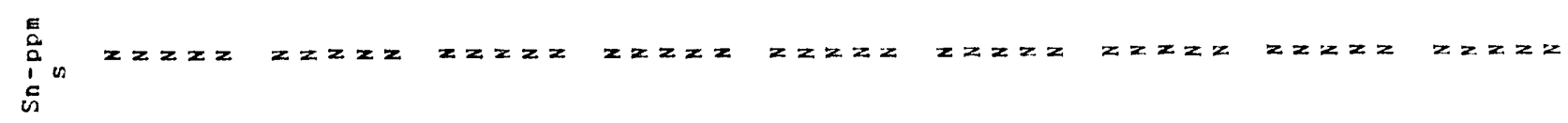

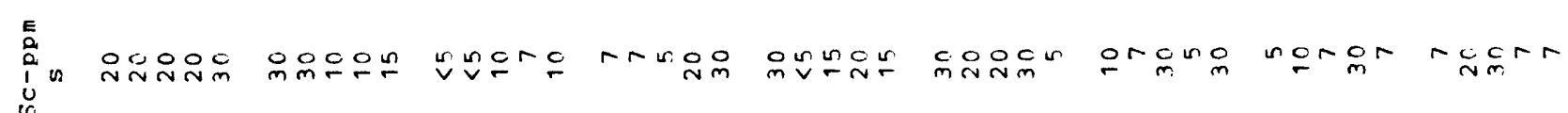

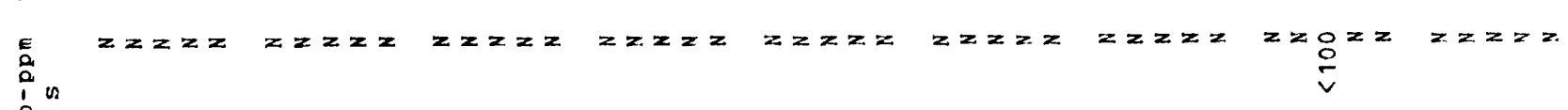
is

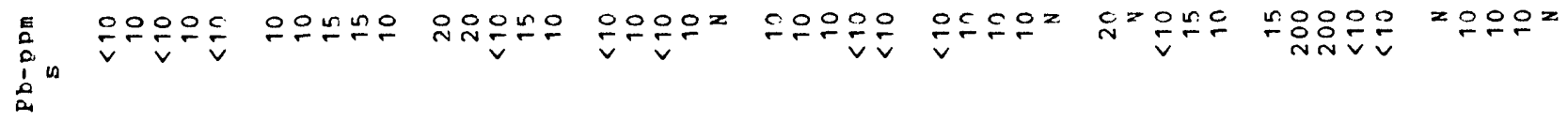

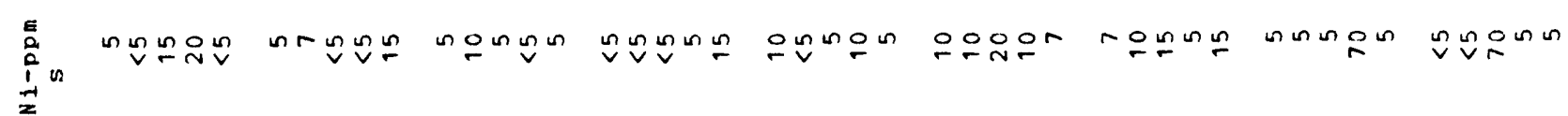

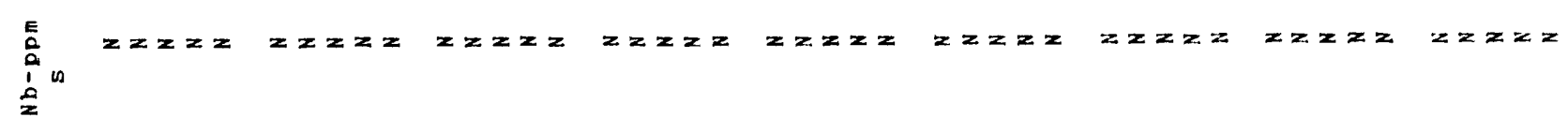

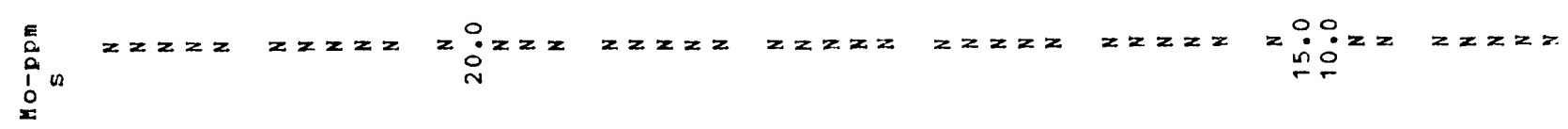

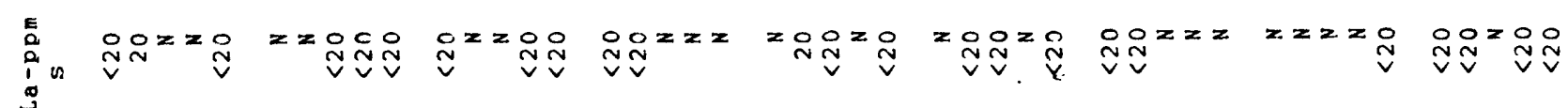

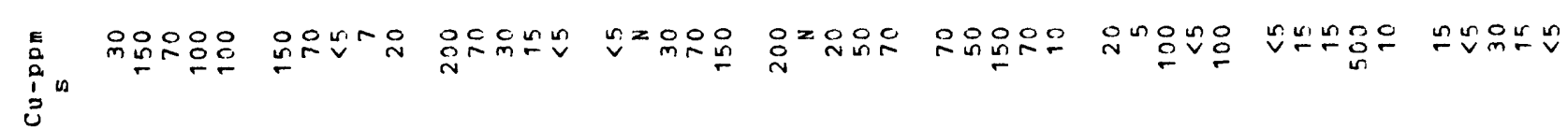

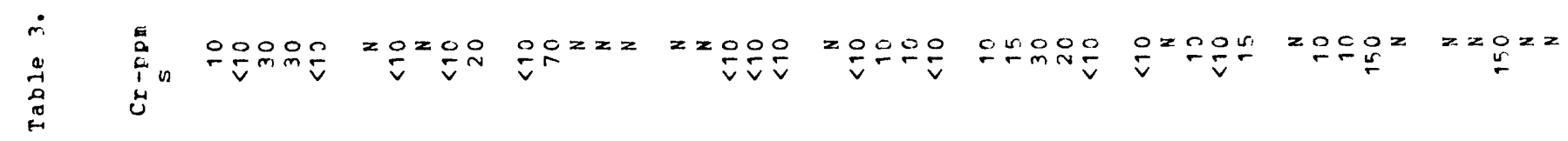

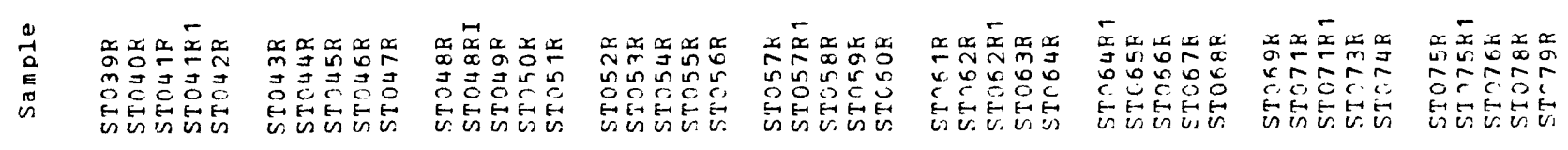




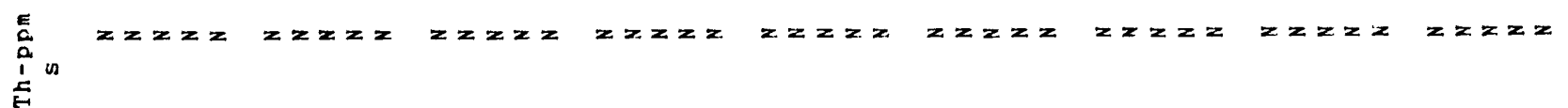

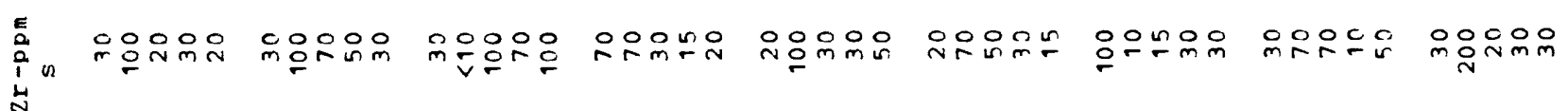

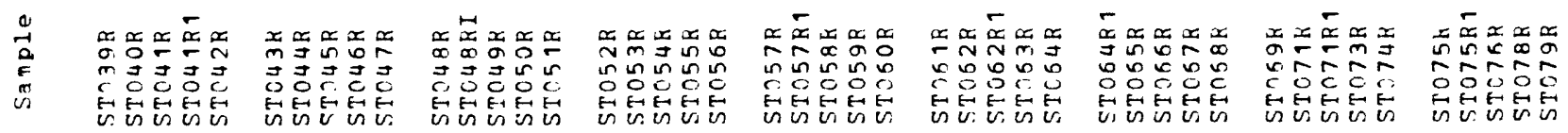




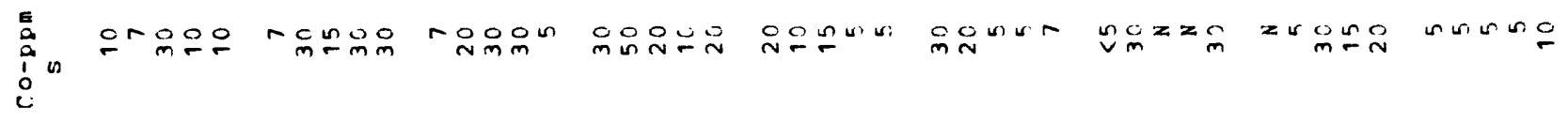

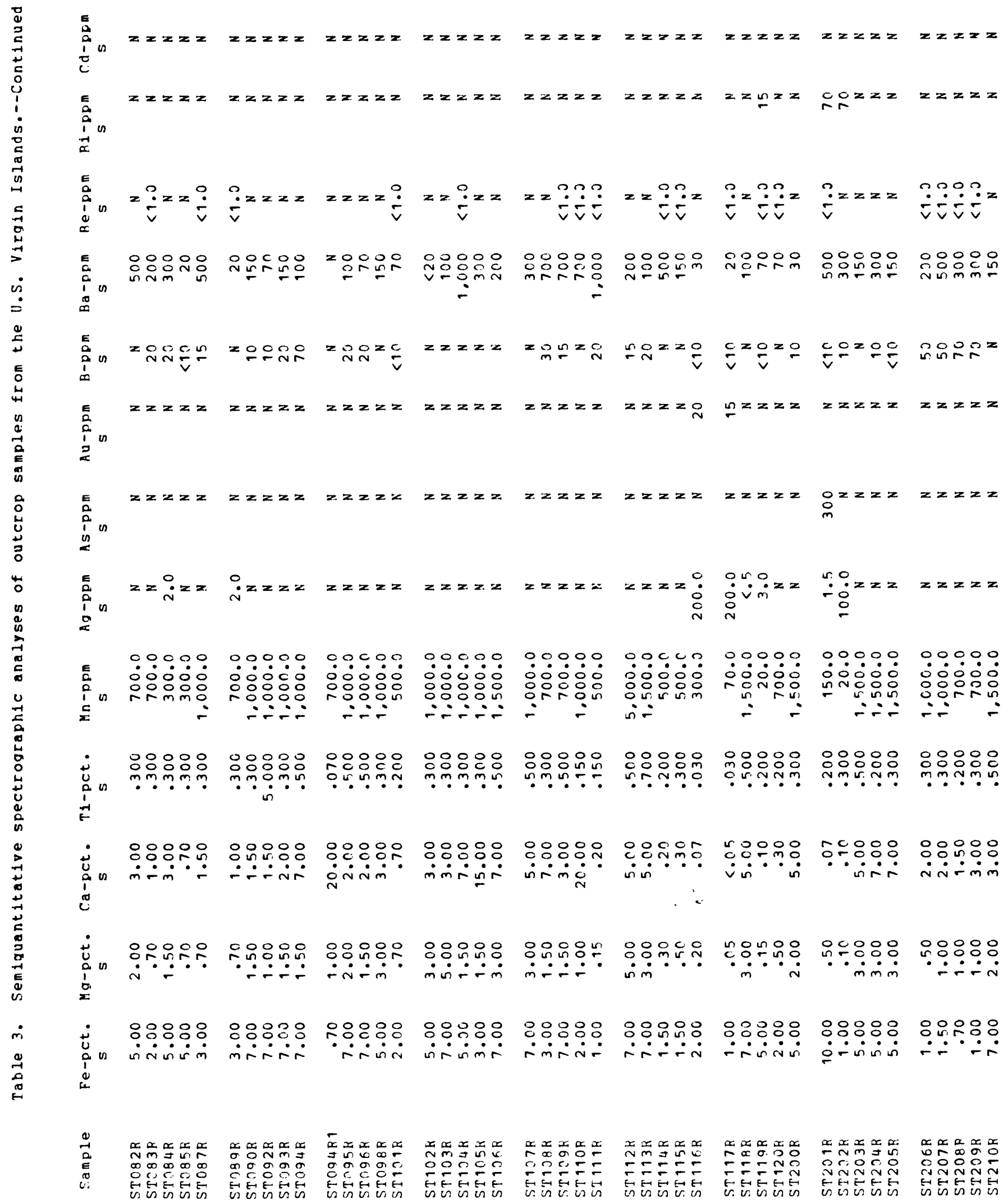


$z z z z z$

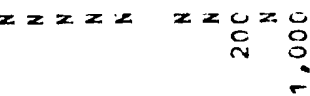

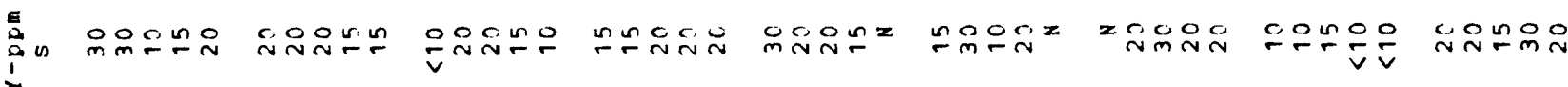

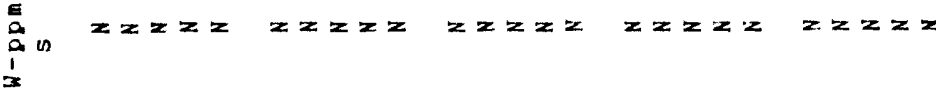

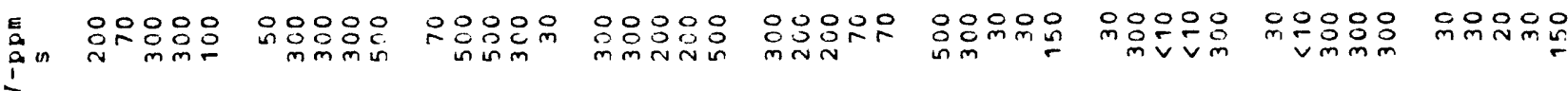

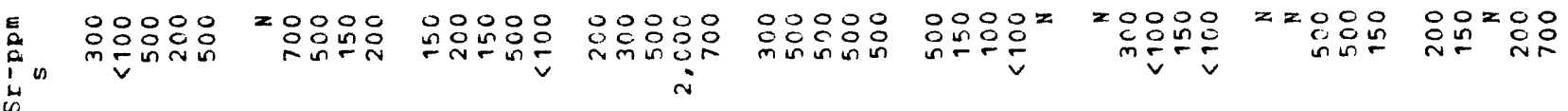

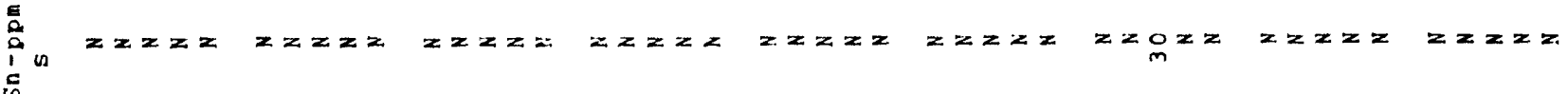

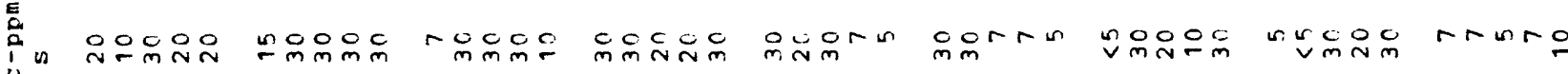

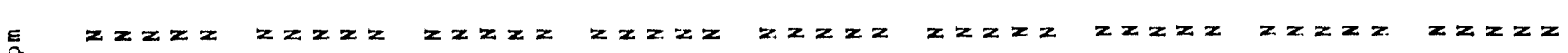
: है

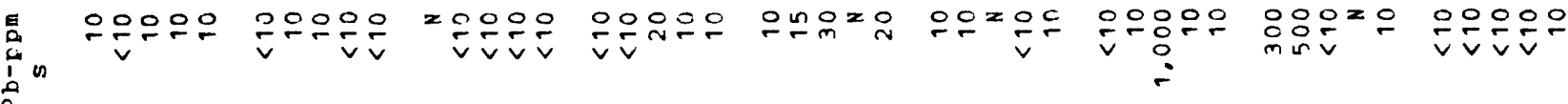

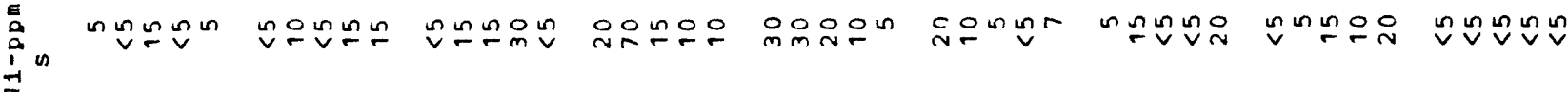

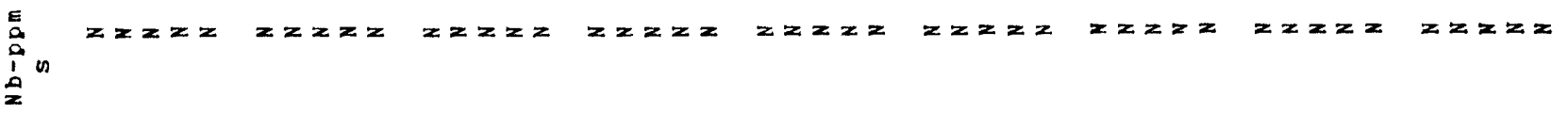

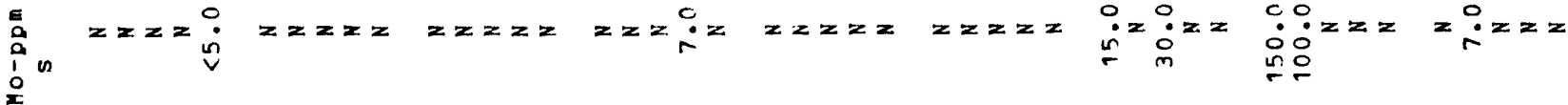

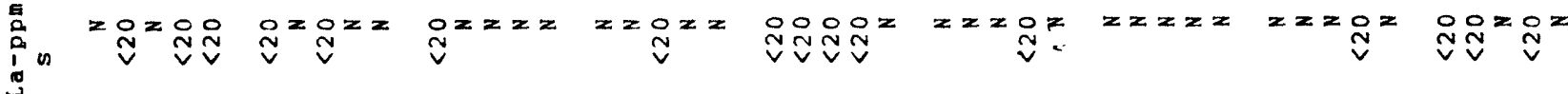

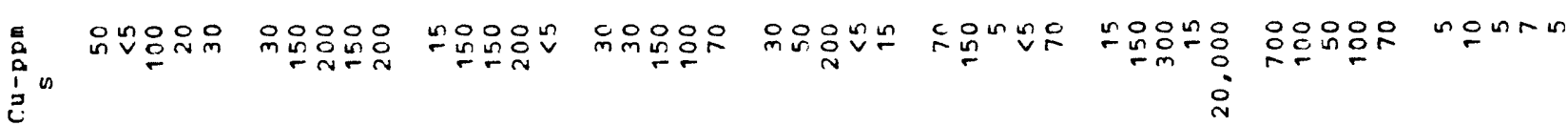

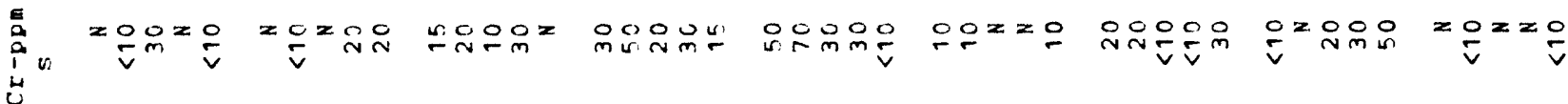

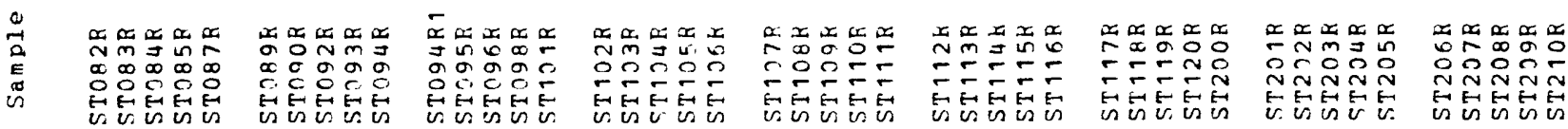




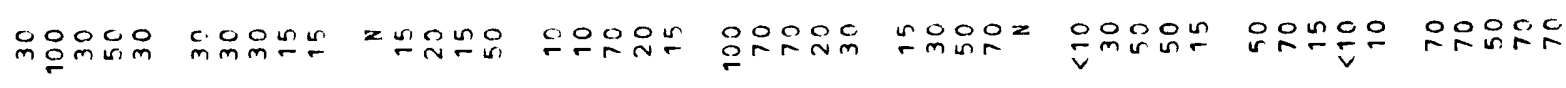

$\stackrel{0}{\frac{0}{\pi}}$

in 剀

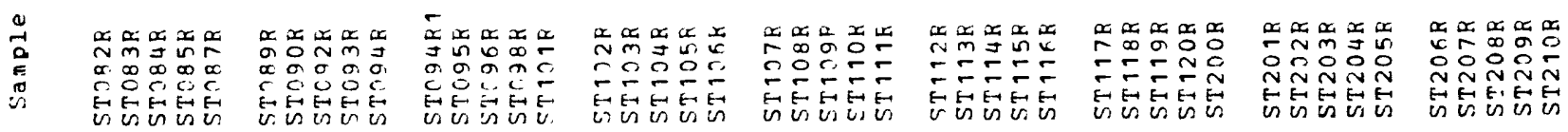




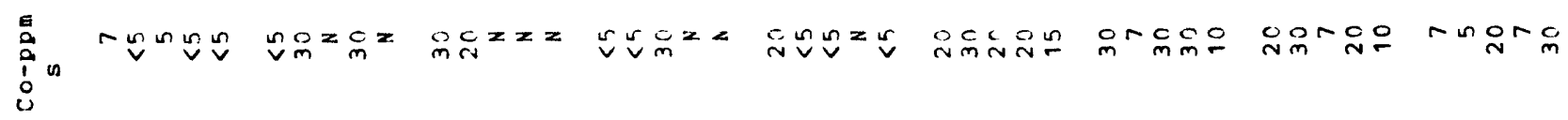

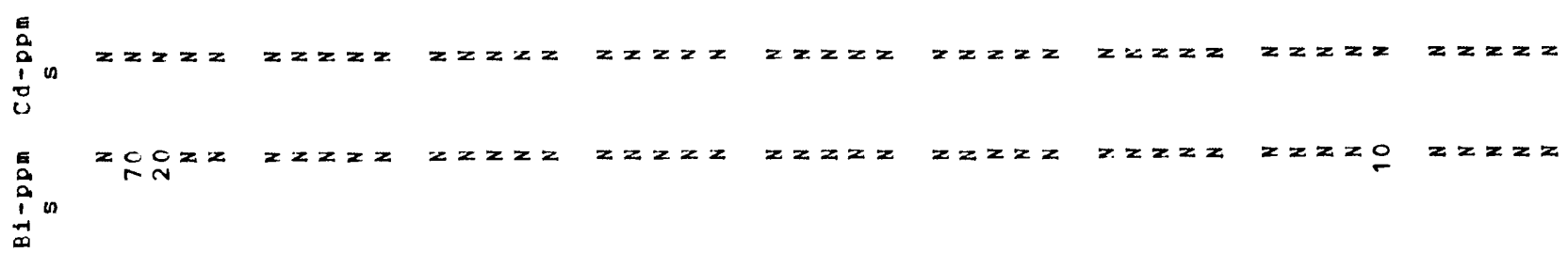

in

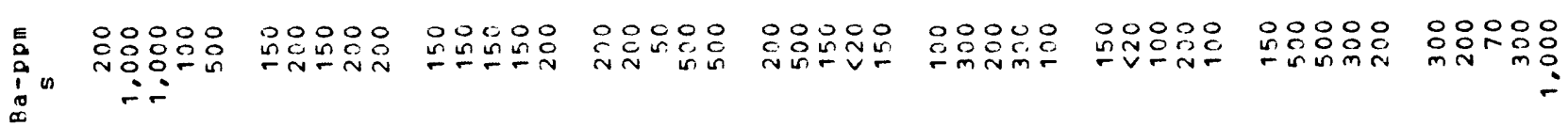

E⿱

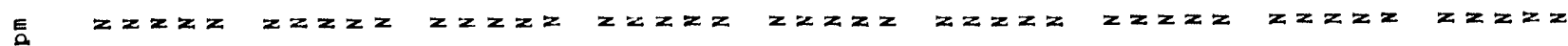
$\stackrel{a}{a}$

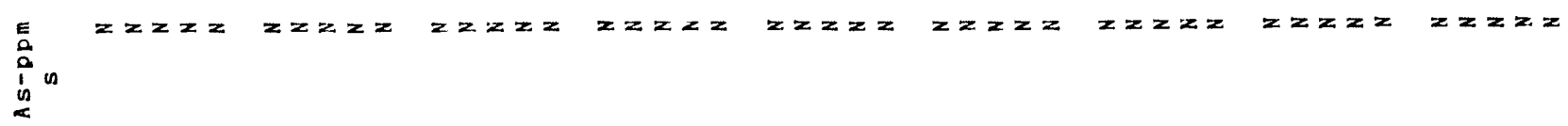

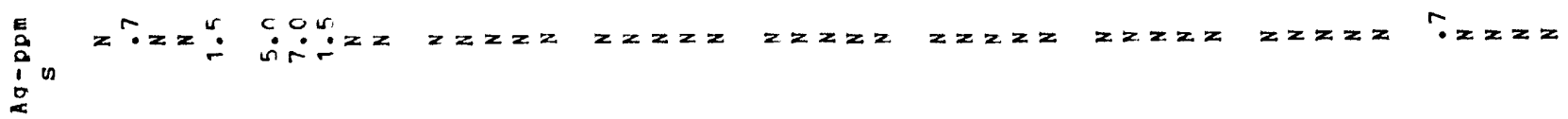

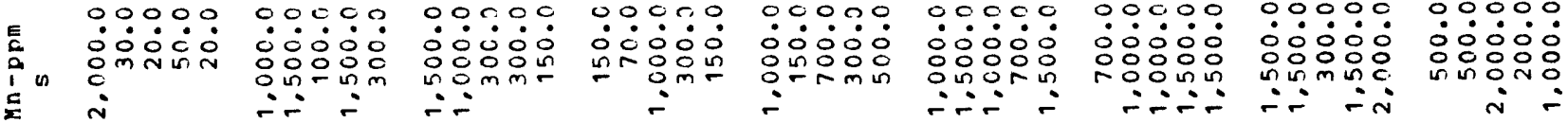

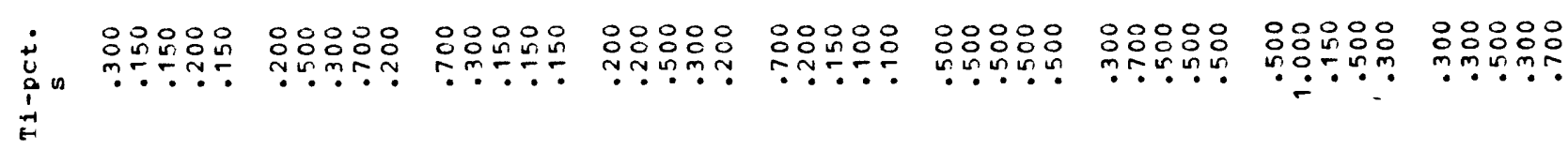

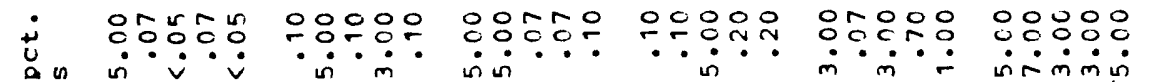

is

is

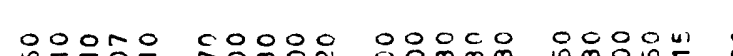

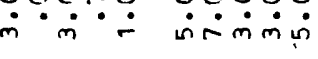

응응응응

우쇼

응응융ㅇㅇ 응영잉응 붇ㅇ min்

웄윢유

00000

$\because: 0: 0$

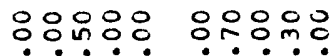
$\dot{\sim} \cdot \dot{\sim} \dot{n} \dot{m} \dot{\sim}$ $\dot{m} \dot{\dot{m} \dot{m} \boldsymbol{i} \dot{N}}$ $\dot{N} \dot{n} \cdot \dot{m}$

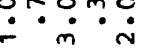

$\stackrel{\dot{m}}{\stackrel{0}{-1}}$

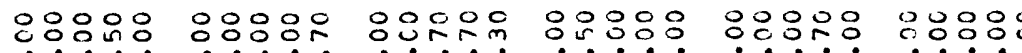

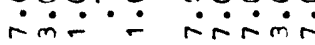

$\therefore 8: 8:$

영요 용요 und $\dot{\circ \dot{ }+\dot{0}}$ $\therefore \dot{r} \dot{i} \dot{0}$ ingrivio ríniri $\dot{m} \dot{m} \dot{r} \dot{0}$ 


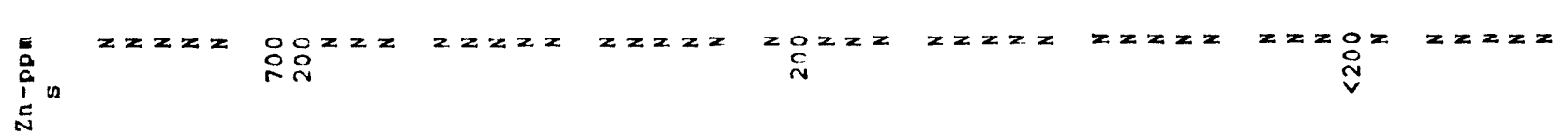

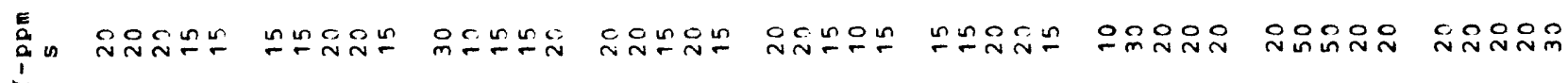

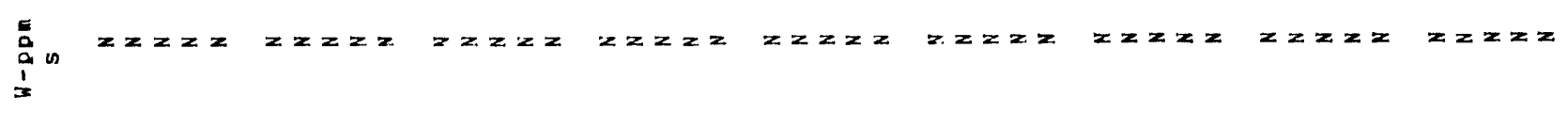

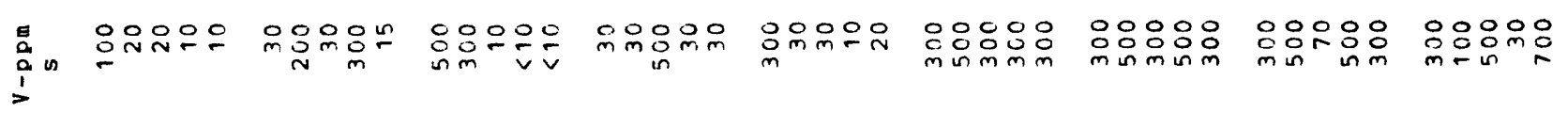

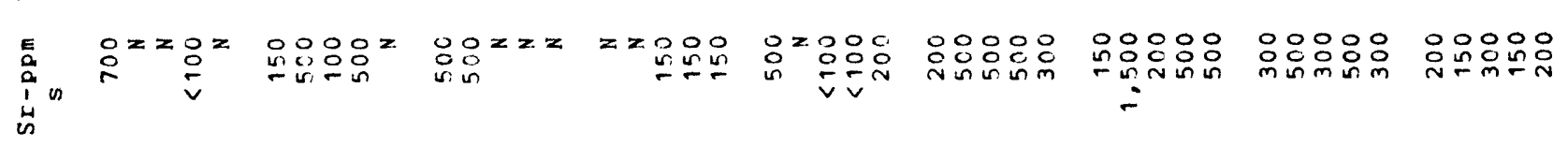

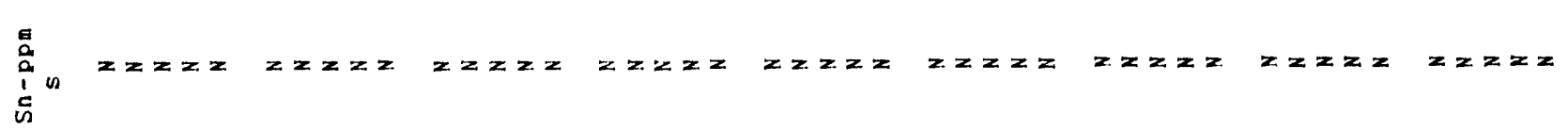

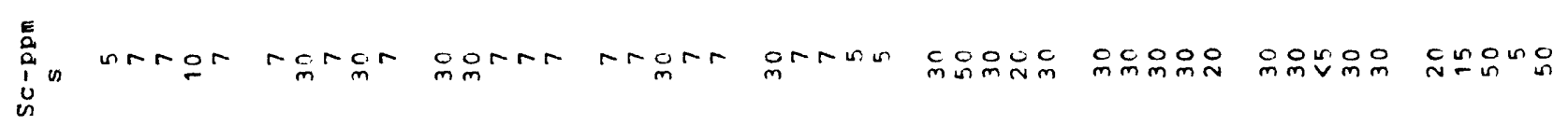

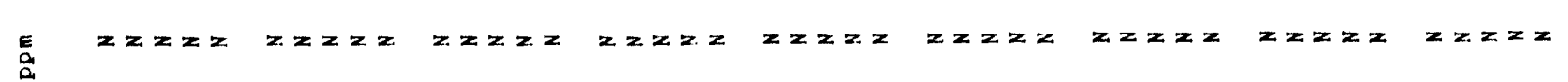
ầ
in
is

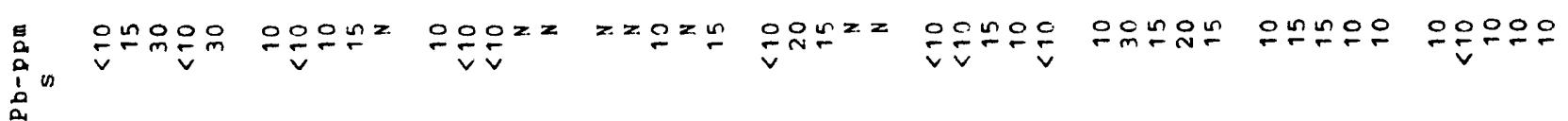

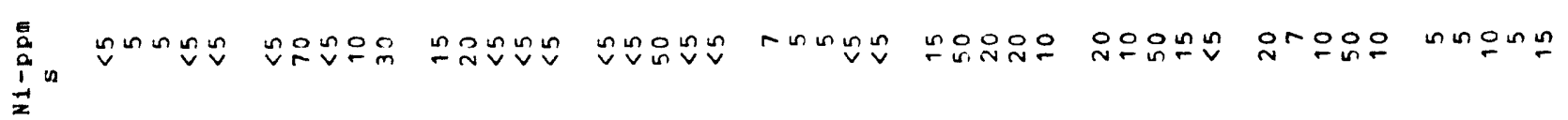
峟

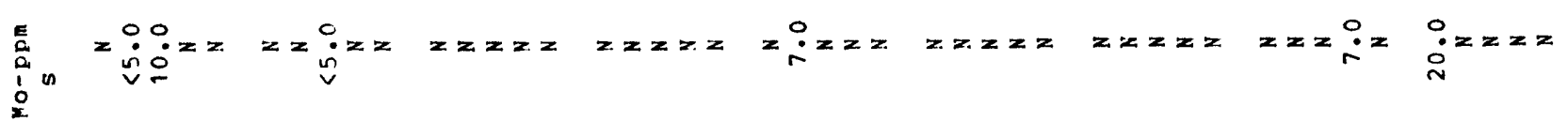

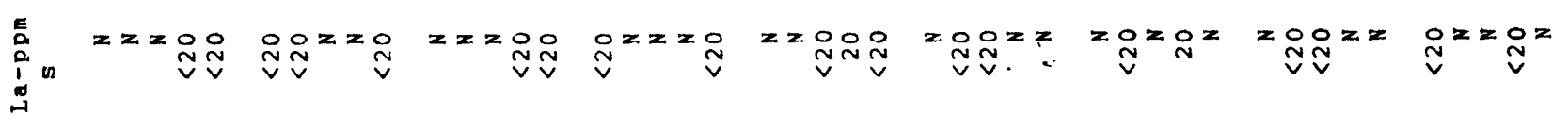

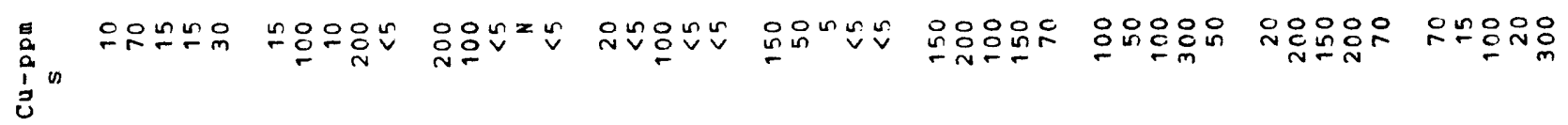

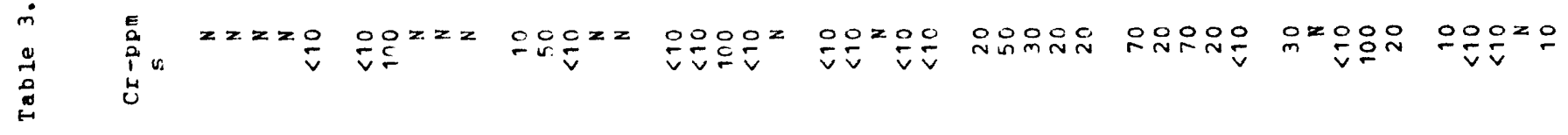

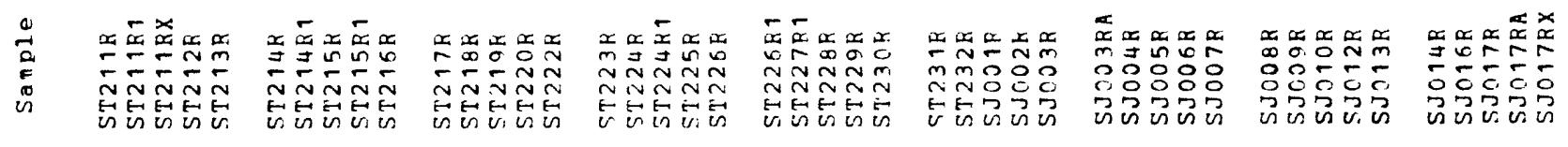




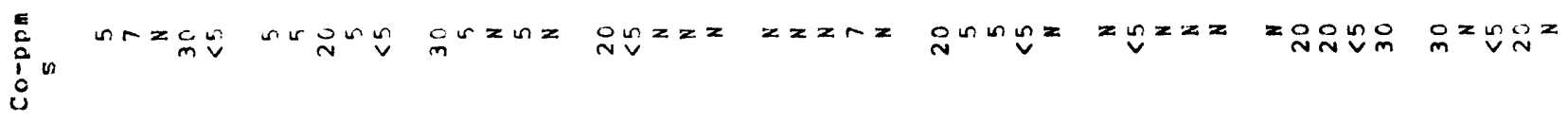

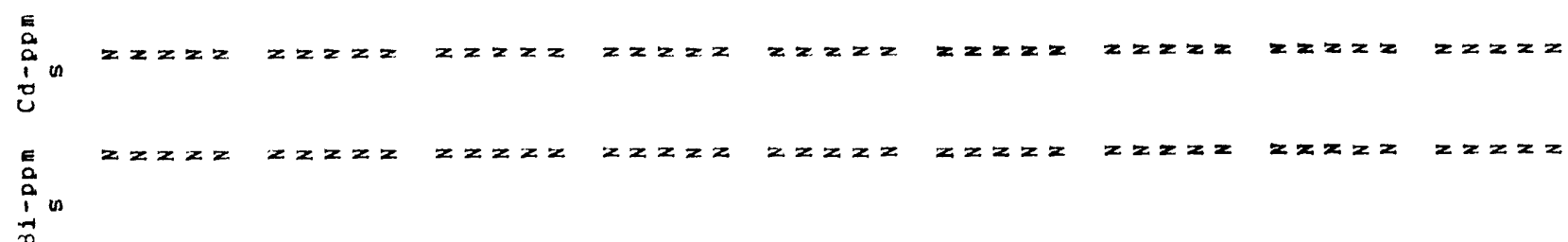

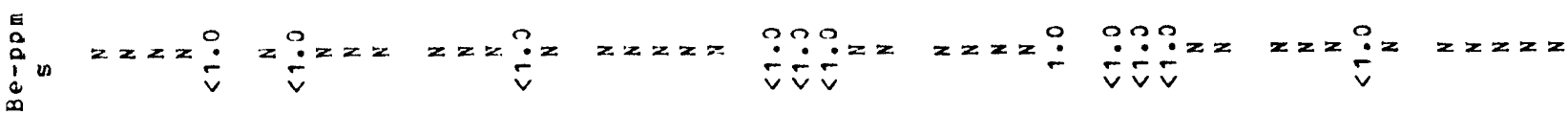

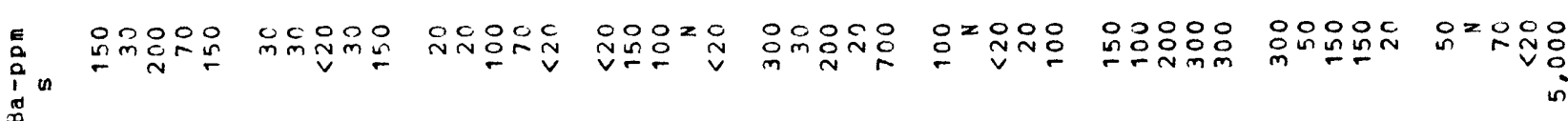

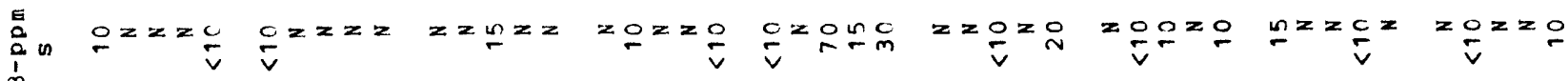

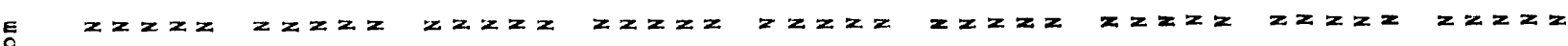
$\sum_{\substack{2 \\ 0}}^{2}$

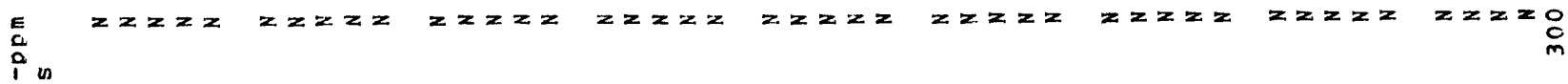

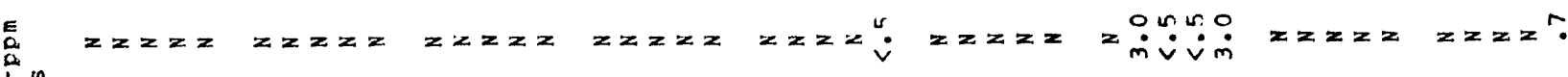

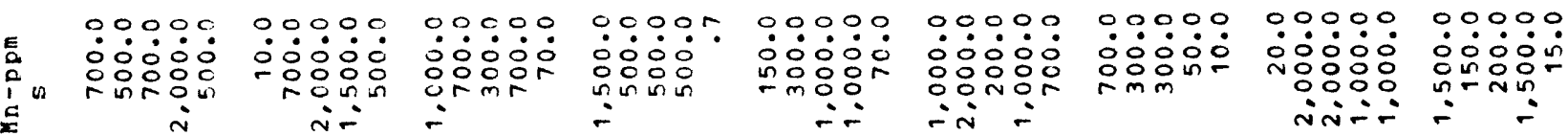

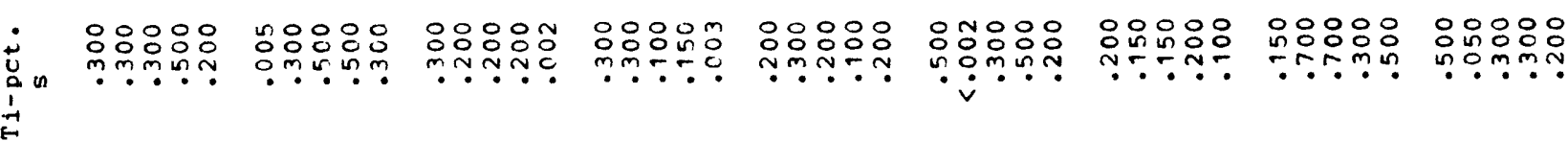

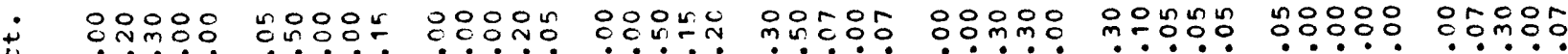
苔n

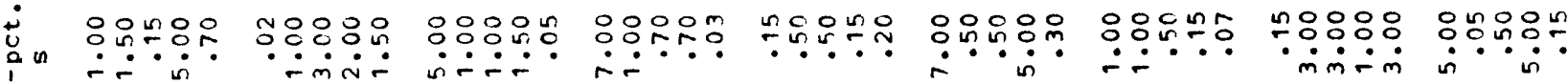
ón

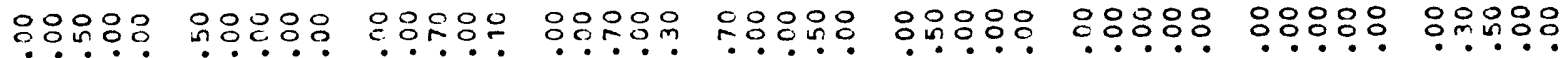

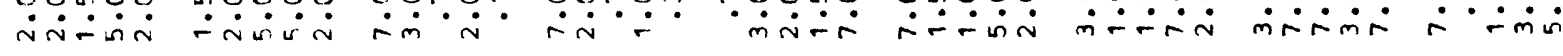
is

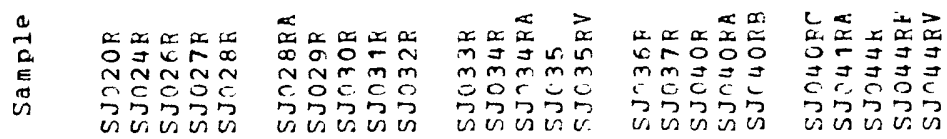

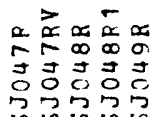

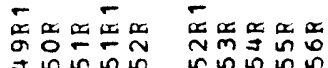
cic

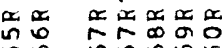

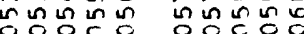

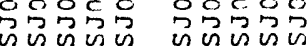




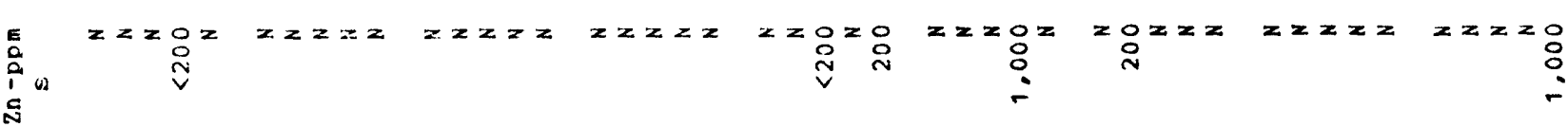

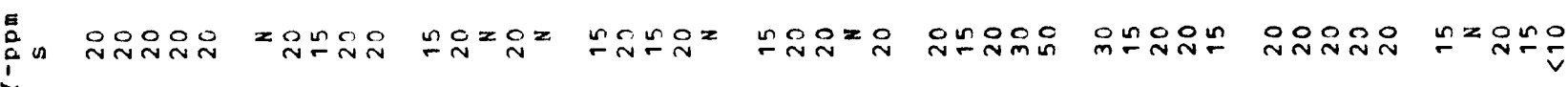
E

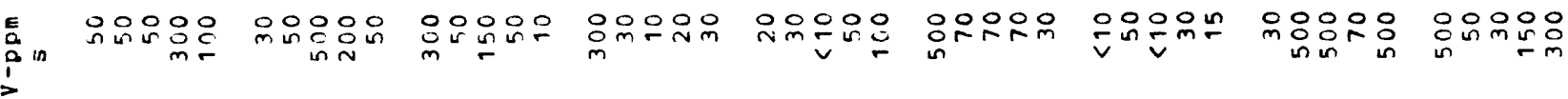

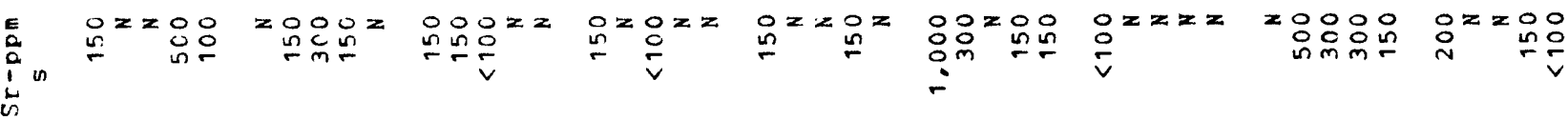
唇

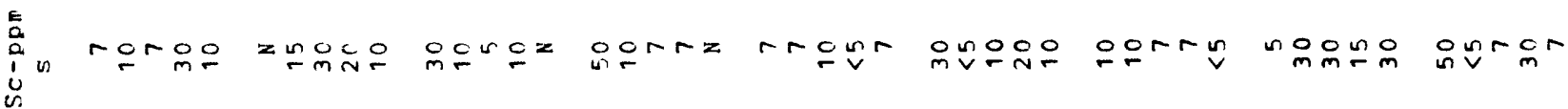

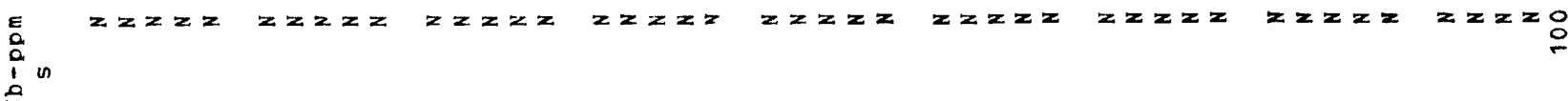

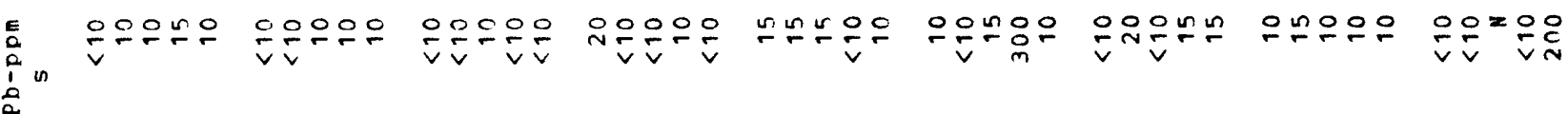

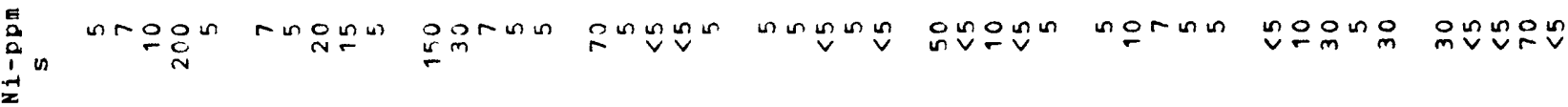

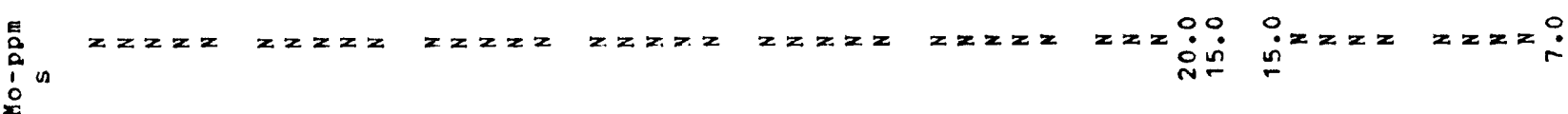

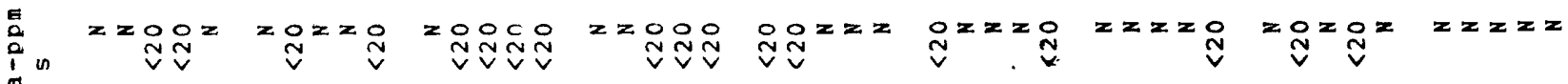
$\stackrel{1}{3}$

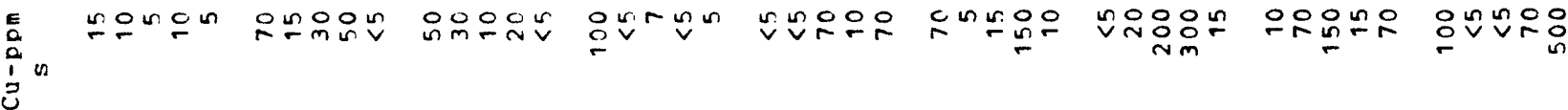

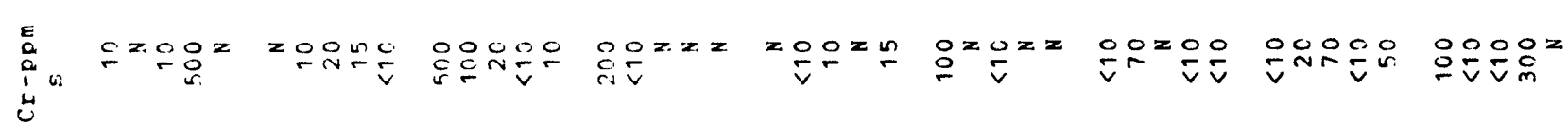

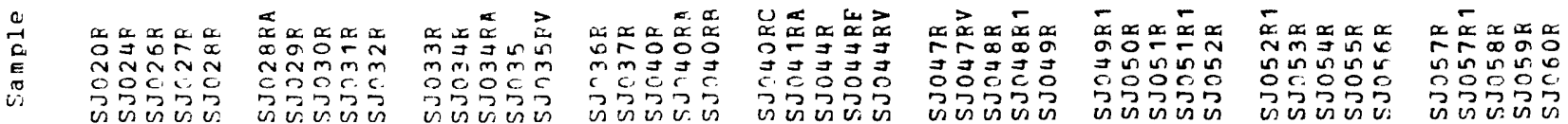




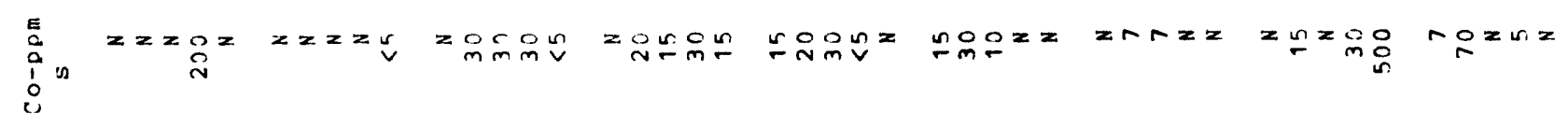

1 - …

E

$\frac{4}{\infty}$

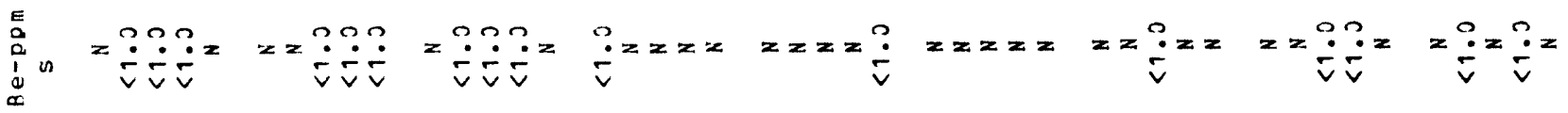

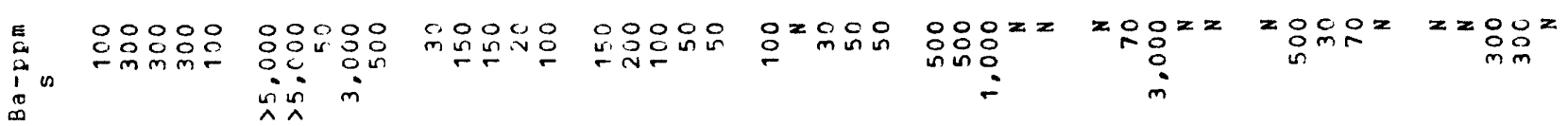

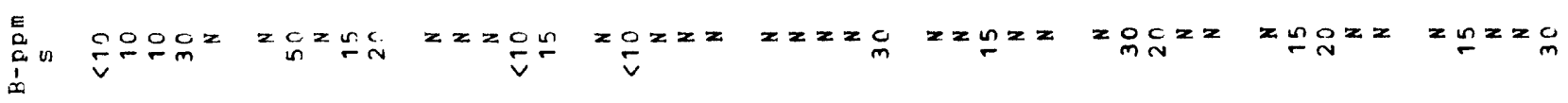

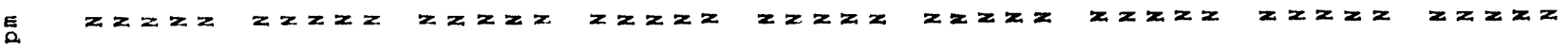
$i_{0}^{2}$ in

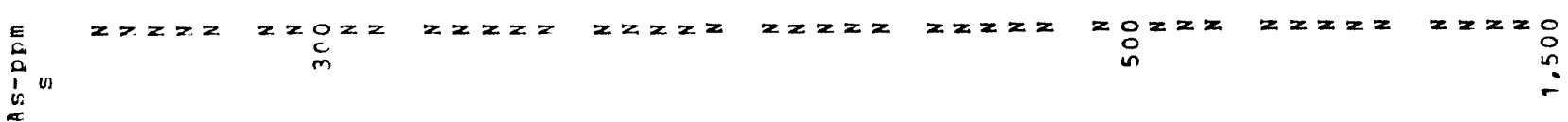

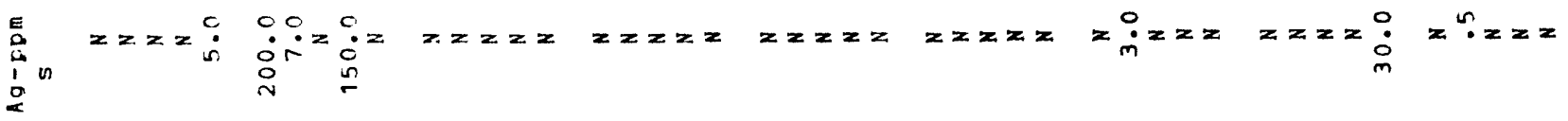

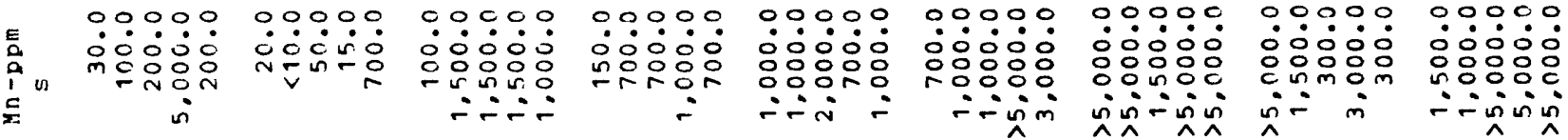

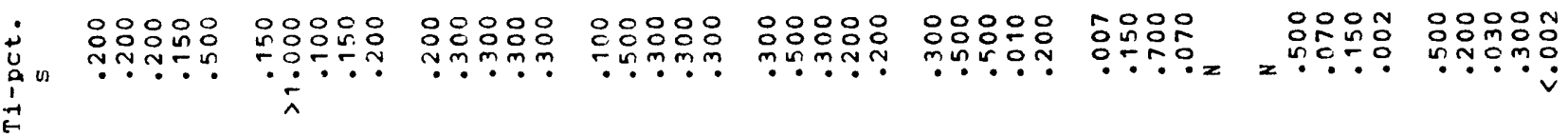

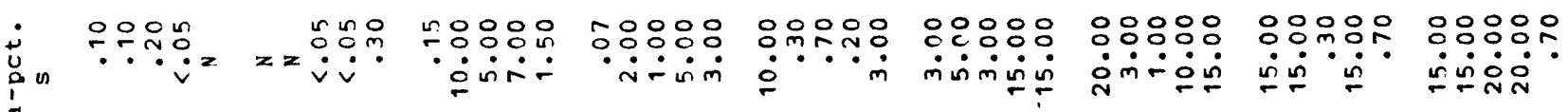

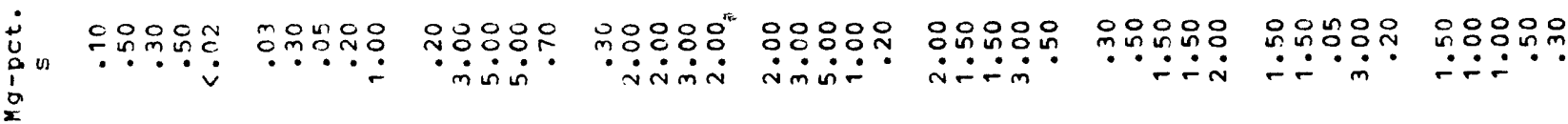

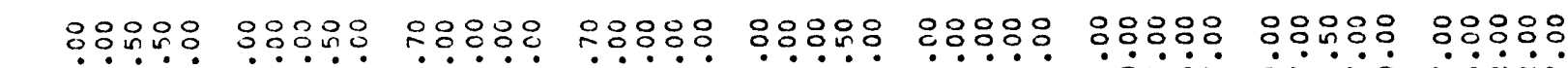

un

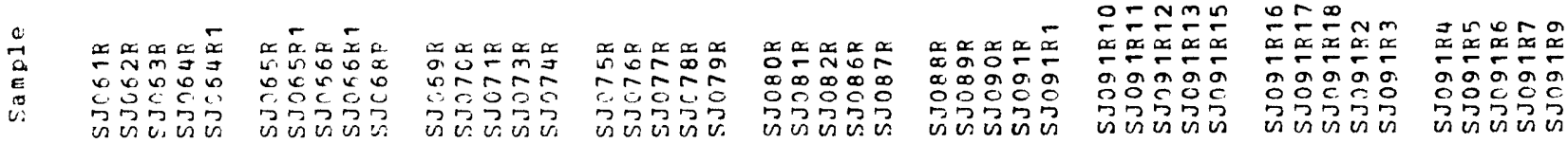




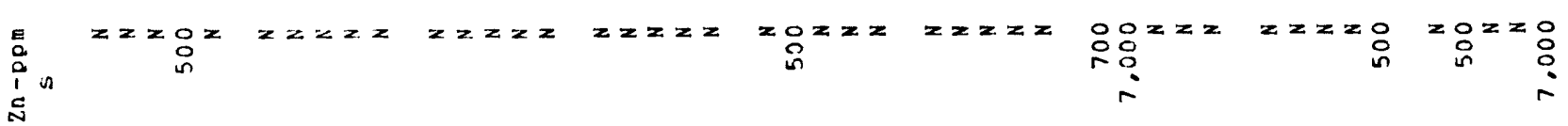

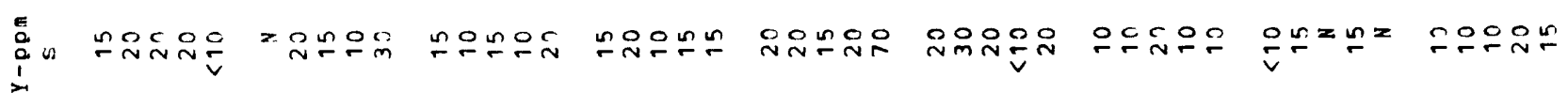

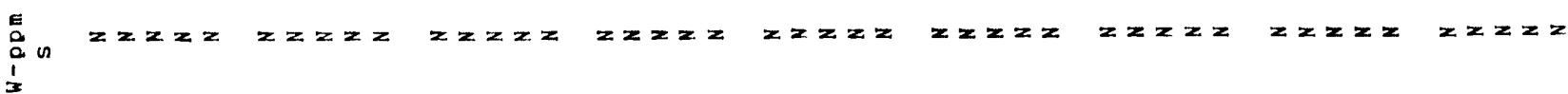

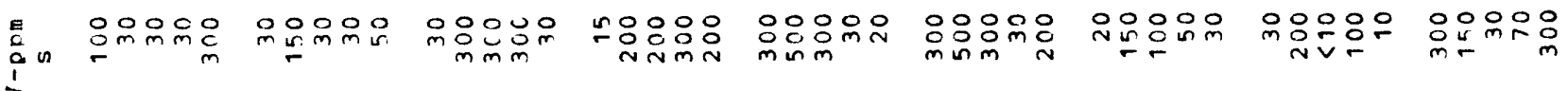

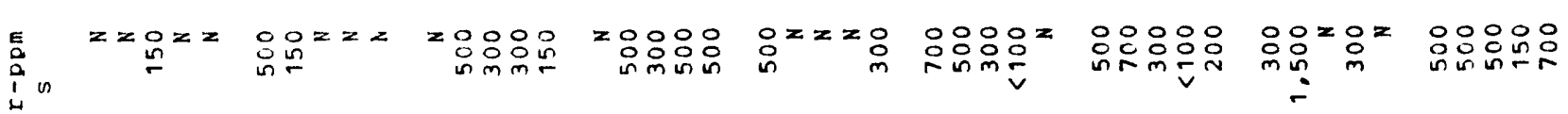

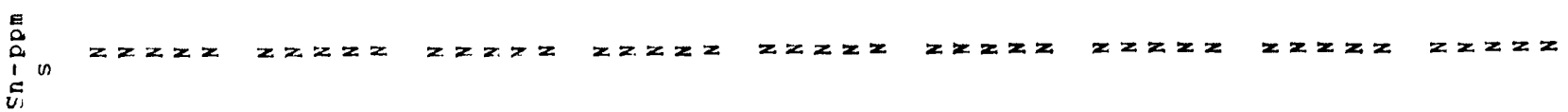

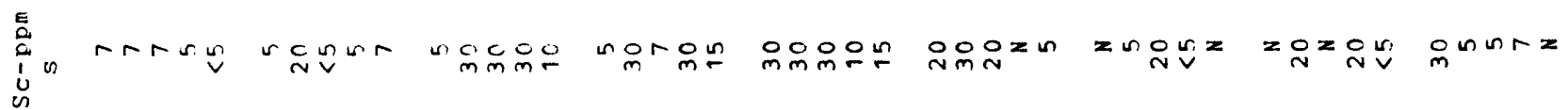

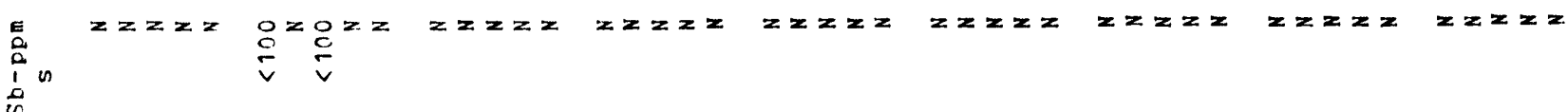

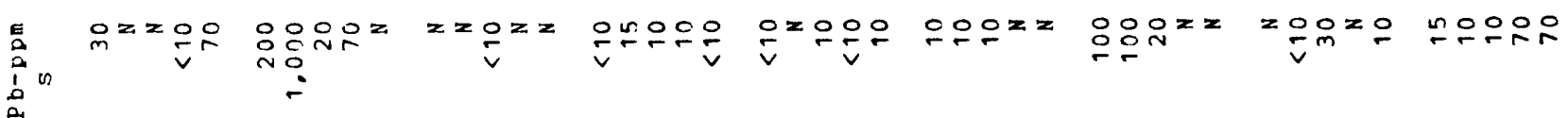

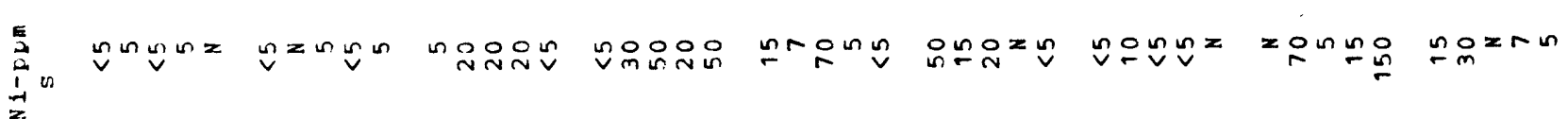

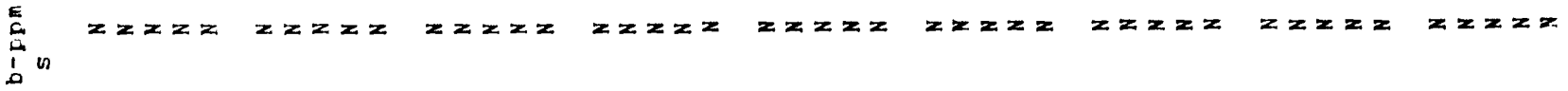

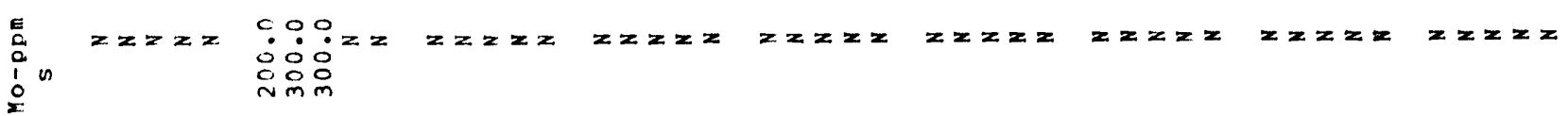

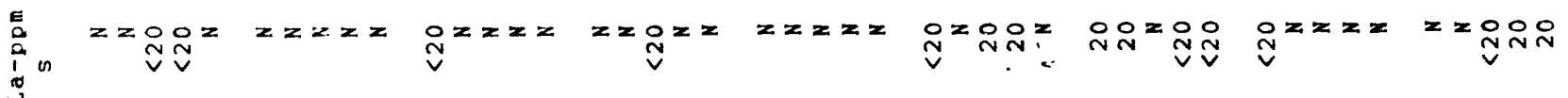

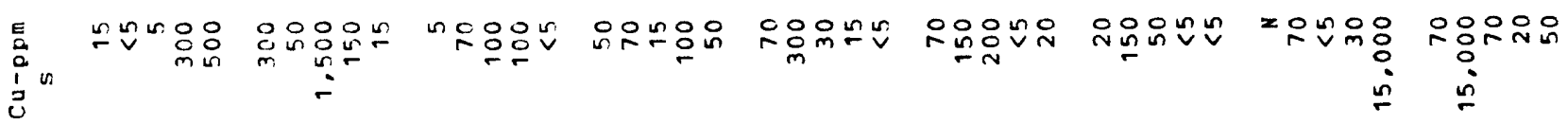

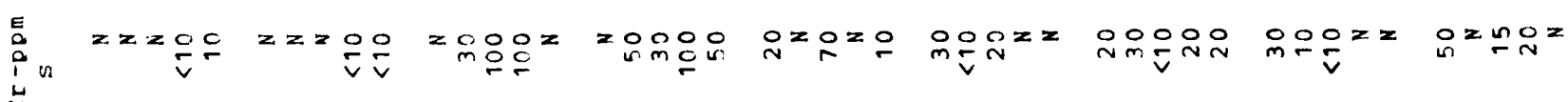

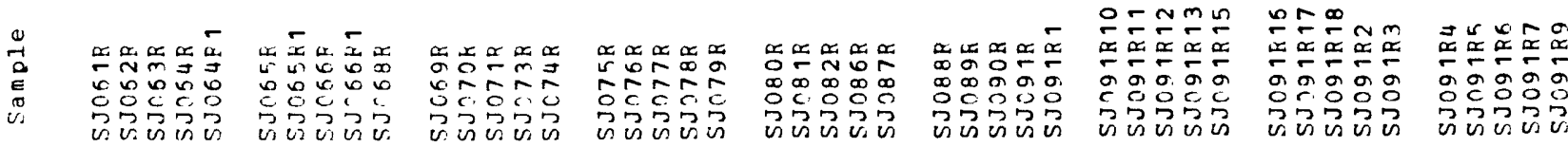




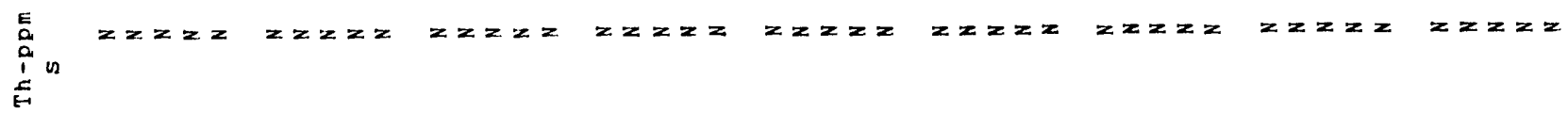

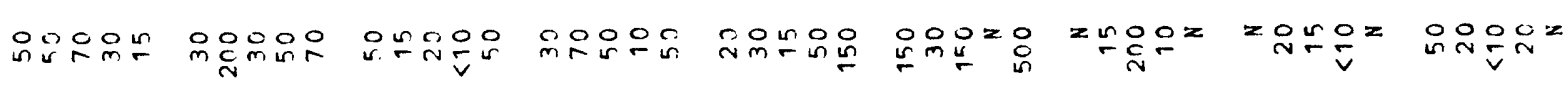

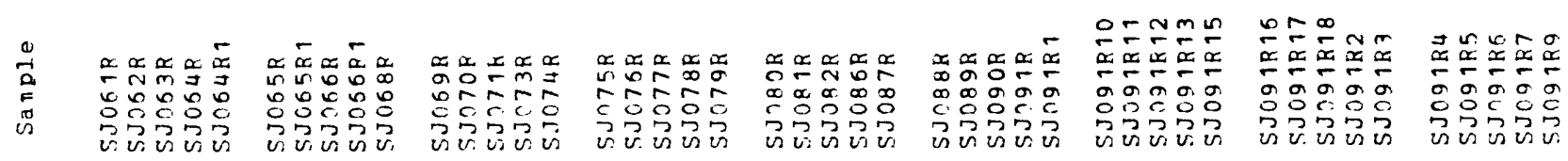




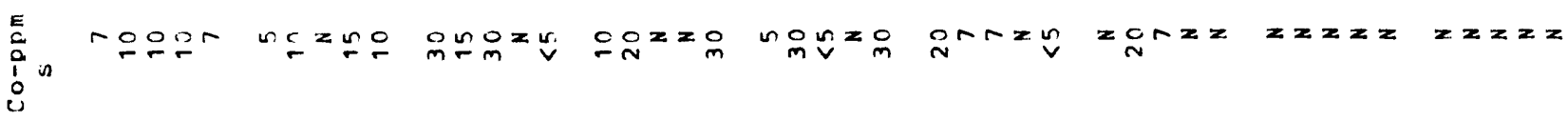
D

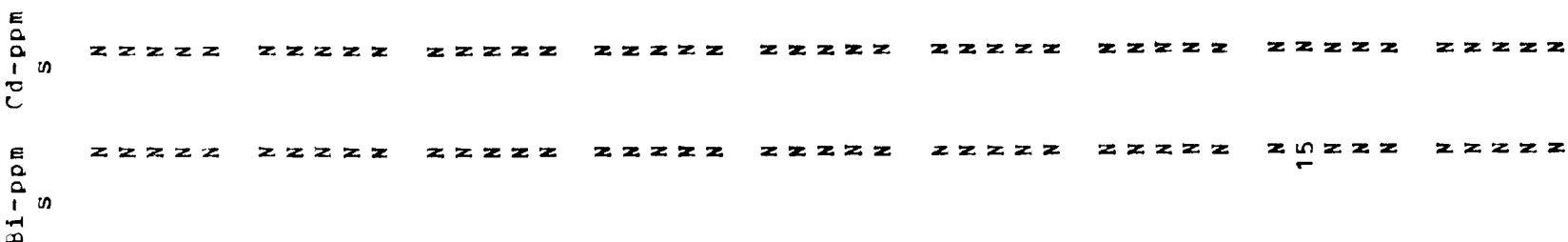

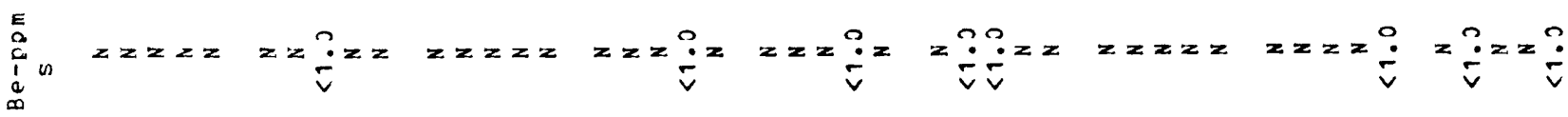

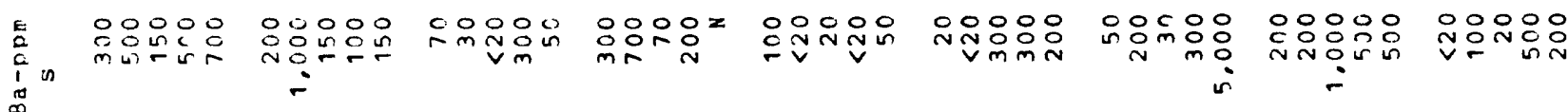

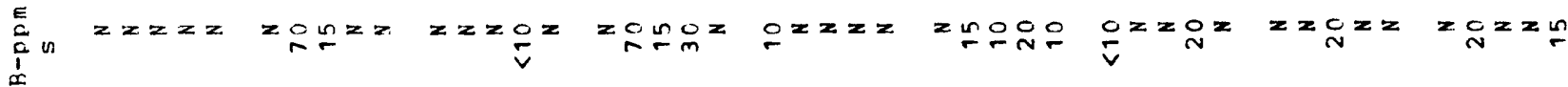

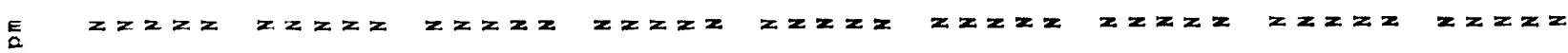
$\sum_{\substack{2 \\ c}}^{1}$

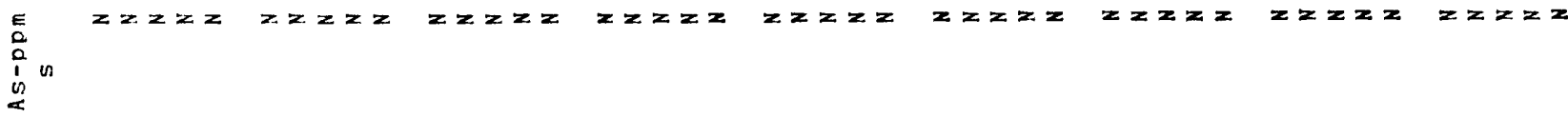

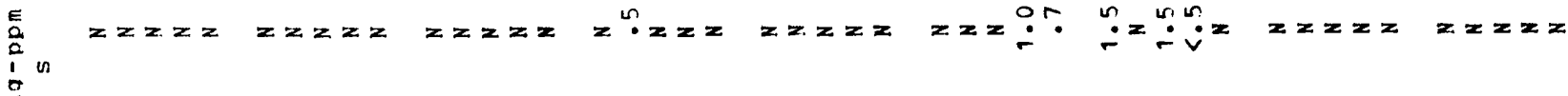

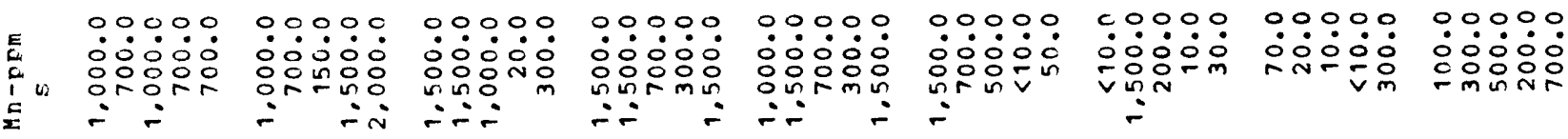

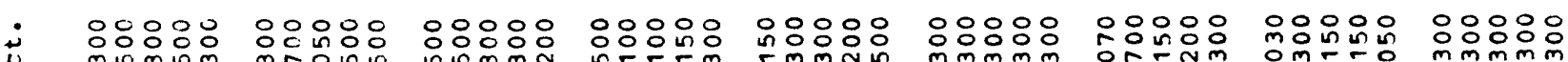

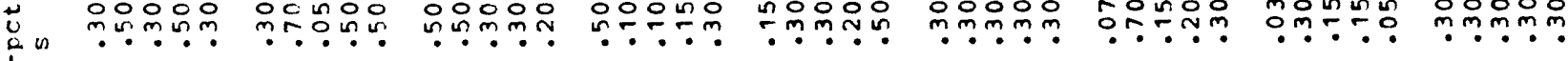
$\rightarrow$

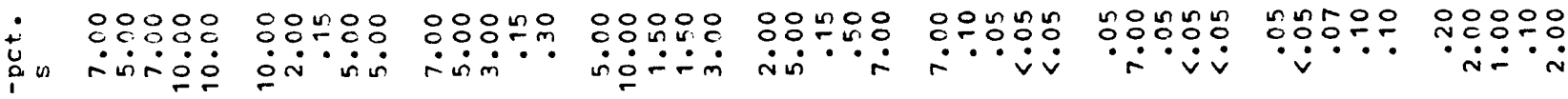
i

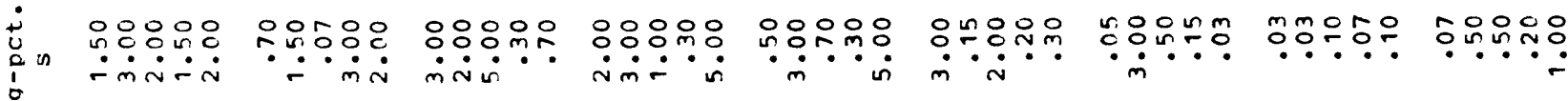

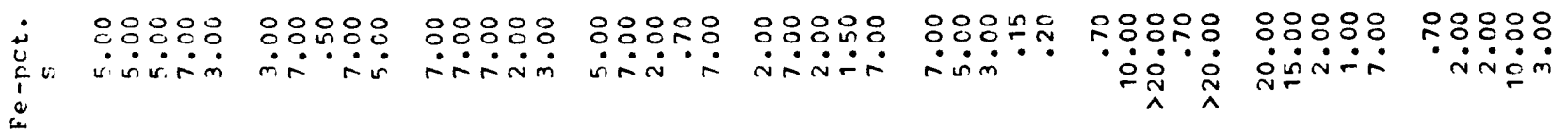

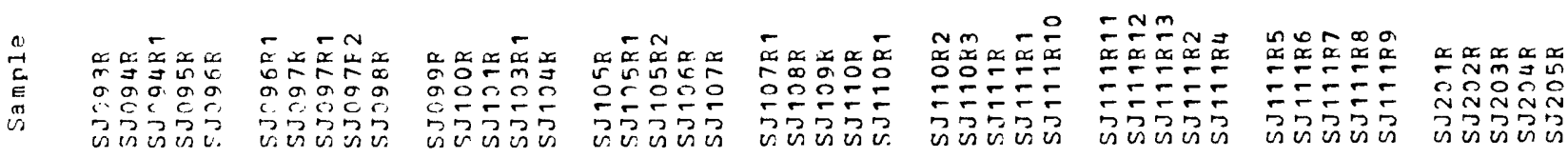




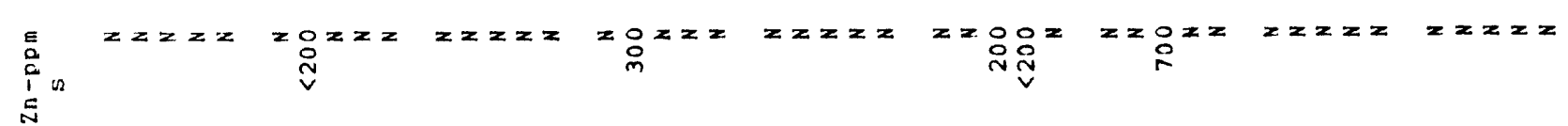

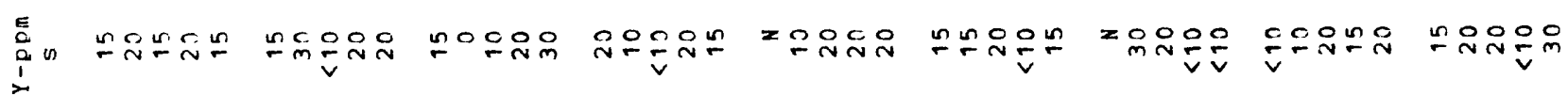
으의

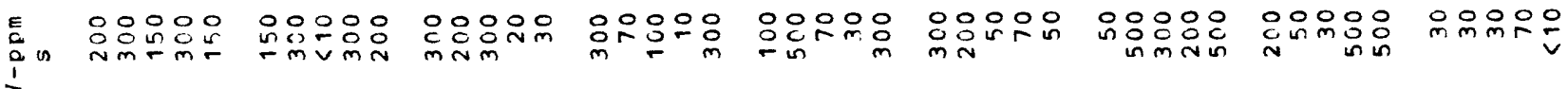

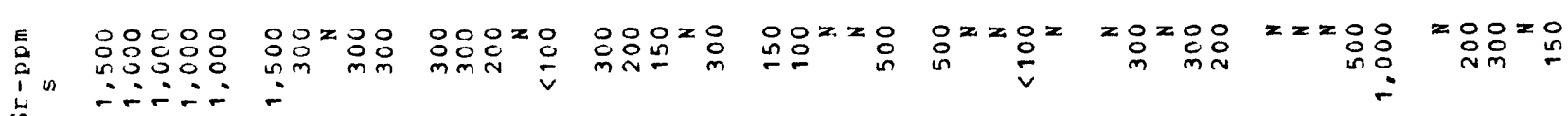

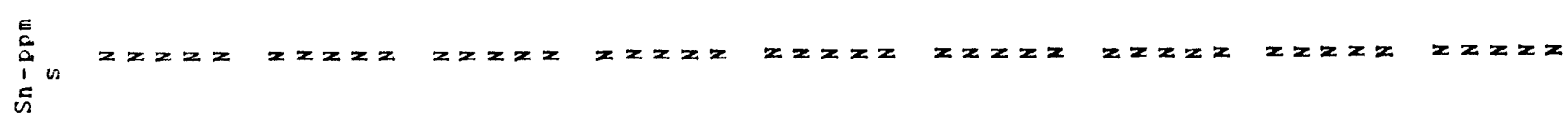

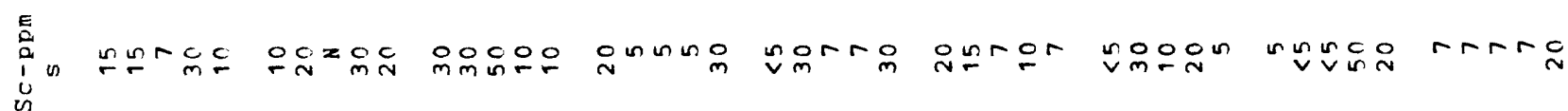

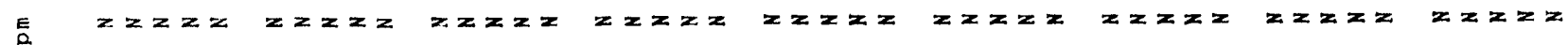
$\stackrel{0}{1} n$

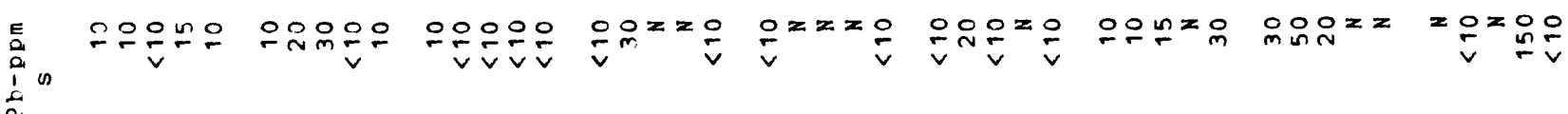

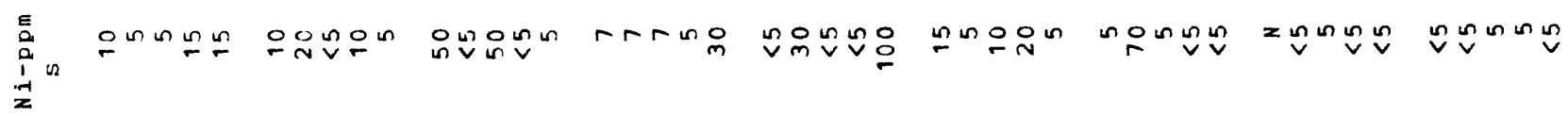

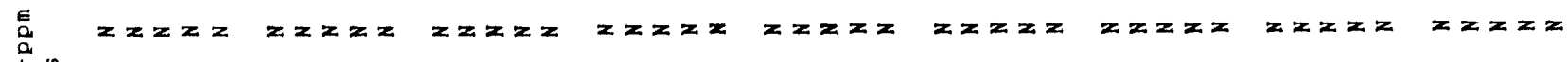
$\stackrel{1}{1}^{1}$ in

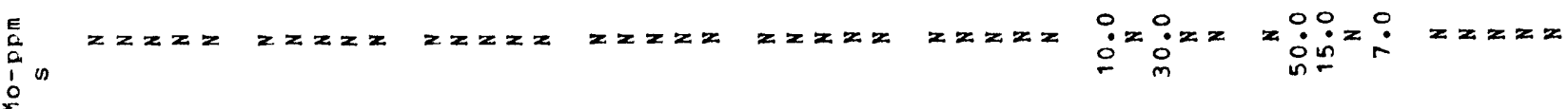

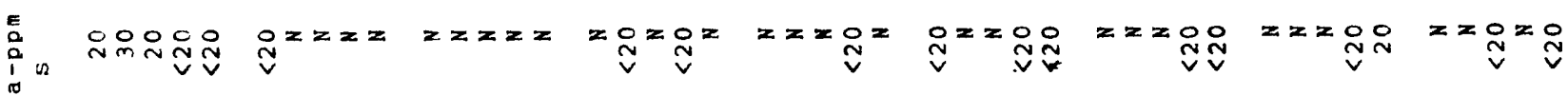
$\stackrel{\pi}{\oplus}$ E

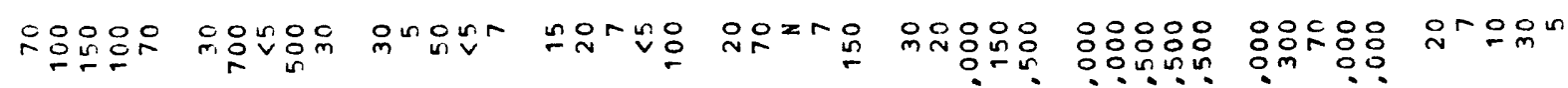

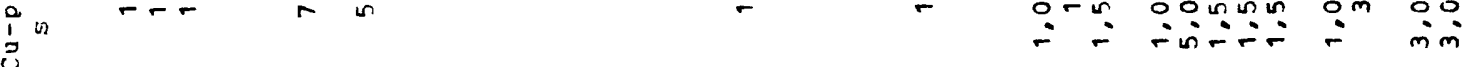

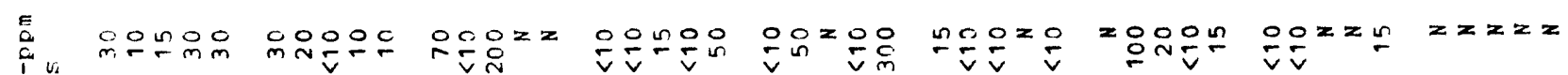
c

\begin{tabular}{|c|c|c|c|c|c|c|c|c|}
\hline 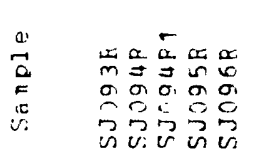 & 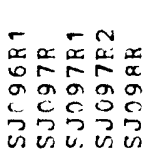 & 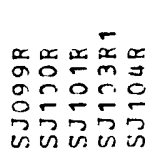 & 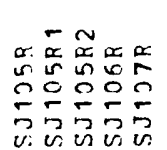 & 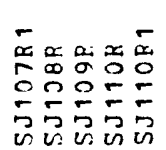 & 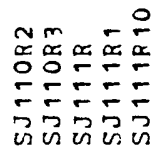 & 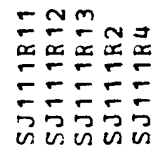 & 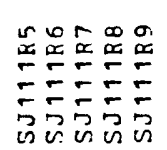 & $\begin{array}{ll}5 \\
\text { on } \\
\text { on } \\
\text { on }\end{array}$ \\
\hline
\end{tabular}




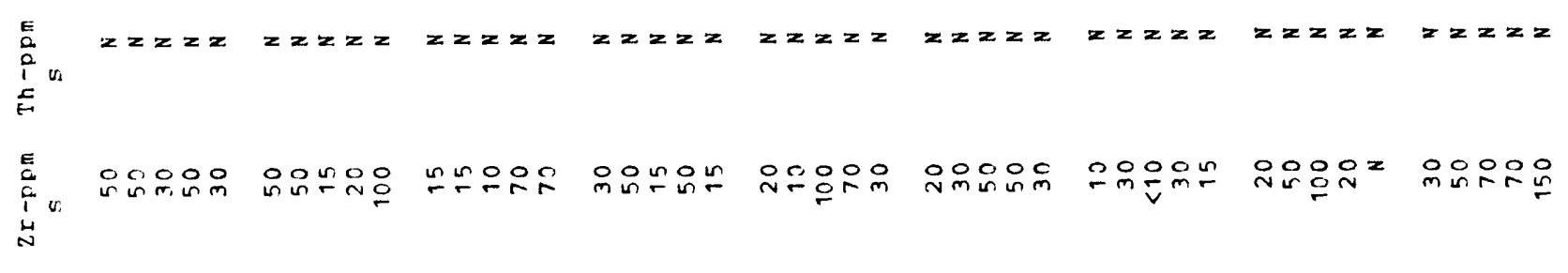

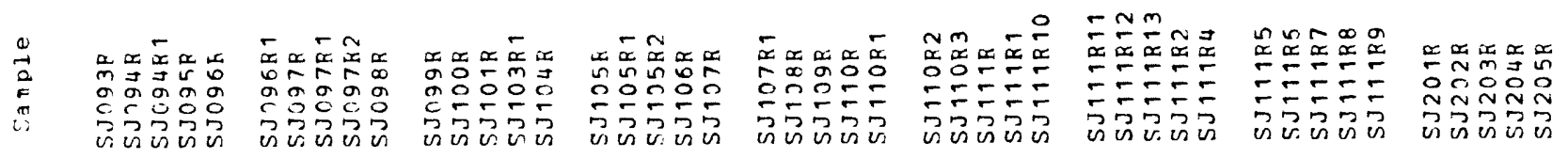




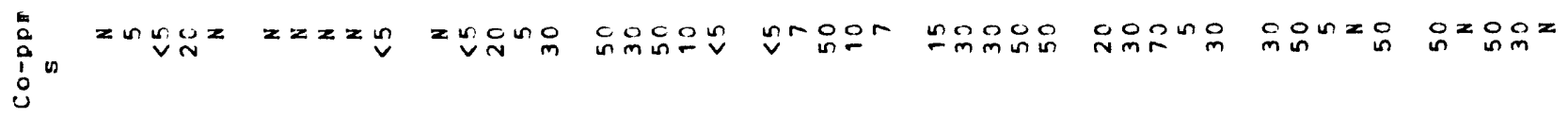

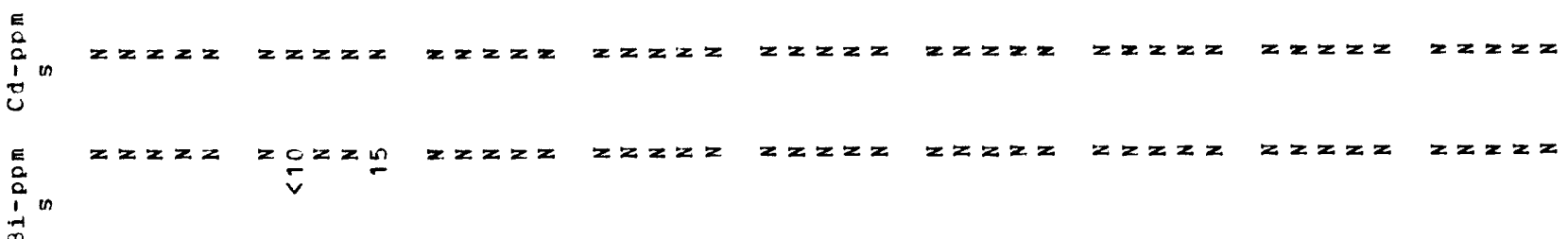

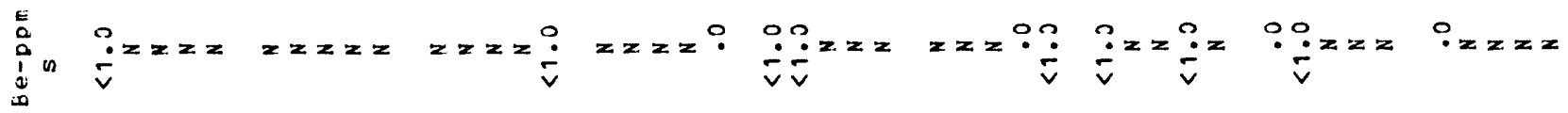

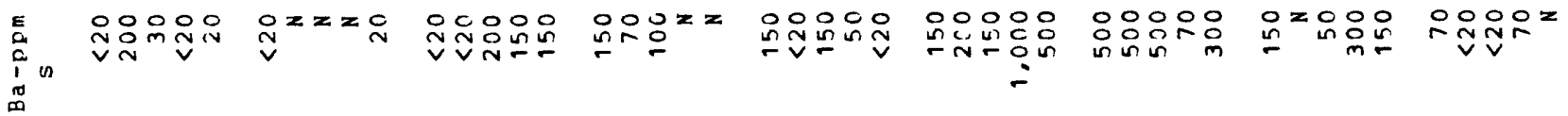

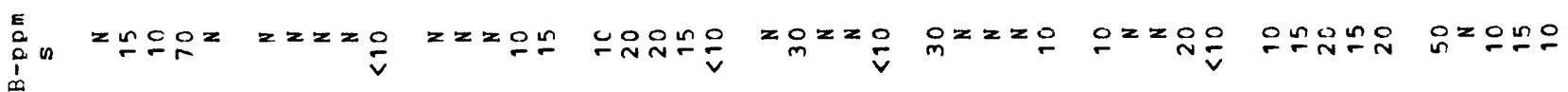

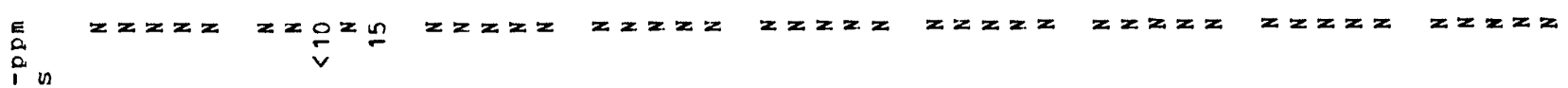
$\stackrel{1}{1}$ in

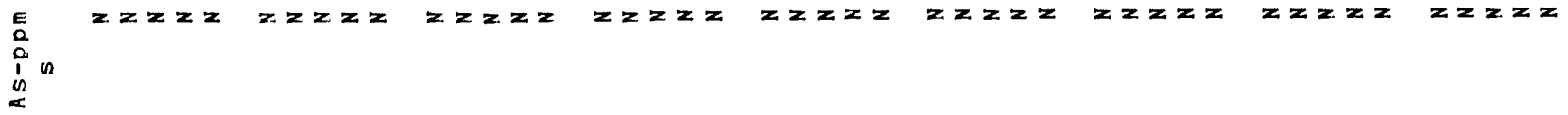

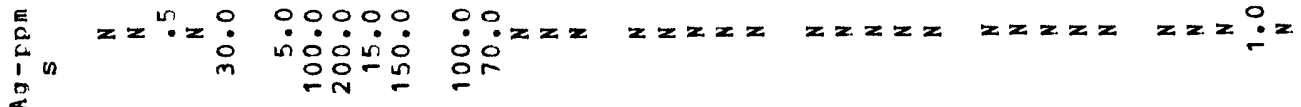

E $\underset{c}{c}$

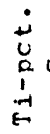
$\dot{0}$
0
0
0
0 is

$\dot{0}$
$\vdots$
$\vdots$
$\vdots$

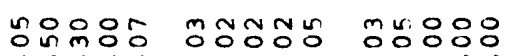
$\because \frac{\dot{n}}{0}$ inis. 00000 $\therefore \dot{0} \dot{0} 0$

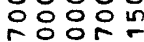
$\therefore$

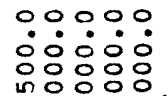
부요

00000 $\therefore \dot{0} \dot{0}:$

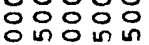

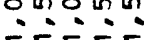

0.000 뭉요

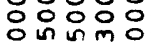
mi:

00000 $\therefore \circ \dot{0} 0$ oomou in:

00000 융ㅇㅇㅇ응 on in

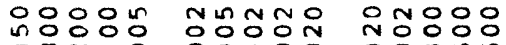

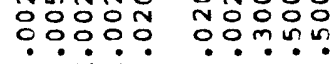

\section{응융ㅇㅇㅇㅇㅛ}

응응ㅇㅇㅇㅇㅜ

00000

응응용ㅇㅇ

응응융응

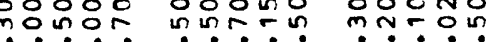

응웅ㅇㅇㅇㅇㅛ U.!.?

ooror nninn ninoo

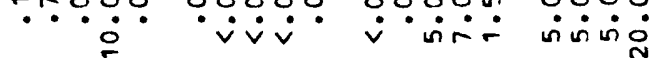

영영으 는응용 inisi: íri

응응ㅇㅇㅇㅇㅇㅇㅇㅇㅇㅇㅇㅇ $\dot{m} \dot{m} \dot{m} \dot{m} \dot{0}$ mingin

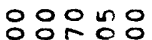
ㅇㅇㅇㅇㅇㅇ mino

.

영영융ㅇㅇㅇㅇㅇㅇ은

응ㅇㅇㅇㅇㅇ 응ㅇㅇㅇ응 $\dot{\sim} \dot{\sim} \dot{m} \dot{n} \dot{m} \dot{m} \dot{m}$

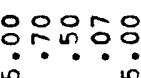

응응영용요

$\stackrel{2}{2}$

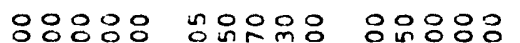
-min\&

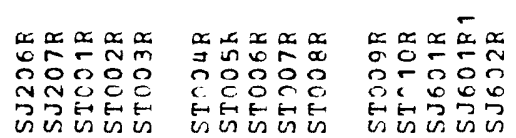

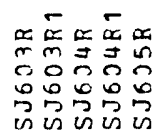

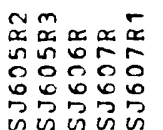

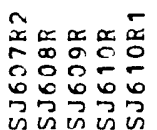

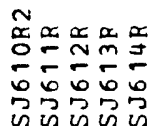

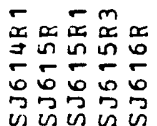

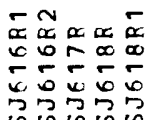




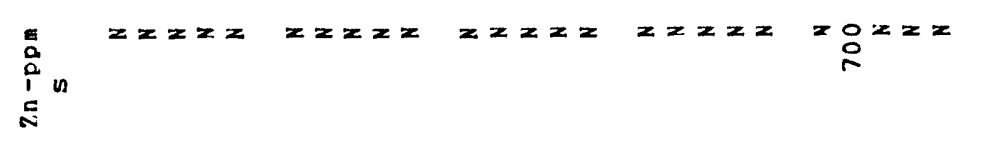

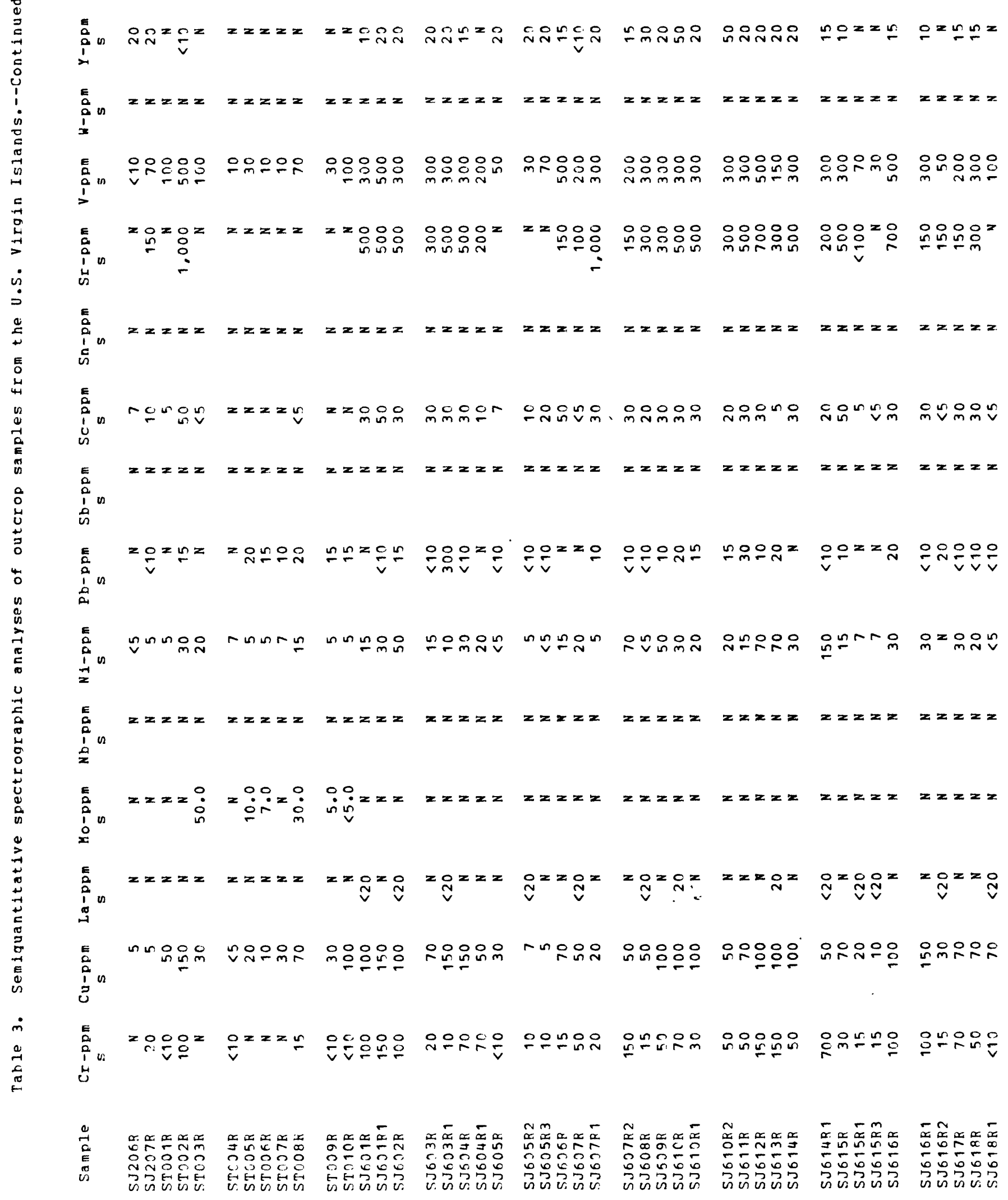


E⿱

$\frac{1}{2}$

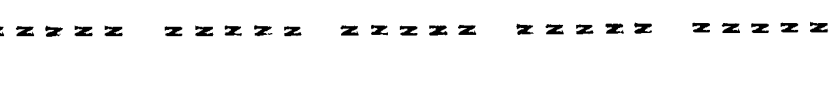

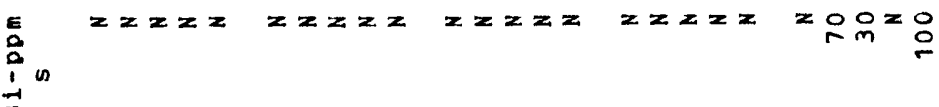

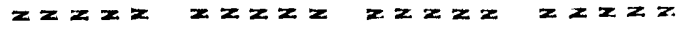

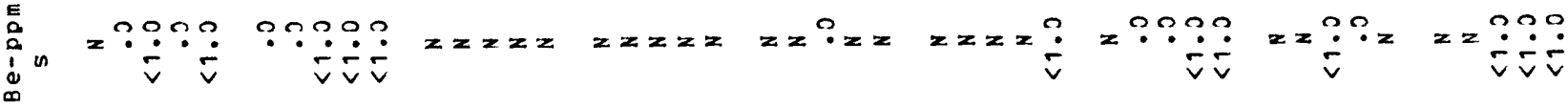

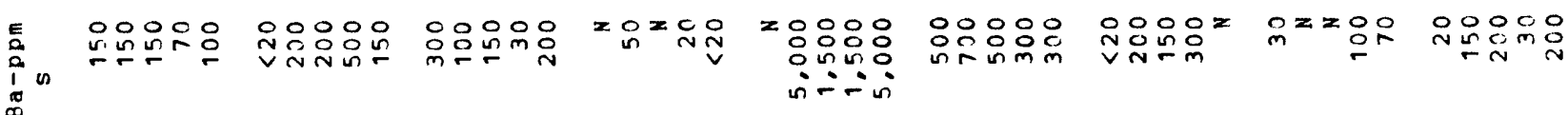

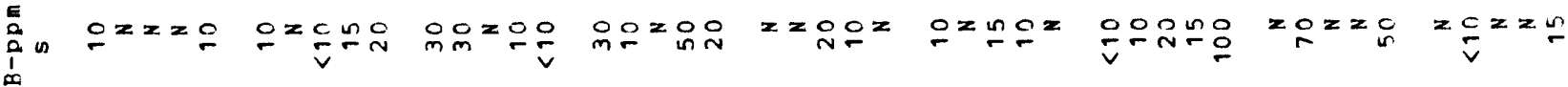

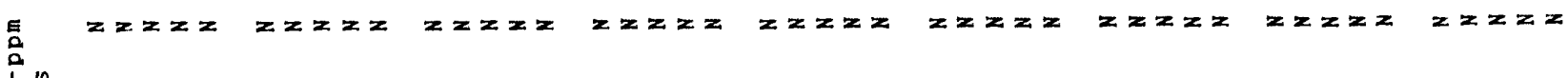
$\operatorname{lin}_{2}$

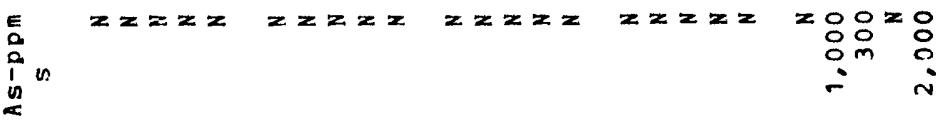

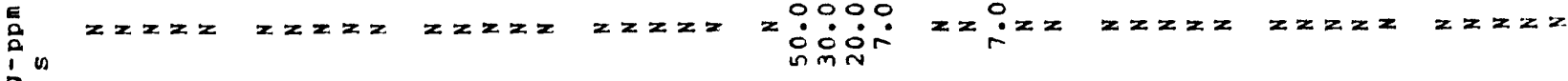

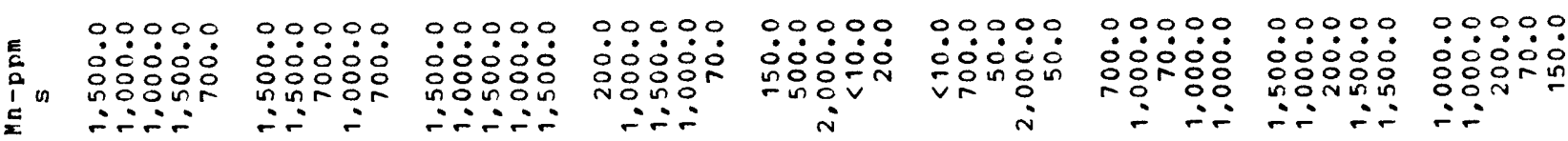

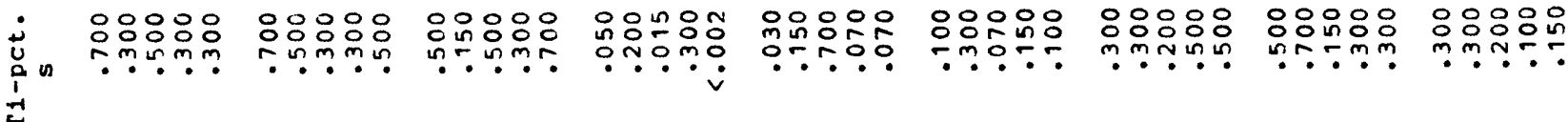

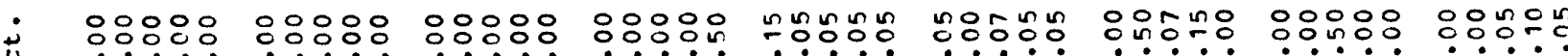

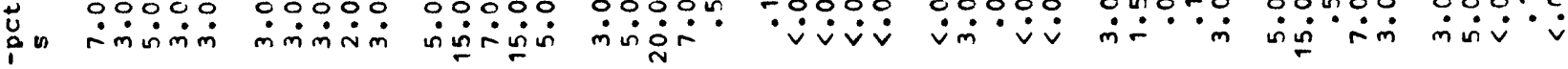
i)

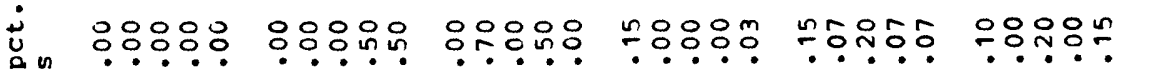

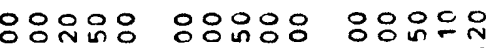

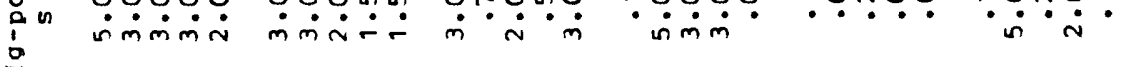

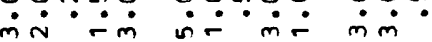

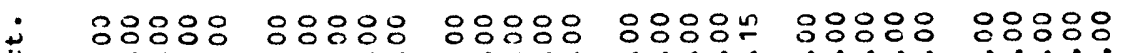

in

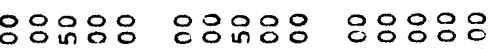
$\stackrel{i}{i}$

$\dot{m} \dot{m} \dot{0} \dot{n}$ viririn

$\dot{n} \dot{\sim} \dot{i} \dot{\sim}$

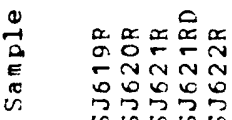

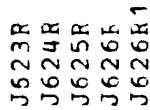

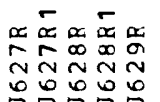

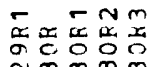

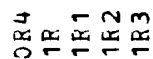

N⿳⺈⿴囗十⺝⿱⺈⿻コ一心

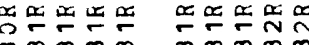

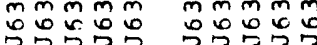

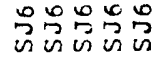

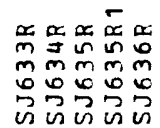

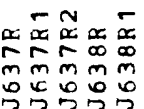

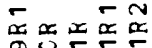

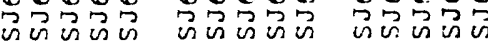

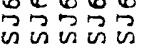

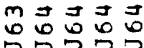

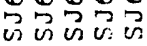




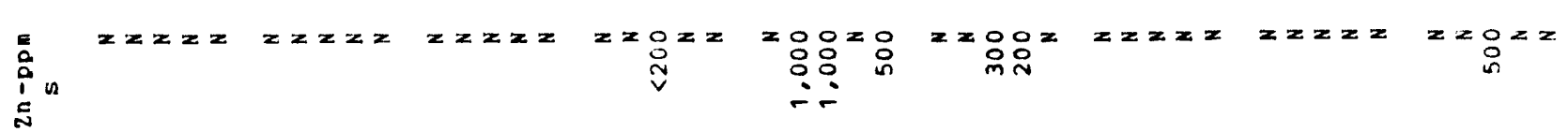

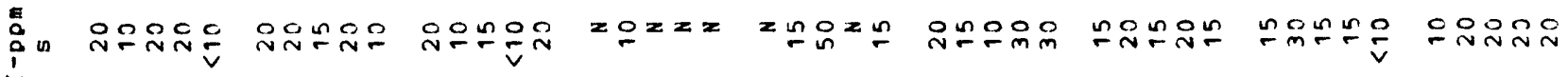

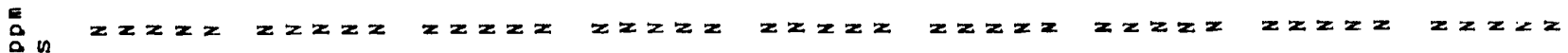

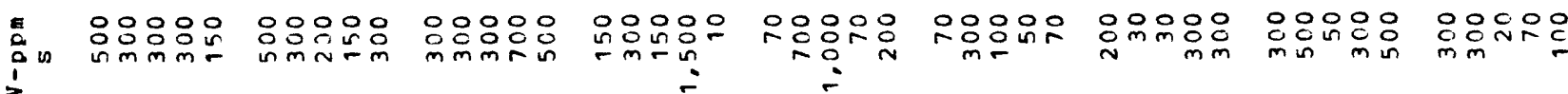

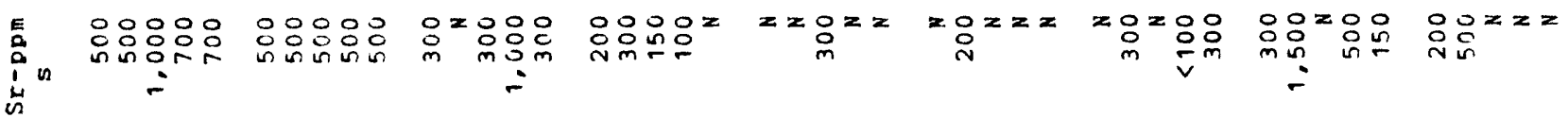

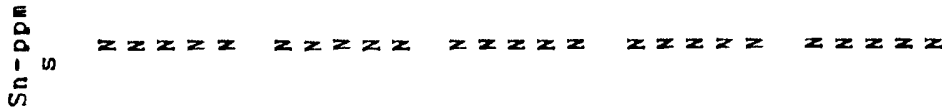

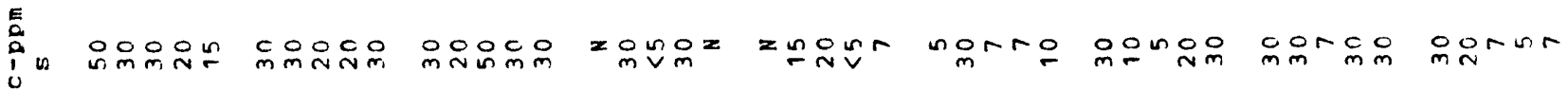

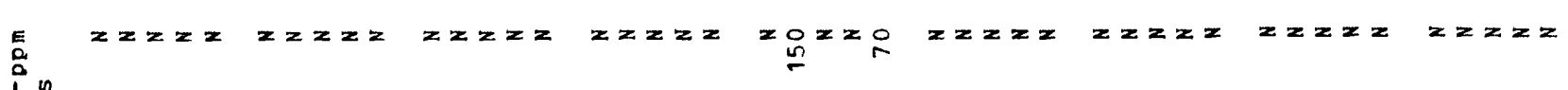
is

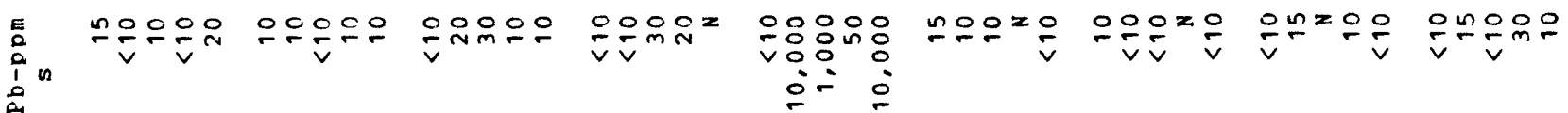

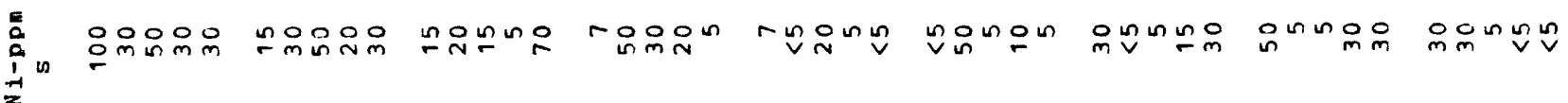

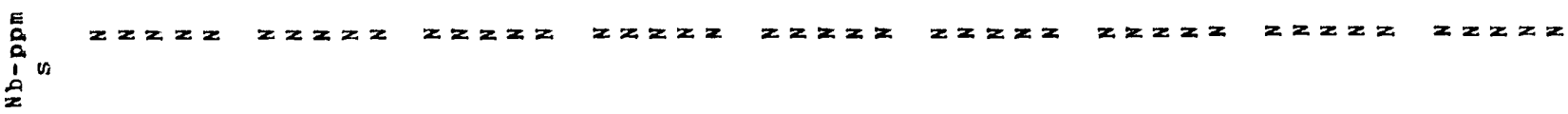

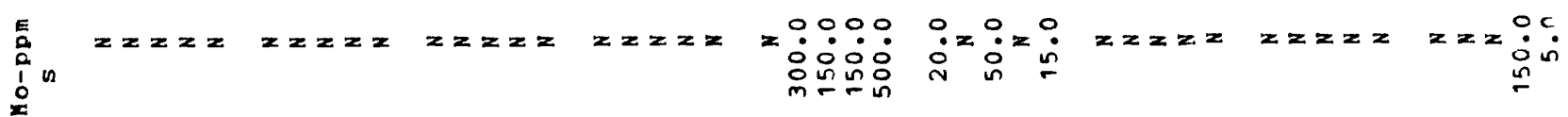

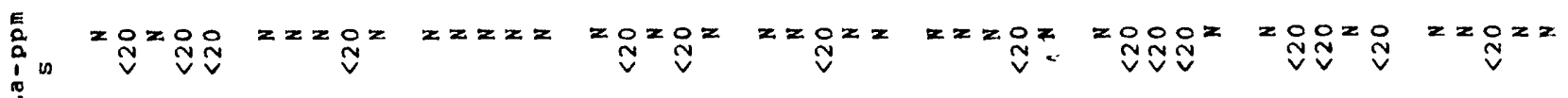

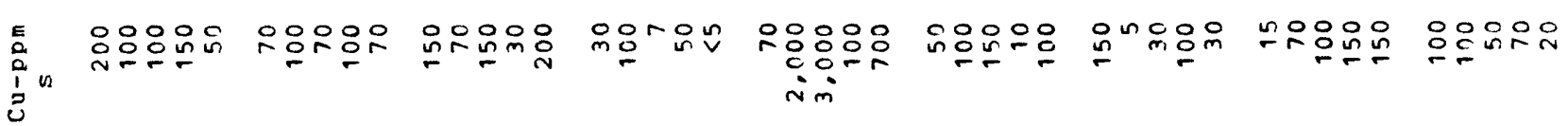

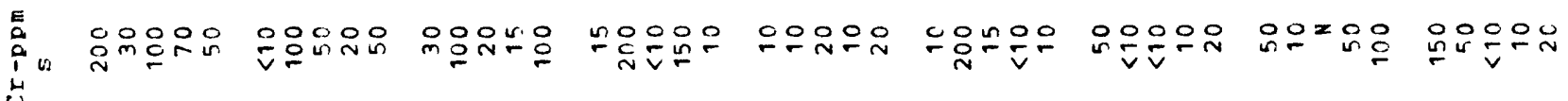

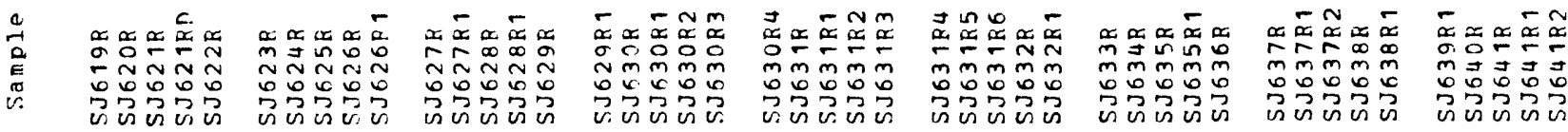




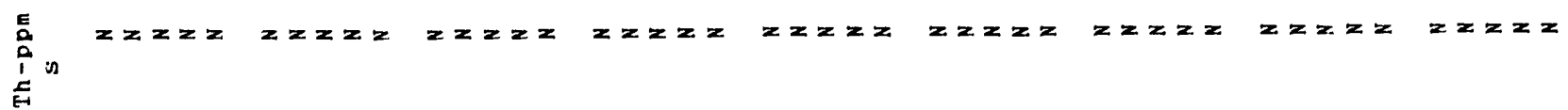

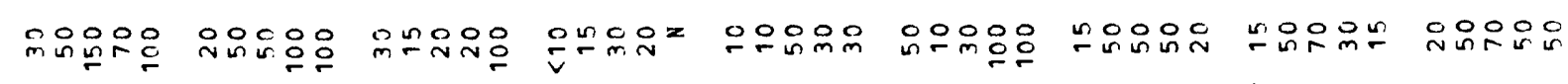

$$
\begin{aligned}
& \text { 站 }
\end{aligned}
$$

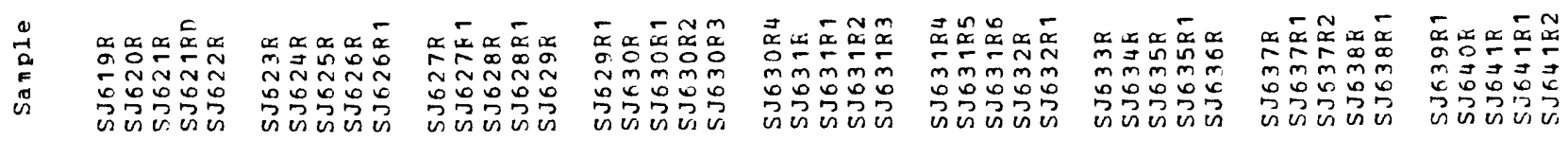




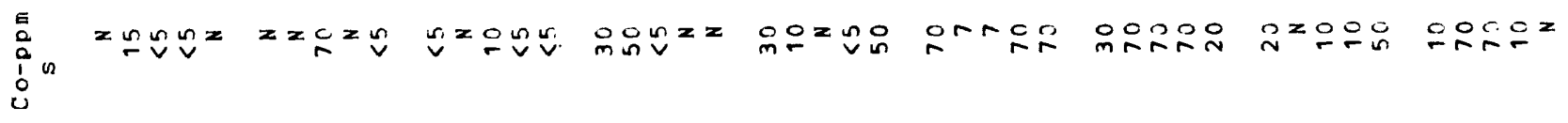
D

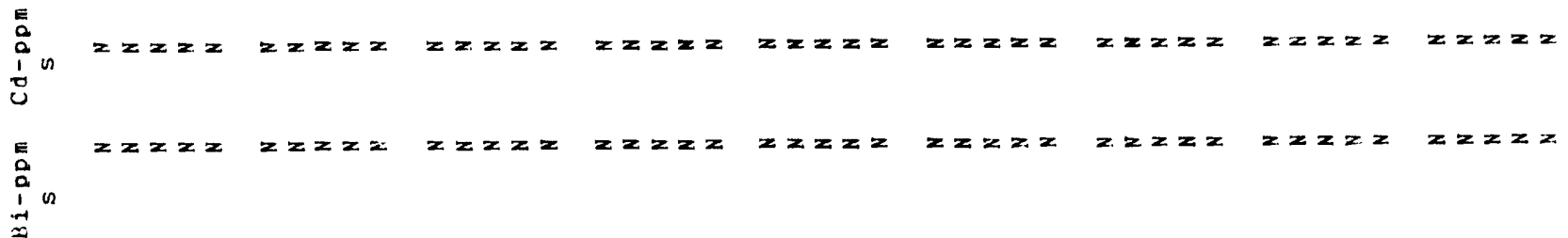

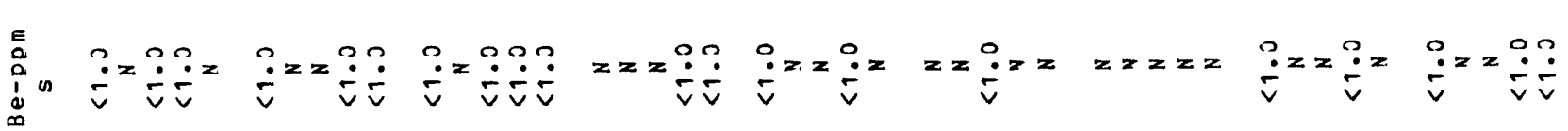

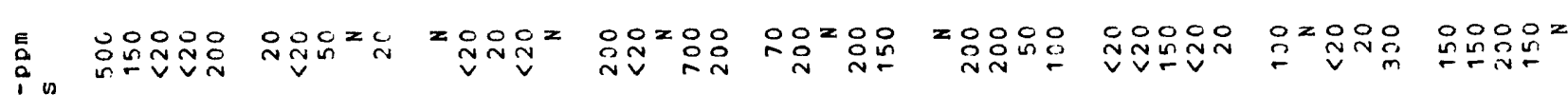
in

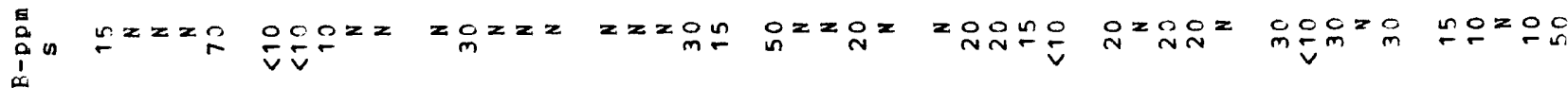

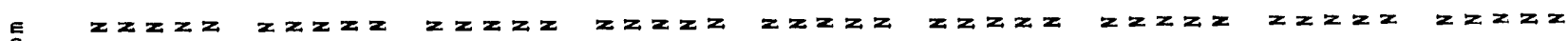
$\underset{2}{1}$

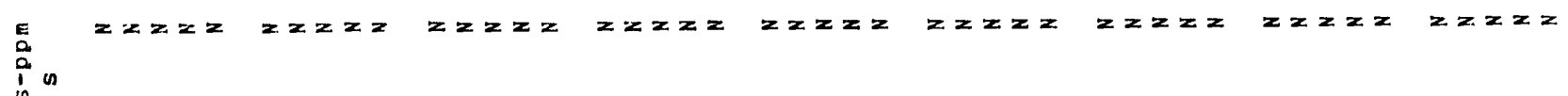
总 $z z z=\stackrel{n}{i} \quad z z z z z \quad z z z z z$

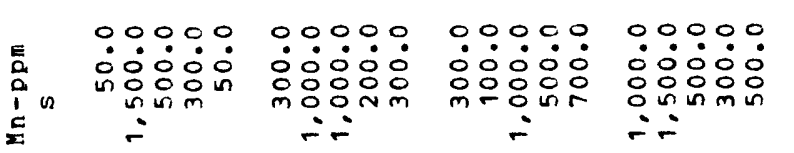

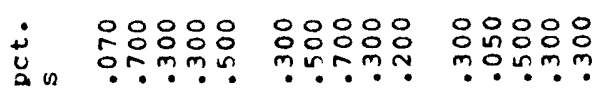
$i^{2} n$

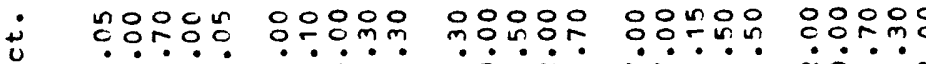

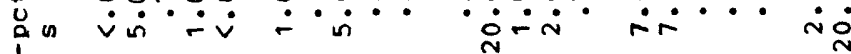
i $\dot{r}$

00000

\section{$\circ \circ \circ \circ \circ$}

oonoo

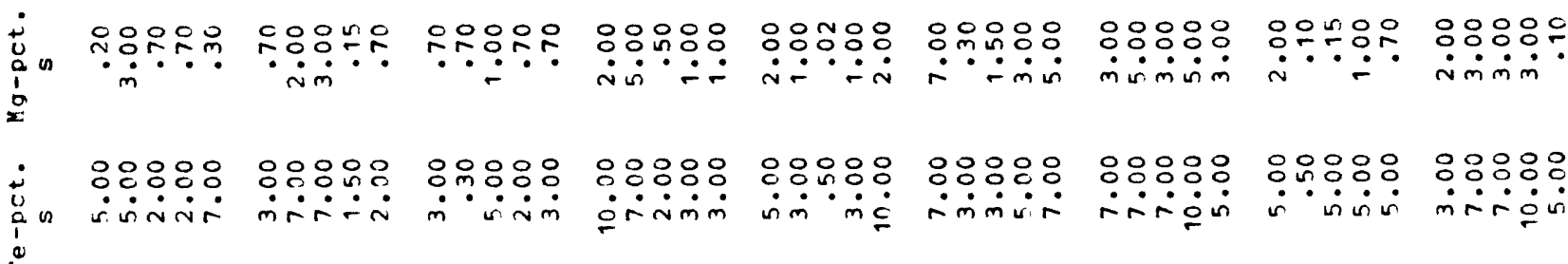

\begin{tabular}{|c|c|c|c|c|c|c|c|c|}
\hline 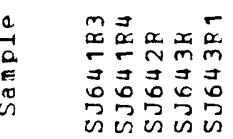 & 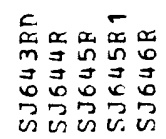 & 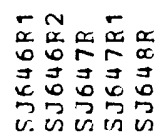 & 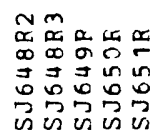 & 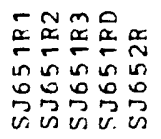 & 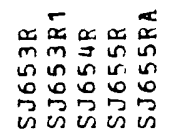 & 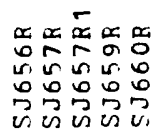 & 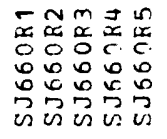 & 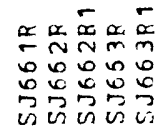 \\
\hline
\end{tabular}

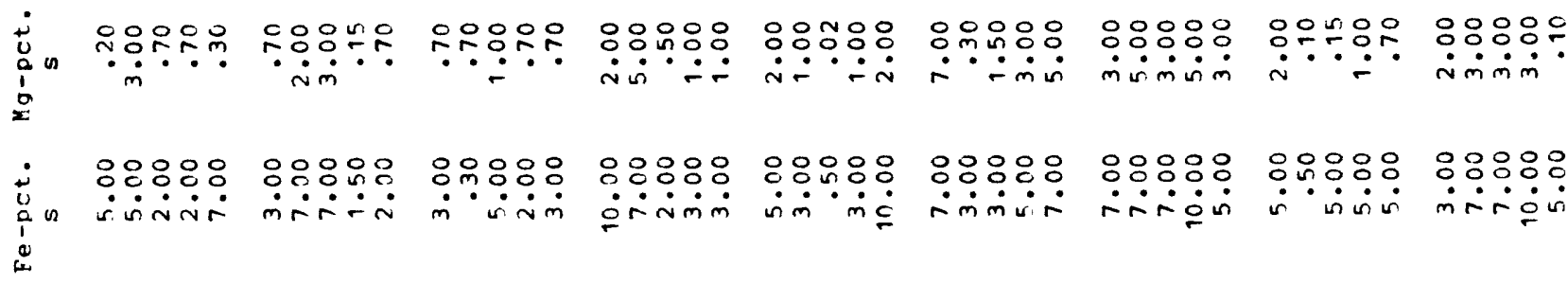

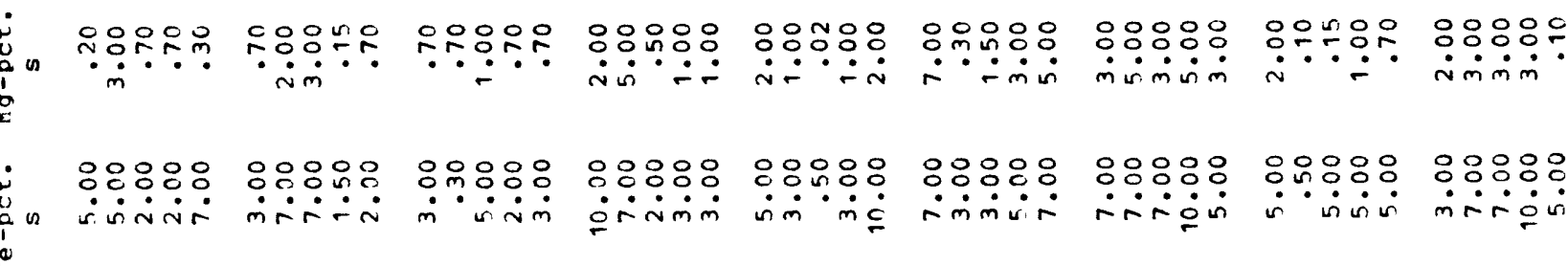

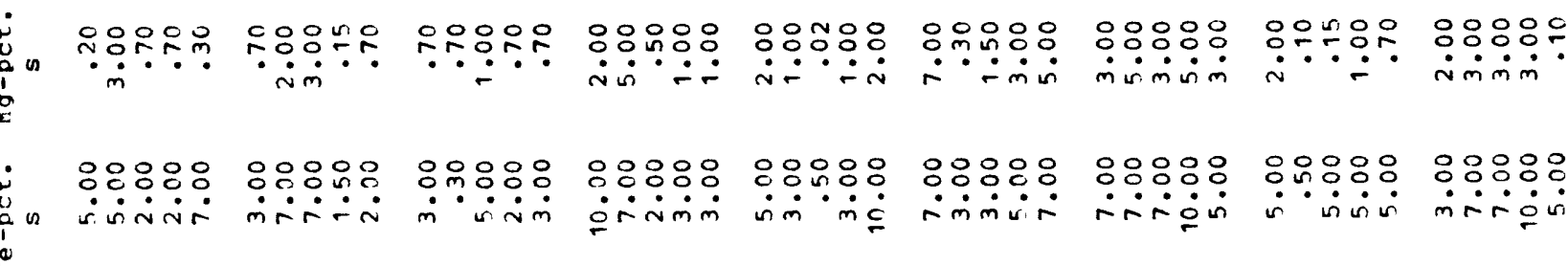

$0: 000$
0
0
0

00000

00000

$\therefore \therefore \therefore \circ:$

응응ㅇㅇㅇㅇㅇㅇ

$\because$ in $\because$ ?

$\because \because \because 9$

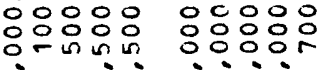

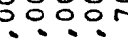

영ㅇㅇ 웅ㅇㅇ웅

동ㅇㅇㅇ

ㅇㅇㅇㅇㅇㅇㅇㅇㅇ

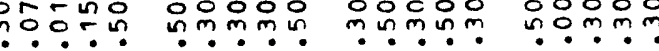

m.?.:? 


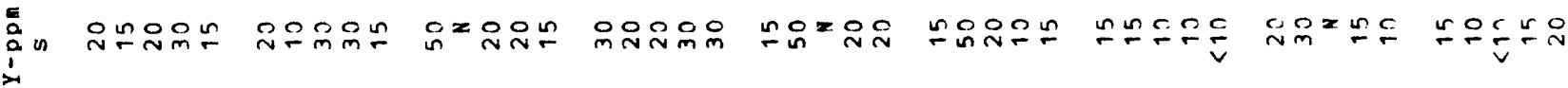

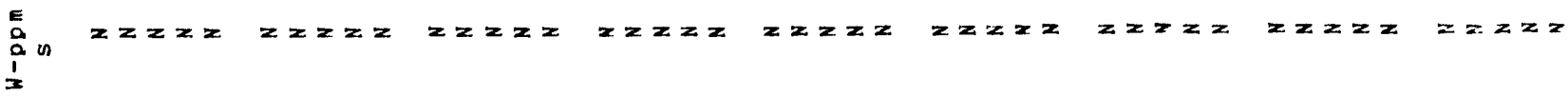

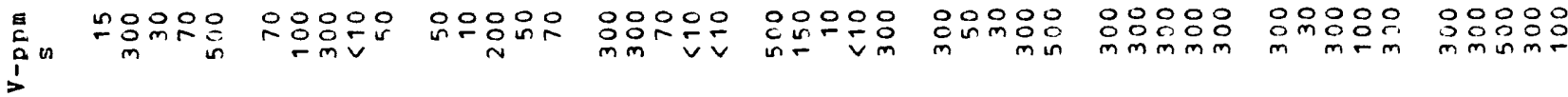

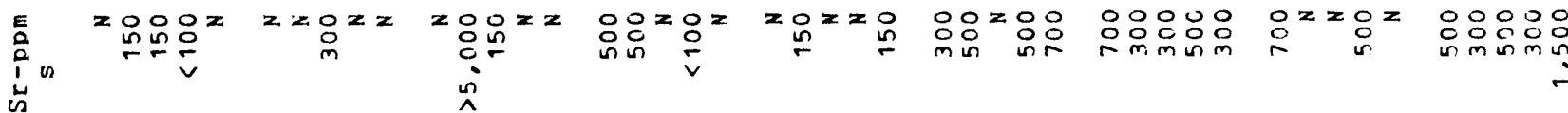

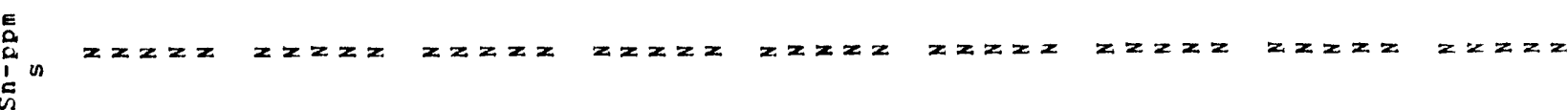

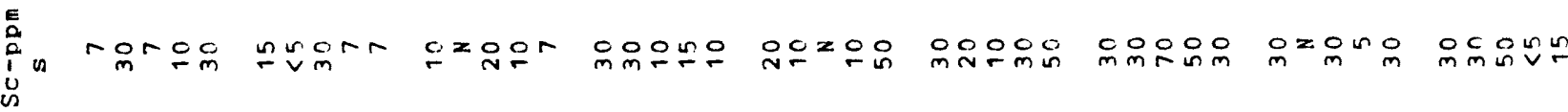

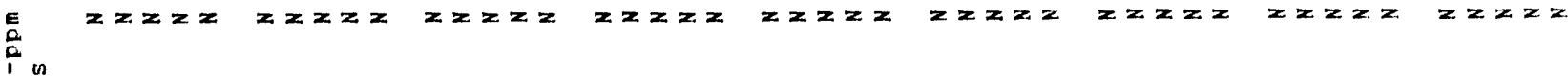
$i^{1}$

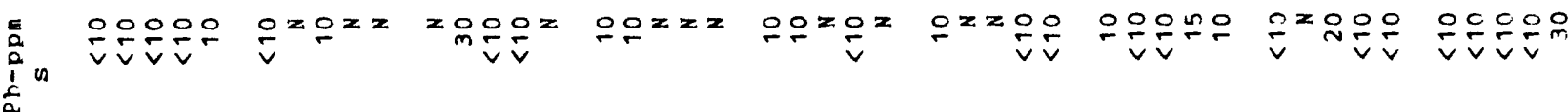

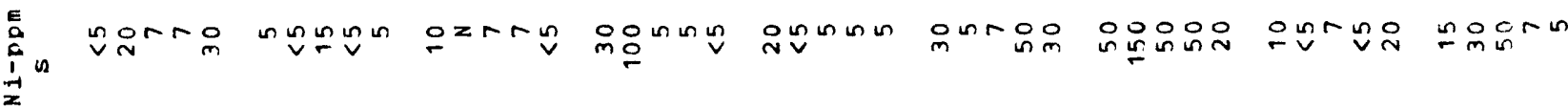
E $i^{1}$

i⿱

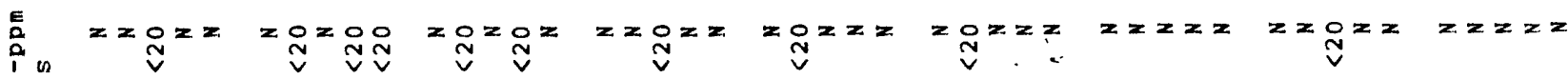

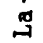

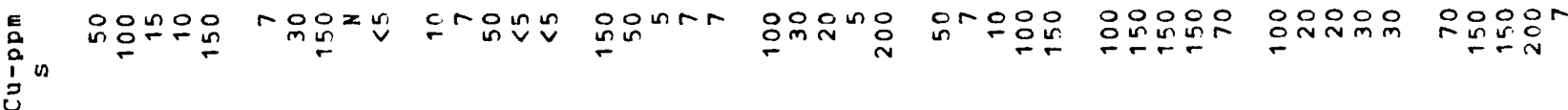

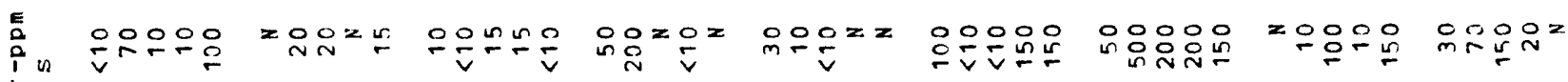
$\mu$

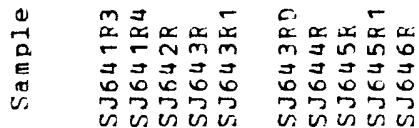

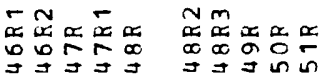




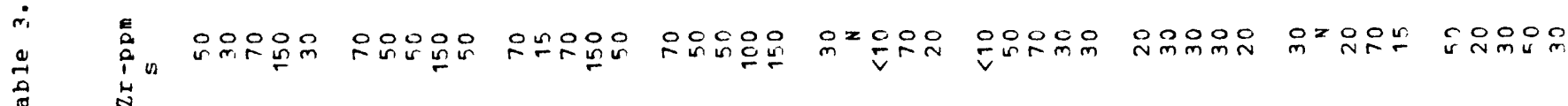

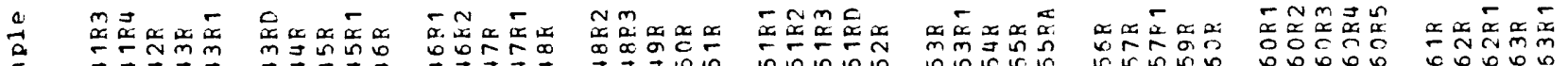

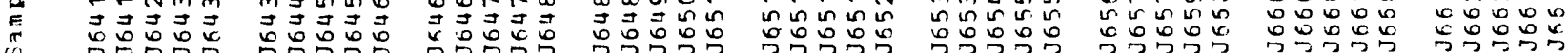

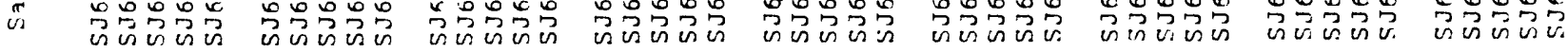




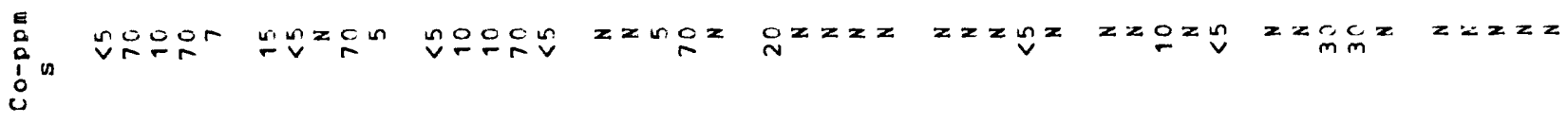

造

$\sum_{0} \quad z z z z=z z z$

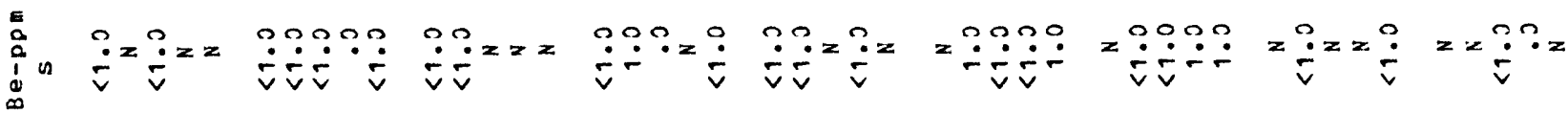

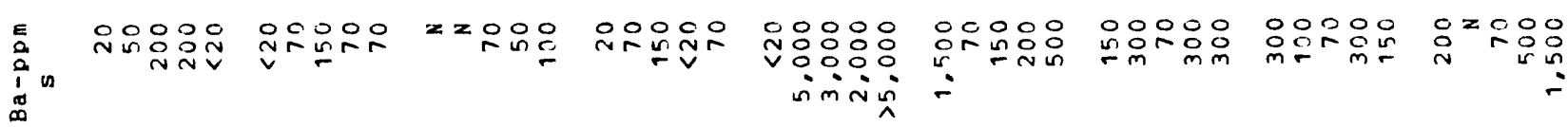

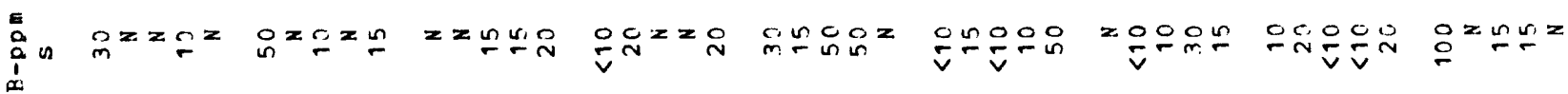

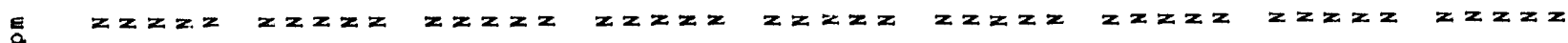
$\stackrel{3}{i}$

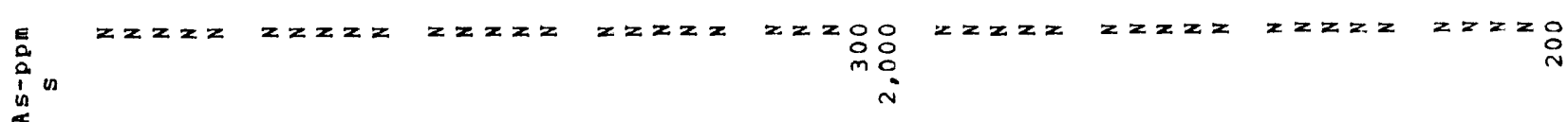

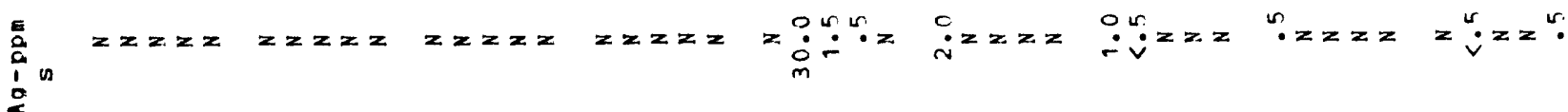

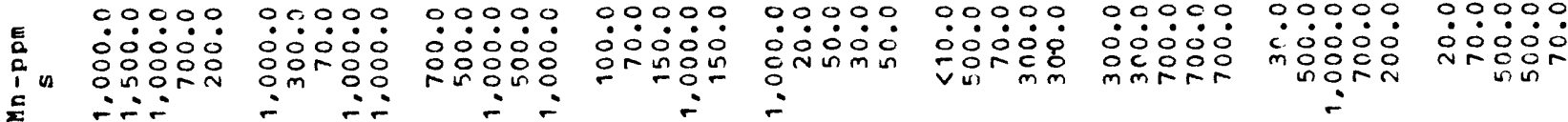

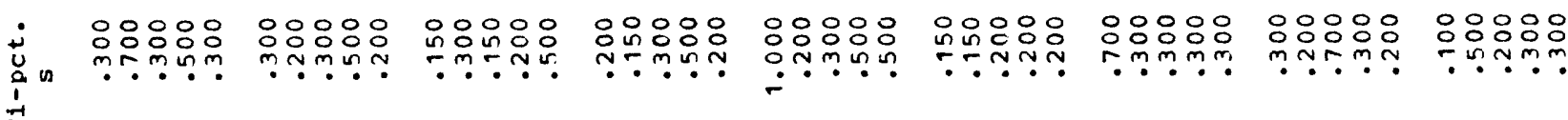

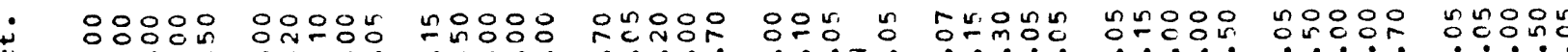
䓪

$\stackrel{\leftrightarrow}{0}$

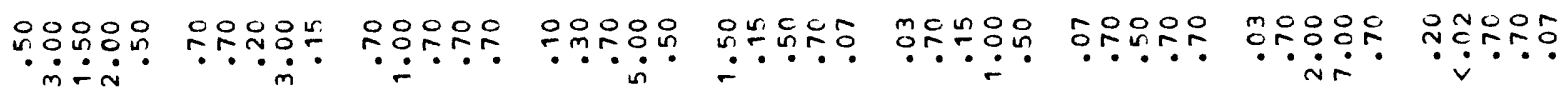

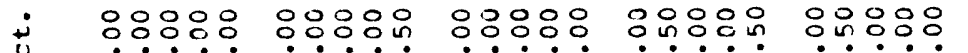

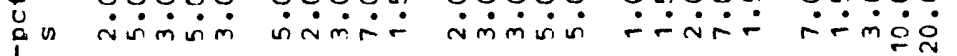
응응유 응응유 응응응

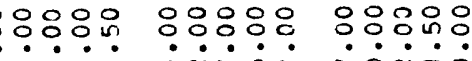
$\underset{\substack{m \\ \stackrel{0}{0}}}{\stackrel{0}{\infty}}$

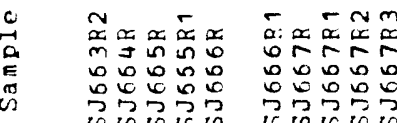

$\approx \underset{\alpha}{\infty} \underset{\infty}{\infty} \vec{\alpha}$

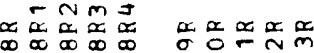
요요

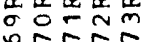

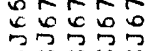

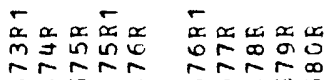

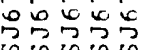




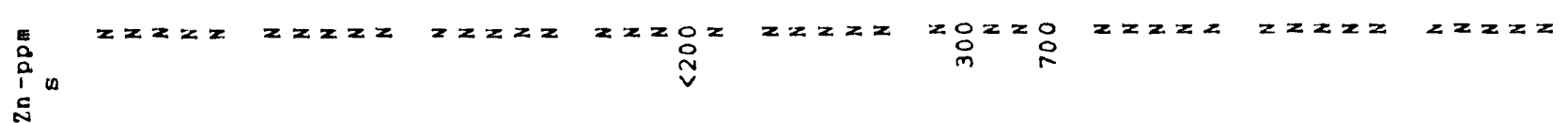

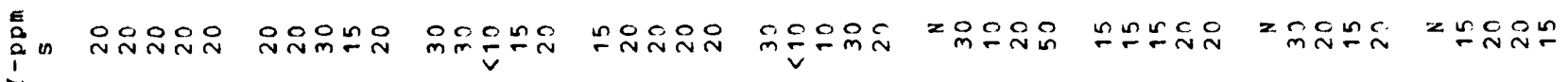

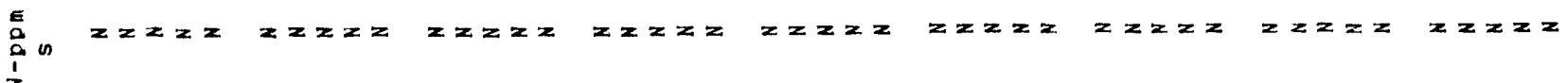

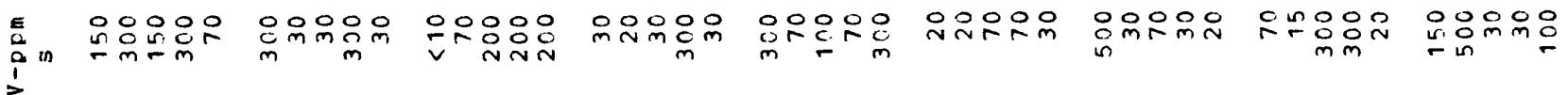

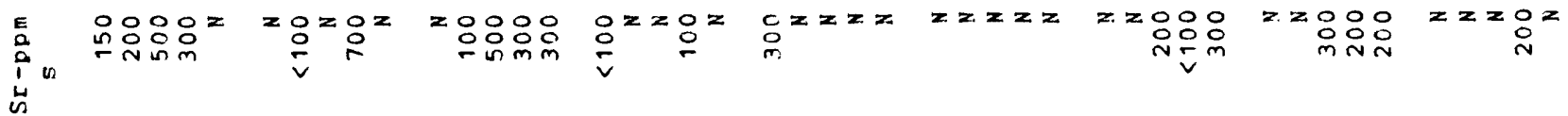
兽

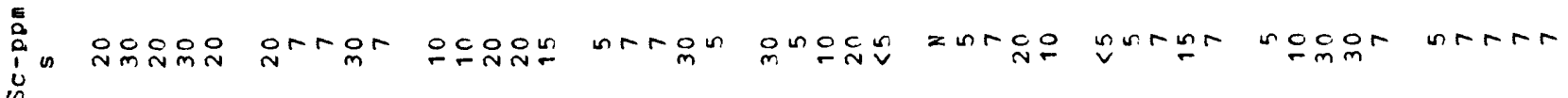

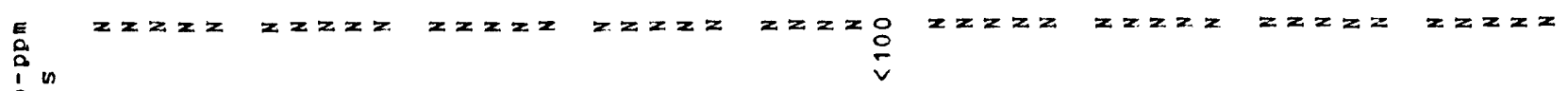
in

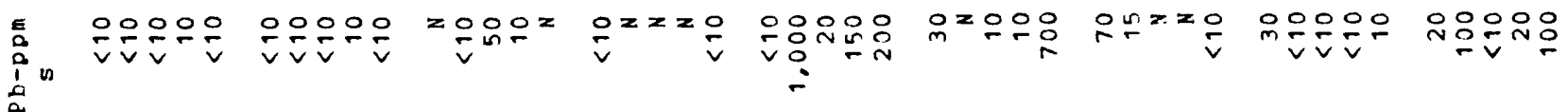

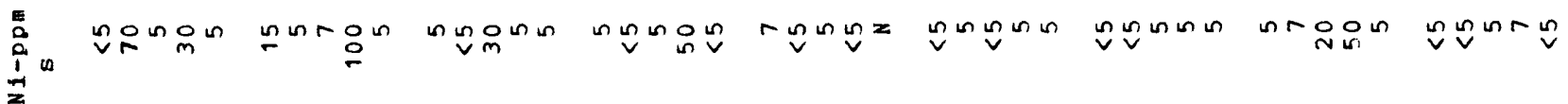
E

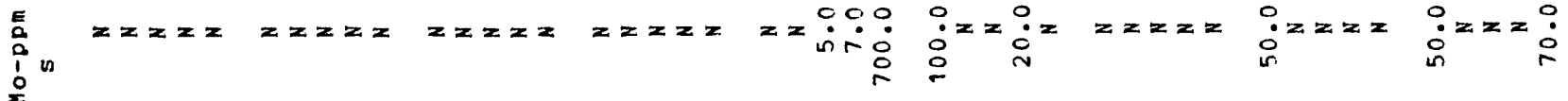

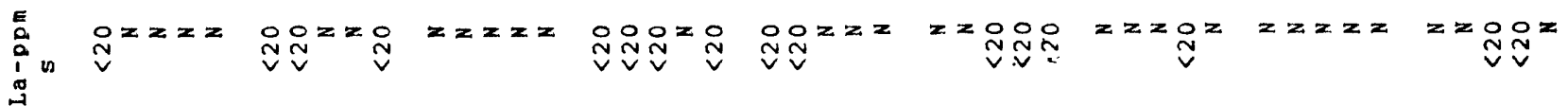

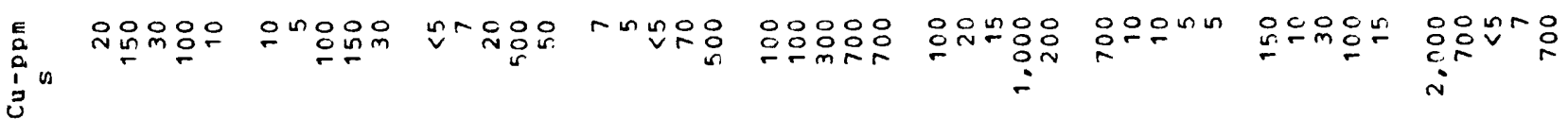

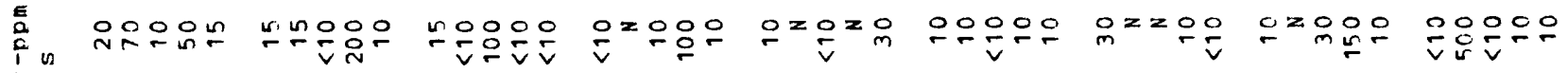
U

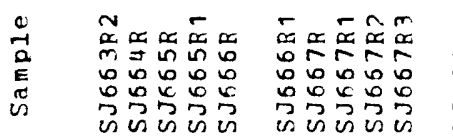

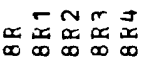

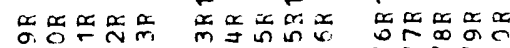
c00

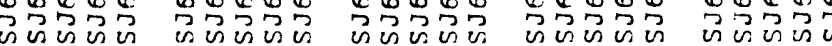

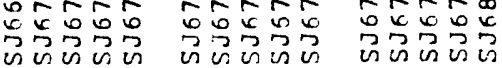

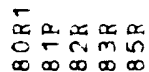

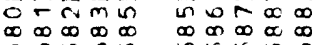

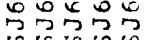

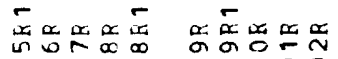

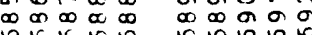

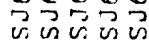


E⿱

$z z z z z \quad z z z z z \quad z z z z z$

$z z z z$

$z 2 z 2$

$z z z z$

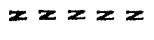

$z z z z$

$z=z z$

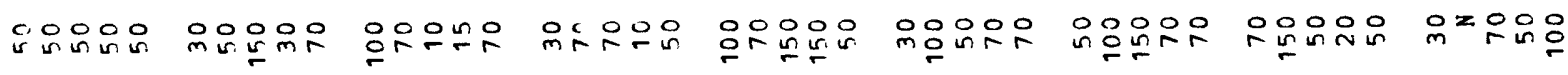
岕

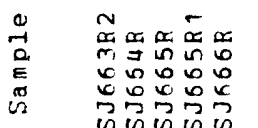

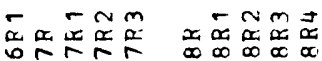
0 正它 0

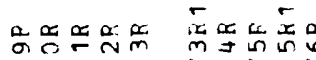

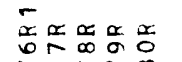

$\bar{x} \simeq \stackrel{\infty}{\sim}$

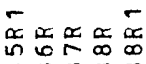

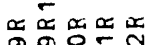

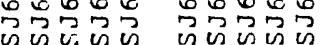

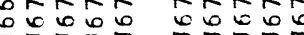

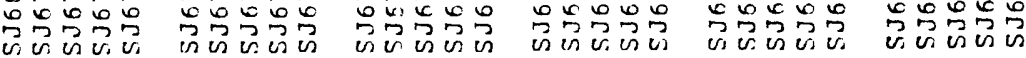

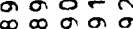

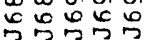




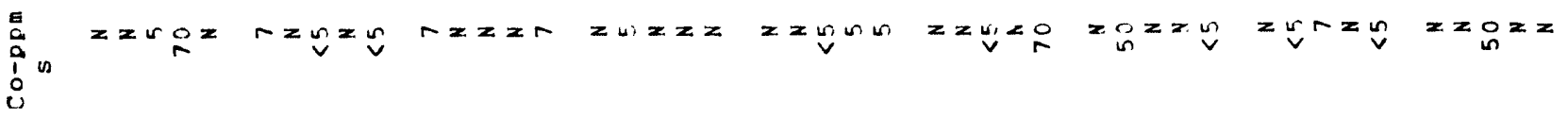

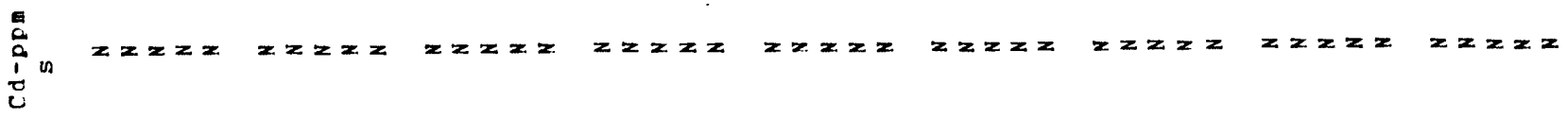

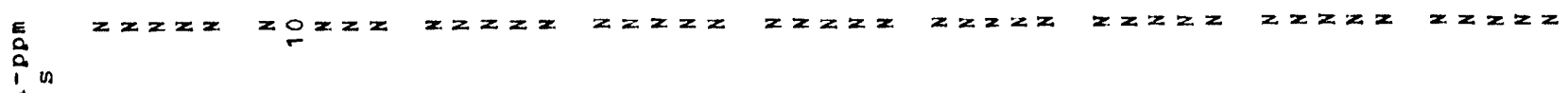

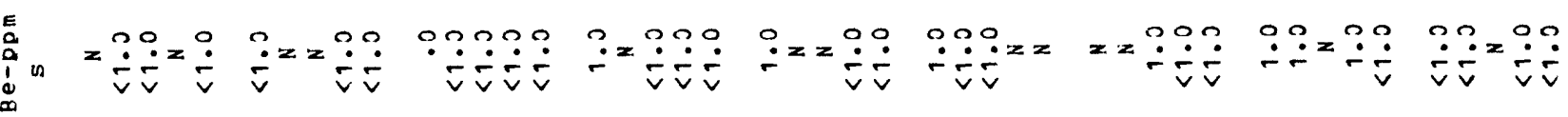

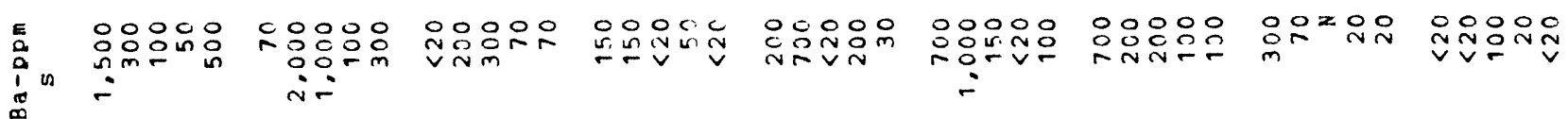

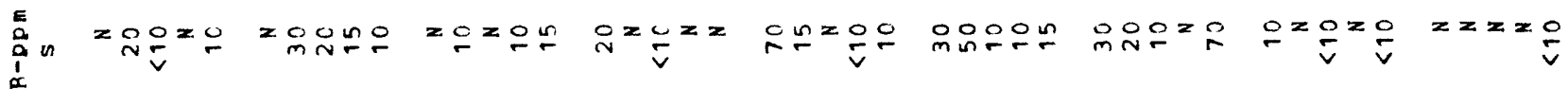

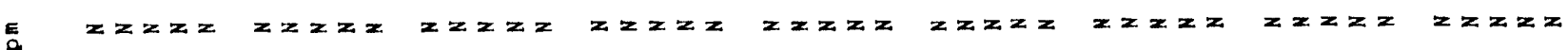
$\frac{a}{2}$ (

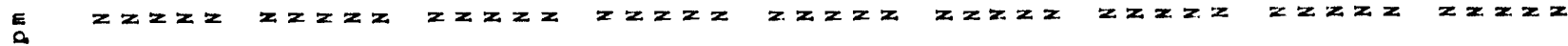
$\sum_{i}^{2} n$

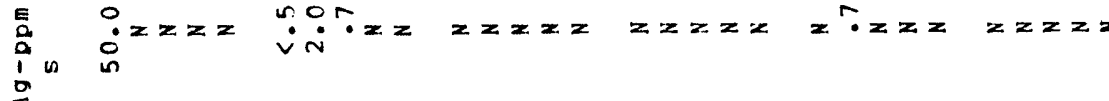

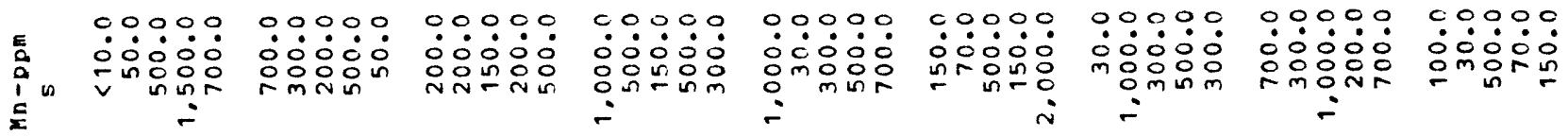

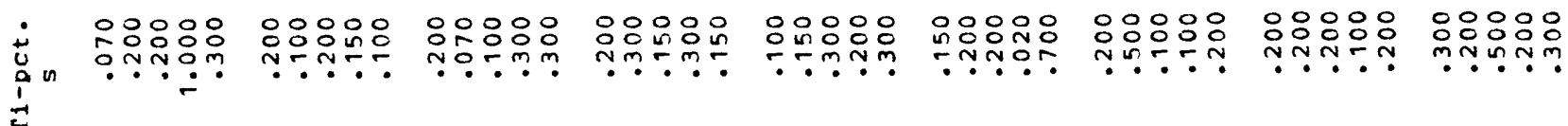

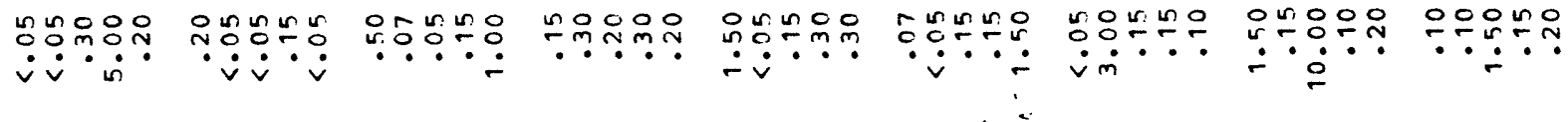
范

$\stackrel{i}{0}$

NoOOO

응웅ㅇㅇ 운으운

응은ㅇㅇ웅

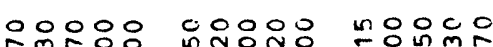

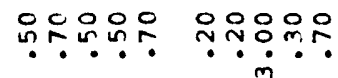

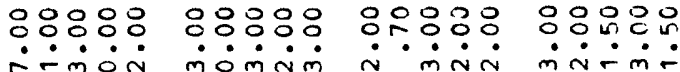

응응으 응응우응

in.

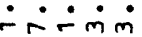

응ㅇㅇㅇ응ㅇㅇㅁ

응응융으 용응유은

1 $\stackrel{0}{2}$

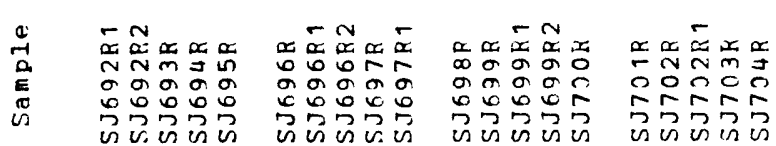

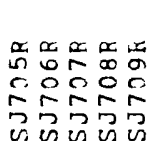

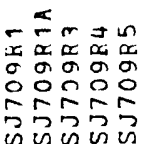

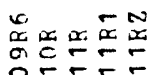

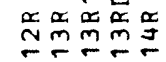

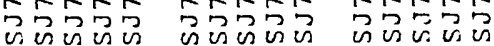




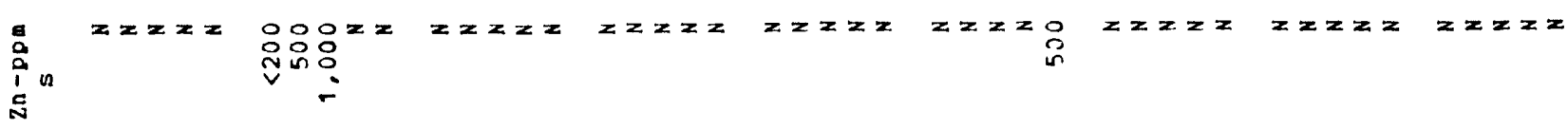

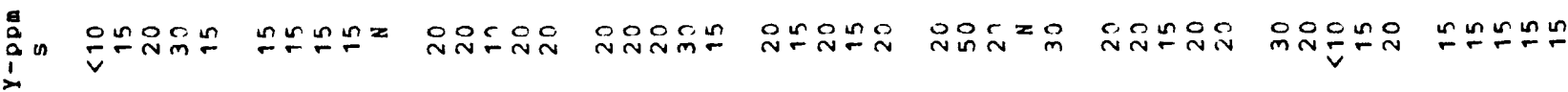

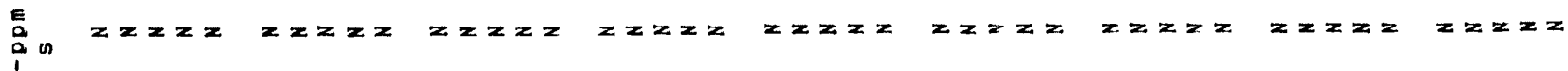

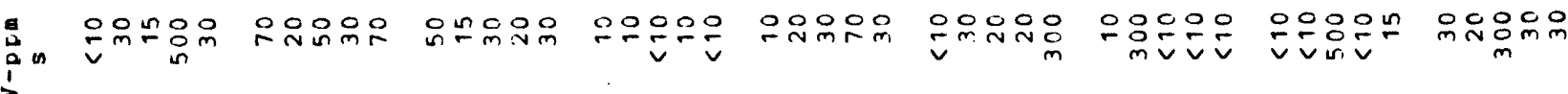

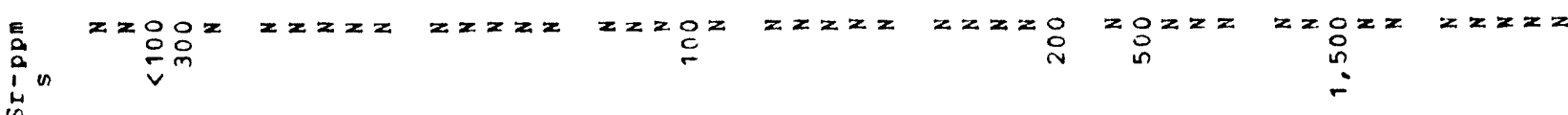

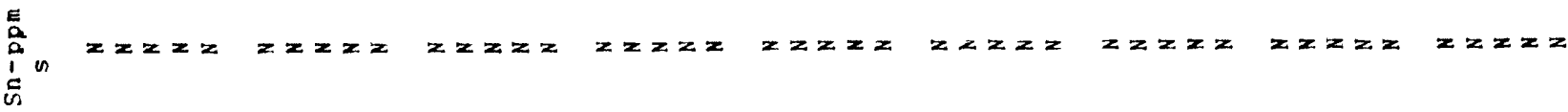

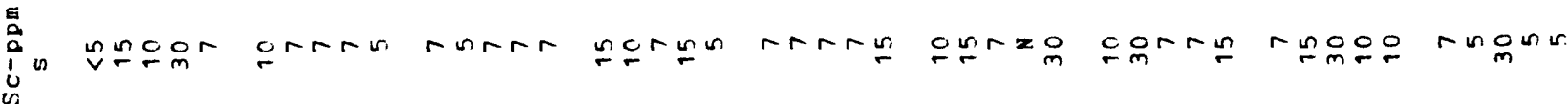

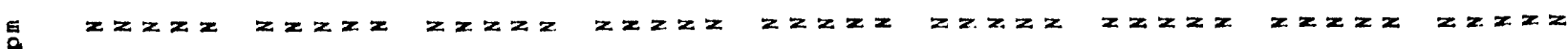
$\sum_{0}^{0}$

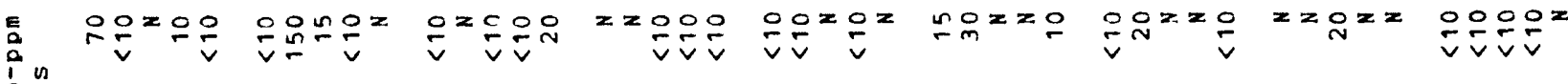

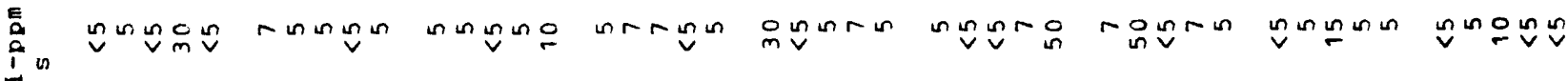

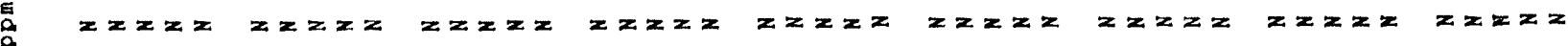
$i$

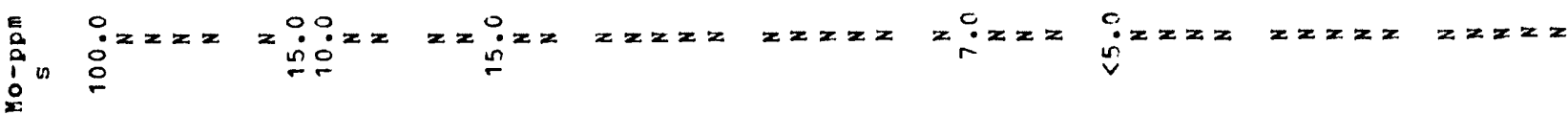

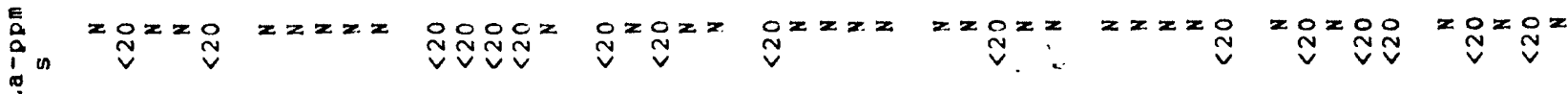

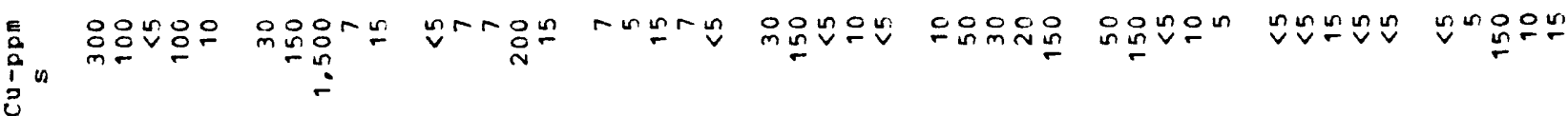

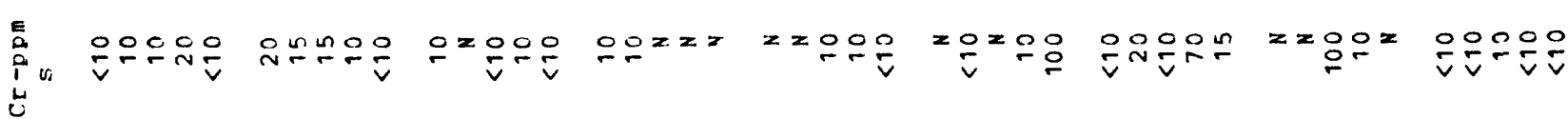

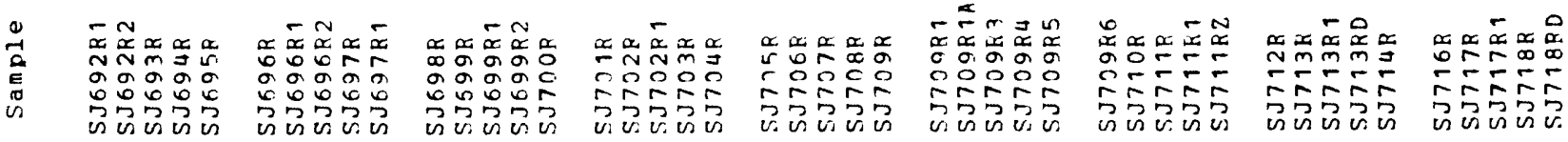


$z z x z z$

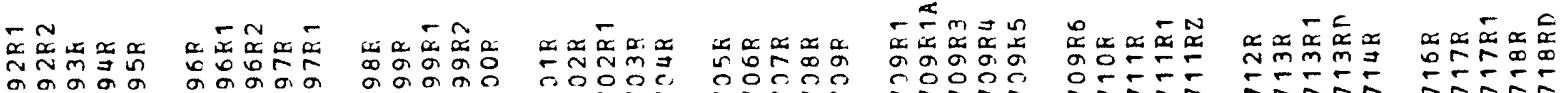

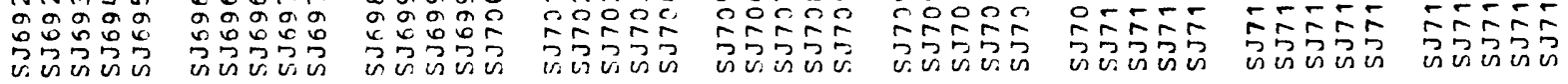




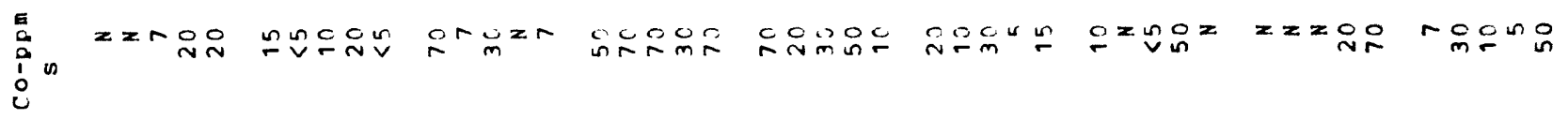

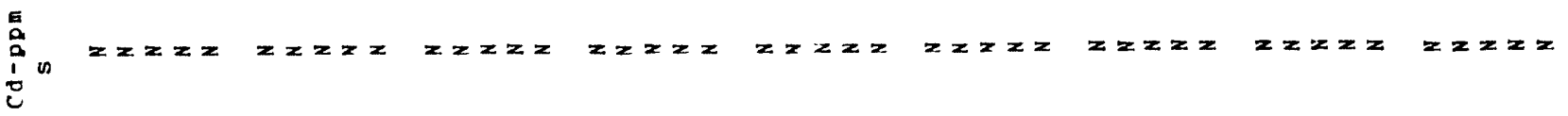

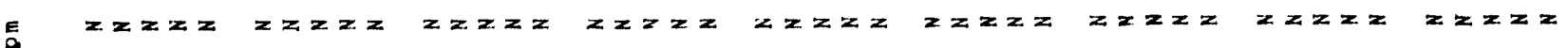
$\prod_{i=1}^{\infty} n$

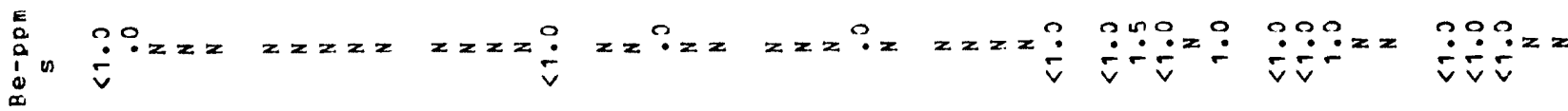

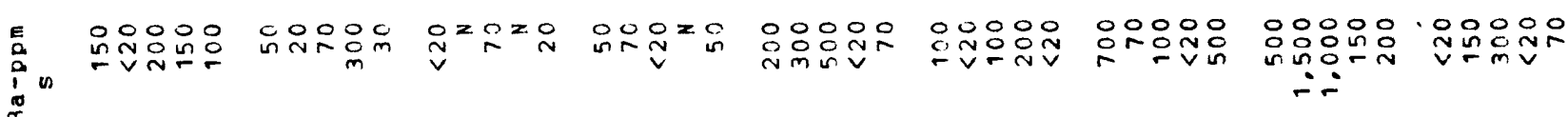

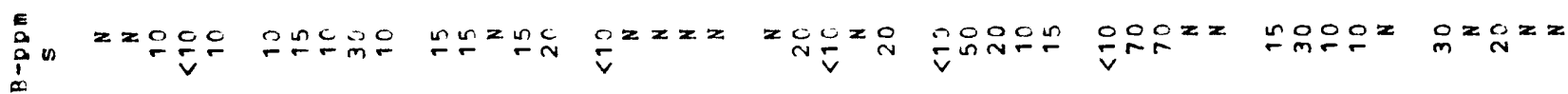

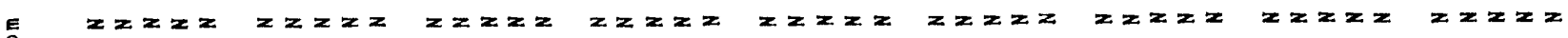
$\stackrel{0}{1}$ $\underset{3}{2}$

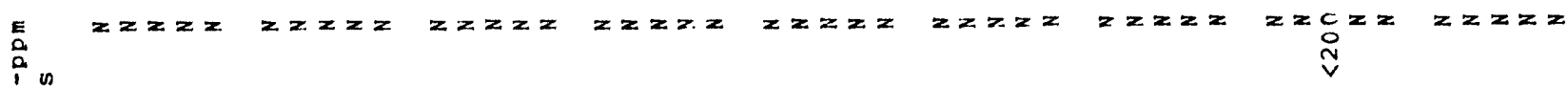

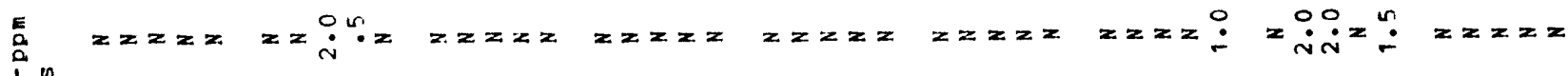

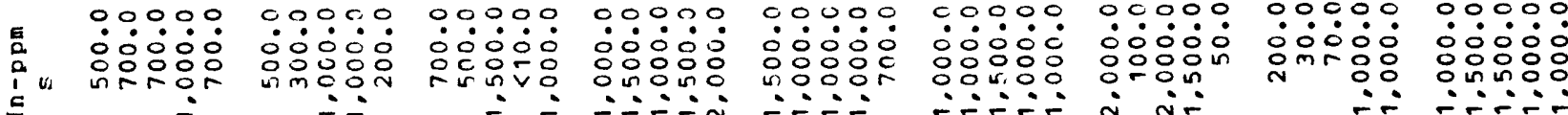
2

$\stackrel{+}{\stackrel{4}{a}}$

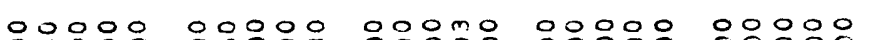

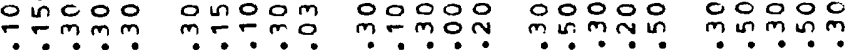

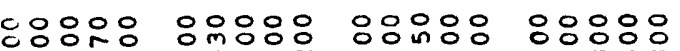

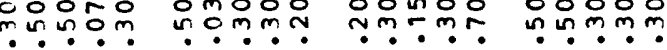

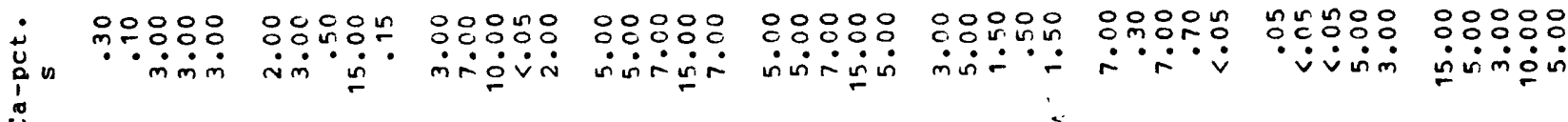

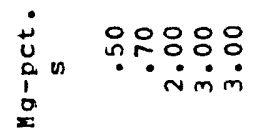

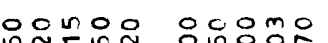

응응응

00000 $\dot{-1 .} \dot{0} \dot{0} \cdot$ तinis i் $\dot{\text { nंm. }}$

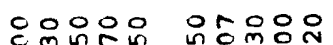

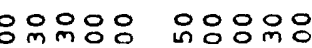

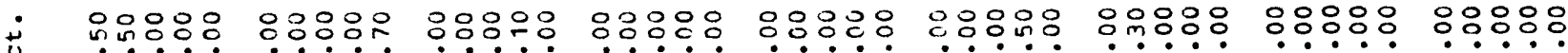
un $\stackrel{0}{\pi}$ $\stackrel{0}{\text { Lิ }}$

$\stackrel{0}{2}$

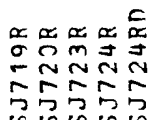

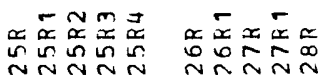

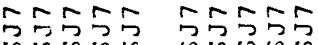

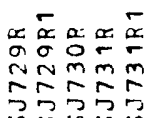

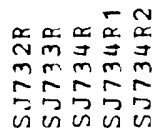




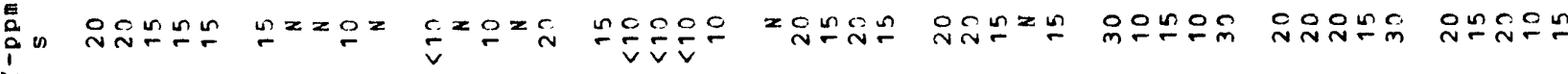

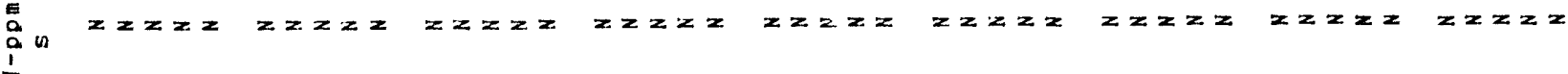

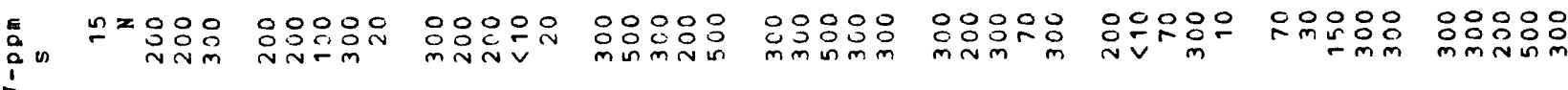

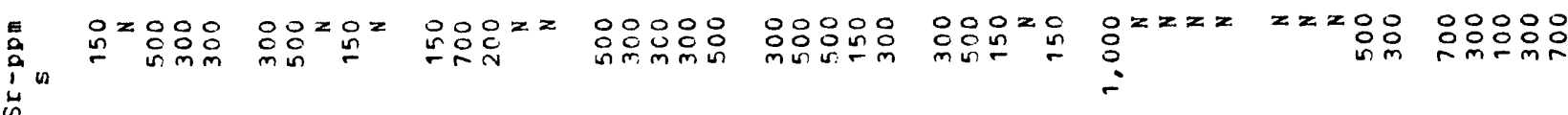

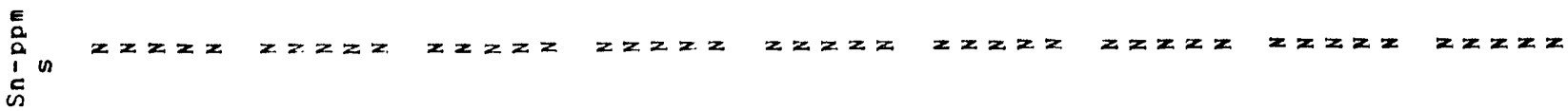

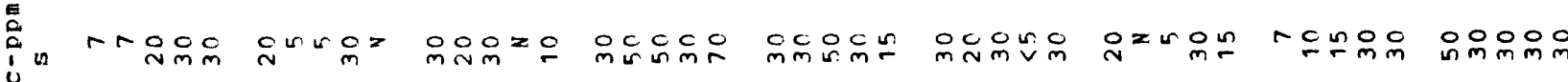

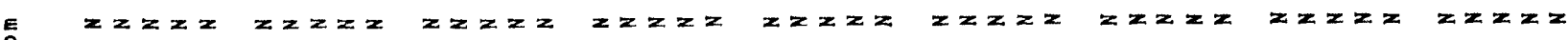

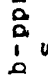

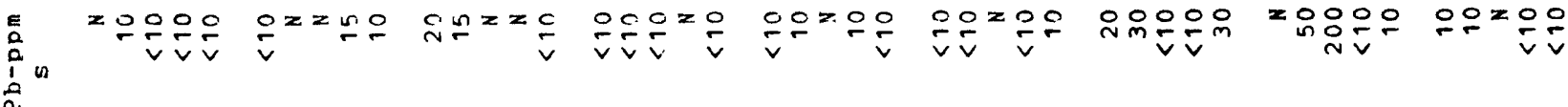
簋

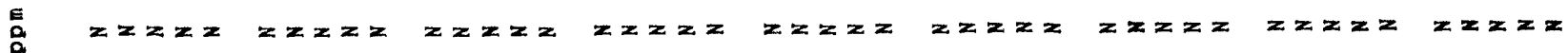
$i^{\circ}$

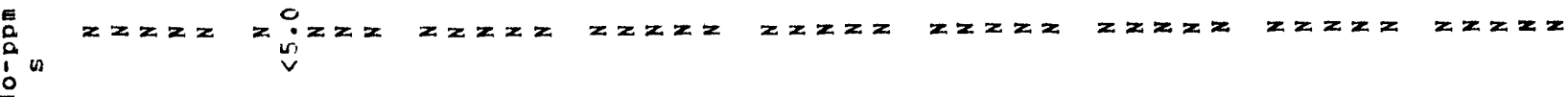

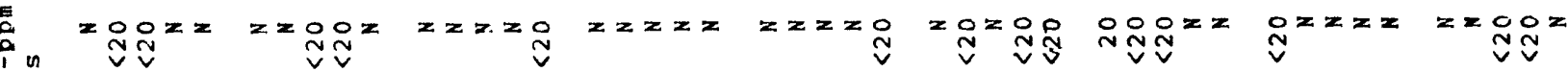
(⿻)

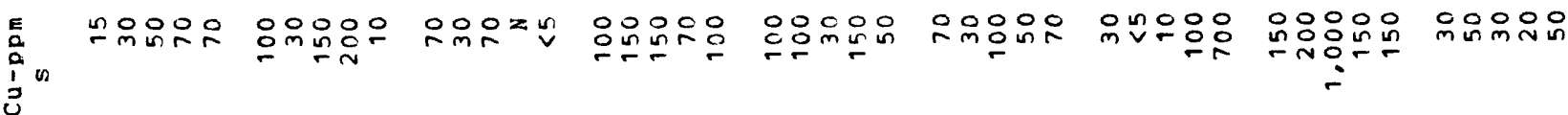

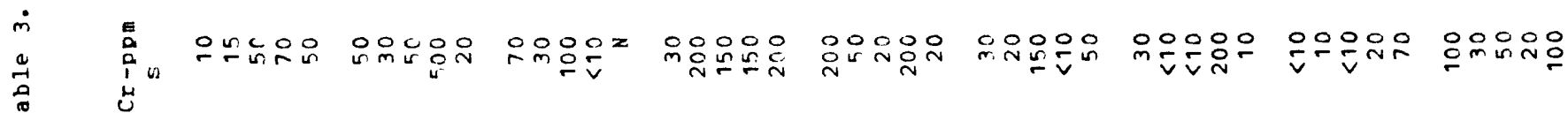

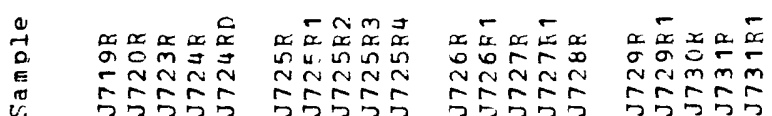

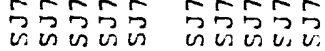

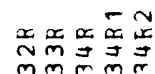

ming

visuse

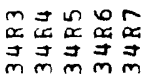

ming

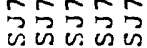

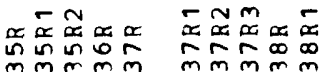

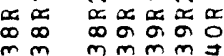
rrir minm mmmma

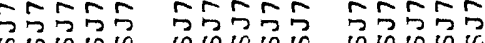




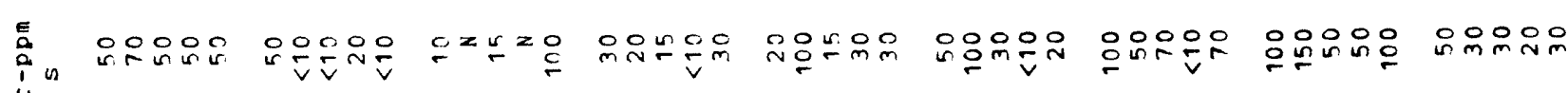
$\stackrel{\leftrightarrow}{\sim}$

\begin{tabular}{|c|c|c|c|c|c|c|}
\hline 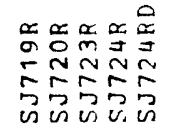 & 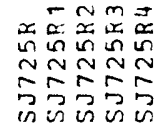 & 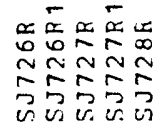 & 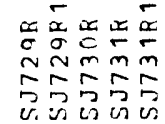 & 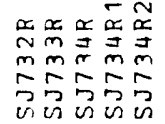 & 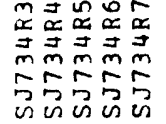 & 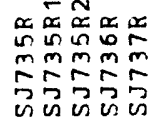 \\
\hline
\end{tabular}




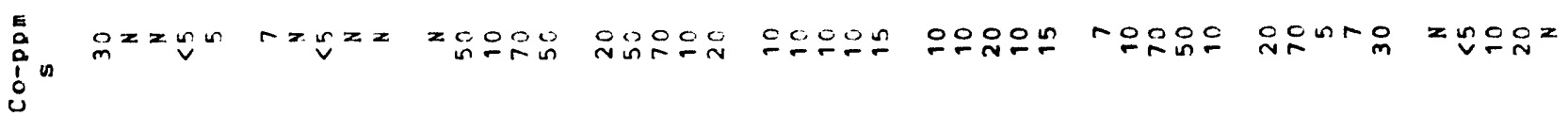

ton.

$\stackrel{\text { E }}{2}$

$z z z z=z z z y z z z$

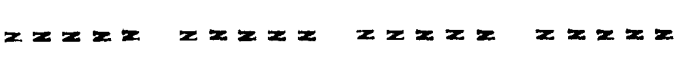

$z z z z z \quad z z z z z$

$z z z z z \quad z z z z z \quad z z z z$

$z x z z x$

$x \geq 2 z=$

$z z z z=2 x z z$

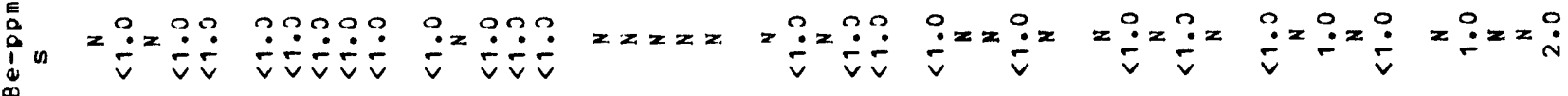

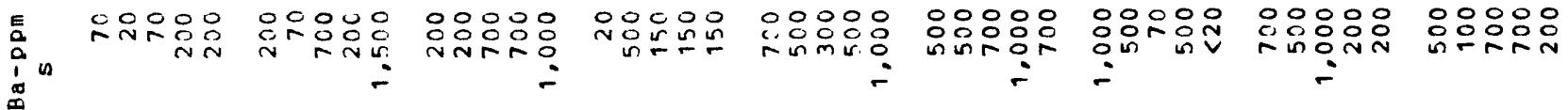

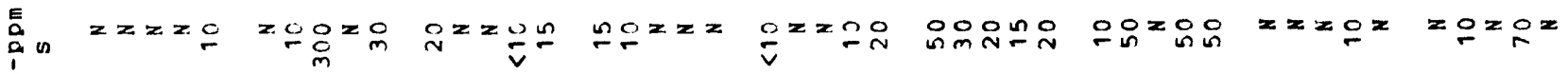

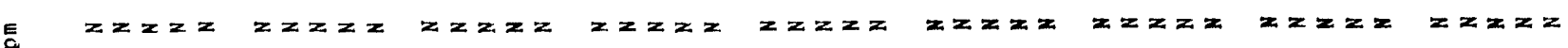
in

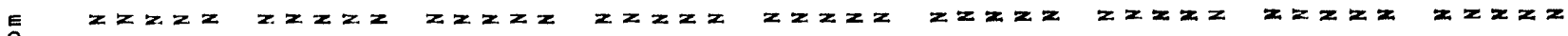
in U

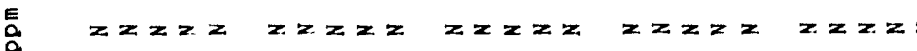

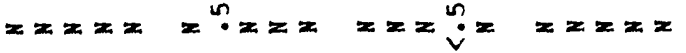
$a^{1}$

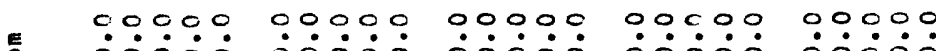

$0000 \% 00 \% 00$

00000

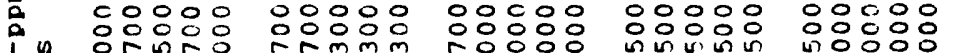

$\therefore \div=$

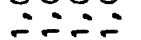

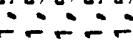

$\because \div-\div$

응응ㅇㅇㅇㅇㅇㅇㅇㅇㅇ

in:

웅ㅇㅇ

$\circ \circ \circ \circ \circ$

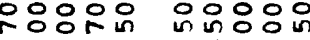

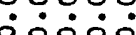

은아운

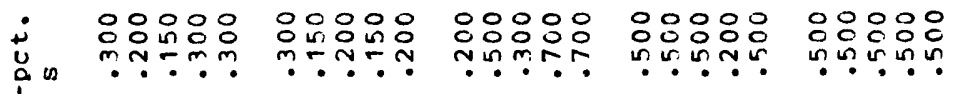

:ஃ:: :::

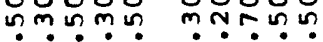

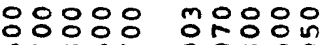

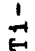

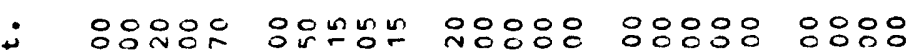

莦我

웅ㅇㅇㅇㅇㅇㅇ

n்m

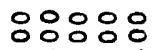

$\therefore$ in்:

00080

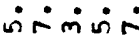

80000

ư

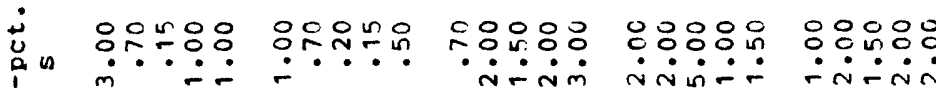

응ㅇㅇㅇㅇㅇㅇ 운응ㅇㅇㅇㅇㅛ

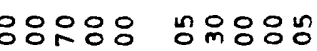

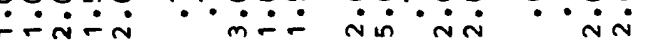

$\dot{m}$

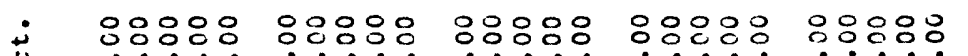

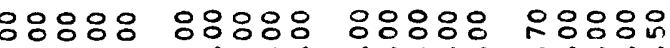

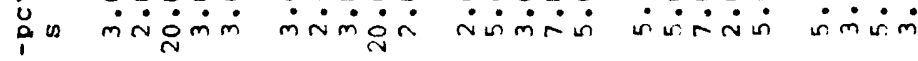

$\dot{m} \dot{m} \dot{\text { in }}$ in

mimiri

iñmi

inis

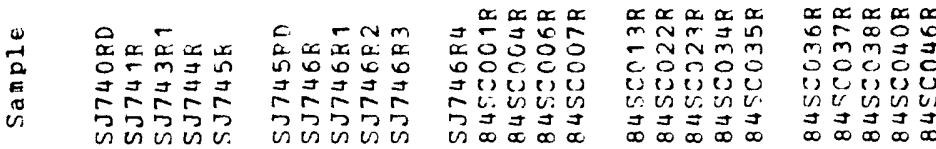

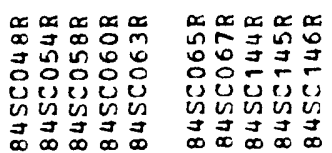

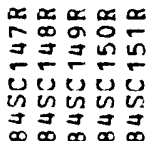

웅 番

ํํำ

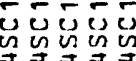

记 


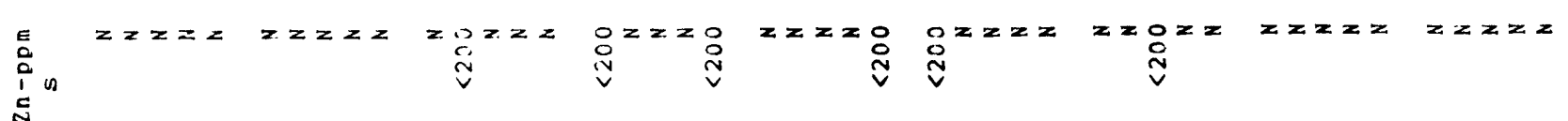

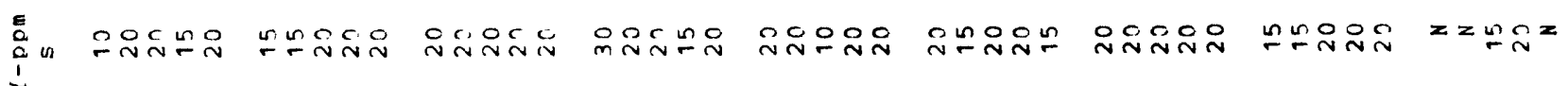
을 E 음

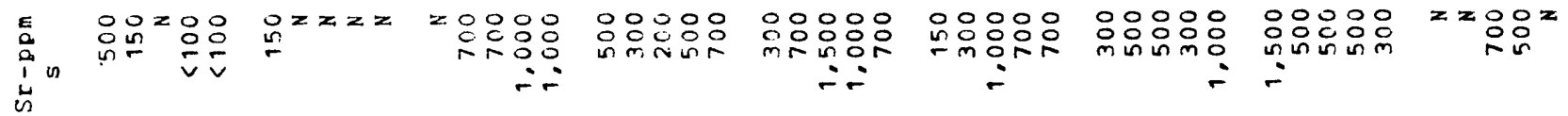

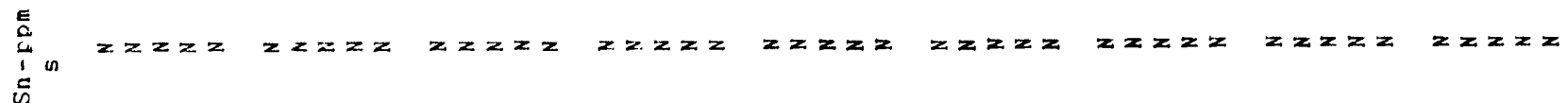

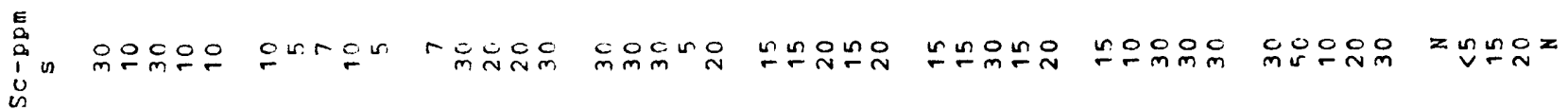

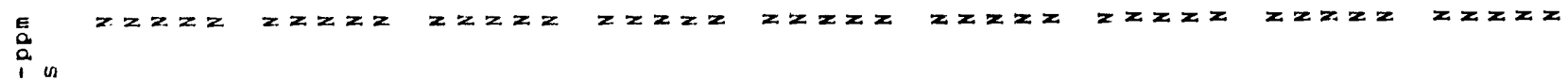
is

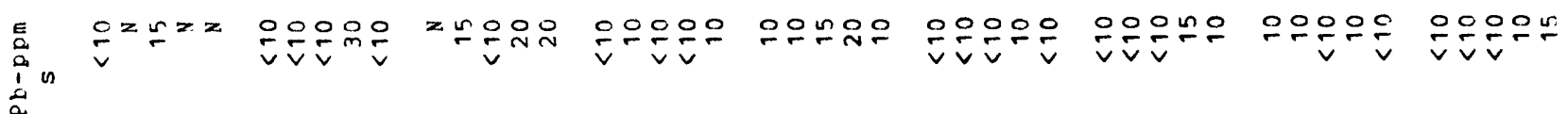
吾

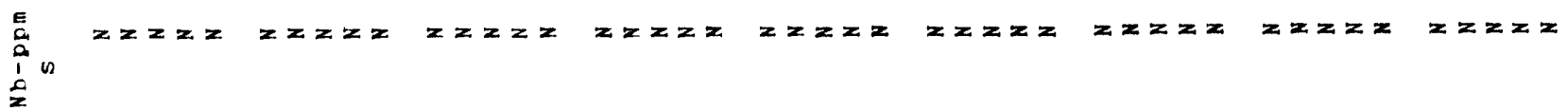

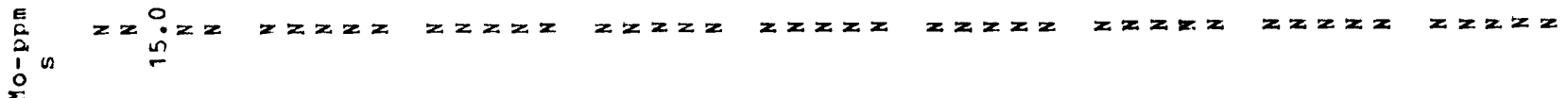

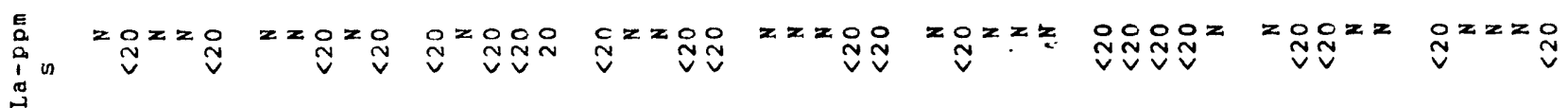

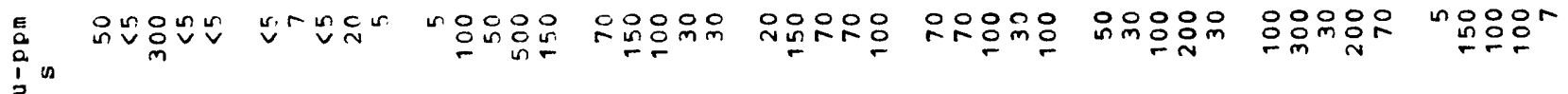

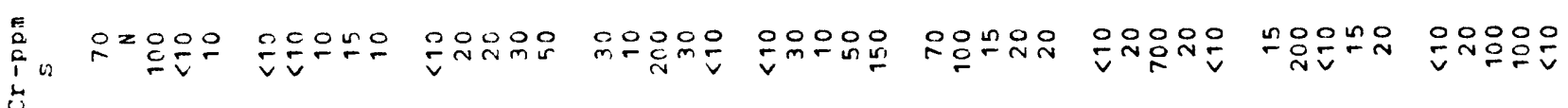

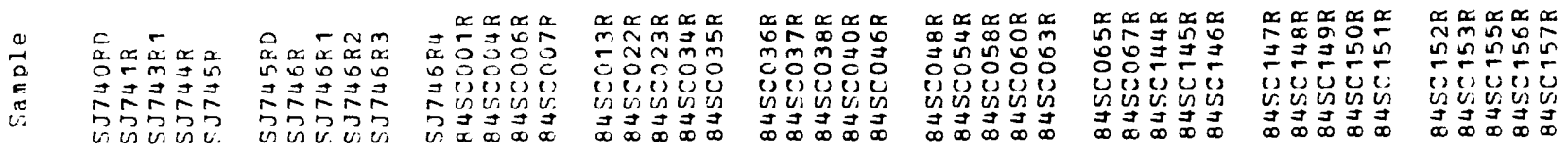




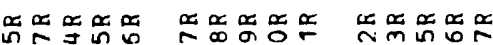
○

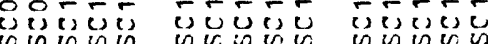

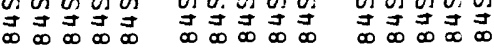




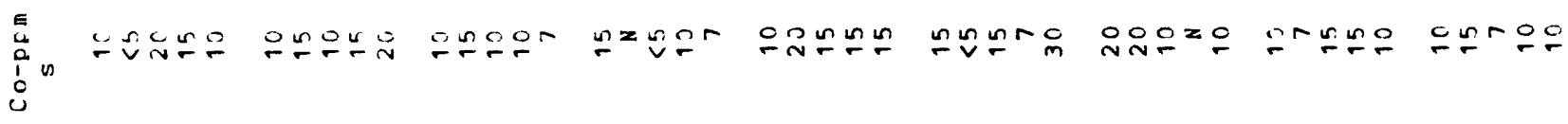

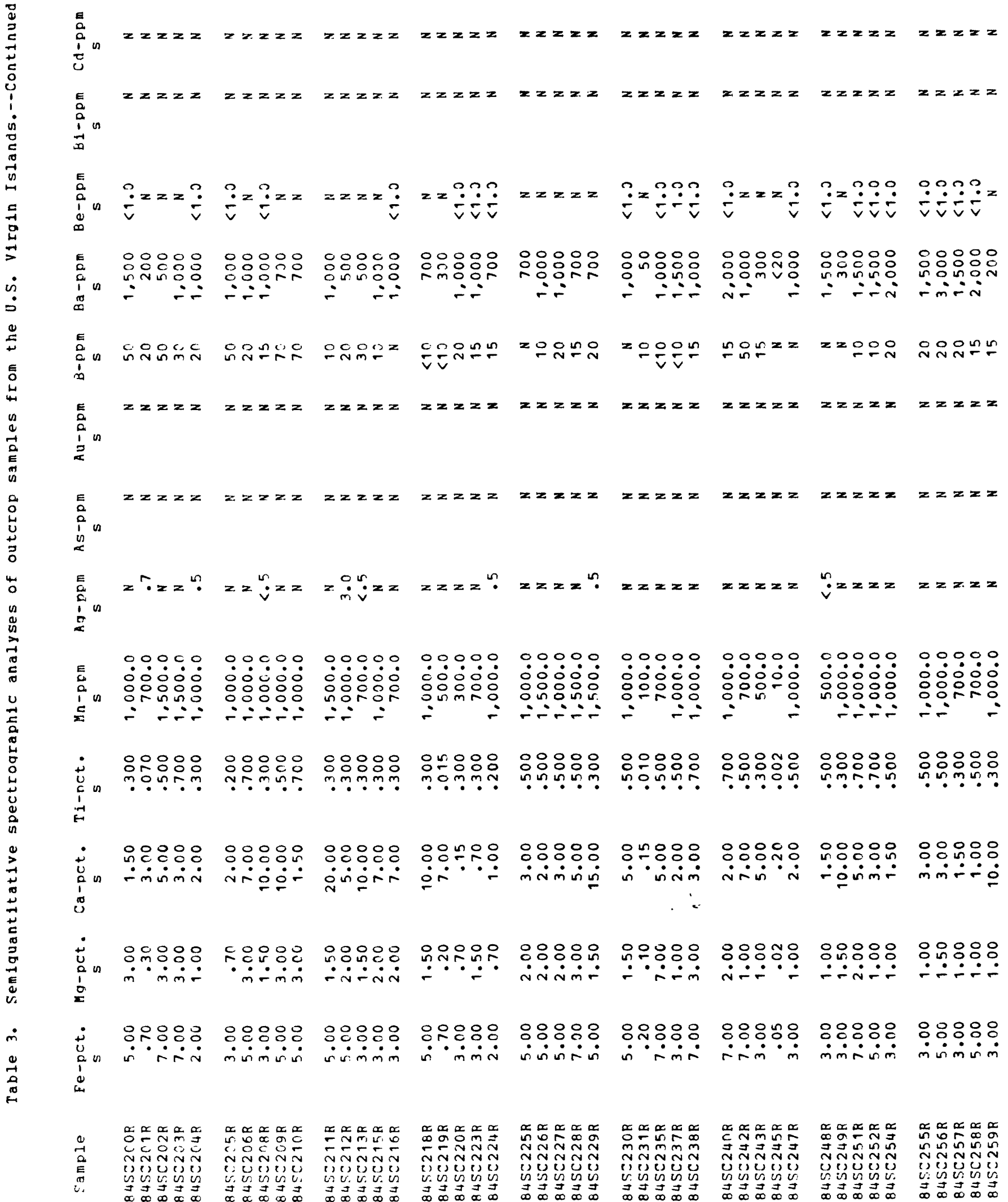




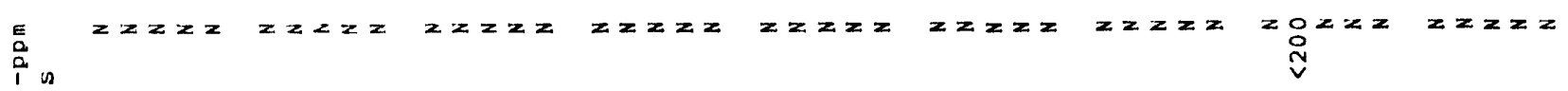
兄

总纱

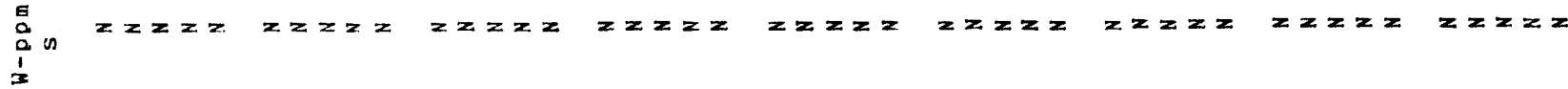

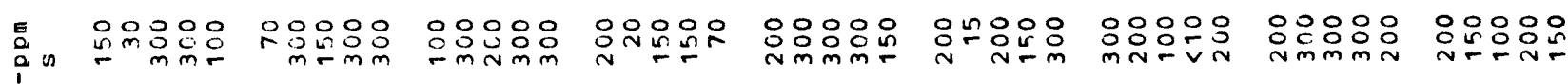

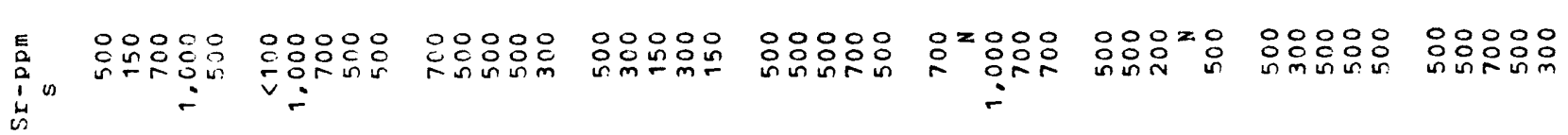

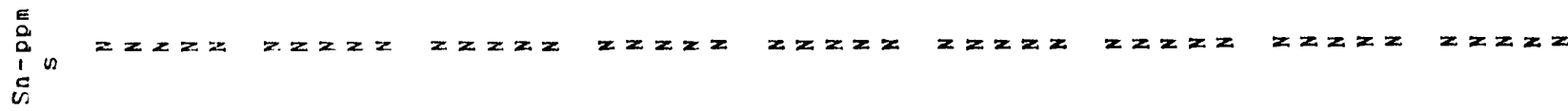

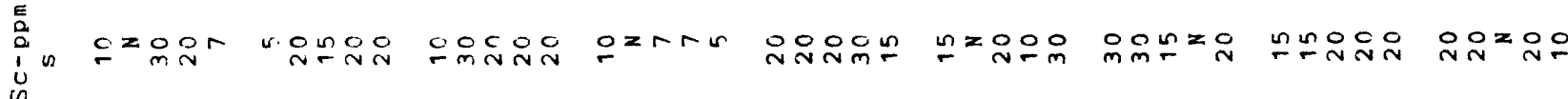

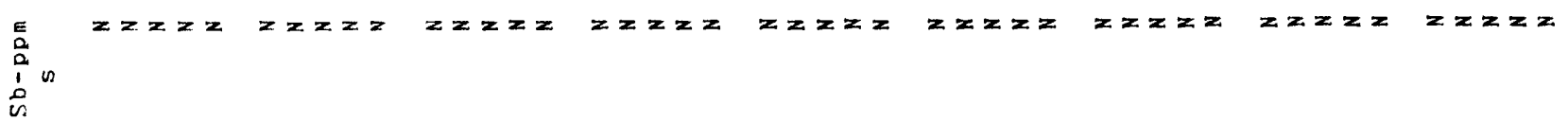

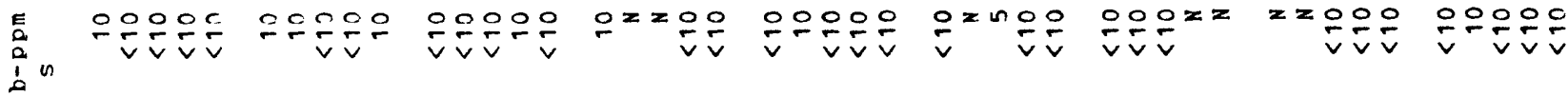

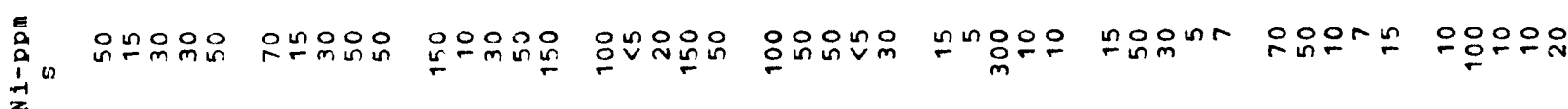

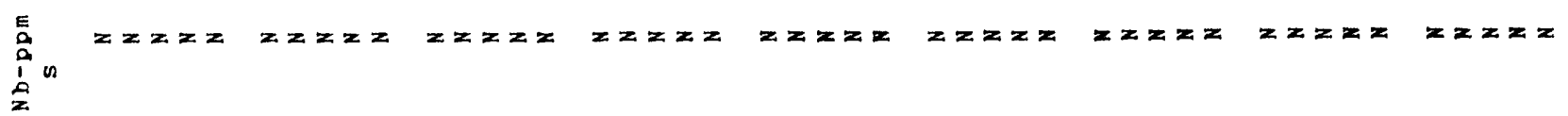

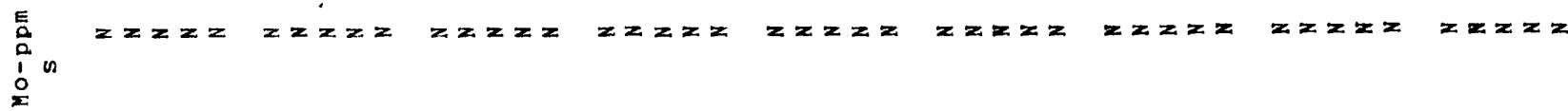

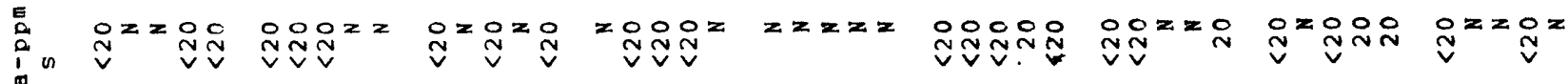

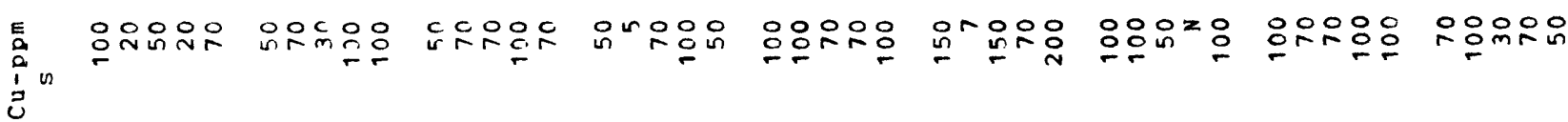

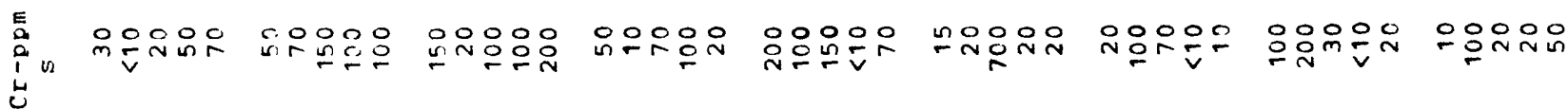

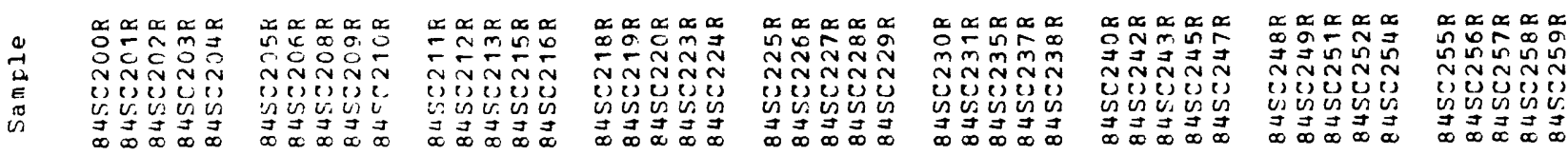


草

noco

있웅응요

0000000000

응ㅇㅇㅇㅇㅇㅇ

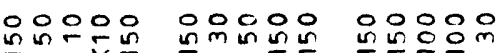
N

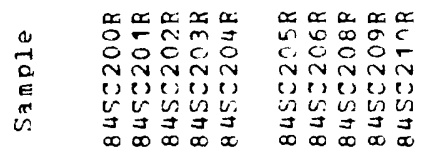

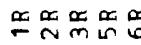

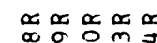

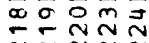

NNNNN

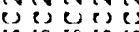

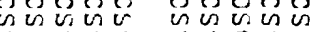

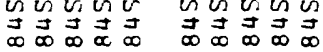

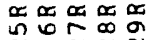

국료

NiN

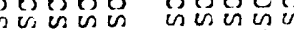

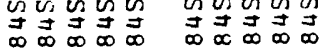

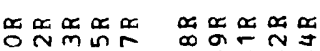

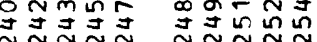

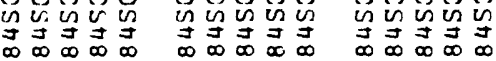




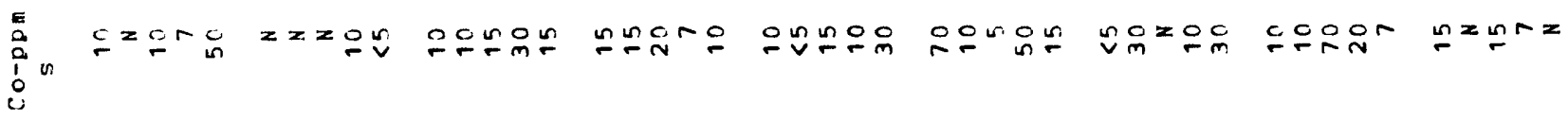

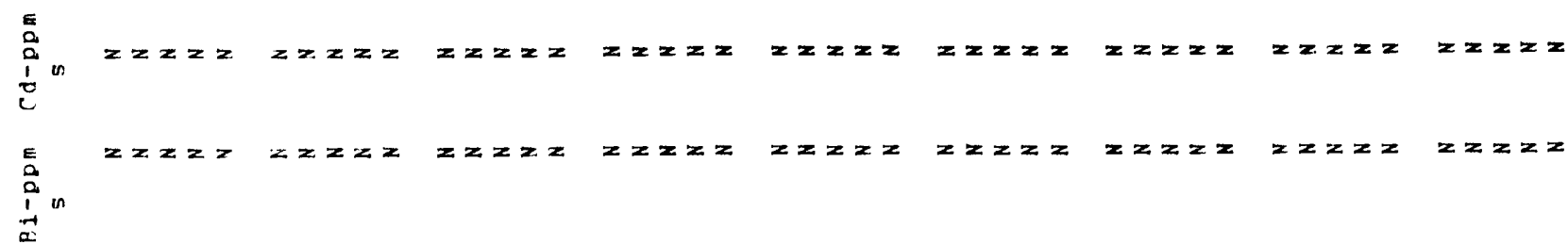

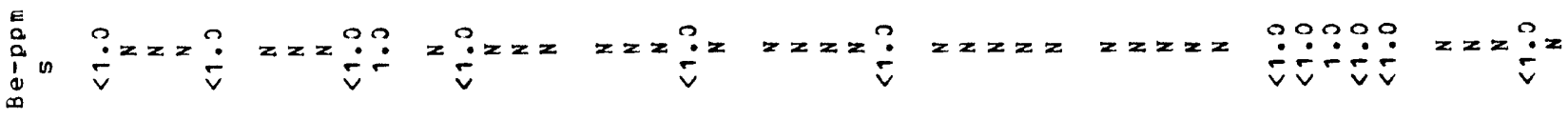

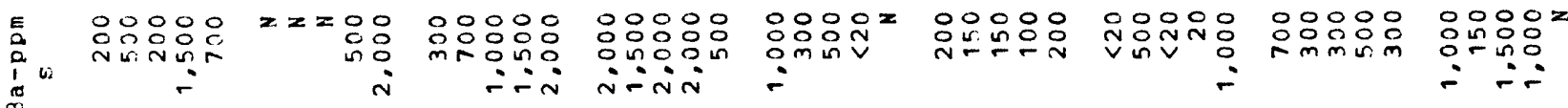

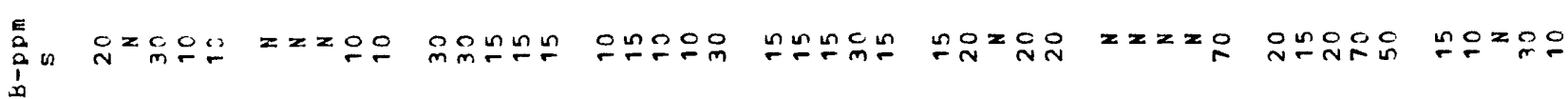

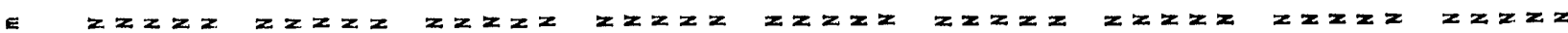
$\sum_{\substack{0 \\ 0}}^{1}$

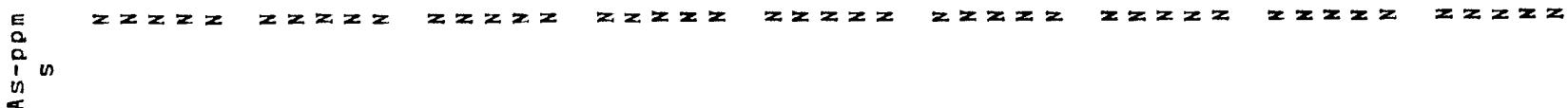

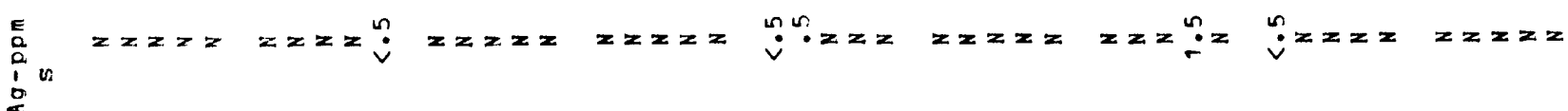

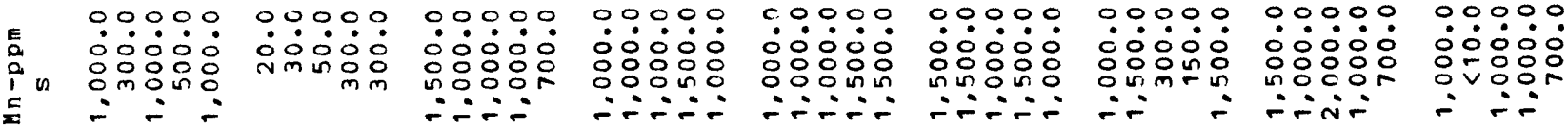

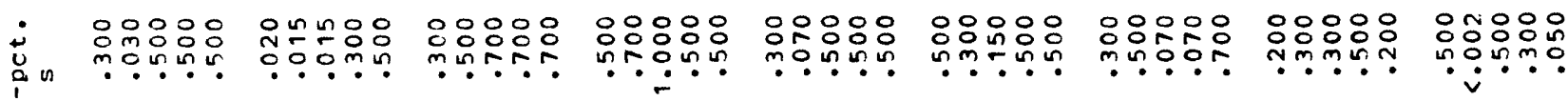
$\rightarrow$

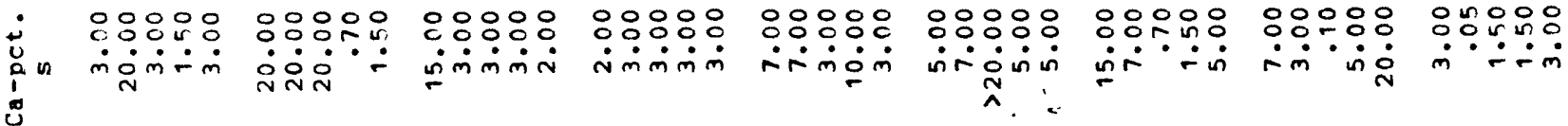

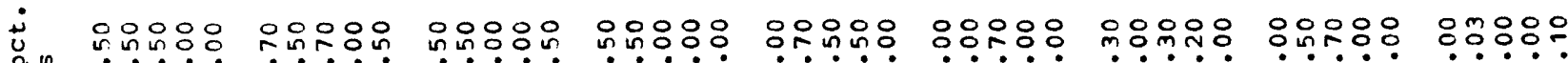

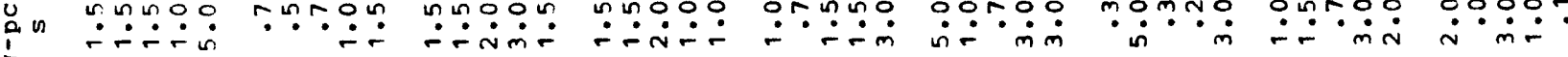

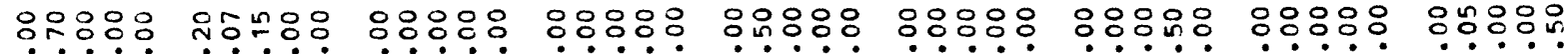
U u :
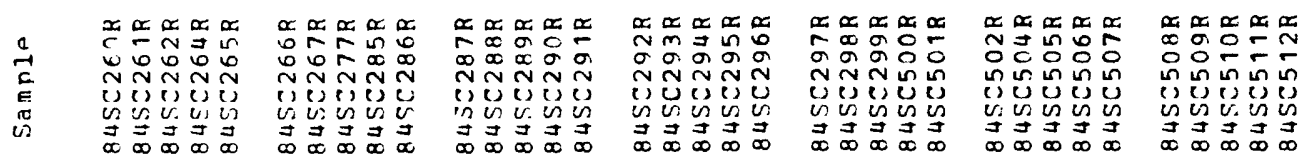

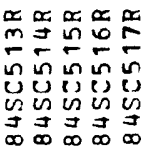

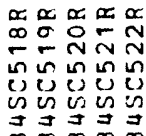




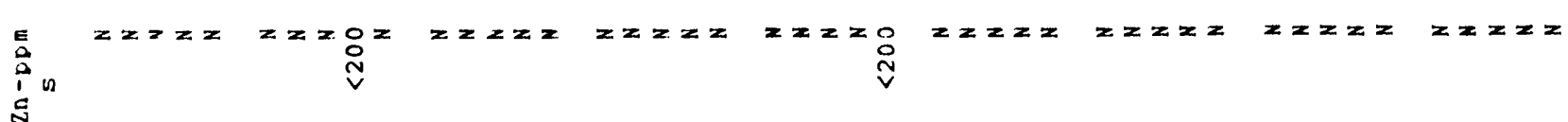

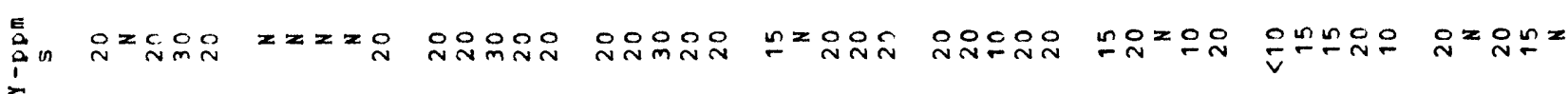
E E

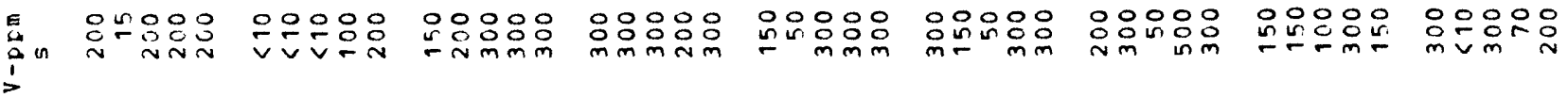

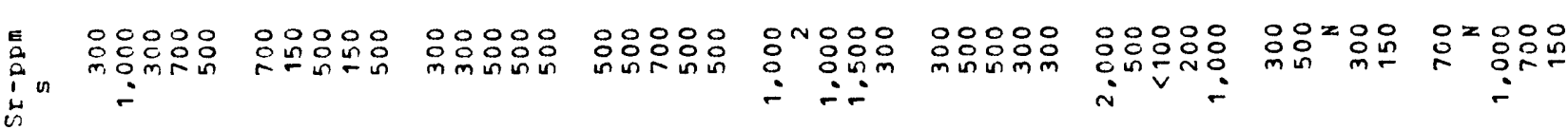
E
에
의

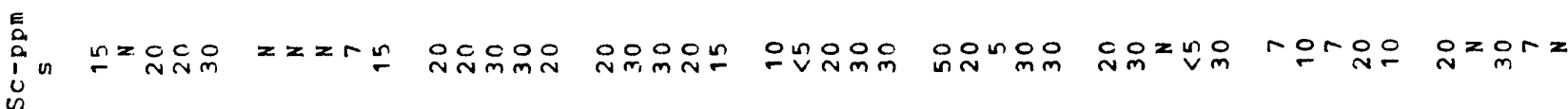

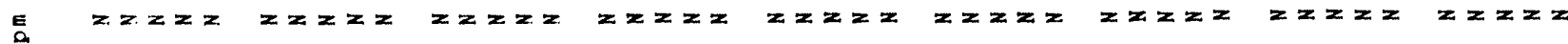
i.

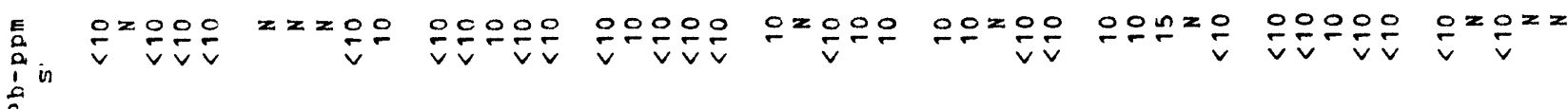

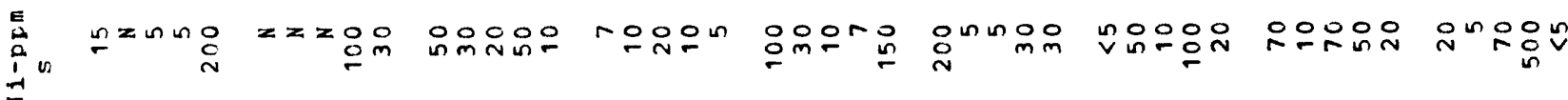
E

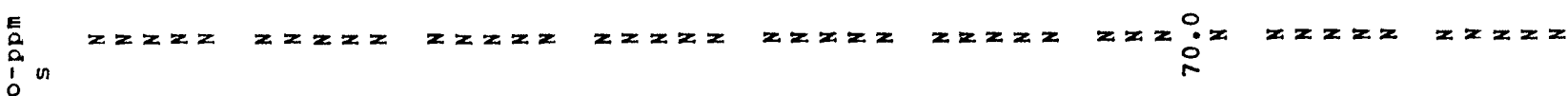

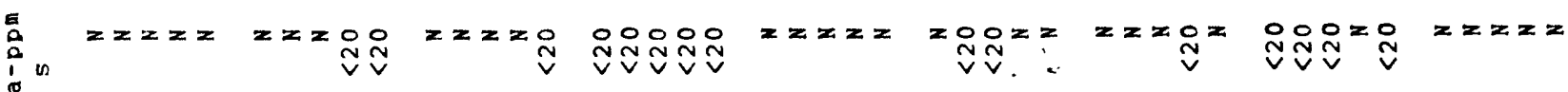
I

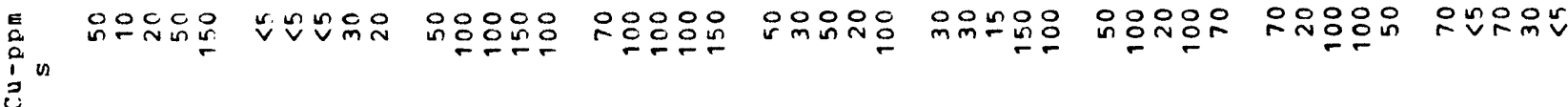

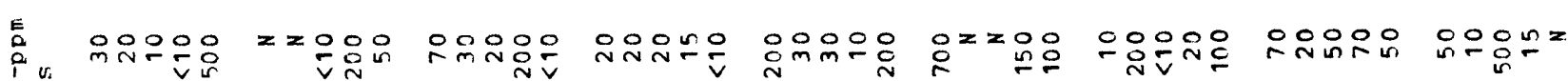
已ै

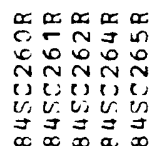

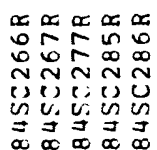

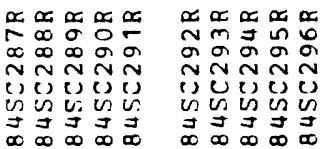

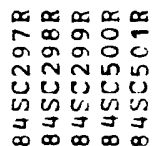

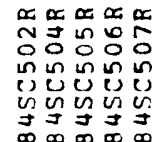

in in in in

i)

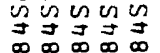

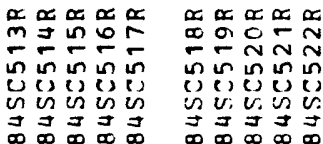




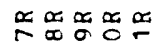
$\infty \infty \infty$ a NUNN

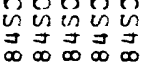

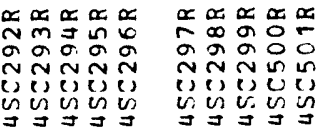

的的的

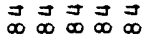

웅 응응응

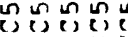
约比记

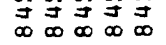

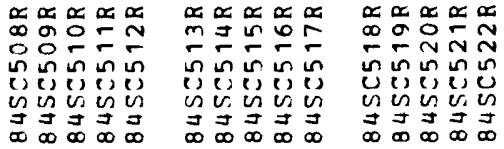




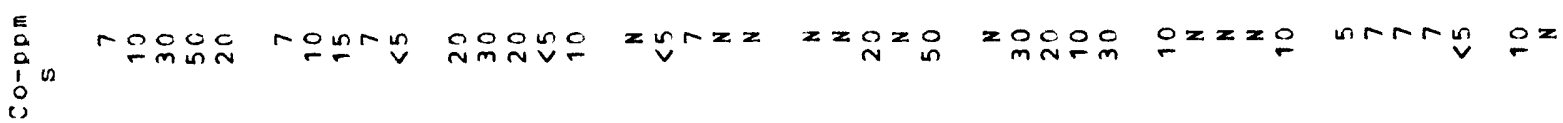

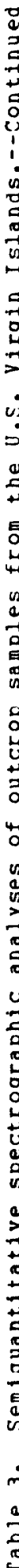

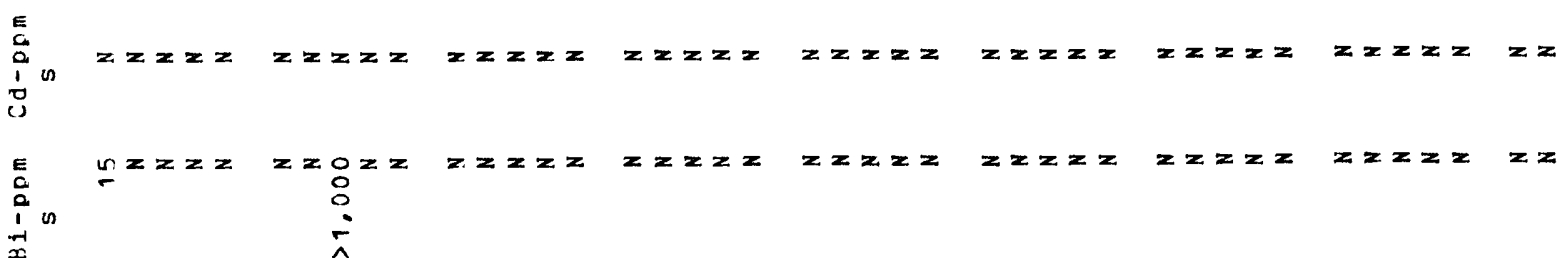

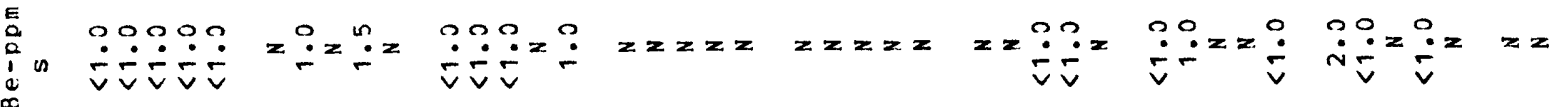

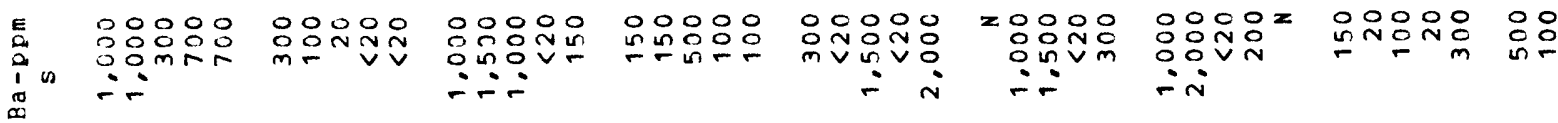

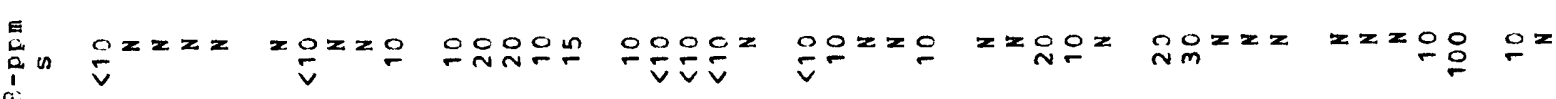

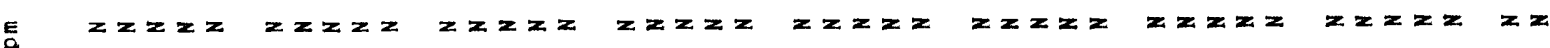
$\stackrel{a}{a}$

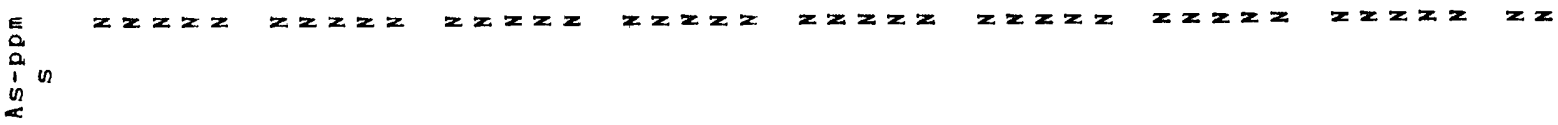

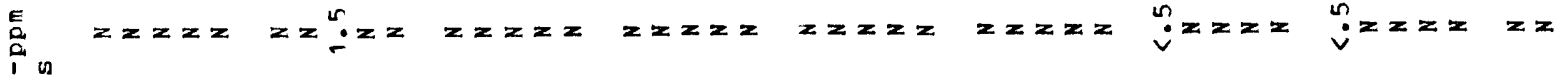

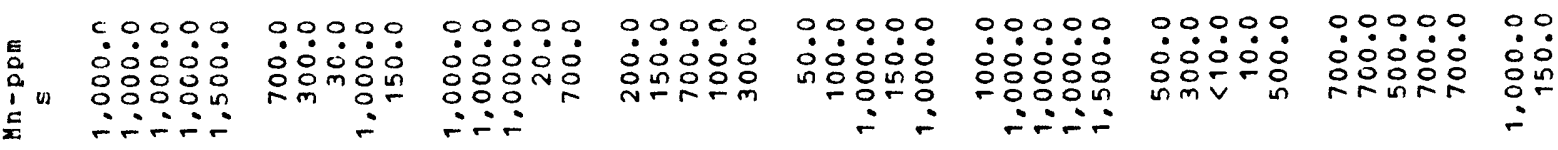

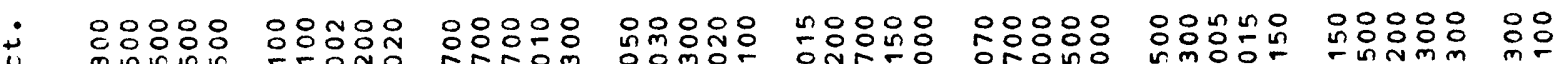

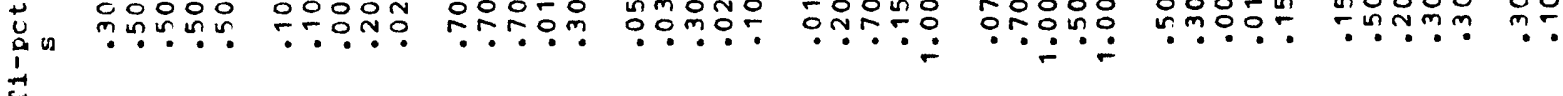

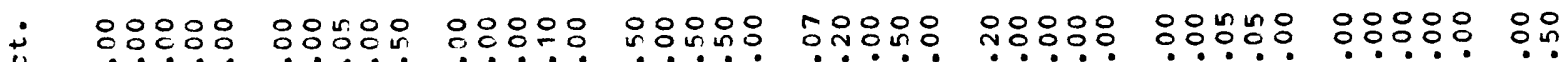

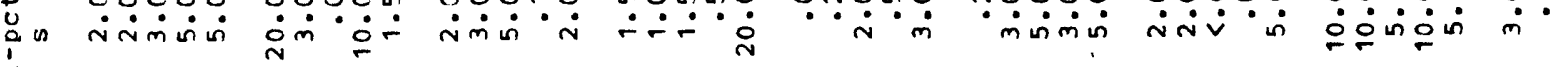
ư

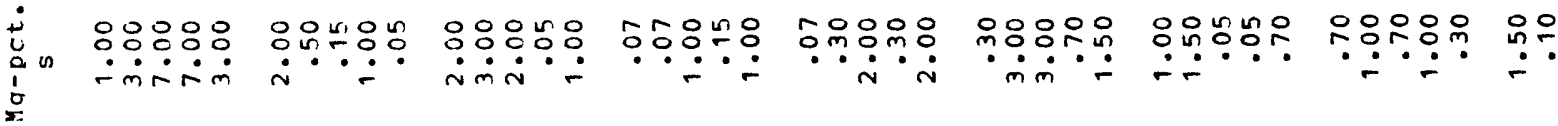

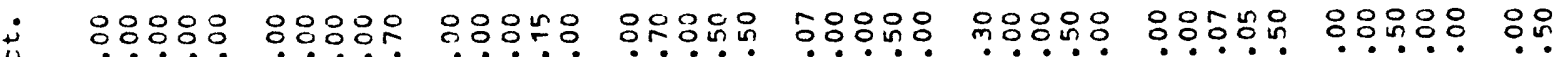
品

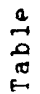
cis.

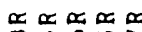

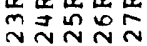
กำ

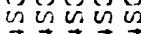

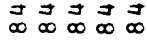

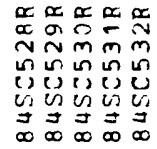

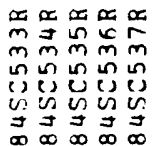
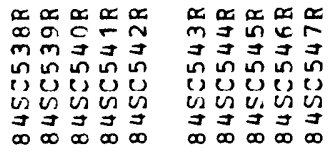

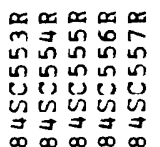

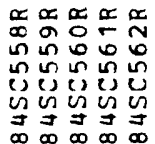

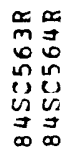




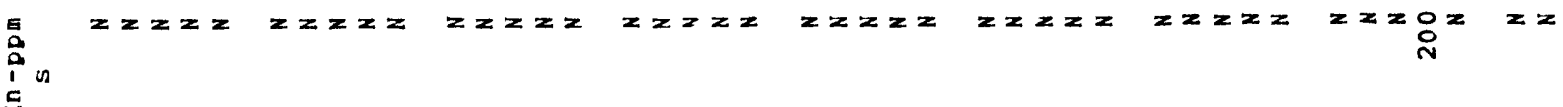

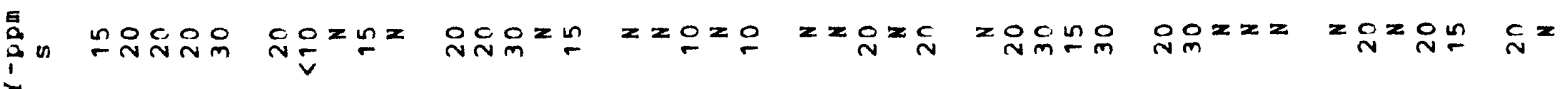

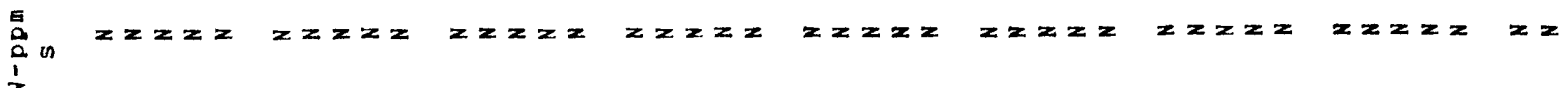

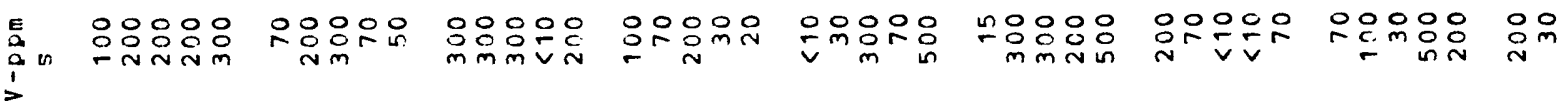

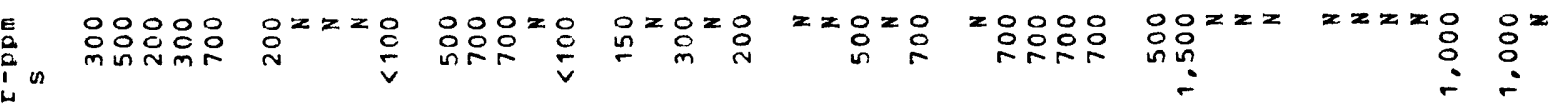
出

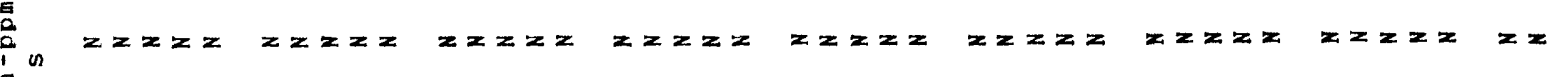
ह

总

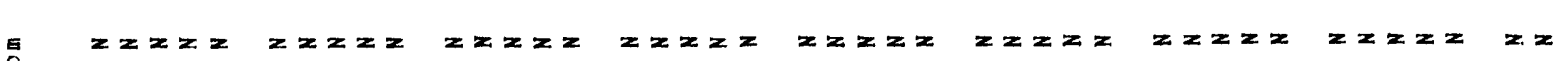
$\sum_{0}^{0}$

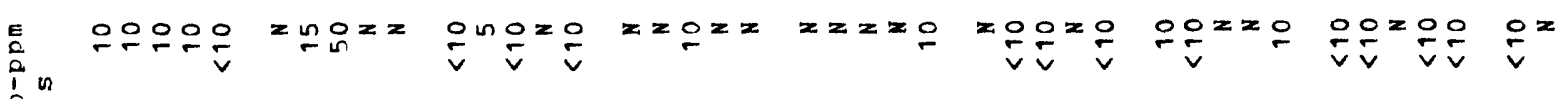
$a$

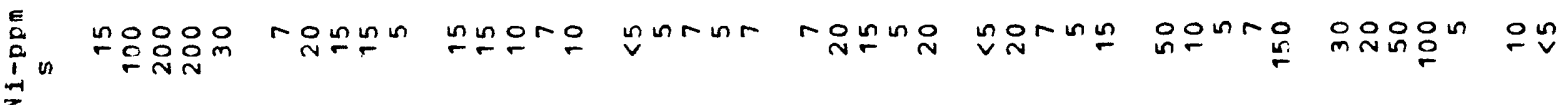

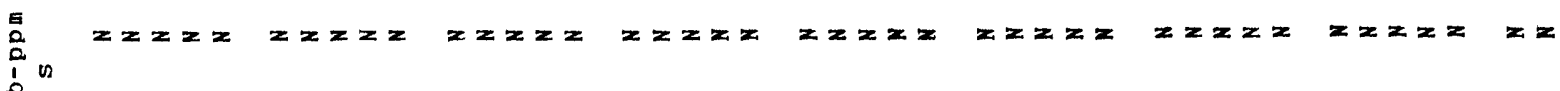
E

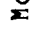

i

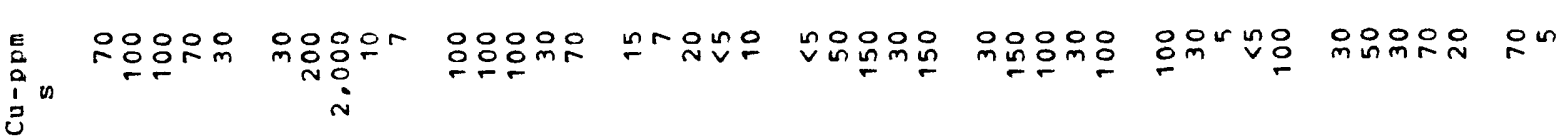

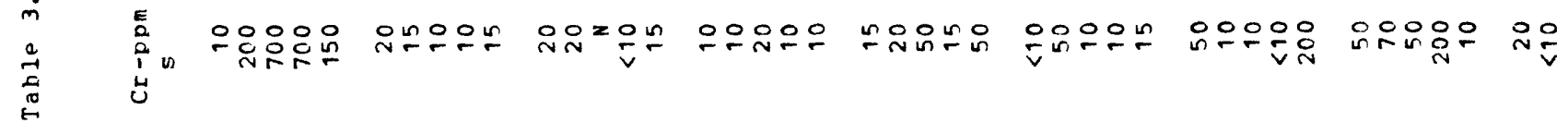

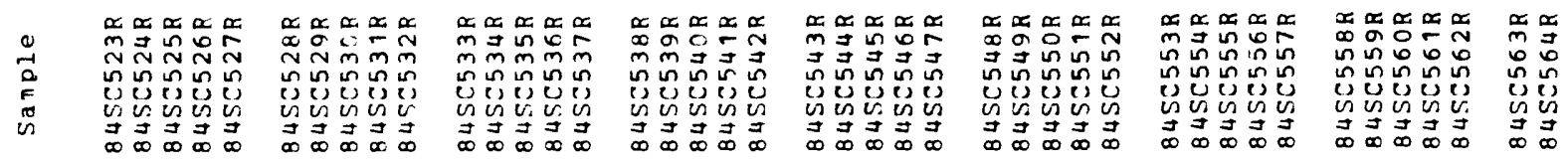


$\dot{m}$

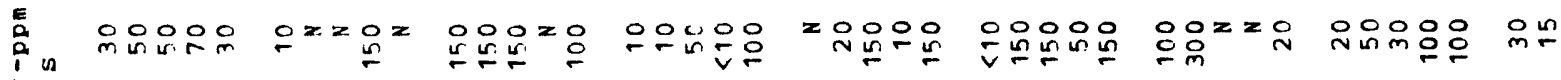
N

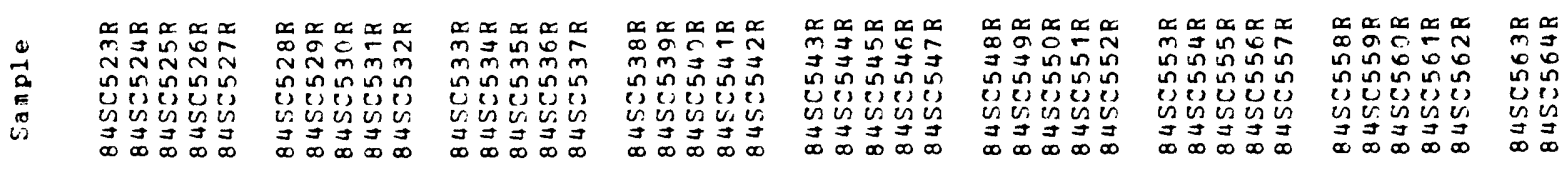




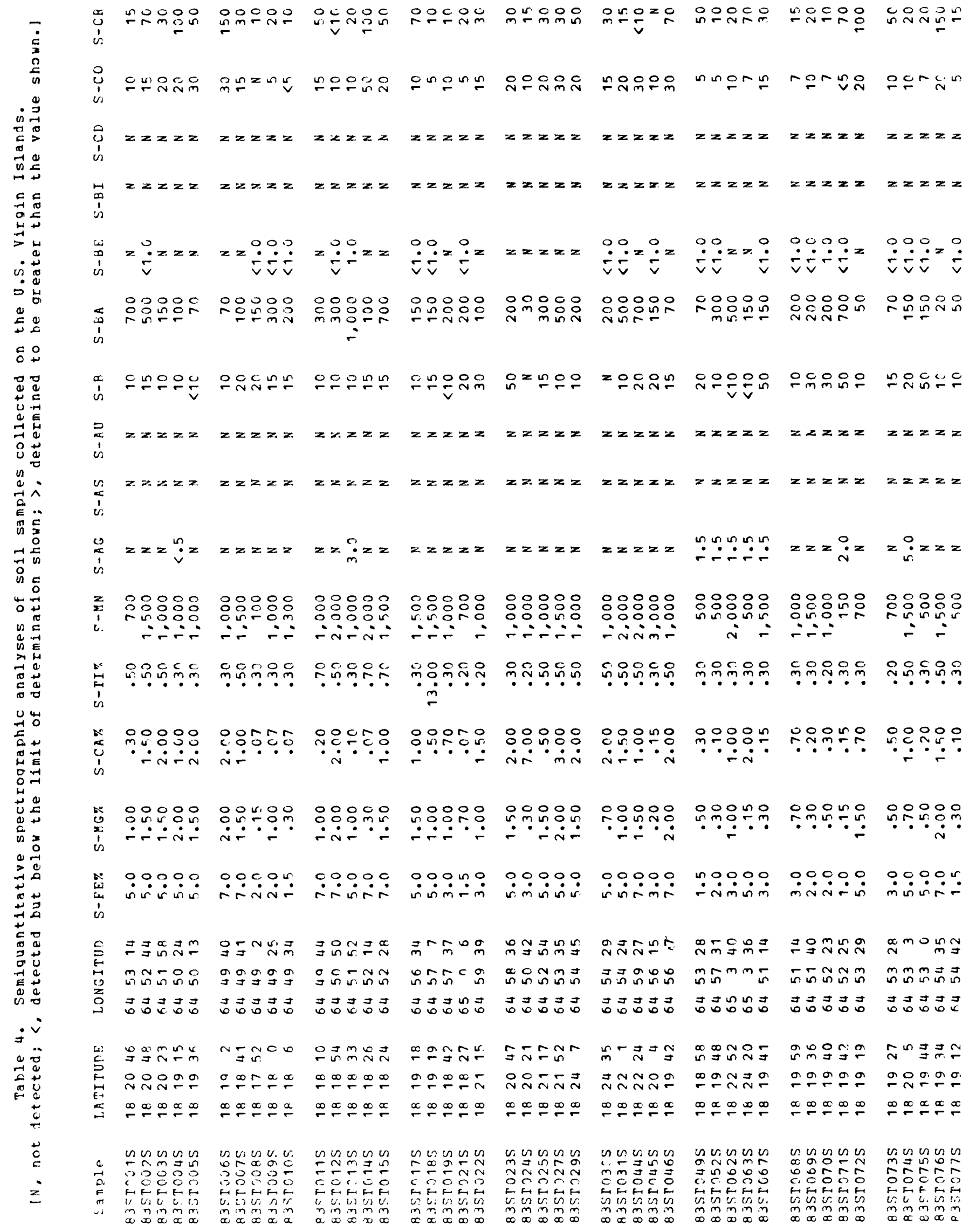


z.

is

3

is

is

zis

on

is

is

s.

$\sum_{1}$

$z_{1}$

5
$z$
1
U:

0
s.
is

ì

$\stackrel{c}{\sim} \stackrel{c}{\sim} \stackrel{c}{v}$

i

옹응응 영으 red

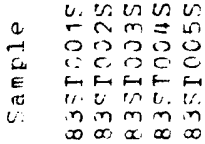

$z=z z$

옹ㅇㅇㅇㅜ $z=0$
$00^{x}$
0

웅으는

엄일요

$z z z=$

$z z z z$

$z$

응응요

은응용ㅇㅇㅇㅇ

\section{용}

웅용은

웅ㅇㅇ은ㄷㅇ

으 은은용

$z z z z \quad z z z z$<smiles>C1CCC1</smiles>

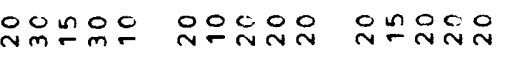

$z z z z$

2

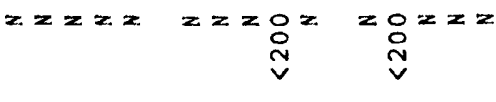

는유은

운유느 유유유

$z z z=$

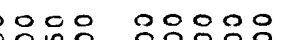

응웅요

-n

N Nm

mim

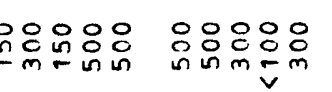

$\stackrel{i}{i} \stackrel{\text { n }}{\circ}$

에유

$z z z z$

$z z z z z$

$z z z z$

$z z z z$

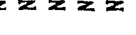

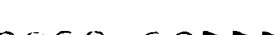

Nmmingrer

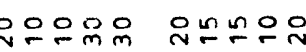

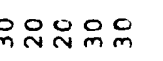

웅요음

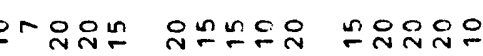

$z z z z z \quad z z z z z \quad z z z z z$

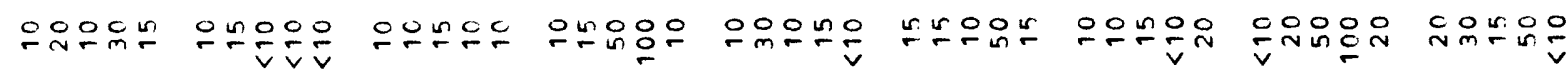

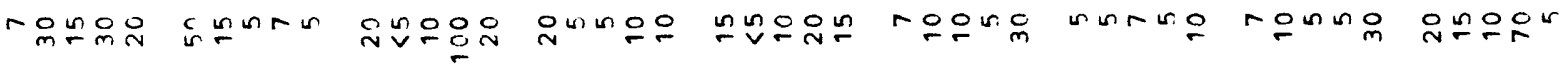
$z z z z z \quad z z z z z$

$z z z z z z z z$

orzerza

$z z z z$

$z z z z z$

$z z z z$

$z z z z z=z z n z z z z z z$

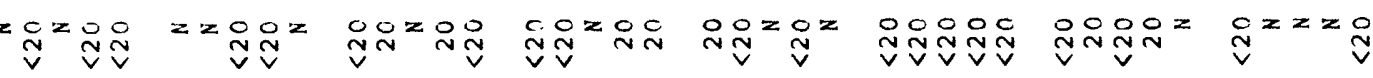

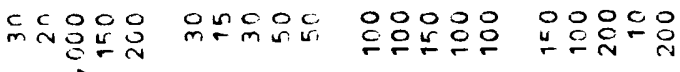
i

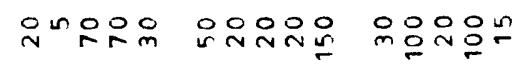

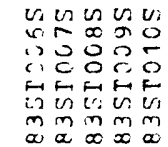

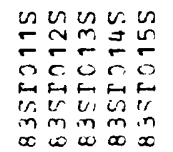
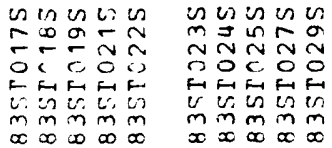

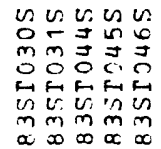

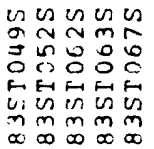

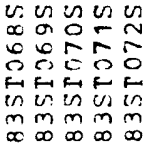

$\min \sin \sin$

rorrio

t5

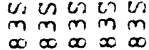




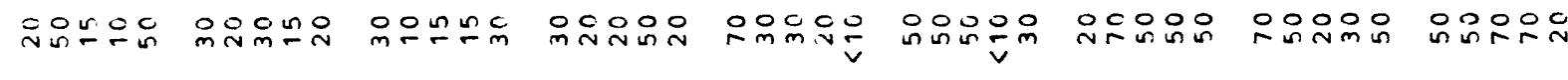

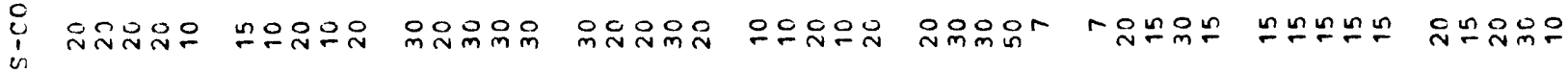

is

s.
i
in

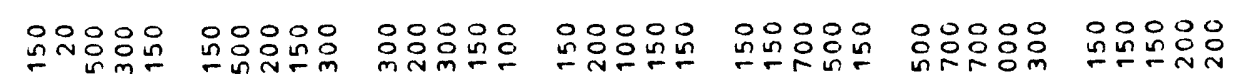

$z z z z$

$z \geq 2 x=$

$2 \quad z$

$z z z z$

$z z x z z$

$z z z z z z z z z$

$\stackrel{\leftrightarrow}{i}$

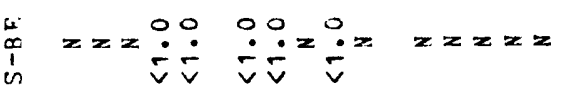

$z z z z$

$\because \div \div=$

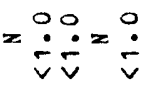

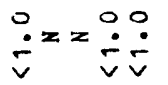

$\stackrel{\dot{v}}{v}=\stackrel{0}{\dot{v}}$

$\stackrel{i}{i} \ddot{\dot{v}} \dot{v}=$

웅응영응ㅇㅇㅇㅇㅇㅇㅛ

ming

은

c

$\cong$

i

$z z z z$

$z z z$

$z \geq z z$

$z z z z$

$z z z z$

$z z z z$

$z z z z$

$z z z z z$

$z z z z z$

$c:$
1
$i$
$v$

i

$z z z z z \quad z z z z$

$z z z z$

$z z z z z \quad z z z z$

$\dot{m}_{1} x z=z$

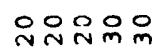

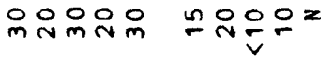

ㄱㅇㅇ응응 응응응 응영응

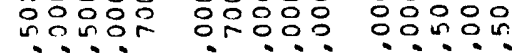

영ㅇㅇㅇㅇㅇㅇ 응영융영

응ㄷㅇㅇㅇㅇㅇㅇㅇ

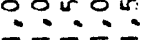

$\because \because-i$

$\because \therefore$ in-

응응용ㅇㅇㅇㅛ

n?

응응ㅇㅇㅇ응ㅇㅇㅇㅇㅇㅇㅇㅇ음

nin ino in ino in in

octso icoco

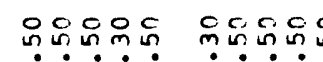

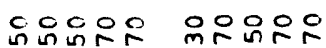

00000 oc.ooc

om.? nn in m.?

กำำกำ

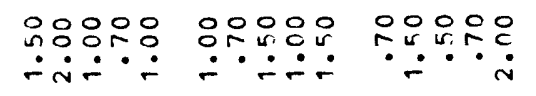

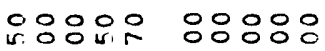

웅웅ㅇㅇㅇ

$\because \therefore \because \div \quad \therefore \dot{0} \dot{m}$

$\dot{m i n} \dot{m} \dot{\sim}$

응옹ㅇㅇㅇㅇㅇㅇ ن́ं $\dot{1} \dot{m}$

응웅용ㅇㅇ

min்

응응응엉

0
0
$i$
$i$.
0
0

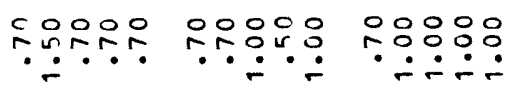

은응응응

옹유엥응

응응응요

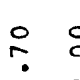

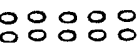

$\ddot{-} \dot{\sim}$

$\ddot{\because} \dot{\sim} \dot{\sim}$

$\dot{\sim} \dot{\sim} \dot{\sim} \dot{\sim}$

نंi்i

0000000000

$0000 c$

00000

00000

00000

00000

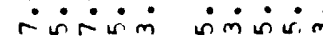

in mint

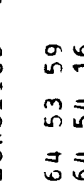

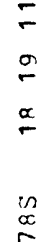

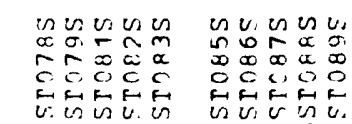

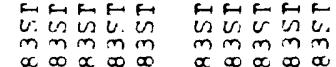

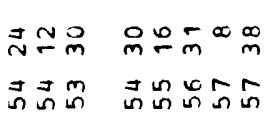

जี

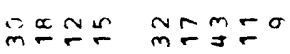


is

z

is

离

$z$
$i$
1
is

in

is

i

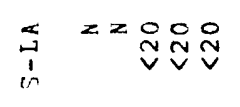

3
1
u

웅ㅇㅇㅇㅇ

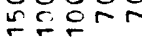

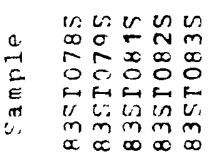

00000

00000

$z z z z$

:

.

octio is

$i_{i}^{\infty} z z z z z$ noño

유유융ำ

$z z z z$

$z z z z$

$z z z=$

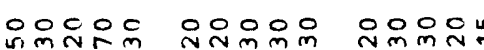

$z \geq z$

$z z z z z$

$z z z z z$

$z z z z=$

$\begin{array}{rl}z z & z 0 \\ & \stackrel{0}{V}\end{array}$

O
$\stackrel{V}{V}$

n융ㅇㅇ nn nOOO

OOO요요

ocoun

$z z z z$

$z z=2$

$z$

$z z z z$

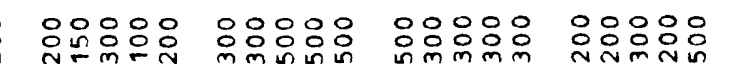

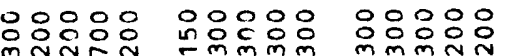

응ㅇㅇㅇㅇㅇㅇㅇㅇㅇㅁ

읃응영을 융ㅇㅇㅇㅇㅇ응

옹ㅇㅇㅇ용ㅇㅇ

웅요

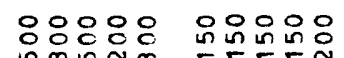

윰응응요응

$$
\therefore
$$

$z x z$

$z z z z$

$z z z z$

$z z z z$

$z z z z$

0000

00000

ocooo

on $\ln 00$

0000

nonoo

응요요

은유유

$z z z=$

$z z z z$

$z z z=$

$z$

$z z z$

$z$

$z=z$

soeve

,

s:

응유유

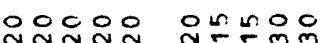

은요용

응응으을 $-$

$z z z z$

oon

nom 0

ncodon

$\ln$ in 000

not in

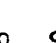

occ .

$z z z z z \quad z z z z$

$z z z z z$

$z z z z$

$z$

$z z z$

$z z z z z \quad z z z z z \quad z z z z z$

$z \geq z z$

$z z z z$ $z$

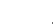

roำㄴำ 
é

i

$\frac{1}{1}$

$\frac{x}{1}$

is

í

as

is

$z$

응ㅇㅇㅇㅛ

ino

$\because$ 到:

응응융응

$\therefore \dot{n} \therefore$

융요응

iñ⿰氵亡)

웅용ㅇㅇㅇ

i $\because \because$

$\dot{i}^{z z z}$

$z z z z$

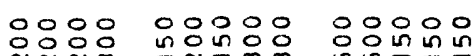

유유유ำ

등융요이

$\because z z z z$

$z z z z$

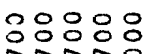

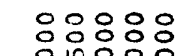

$\therefore \therefore \therefore$

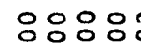

응요 $\therefore$ :

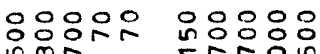

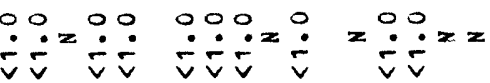

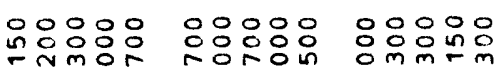
in $\therefore \dot{m}$

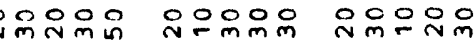

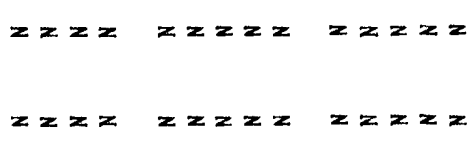

응ㅇㅇㅇㅇㅇㅇ
돈유유은

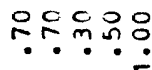

这

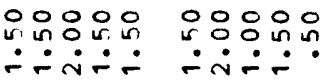

윰응요웅

응운웅응

수웅

$\because \because \dot{m}$

응응용응

영웅ㅇㅇ웅

$\therefore \dot{0}$

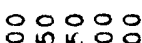

$\therefore \because \dot{\dot{n}}$

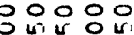

$\because \because \dot{4} \dot{\circ}$

옹우용우

$\therefore$

봉ํํㅇํำ

室

0000000000

móg vim

miñ்

00000

ómińm

09000

응용응

$\dot{4} \dot{4} \dot{4}$

은운응

$\because \therefore$ -

영ㅇㅇㅇ

ஸ்:

오옹요

오웅유응

$\because \because \because$ - $\dot{m} \dot{i} \dot{x}$

응ㅇㅇㅇ응 نंत्रं

익웅ㅇㅇ응

누운

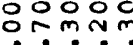

는?

00000

00000

तेंin

misis

00000

00000 nmon

mining

90000

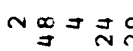

的n

ํㅜ음ำ

กำㅇํ유

$\Rightarrow g$ in

กิ고웅

N-正=0

궁ㅇㅇㅇㅇ

$\exists$

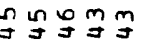

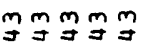

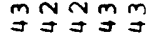

m急可方

욱워ㄱㅝㅝㄱ

곸ำ $\stackrel{9}{\exists}$

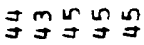

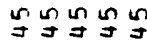

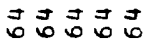

जै

चै च

जै 吉吉吉古

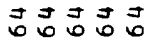

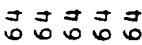

$\stackrel{n}{r}{ }_{m}=\hat{n}$

กำmo

음ํํㄹ

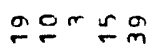

구ํํำ

ำลำำ

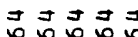

공ํำ

$\operatorname{can} \pi$

I $w=?$

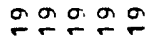

뜨유유유

주숫

우슨

수숫유응

영응

$\stackrel{\infty}{\sim} \stackrel{\infty}{\sim} \underset{-}{\infty}$

$\stackrel{\infty}{\infty} \stackrel{\infty}{\infty}$

유윰유유

$\infty \infty \infty \infty \infty$

구숫유으

$\propto \infty \propto \infty \infty$

ngencus

$\cos \cos 2 \cos \theta \sin$

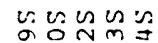

$\stackrel{\infty}{\sim} \stackrel{\infty}{\sim} \stackrel{\infty}{\sim}$

$\cos \cos c \cos c \cos c$

în

-두월

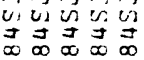

veves

Oogoc

든?口卄.

금ำ

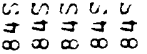

듬음요

约证记
등응

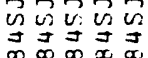

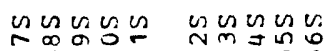

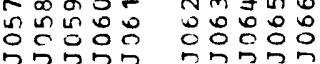

包记证

勿动向

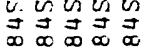

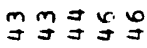

ีื

กำำกำ

우유슈슈

$\stackrel{\infty}{\infty} \stackrel{\infty}{\sim}$

$\cos \cos 2$

600?

可的记 

(

in

$z z z z z \quad z z z z \quad z z z z$

$2 z 2 z=$

$z z z z$

$z=z z z \quad z z z z z$

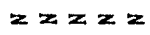

$z z \geq z z$

$z z z z$

is

is

is

is

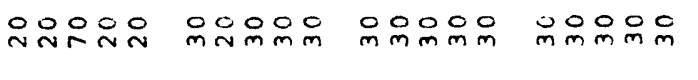

10000000

$z z \underset{v}{\hat{n}} z z \quad z z z z z$

$z z z z$

$z z z z$

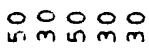

었융요

$\stackrel{0}{\Omega} x=x$

$z z z z$

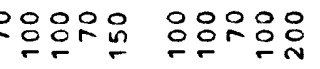

응응ㅇㅇㅇㅇㅠ

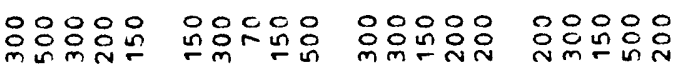

으요요용요

동용ㅇㅇ응

은은응용요
응
$z=\log _{\substack{0 \\ \text { in }}}=$

$x z z z$

is

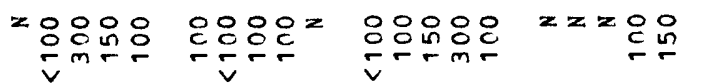

윤은

응응

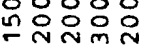

융응응요음

i $z z z z z \quad z z z z \quad z z z \frac{0}{v} \quad z z z z z$

$z$ in $z z=$

$z z z x \quad z z n z z$

$\circ: x=z$
$ㄷ$

z응ㅇㅇㅇ응

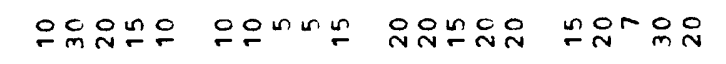

응유은 우음유유

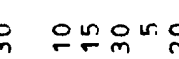

$z z z z$

$z z z z$

i

noo 00 ocono en

is

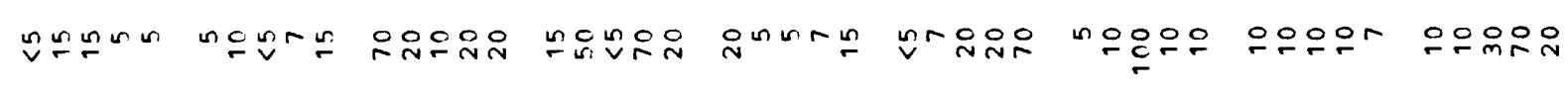

$\infty$
$z$
$i$
$i$

$z z z z y \quad z z z z y z z z y z z z z$

$z x z z$

$z z \geq z$

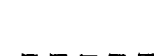

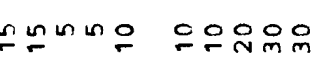

0
$\substack{x \\ 1 \\ \text { is }}$

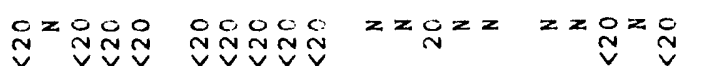

$\stackrel{\circ}{\circ}$

$z=z=z z=0$

$z z n z$

$z z z z z$

$z z z z z$

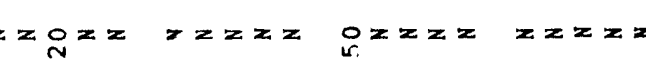

음

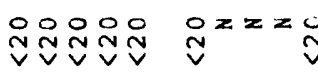

$00 \geq 00$

$z=$ z요

$O_{0} z z=x$

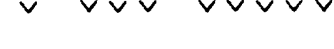

00000 00000 00000 00000

00000

응ㅇㅇㅇㅇㅇ

웅

응ㅇㅇㅇㅇㅇㅇ

\section{일}

z윤유 $z \stackrel{i}{V} z=\stackrel{\sim}{V}$

îninr romain omrmar

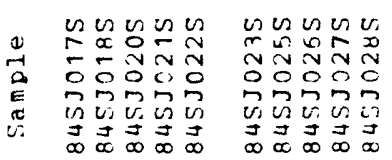

ขึ.

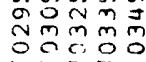

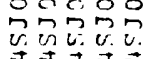

$\operatorname{lic} \pi \underset{\infty}{\cos }$

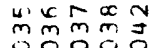

设识证

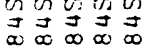

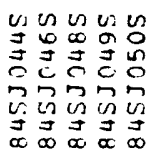

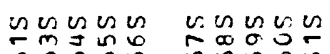

กิ

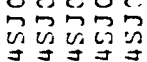

in vive.

$\vec{\infty} \underset{\sim}{\infty} \vec{\infty} \vec{\infty}$

舟为里里

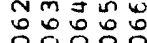

v. vivin

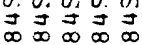

$\cos 2 \cos$

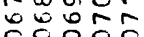

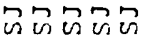
$\vec{\nabla} \exists \overrightarrow{=}$ 


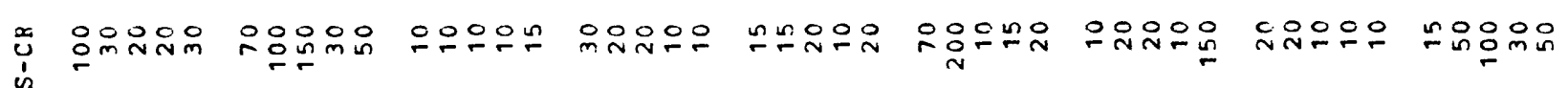

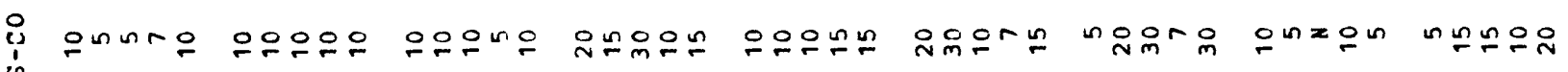

in

$\pi \quad 0000$

0000

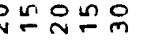
Nin

응옹유 운

응웅요 $\therefore$

$\because \because \because \because z$

$\dot{\bar{v}}=\stackrel{0}{\dot{v}}=\stackrel{0}{\dot{v}}$

$\because x=\stackrel{0}{\dot{v}}=$

$=\stackrel{0}{\dot{v}}=\frac{0}{v}$

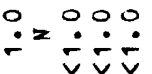

is

is

$z z z z z=z z z y z z z$

잉은요

융유우

우융ㅇㅁㅇㅡ

둥융ㅇㅇㅇㅇ

응은응웅

응ㅇㅇㅇㅇㅛ

응응ㅇㅇㅇ

융으으윰우

$z z 2 z z$

$z z z z \quad z z z z z$

$z z z z$

0
1
is

$z z z z$

$z z z z$

$=z z 2 z$

$z=2 z 2$

$z z=2$

$z z z=$

$z z z z$

$z z z z$

$z z: z z$

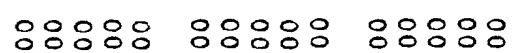

용요

응유

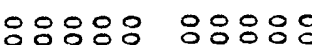

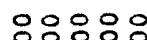

응ㅇㅇㅇ

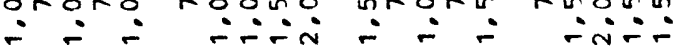
$\because \because \because \dot{x}$

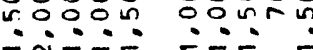

$\therefore$ ins

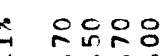

\section{0}

00000

용ㅇㅇ

웅ㅇㅇㅇㅇㅇㅇ

두응

웅유웅

응응유음

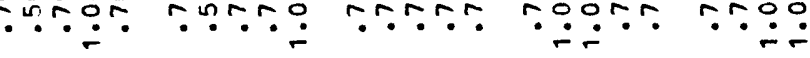

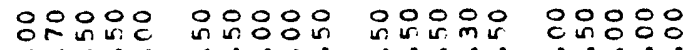

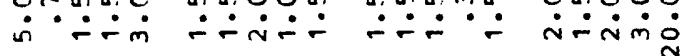

$\therefore \circ: 0: 0$ ․․․․

운유유요

ํำำ.

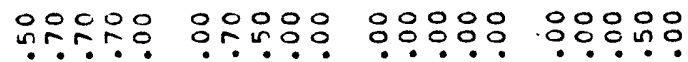

용ำ

옹웅ㅇㅇㅇ

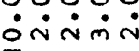

욷요요용

응용요

옹용요 옹응요 i nn

$\dot{\sim} \dot{-} \dot{\dot{N}}$

응응요응

$\therefore \dot{\sim} \dot{N}$

तं்-

\section{0 \\ 0000000000 \\ 00000}

00000

$\dot{m} \dot{m} \dot{-}-\dot{0}$

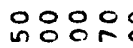

웅응요응

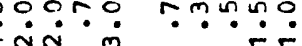

응응ㅇㅇㅇㅇㅇㅇ $\dot{\sim} \dot{m} \dot{m} \dot{0}$ जिminisinim in $\cos$ is in

is in

00000

00000

00000

00000

- Nํำ

\section{m}

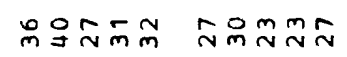

ํํㅇำ

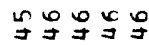

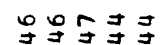

寻寻寻寻寻

ก⿻

ㄴํำำ

mirim

نिं

ज可者

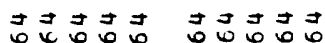

जुचु चु चै

考寻色

$=\hat{N}$

nom

$\operatorname{ing} \pi$

กำํำㄹํ

$\operatorname{mon} 0$

ry은

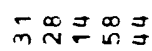

$\leq n \infty=m$

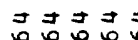

ज्ञ

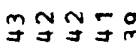

寻寻寻寻

马コ马寸

in 0000

은유은

유윰의

rerta

ams g

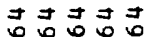

苛寻寻寻

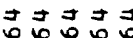

尚寻寻寻寻

$\stackrel{\infty}{\square} \simeq$

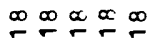

$\stackrel{\infty}{\square} \dddot{\infty}$

$\alpha \infty \infty \propto \infty$

กำกับ

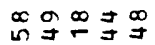

은제

on용

$\exists \underset{m}{\infty} \stackrel{m}{\pi}$

$\infty \infty \propto \infty \infty$

유유윰ำ

$\because \dddot{\infty} \stackrel{\infty}{\sim}$

윳유웅ㅇ

움유음

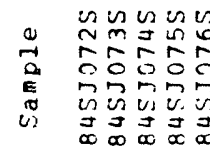

cosens nesing

uns os on

$\propto \infty \infty \infty$

$\stackrel{\infty}{\infty} \stackrel{\infty}{=}$

$\stackrel{\infty}{-\infty} \stackrel{\infty}{-}$

$\cong \stackrel{\infty}{\sim} \stackrel{\infty}{\sim}$

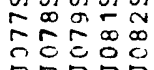

c.

m约织

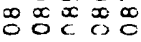

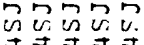

a $0=4$

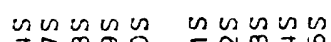

usencus

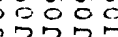

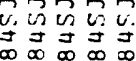

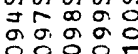

D包鸟

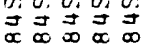

등응르는

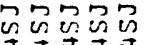

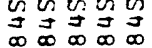

0
05000
0000

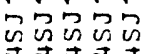

$\sin \operatorname{sen}$

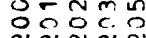

드워ำ

NNob

的的点

$\Rightarrow \exists=$ 
T.

2
$i$
$i$

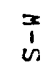$$
\text { ì }
$$

is

(n)

is

西离

密

$n$
1
$n$

2

i

$\frac{1}{3}$

苟

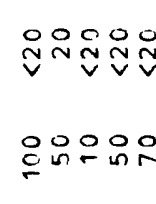

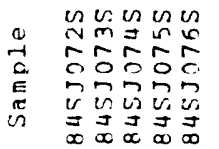

응으뭉ㅇㅇㅇ

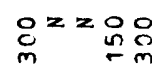

$z z z z$

ons n m

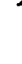

(n)

$z z z z$

$z z z$ $z z z z$

$z z z z$

$z z z 2$

응응용응응응

ror

$z z z z$

7

$$
20
$$

no

00000

0000잉

$z=z z=z=z$

$000 \mathrm{cos}$

$2 z 22$

용요 요웅

$m \div$ -

กr

$z z z z z \quad z z z z$

zO 근

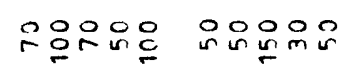

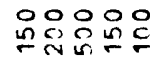

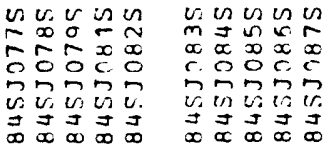

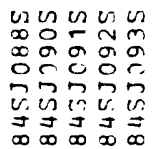

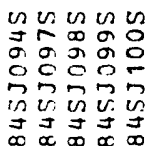

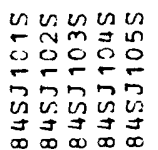

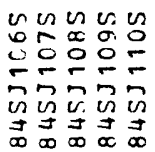

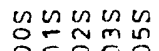

응유

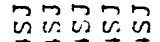

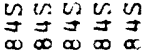

$z \geq z$

은으응

$z z z z$

00000 00000 00000 0nots. 00 min

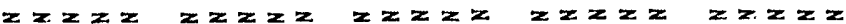

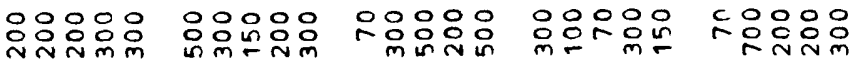

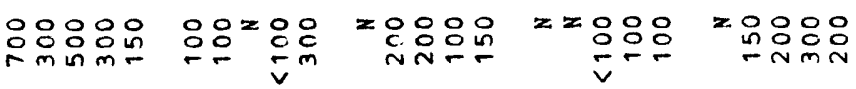

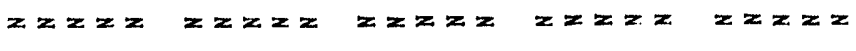

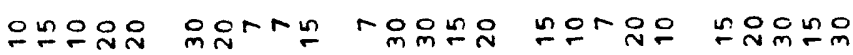

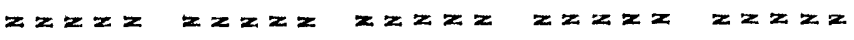

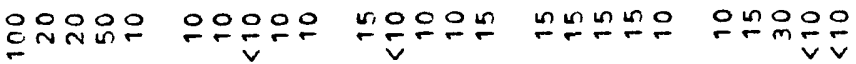

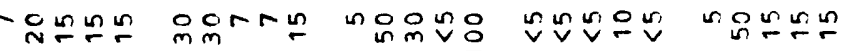

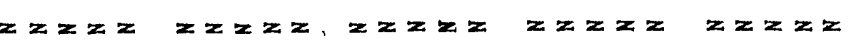
$z z z z 0 \quad z z=z z \quad z z z z z \quad z$ w $z z z \quad z z z z z$

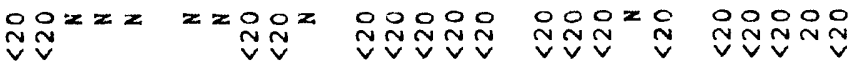

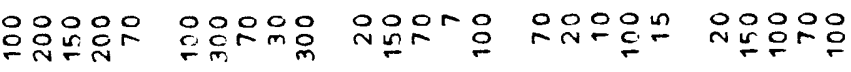
(1) 


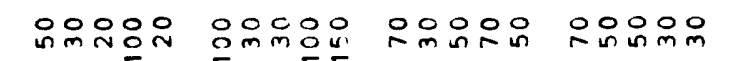

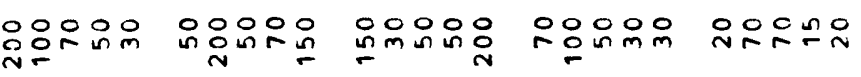

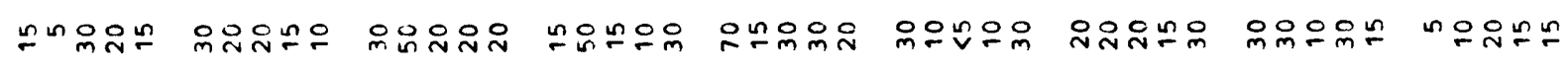
过 $x z z z z y z z z y z z z z z y z$

$z x z z x \quad z z z x y \quad z z z z y z z z y z z z$ is

00000

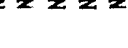

$z z z z$

$z z z z x \quad z z ㅇ=z$

$z z z z$

$z z z z z \quad z z z z z$

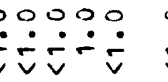

0.00

0000

0000 z⿺辶一

$\because \div \div$

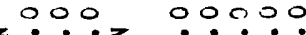
$\dot{\bar{v}} \dot{\mathrm{v}} \dot{\mathrm{v}}$

デす $\dot{v} \dot{v} \bar{v}$

$\dot{\circ} \dot{v} \dot{v} \dot{v}$

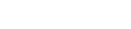

\section{웅ㅇㅇㅇㅇ}

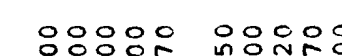

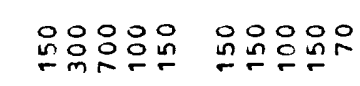

co0zo c0000 00000 $\therefore$

r.t. n-nim

우윰음

$$
\text { in }
$$

$z z z z$ $z$

$z=x z$

$z z z z$

$z z z z$

$z z z z z$

$z z z z$

$z z z z$

$z z z z z$

$z z z z z \quad x z z z$

응ㅇㅇㅇㅇㅠ

in요유.

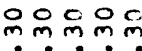

in $\mathrm{m}$ in in

으은듀을

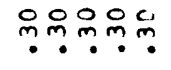

유ํํํํํํํำ

ำกำ.

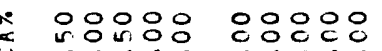

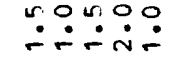

Nंmí:

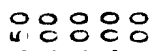

$\therefore: \because 8:$

ㅇㅇㅇㅇㅇㅇ

$\therefore \dot{\sim} \dot{\sim} \dot{\sim} \dot{\sim}$

نंतi்i

imini

윰웅ㅇㅇㅇ

온동요

$\because \because \because \dot{\circ}$

을유융은

$\dot{\dot{n}} \dot{0}$

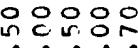

is

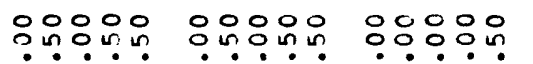

응응우요

00000

In

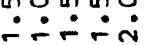

0 ino

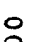

000000

$\ddot{i} \dot{n} \dot{0}$

$\dot{\sim} \dot{\circ} \div \dot{\circ}$

$\dot{n} \dot{\dot{r}} \dot{m} \dot{\circ}$

$\therefore \dot{\sim} \dot{\circ}$

$0000000000 \quad 00090$

00000

00000

$\dot{4} \cdot$

ํำ

응웅ㅇㅇ 응응욷

iि

inmini

0.0900

00000 i的・

$\because \therefore \dot{0}$

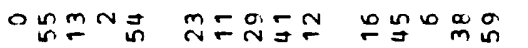

㶽きシํํํำ

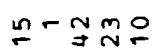

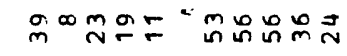

0000000000

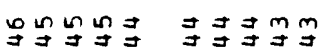

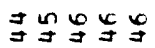

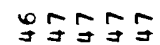

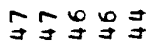

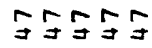

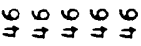

चี

चี

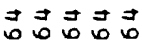

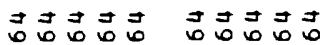

루

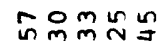

는

ถึกำกับ

aramn

Fanor

踥쿠요

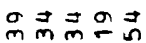

$-m=\stackrel{n}{\sim}$

m엥으구

ลีำำำ

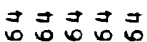

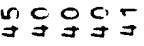

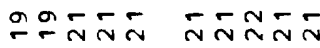

กำกำ

두슈유

유슈ำ

아의의

으뭉ㅇㅇㅇㅇ

ヨコะก

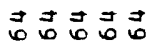

$\stackrel{\infty}{-} \stackrel{\infty}{-} \stackrel{\infty}{-}$

$\stackrel{\infty}{-} \stackrel{\infty}{-} \stackrel{\infty}{-}$

$\stackrel{\infty}{\infty} \stackrel{\infty}{-} \stackrel{\infty}{=}$

$\stackrel{\infty}{-} \stackrel{\infty}{\sim} \stackrel{\infty}{=}$

$\stackrel{\infty}{\infty} \stackrel{\infty}{\sim} \stackrel{\infty}{\sim}$

$\stackrel{\infty}{\sim} \stackrel{\infty}{\sim} \stackrel{\infty}{\sim}$

$\stackrel{\infty}{-\infty} \stackrel{\infty}{-} \stackrel{\infty}{=}$

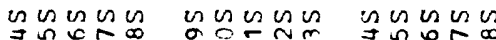

vicucen unengen ungen

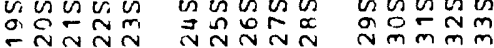

ธू一ำ

ơ응

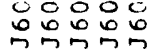

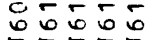

605

的的电

u.

v. $\sin 0$

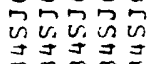

טํํํํํำ

U.

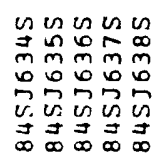

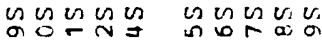

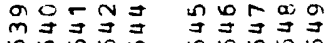

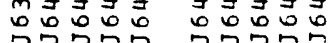

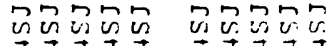

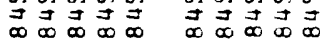

$\vec{\infty} \vec{\infty} \underset{\infty}{\infty} \vec{D}$

œ $\vec{\infty} \underset{\infty}{\infty} \vec{\infty}$

$\infty \vec{\infty}_{\infty} \infty \vec{\alpha}$ 
$z z z z z z z z z$

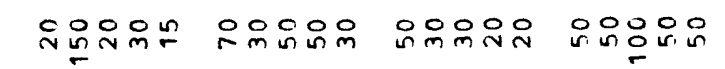
v.

i

$z z z z=z z=\frac{O}{\stackrel{O}{V}} \quad z z z z$

$i$

x
is

is

in

is

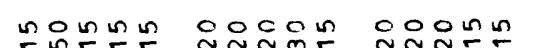
กำก

$z=z z$

$z z z z$

옹응ㅇㅇ응 윤응응

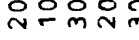

융응으은

00000

v

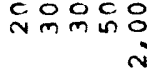

$z$
$i$
in

is

in

in

is

$\sum_{i}^{\infty}$

$x_{x}^{0}$

in

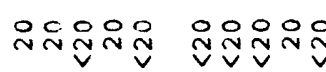

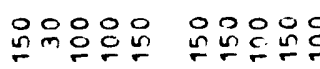

u

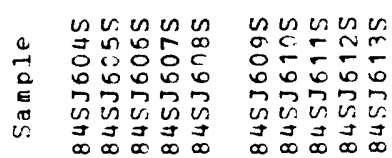

皮为为

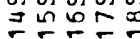
0000

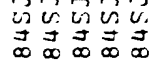

$x z=z$

$\operatorname{ing} \Omega \infty$

nc

o0000 cooor

음웅으음

읐융유으

$z z z z z$

\section{운융유우}

00000 은응ㅇㅇㅇ बूn

-

ตำำ

$\vec{\infty} \vec{\sim} \overrightarrow{\vec{D}} \vec{\infty} \vec{\infty}$ $z z z z y z z z z$

ㅇํ은ำำ

$z z z z$

응응유우

$z z z z$

$z z \quad z$

$z=0$

$\underset{4}{2}$

옹응이용요

잉ㅇㅇㅇㅇㅇ

nom

응ㅇㅇㅇㅇㅇㅇ

$z z z z$

$x=\stackrel{O}{O}=0$

$z z z z$

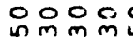

$z x z=$

운유윤으

证

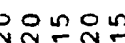

r

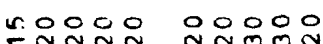
$z z z z z \quad z z z z z$

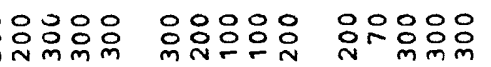

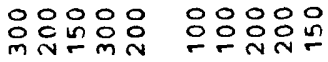

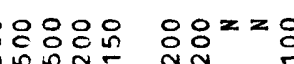
:20:8: 㗭 $z z=z z z z z z$

$z z z z$

$z z z z \quad z z z z$

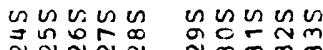

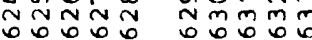

पिज?

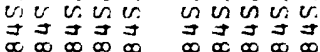

$\ln \sin 2 \cos$ minm

ชั0ํำ

en in vev $\vec{D} \vec{D} \vec{\sim} \overrightarrow{\vec{D}} \overrightarrow{\vec{a}}$

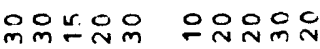

$z z z z z \quad z z z z z$

은운으는 은은은은

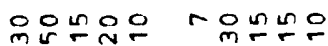

$z z z z$ $z z n z z \quad z z z z z$

운우우 운우z $\mathcal{N} \mathfrak{N} \mathcal{N} N \mathcal{V}$

응은운은 운응응

ensen unesen

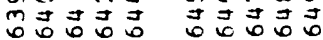

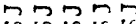

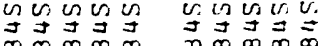




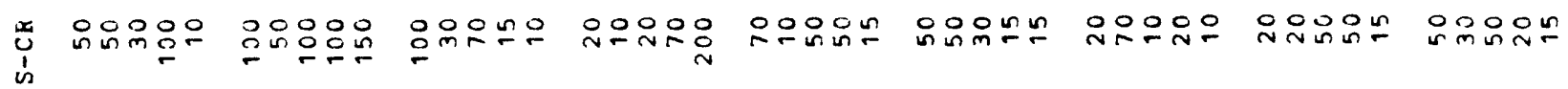

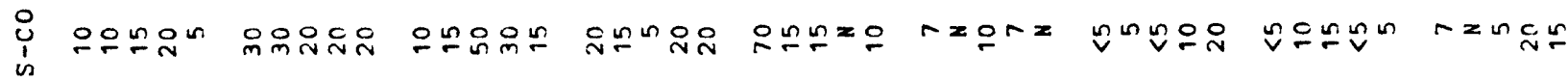

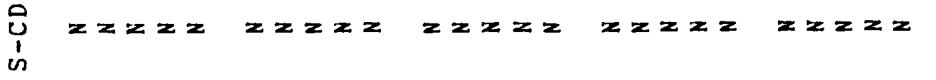

fi $z z z z z \quad z z z z \quad z z z z$

$z z z z$

$z=2 z z$

$z \geq z z$

$z z z z$

$z z z z$

z. $x z z z$

की $\stackrel{\square}{\therefore}=\stackrel{0}{\circ}$

000000000

$\because 0.0 \quad 00000$

00000

00000

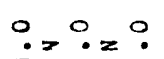

$\because=000$

c 응요요용

ธะทัท

$\dot{\bar{v}} \dot{\mathrm{v}} \dot{\mathrm{v}}$

レ゙ $\bar{v}$ v $\bar{v} \bar{v}$

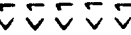

㐫㐫㐫

$\checkmark \dot{v} \bar{v}$

v v

융 $=$

iㅏ

응음요

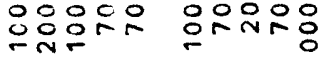

응요

00000

군용영

응웅용 in

in

$\therefore$

$\frac{x}{1}$

$z z z z z \quad z z z z z \quad z z z z z$

$z z z z$

$z z z z z$

$z z z z$

$z z z z z$

$z z z z z$

$z 2 z z z$

$z z z z z \quad z z z z \quad z z z z z$

$z z z z z$

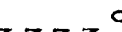

2 00000

융ㅇㅇ 융ㅇㅇㅇ

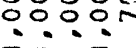

$\therefore$

$\therefore: \div$

응융요

80000

$v^{z}=$

$z z z ? z$

$z=2 \stackrel{n}{\dot{v}}$

$\because z z z z$

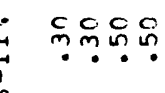

응이잉 등ㅇㅇㅇ

$\therefore \because$

-

응응ㅇㅇㅇ

응옹용요

응응ㅇㅇㅇ

응등ㅇㅇ응

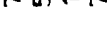

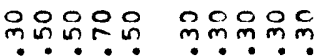

응은동

옹ㅇㅇㅇㅇ

$\therefore$

$\because 05$

过

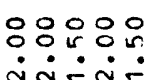

응응은은

o on 0

nㅇㅇㅇㅇㅛ

Troos

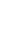

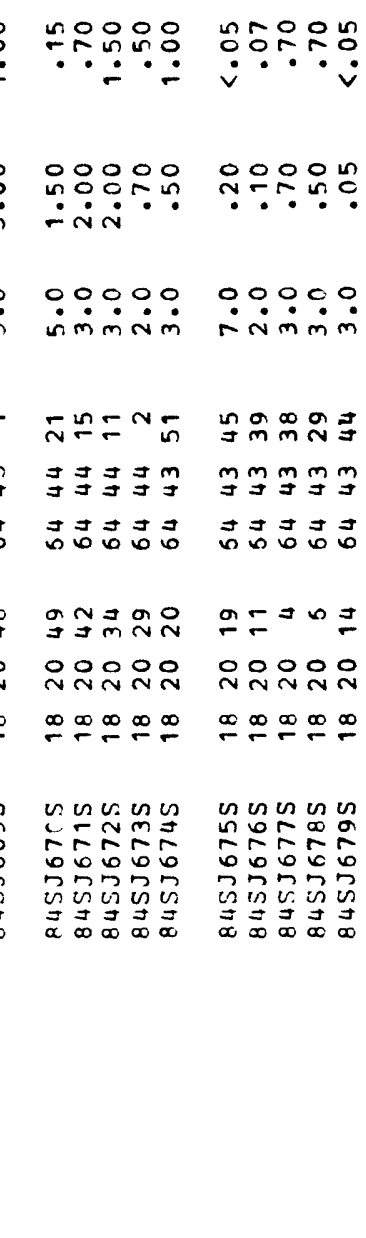

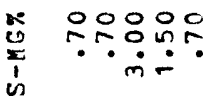

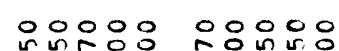

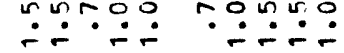

응용ㅇㅇㅇㅇㅇ

$\therefore \because \because \dot{m}$

응ㅇㅇㅇㅇㅇ

운은온ํㄴ

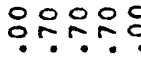

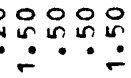

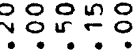

$\dot{n} \div \dot{-}$

inㅇㅇㅇㅇㅛ

0.90 0.000 0000

is

gon NO

noms

กิ $\stackrel{\infty}{\sim} 0$

00000

กinm in

żag

我果里

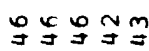

กำำก

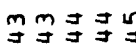

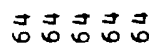

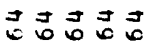

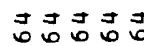

可司寻寻手

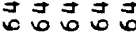

곡율옹

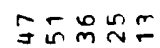

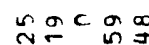

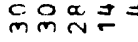

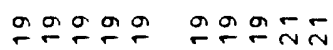

กักลำㅇำ

nnnn

$\infty \infty \infty \propto$

$\stackrel{\infty}{-\infty} \div$

$\stackrel{\infty}{\infty} \stackrel{\infty}{\leftarrow}$

$\cos u \cos$

unuse

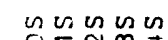

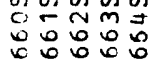

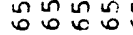

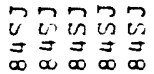

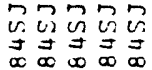

«n

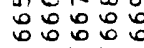

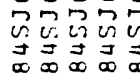

co

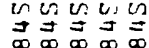

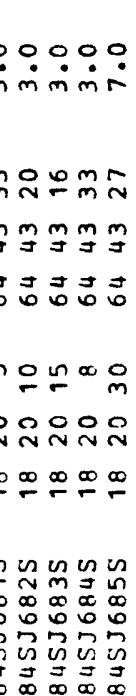

o o ono

응ㅇㅇㅇㅇㅇㅇ

ำ? 


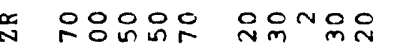

is

is

$z z z z z \quad z z z z z \quad z z z z$

$\geq \stackrel{O}{O}=0$

$\stackrel{ }{N}^{z z}:$

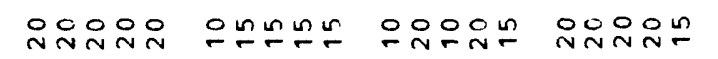

00000

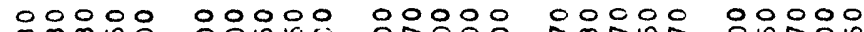

in

3
is

$z z z z$

$z \geq z z$

$z z z z$

$z z z z$

$z z z z=$

is

웅응요 응응응

응응응응 응웅응응

o0000 00000

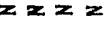

$z z z z=2 z z z$

is

a
i
in

웅웅으 응응은

잉이

min

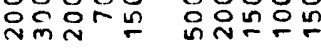

우우응ㅇㅇㅇㅇㅡ

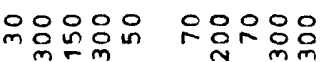

둔

NNN

imen

운은 은은

$z=$ 윰은

$x z z=2$

$z: z=0$

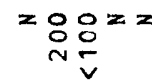

$=\stackrel{n}{O}^{2}=0$

$z z z z z \quad z z z z$

$z z z z$

$z z z z z$

$z z z$

$z z 2 z$

$z z z z$

$z z z z z \quad z z z z$

oroos oo

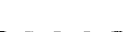

1000

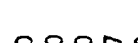

arinos

$\ln n 0$

웅으 rro을

in

$z z z z z \quad z z z z z \quad z z z z \quad z z z z$

$z z z z$

$z z z z z$

$z z z<z$

$z z z z z z z z z$

$\frac{1}{2}$

은은은 은윤은 z윤은 은은은

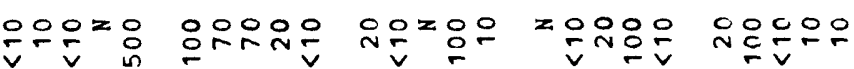

tis
1
in

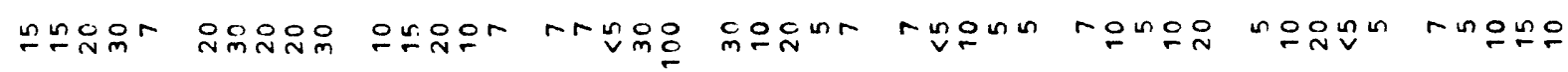

$\sum_{\substack{2 \\ 1}}^{\infty}$

in

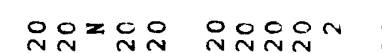

유슌유유 z유융유

은유융ำ

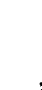

$z=2 x z$

$z z z z=2$

$z z x z$

$z z z z x \quad z z z z$

$z x z z \geq 0 z z z$

$z z z O=z z z 0 z$ z $z=z z$

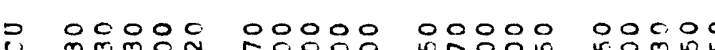

oo $\dot{a}$ is

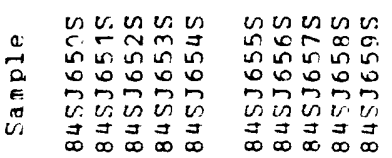

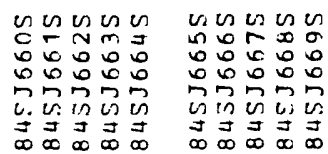

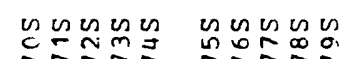

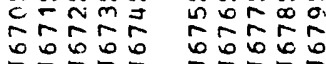

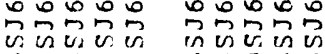

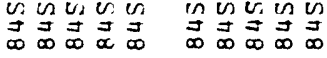

$\operatorname{nin} \cos$

$\infty \begin{array}{lll}\infty & \infty & \infty \\ 0 & 0 & 0 \\ 0 & 0 & 0\end{array}$

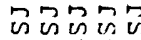

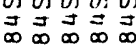

is

$\infty \infty \infty \infty \sigma$

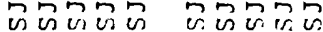

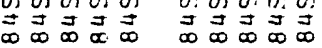




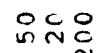

is

sener

,

U in

h

00000

는

엥웡ㅇㄴ

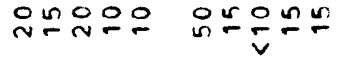

옹요요요

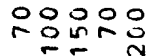

00000

MO

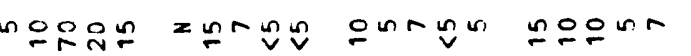

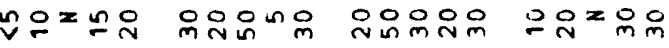

in is

co요용

is

is

$z z z z$

$z=z=$

응요은융ㅇ

0.0000

$\div \div \div \div$

? 00000000

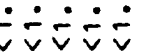

$\div 0 \div 00$

$z z=\stackrel{0}{v}$

$\ddot{0} \div=\stackrel{0}{0}$

00000

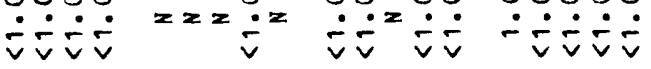

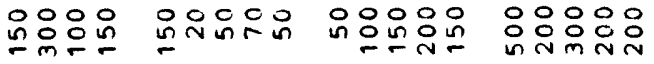

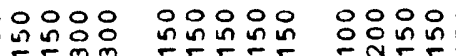

$\stackrel{n}{1}$

is

$z$
1
v.

응응융

$\because \because \because$

$\stackrel{2}{1}$

c000

ำ.?

옹유.

운음욤

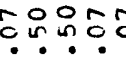

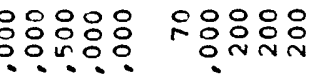

응응ㅇㅇ

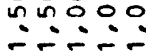

conoco

00000

운유웅유

mำกำ

ל⿺辶一

00000

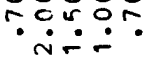

웅ㅇㅇㅇ

ำกำ

웅응요우

$\because \because י$

옥은요운

?.?

으누ํㅇํ은

0000

$\ddot{\dot{m}} \dot{0} \dot{0} \dot{0} \dot{0}$

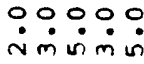

00000

00000

minm

जित्रंजि

$\dot{m} \dot{\dot{m}} \dot{\sim}: \dot{\sim}$

$\dot{m} \dot{m} \dot{m} \dot{0}$

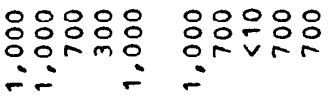

응요용

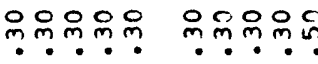

$\because \div$

읍윰유유요

운윢ํํํํำ

응융ํㅇ응

응용요융

$\dot{n} \dot{\sim} \dot{m}-\dot{m}$

응응영

mंnिंक्ष

웅응응

品

몸mㅛ

的战吕=

을 - 웅

กำลำ

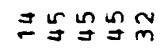

舟

$\mathfrak{I} \mathbb{\exists} \mathfrak{I}$

急寻寻

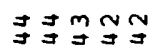

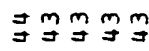

可寻寻寻寻

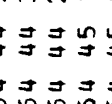

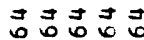

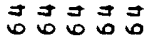

ํmㄴㄷㅗ

뜬목

유윳ㅇㅇ

유으무유수

웅스믈

$\dddot{\infty} \simeq \stackrel{\infty}{\longrightarrow}$

$\stackrel{\infty}{\infty} \stackrel{\infty}{-}$

$\sin \cos 2$

는

$\cos 20$

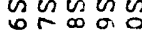

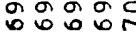

敏矛跑

nesenes

isenges

둥ㅇㅇㅇㅇㅇ

知的

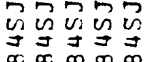

的的出

$\omega$
$\vec{a}$
$\infty$

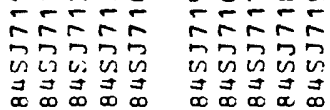

uneses

กNNNㅗN

ज的句告

थै
유문유

$\dddot{\infty} \cong \stackrel{\infty}{\simeq}$

운웅유융

imi்:

웅의응음

00000

00000

00000 $\dot{m} \dot{0} \dot{\sim} \dot{s}$ in

nूñ 乌บำ

옹ํㅡㄴํำ 可司可

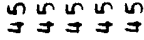

寻寻寻寻寻

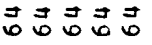

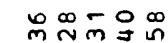

\pm 距

유숫유

운돈

$\stackrel{\infty}{\infty} \stackrel{\infty}{-} \simeq$

$\cos \cos 2$

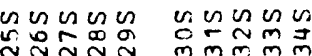

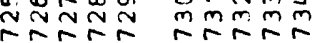

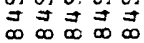

응읃요요

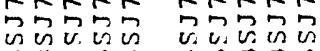




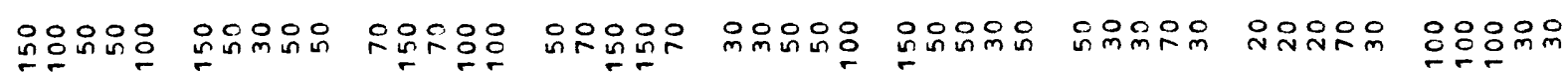

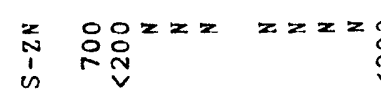

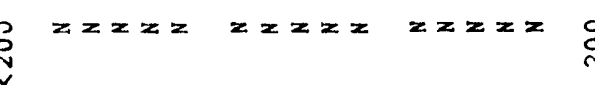

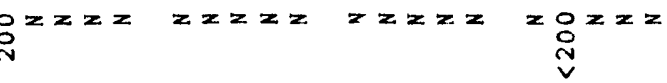

- 00000 i00

i

co

is 2

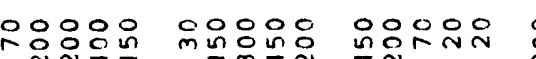

이융ㅇㅇ

응은다웅 은요응응

응응용으

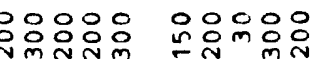

융을

$z=0$ 응응

$z \underset{N}{:}=x=$

$z x=\frac{8}{v}$

융유

z

응율유

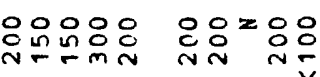

$z \quad z z z z$

$z z z z=2 z x z$

$z x=z$

$z z z z$

$z z z z$

$z z z z$

$z z z z$

$z z z z$

í

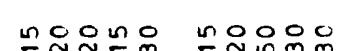

10

$\operatorname{ros} 10$

oorto

isiono

0000

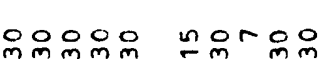

$z z z z y z z z$

$z z z z$

$z=z$

$z z z z z \quad z z z z z$

$z z z z$

$z z z z z$

i

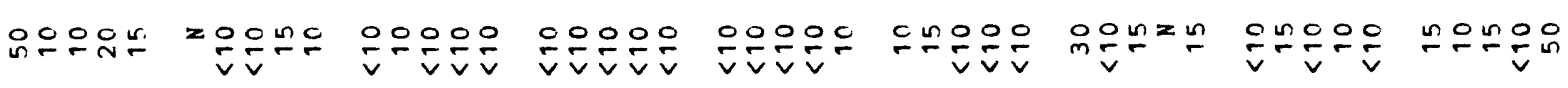

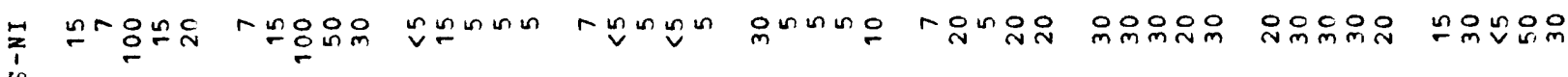

$\sum_{i}^{\infty}$

$\sum_{i}$

is

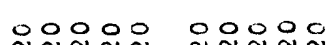

o o o 00

운융워

$z$

$z z z z$

$z z z$

$z z z z$

$z z z z z \quad z z z z z$

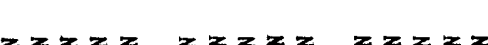

$z z=z$

$z z z z z$

$z z z=$

$z \geq z z$

$z z z z z \quad z z z z z$

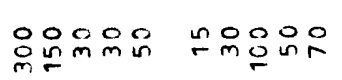
マレvレv

V

z유윤유 윤윤유

웅으

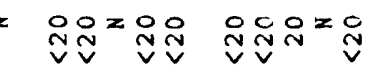

엉요

유윰유

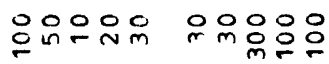

웃옹으웅

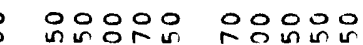

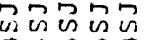

包的它

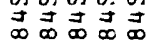

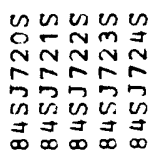

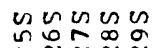

NNNN

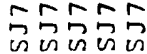

$\vec{\infty} \infty \vec{\infty} \vec{\infty} \vec{\infty}$

c⿻sen ⿻上丨

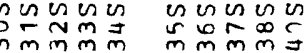

솟 mmma

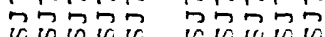

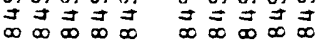


으요요

ì

w
$\dot{1}$
in

$\because 0000=0 ?=$

这

000000000000000

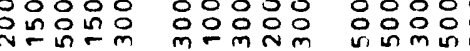

1

$z z z z \quad z z z z=$

$z z z$

$z z z z$

\section{ㅇ:용}

$\div \div$

00000

in요용

응ㅇㅇㅇ

年

$\therefore \because \because 2$

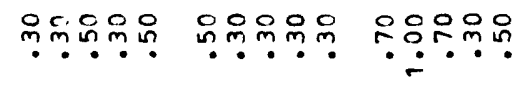

운유융

응요용

용요

$\dot{m} \dot{m} \dot{m} \dot{\sim}$

minisin-

$$
\text { : }
$$

$$
\text { 을 }
$$

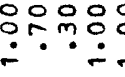

\section{0}

응응요요 $\therefore \because \because$

i-m户

움웅ํํํํํ

ㅇiㅇ용

ㅇ:웅

$\because \because \because 二$

양요

$\therefore \therefore:$

웅요

$\therefore=5$

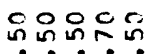

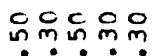

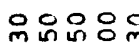

กับำ

응요

용ㅇㅇㅇ

웅요용

$\dot{\sim} \dot{\sim} \dot{\sim} \dot{\mathrm{N}}$

نंत्रல்

$\dot{m} \dot{m} \sin$

ㅇ::응 i $\dot{n} \dot{m} \dot{m} \dot{N}$

응응 운웅요

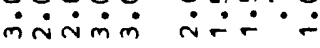

$\dot{m} \dot{m} \dot{m} \dot{m} \dot{m} \dot{m} \dot{m} \dot{m} \dot{m} \dot{m} \dot{m} \dot{m} \dot{m}$

00000

00000

응요용

$\dot{-1} \dot{-1}$

응요우음 $\dot{-10}$

웅ㅇㅇㅇㅇㅛ

กั?

영우운

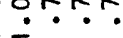

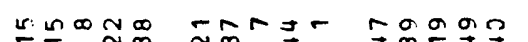

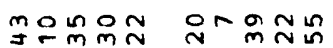

00000

00000

0.00000000

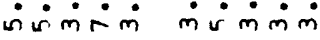

\section{可寻寻寻寻 \\ $0 \infty$ o 0 \\ on 0 in}

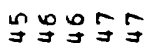

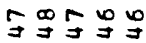

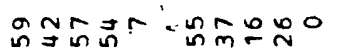

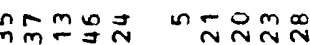

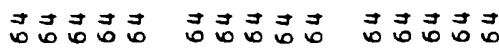

局可可

局宁可者

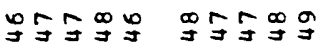

man

Do

$=\stackrel{n=}{5}$

gin $\min$

m户̈m $\ddot{m} \dot{m} g$

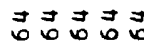

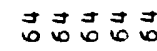

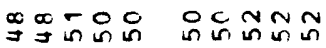

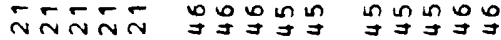

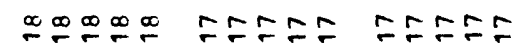

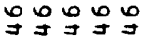

$g$ 马ำ

min

-

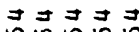

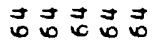

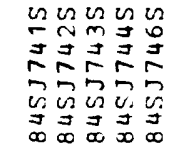

$\sin \backsim \sin$

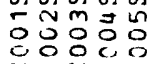

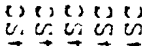

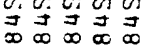

뉴용ㅇㅇ

Iㅡ

ๆニะニะ

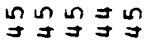

刍寻表寻寻

00000

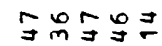

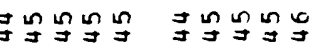

도

ระะะร

ar

Fะะニ

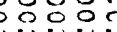

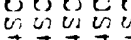

$\operatorname{sen} \operatorname{ses}$

$\cos \cos e$

$\sin \sin$

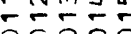

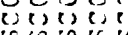

00020

이웅요

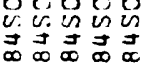

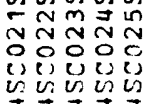

$\cos \cos 20$

ํำ

isieis

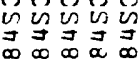


z $z z z z z$

$\stackrel{\infty}{N}$

0000000000.0000

요

is

i

ooooo nnmon ooono

i

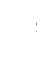

7 응웅요 응응응 영영응 is in is

is in

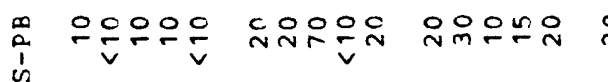

$n$
1
$i$

o

응유

욤 $z=2$

응응용요

응옹용응

\section{(1)}

$\circ \circ 000$

$z=2 z$

$z z z z=$

$z z z z$

odinoo

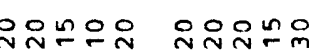

$z z z z$

\begin{abstract}
$x z z$
\end{abstract}
은유은오음

응

00000

$z x \geq z$

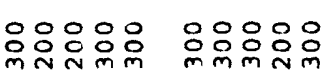

응응응요

읏용ㅇㅇ응음

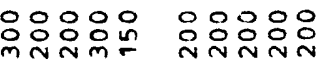

$$
\text { (a) }
$$

is

$\stackrel{i}{i}$

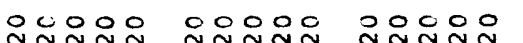

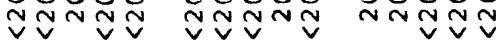

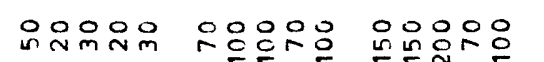

is

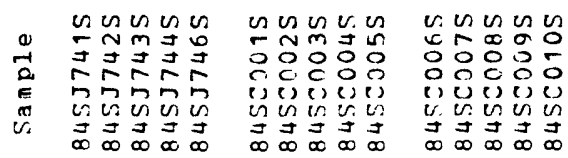

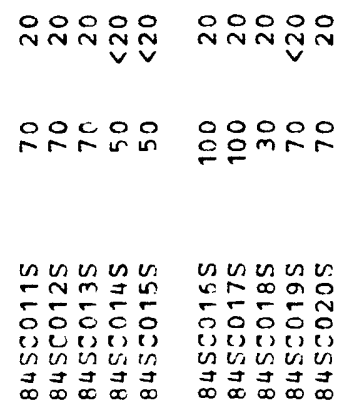

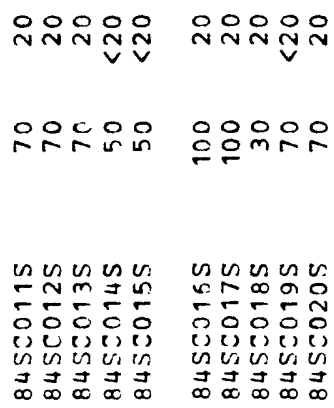

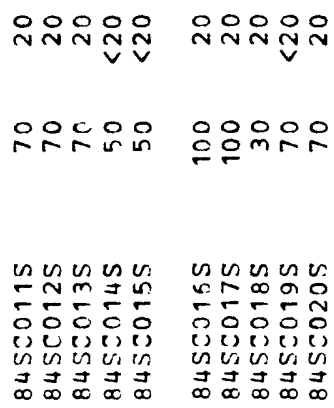

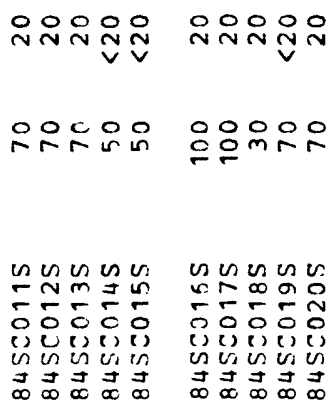

워늄윰ำ

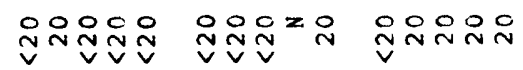

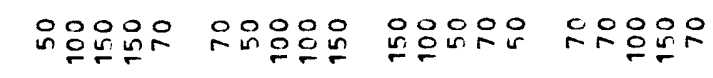

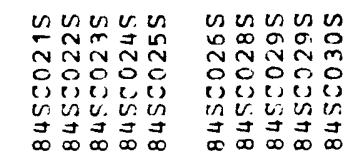

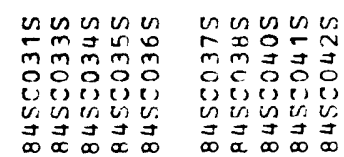




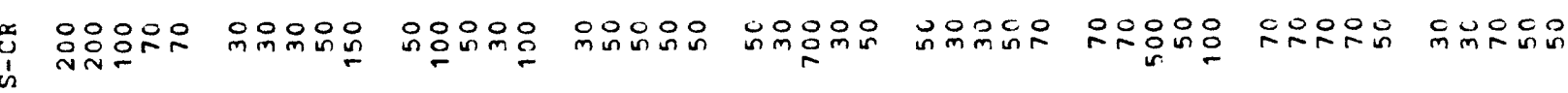

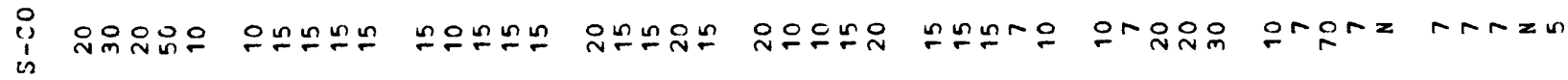

in

(4) 0000

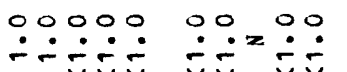

$\dot{v} \dot{v}=\stackrel{i}{\dot{v}}$

0.000

$\dot{v} \dot{v} \dot{v}$

00000

$\dot{\bar{v}} \dot{\mathbf{v}} \dot{\mathrm{v}} \dot{\mathrm{v}}$

․ำ.

$\frac{\dot{v}}{\dot{v}}$

0.000

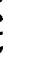

0000

\section{$\stackrel{2}{\circ}$}

0000 $\dot{\square} \dot{\dot{v}} \dot{\mathbf{v}}=$

00000

영영융응요 응융

\section{응응용}

000000000

용

응ㅇㅇㅇ응 $\therefore$

0000 (2)

i

\section{용}

웅ㅇㅇ웅

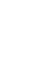

is

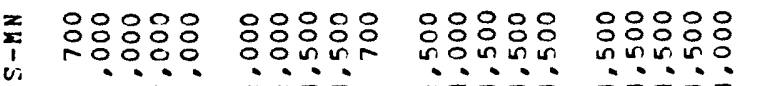

$z z z$

$z z z z x$

$z z x z z$

$z$

$z \geq z \geq z$

$z z z z z z z z z$

$z z z z$

$z$

$z z z z \quad z z z z z$

$z z z z z$

$z x z z=$

$z z z z z$

$x^{n}:$
$\circ 80$
$\circ 80$
$\therefore \therefore$

$r: 0: 2=$

$z x z z$

$z z z ?$

$z x z z z \quad z z z z$

$x z 2 x z$

$z z z z y z z z$

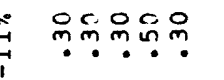
$\because \because \div \div \div$

$\because \because \because \div$

응융요 응응용요

nn!n? n?

응ㅇㅇㅇㅇㅇㅇㅇ

․․ㄴ?

응융ㅇㅇㅇㅇㅇㅇ

응ㅇㅇㅇㅇㅜ

$\therefore$ i

$\therefore \because$

w

ind

is

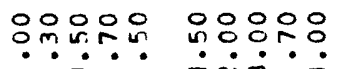

옹응ㅇㅇㅇㅇㅛ

응요은든

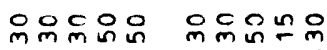

돈듀윰ㅇ

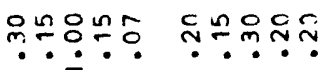

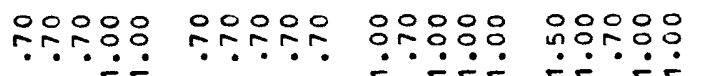

$\because \because \div \dot{0}$

$\therefore \dot{\therefore}$

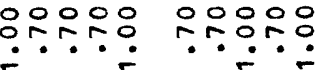

응응요용ㅇㅇㅇㅇㅇㅇㅇㅇ

응ㅇㅇㅇ융응

मिंن்

$\dot{m} \div \dot{0} \dot{-1}$

نं $\dot{0} \dot{0}$

옹응ㅇㅇㅇ

부용

00000

roini

응ㅇㅇㅇㅇㅇ 무요요

000000000000000

00000

ind

0000000000

00000

oboso ocoso

च

○ำ

0000 $\therefore$ i

…ㄴ.5

OCOOOO

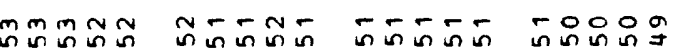

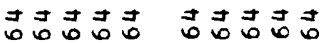

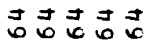

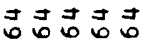

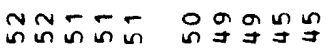

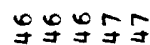

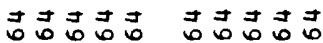

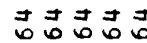

ondom omono

$m \bar{n} \vec{\sim} \tilde{N}^{n}$

ขึก

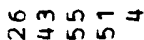

$=$

织 $\vec{m}^{\circ}$

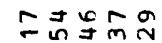

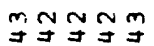

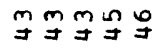

舟寻寻寻寻

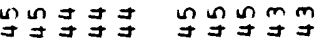

m当寻寻寻

寻寻寻寻寻

キュะะะ

エะะกะ

ทะェニะ

0000 un 0.0000 $\dot{m} \dot{N} \dot{n} \dot{N} \dot{m} \dot{m} \dot{m} \dot{N}$

$\sin \cos$

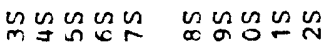

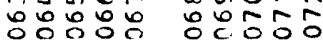

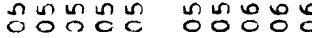

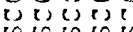

is

iuscis

us un un

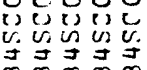

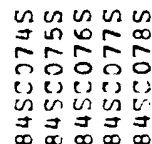

$\prod_{m}^{\infty} \stackrel{x}{\sim}-\vec{n}$

mシะ orgy

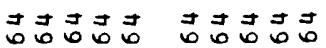

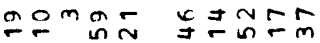

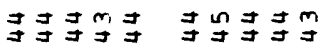

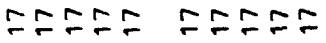

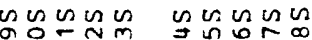

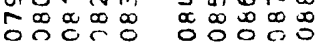

(1)

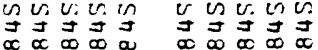


E

is

z

is

3

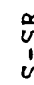

in

in

is

n

a

蓄

$\frac{1}{1}$

is

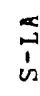

0
1
$v$

웅ㅇㅇ융ㅇㅁㅇ

웃ㅇㅇㅇ음

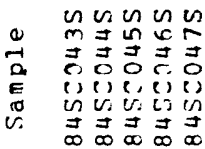

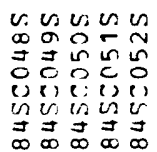

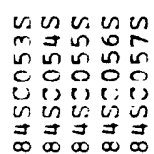

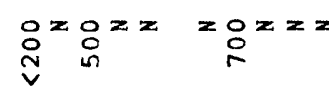

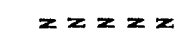

응응유 응응요은

응응용응

응응ㅇㅇㅇㅇㅇㅇ

$z x z z z \quad z 0 z z z$

는유윤 듀윳유 in

$z z z z z$

$z z z z$

$z=2 z$

$z z z z z \quad z z z z$

c0000 00000 00000

00000

0000

00000

응음유으 읐있을

$z z z z$

$z z z z$

$z z z z$

$z z z z$

$z=z z$

$z z z z$

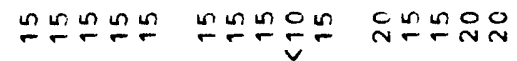

no $\operatorname{nin} 00$

$\ln \ln \pi$

oOnos

on 000

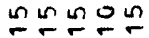

응웅ㅇㅇㅇㅇ

응용응

응유융은

우우은은응

응유윰요

응우응웅

응융ㅇㅇㅇㅠ

옹ㅇㅇㅇ웅ㅇㅇ

옹응ㅇㅇㅇ응

응옹ㅇㅇㅇ응

은응응요

응ㅇㅇㅇㅇㅇㅇㅇㅛ

$z=z z$

$z=2 z$

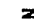

$z z z z$

$z x z z$

$z x z z$

읐읐유음

onn $n$

oooro

$\operatorname{nnog}$

gromentrat

$z z z z z z z z z$

$z z z z$

$z x z z$

$z z z z z$

$z \geq z z$

웅ㅇㅇㅇㅇ

는웅ㅇ 애음ㅇㅇㅇㅇ

있유융ㅇ

은유을은

읐읐은웅으

뜬은

등ㅇㅇㅇㅇㅇ

있있유읶요

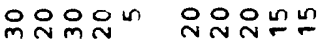

$z z z$

$z x=z$

$z x=x$

$z \geq z z$

$z x z z$

$z z z z$

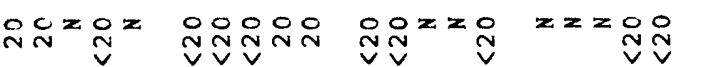

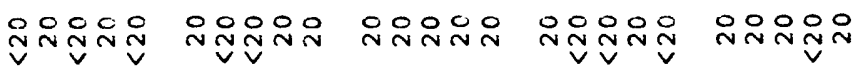

웅ㅇㅇㅇㅇ 운동ㅇㅇ

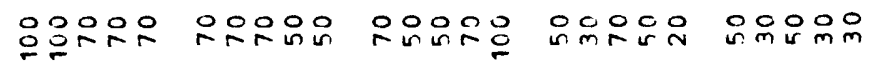

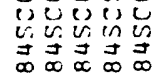

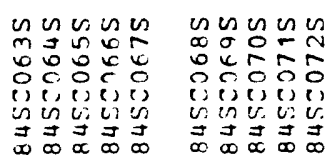

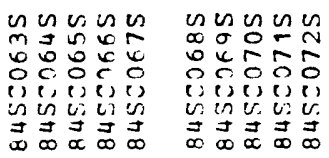

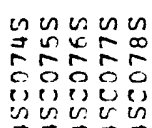

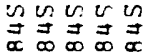

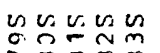

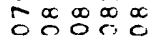

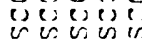

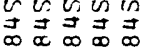

vin $\ln 20$

$\infty \propto \infty \propto \infty$

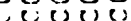

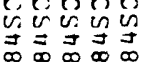




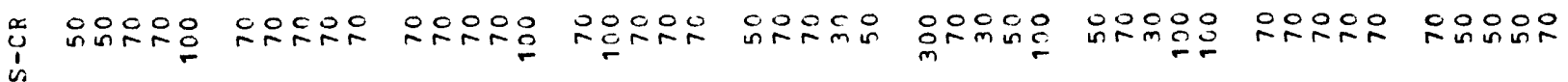

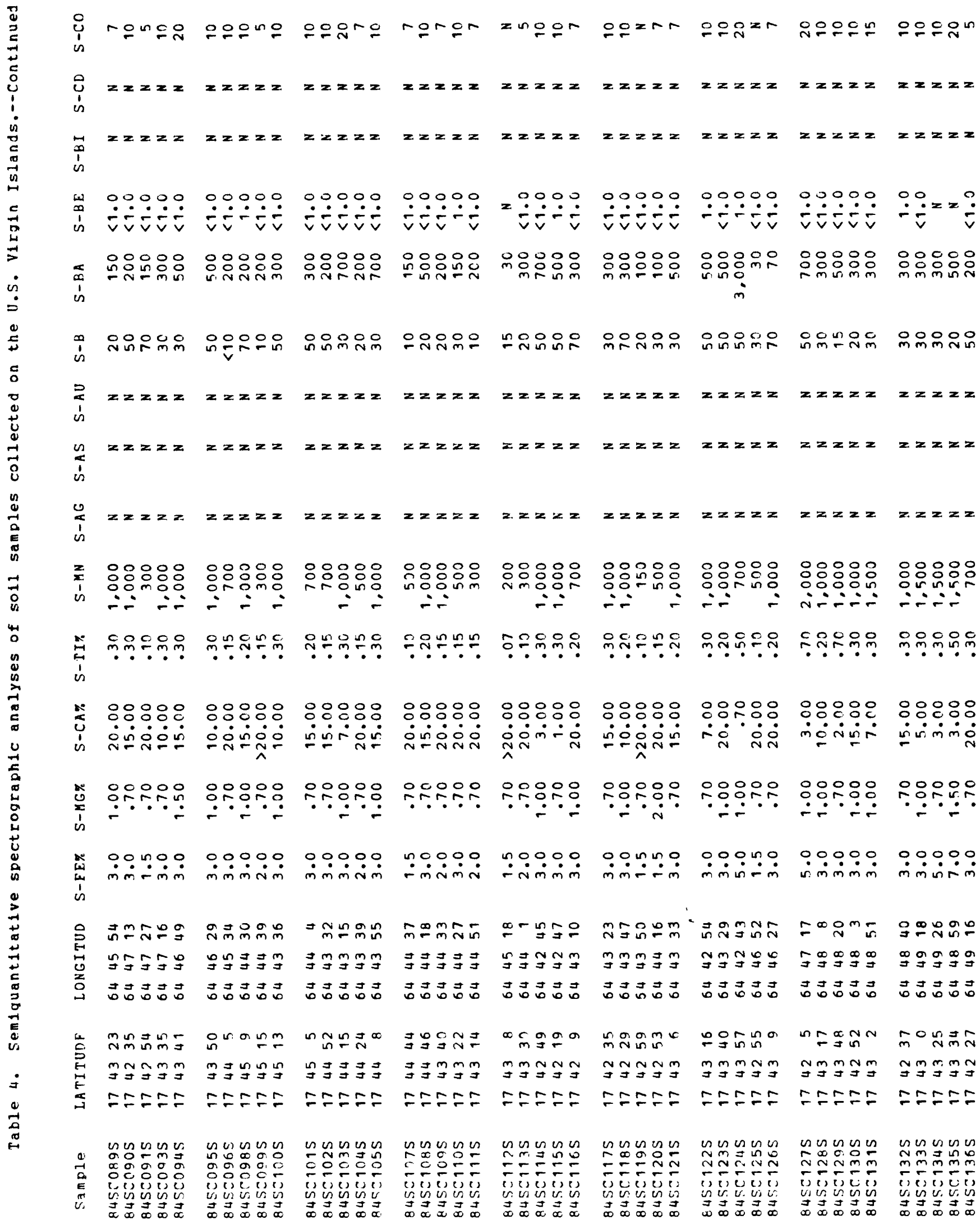


I
i
is

is

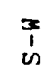

i

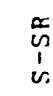

c.

zis

in

cris

品

$n$
1
is

$\frac{\pi}{2}$

i

is

i

응욱응

윤응융을

$z z z$

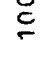

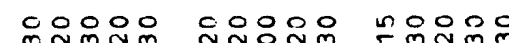

$z z=x$

$z z z$

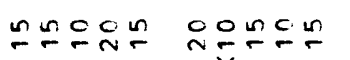

$z z=2$

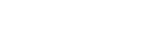

\section{은}

80000

$x z z=$

\section{(1)}

00000

임임

$z x z$

$z$

roron

ororo

orempromer

$z z z z z$

$z=z$

$z 2 z z z$

$z \quad z z z z$

00000

느유은요

유느유으은

유느유유음

$z z z z$

$z$

$z z_{x} z$

ํํํํํํำ

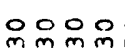

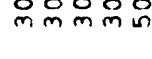

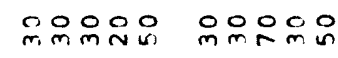

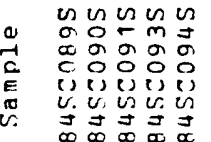

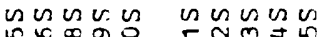

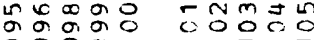

Se인

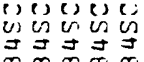

ए人i,

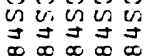

$\cos 2 \pi 0$

응을

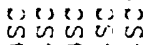

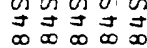

$z z z z$

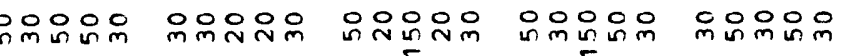
$z x$ in $x$$$
=
$$

$z=2 x$

$z z=0$
$\vdots$
$\vdots$

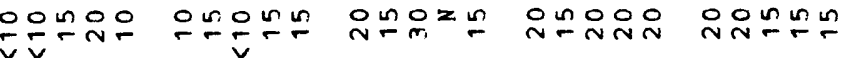

$z=z z=$

$z z z z$

$z z z$

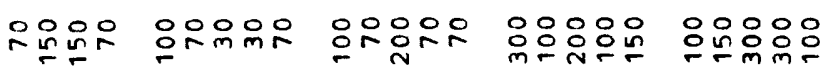

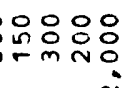
i

응응요요

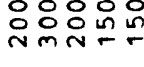

옹응ㅇㅇㅇㅛ

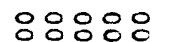

응응응ㅇㅇㅇ

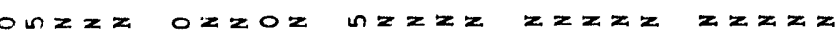
$r+2=2$

$\sin \operatorname{sen} n$

$z z z z$

우으는은

으으웅요

$z z z z$

은안응 은

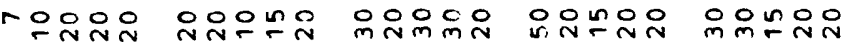

$z z z z$

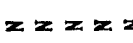

$z z z z$

$x_{1} z_{z} z$

$z z z z z$

$z_{1} z z z$

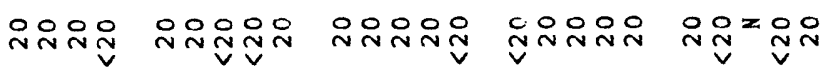

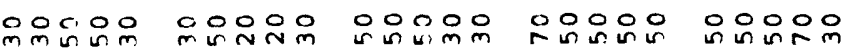

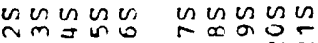

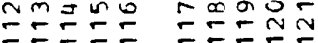

is (i) is

$\vec{\infty} \vec{\infty} \vec{\infty} \vec{\sim} \vec{\sim}$

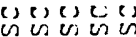

$\vec{\infty} \vec{\infty} \vec{\infty} \underset{\infty}{\vec{b}} \vec{\infty}$

in usin

$\underset{\sim}{\sim} \underset{\sim}{\sim} \stackrel{\sim}{N}$

단

v. U: vis

$\vec{\infty} \vec{\infty} \vec{\infty} \underset{\infty}{\vec{b}} \vec{\infty}$

ज为告里

$\approx \sim N m m$

(i) (i) (i)

$\vec{\infty} \underset{\infty}{\infty} \vec{\infty} \underset{\infty}{\vec{P}}$

ancus

$\min _{m}^{m} \vec{m} \tilde{m}$

-

unusu $\vec{\infty} \vec{\infty} \vec{\infty}_{\infty} \vec{\infty} \underset{\infty}{\vec{D}}$ 


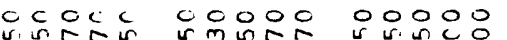

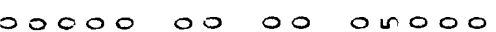

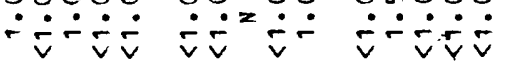

000000000

\section{응요}

is

$\frac{1}{i}$

1

i:

0
0

$\because 5 .: 3050$

$\therefore$ ini

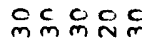

든오ㅇㅛㅛㅇㅛ

品:

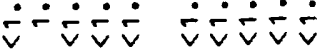

$\frac{i 20.00}{0.000}$

产玄方玄

웃융요

$\therefore \div$

ঃ:

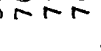

은응ㅇㅇ유은

co000

00000

i玄玄.

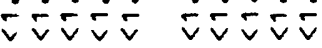

$\stackrel{+}{\stackrel{H}{H}}$

¿্̃

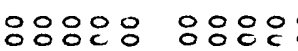

$\dot{n} \dot{\sin } \dot{\sin }$

نंखिंत्:

운운요

$\therefore$

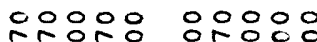

$\because \because \because \div$

$\therefore \dot{m i}$

00000

í:

$z \stackrel{n}{v} \dot{v}^{n}=\stackrel{n}{v}$

$z z z z$

$z z z z$

$z z z z$

$z z z \because \stackrel{n}{\dot{v}} \quad z z z z z$

$\therefore: \circ: 0$ $\because \because \div$

: ::웅

$\because \because \because=$

$\therefore \circ: \circ:$

$\operatorname{ing}$

::ㅇ

웅ㄷㅇㅇㅛ

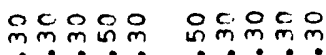

$\therefore$

$\because 20.9$

응ㅇㅇㅇㅇㅇㅇ

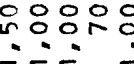

8ㅇㅇㅇㅇㅛ

$\therefore \div-$

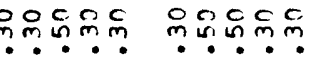

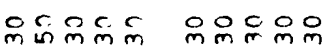

is

00000 00000 00000

$\dot{0} \dot{0} \cdot$

안오응요 웅은응응

m.?

ำำ

…ㄴ.

Nmกmmor viming

00000 $\because \therefore \dot{\sim} \dot{0}$

얻ㅇㅇㅇㅇㅇㅇㅛ

웅ㅇㅇㅇㅇㅇ

옹ㅇㅇ은

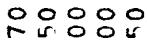

ㅈ. $\therefore \dot{4}$

$\because \div \dot{\circ}$

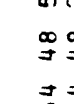

\section{$\infty$}

픈ํㅛ음

SON的前

可局

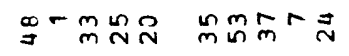

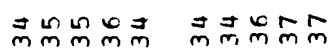

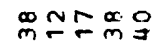

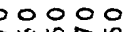

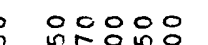

10

ํㅜㄴ

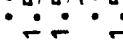

……

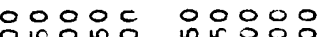
$\because \because \because \because \because \because \because$

moำ

$\rightarrow \exists \exists m$

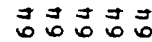

चैं

जै

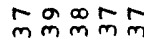

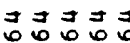

00000

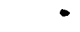

इ5

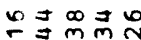

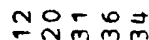

$\propto \infty m \propto$

cron

$-\frac{\pi}{a} \pi n$

ยูป

กㄹコㄹ

$\exists \operatorname{gng} g$

FEะF

J

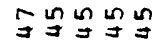

Nㅗ

Nㅗ

กะระ⿱

mํำ용

mimm

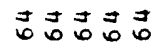

กะ5

$\cos \cos \cos \cos \theta$

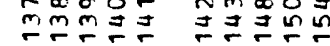

तथ 50

कीजिए

$\vec{\alpha} \vec{\infty} \vec{\infty} \underset{\infty}{\vec{\infty}} \vec{\infty}$

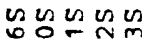

$\cos \cos 2$

ตูํํำ

듀융유

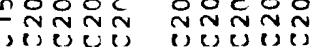

क U.

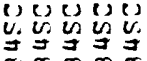

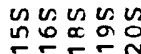

กักลกัก

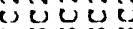

iriugu

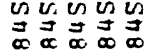

유ำ

00000

00000 


\title{
00000000000000000000
}

is

is

$z x z=x$

$x x=x$

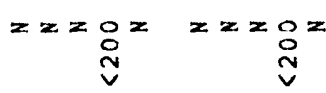

$z x \geq z$

$z z x z$

$\begin{aligned} & x= 0 \\ & \stackrel{N}{V}\end{aligned}$

$x=2 x=$

$z z 2 x z$

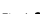

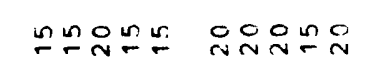

웅요으

엉ㅇㅇ n웅으

nin ino

우응으

엉ㅇㅇㅇㅇ 1 $x \geq z x$ $z x z z x$

$z=z z$

$z z z z$

$x z x z$

$x \geq z x=$

$z z x z$

$x z z z$

$z z 2 x z$

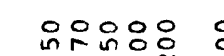

응응ㅇㅇㅇㅇㅡ

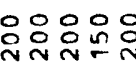

은유윰유

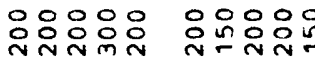

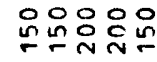

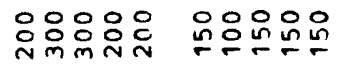

a 응융ㅇㅇㅇㅇㅇ

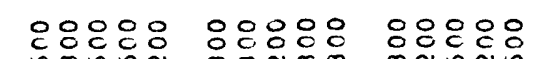

응응응 응응음

응응응ㅇㅇㅇ

응ㅇㅇㅇㅛ

응응ㅇㅇㅇㅇㅇㅇ

$002 x$

$z x z z \quad x z z z x$

$z x z x$

$x z z$

$z z z=$

$=$

$z z z$

$z z z z$

$z z z z$

is

$\cos (\cos )$

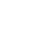

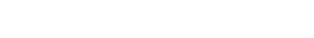

$\infty$
$a$
$\vdots$
$i$

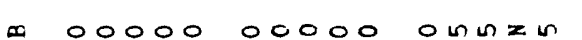
in

ononn noooo o0000

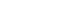
$\sin$

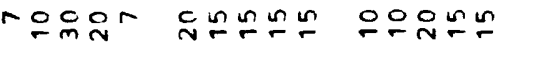

$\sin \sin 0$

conom

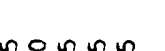

n유유 non non

is

$z x=2$

$z x z=$

$z z z z$

$x z x=$

$x$

is

$z z z z x \quad z z z z$

$z z z z$

$z x z z$

\begin{abstract}
운
\end{abstract}

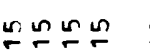

뜨은유

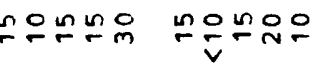

100

$x$

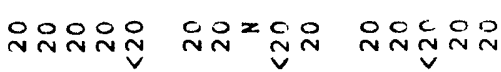

oroos

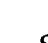

00000 00000 00000

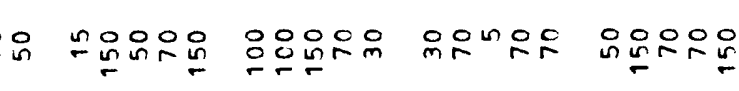
i $\log$ ind is

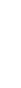

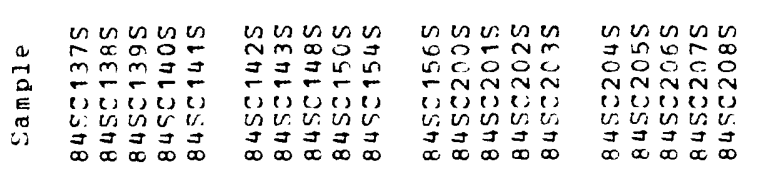

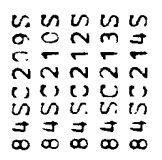

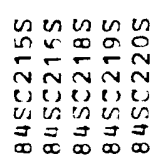

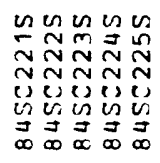

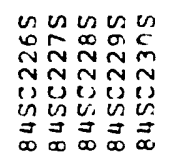

ancon N N N

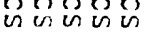

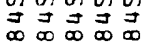


$\cos \sin \theta$

i

$\stackrel{\infty}{1}$

$z z z z z \quad z z z z z \quad z z z z z$

$z x z z$

$z 2 x 2 x$

$z x z z$

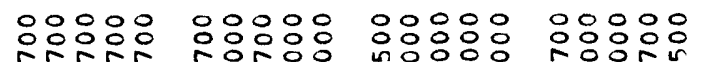

00000

00000

00000

กำ:옹

$\because 00 \%:$

00000 - $\dot{\bar{v}} \dot{\bar{v}} \dot{\bar{v}} \dot{\mathrm{v}} \dot{\bar{v}} \dot{\bar{v}} \dot{\bar{v}} \dot{\bar{v}}$

$\dot{n} \dot{\sim} \dot{v} \dot{v} \dot{v}$

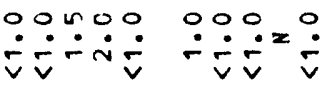

웅ㅇㅇㅇㅇㅇ

응응요

응응ㅇㅇㅇ

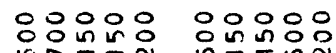

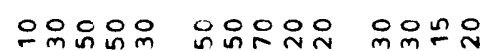

응ㅇㅇㅇㅇ

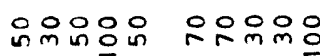

옹응으운

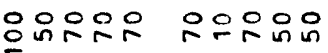

is

$z z x z$

$x z z=$

$z z z z$

$x z x z$

$z z z z$

$z z z z$

$z z z z \quad z z z z z \quad z z z z$

$z x x z$

$z z z z z$

$z x z=x$

$z z z=$

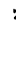

$z \geq z=$

$z z z z=$

$z z z z z$

$z z_{z} z$

$z z z z$

$z z 2 z z$

$z z z z=$

$z z z z$

$z x z z$

$z z z x z z x z z$

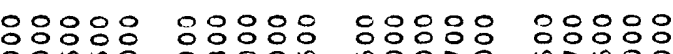

$\because \because n=$

$\because 00$ n

$\therefore i=$

ins

응응융ㅇㅇㅇㅇㅇㅇㅇㅇㅇㅇㅇㅇㅇㅛ

in i

응응응응음

$\therefore$ in:

응응응응

$\therefore \because \because$

응응ㅇㅇㅇㅇ

웅웅요 궁응우

웅ㅇㄷㅇㅇㅇ

드응요유요

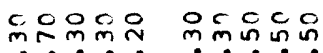

등으있웅

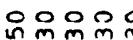

$\therefore \therefore$

$\stackrel{-1}{a}$

…? m.?

.

(4)

융ㅇㅇㅇㅇㅇ

응ㅇㅇㅇ웅

00000

\section{웅}

0000

운용요 응응응

응융ㅇㅇ응

เท.?

도ํํํํํํำ

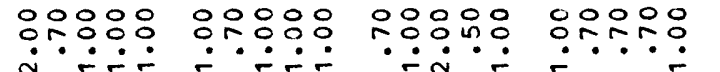

$\because \because \ddot{\circ}$

$\because \dot{\sim} \dot{\sim} \dot{\sim}$

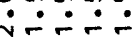

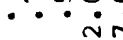

$\dot{\dot{n}} \dot{\dot{\circ} \dot{m}}$

우우

응영ㅇㅇㅇㅇㅇㅇㅇㅇㅇㅇㅇㅇ n-rí ió

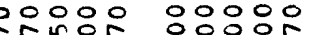

운웅요운

00000

은유누오 웅응은

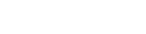

$\because \div-$

$\because \dot{n}$

……

$\ddot{\circ} \dot{\circ}$

\section{min}

00000000000000000000

00000

$0: 090$

00000

00000

जिं

00000$$
\text { 옹 }
$$

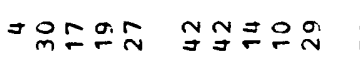

ติธลำ

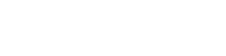

ㄹㄹㄹ

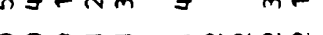

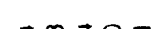

mingin

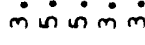

느율

品的约

a월도

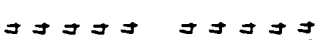

a $7 \vec{a}$

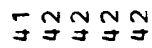

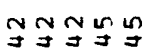

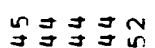

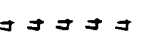

$\vec{B} \vec{B} \overrightarrow{0}$

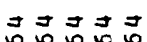

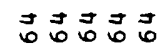

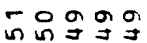

ดnแ

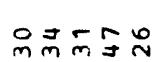

๙ே⿻コ一ำ

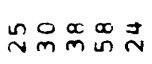

ज्ञ

있 $\mathrm{m}_{m}^{\infty}$

$\underset{m}{m} \infty 0 \underset{n}{n} \frac{m}{m}$

当可可

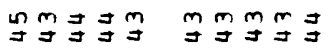

$\vec{\exists} \vec{\exists}: \vec{g} \vec{\exists}$

寻寻寻寻寻

ํㅣㄱำ

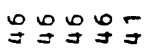

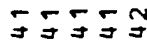

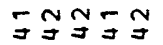

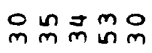

FระF

fFFi:

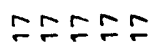

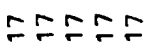

Fะระ⿱

fะFI

Iニュニ

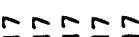

งฺュラュ

$\cos \cos \pi \cos u$

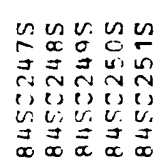

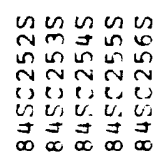

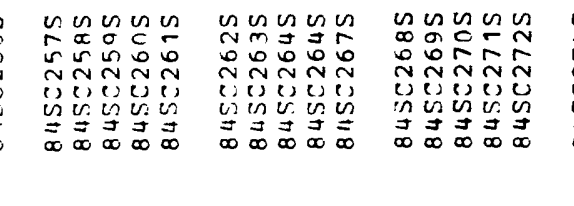

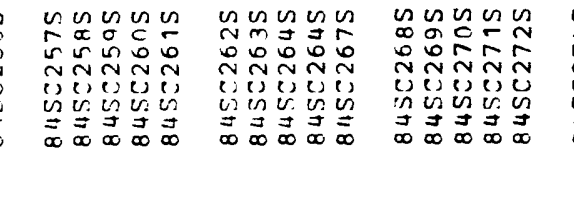

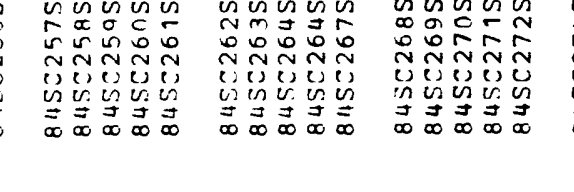

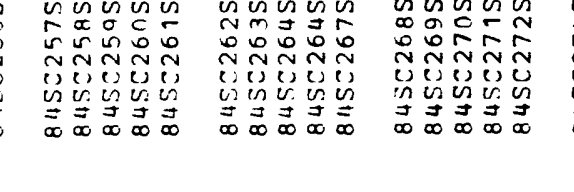

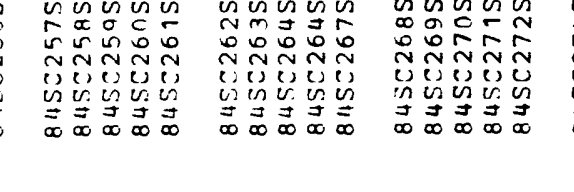

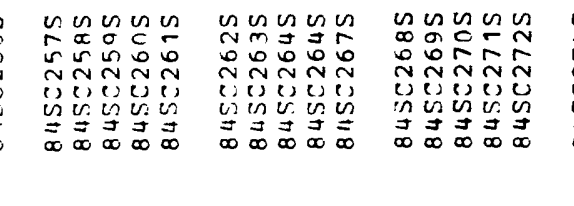

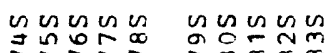

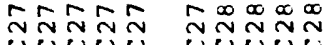

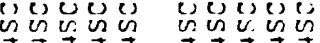

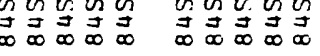




$$
\text { F }
$$

is

$\dot{3}$

$\stackrel{ \pm}{\ddagger}$

is

疋

ì

\section{(n)}

a
1
1
s.

$z$
5
1

is

$\infty$
in
1
0

$z_{1}$

$\infty$
$\vdots$
$i$

일

is

i

is

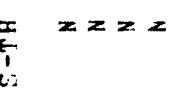

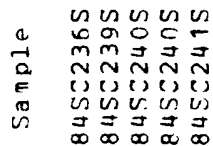

$z x z=$

is

n⿻ำ

$x x z=$ -4-2

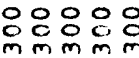

$z z z z$ (n)

$z z z z$ (1)

음웅요 ה

$z z z z$

$z z z=$

유융ㅇㅇ $\cos$ 웃응옹ㅇ $z z z z$

은우웅ㅇ

이요용

응응요

onoco $z=0 z=$

도윰유 웅

$z z z z$

듕유는

웅요

웅응

$2 \geq 2$

운은ㄷㄴ웅

$x_{0}$

$z z z=$

$z z z z$

우웅우이 $\checkmark$

은은온은

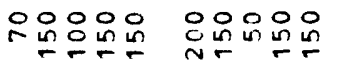

유융유

$z z z z$

00000

응응영응

\section{용ㅇㅇㅇ}

minmm inm

$x z z z z \quad z z O{ }^{2 z}$

$z z=2 z$

\section{2}

-

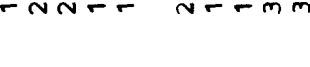

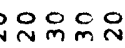

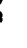

윤유은

0000n

soinoo

은유는은

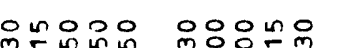

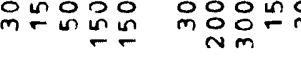

$z z x z z$

\section{$z$}

$z x z$

$z z 2 z$

$z z z z$

유유ํ우

웃두유

우윳ํ유

음응ㅇㅇㅇ

웅온응

\section{indor}

ํํำ

$z z z z$

$z z x z z$

$z z z z z \quad z z z z$

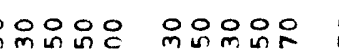

웄윴있 으옹유

$z z z x \quad z z z z$

$z x z z$

$z z z z z$

ㄷN윤유 유유유

o on on

느으은유

$z z z z$

$x z=2$

$z z z z$

$z z z z$

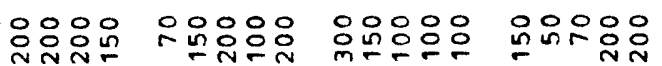

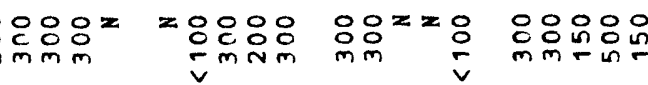

$z z z z \quad z z z z=\quad z z z z z \quad z z z z z$

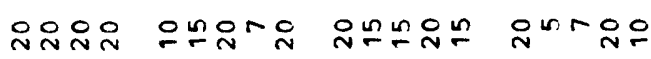

$z z z z z$ zxzzz $z x z z z \quad z z z z z$

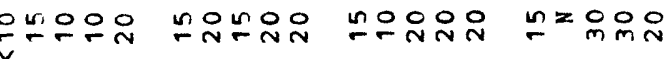

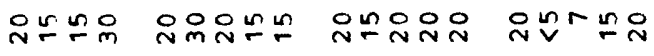

$z z z z y z z z \quad z z z y z y z z z$

$z z z z x \quad z z z z z \quad z z z z z$

$z=z$

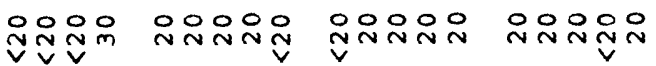

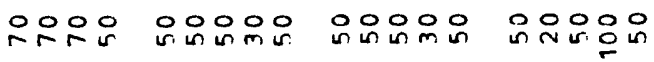




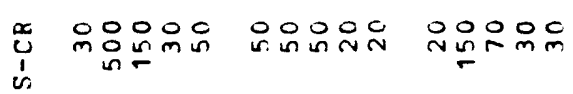

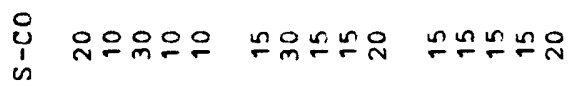

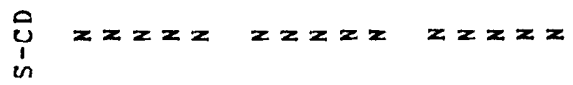

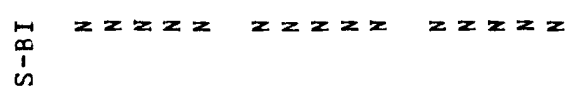

u

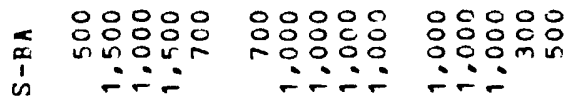

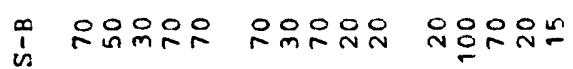

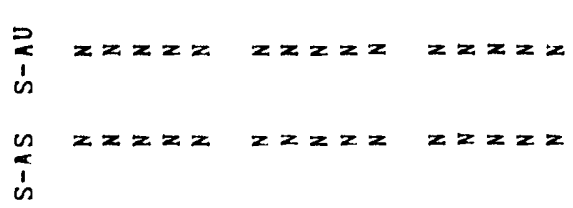

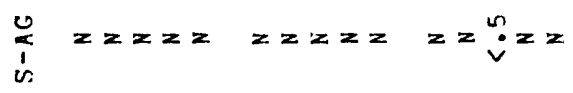

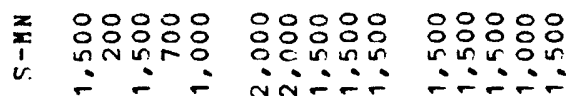

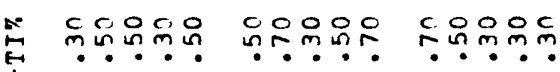

i

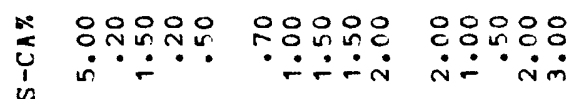

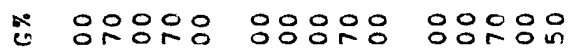

站

000000000000000

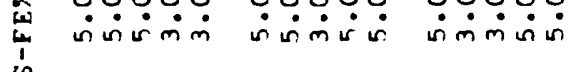

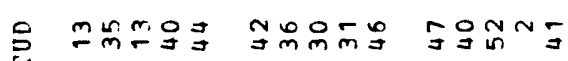

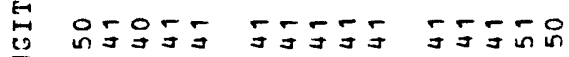

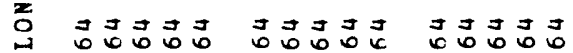

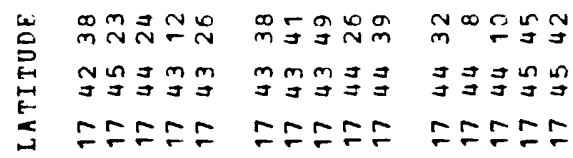

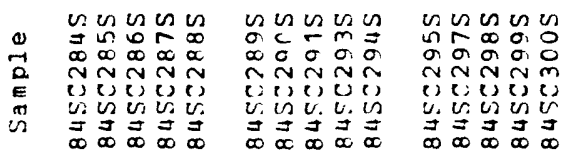




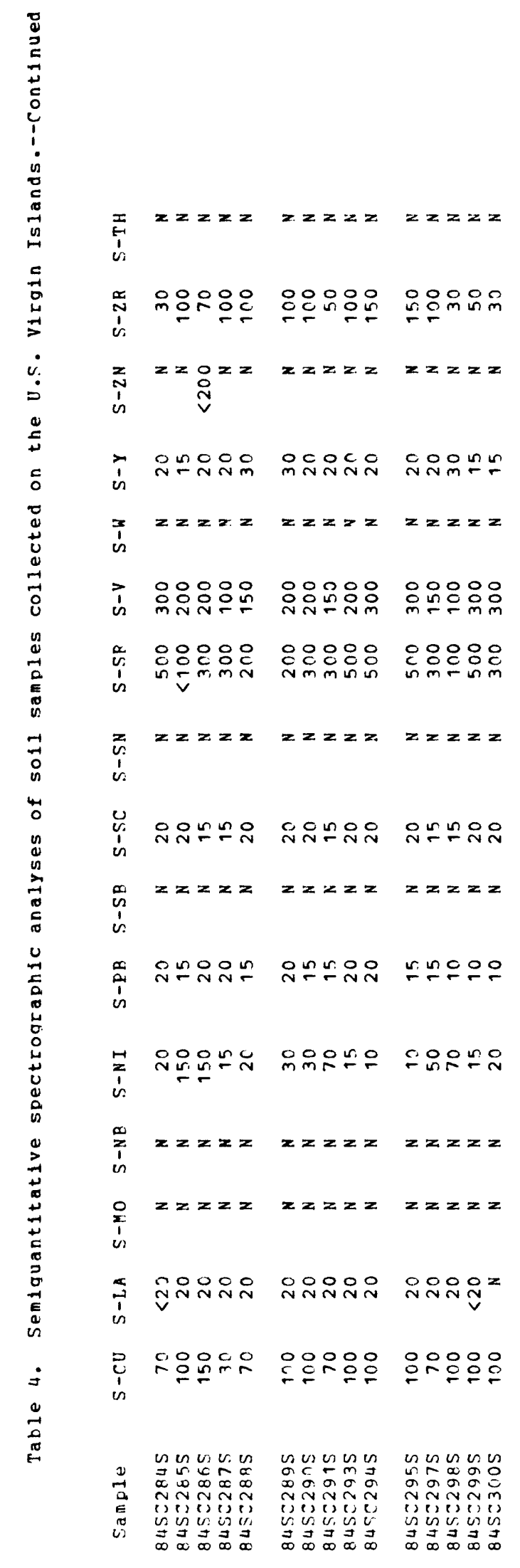




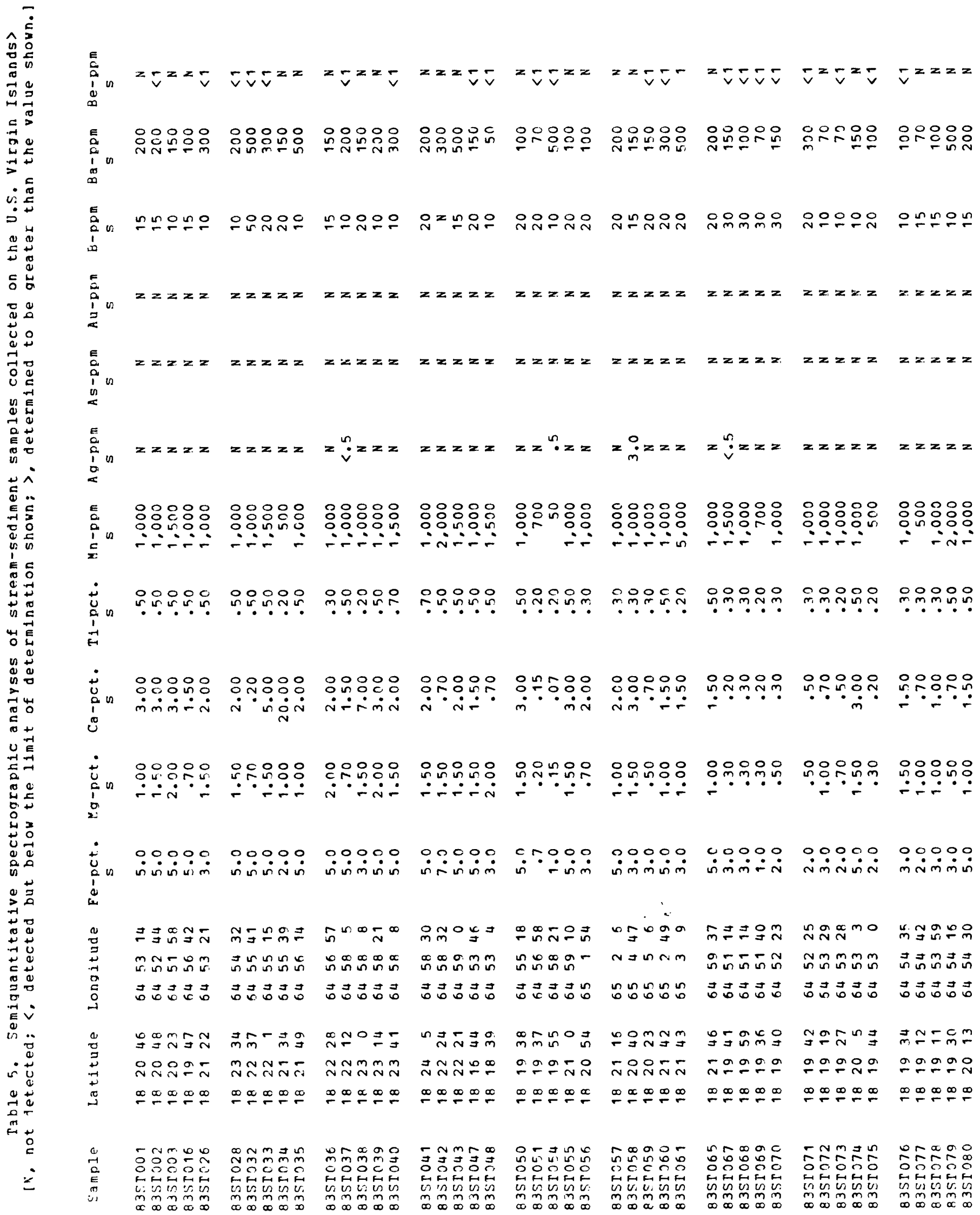




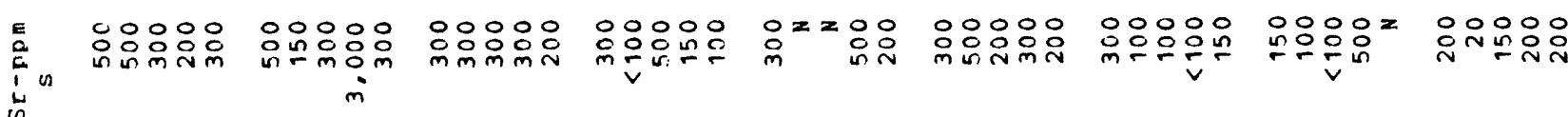

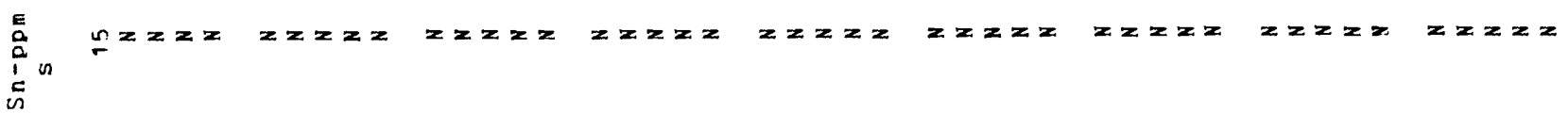

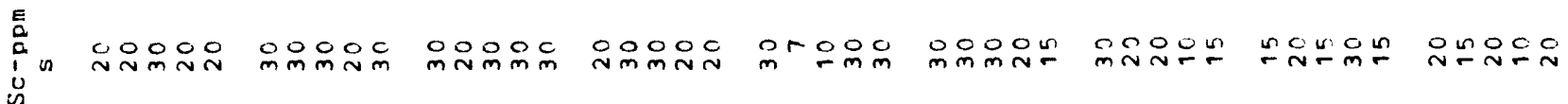

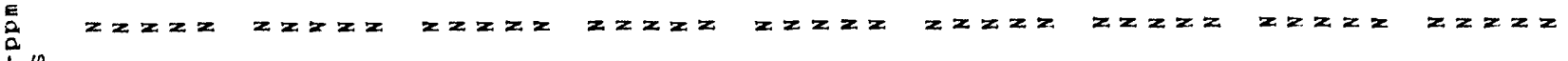
is $\frac{E}{a}$

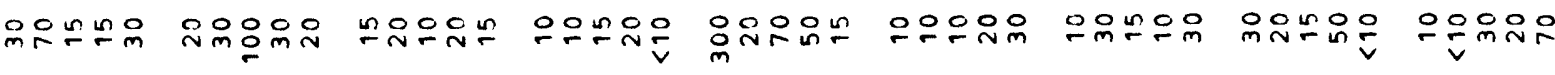

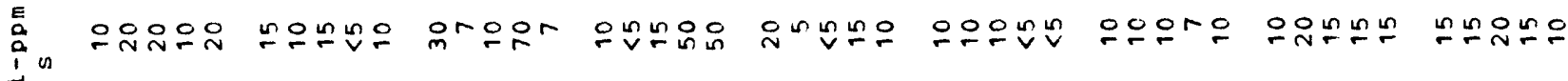

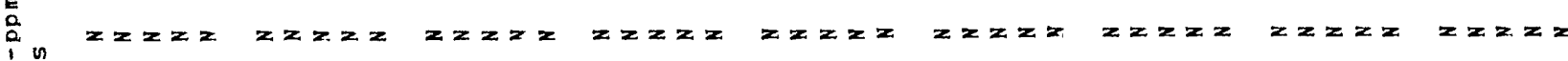

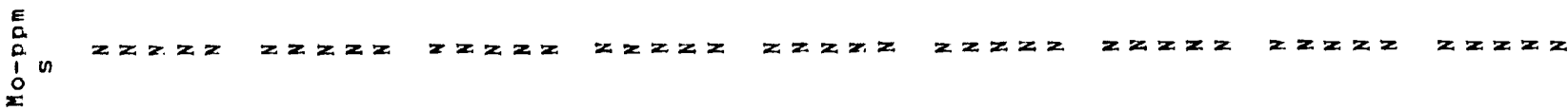

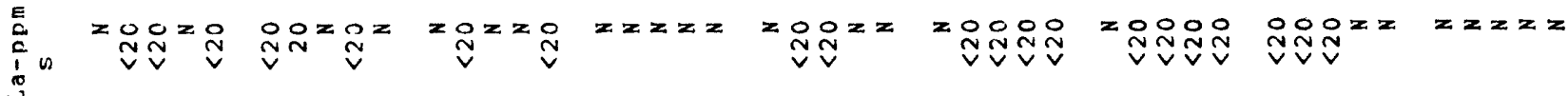

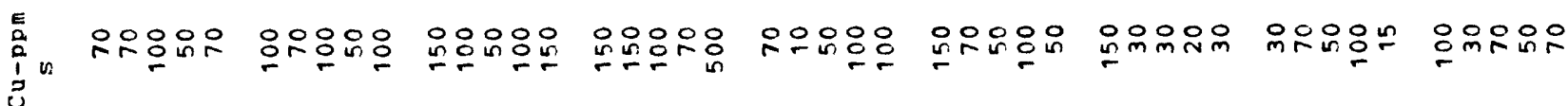

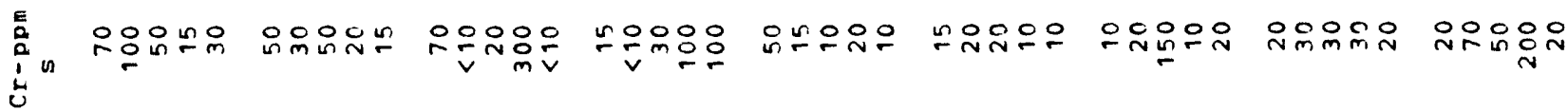

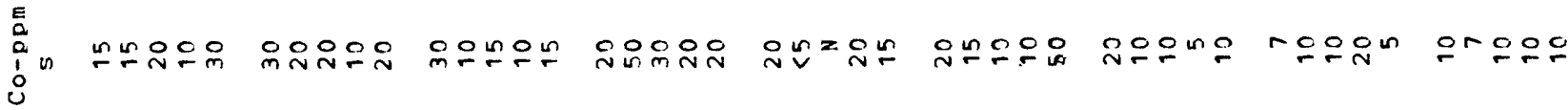
否，

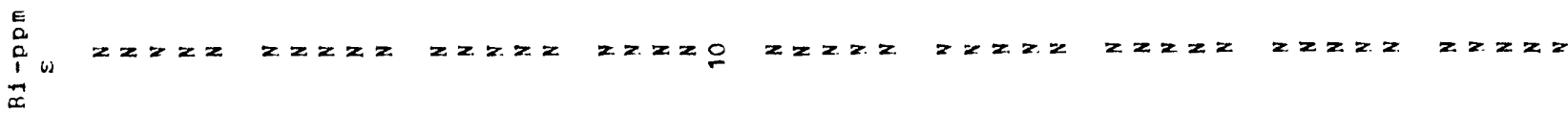
in $\underset{\substack{n \\ \stackrel{0}{c}}}{\stackrel{0}{\infty}}$

\section{$-\pi 0$
2
2

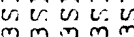
$\prod_{\infty} \infty \prod_{\infty} \infty$

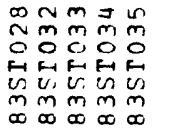

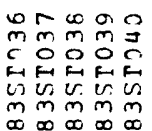

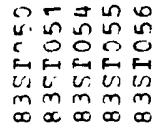

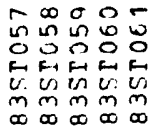

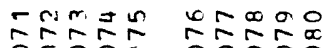

OCOOOC

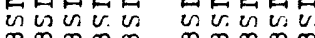

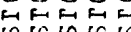
$\min _{\infty} \operatorname{mim}_{\infty} \prod_{\infty} \underset{\infty}{\infty}$ 


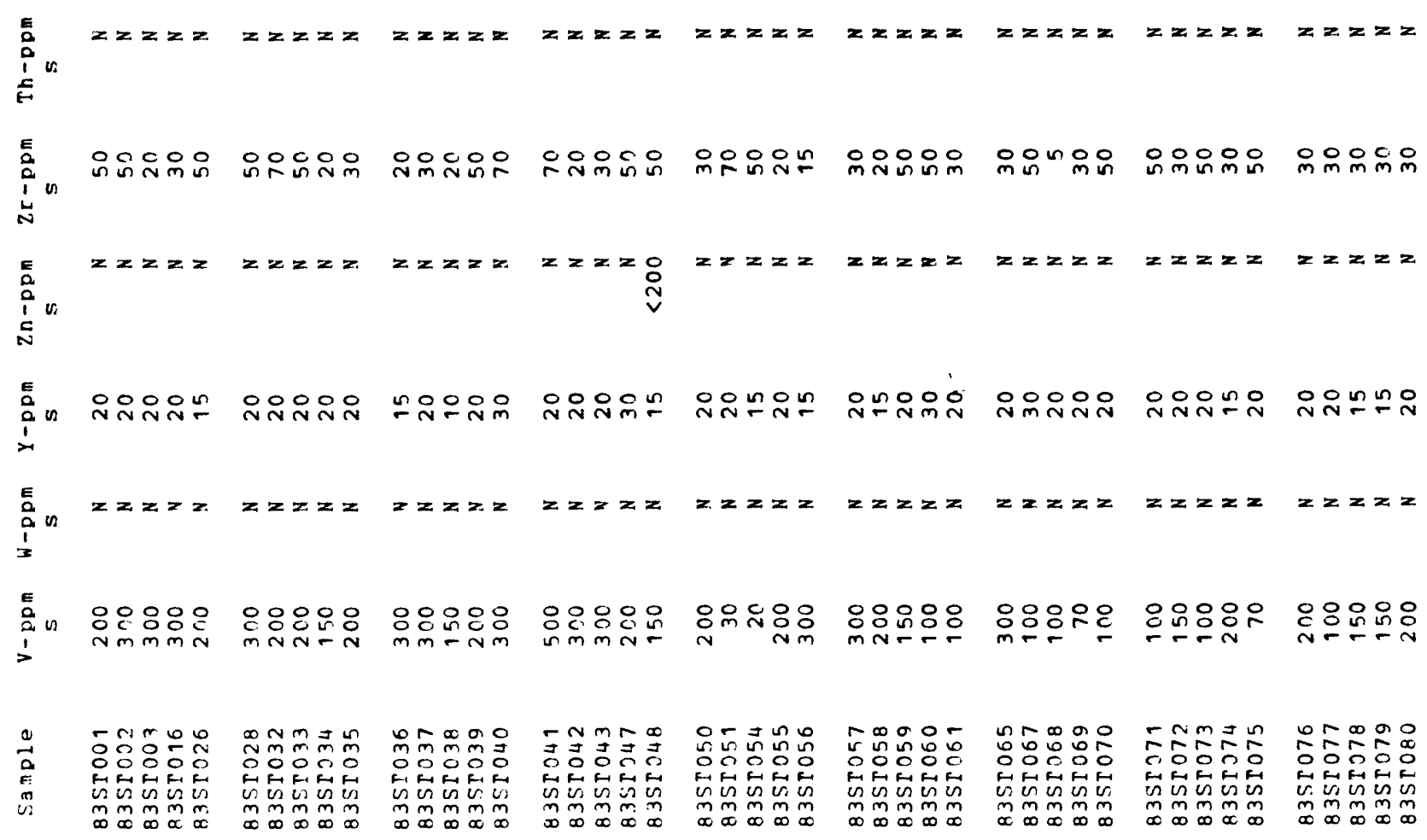


$z=v_{v}=$

$z r \bar{v} z$

$\bar{v} z z z \quad z z z^{2} z$

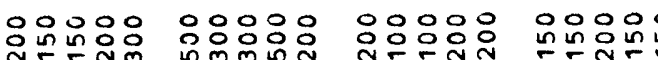

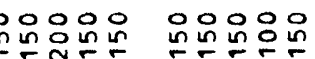

$\because \simeq$

등ㅇㅇㅇㅇㅇㅇㅇ $\therefore$

응융용ㅇㅇㅇㅛ

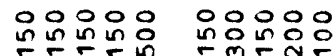

E

noomin $0000 \mathrm{n}$ noooo

$n \geq 0$ in

$\ln 2 n ㅇ ㅡ$

$2 \leq 00$

뇨의은

은으우는 드는준$$
=
$$

\section{응영응 옹영응 응영응}

응ㅇㅇ

n.

응ㅇㅇㅇㅇㅇㅇㅇ

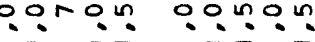

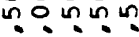

응용ㅇㅇㅇ

$0.9 \ln$

응ㅇㅇㅇㅇㅇㅇ

$\because: 9 \%$

$8: 800$

c

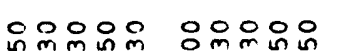

은응용으

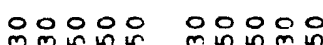

웅ㅇㅇㅇㅇㅇ

응으은은

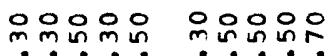
1

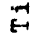

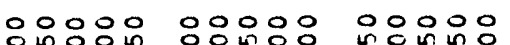

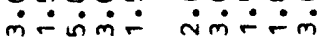

$\because \dot{n} \div \dot{m}$

영ㅇㅇㅇㅇㅇ

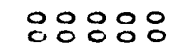

minis:

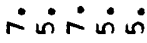

응ㅇㅇㅇㅇㅇㅇ

$\dot{n} \dot{\mathrm{i}} \dot{\mathrm{n}} \dot{\mathrm{n}} \dot{\mathrm{m}}$

응ㅇㅇㅇㅇㅇㅇ

$\dot{\sim} \dot{m} \dot{\sim} \dot{m}$

응응용요 iே문

응영ㅇㅇㅇ은

$\dot{m} \dot{i} \dot{\sim} \dot{N}$

过范

웅ㅇㅇ 응ㅇㅇㅇ

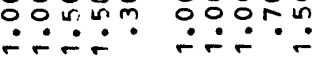

응응유욘

옹응용으

응응ㅇㅇㅇㅇㅇ

응응용요

nंतें

$\therefore \dot{m} \dot{n}$

은응용ㅇㅇㅇ

$\dot{\sim} \dot{\sim} \dot{0}$

응응용ㅇㅇㅇ

$\therefore \because \div$

응응웅응 $\therefore \dot{4} \dot{\circ} \div$
000000000000000 范 i

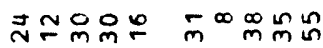

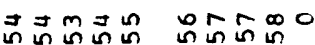

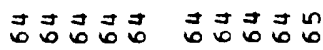

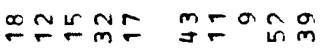
윰ำ $\stackrel{\infty}{\sim} \stackrel{\infty}{\sim} \stackrel{\infty}{\leftarrow} \stackrel{\infty}{\leftarrow} \stackrel{\infty}{\sim}$

กำกีน -r. 0 กูก

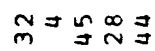
ㄸํ유유 $\stackrel{\infty}{\sim} \stackrel{\infty}{\sim} \stackrel{\infty}{\sim}$

0.000

00000

$\infty \underset{7}{\pi}=$ hin

m이름 웅원의

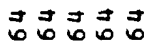

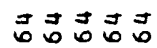

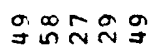
$m \propto N \cong N$ 위유유유 유른 $\stackrel{\infty}{\infty} \stackrel{\infty}{\sim} \stackrel{\infty}{\sim}$

$\stackrel{\infty}{\sim} \stackrel{\infty}{\sim} \stackrel{\infty}{\sim}$

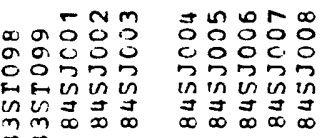

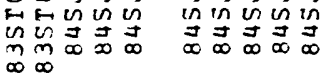

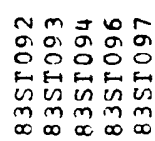

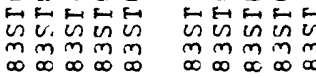

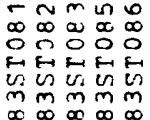

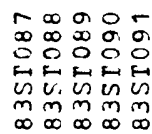

:90ㅇํㅇ

0.0 .00 பெர்

00000 $\dot{m} \dot{m} \dot{\min }$

ario 吅寻主要 जコココ

กับ

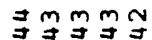

ก고ำ

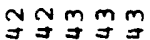

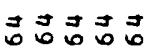

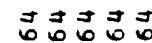

ำกี่ กับกัก $\stackrel{\infty}{\sim} \stackrel{\infty}{\leftarrow}$

윤ㄷㄴ กลกับข $\stackrel{\infty}{\infty} \stackrel{\infty}{\sim} \stackrel{\infty}{\leftarrow}$

우은 는 춘유 $\stackrel{\infty}{\sim} \stackrel{\infty}{\leftarrow} \stackrel{\infty}{\leftarrow}$

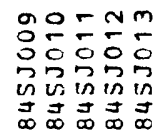

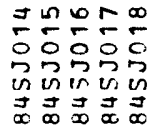

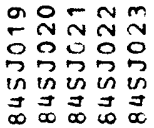

00000

는ํำ

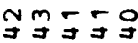

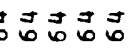

ํํำ ㅇํำก $\stackrel{\infty}{\sim} \stackrel{\infty}{\sim} \stackrel{\infty}{\sim}$

로ำำ ㅇㅇㅇㅇㅇㅇ in in in in $\vec{\infty} \underset{\infty}{\infty} \vec{\infty} \vec{\alpha}$ 


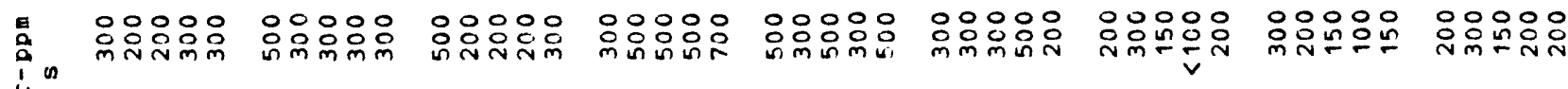

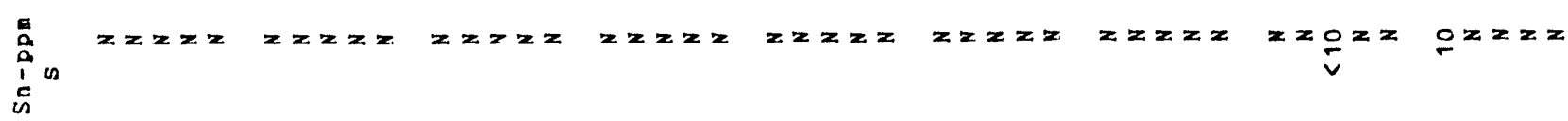

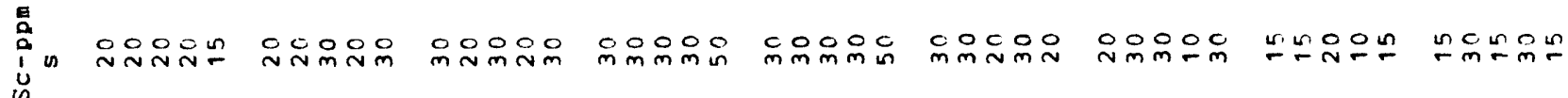

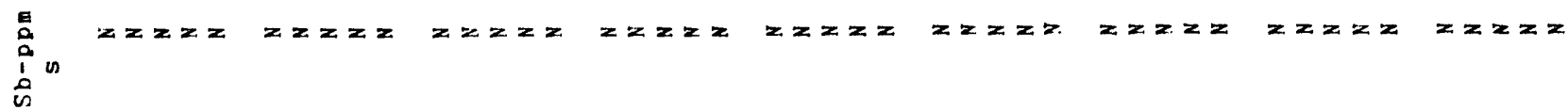

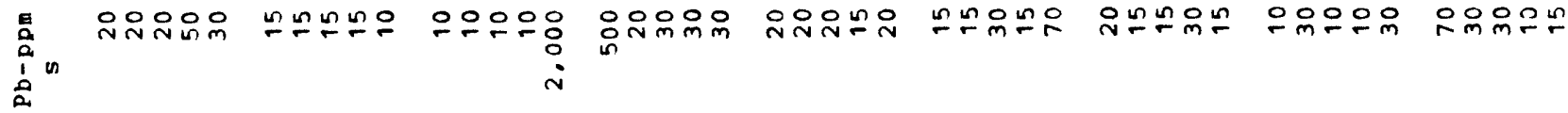

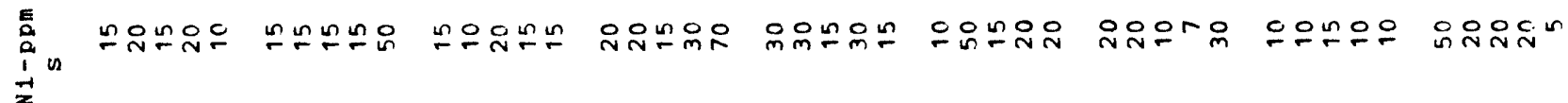

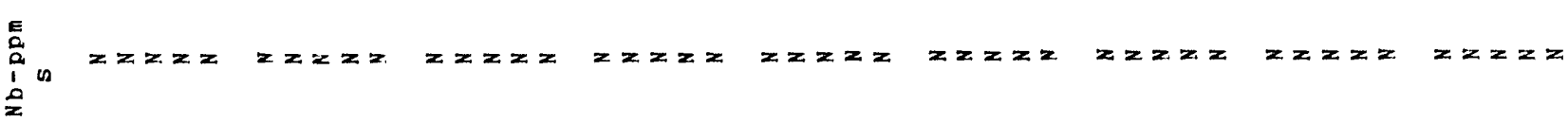

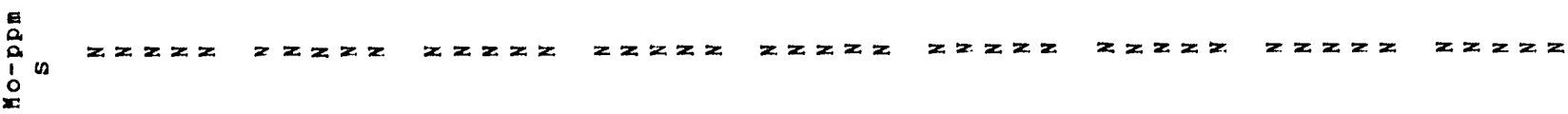

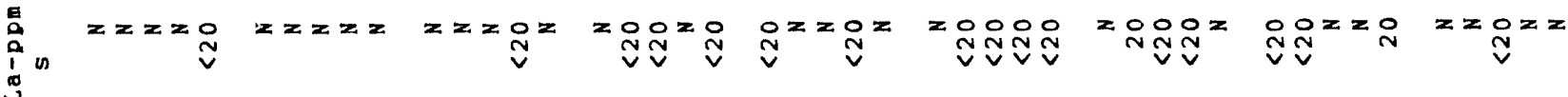

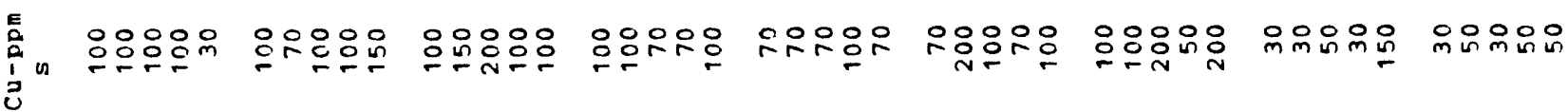

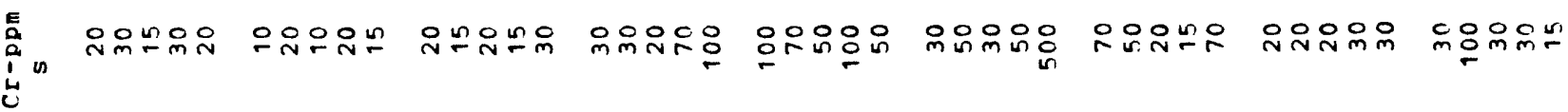

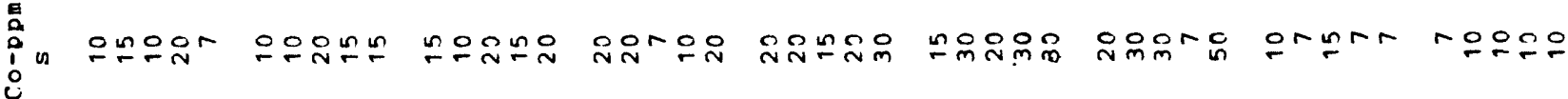

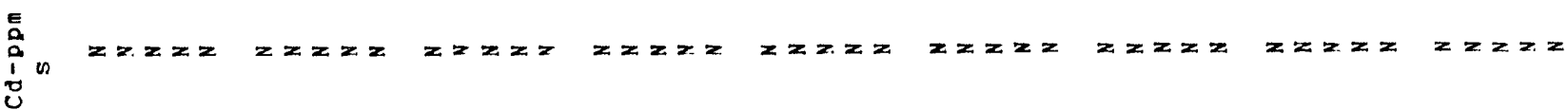

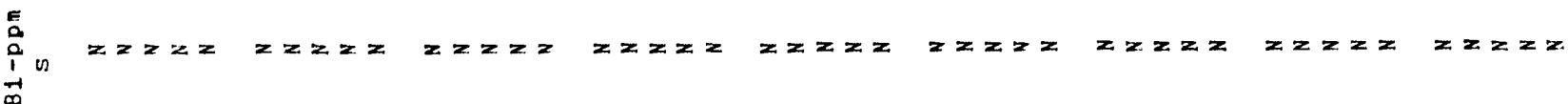
in $\stackrel{0}{a}$ $\begin{array}{llllllllll} & & & \end{array}$ 


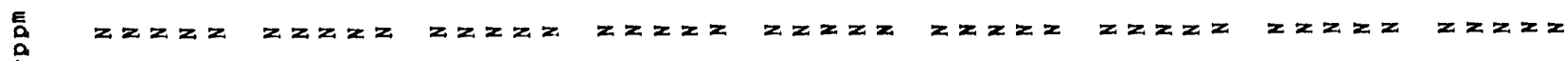
$\sum_{i=1}^{\infty}$

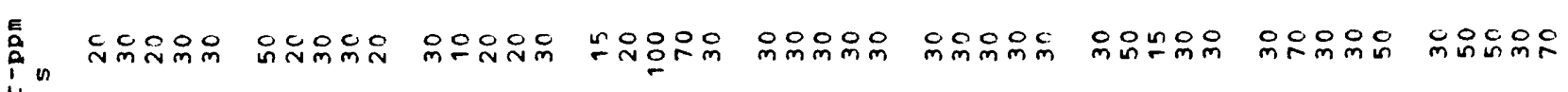
岕

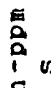
$\stackrel{1}{n}$

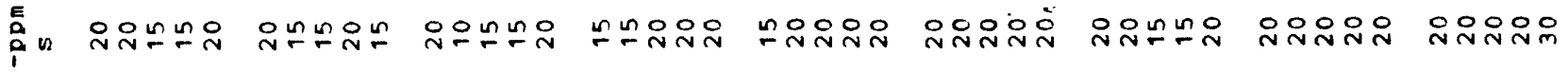

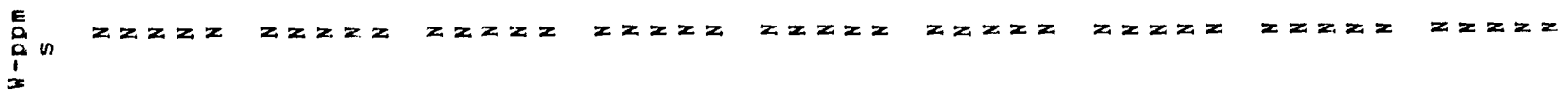

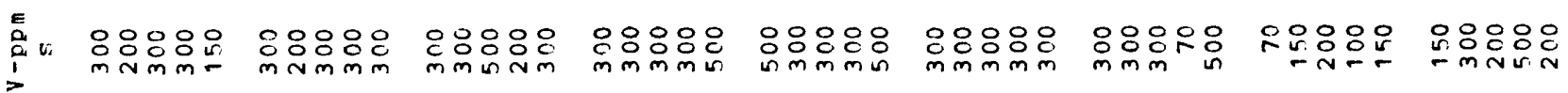
in 
응응응 운응으 응응응

응유옹으음

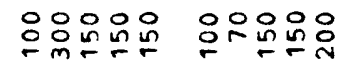

은은윤윤

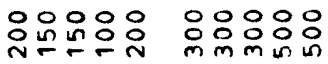
$\infty$

䜿我

$0 \geq \ln 0$

in

우는윤

은으는

웅우요

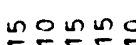

능ㅇㅇㅇㅇㄴ

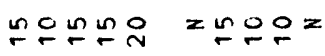

E

$z z z z$

$z z z 2$

$z z z z z \quad z z z z$

$z z z=$

$z=x z$

$z z z z$

$z z z=z z z z z$

$z x z x z \quad z x z z z$

$z=z z$

$z=x=$

$x \geq z x$

$z 2 z=2$

$z z z z z z z<z$

in

a

$z z z z y \quad z z z z$

$z z z=2$

$x z \stackrel{n}{n} x z$

$\ddot{v}^{2}=2 z$

$x \geq x=2$

$z=2 z x$

$z z z z y z z z z$

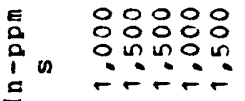

응ㅇㅇㅇㅇㅇㅇ

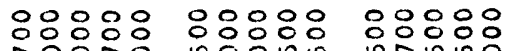

웅 ing?

응용ㅇㅇㅇ

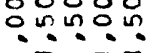

응ㅇㅇㅇ음

웅요의

응ㅇㅇㅇ융요 응ㅇㅇㅇㅇㅇㅇㅇㅛ

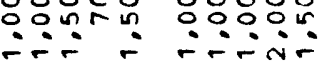

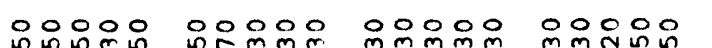

00000

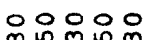

웅ㅇㅇㅇ

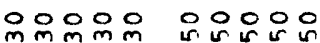

$+1$

nก.?ำ.

$\underbrace{}_{\substack{a \\ 0}}$

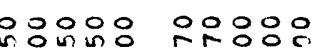
(1)

-.・.

•.・

...

iั

-

응용ㅇㅇㅇㅇㅇㅇ

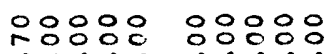

$\circ: 0808$

응ㅇㅇㅇㅇㅛ

نrivini

rimin

ㅇㅇㅇㅇㅇㅇㅇㅇㅇ

minisicis

응읃응응

ư

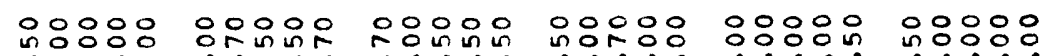

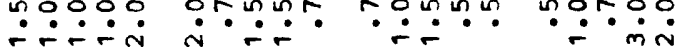

$\dot{n} \dot{i} \dot{n}-$

$\dot{\sim} \dot{\sim} \dot{m} \dot{n}$

응ㅇㅇㅇ응

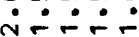

응응ㅇㅇㅇㅇ 응ㅇㅇㅇ응ㅇ

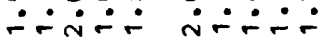

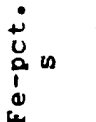

0000000000

000 no

n.0.0:

0.000

00090

00000

0000090000

mํํำ

$\operatorname{Inm} n \sigma$

a

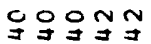

Nㅗำ

$a n=0$

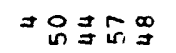

음ํํํํำ

$=\underset{7}{-10} \rightarrow$

जिए in

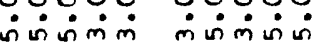

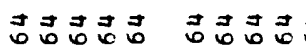

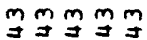

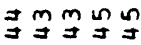

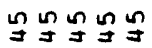

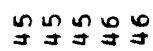

ronmo

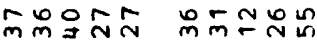

可寻寻

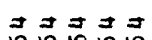

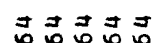

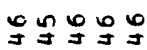

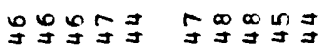

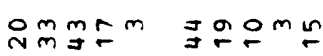

윰요

고ำํำ

กำกัก

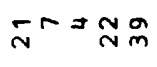

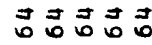

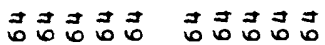

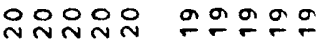

og

엉의

맘유융

유윰융

Nm요의

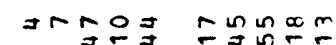



$\dddot{\infty} \infty \stackrel{\infty}{\infty} \stackrel{\infty}{\leftarrow}$

$\infty \stackrel{\infty}{\infty} \infty$

$\stackrel{\infty}{\infty} \stackrel{\infty}{\sim}$

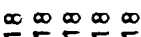

우유유유

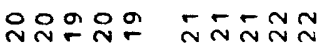

in

$\underset{\substack{\infty \\-1}}{n}$

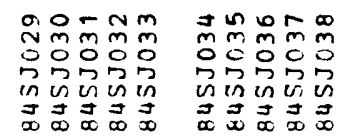

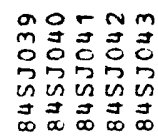

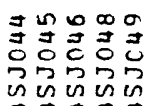

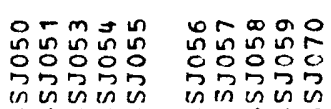

$\stackrel{\infty}{\circ} \stackrel{\infty}{-\infty} \stackrel{\infty}{-}$

$\stackrel{\infty}{\infty} \stackrel{\infty}{\infty} \stackrel{\infty}{-\infty} \stackrel{\infty}{-\infty}$

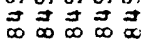

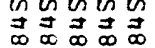

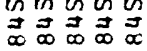

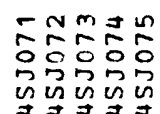

수숭 moint

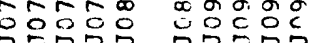

nuinuen $\cos$ in

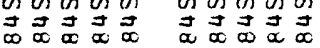




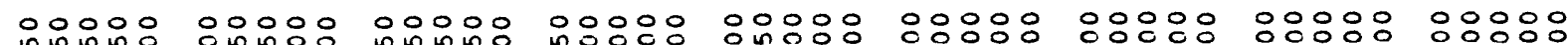

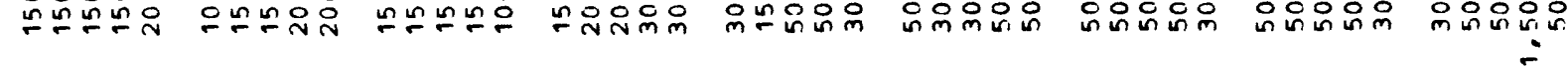

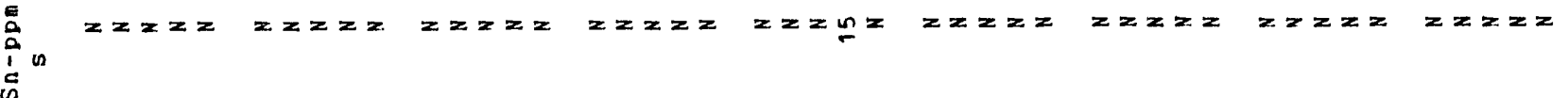

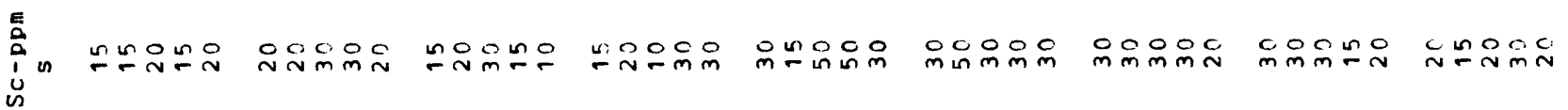

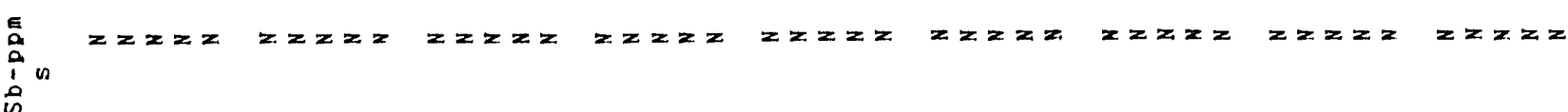

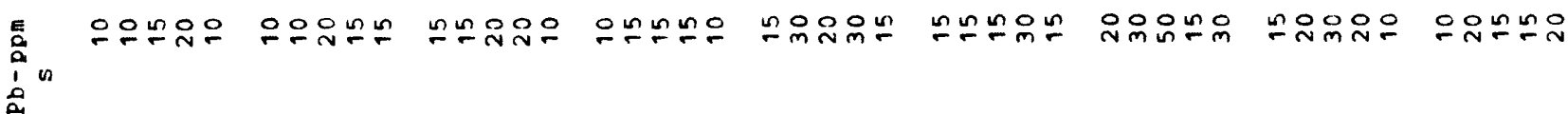

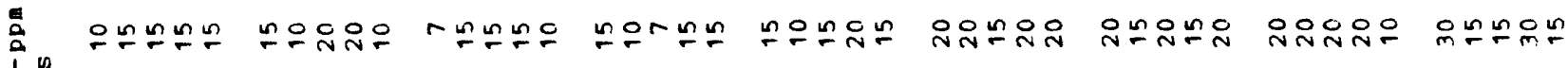
z

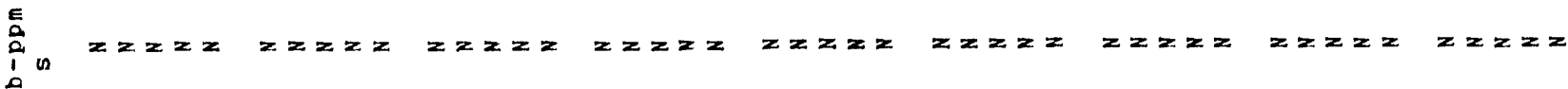
唇

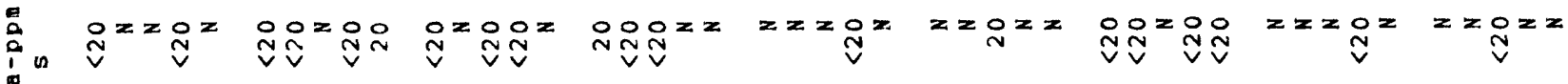
$\stackrel{\infty}{\rightarrow}$

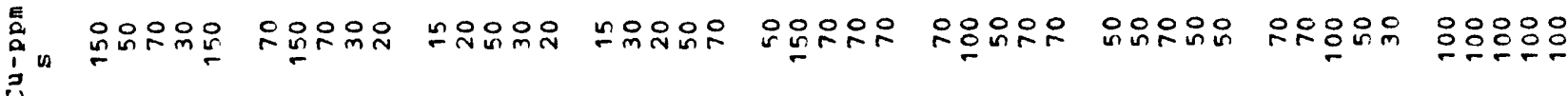

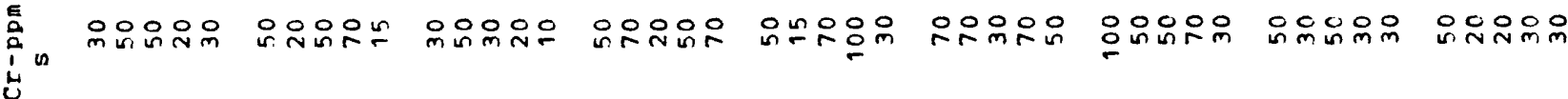

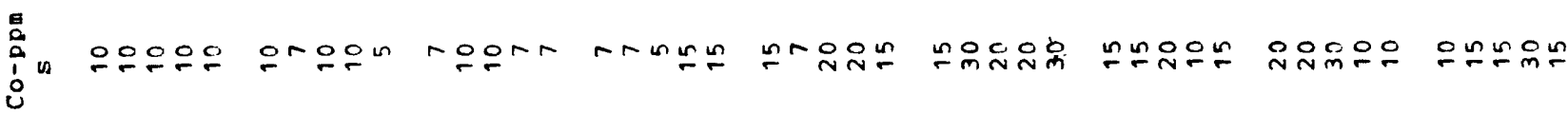

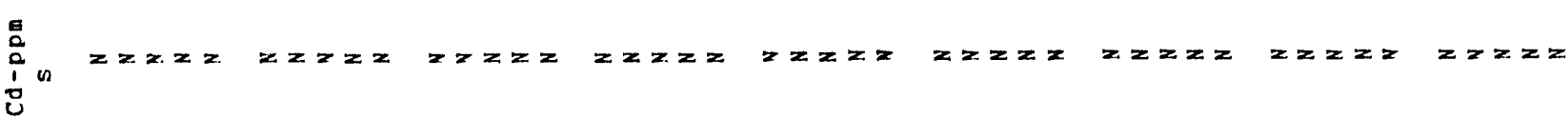

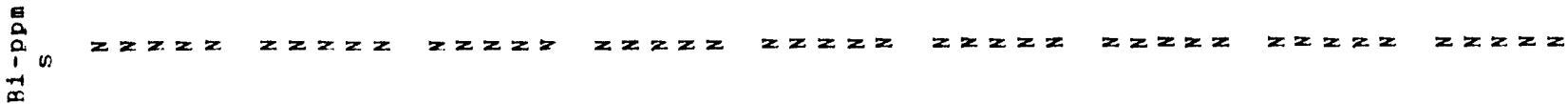
in

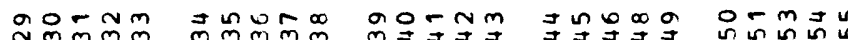

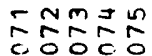




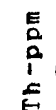

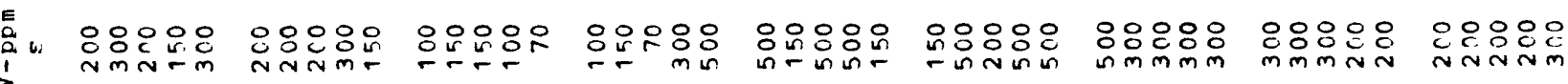

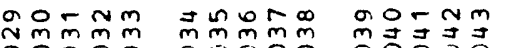

oOoco coón

웅응응

\section{응ํำ}

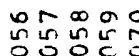

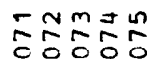
둥ㅇㅇㅇㅇㅇ

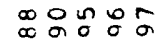

co: 00 in in in in in 
a

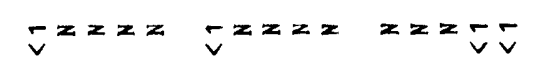

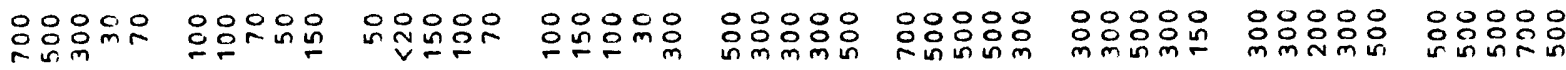
is

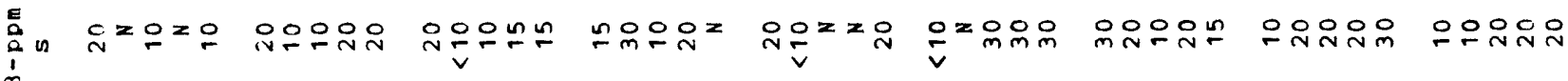

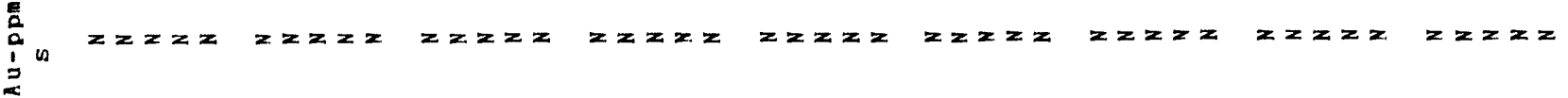

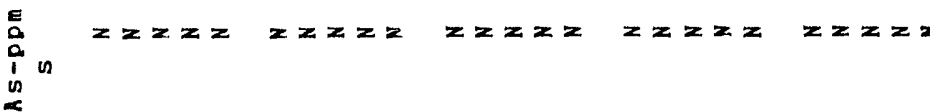

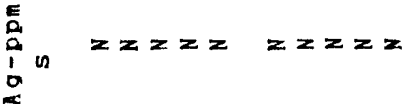

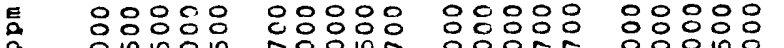

a o nino no roo int

$\because \because$

$\therefore \because \because i$

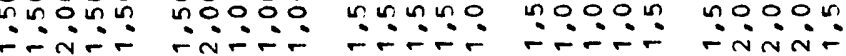

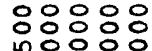

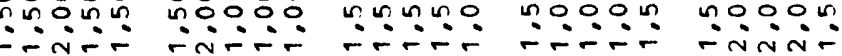

용요 $8: 08:$

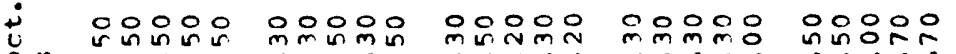

$\frac{1}{1}$

ก...………

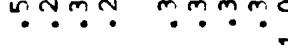

$\because \because$

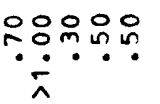

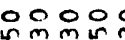

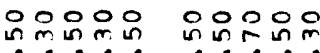

苑

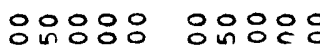

응응응

응융ㅇㅇㅇ

응용ㅇㅇ

$\therefore: 8: \circ$

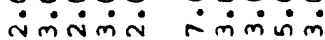

$\therefore: 0: 0$

iั

$\dot{m} \dot{m} \dot{m} \dot{-} \dot{\sim} \dot{\sim} \dot{\sim} \dot{m} \dot{m} \dot{m} \dot{m} \dot{r}$

mirim

\section{(n)}

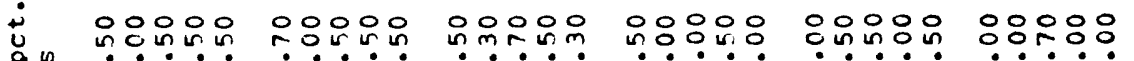

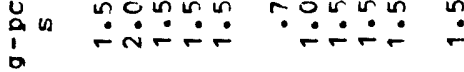

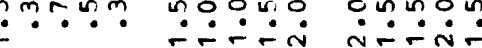

$\therefore \dot{\sim} \div$

응응ㅇㅇㅇ 응융ㅇㅇ

ப்ச்

irínin

- 0000000000

0000 in 00000

00000

00000

00000

00000

0.0000

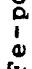$$
\text { a }
$$

에를

$\min \log 0$

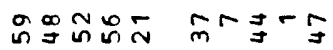

igogo

mำกำ

in

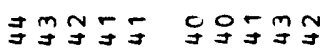

为向寻寻寻

局寻寻寻守

舟毛学㶽东

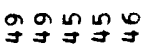

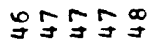

mกลูก

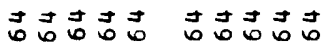

苛苟芯吉

吉苚苛吉吉

जै

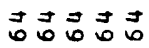

$\overrightarrow{0} \overrightarrow{0} \overrightarrow{0} \overrightarrow{0}$

予号昌昌昌

ถู่ี่ ถูก

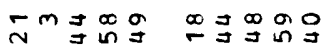

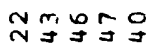

$\stackrel{N}{N} \geq \prod_{m}^{\infty}$

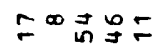

D-NIO

กํㅅํำ

$\overrightarrow{0} \overrightarrow{\vec{b}} \overrightarrow{0} \overrightarrow{0}$

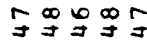

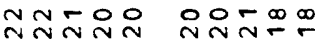

뜨유유워

우순뎐

ㅇํㅇำ

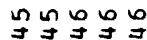

웡워워

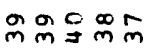

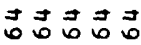

$\stackrel{\infty}{\sim} \stackrel{\infty}{\sim} \stackrel{\infty}{\sim} \stackrel{\infty}{\sim} \stackrel{\infty}{\leftarrow} \stackrel{\infty}{\leftarrow} \underset{\sim}{\infty}$

$\stackrel{\infty}{\sim} \stackrel{\infty}{\sim} \stackrel{\infty}{\sim}$

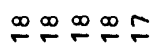

hratar

กヘニ

ヘニะニ

읠의

员骂的一向

吅寻吅寻寻

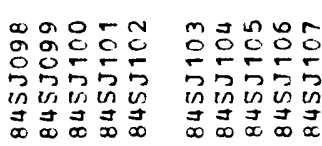

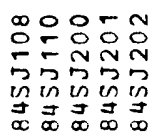

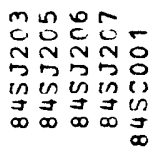

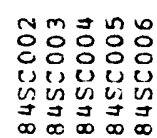

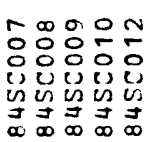

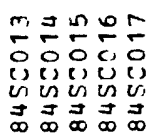

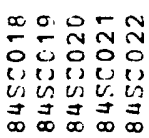

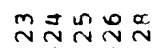

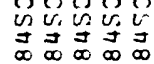




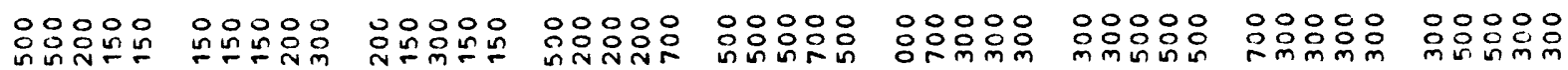
(n)

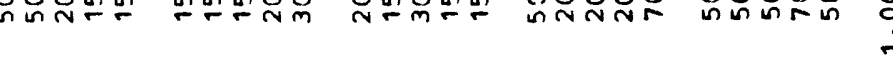

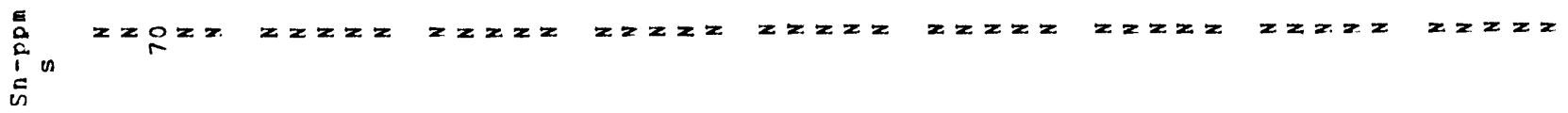

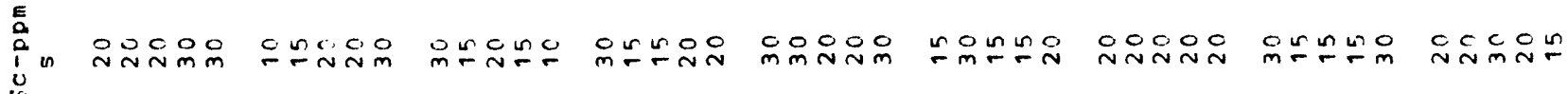

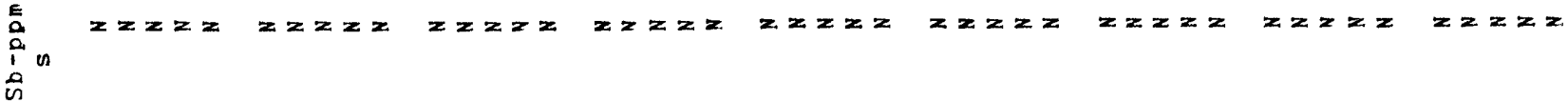

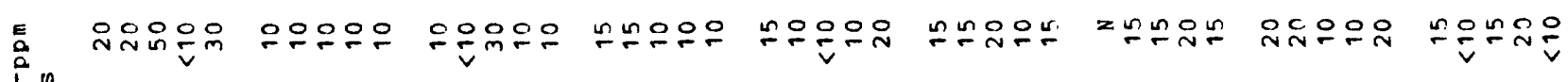
ลิ

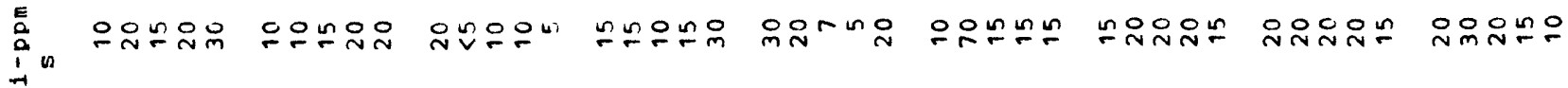
若

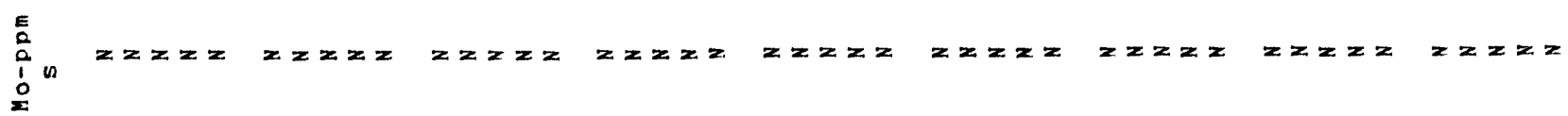

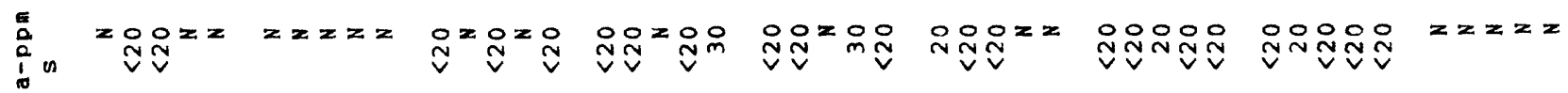

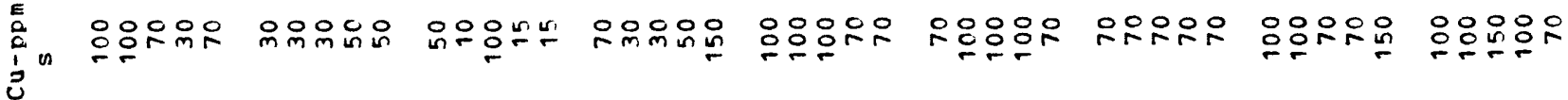

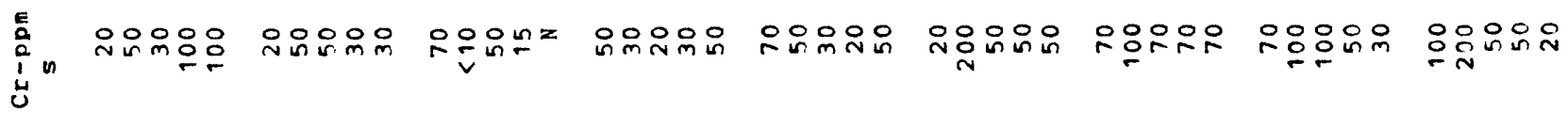

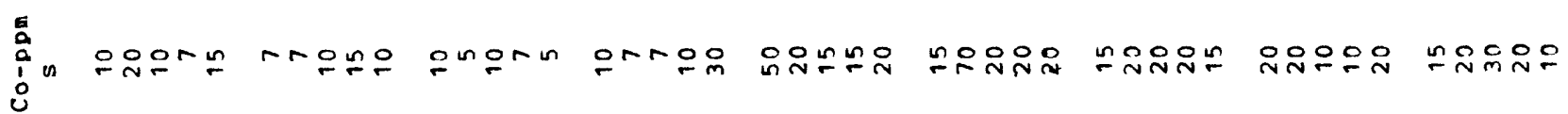

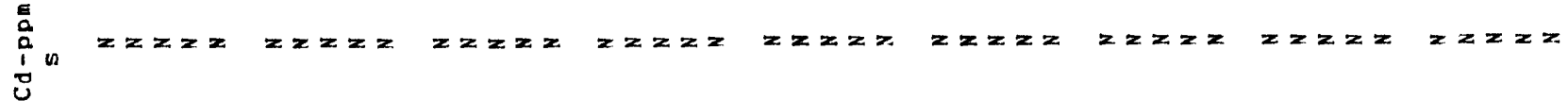

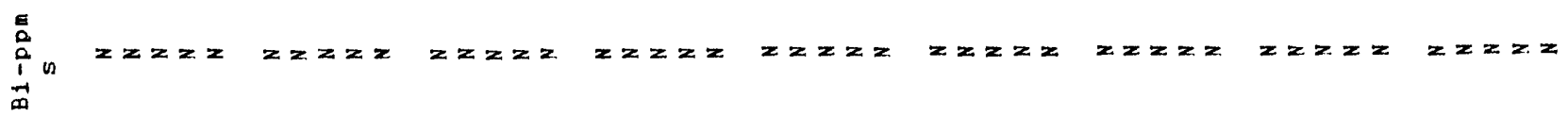
in a

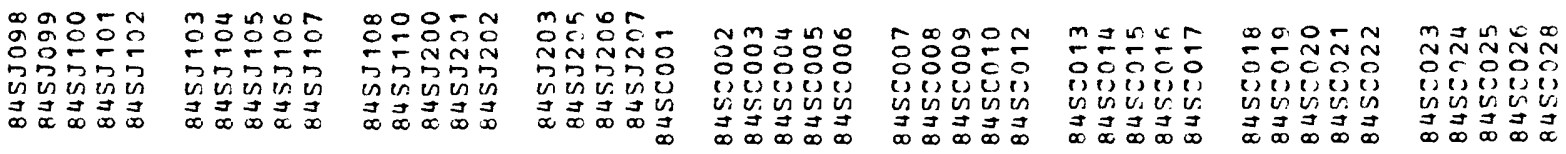




$$
\frac{E}{0}
$$

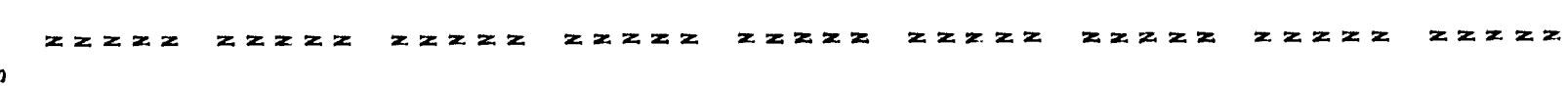
$\Leftrightarrow$

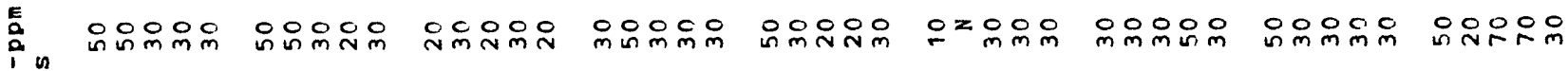
岕

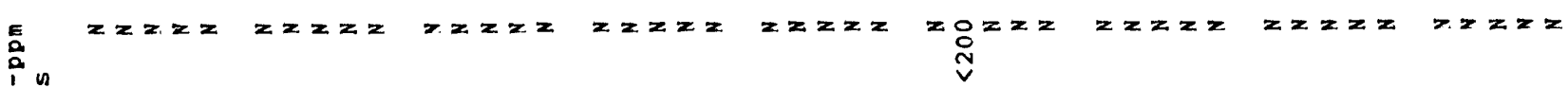

s

a E.

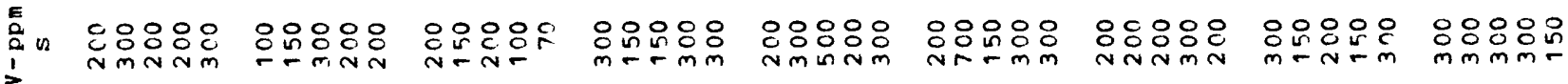
in

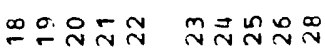
OOOOOO OOOOO

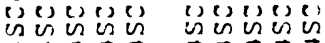

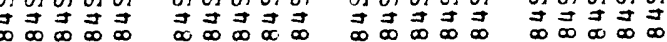




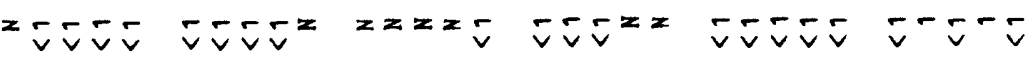

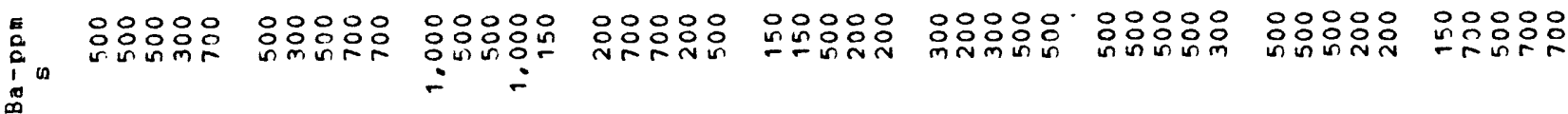

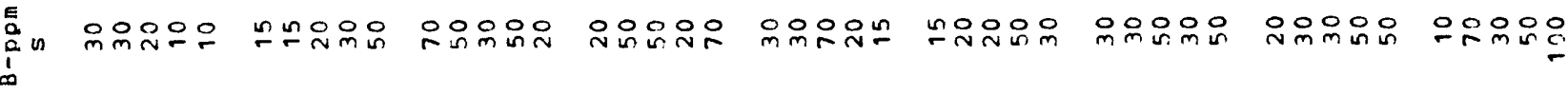

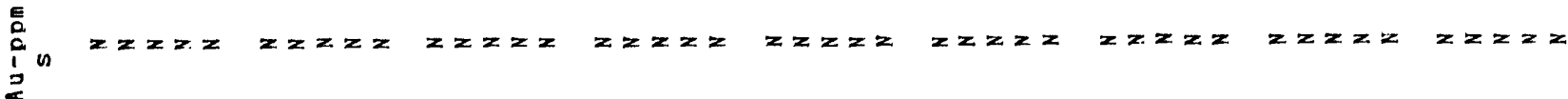
$\log _{\substack{0 \\ \text { in }}} z z z z z z z z$

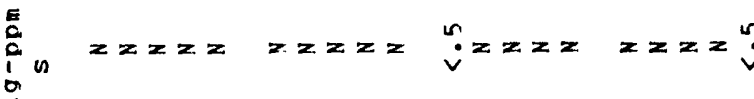

in

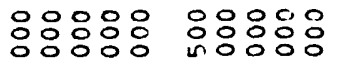

응ㅇㅇㅇㅇㅇㅇ $z z z z z$

$z z z z z$

$z z z z$

$z z z z z$

$z z z z z$

c

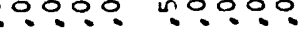

$\because n$

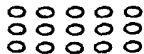

응ㅇㅇㅇㅇㅁ

$\div: \frac{10}{0}$

$\therefore$

$\therefore \circ ㅇ ㅇ ㅇ$

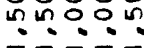

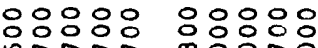

in:

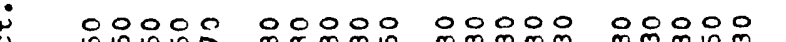

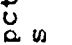

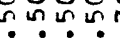

mำm

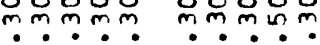

있있일요

울윴융용

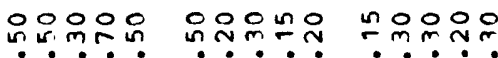

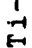

$\dot{\leftrightarrow}_{\substack{0 \\ i}}$

00000

00000

웅ㅇㅇㅇㅛ

용ㅇㅇㅇㅛ

요요

웅융요용

응응응

80000

응ㅇㅇㅇㅇㅠ

응응ㅇㅇㅇㅇ in $\sin \sin$

$\dot{m} \dot{0} \div \dot{\circ}$

$\because \therefore \dot{0}$

نंim

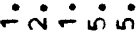

ininim -

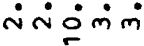

जiำing

运品品

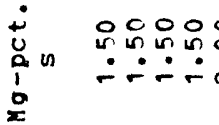

웅유웅웅

응요

운운ㅇㅇㅇㅇㅜ

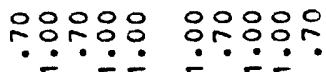

$\therefore: \circ: \circ$

$\because \because \because ロ$

응웅웅요

옹유웅우

ث艹 00000 두용

00000

0000000000

00000

00000

000000000000000 a

우요

윰 $\stackrel{\infty}{\sim}=$ min in

$\dot{m} \dot{m} \dot{m}$ in

minisin

जिंजिं

जिं

$\dot{n} \dot{m} \dot{m}$

तंत्रm

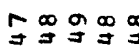

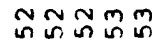

$\sim \infty^{\infty} \infty \mathbb{g}$

ํㅗำ品的巨

象ํำำ

№m

$\infty=$ 웅

요골요

ํํำกำ

जै

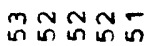

万त此的的

的的的品

응ํำํำ

的的员

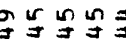

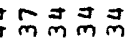

ormo

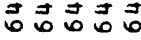

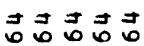

है

可可

司责䓃古

구ㅇㅕㅛ

可苟吉吉

䓃苟芯吉吉

几

可昌三品

कomom

어윤드

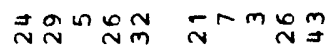

$n=50$

กำ

Nㅜㅇำ

मRAR

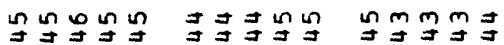

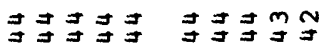

$\rightarrow \sim m m$

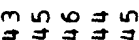

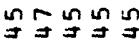

エะニะ

ะะะะ

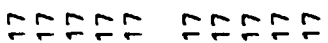

ระะะ์

FFะ

กะะニ

ระニะก

Fะニะ

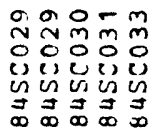

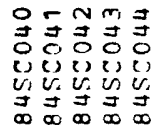

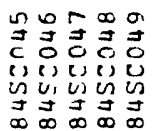

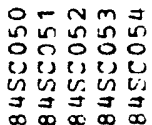

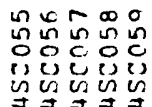

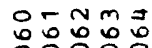

i只只只i

in $\sin 0$

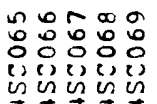

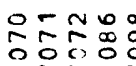

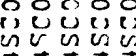

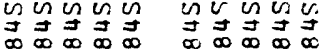

올ㅇㄷㅇㅇㅇ

()ण

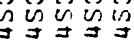

$\vec{\infty} \vec{\infty} \vec{\infty} \vec{\infty} \vec{\infty} \quad \vec{\infty} \vec{\infty} \vec{\infty} \vec{\infty} \underset{\infty}{ }$

. 


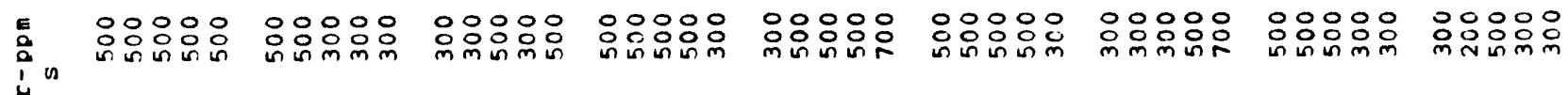
in

E is

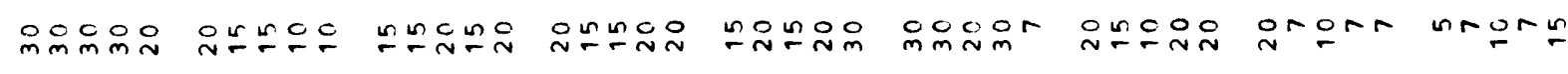

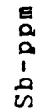

$z x z y \quad z 2 x z$

$z=2 x=$

$z x z z=$

$z x z$

$z z z=$

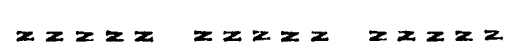

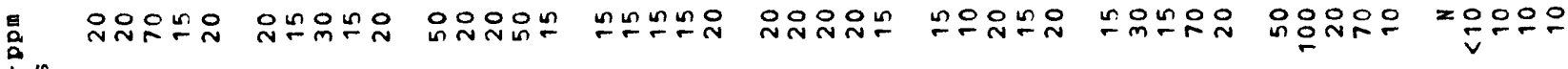
10

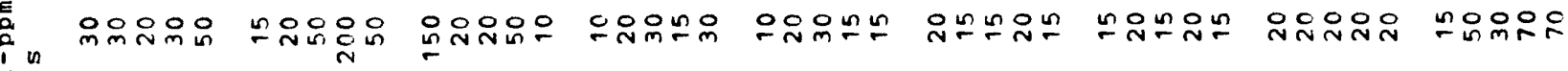
$=$

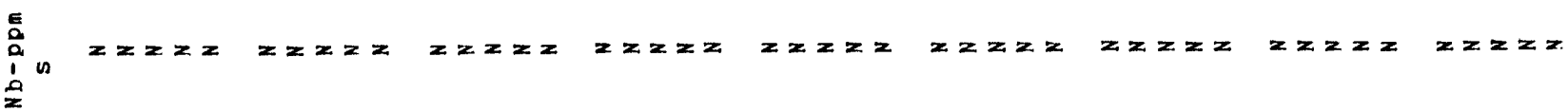

in

$z z z z y z z z y z z z$

$z z z z$

$z z z z$

$z \geq z \geq z$

$z=z$

$x z z x \quad z x z z$

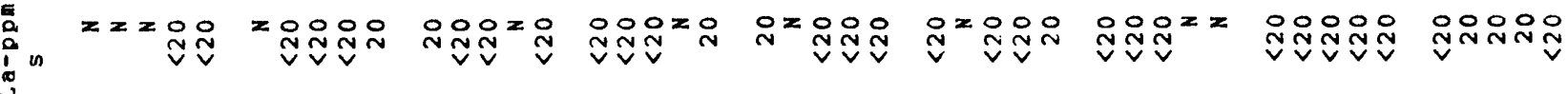

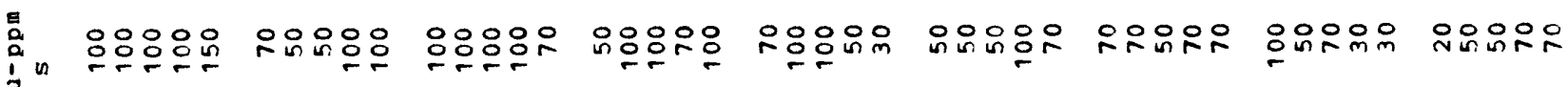

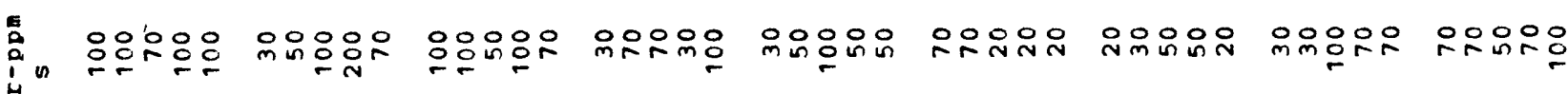

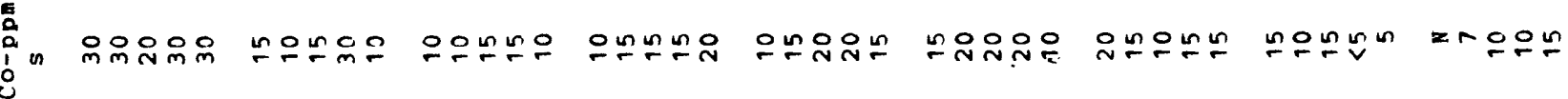

否

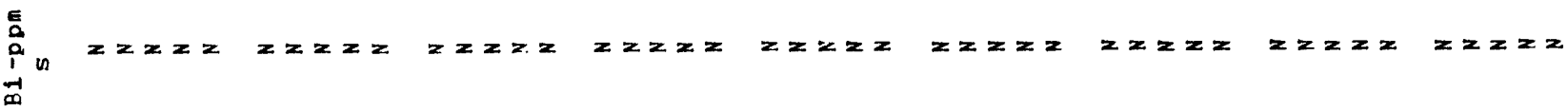

in

$\stackrel{0}{\stackrel{0}{\infty}}$

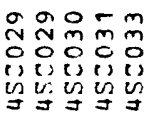

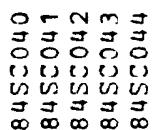

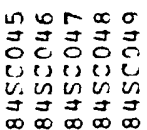

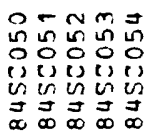

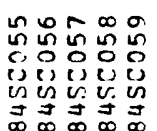

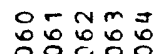

负

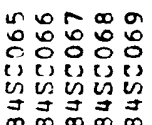

웅주의

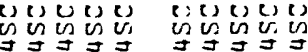

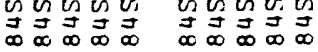




$$
\frac{5}{2}
$$

$z z z z z \quad z z z z y z z z z$ . 章

0000

c응ㅇㅇ

응ㅇㅇㅇㅇㅛ

00000

응으응

응응요요

은요을

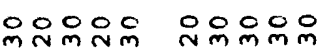

$z z z z$

$z z z$

$z=2 z z$

$z z z z$

z. $z z z$

$z=2 x$

$z z z z$

$z z z z$

in

章

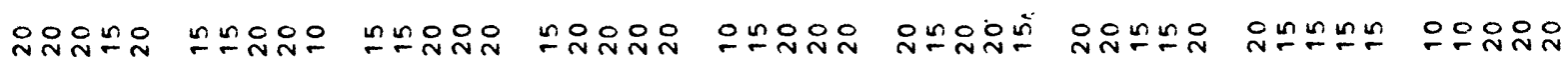
${ }^{5}{ }^{5}$

$z z z z \quad z z z z=2 z z$

$x \geq z=2$

$z z z=$

$z \geq z=2$

$z 2 z 2$

$z z z z$

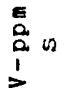

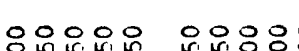

영용ㅇ 용ㅇㅇㅇㅛ

응응요유

응ㅇㅇ융ㅇㅇ음

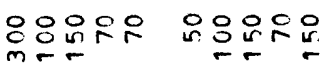

in

$\stackrel{0}{0}$

$\underset{\substack{a \\ 0}}{\infty}$

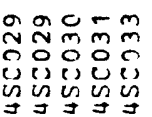

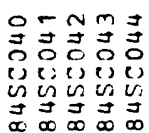

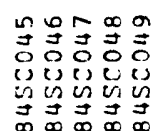

은 $2 \pi m=$

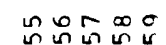

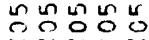

두ำ

is $\begin{aligned} & \text { ing } \\ & \text { in }\end{aligned}$

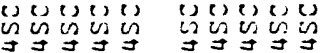

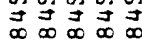

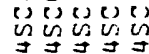

$\vec{\infty} \underset{\infty}{\vec{P}} \overrightarrow{\vec{D}} \overrightarrow{\vec{D}}$

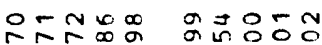

O०000 o-4nN

ज诲出

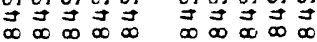




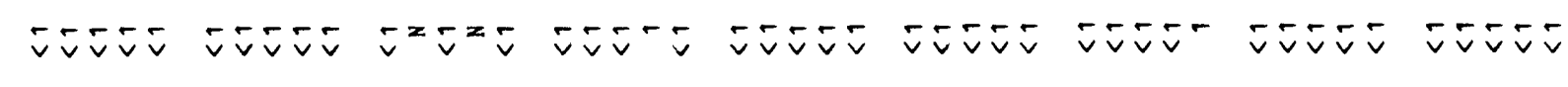

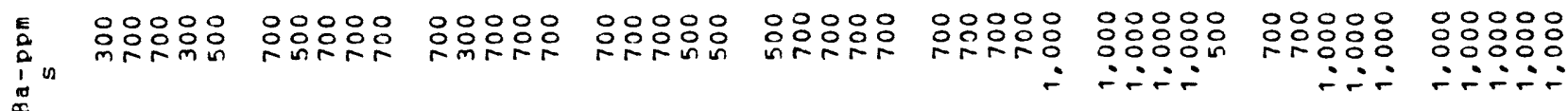
$\stackrel{\pi}{\infty}$

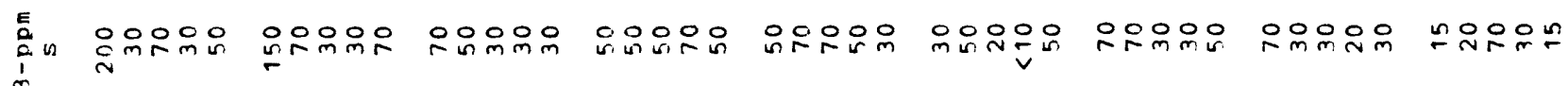
否,

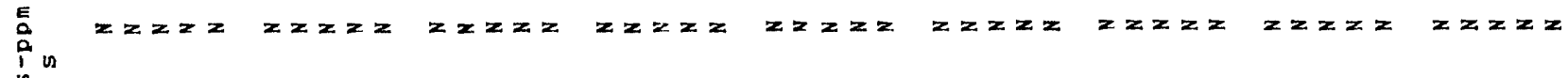
is $E$
0
0
0
0
2

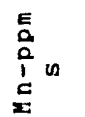

응용응ㅇㅇㅇㅇㅇ응

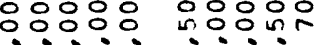

응ㅇㅇㅇㅇㅇㅇ

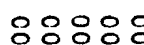
$\therefore \because \because 5$ 요욘? 응ㅇㅇㅇㅇ 응ㅇㅇㅇㅇㅇㅇ $\operatorname{in} 2.00$

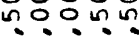

옹응응웅

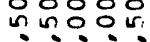

응응ㅇㅇㅇ음 กํ.:용

응응응응

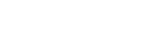

(1)

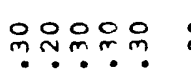

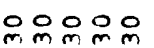

00000

00000

00000

응ㅇㅇ응

웅ㅇㅇㅇㅇ

응응ㅇㅇㅇ

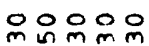
$\frac{1}{1}$

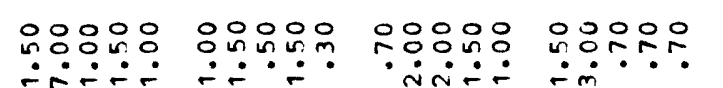

응응응용으 엔응ㅇㅇㅇ응 $\because \because \because \dot{m} \ddot{-} \dot{i} \dot{\sim}$

유은응웅 $\ddot{-} \dot{\sim} \dot{\circ}$

응ㅇㅇㅇㅇㅇ $\therefore \because \dot{4}$

응ㅇㅇㅇㅇㅇ응

0000000000

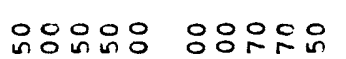

00000

옹ㅇㅇㅇㅇㅇㅇㅇ

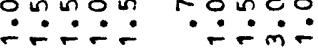

응ㅇㅇㅇㅇㅛ

웅융ㅇㅇㅇㅇ

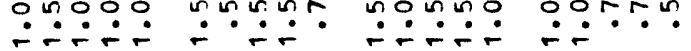

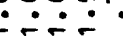

부뭄

응웅요안 宝

$00000.0000 \quad 00000.00000$

0000000000

00000

00000

00000 is

ตัฒ

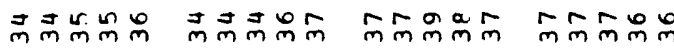
ㄱำ $\stackrel{m}{\sim} \underset{m}{m}$

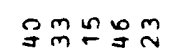

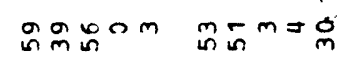

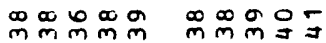

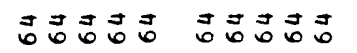

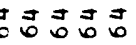

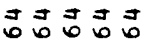

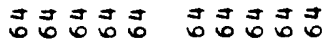

m $0-2-a$

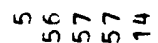

mm음요

Cᄃmog

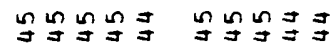

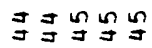

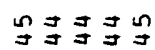

FFFร

FIF

FFFF

FEFF

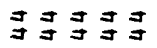

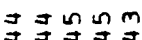

FFFF Fะ

กลำ

żjez

픙ำำ

añ

$\dot{n}$

a

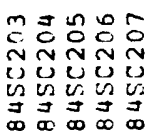

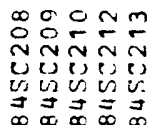

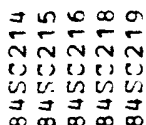

$\stackrel{\sim}{\sim} \underset{\sim}{\sim}$

กNNN

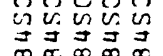

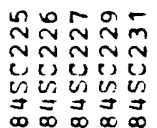

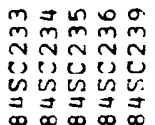

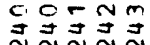

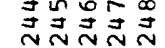

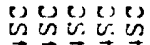

$\vec{\infty} \underset{\infty}{\vec{b}} \vec{\infty} \underset{\infty}{\vec{b}}$

unguv

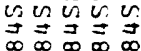

임도

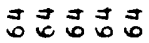

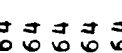

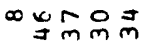

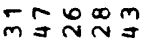
孚孚寻寻寻

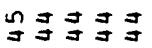

ㄷF 


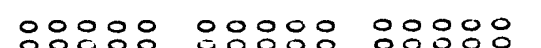

00000

욷용응 응영웅

웅응ㅇㅇㅇ응

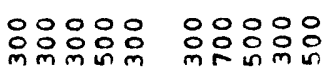

in

통

$z z x y z$ zyzz $z z z z y$

$z z z z$

$z z z z$

$z z z z$

$z z z z$

$z z z z z \quad z z z z$

总电

orumo ciroos nutmo

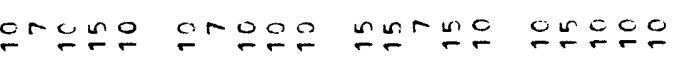

$z x x_{1} z$

$z z z z$

$z z z z$

$z z z z$

$z z z z z$

$z z z z z$

$z z z z$

$z z z z z y z z z$

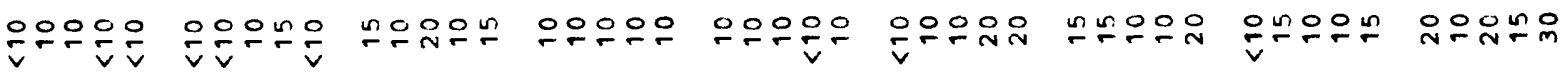

$\frac{5}{a}$

$\stackrel{5}{0}$

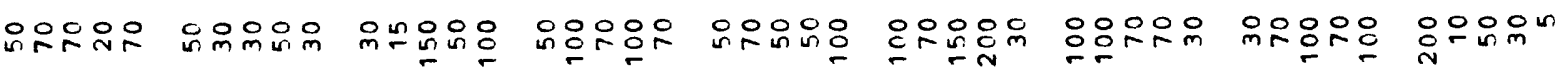

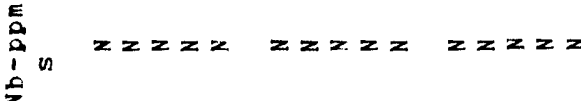

$z z z z$

$z z=2$

$z=z z$

$z z z z$

$z z z z z z z z z$

${ }_{0}^{\text {E }}$

$z z z z \quad z z z z z$

$z z z z$

$z z z z$

$z z z$

$z=2 z$

$z z=2$

$z z z z z y z z z$

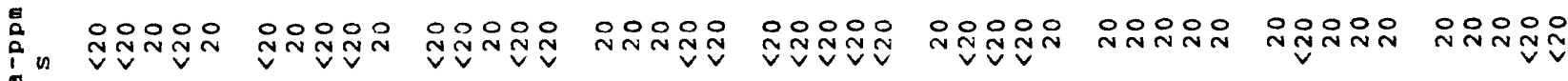

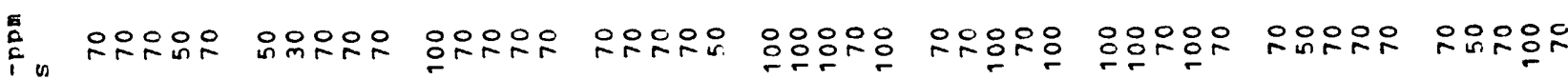
马

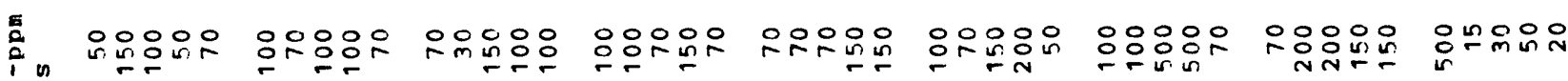
㟧

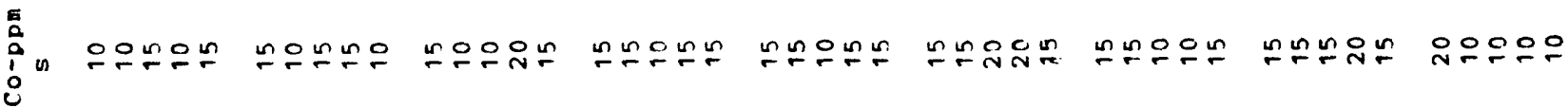
in 否 i 


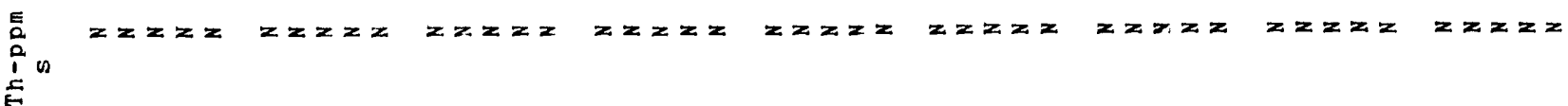

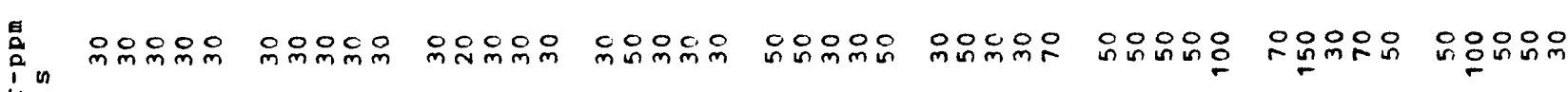
岕

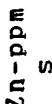

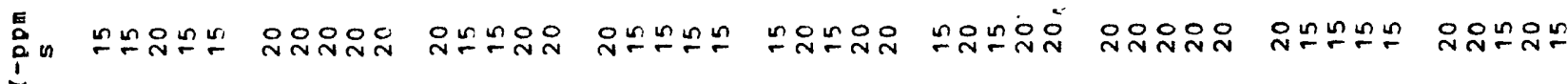

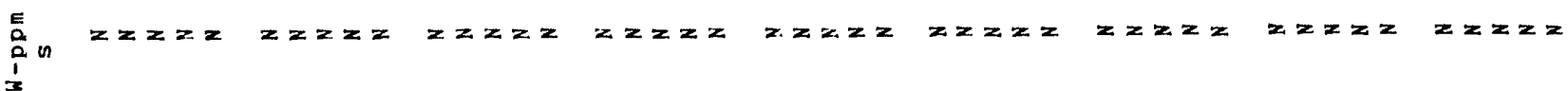

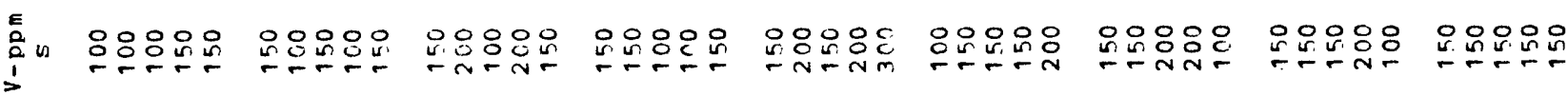
$\dot{4}$ 


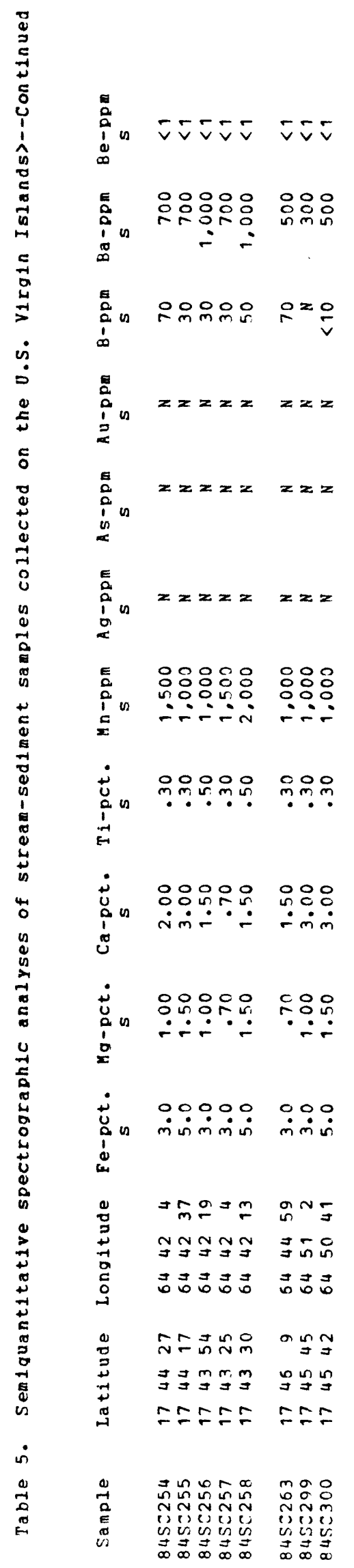




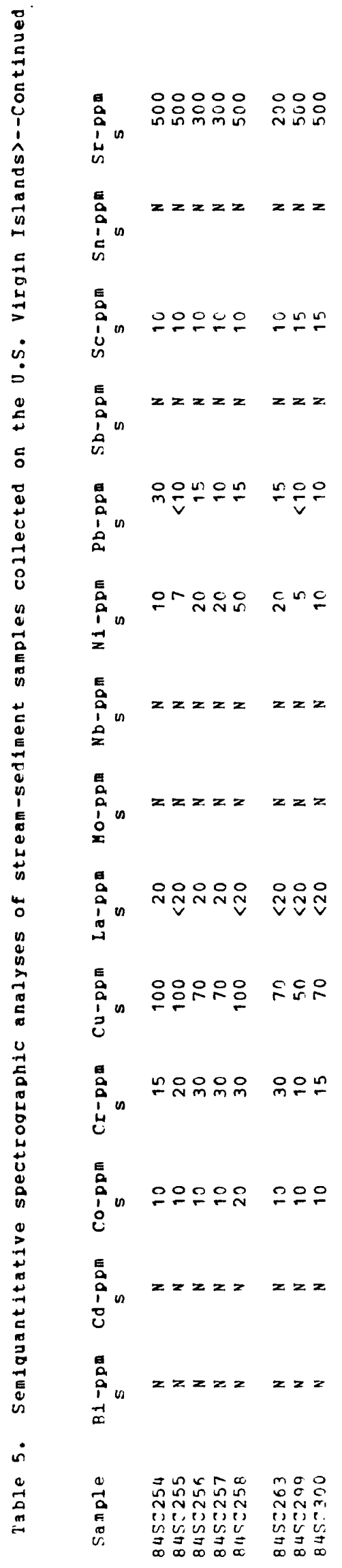




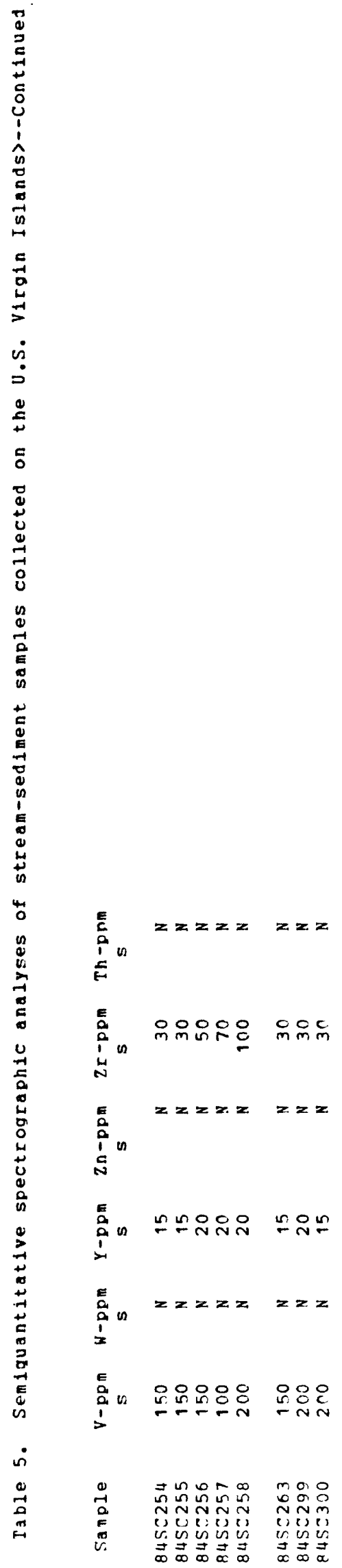

108 


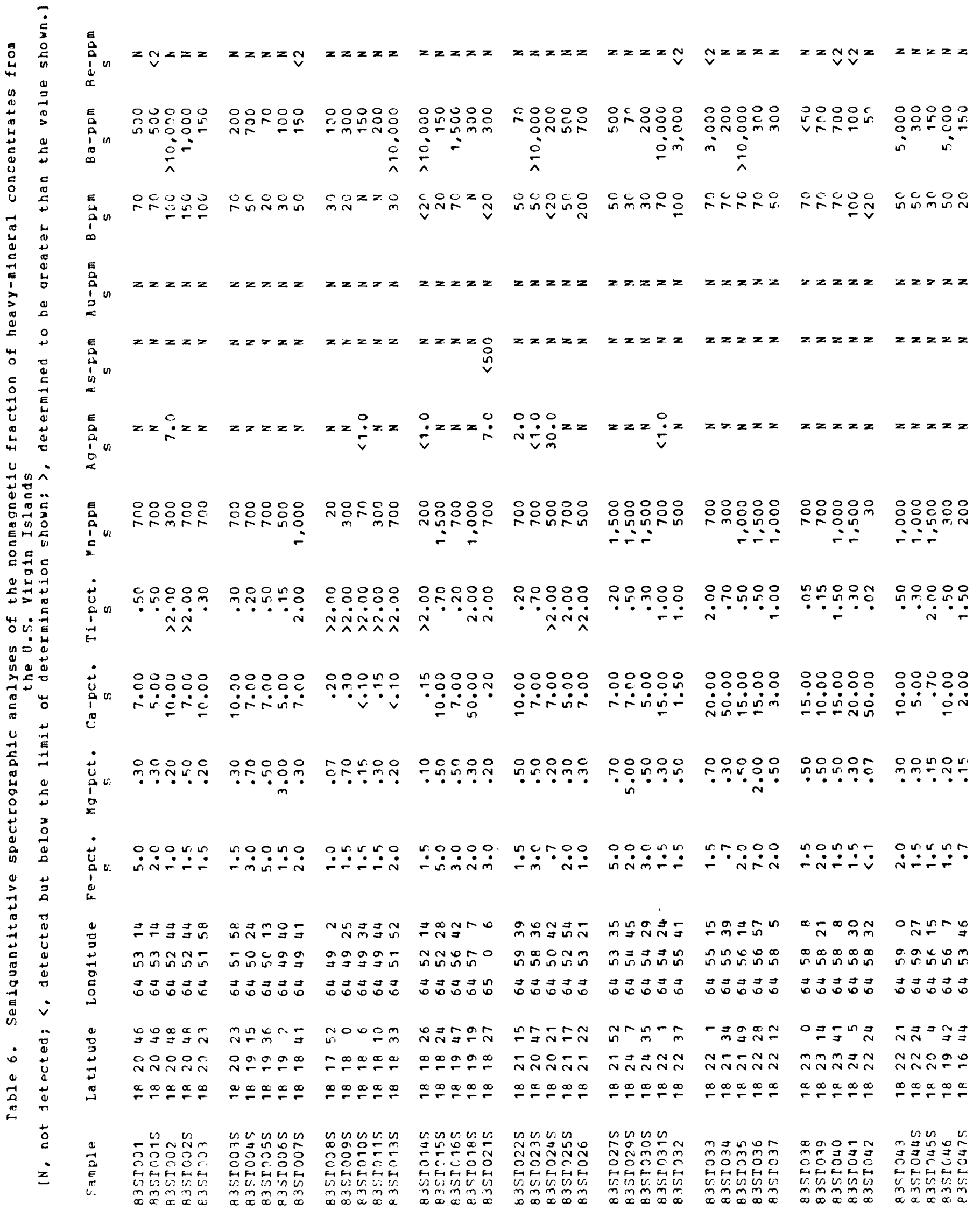




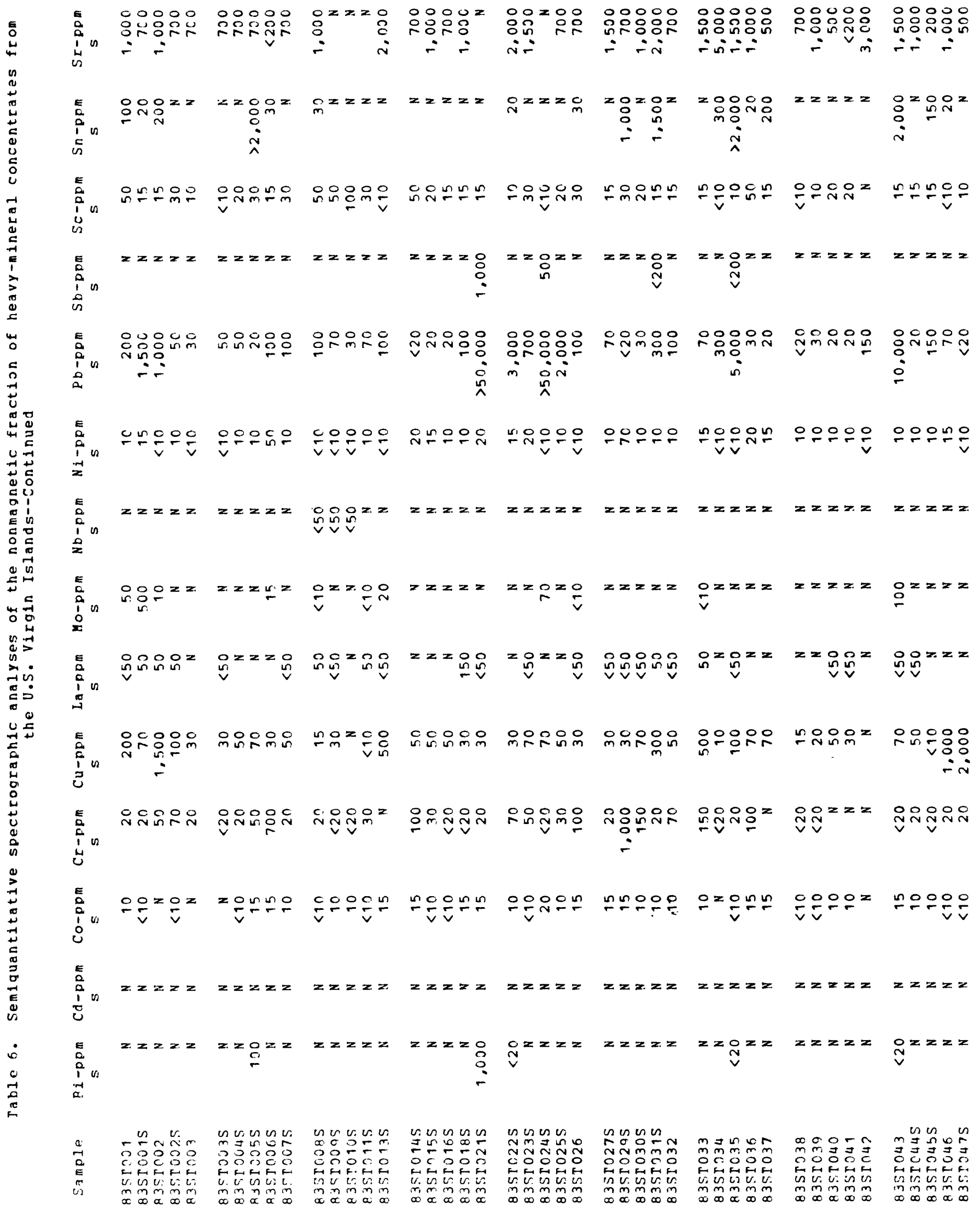




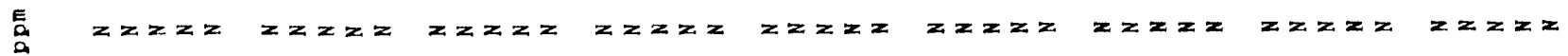
$\sum^{\infty} u$

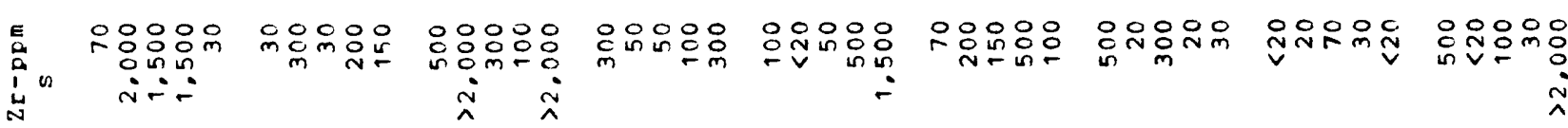

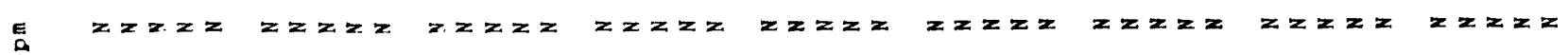

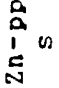

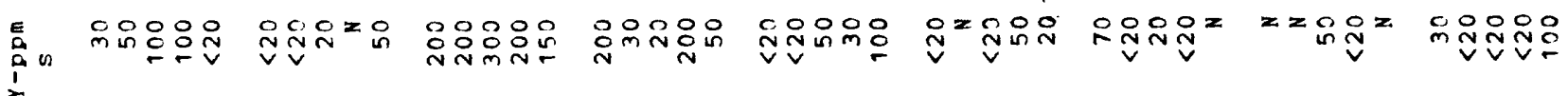
E

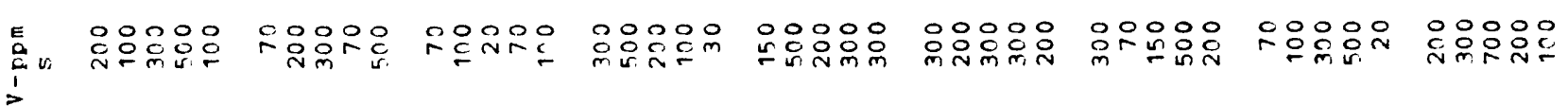

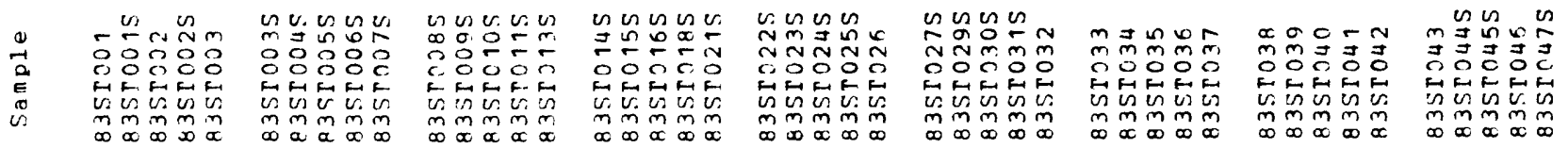




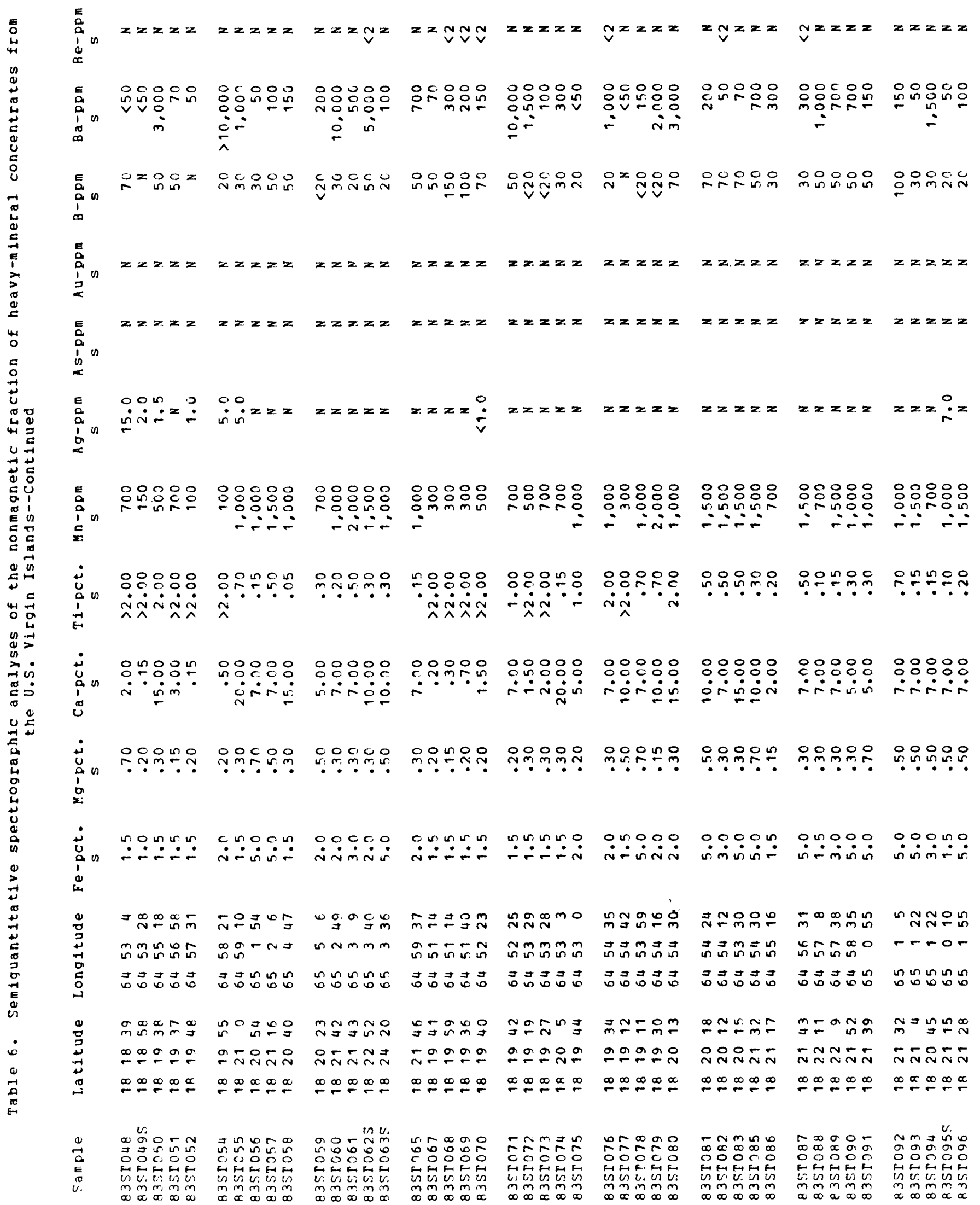




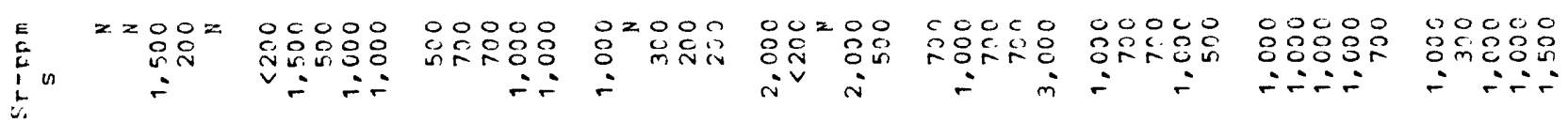

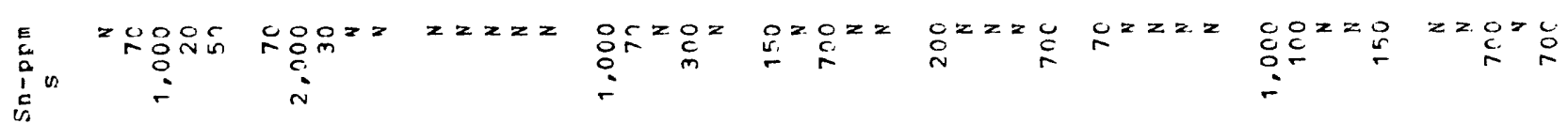

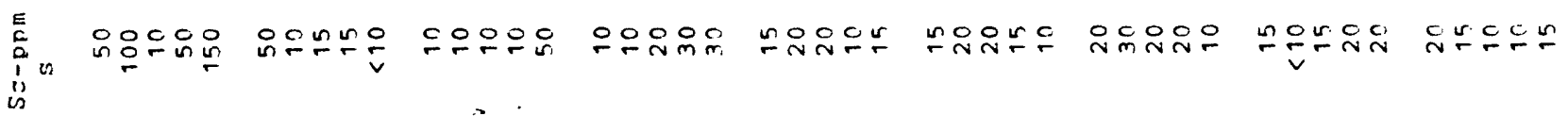

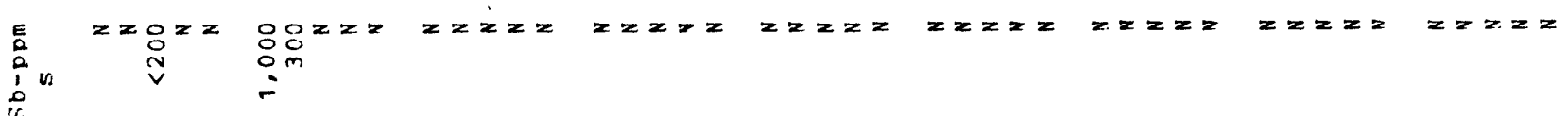

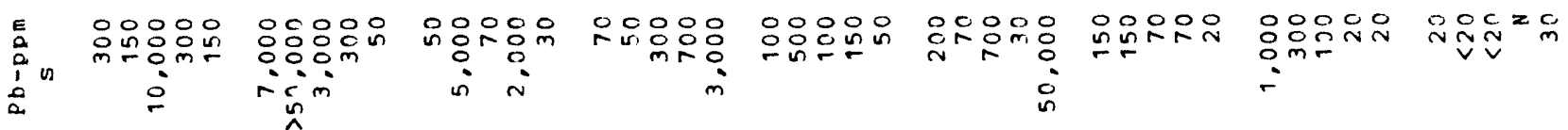

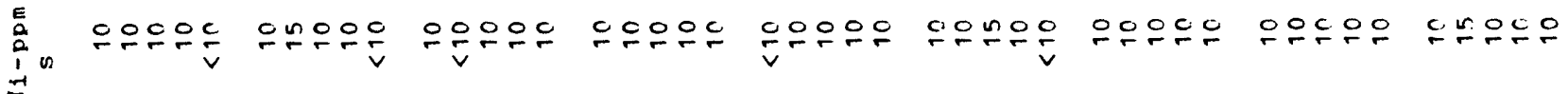

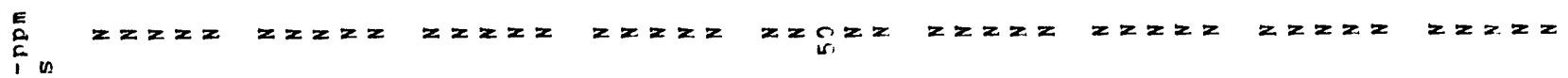
$z$

E
!n
$\vdots$

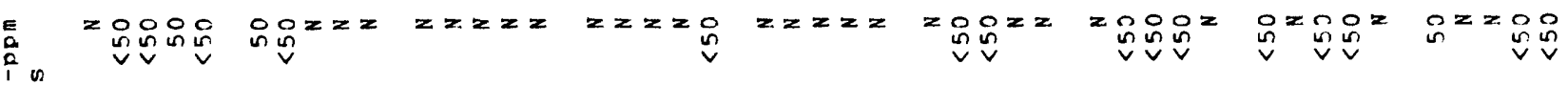

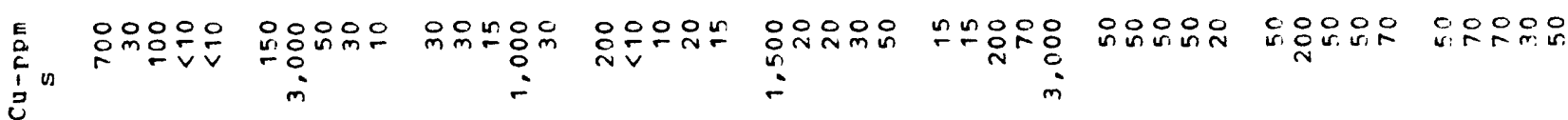

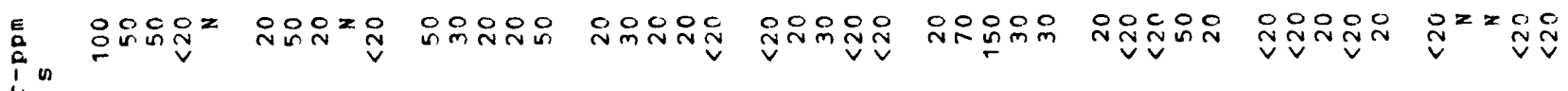
ư

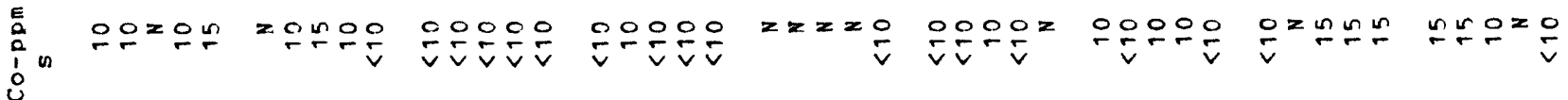

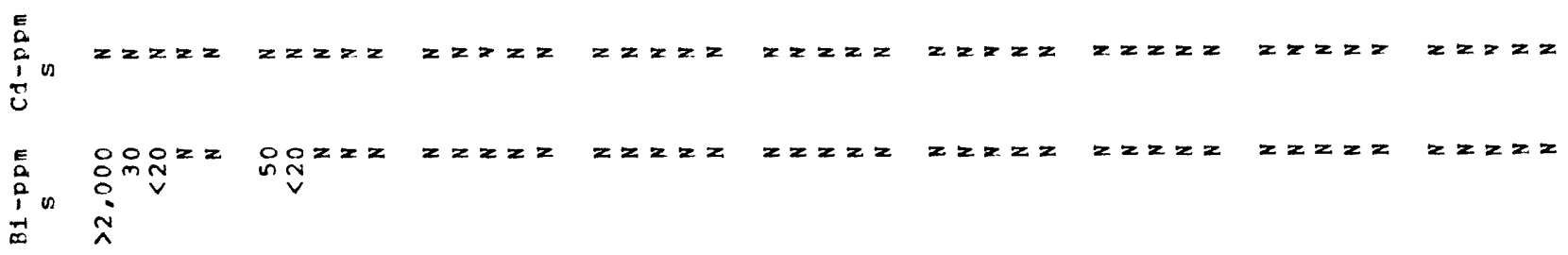

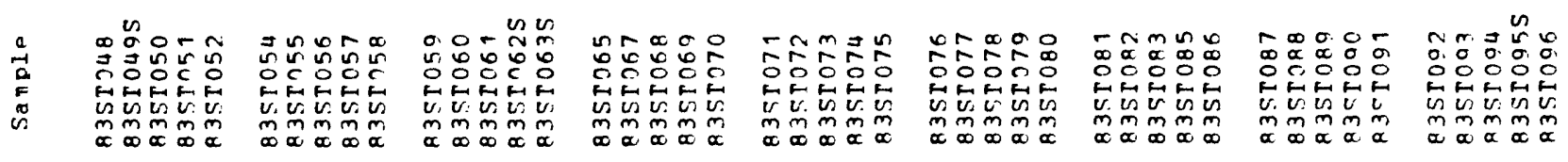




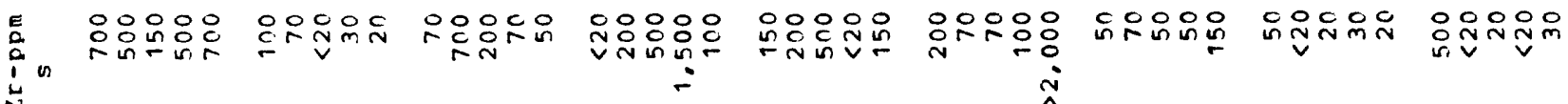

E

$z z z z=\quad z z z z \quad z z z z \quad z z z z$

$z z z z z z z z$ i

ธ

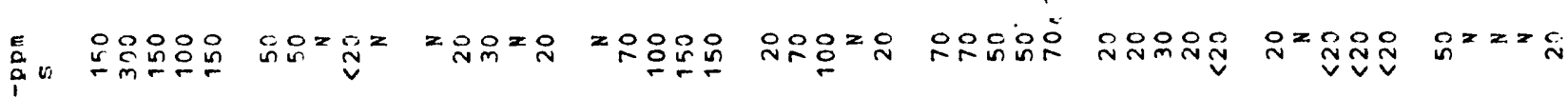

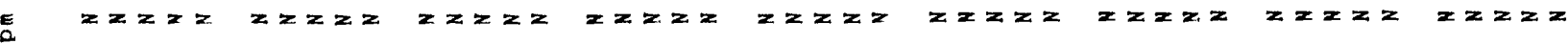
$\sum^{2} n$

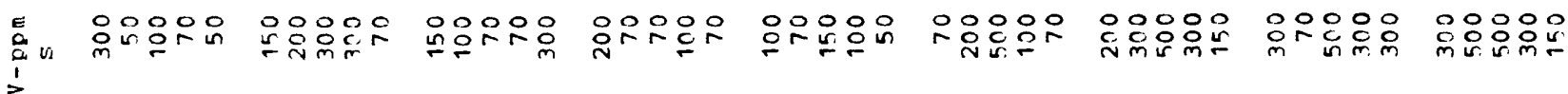

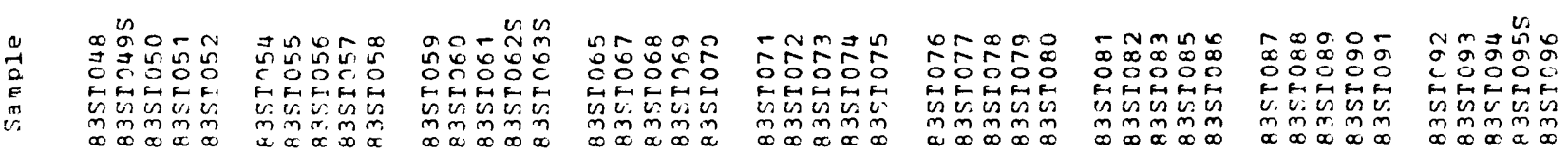




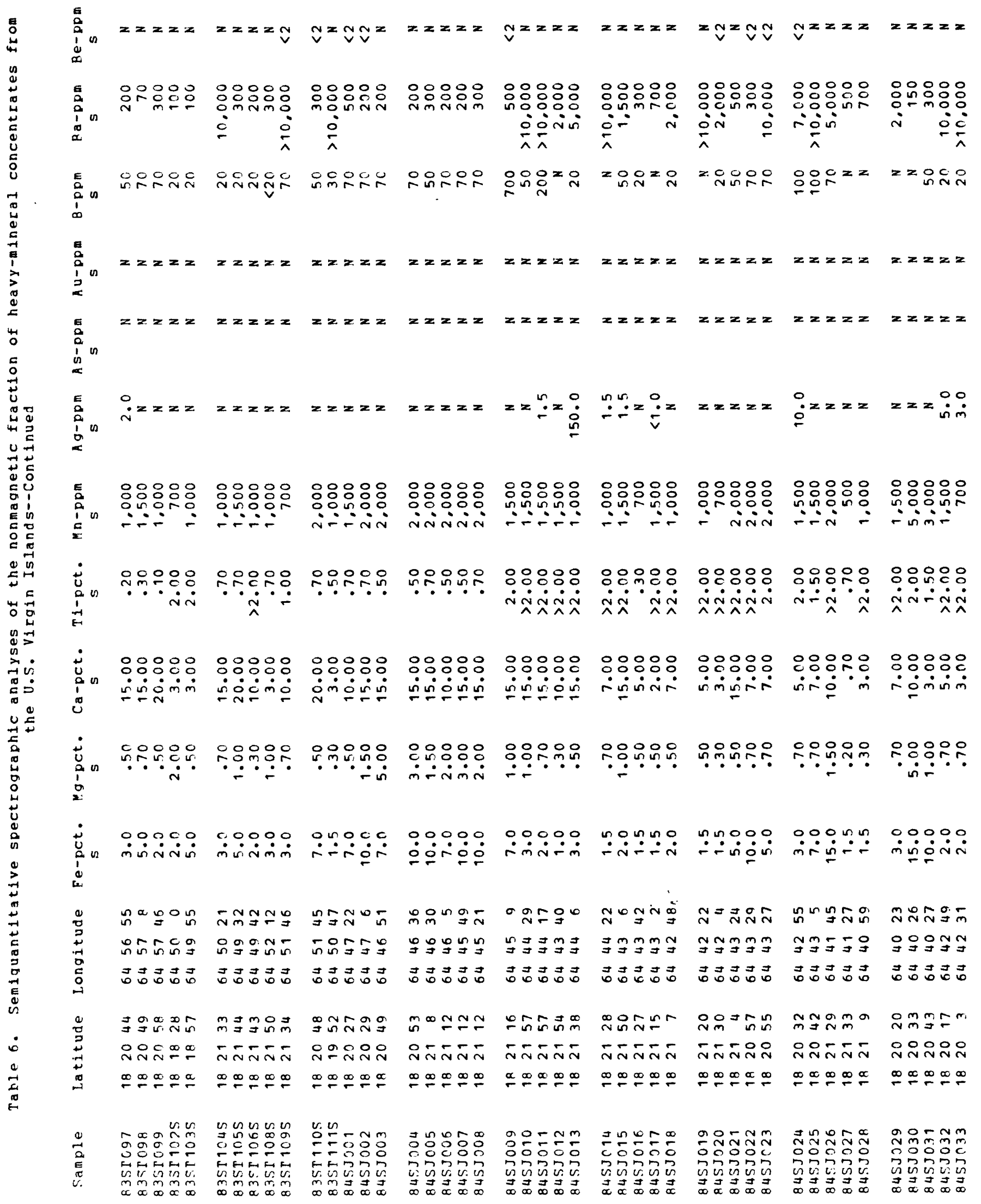




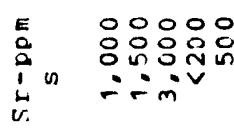

응웅웅

得

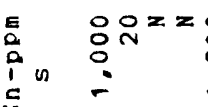

$x+\underset{N}{i}=$

2

$x=x$

웅움

울 =

$x=$

$x=0$

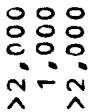

용요

in

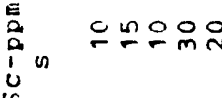

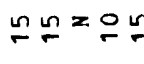

드으는은

은ํㄴ은

은은은은

$z=\stackrel{\circ}{\text { o }}$

E ${ }^{2} z z z=$
D.
in
in

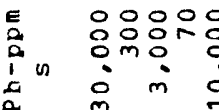

응응유음

은

E
0
0
0
1

응ㅇㅇ은ㅇ

는응ㅇㅇㅇ

$\checkmark v$

는으우요

을유음음

운원은

$\stackrel{\circ}{\stackrel{0}{ }}$

$\stackrel{O}{V}^{x z z}$

${ }^{2} \stackrel{O^{2}}{V}=2$

$\stackrel{\circ}{0}$

$g^{2} z z z g^{2}$
$m$

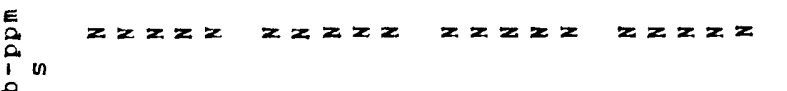
2

$\frac{\mathrm{E}}{2}$

$z z z x z \quad z 0 n z z$

$z z z x=2 z z z$

$\underline{\ln } z=z$

응웅ㅇㅇㅇㅇ

$\because: 0$

nio

in

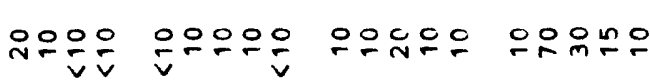

E 유 $z z z z$ 응ㅇㅇㅇㅇㅇㅇ

in

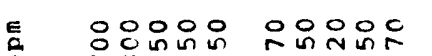

$\frac{1}{2}$ rom in

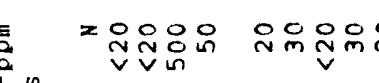

i

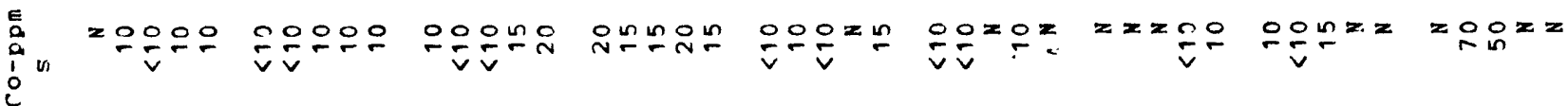

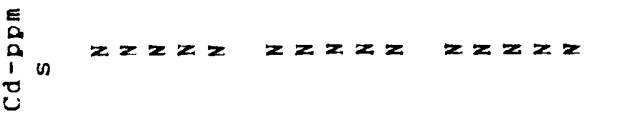

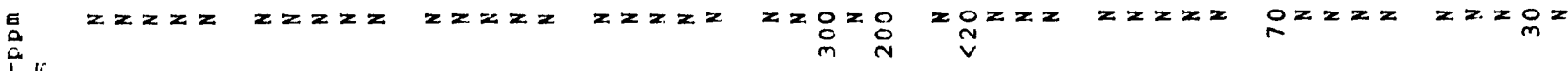
a.

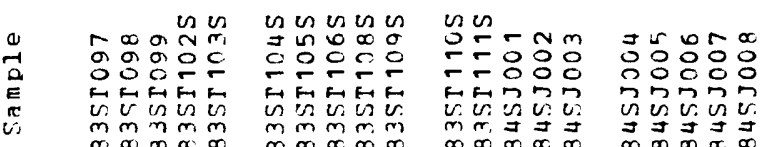

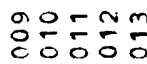
วกำ

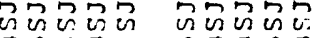

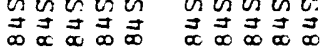

$\operatorname{rin} \tilde{N} \stackrel{n}{2}$

융ㅈㅇㅇ

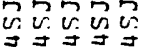

$\vec{D} \vec{\infty} \underset{\infty}{\infty} \vec{\infty}$

ำ웅

ํํㅇ유유

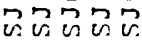

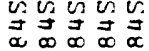

a음

ํํㅇํํㅇํㅇ

근든

w. Un w v 


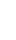

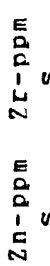

응유듕응 웅응응

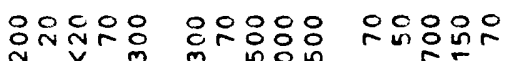

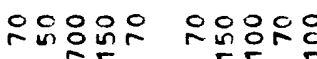

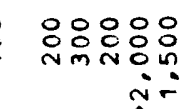

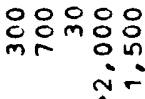

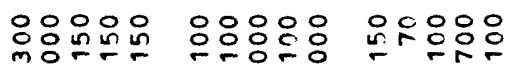

$z z z$ $\therefore$ in:

통 율 E $z z z z z \quad z z z z \quad z z z z z \quad z z z z z$ $\stackrel{E}{c}$

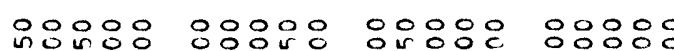

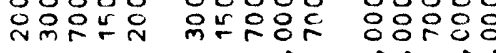
$\therefore \because \because$ 웅옹융ㅇㅇㅇ 음영웅유음

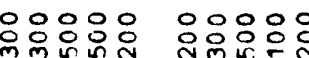
$\therefore$

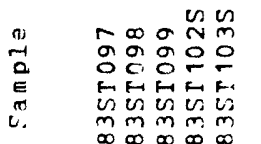

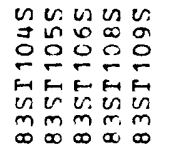

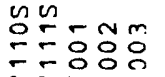
트르을

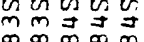

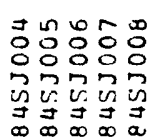

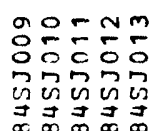

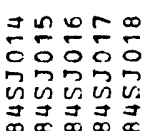
유ㅇㅝㅠ웡 푸요

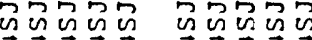
nी $\sin$

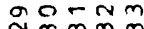

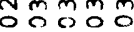

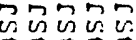
$\vec{D} \overrightarrow{\vec{D}} \overrightarrow{\overrightarrow{0}}$ 


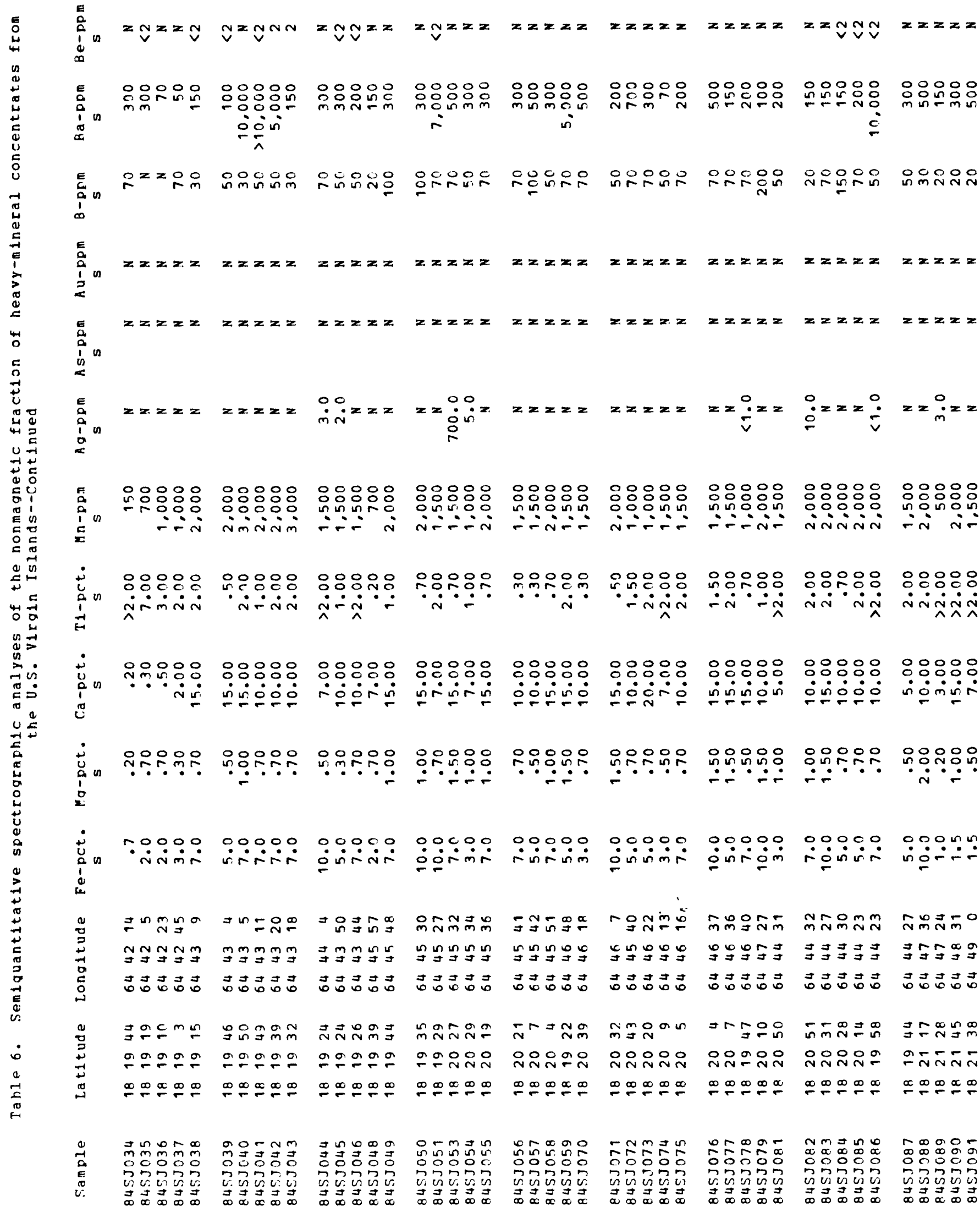




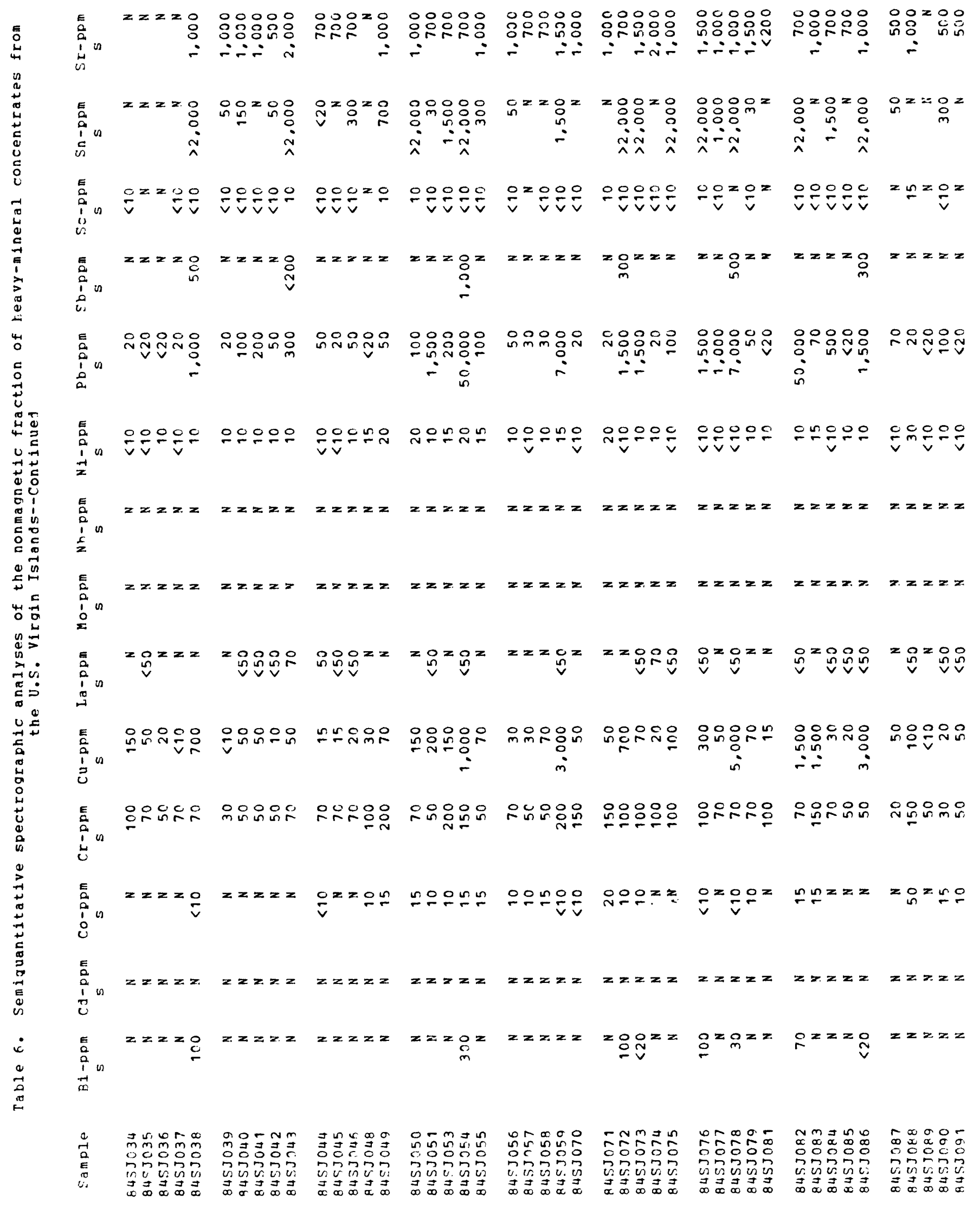


응영융응ㅇㅇㅇㅇㅇㅇㅇㅇ

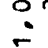

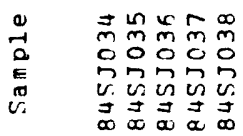

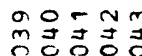
$\sin \cos 20$ $\vec{\nabla} \vec{\infty} \vec{a} \vec{\infty} \vec{\infty}$

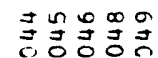

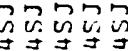

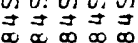

\section{유ำตี่}

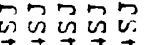

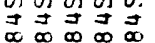

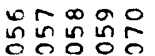

ํํำ जि $\vec{\infty} \vec{\infty} \vec{\infty} \vec{\infty} \vec{\infty}$
응웅융유

옹ㅇㅇㅇㅇㅇㅇㅇ

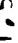

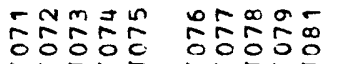

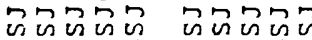

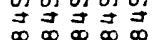




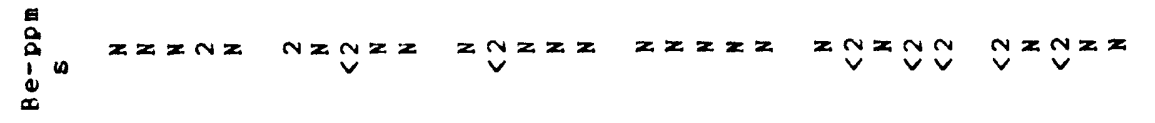

至

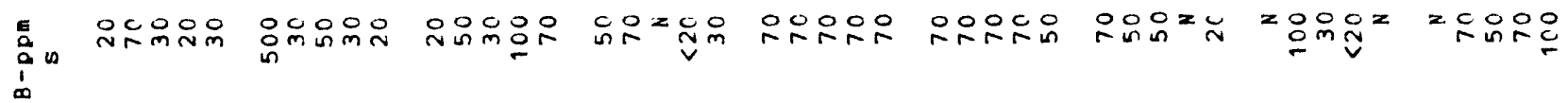

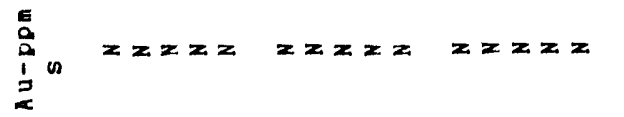

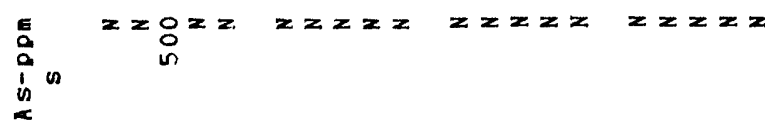

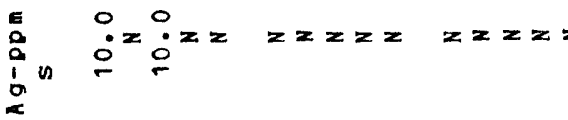

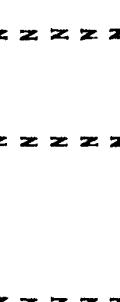

$z z z z$

$z z=2$

$z=z=2$

$z z z z$

$z x=2$

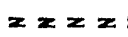

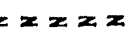

$z x z=$

$z x z z$

$z=2$

U

\section{영융ㅇㅇㅇㅇㅇㅇ응}

mininin

ind

ininn

응ㅇㅇㅇ

n:․․․

음융ㅇㅇㅇㅇㅛ

용ㅇㅇㅇㅇㅇㅇ

$\therefore \div \div$

$\because$ in

응응웅유웅

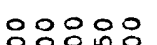

00000

웅ㅇㅇ응

웅웅

0000

00000

웃으는

on 000 ì

तं山ें

- $\dot{\sim} \dot{\sim} \dot{\sim}$

$\dot{\sim} \dot{\sim} \dot{\sim} \dot{\sim}$

$\dot{i} \dot{\wedge}$

iั

ㄴ.?ㄴ.

ㅇํㄴํํㅇำ는

落

응응응응

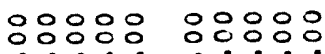

응운웅응

ํํำ

무우요

부욤요

웅

응응

응응응

응응음

응요영우

응요

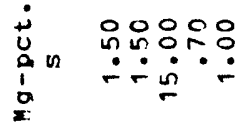

웅ㅇ 웅요웅

00000 돈

ritio

iñir

irí

穴穴实

$\because \because$ in min்

ํำ

웅ㅇㅇㅇㅇ

으웅ㅇㅇㅇ

웅ㅇㅇㅇㅇㅇ

등웅ㅇㅇㅇㅇ

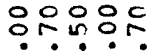

00000

0.000000000

o요요

$\because 0000$

00000

00000

웅요

00000

nnno oding

ori-í

oritit

minisin

$\sin \sin \sin ^{\circ}$

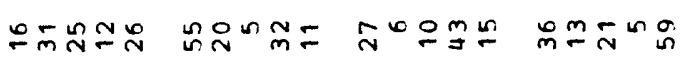

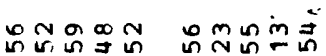

$\cong \mathscr{m}-$

m

$\min m$

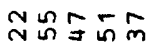

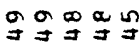

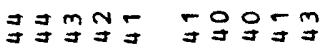

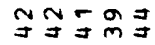

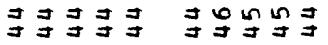

当寻第等

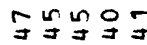

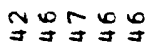

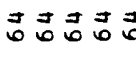

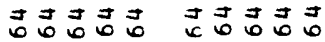

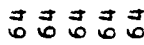

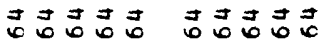

च可局

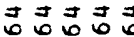

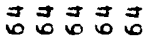

于承织

$\operatorname{m}$ -

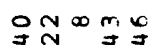

$\sin N$

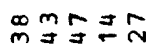

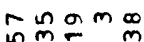

오논

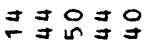

กักลก

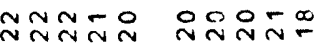

$\stackrel{\infty}{\infty}$ 음유

우윢유

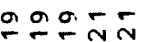

추슈은

윰유스

두웜의

$\stackrel{\infty}{-\infty} \stackrel{\infty}{-}$

$\stackrel{\infty}{\sim} \underset{\sim}{\sim} \stackrel{\infty}{\sim} \stackrel{\infty}{\sim} \stackrel{\infty}{\sim}$

$\stackrel{\infty}{\infty} \infty \infty$

$\stackrel{\infty}{-} \stackrel{\infty}{-} \stackrel{\infty}{-} \stackrel{\infty}{-} \stackrel{\infty}{-} \stackrel{\infty}{-}$

$\stackrel{\infty}{-\infty} \stackrel{\infty}{-}$

$\stackrel{\infty}{\infty} \underset{\infty}{\infty}$

$\stackrel{\infty}{\sim} \stackrel{\infty}{\sim} \stackrel{\infty}{\sim}$

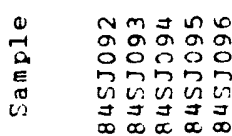

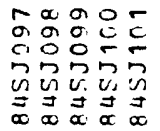

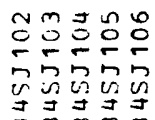

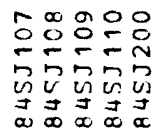

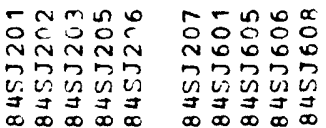

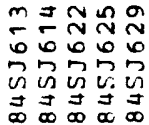

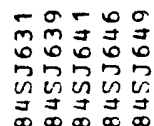

요요

잉요

可政它

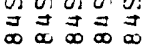




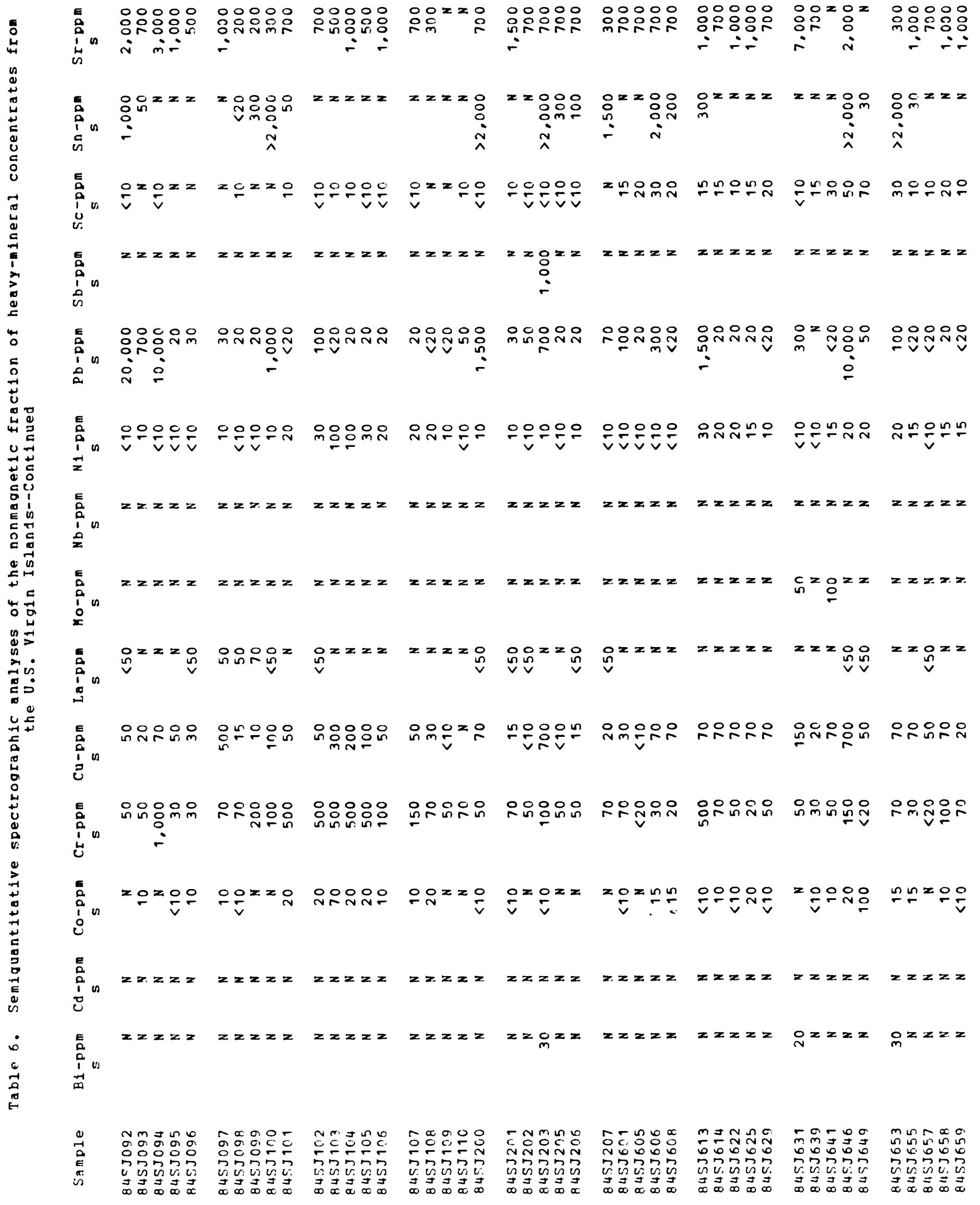




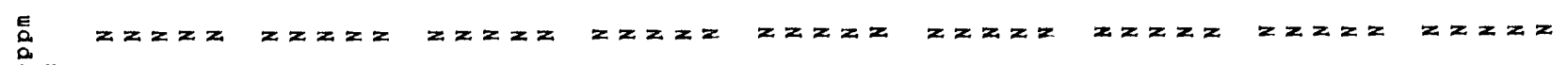
E-

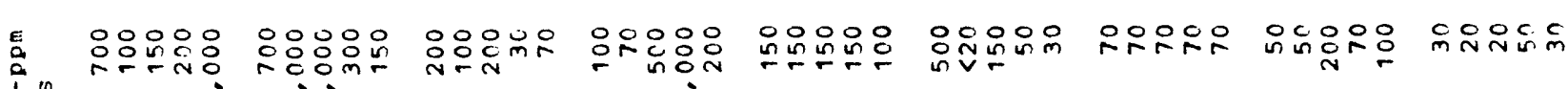
inn

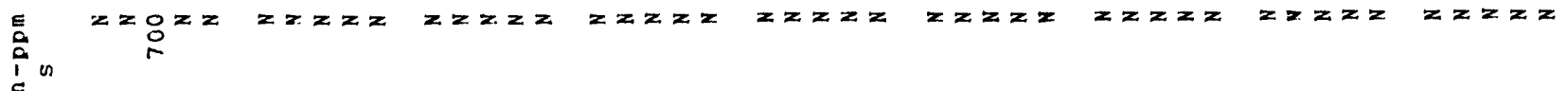
N

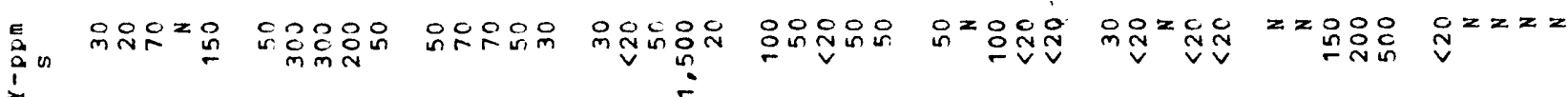

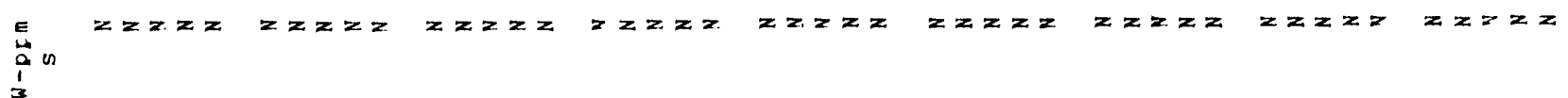

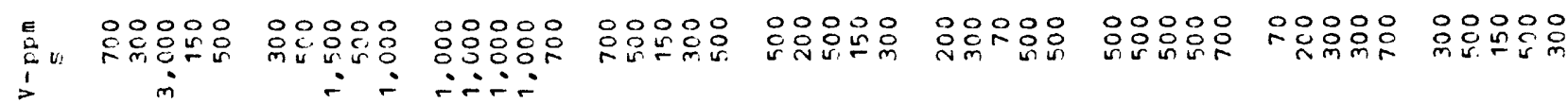

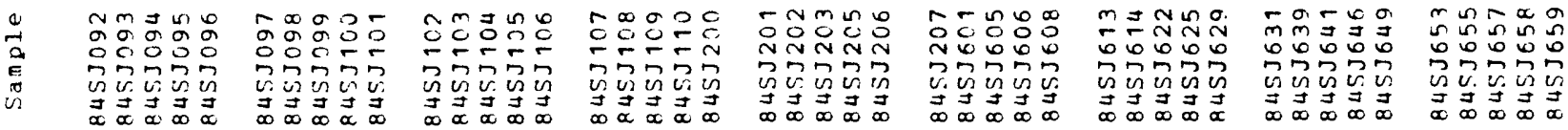




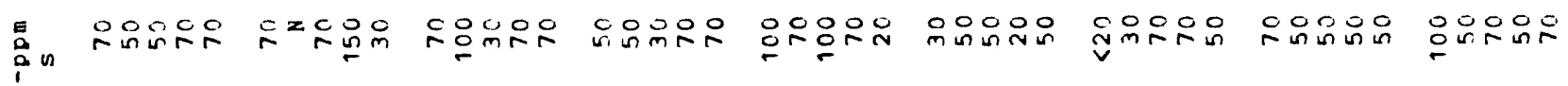

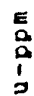

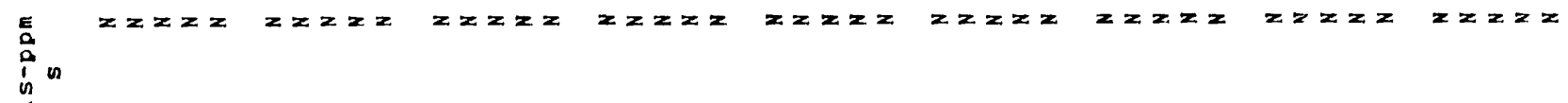

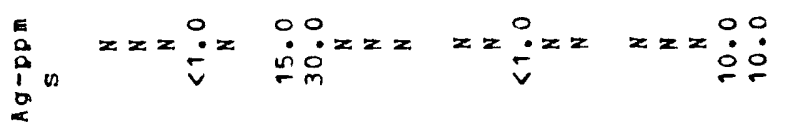

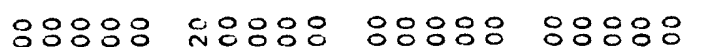

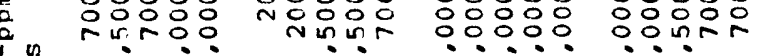

100000 iniำ

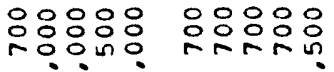

$8: 8: \circ$

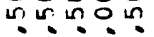

요요잉 $=$

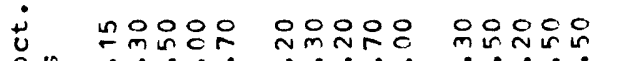

00000

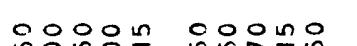

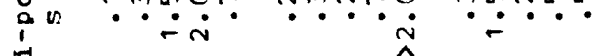

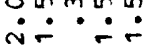

$\because \because \dot{x}$

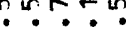

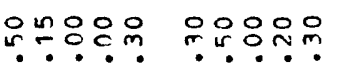

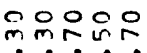

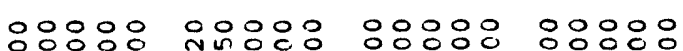
$\dot{0} \dot{0} \dot{0} \dot{r}$

- irm rirrir $\dot{\sim} \dot{\boldsymbol{r}} \dot{\mathrm{m}} \dot{\mathrm{m}}$

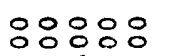

응ㅇㅇㅇ응

ㅇㅇㅇㅇㅇㅇㅇㅇ

응ㅇㅇㅇㅇㅇㅇ

rirri

ㅁㅇ용

뭉ㅇㅇ

óríri

영응요 v

응ㅇ nnooo o0000

옹응ㅇㅇㅡ

응ㅇㅇㅇㅡ

응ㅇㅇㅇㅇㅇ

응응응ㅇㅇ

응응ㅇㅇㅇㅇㅇ 분.

$\because \because \div$

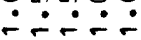

응웅요의 :

苍

0.00

ro000 00000

00000

0000 in

o 00 ino

no 000

00000 무웅-

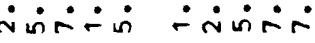
$\dot{\sim} \dot{\operatorname{rin}} \dot{\mathrm{m}}$

00000 á.

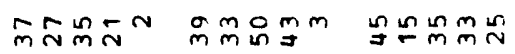

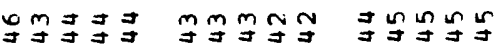

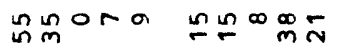

m

의의의

으능ํำ

$\min \underset{\text { in }}{\operatorname{mon}}$

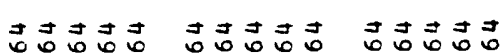
妾豆寻寻 寻寻寻寻早

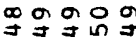
of $\begin{aligned} & \ln \\ & y\end{aligned}$

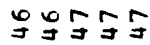
年守电包 $\stackrel{2}{0}$

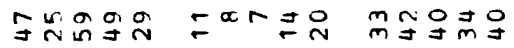

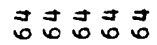

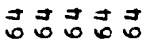

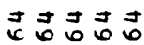

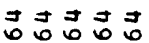

जै $\overrightarrow{0} \overrightarrow{0}$ चु

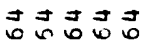

군 $\underset{m}{\infty} \stackrel{\infty}{m}$

$m-\frac{4}{n}$

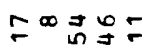

$m-n \mp z$

กิธกัก

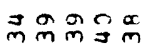
$\stackrel{\infty}{\infty} \stackrel{\infty}{\infty}$

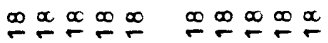

กำกัก

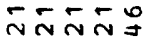

잉 in

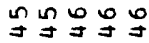

Jg0 000

ㅇํㄹำ $\stackrel{\infty}{\leftarrow} \stackrel{\infty}{\circ} \stackrel{\infty}{\leftarrow} \stackrel{\infty}{\leftarrow}$

ㄷำ

든

FE:

ำF
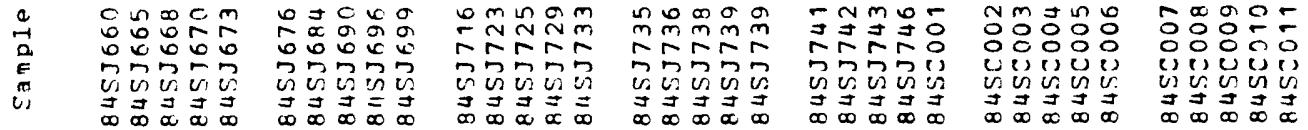

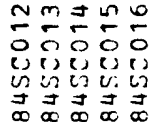

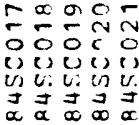




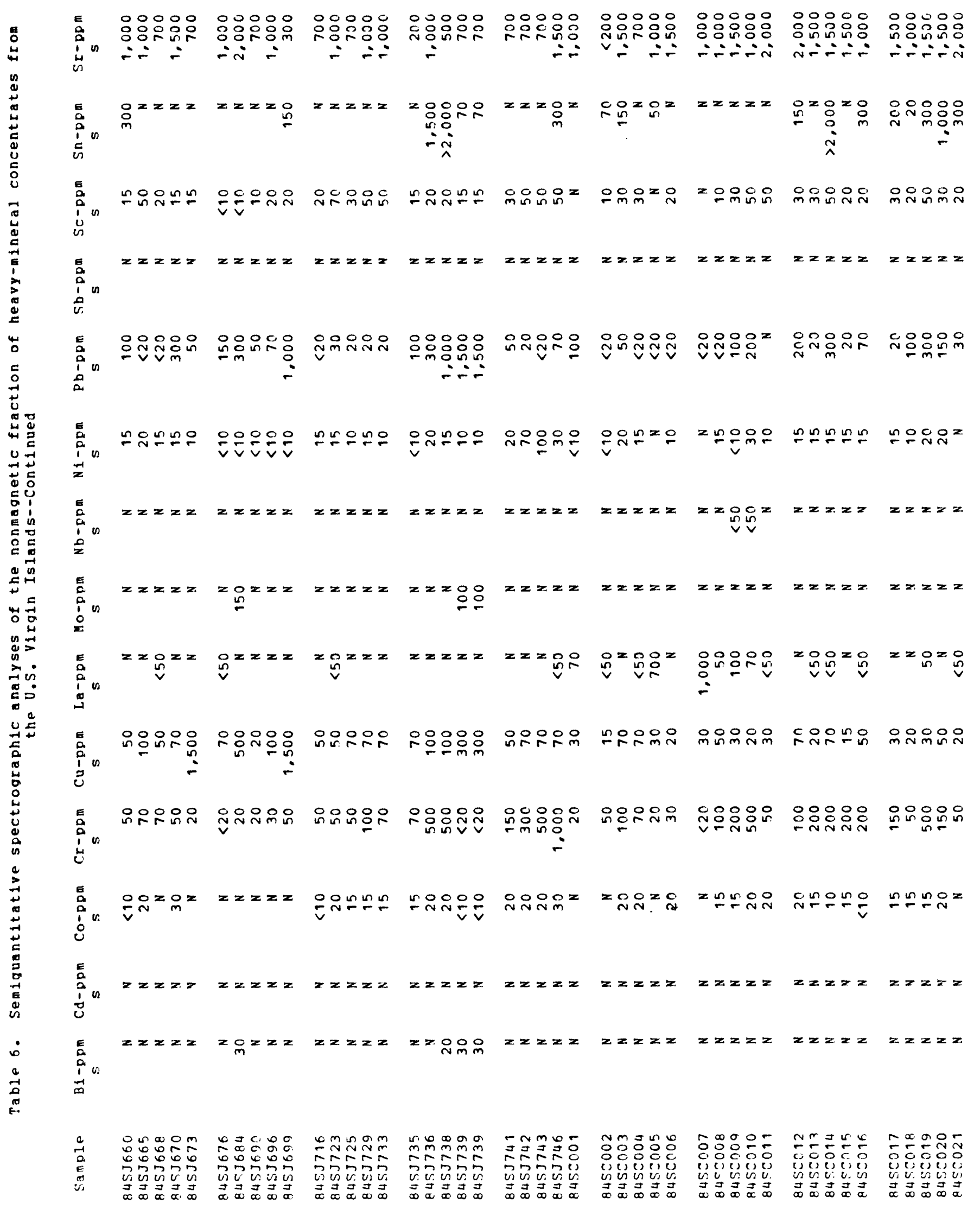




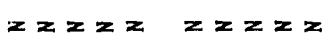

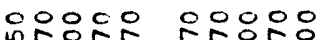
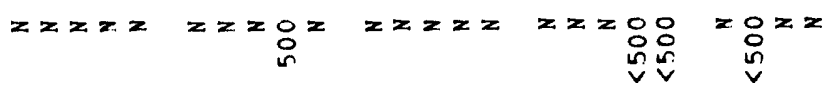

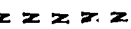

E

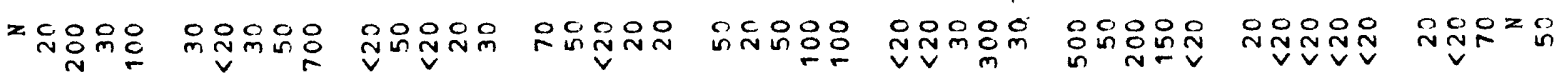

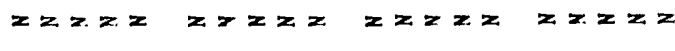

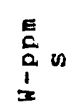

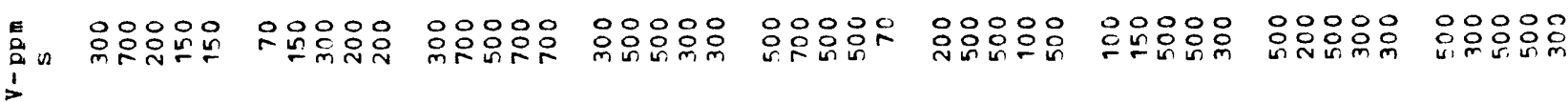

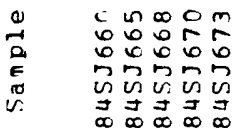

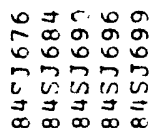

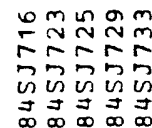

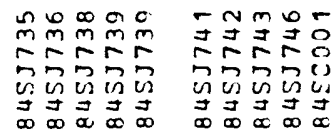

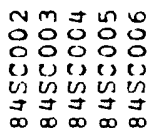
S용을

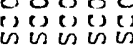

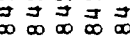

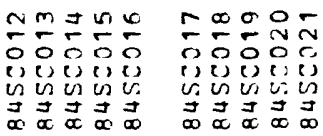




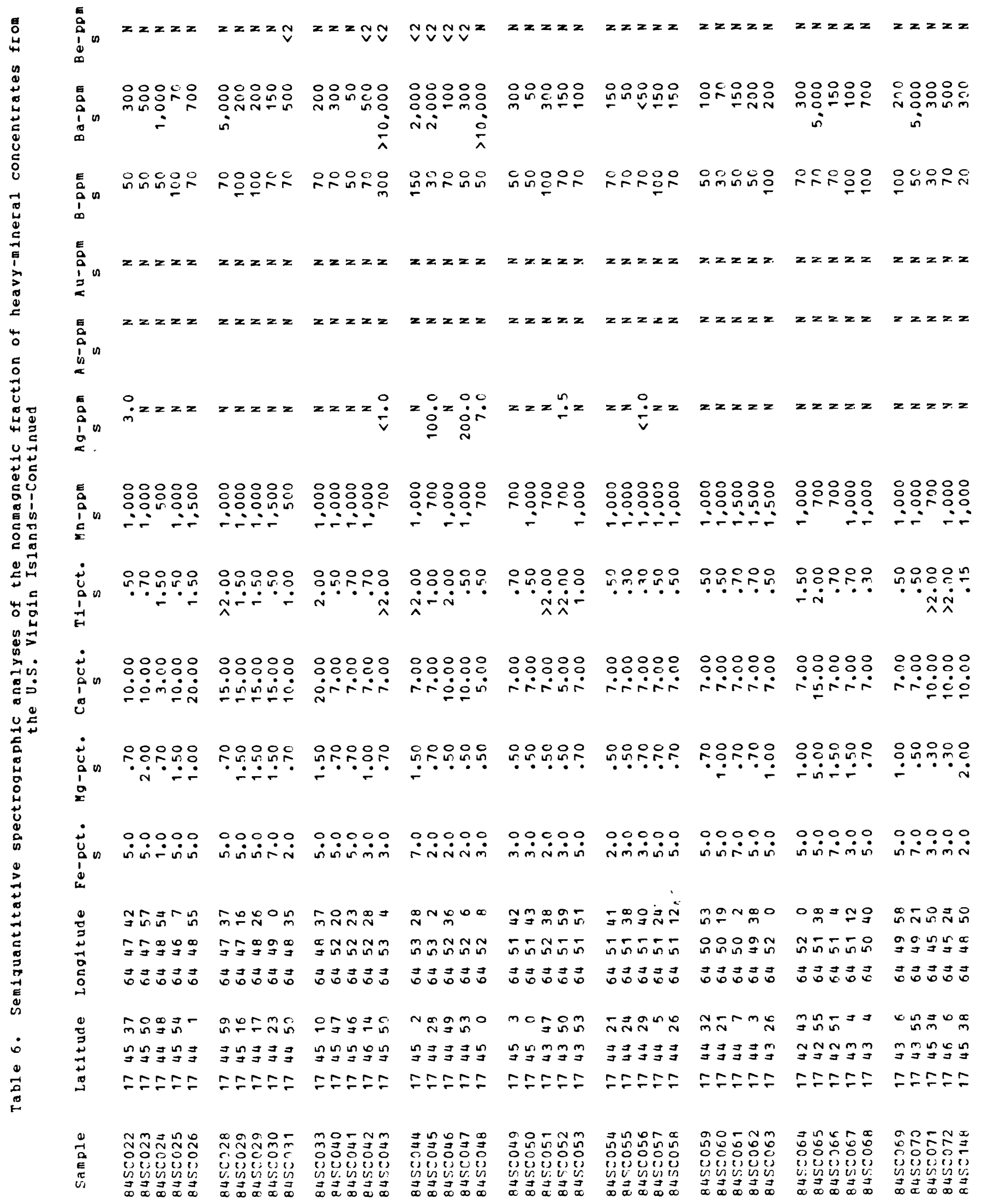




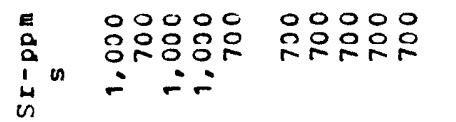

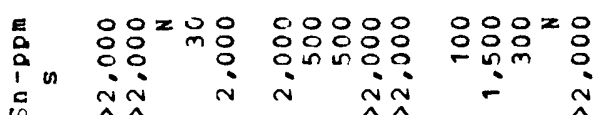

$E$
$c$
0
0
0

E

E $z=z z$

䈍

: $\vec{z}$

E

$z z z z$

$z z=$

$\therefore \div$

iñ-

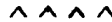

으무숭요

응음응응

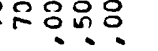

$\therefore \therefore$

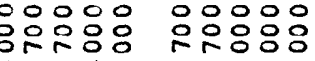

$\therefore$

응응응

응요

$\because=$

응웅으웅요

in

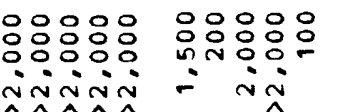

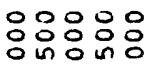

in

옹ㅇㅇㅇㅇㅈ

1
$i$
$\vdots$
0
0

등응으

잉요

i

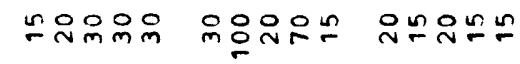

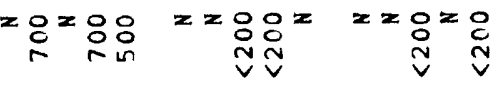

$z=2 x=2 x g_{i n}$

$2 z 2 z 2$

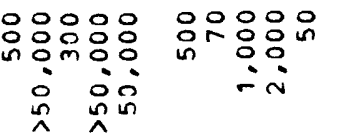

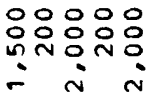

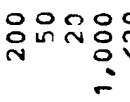

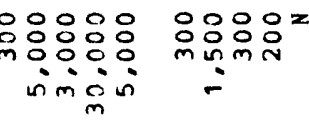

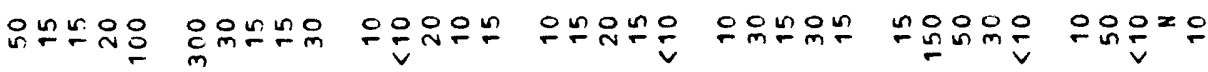

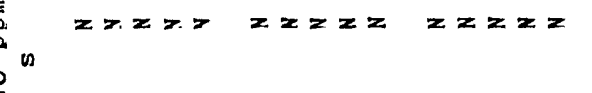

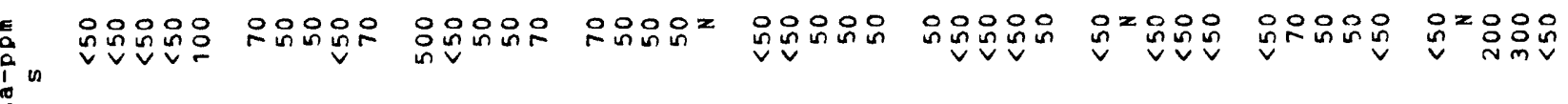

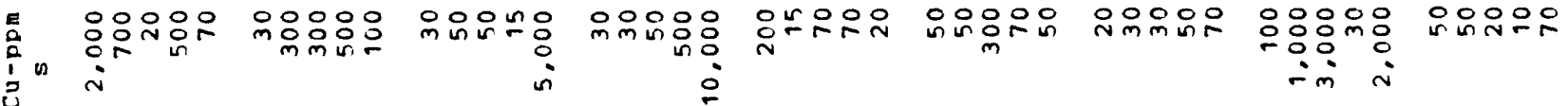

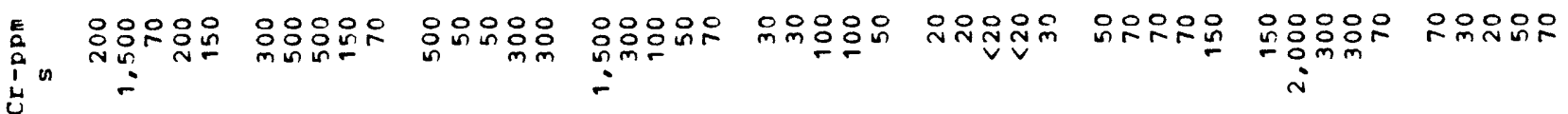

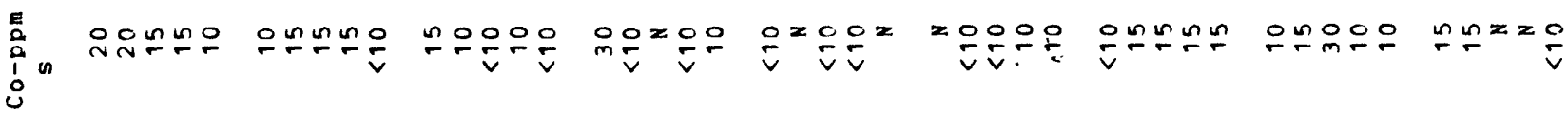
否

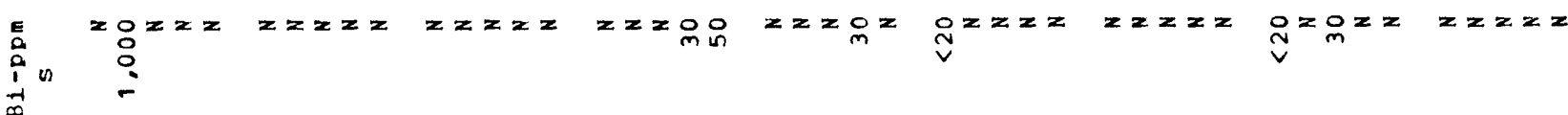

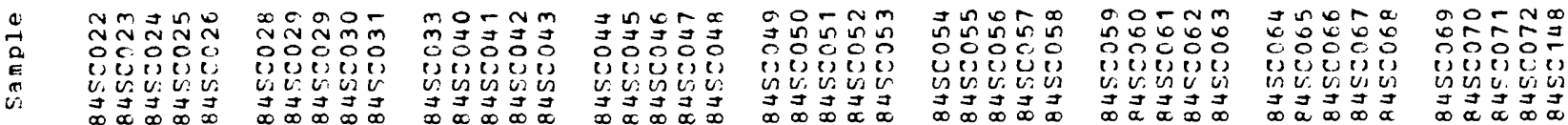




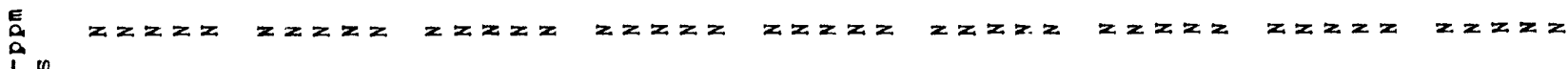
E

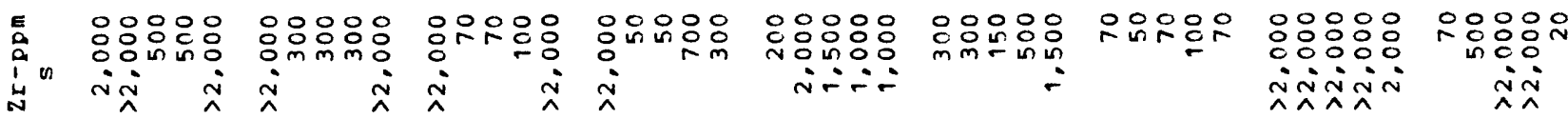

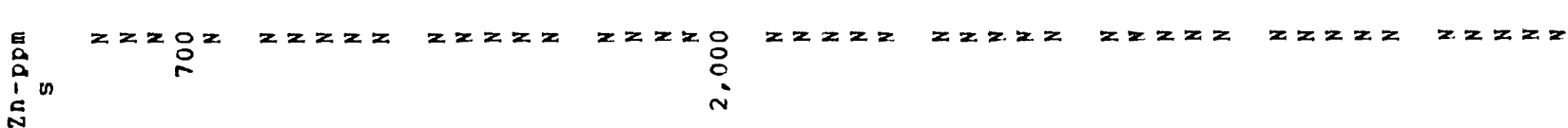

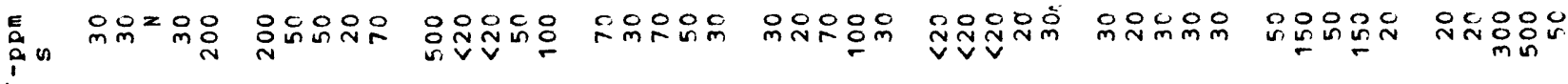
E

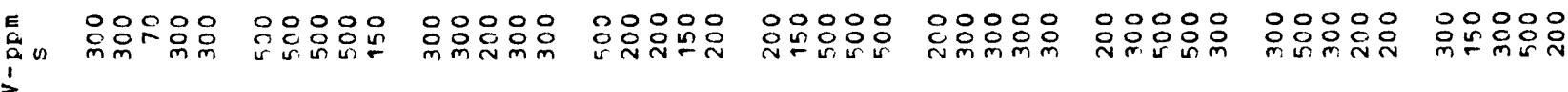

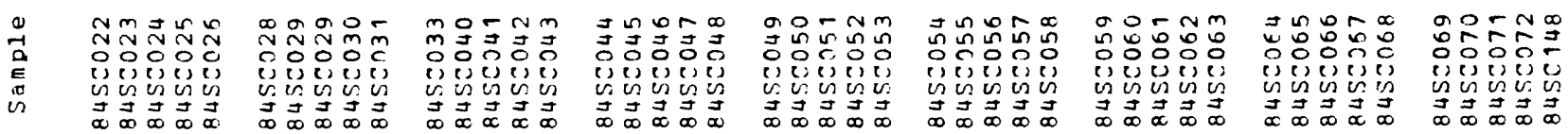




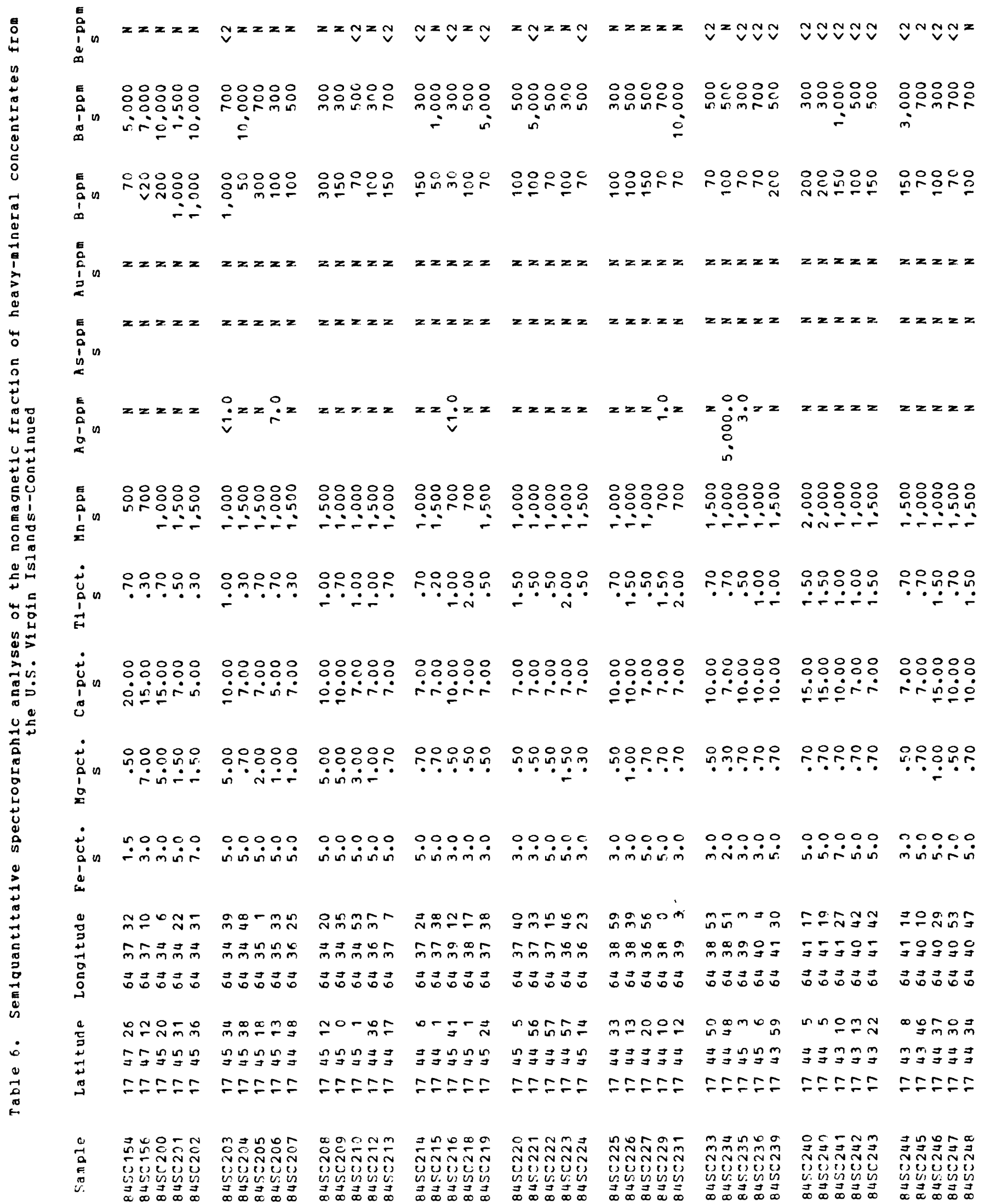




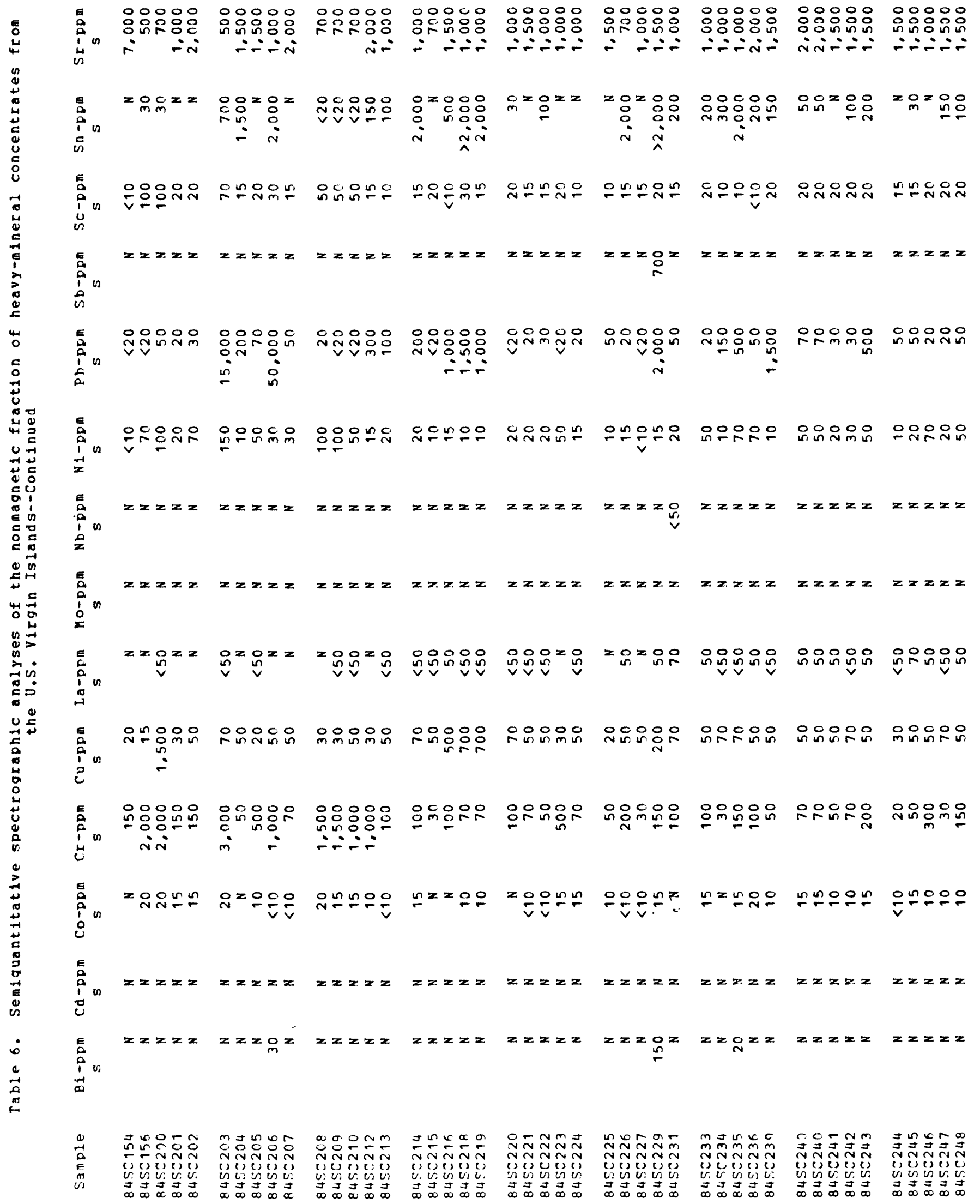




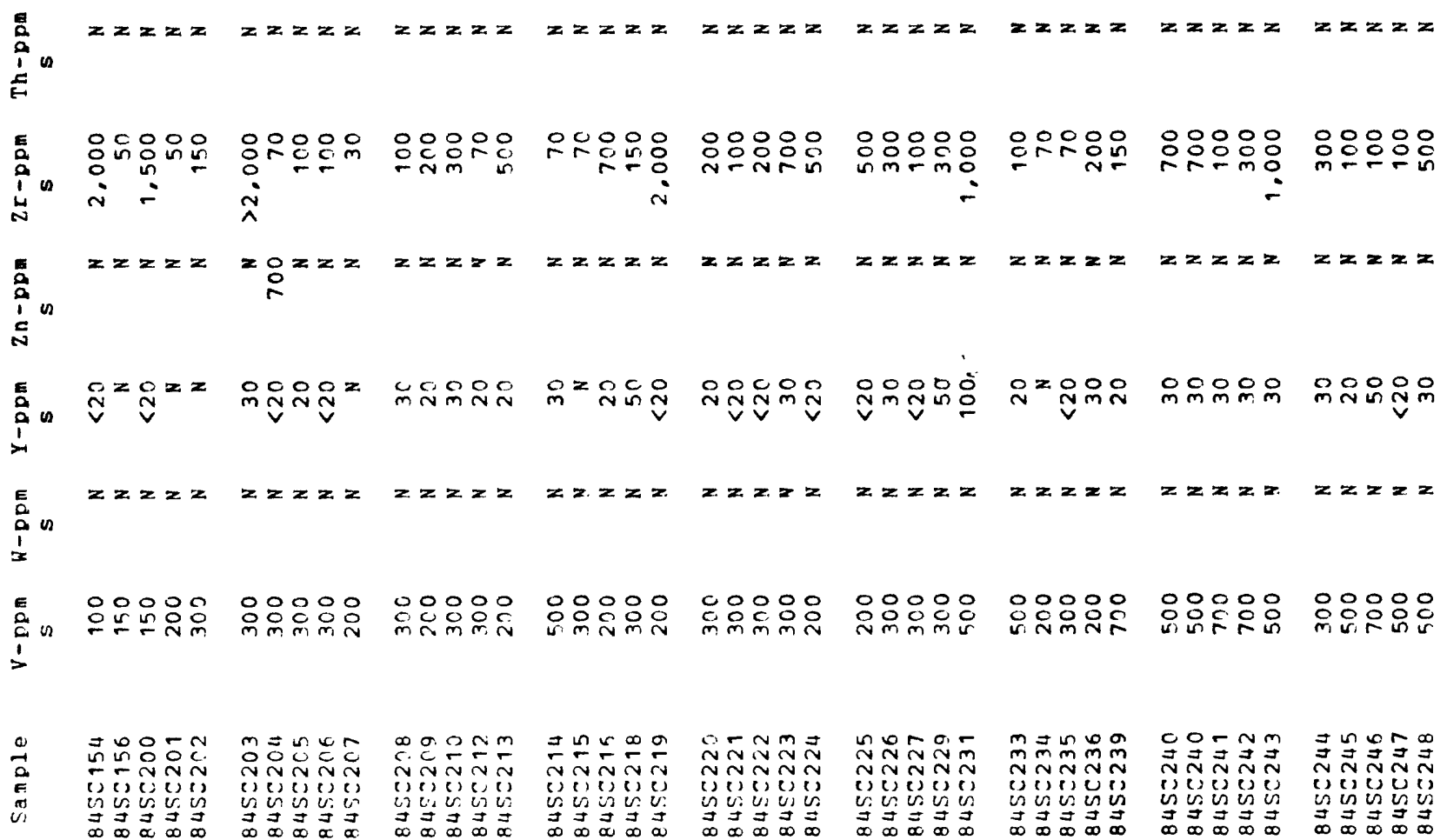




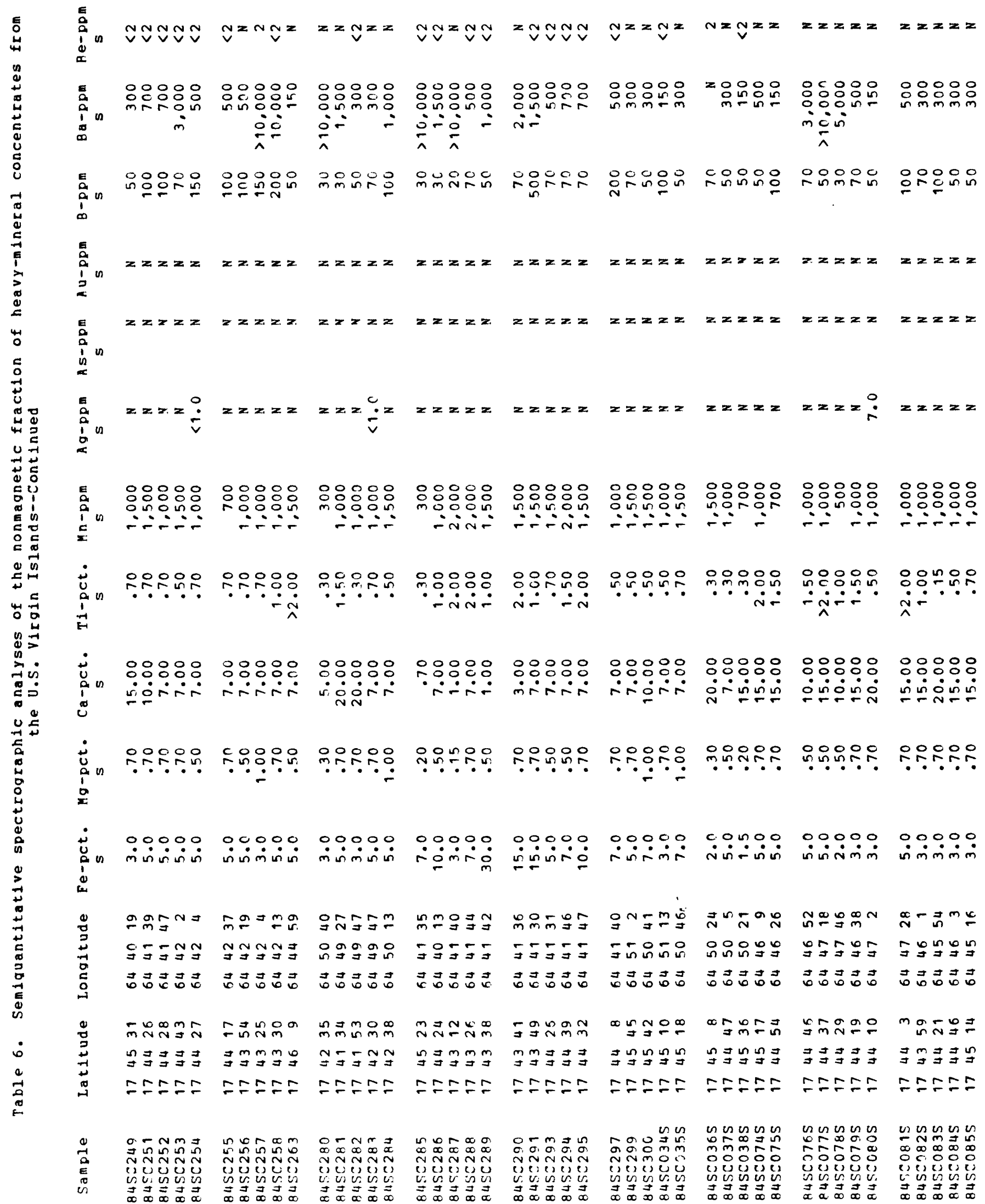




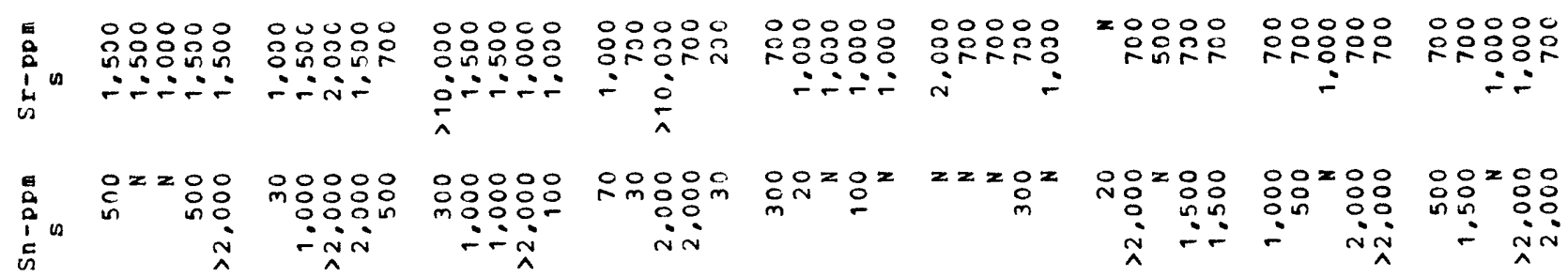

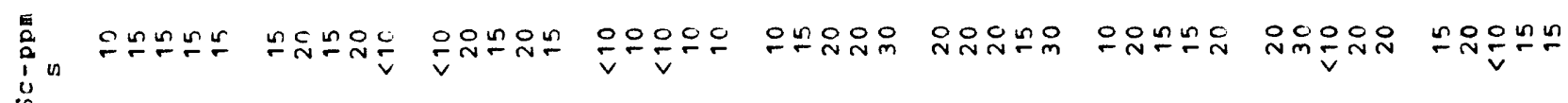

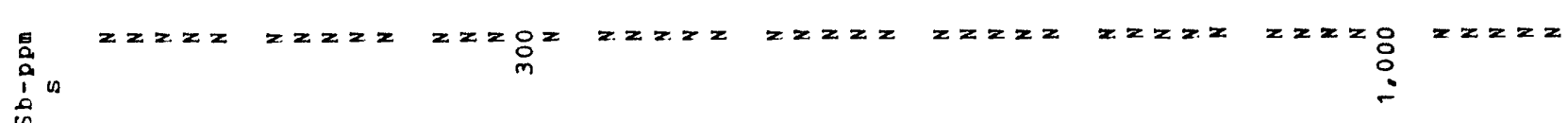

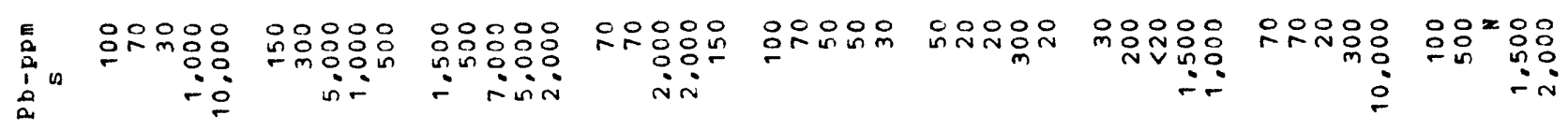

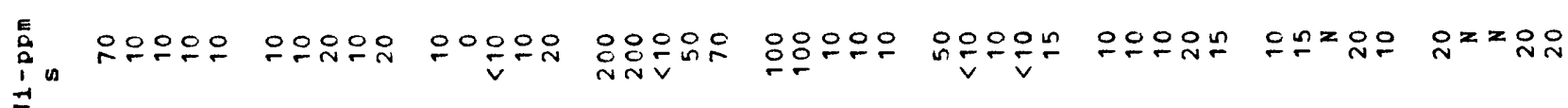

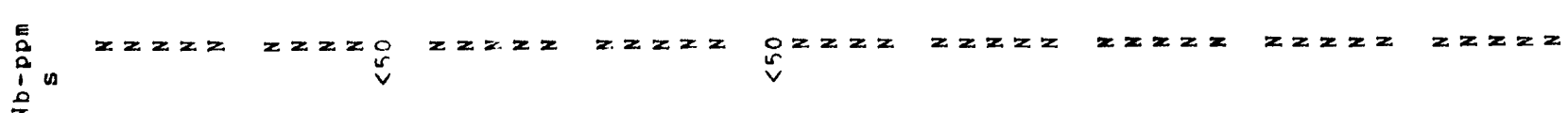

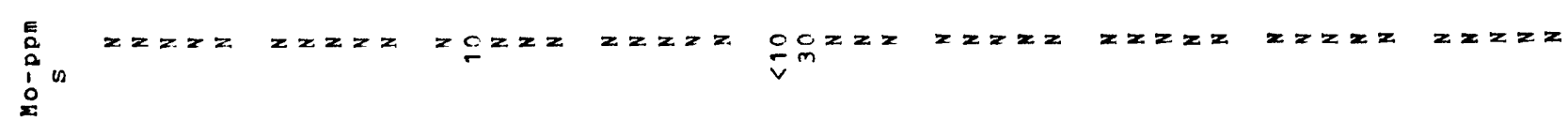

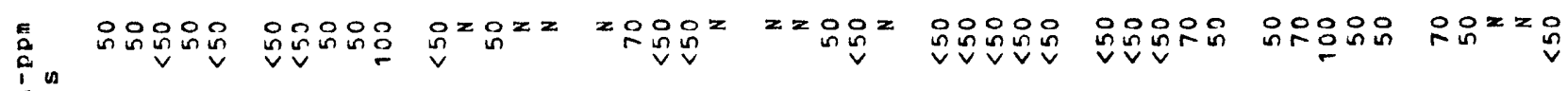
$\stackrel{\text { m }}{\rightarrow+1}$

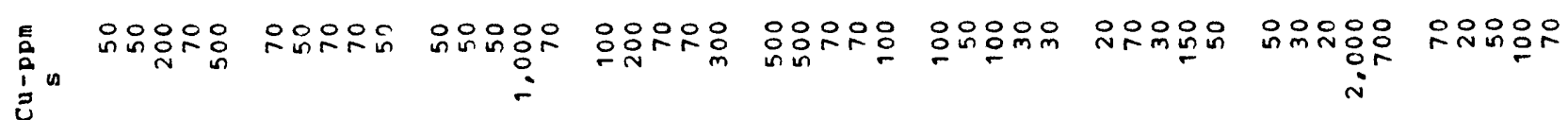

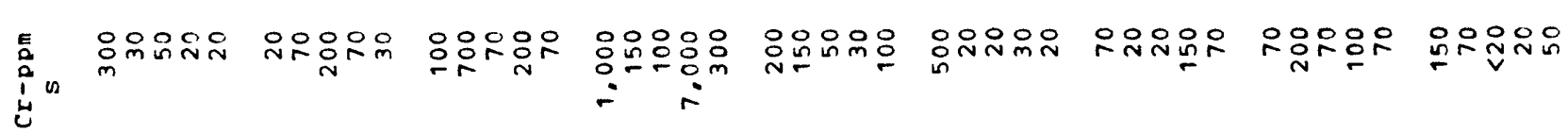

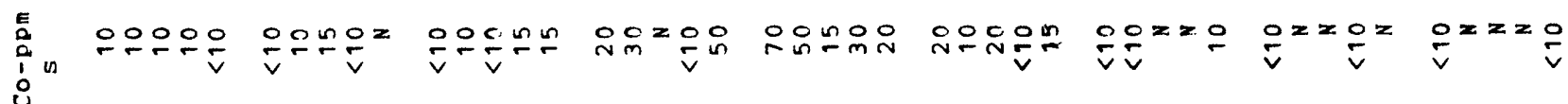

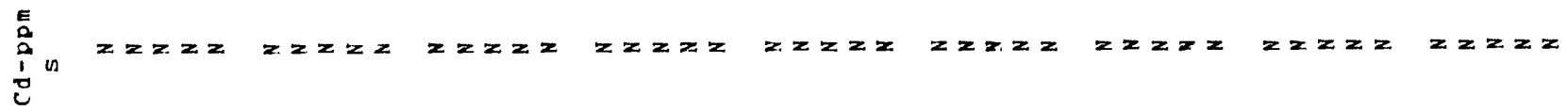

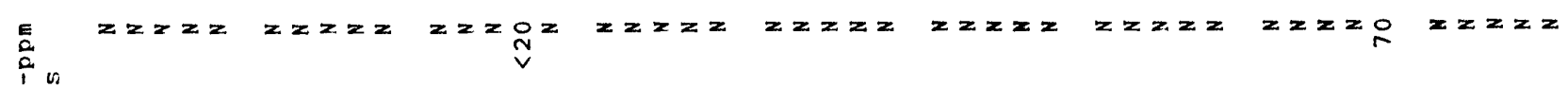
$\vec{x}$

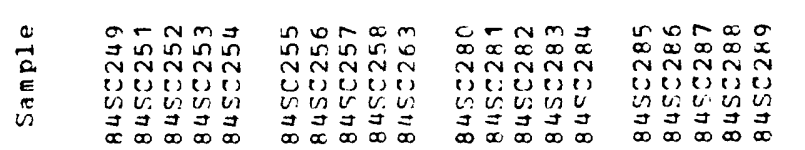

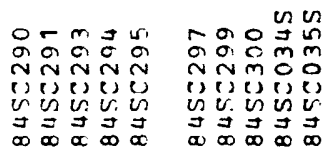

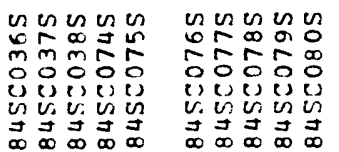

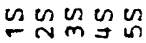
$\infty \infty \infty \infty$

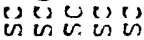

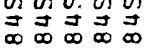




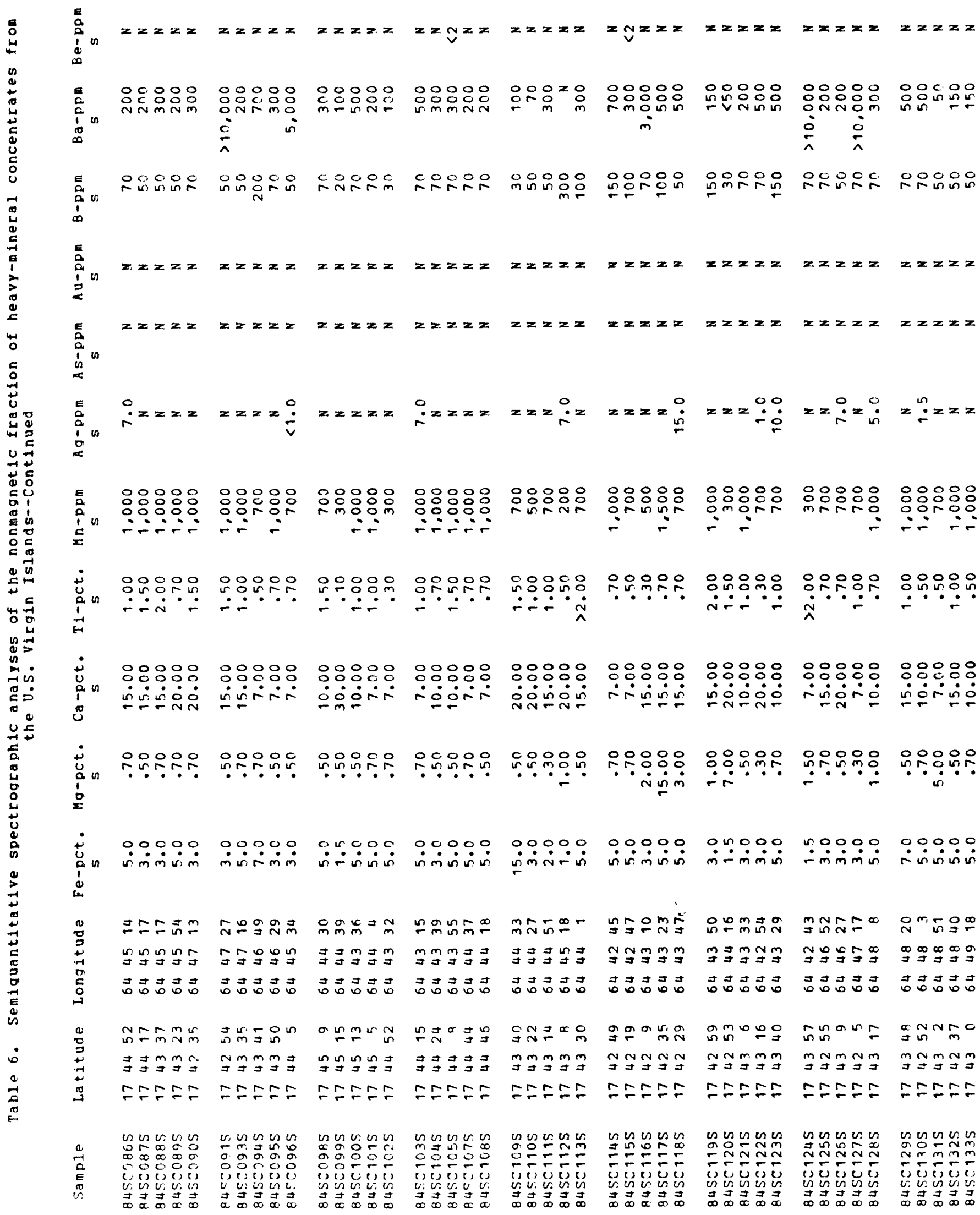




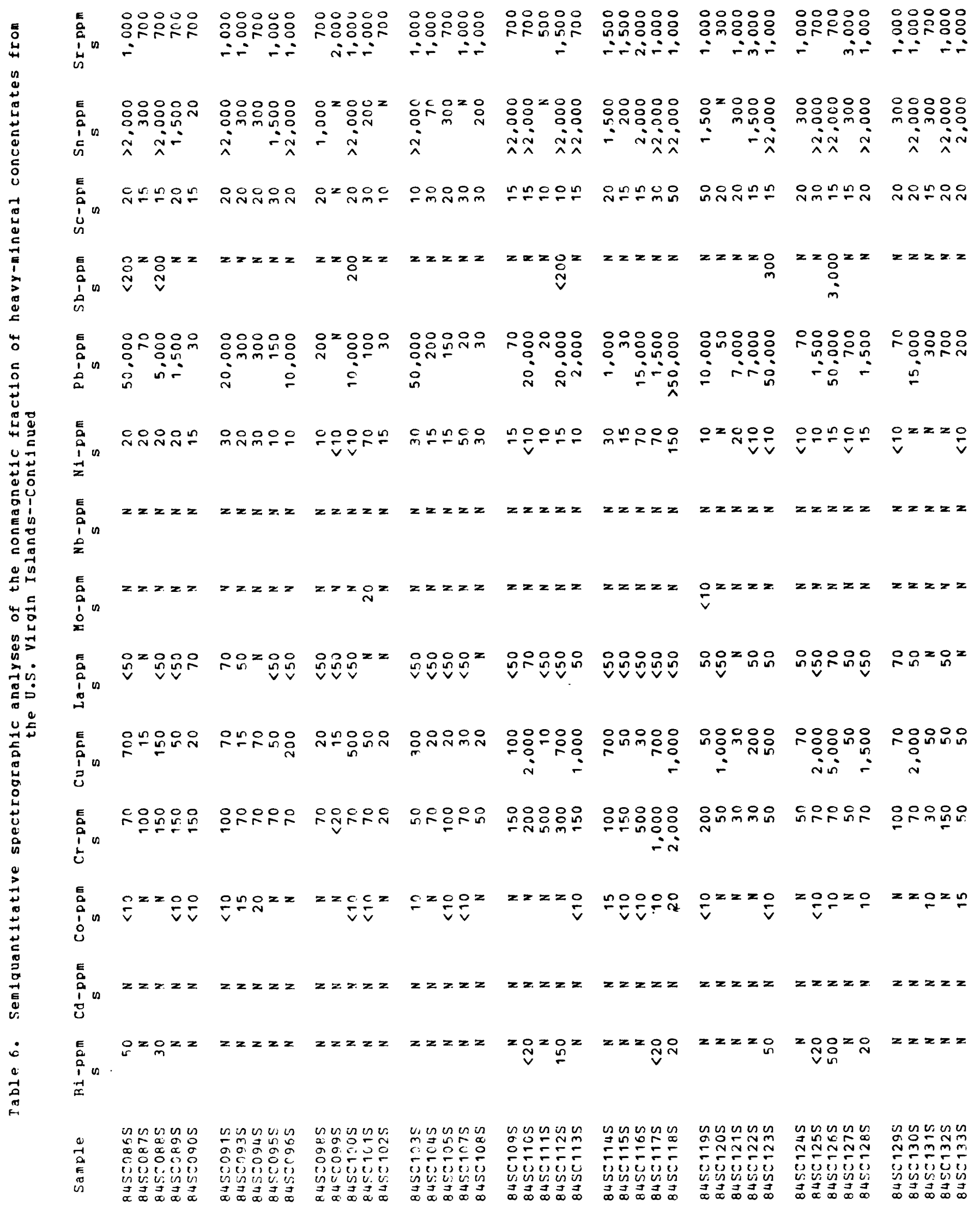


E⿱ ti

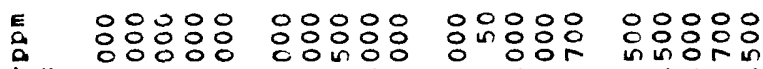

in ninininininin i

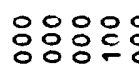

융융ㅇㅇㅇㅇㅇ

ini i

ninin

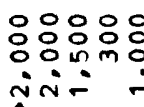

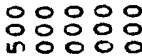

nin:- ininin

응ㅇㅇㅇ

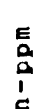

$z z z z$

$z z z z=\quad z z z z$

$z z z z$

$z z z z$

$z \geq z=x$

$\begin{array}{ll}: z z z z & z: z z z \\ \vdots & 0 \\ \dot{j} & \dot{m}\end{array}$

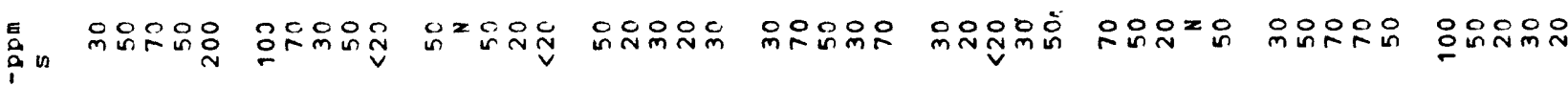

E⿱
$\vdots$
$\vdots$
$\vdots$

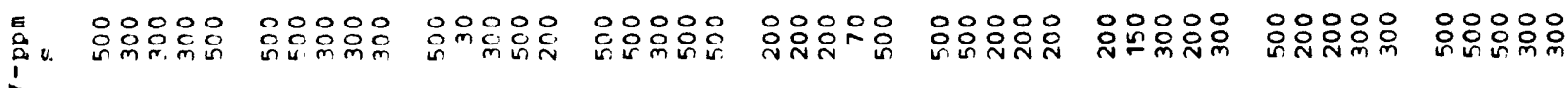

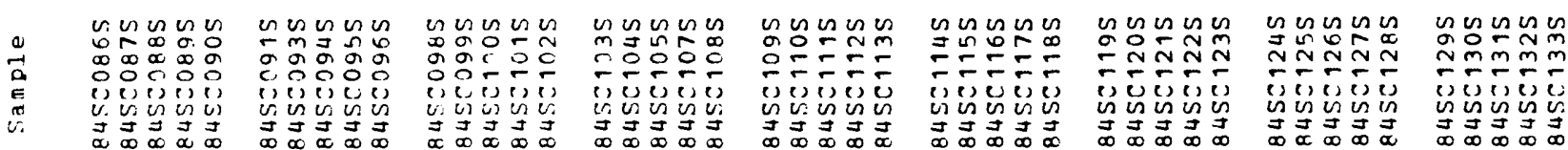




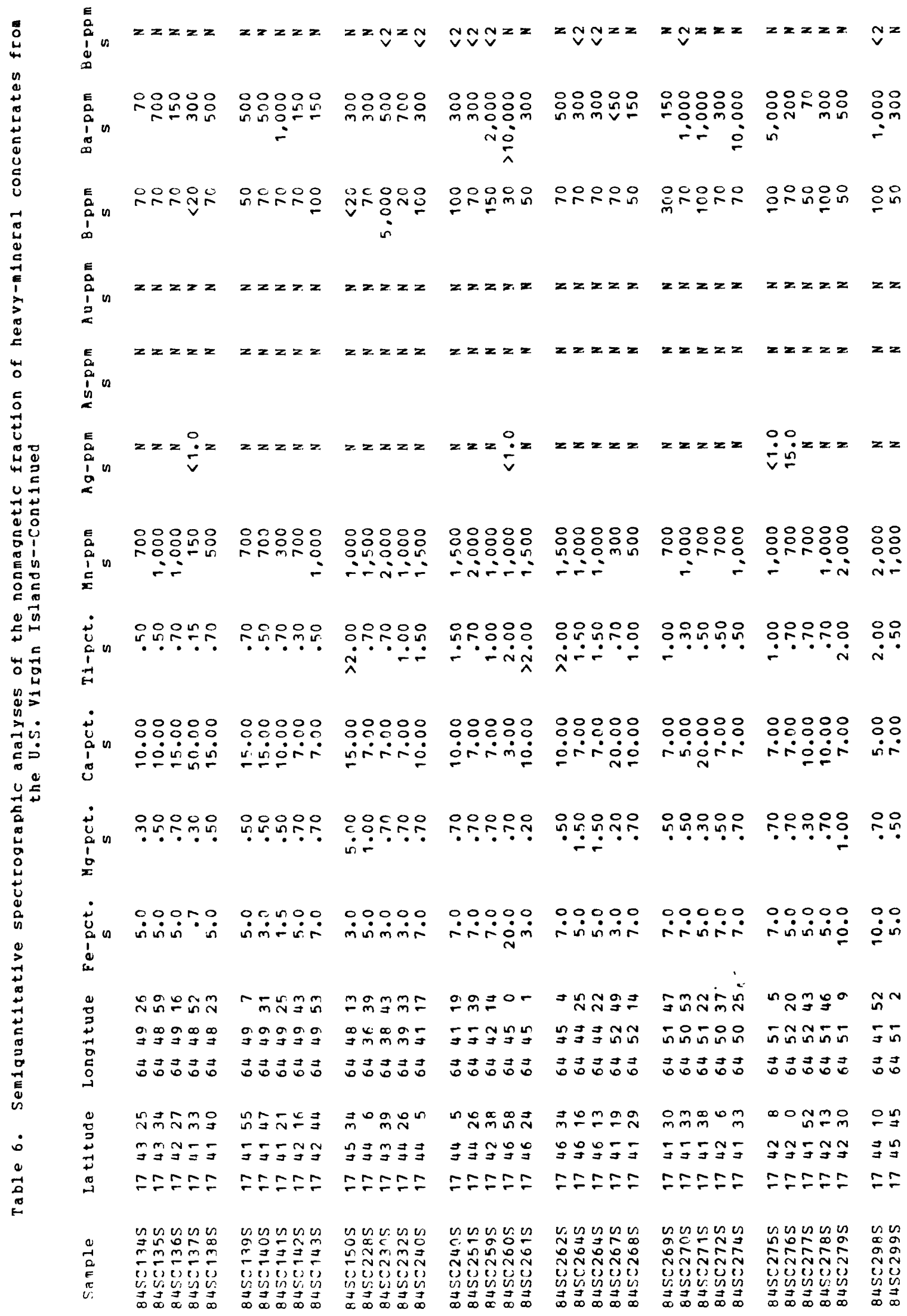




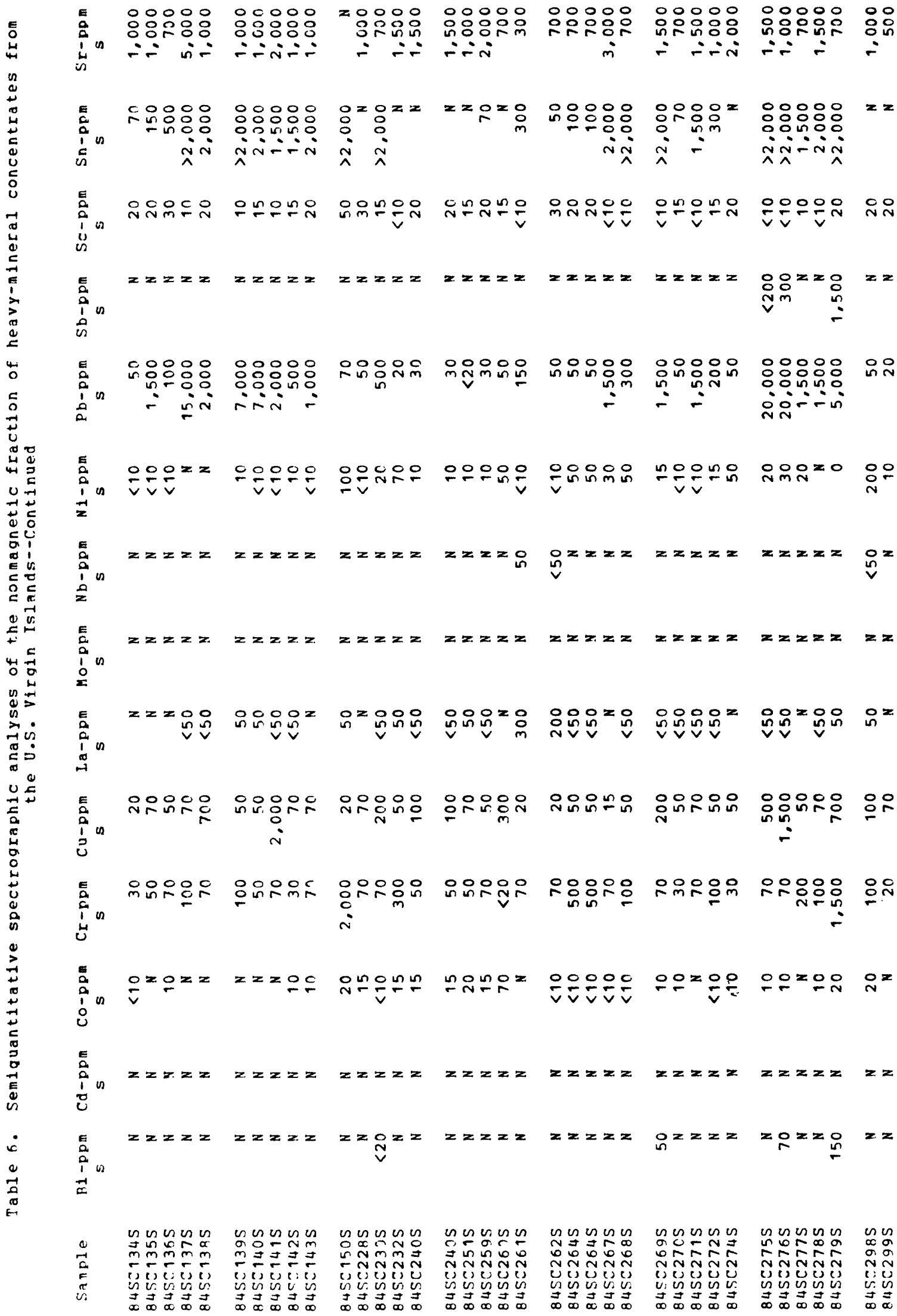




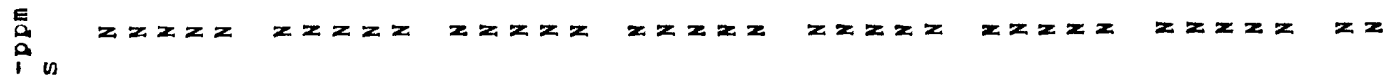
$\sum_{\mathrm{H}}$
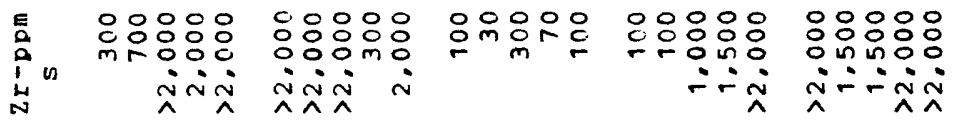

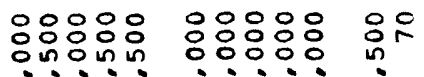
inis NiñN

$z z z z z$ zzzz zzzzy zzzzy zzzzz

点电

宓

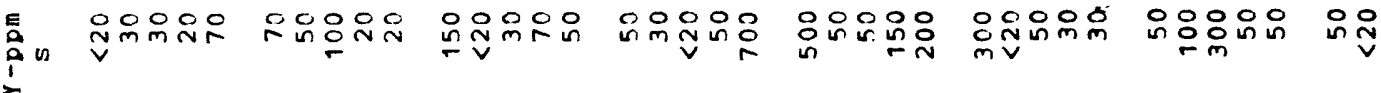
$\overbrace{0}^{1}$ $z z z z z z z z z=z z z$

$z z z z z$

$z z z z$

$z z z z=$

$z z z z z \quad z z$

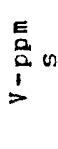

$\circ 000$

은응웅응으 응웅융응

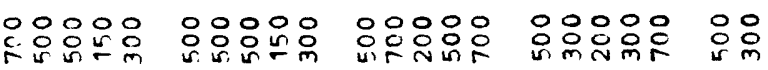

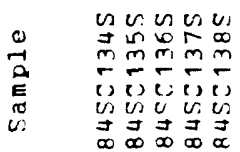

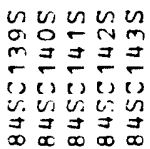

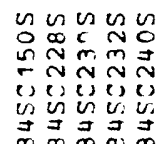

$\cos 2 \cos 2$

$\vec{\sim} \cong \stackrel{0}{\sim}$

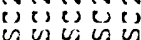

$\exists \exists \exists \exists \exists$

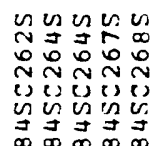

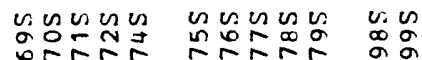

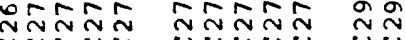

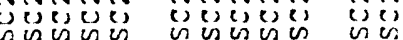

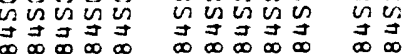




\section{a}

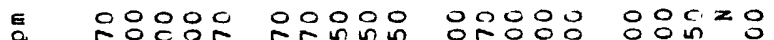
$\frac{1}{2}$ a

E⿱艹 $\stackrel{1}{c}$

$\frac{E}{a}$

E $\quad z=z z$

in

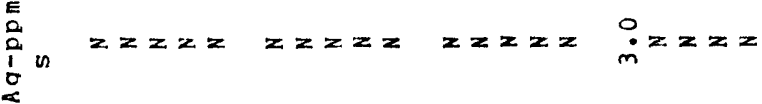

E $\quad \circ \circ 000$

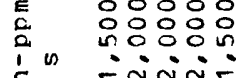

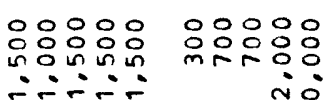

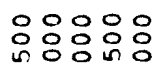

$\therefore \dot{i}=m$

$z$

-

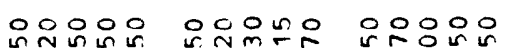

$\underset{u}{0}$

$\operatorname{lin}$

$\stackrel{1}{2}$

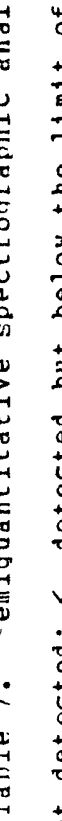

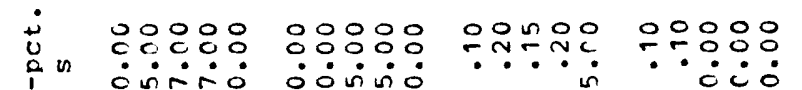
둥

0.0000

수요

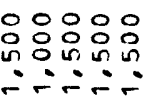

응응ㅇㅇㅇㅇㅇㅇ $\therefore \therefore$ in

응웅응응요 min:-

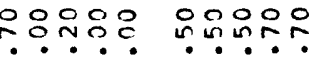

8

는?

농응

$\dot{n} \dot{\sim}$

in 융으의 o

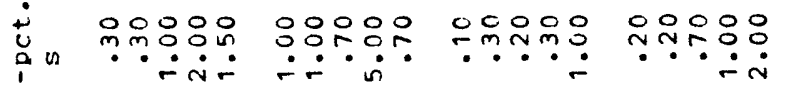

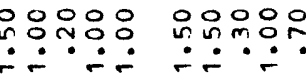

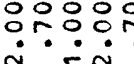

2

$\ln \ln \pi$

范

is

$\stackrel{2}{2}$

ヨココゴ

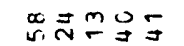

araner

c잉ㅇㅇㅇㅛ

웅으운

능ㅇㅇㅇㅠ

nroc

nror

nom $n$

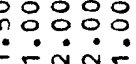

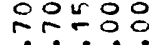

กำกำก

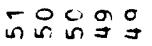

N $\underset{\sim}{ } \vec{m}$ in

กㄹํ $\stackrel{\infty}{\sim} \vec{m}$

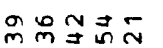

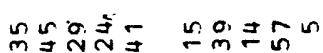

- $\infty$ 을

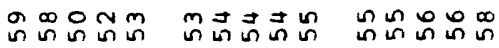

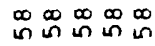

$\overrightarrow{0} \overrightarrow{0} \overrightarrow{0} \overrightarrow{0} \overrightarrow{0}$

$\vec{c} \overrightarrow{0} \overrightarrow{0} \overrightarrow{0} \overrightarrow{0}$

in $\sin$ in

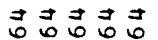

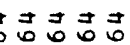

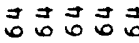

$0, \infty \alpha m$

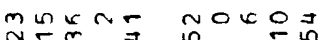

$\stackrel{m}{\sim} \stackrel{0}{\sim} \stackrel{\infty}{=}$

กะกำ

Nึr $\operatorname{m}_{m}-r$

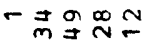

유섯유으

유요

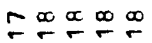

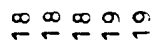

กㅇํ원

กีก

Nลก

$\infty \infty \infty \infty$

$\stackrel{\infty}{\infty} \stackrel{\infty}{\sim} \stackrel{\infty}{\sim} \stackrel{\infty}{\sim} \stackrel{\infty}{\sim} \stackrel{\infty}{\sim}$

$\infty \stackrel{\infty}{\leftarrow \infty}$

$\stackrel{\infty}{\sim} \stackrel{\infty}{\infty} \stackrel{\infty}{\sim}$

$\stackrel{\infty}{\infty} \stackrel{\infty}{\infty}$

$\stackrel{\infty}{-\infty} \stackrel{\infty}{-} \stackrel{\infty}{-}$

$0 \sin \frac{\pi}{2}$ N $\stackrel{m}{\sim} \vec{N}$

Nin

$\infty \infty \infty \infty$

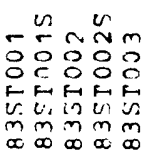

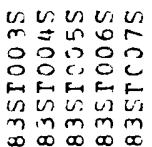

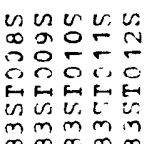

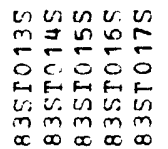

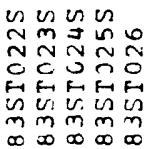

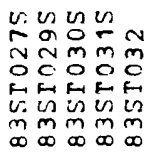

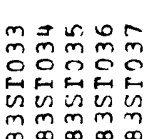

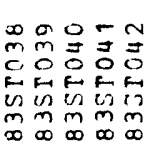

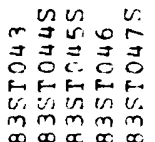




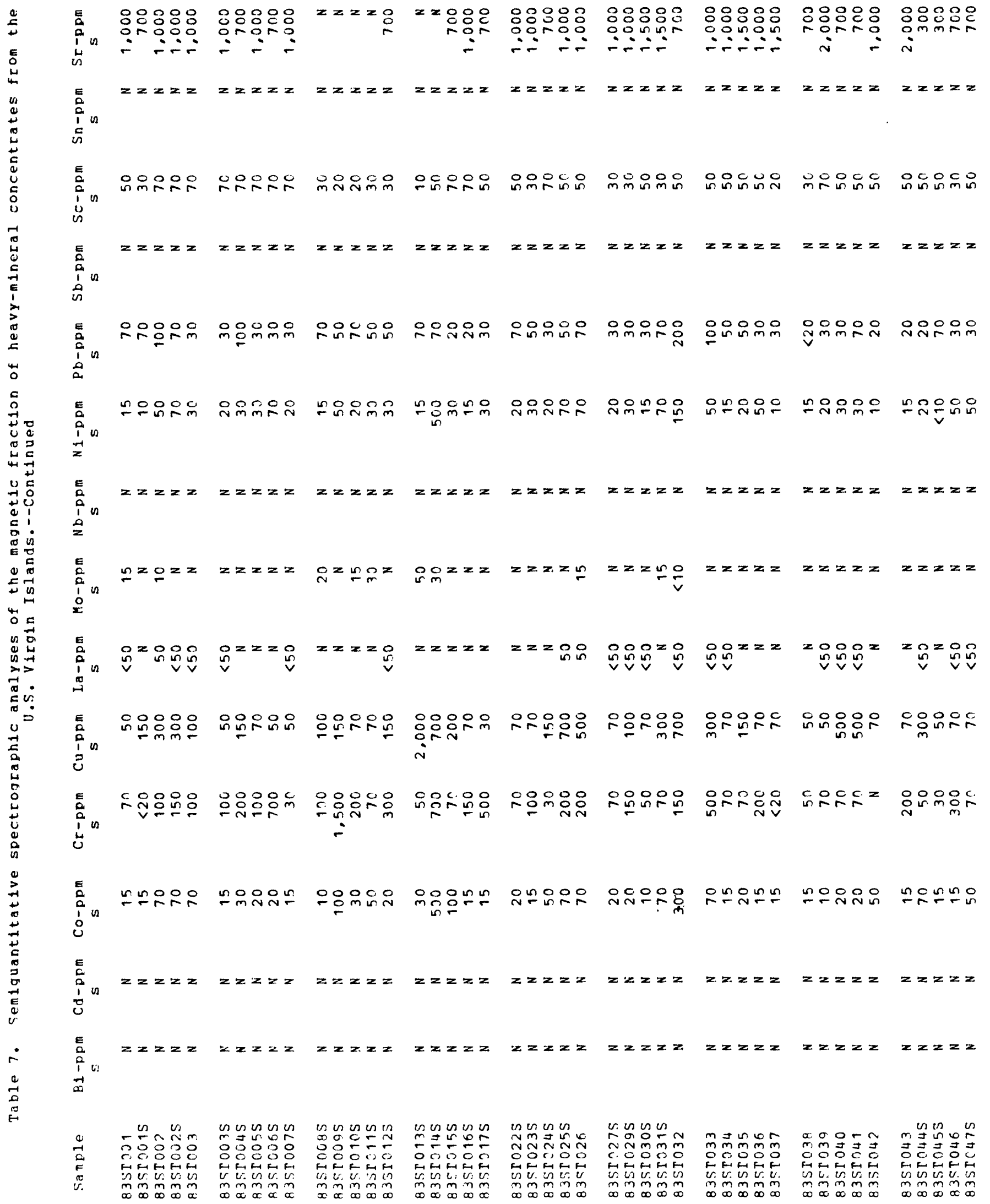




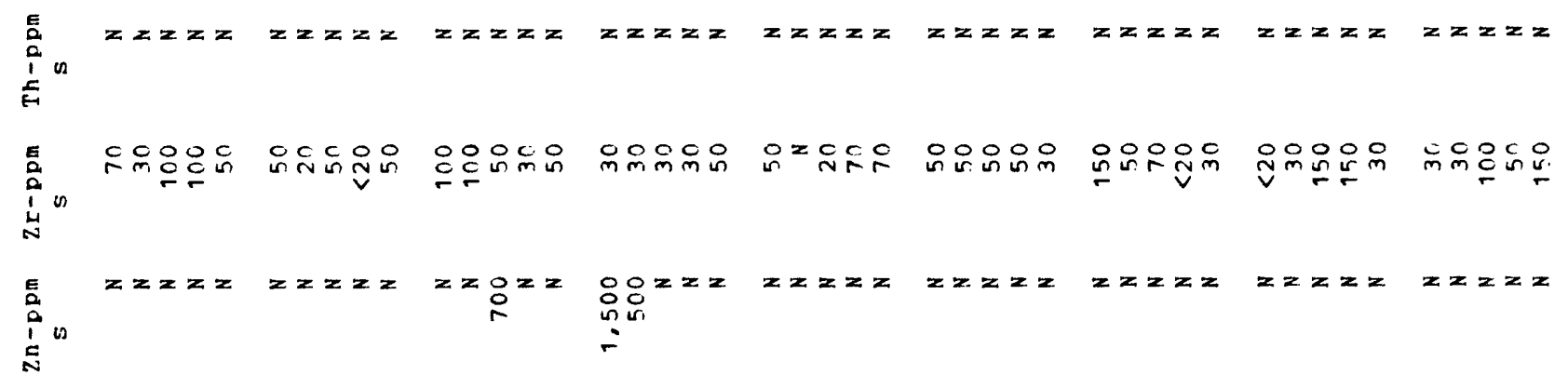

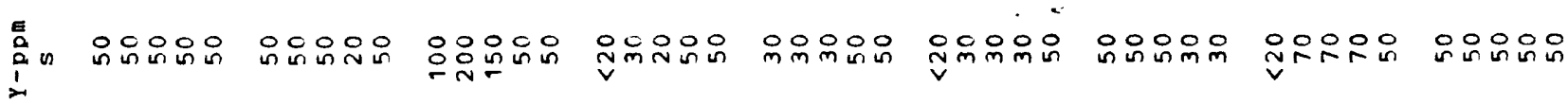

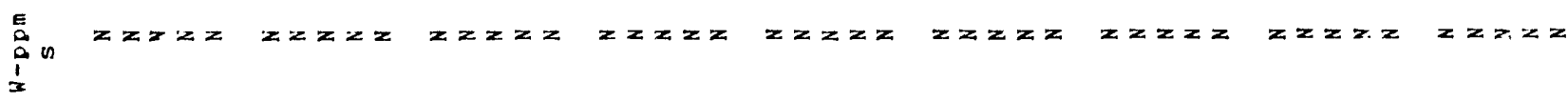

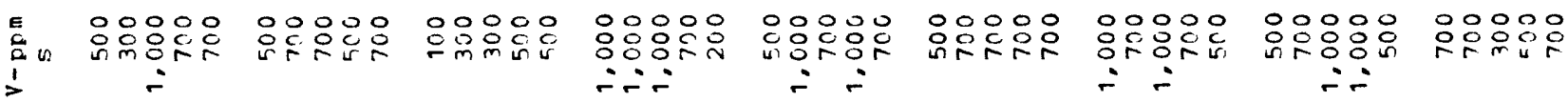

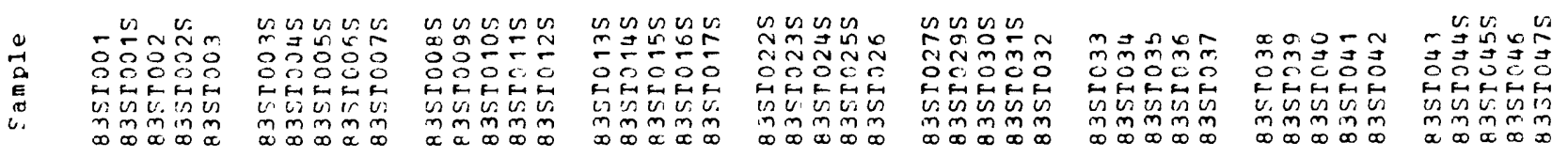




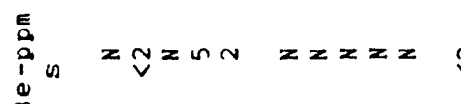

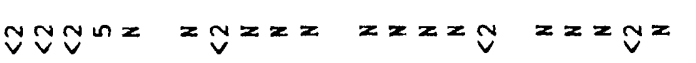

$z=2 x$

$\mathbb{V} z z=2 z=2 z$

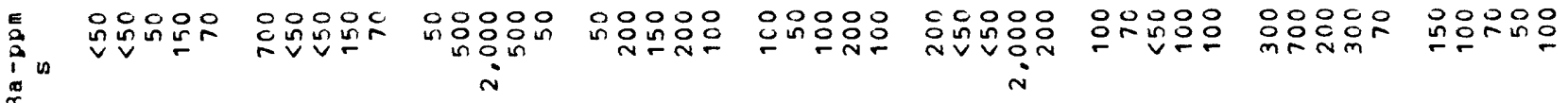

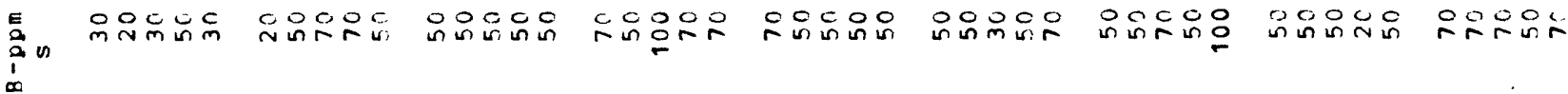

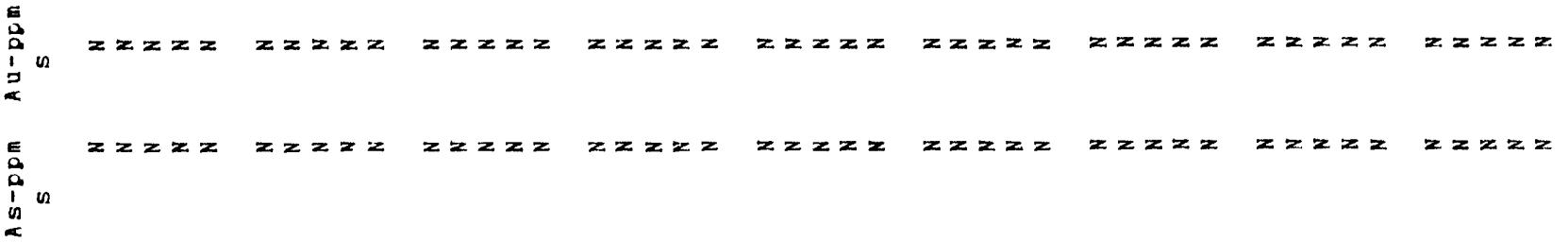

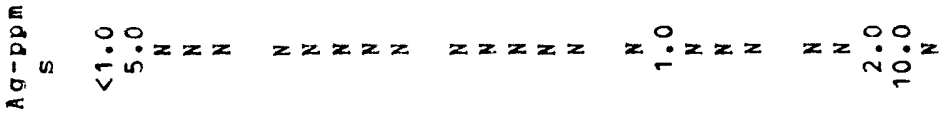

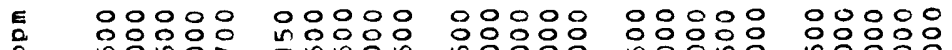

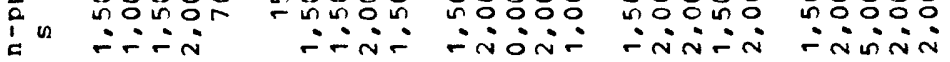

응융ㅇㅇ

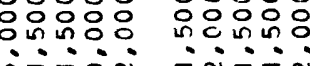

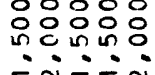
응융ㅇㅇ inisin

$ㅇ ㅇ ㅇ ㅇ ㅇ ㅇ$ $\therefore$ त ininis

i 00000 00000 00000 00000 00000 $\stackrel{0}{0}$ $\because \dot{\sim} \dot{n}$

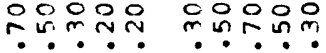

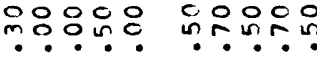

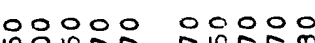

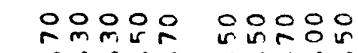

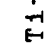
$\dot{n+1}$ $\dot{n}$

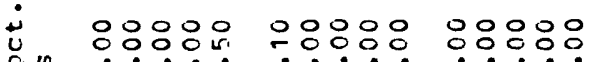

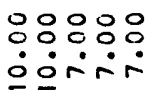

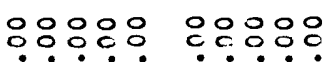

응ㅇㅇㅇ

rírír

rí⿺辶்

읃웅ㅇㅇㅇㅇㅇㅇ

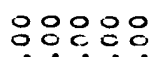

응웅응 i

范

00000

$\ln 0000$

웅ㅇㅇㅇㅇㅇ

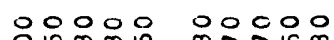

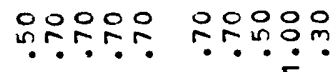

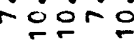

rírir

하iri

$\because \because$

분.

$\because \because \dot{m}$

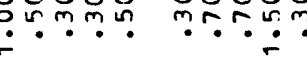

응요응용

웅ㅇㅇㅇㅇㅇ

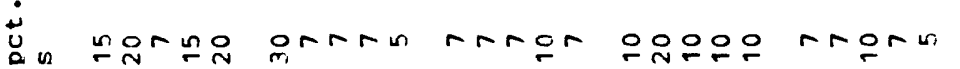

으웅요요

rorr

rro음

reorr

드은

ogago

กேきき゚n

กิำ

กำษั่ำ

ม

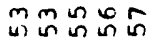

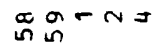

in $\mathrm{mmm}$

嗮的的

กำกำกำ

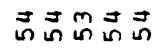

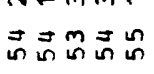

$-\infty m_{m}^{\infty} \sim$

$\operatorname{nnn} 2$

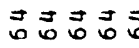

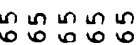

$\overrightarrow{0} \overrightarrow{0} \overrightarrow{0} \overrightarrow{0} \overrightarrow{0}$

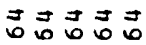

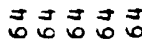

ज्ञै

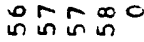

roor

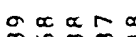

nos $\leq 0$

$m \sim a n s$

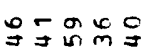

ำกำ

풍음

D는ำ

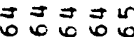

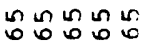

$\infty \propto ⿻ 上 丨$

뜌슈유

กกกำ

듀의

의무용

의뭉ㅇㅇㅇㅇ

유유스

$\underset{\sim}{2}=0$

$\stackrel{\infty}{\infty} \stackrel{\infty}{\infty} \stackrel{\infty}{=}$

$\stackrel{\infty}{\infty} \stackrel{\infty}{\infty} \stackrel{\infty}{=}$

$\stackrel{\infty}{\sim} \stackrel{\infty}{\leftarrow} \stackrel{\infty}{\sim} \stackrel{\infty}{\leftarrow} \stackrel{\infty}{\div} \stackrel{\infty}{\leftarrow}$

$\infty \stackrel{\infty}{\infty} \infty$

$\stackrel{\infty}{\infty} \stackrel{\infty}{-} \stackrel{\infty}{-}$

$\stackrel{\infty}{\infty} \stackrel{\infty}{\infty} \stackrel{\infty}{=}$

anne-

กักำก

wor

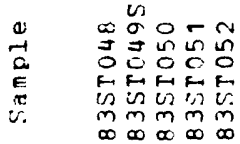

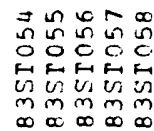

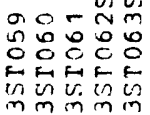

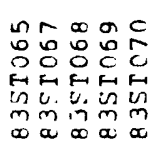

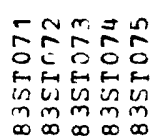

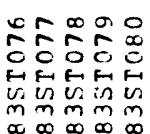

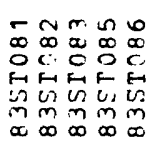

$\infty \infty \infty \infty$

$\stackrel{\infty}{\infty} \propto \infty$ 


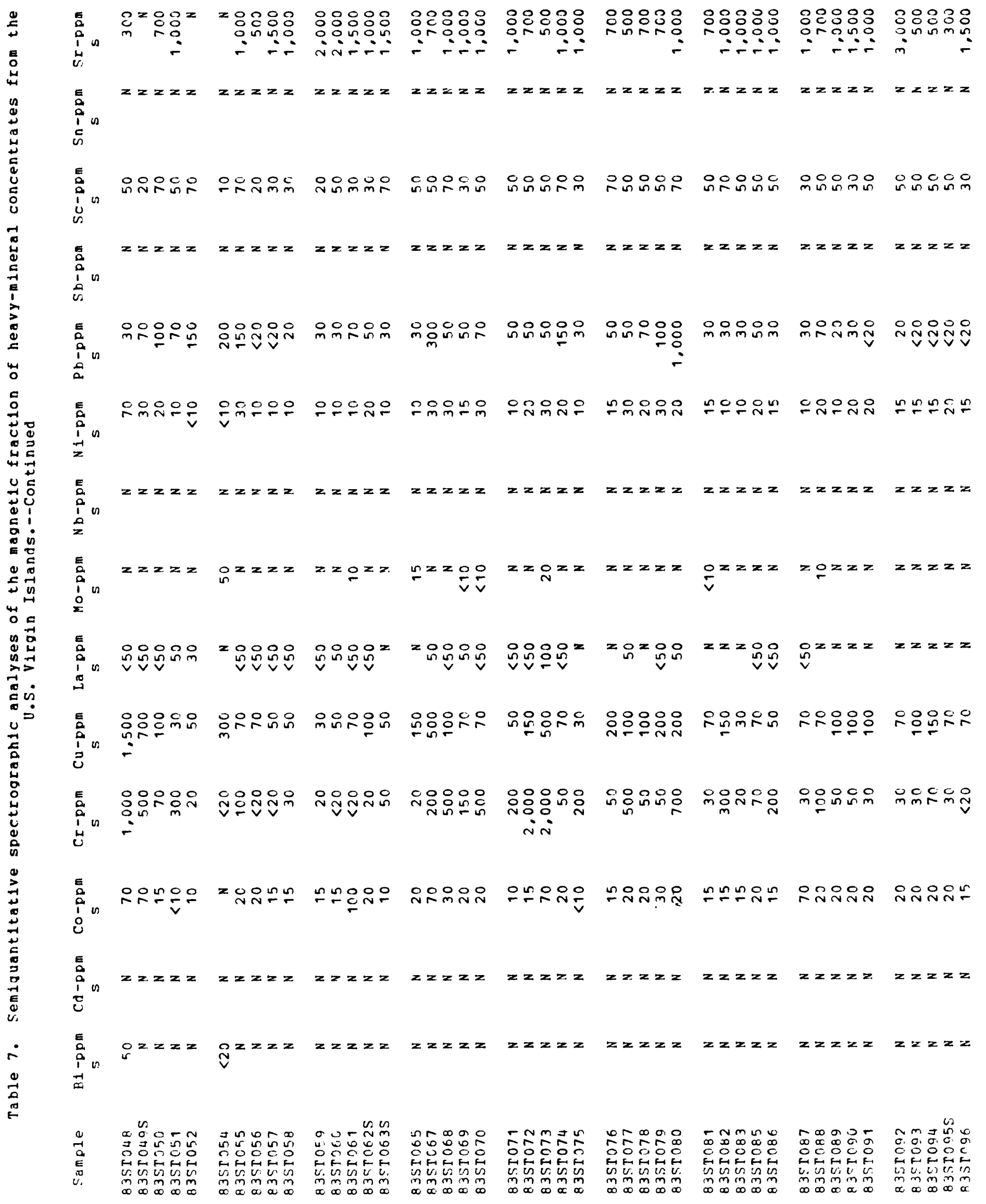




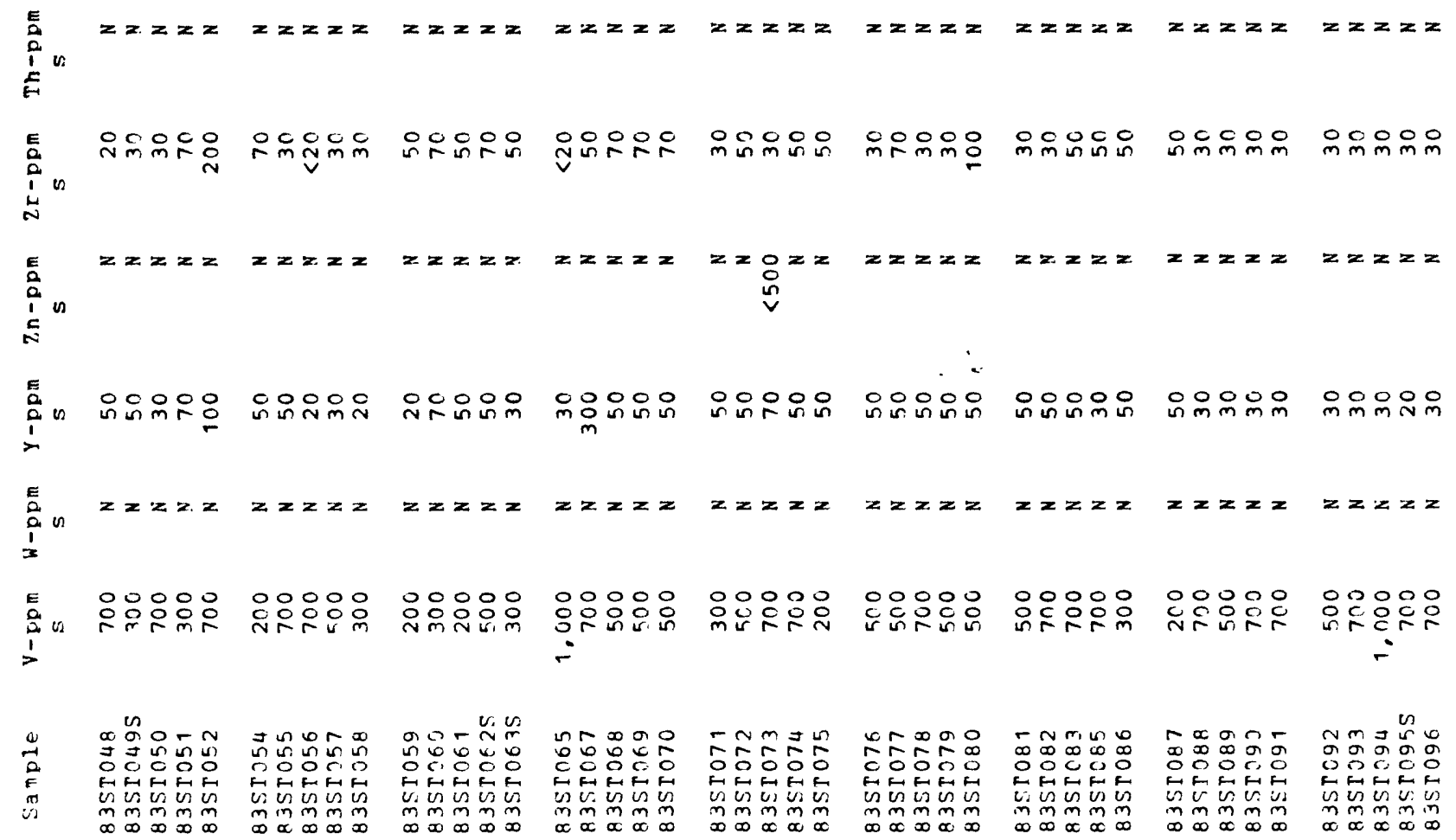




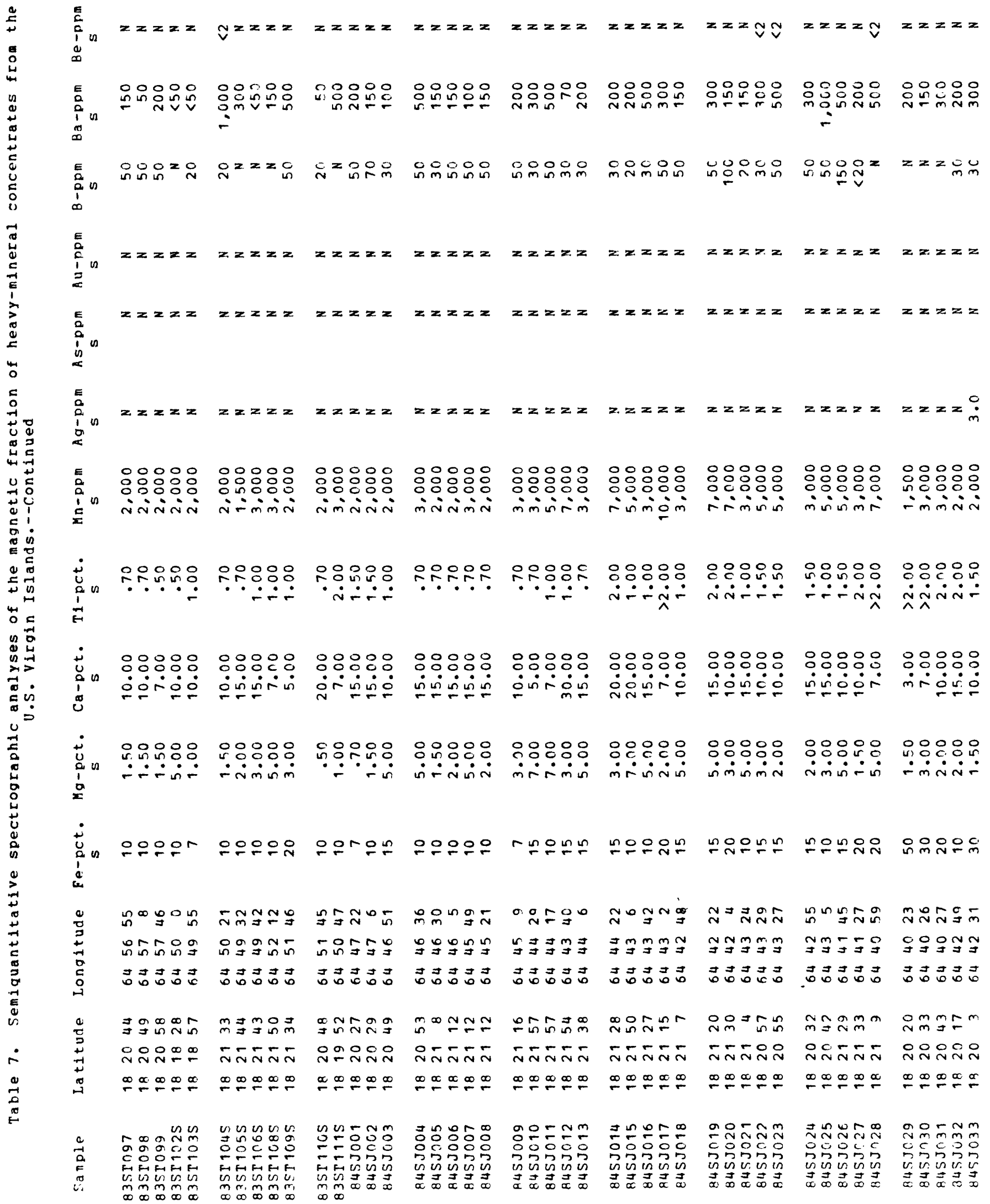




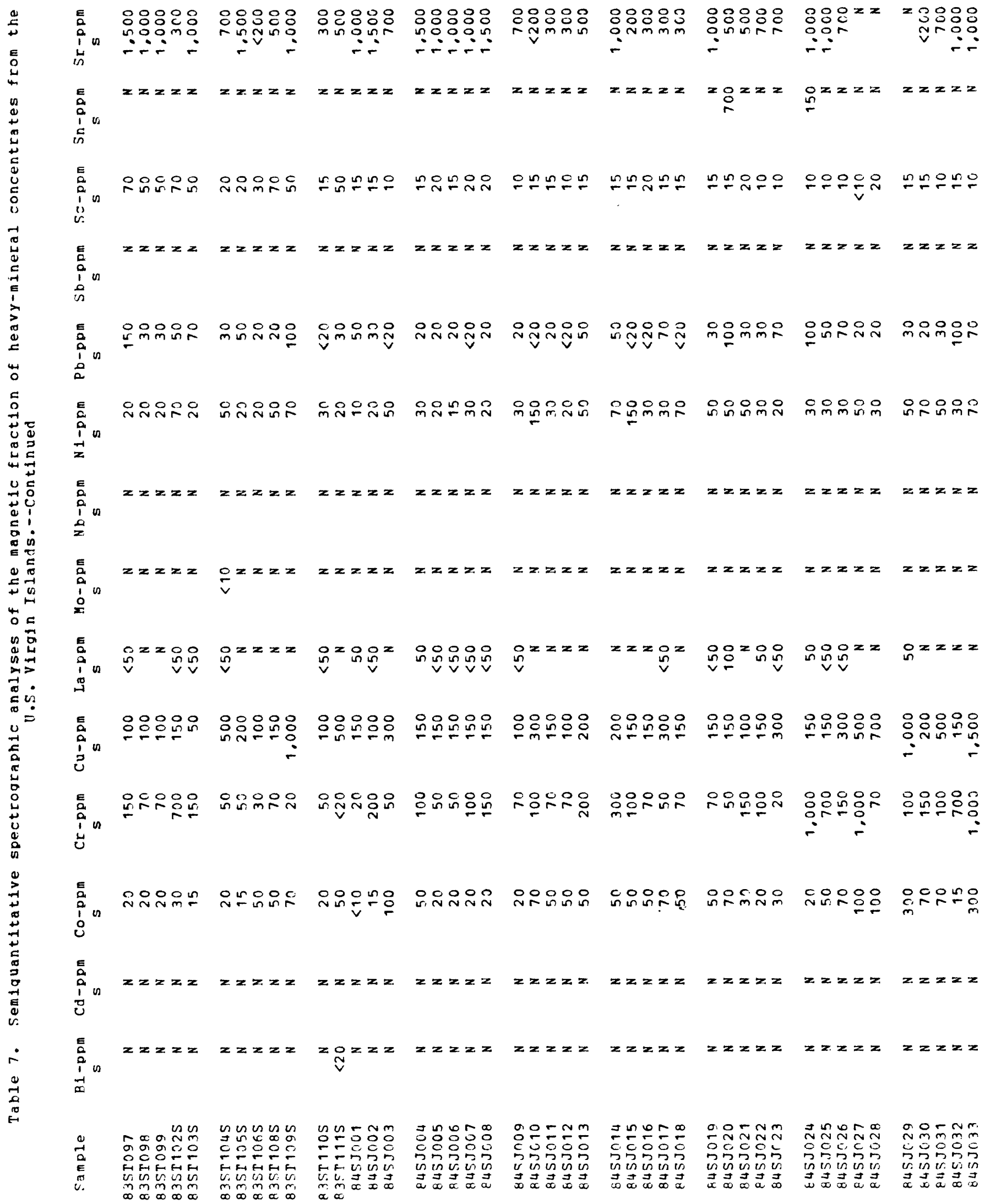




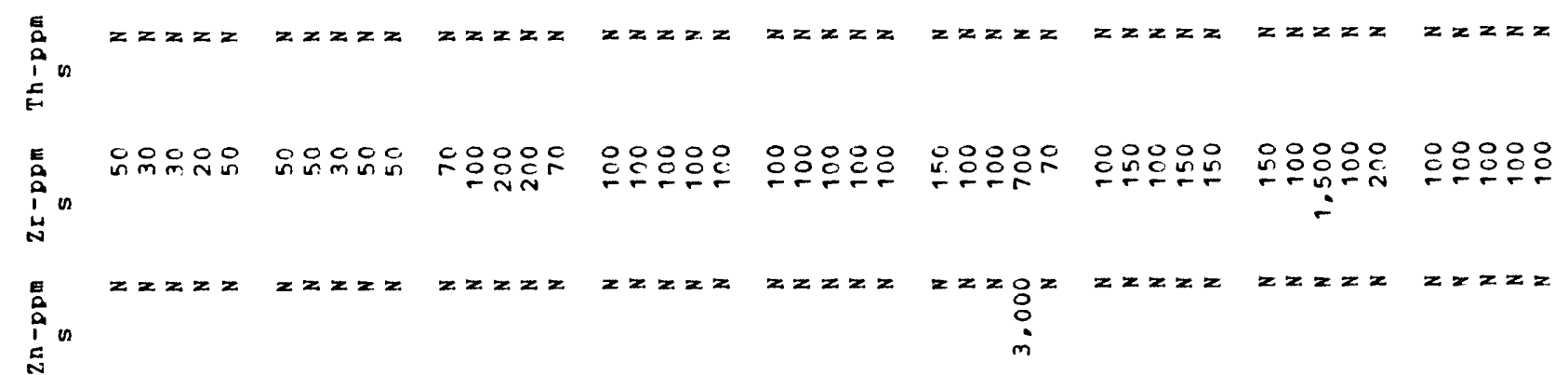

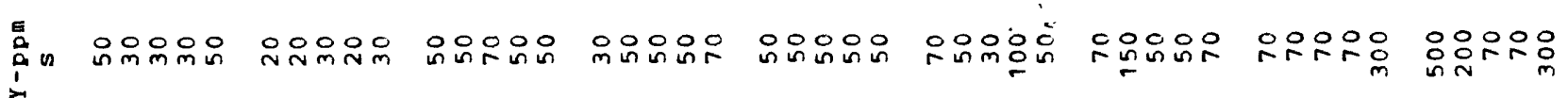

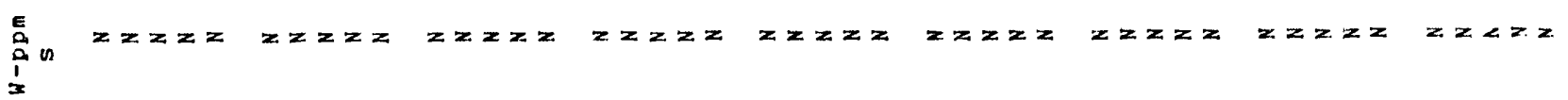

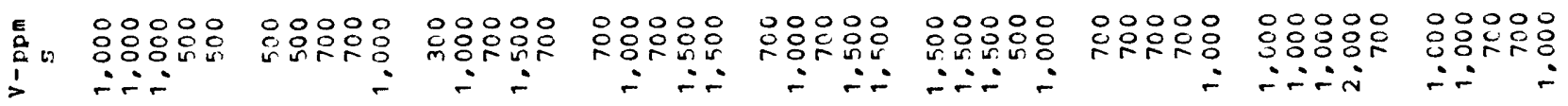

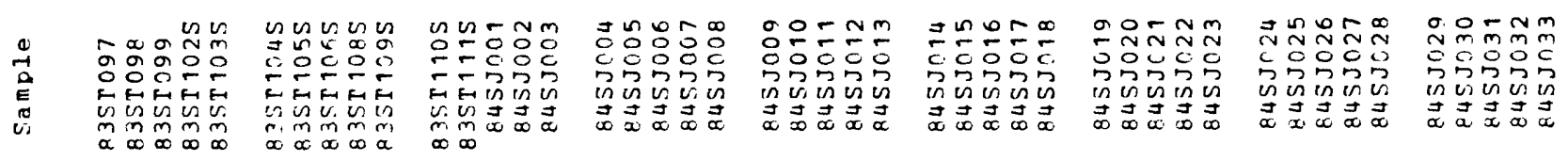


10050

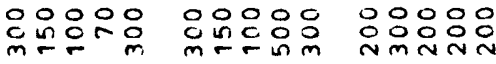
in

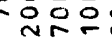

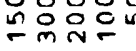

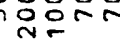

$\operatorname{rin} 20$

$\sin$

m m n

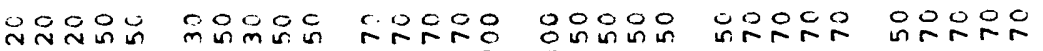
i

E

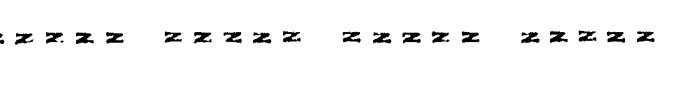
$i_{0}^{2}$

E

$z z z z z \quad z z z z$

$z z z z$

$x z z z z$

$z z z z$

$z z z z$

$z z z x$

$z z x$

$z z z=$

\section{응응응 응응응}

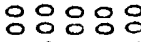

응응ㅇㅇㅇ응

$\therefore: 0: 0$

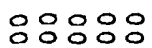

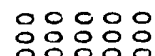

응ㅇㅇㅇ응

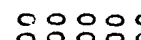

둥ㅇㅇ은

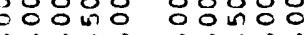

$\circ 0000$ niminin ininin

ininini

inimi:

inivivi

iñin

dind

ininim

$+$

0000

o0

응

00000 유요

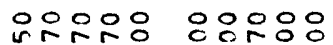

옹웅ㅇㅇㅇ

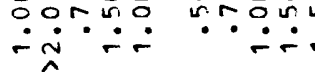

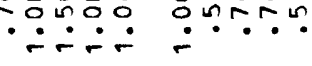

$\because \because 5 ?$

․․․․

$\because \cdots \dot{n}$

$\dot{\sim} \dot{\sim} \because \dot{\sim}$

$\therefore \dot{\sim} \dot{\sim} \dot{\sim}$

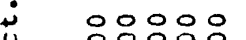

응ㅇㅇㅇ

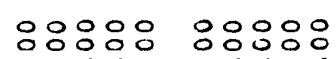

ㅇㅇㅇ응

ㄷㅇㅇㅇㅇㅇ

응응응응

응응음

응응웅응

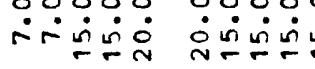

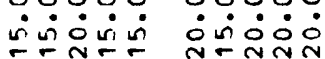

ง்ํำ

ம்i்

n்ining

ஸिंที่ن

பำ实的

년 융용요 웅윰용

范

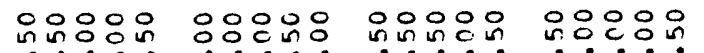

융ㅇㅇㅇㅇㅇ

응오용응

응융응

:

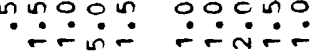

$\therefore \dot{\sim} \dot{ }$

$\therefore$ 둥

$\because \dot{m} \dot{\sim} \dot{\sim}$

$\dot{\sim} \dot{\sim} \dot{\sim} \dot{\sim}$

$\therefore \dot{\sim} \dot{\sim} \dot{m}$

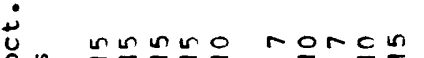

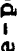

han

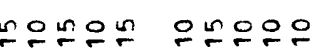

오온드

으웅ㅇㅁㄴㄷㄴ

드웅ㅇㅇㅇㅜ

$\simeq ェ 20$

뜨유ํํ요

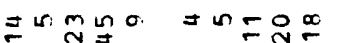

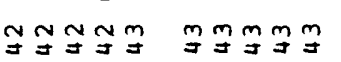

于 을

ㅇํำำำ

ฐすらす

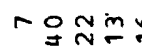

ำกำำำ

ำกำำก

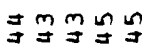

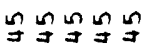

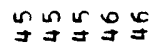

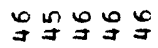

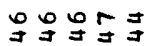

考实寻寻寻

กำลี一ำ

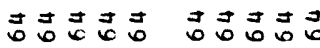

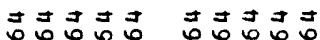

司苛吉吉

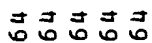

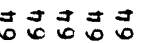

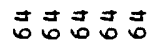

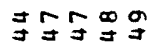

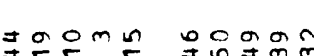

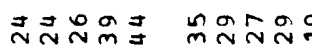

$\cos \pi$

$\operatorname{mm}_{m \rightarrow \infty}$ 舟

Ario

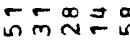

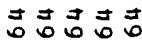

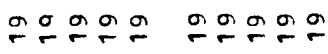

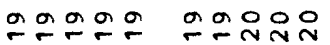

유윰유유

유수슈슈

유뭉유

웅ㅇㅇㅇ

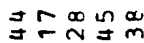

$\stackrel{\infty}{-} \stackrel{\infty}{\sim} \stackrel{\infty}{\sim}$

$\stackrel{\infty}{\infty} \stackrel{\infty}{-} \stackrel{\infty}{-} \stackrel{\infty}{-} \underset{\infty}{-}$

$\nsubseteq \stackrel{\infty}{\sim} \underset{\infty}{\infty}$

$\stackrel{\infty}{\infty} \cong$

$\simeq \infty \infty \infty$

$\stackrel{\infty}{-} \stackrel{\infty}{-} \stackrel{\infty}{-}$

จกลกั

ำก aOrnm

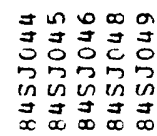

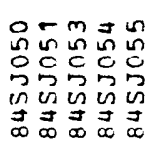

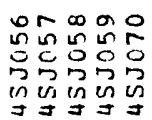

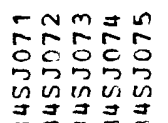

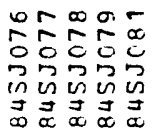

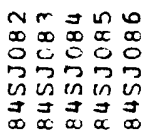

$\stackrel{\infty}{\sim} \stackrel{\infty}{\sim} \stackrel{\infty}{-}$

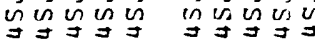

$\vec{x} \underset{\infty}{\overrightarrow{0}} \vec{\infty} \vec{\infty}$

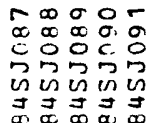




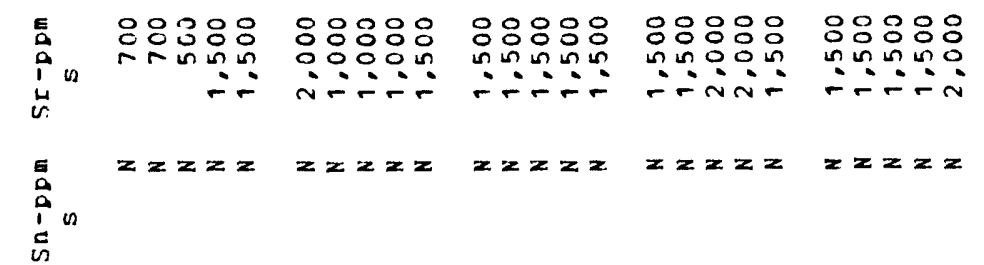

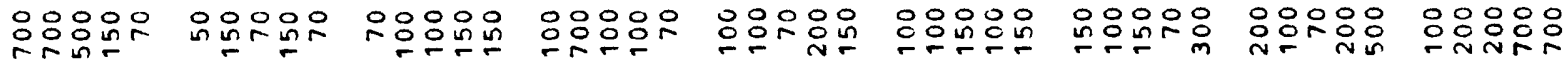
悹 高

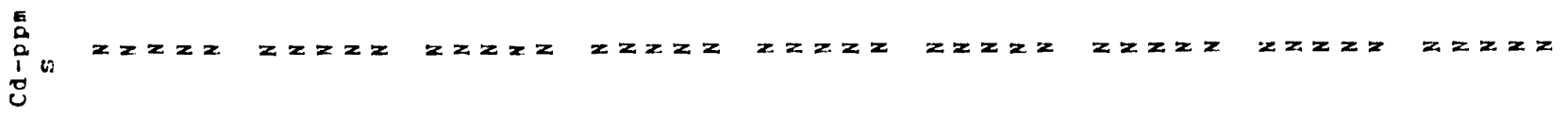
濖

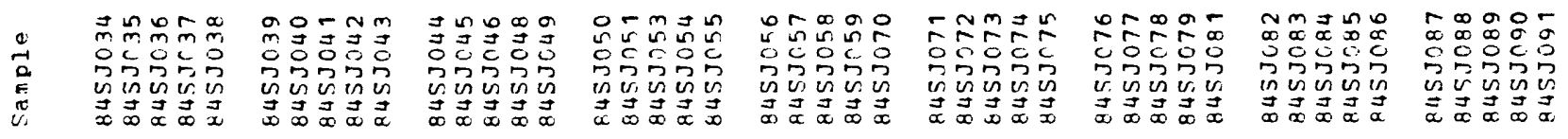




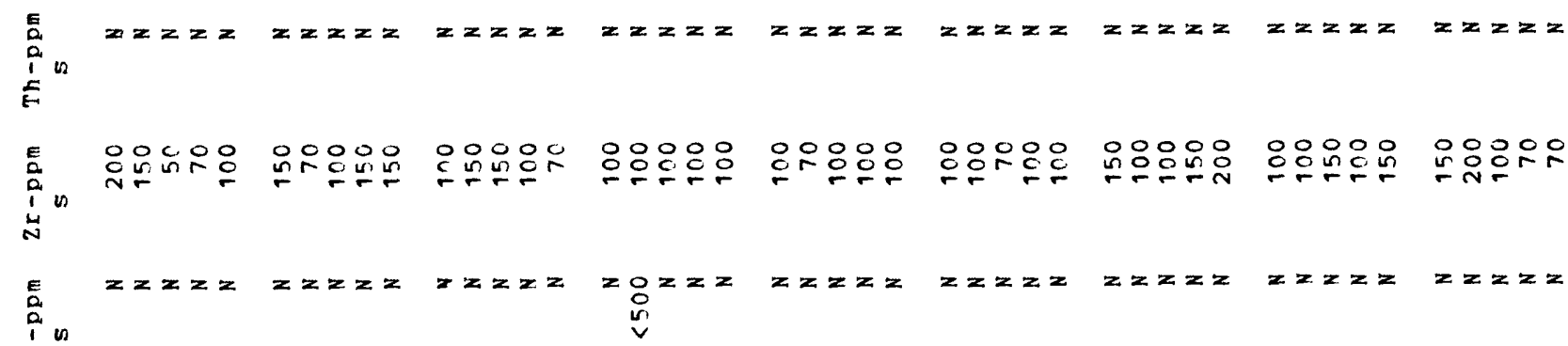
도

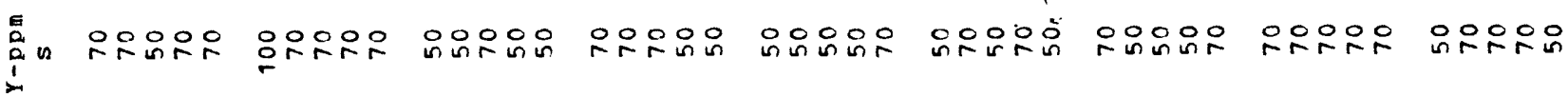

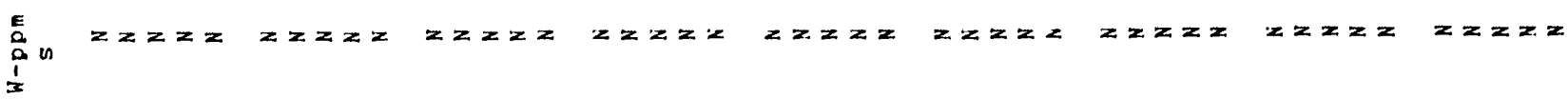

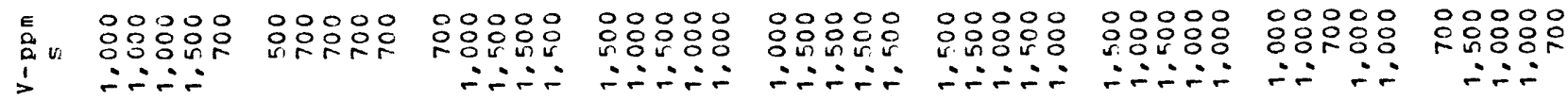

\begin{tabular}{|c|c|c|c|c|c|c|c|c|}
\hline 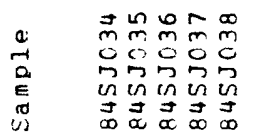 & 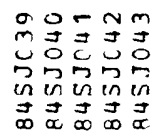 & 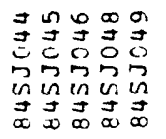 & 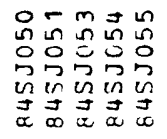 & 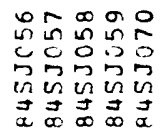 & 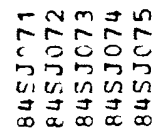 & 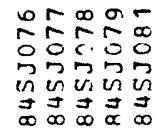 & 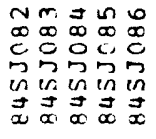 & 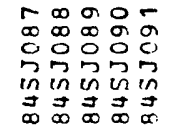 \\
\hline
\end{tabular}




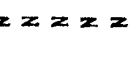

a

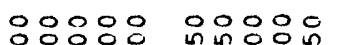

응ㅇㅇ웅

응응ㅇㅇㅇㅇㅛ

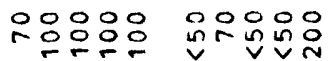

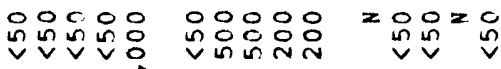

离

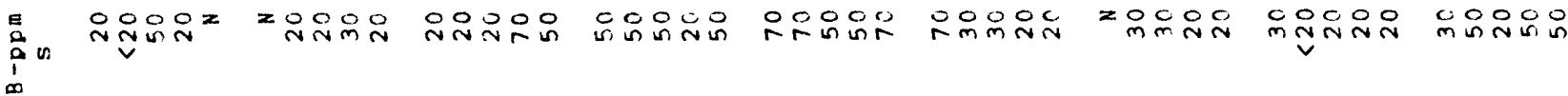

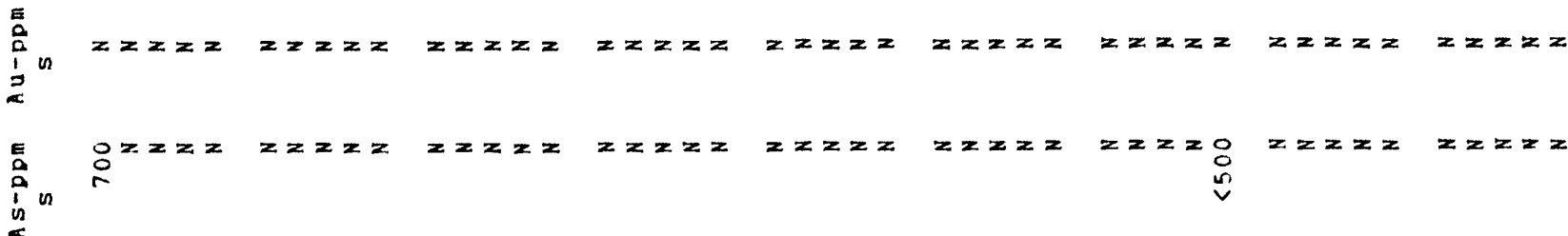

4

E.

$\because z z=2$

$z z z z=$

$z=z=x$

$z z z z$

$z z z z$

$z x z z$

$z z=z$

$z x z z$

$z z z z$

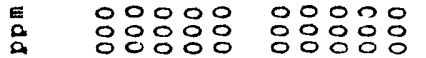

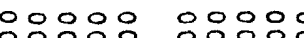

응용ㅇㅇㅇㅇㅛ

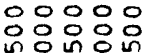

응ㅇㅇㅇ응

응ㅇㅇ웅

\section{응ㅇㅇㅇㅇㅇ}

등ㅇㅇㅇ

웅ㅇㅇ ininis

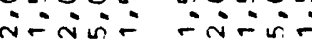

ininin

inr?

는

$\because \because 90$

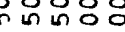

$\because \because \because-$

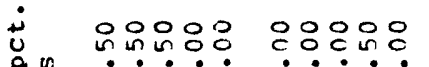

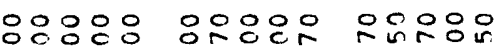

웅유응

우웅ㅇㅇ 웅ㅇㅇ응

은용ㅇㅇㅇㅇㅇ

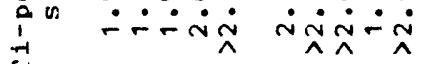

- $\dot{\sim} \dot{\sim}$

$\because \dot{\sim} \dot{N}$

- $\dot{\square} \dot{\circ}$

…・

…

í $\dot{\sim}-$

•.・.

U 능ㅇㅇㅇㅇㅇ 응ㅇㅇㅇㅇㅇㅇ

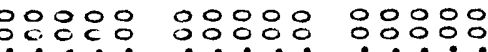

ํํำ

$\dot{0} \dot{1} \dot{\sim} \dot{0}$

○ं் $\dot{0} \dot{0}$

ㅇㅇㅇㅇㅇㅇ응

in

응ㅇㅇㅇㅇㅇ응

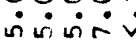

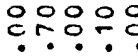

응ㅇㅇㅇ응

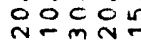

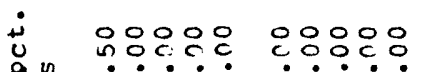

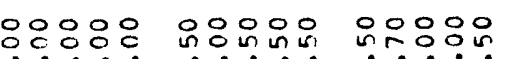

융유옹응

응웅요응

웅ㅇㅇ웅

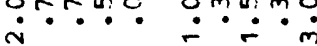

옹응ㅇㅇㅇㅛ $\dot{\sim} \div \dot{\therefore} \div$

范 0

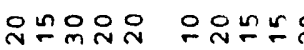

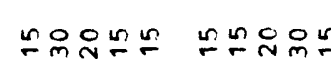

응ํํ느는

$\operatorname{nng} n \sin$

$\operatorname{ran} n$

응요

rringon

$0-\tilde{m}$

$00 \infty \infty n$

กํำ $\operatorname{m}$ F

느의

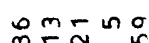

ถึกู

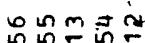

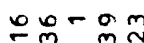

in $\stackrel{m}{\operatorname{ma}} \underset{-N}{N}$

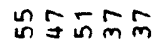

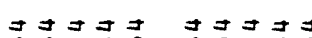

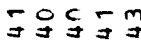

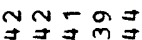

当考古寻寻

$\vec{g} \underset{\exists}{n} \exists g$

コฐงษす

กูบำร

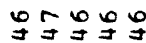

คิ

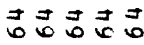

苛苛苛苛

हैं जै $\overrightarrow{0} \overrightarrow{0}$

जै $\overrightarrow{0} \overrightarrow{0} \overrightarrow{0} \overrightarrow{0}$

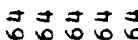

可寻苟

सु $\overrightarrow{0} \overrightarrow{0} \overrightarrow{0} \overrightarrow{0}$

ஏmon

ang $\begin{aligned} & \infty \\ & y\end{aligned}$

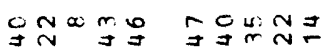

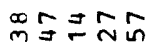

$\ln a m \infty$

$\exists \infty \geq$

코욤의

ลกNำ

웅우웅

뚱ㅇㅇ

웅유웅ㅇ

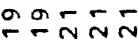

두융응

윰ำ

कीव

$\infty \infty m \infty \infty \infty \infty \cdots \infty$

$\infty \stackrel{\infty}{-\infty} \stackrel{\infty}{-\infty}$

$\infty \propto \infty \infty$

$\infty \infty \infty \infty$

$\stackrel{\infty}{\leftarrow \div \infty}$

$\infty \infty \infty \infty \infty$

$\infty \infty \infty \infty \infty$

$\infty \infty \infty \infty$

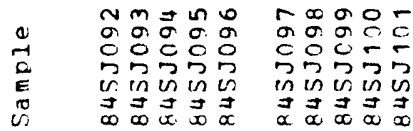

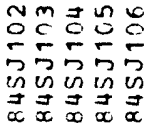

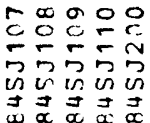

둥ํํ음

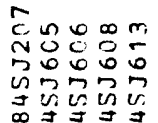

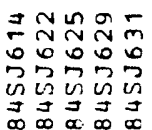

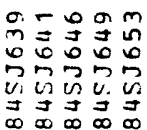

in

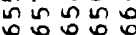

cis in

$\overrightarrow{0}=0$ 


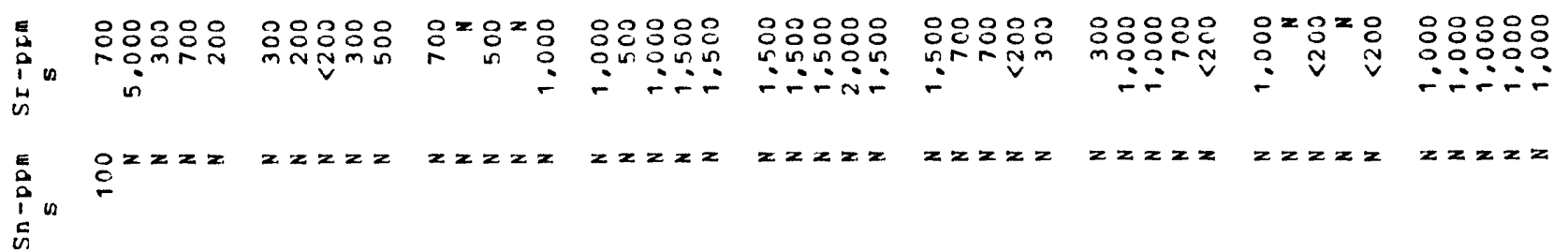

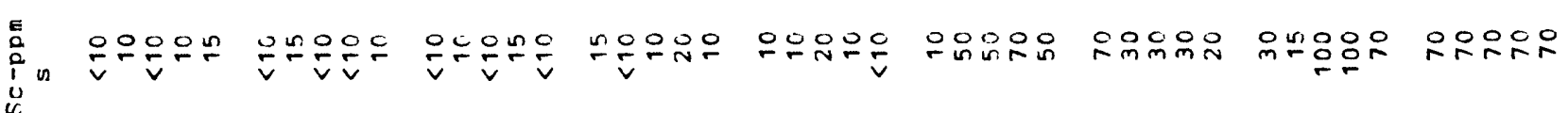

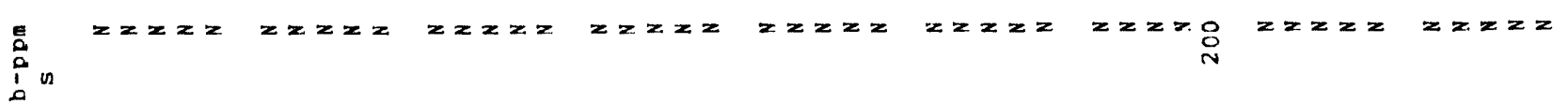

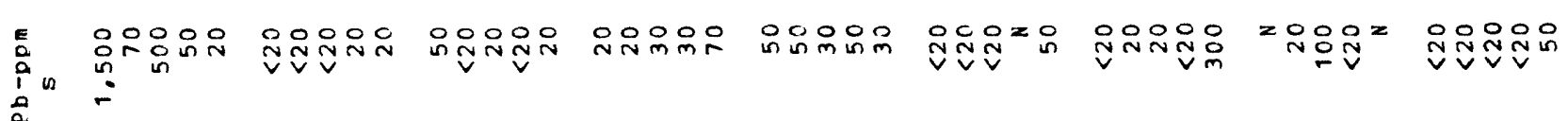

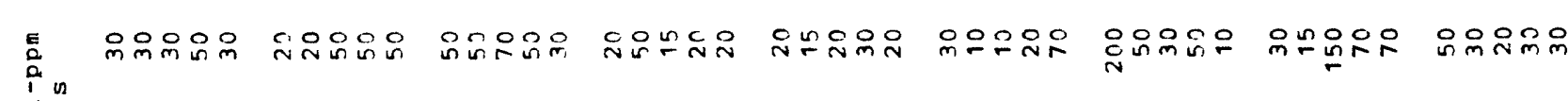
$\stackrel{1}{1}$

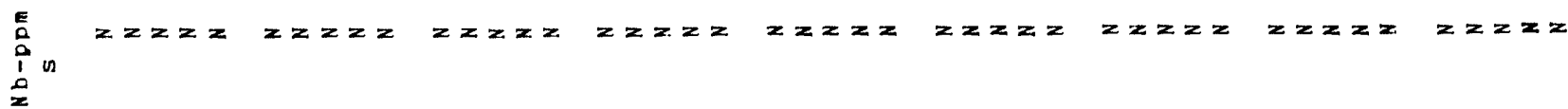

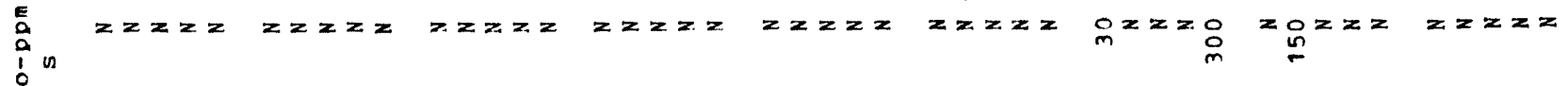

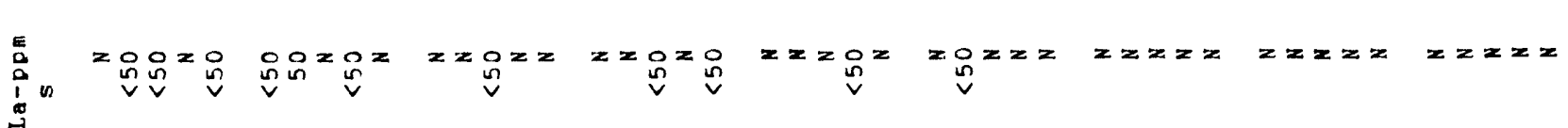

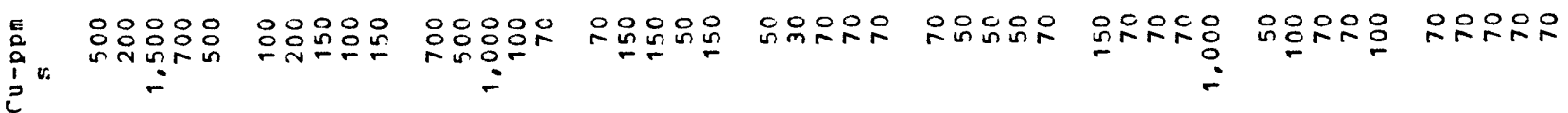

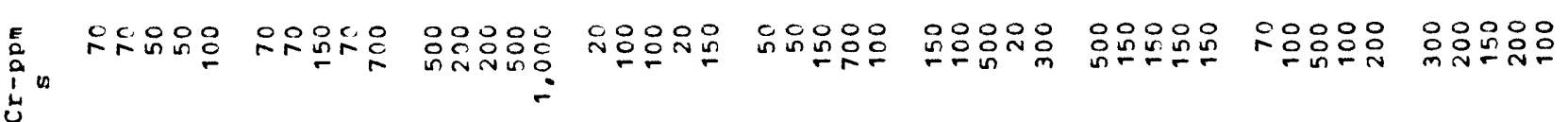

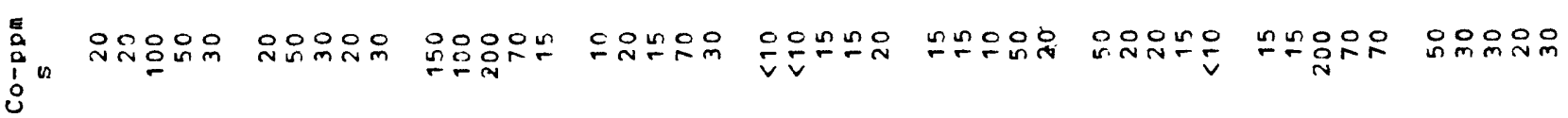

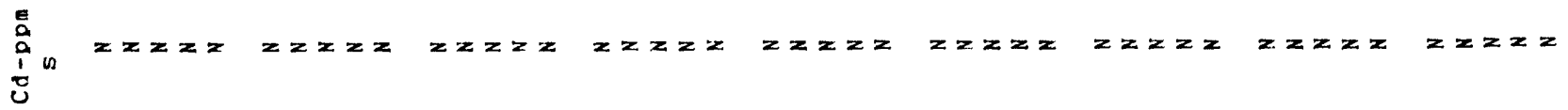
응 $r$

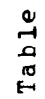

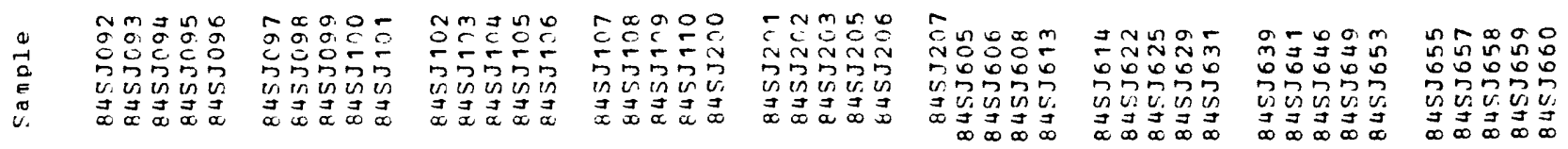


E $i_{i}^{\infty} n$

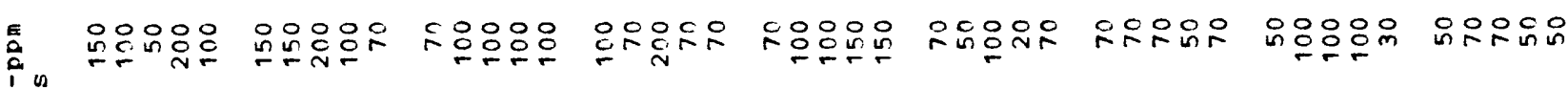
岕

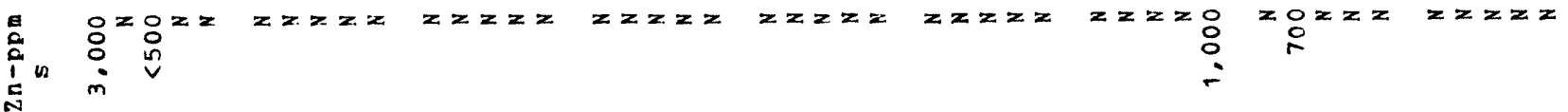
틀 을 을

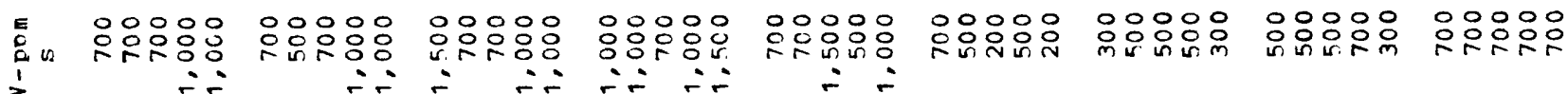

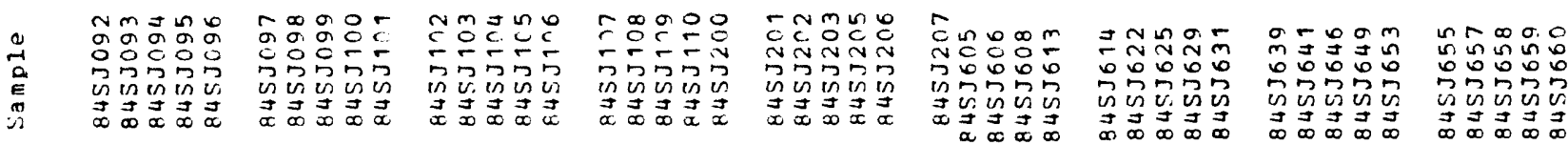




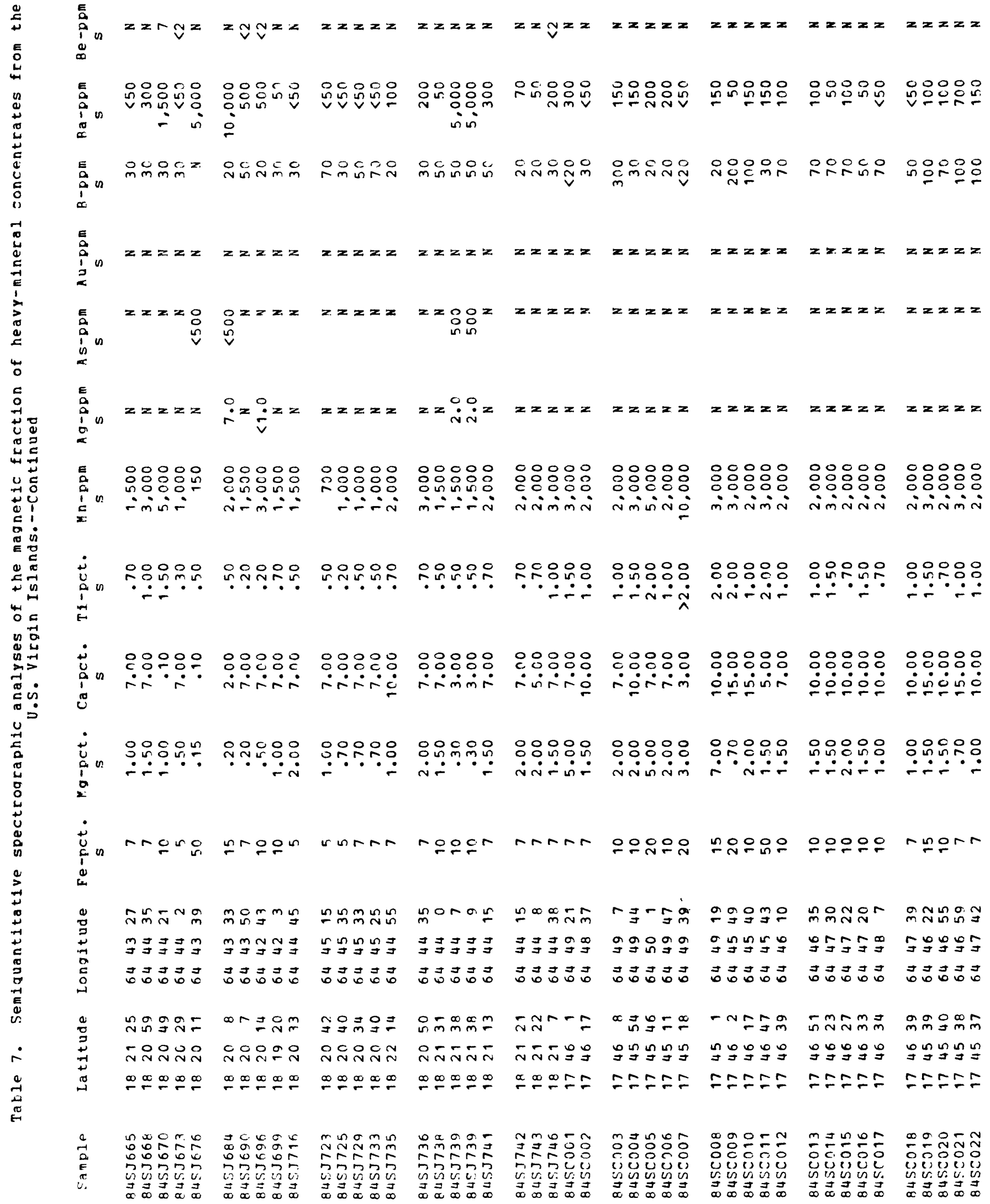




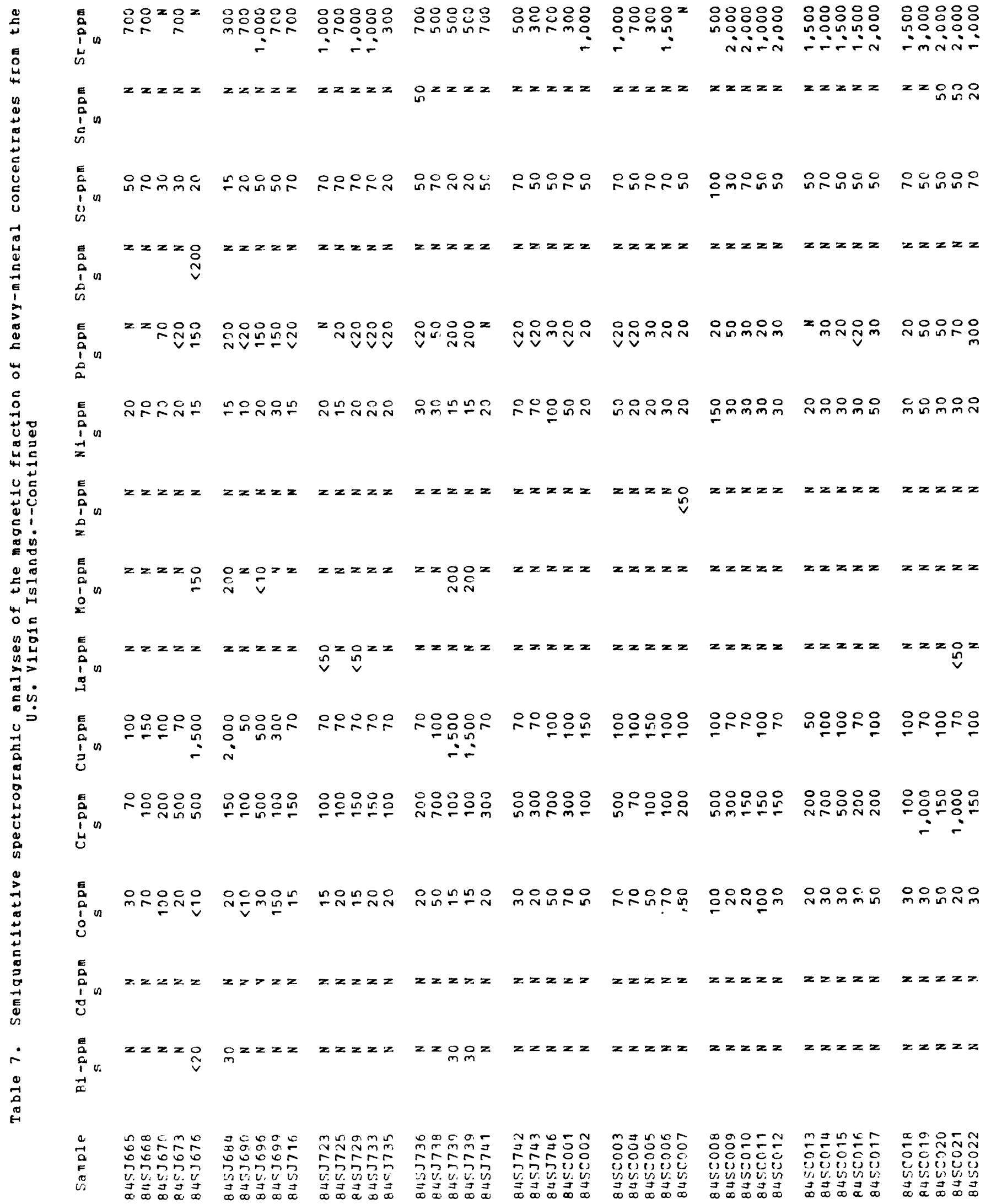




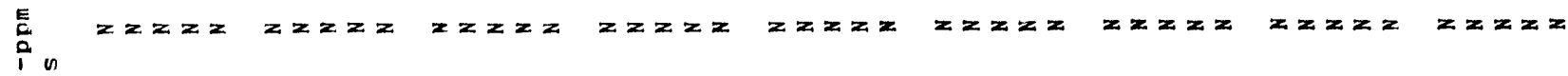
$E$

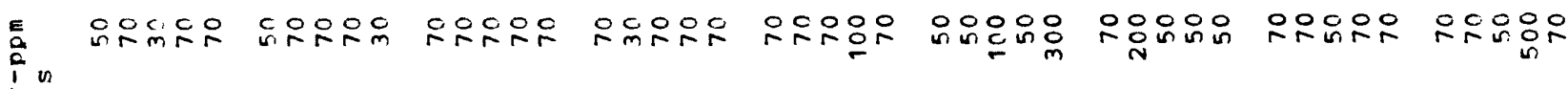
点

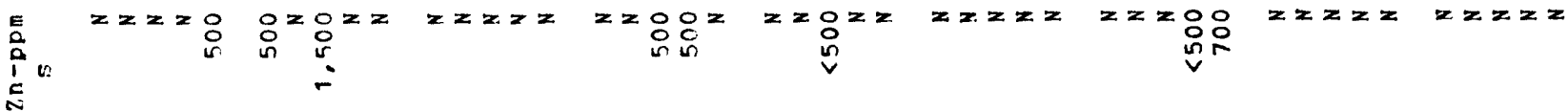

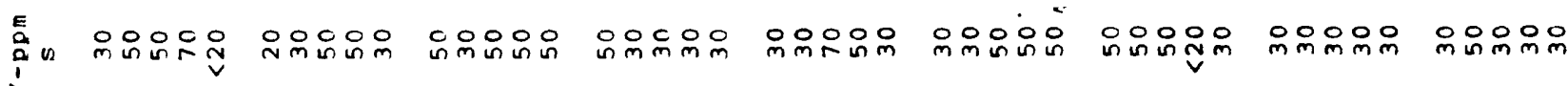

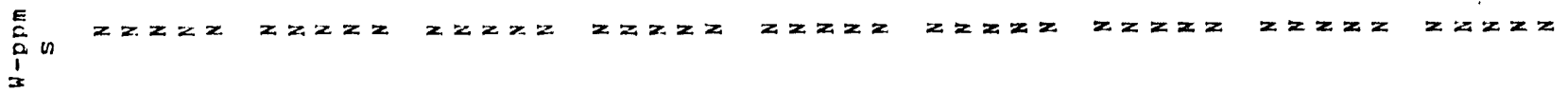

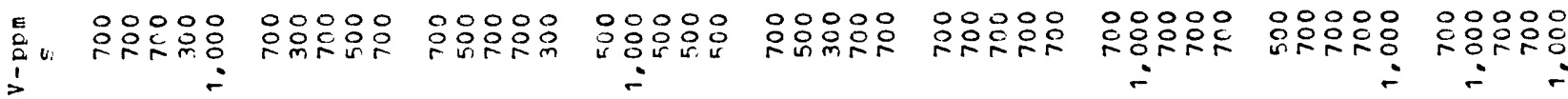

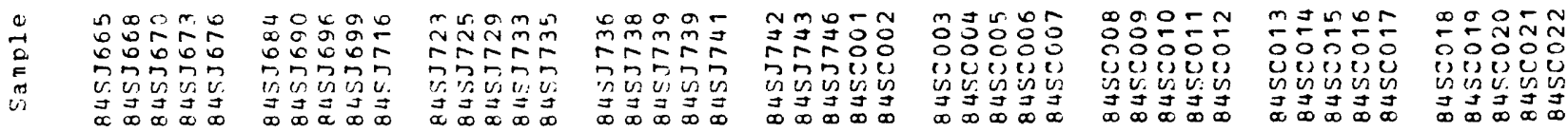


$\frac{6}{i}$

$z z z z z \quad z z z z z \quad z z N z N \quad z z N m n$

$\circ \mathbb{N} N=\geq \mathbb{V}=\mathbb{V}$

$z \underset{v}{ }=2$

$z z=z z$

$z \underset{v}{ }=2$

$\infty$

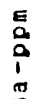

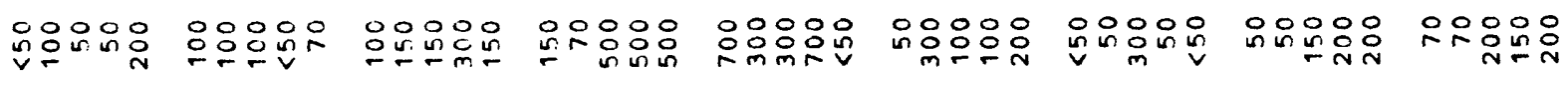
$\pi$

㗭

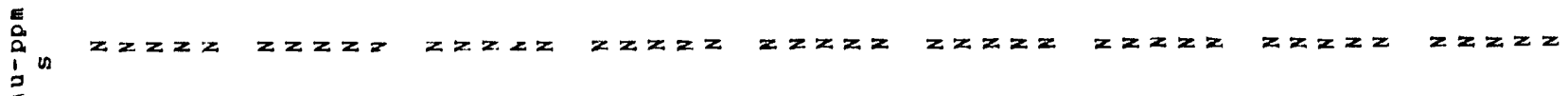

틍

$E$
$a$
$a$
$a$

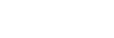

a

a 00000

in $\because$ inimin

00000

$\therefore 8: 00$

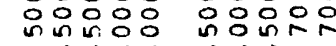

$\therefore \therefore$

응응요융

$\because \because \because \frac{1}{2}$

영유

in

응응융응

ini-im

응응으

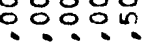

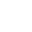

$\dot{0}$
0
0
1
-1

10

$\operatorname{ses} 10$

00000

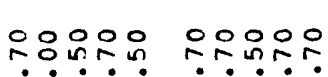

웅용ㅇㅇㅇ

응응응웅 $\because \dot{\sim} \dot{x}$ 숭-

\section{0

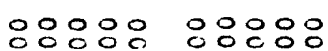 \\ 00000}

00000

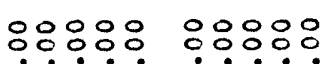

응응ㅇㅇㅇ

응웅ㅇㅇㅇ응

ư ión

穴穴穴 rímín

둥ํ

inimio

穴向任 ririto

órión rivirio

㻤 읃웅응

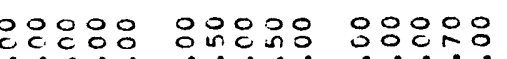

응응웅.

응옹웅우

응웅ㅇㅇㅇ응

응ㅇㅇㅇㅇ

응응응응요 !

भiñ

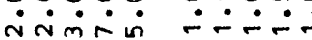

$\because \dot{\sim} \because$

$\therefore \dot{r} \dot{4}$

$\therefore \because$

$\because \div \dot{-1}$

ேேோே் inì-:

0
0
0
1
0
0
0
0
0
0
0
0
0
0
0

orrin

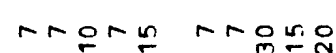

그유유요

읐으요음

유용유

뜨는

으유으우

뜌융ㅇㅇ

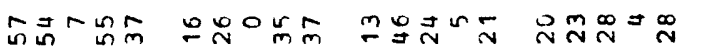

Nopon

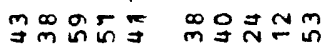

$9 \sim \infty_{m}^{\infty} 00$

$\infty \simeq \pm 9 \infty$

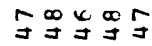

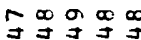

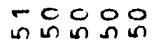

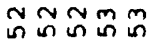

กำกำก

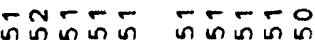

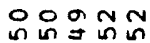

的的品号

吉吉苛吉吉

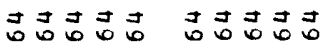

茄芯苛苟

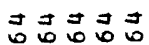

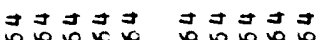

चै

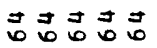

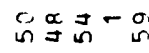

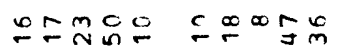

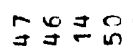

a amom

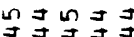

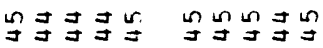

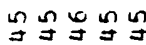

$\exists \exists \exists n$

of

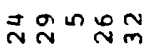

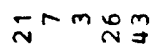

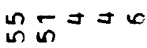

ニュニニ

ヒะニニュ ニュニニュ

ニニニュニ

nNRNa

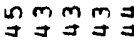

寻寻寻寻寻

寻寻䙵

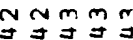

ニニะニ

กะニะ

エะニニ

ะะะ์

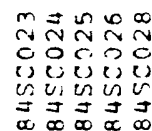

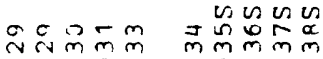

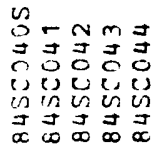

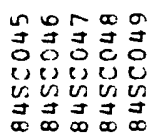

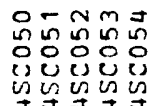

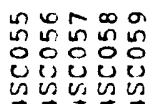

둥ํำ

웅요잉

in us us

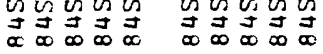

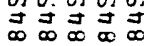

$\sim 0$

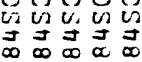




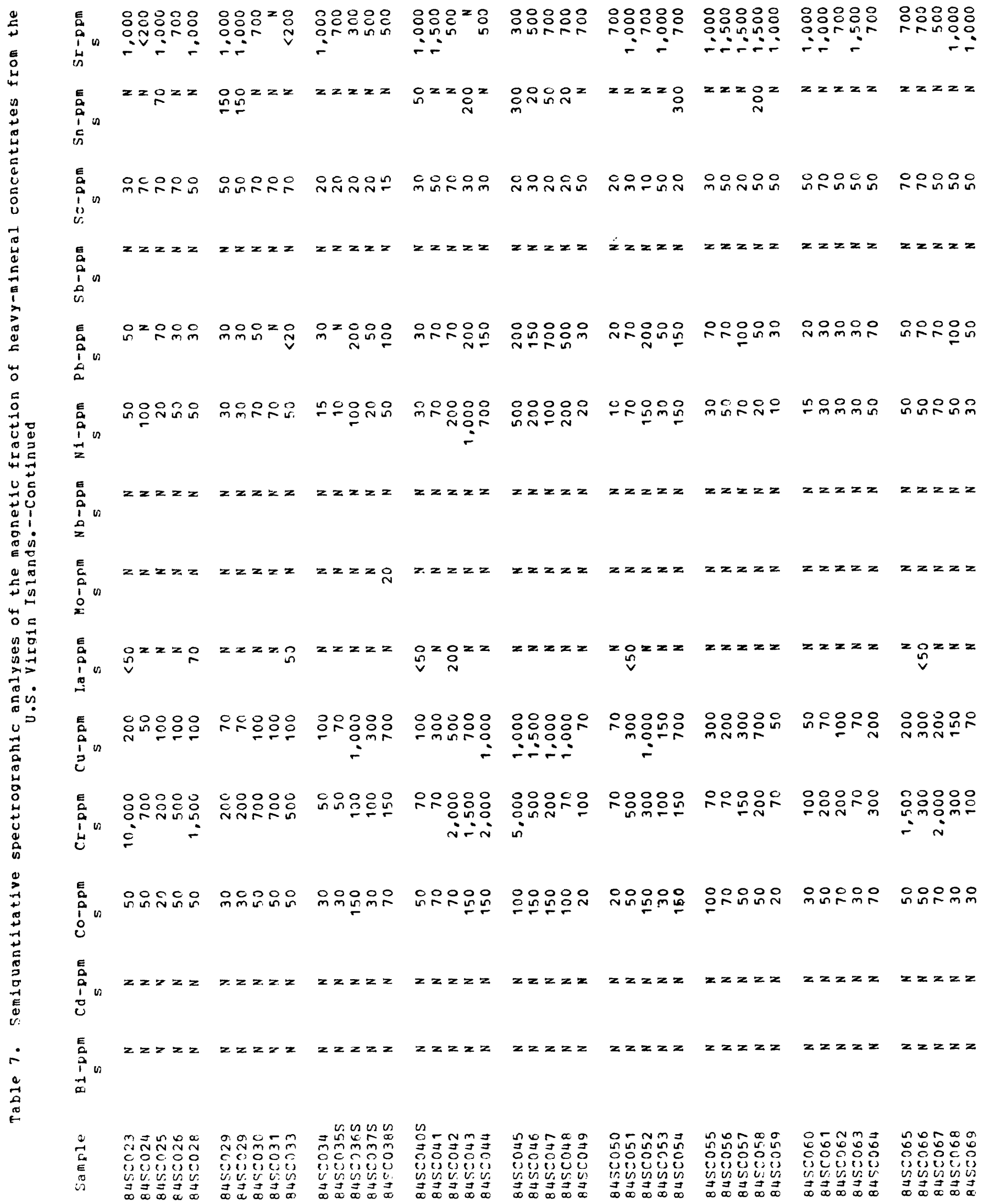




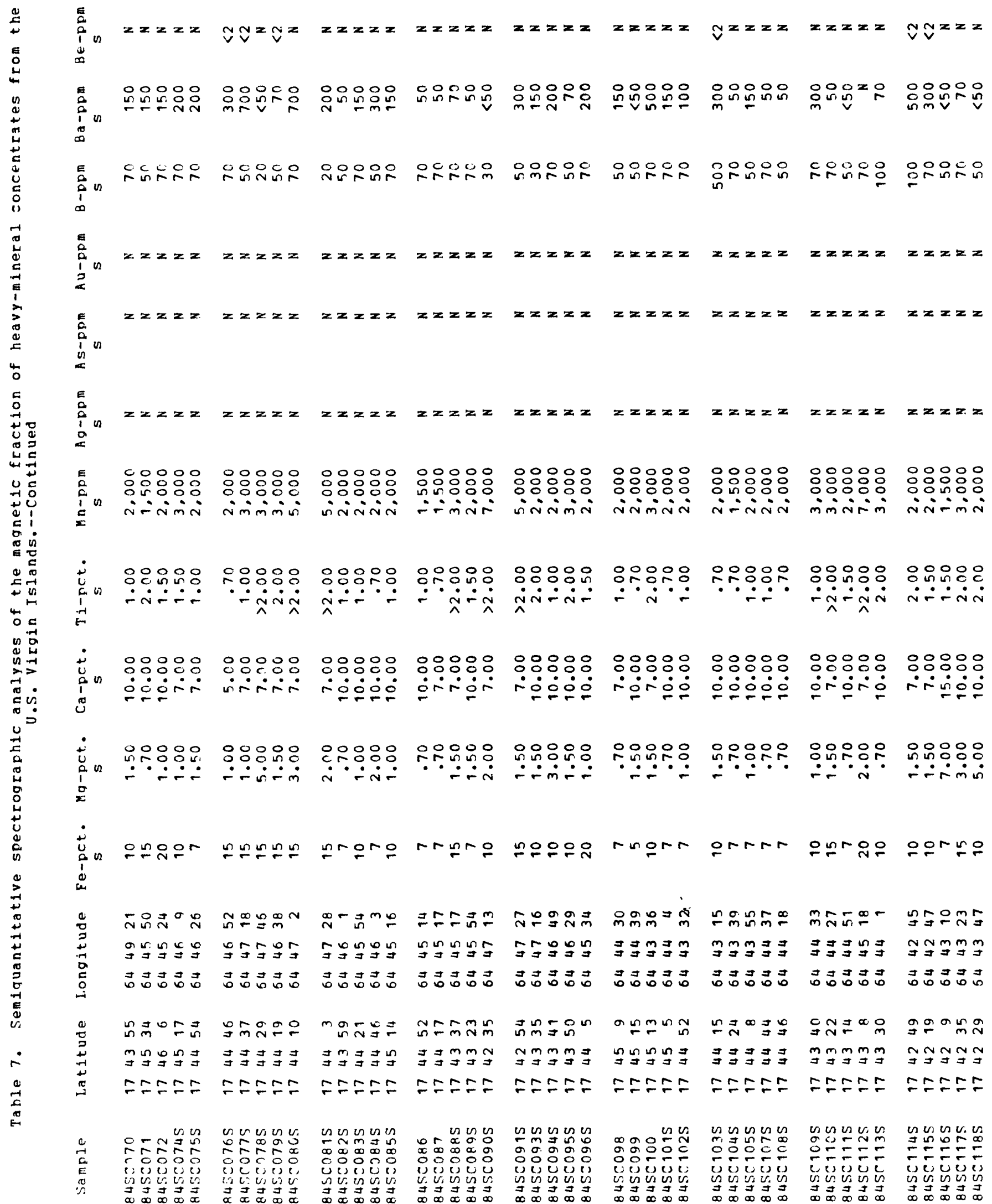




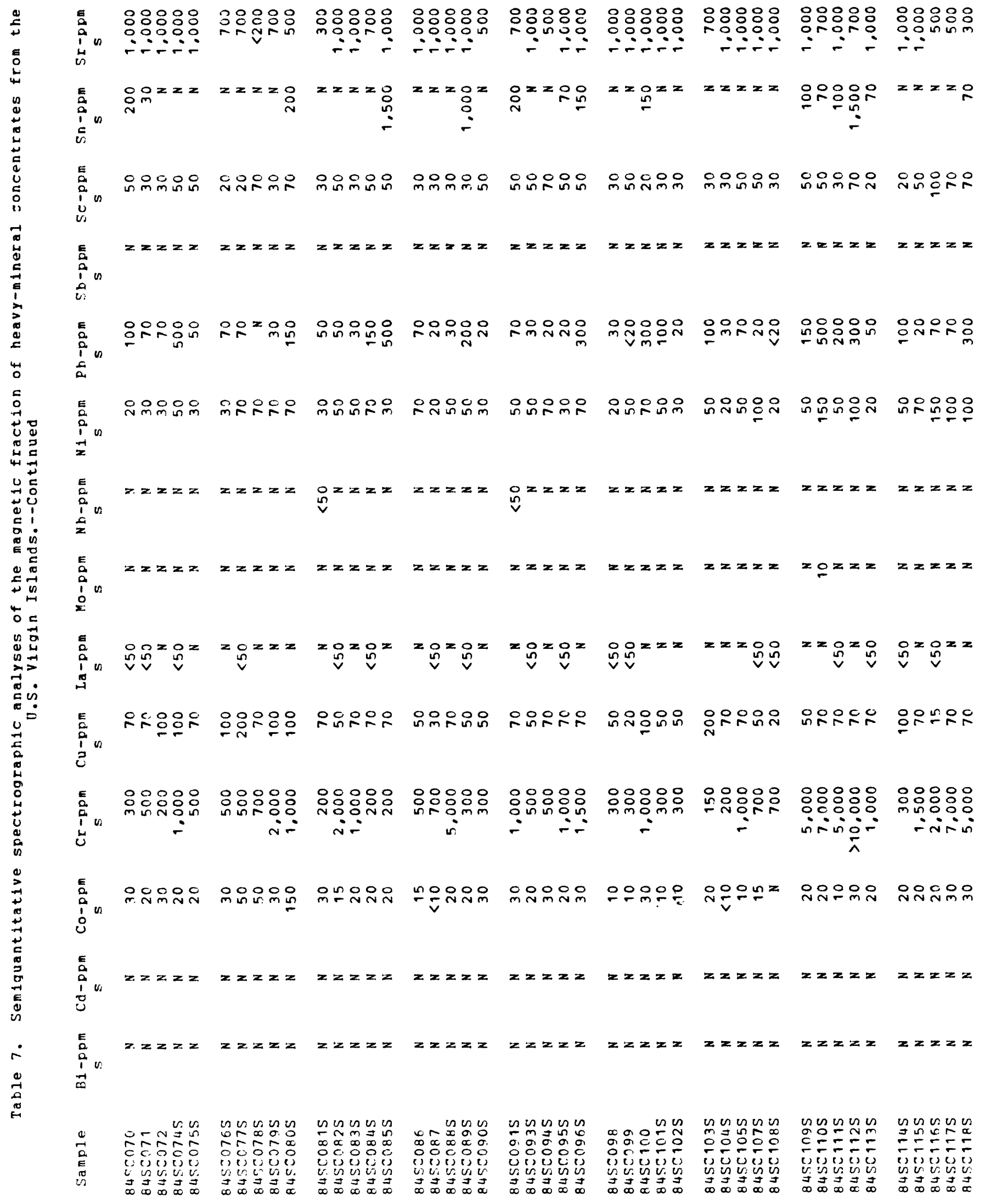




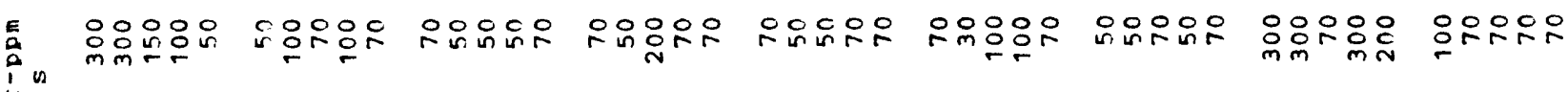
N

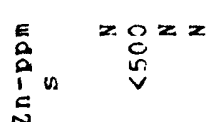

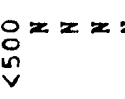

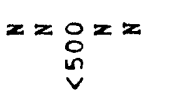<smiles>[C+]#[12CH]</smiles>

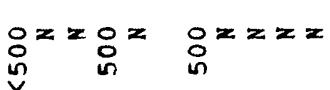

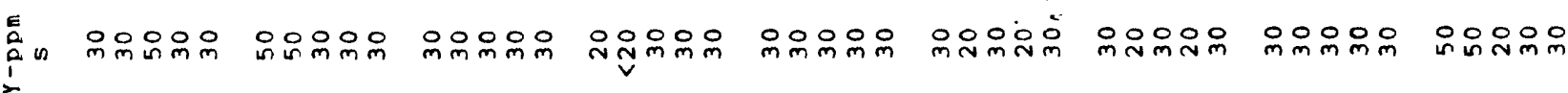
$\underset{0}{1}$ $z z z=$

$x z x z$ $z z z z$

$z z z z$

$z z z z z \quad z z z z z$

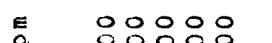

00000

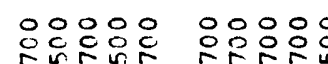
움웅요

응웅웅요

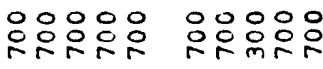
$\rightarrow \quad \because \div$

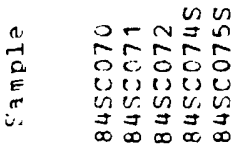

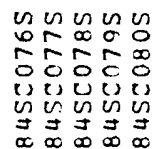

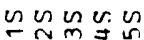

$\infty \infty \infty \infty$

isu纪

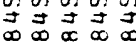

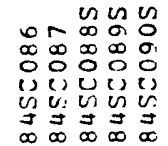

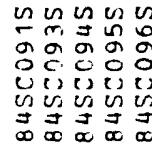

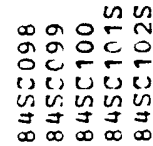

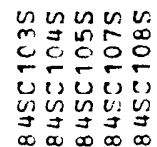

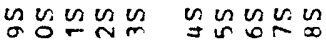

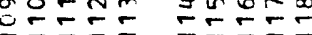

(1)ūa eisese.

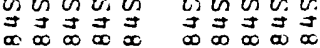




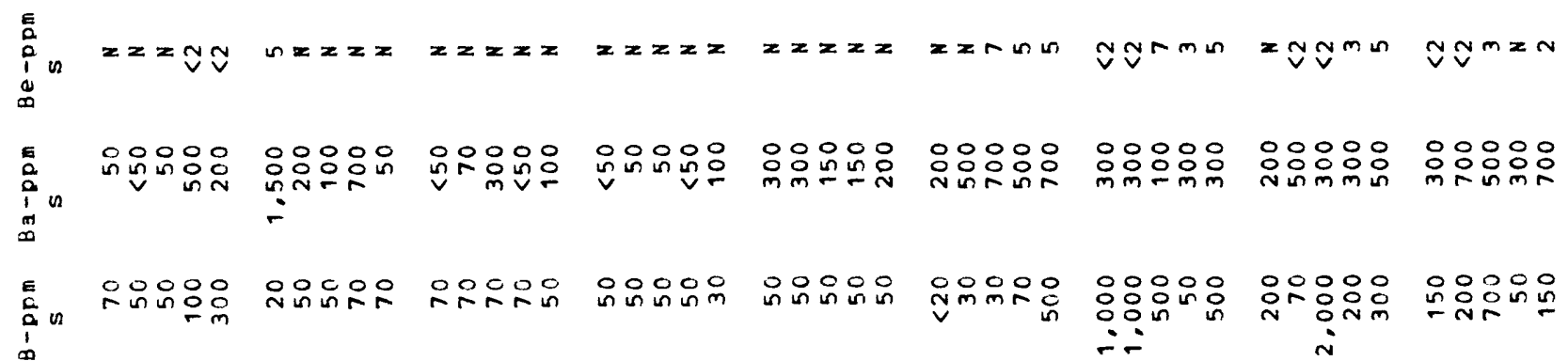

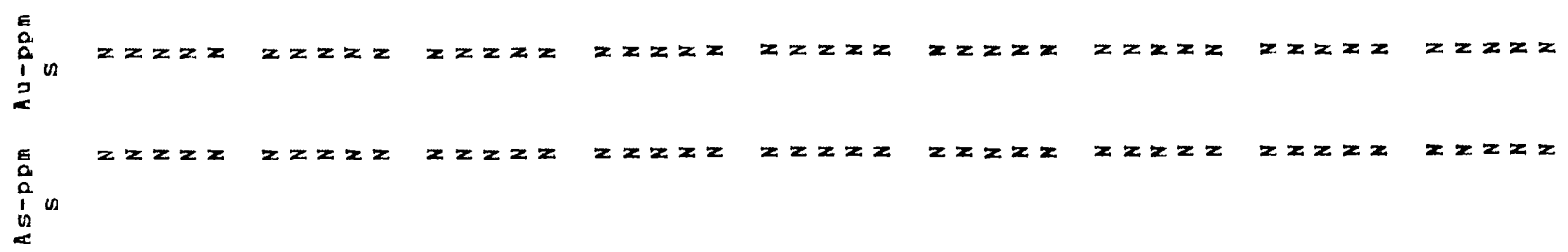

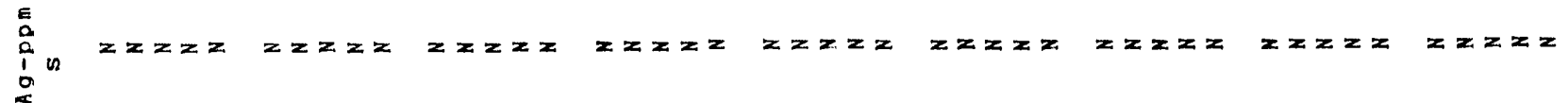
E in minnis

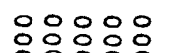
0.0000

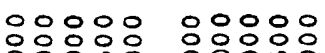

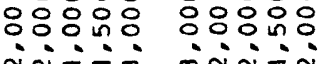
응응응응 응응응응 nnmin nintom 涼的

írin

$\stackrel{+}{u}$

\section{0}

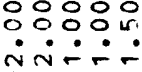

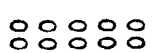

0000

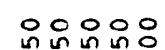

نंNini

$\dot{N} \dot{N} \dot{N} \dot{N} \cdot \because \dot{N}$

응웅응은

$\dot{\sim} \dot{i} \because$

웅융웅 $\stackrel{\dot{u}}{0}$

i

둗ㅇㅇㅇㅇㅇㅇ 욱영ㅇㅇㅇ 向安家

응응음

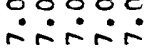

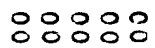
irini

유:웅 후눙

응ㅇํㅇํㅇㅇㅠ 응용융

웅응웅운 inin

영응ㅇㅇㅇㅇ

\section{$\stackrel{\dot{0}}{\dot{u}}$}

00000

00000

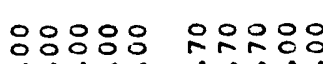

운웅ㅇํ웅

응우유요.

응응으요

응응ㅇㅇ응

iัن்

웅ํㅇ요요 $\stackrel{1}{2}$

莕 :

뭉

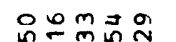

$m N=\infty$

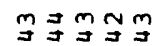

곸ำ品

ㄴm

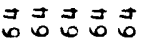

䓃苛苛

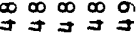

$\bar{m} \stackrel{n}{\sim} \underset{\exists}{m}$

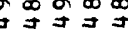

익의의

드을

我芷的解

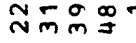

루료

可司苟䓃司

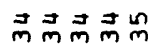

กำก

in $n$

mก

in $\ln ^{\circ} 00$

in

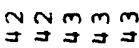

กินก็นn

DNNNO

०ैं

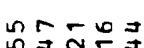

mm

苛苛苛苛

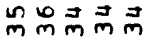

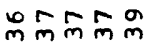

คะะะล

$\operatorname{mim}_{\exists \exists \exists} \underset{\exists}{ }$

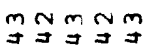

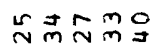

maㅀ

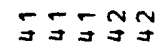

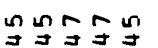

$-0 \rightarrow \infty$

जै

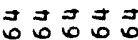

cosenco

FE:

도

エニニュュ

シニะテ

iño-

ニニニニะ

ํำำด

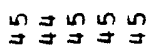

止寻寻寻告

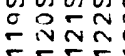

sosesos

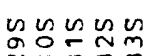

$\exists$ 两

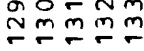

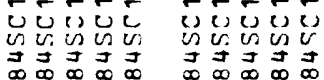

cosenes

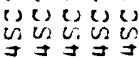

出运更

ūe

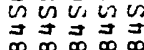

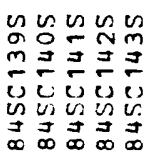

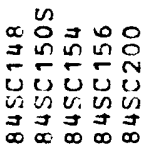

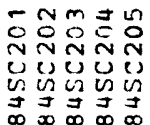

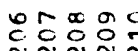

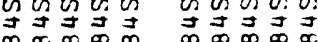




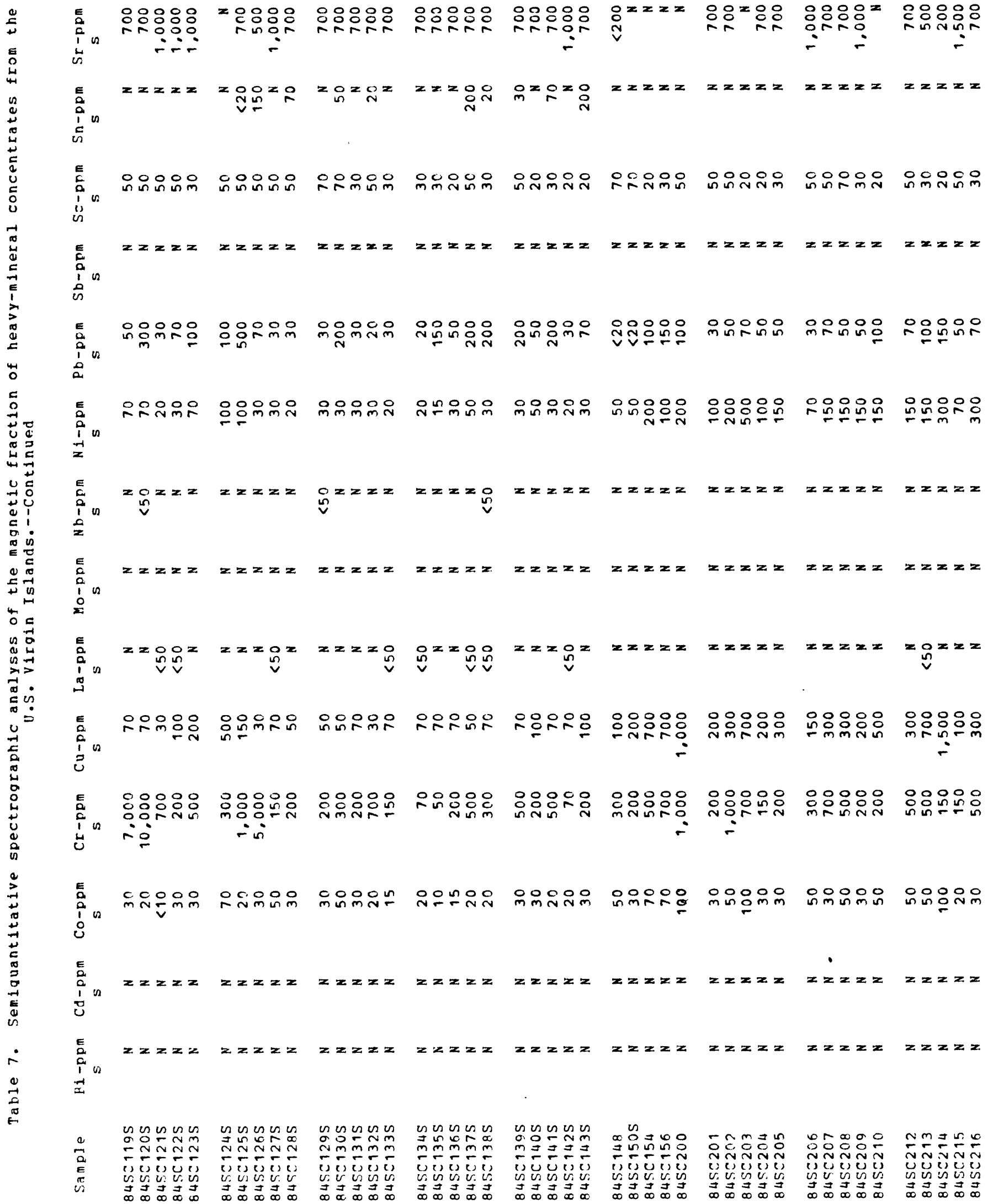




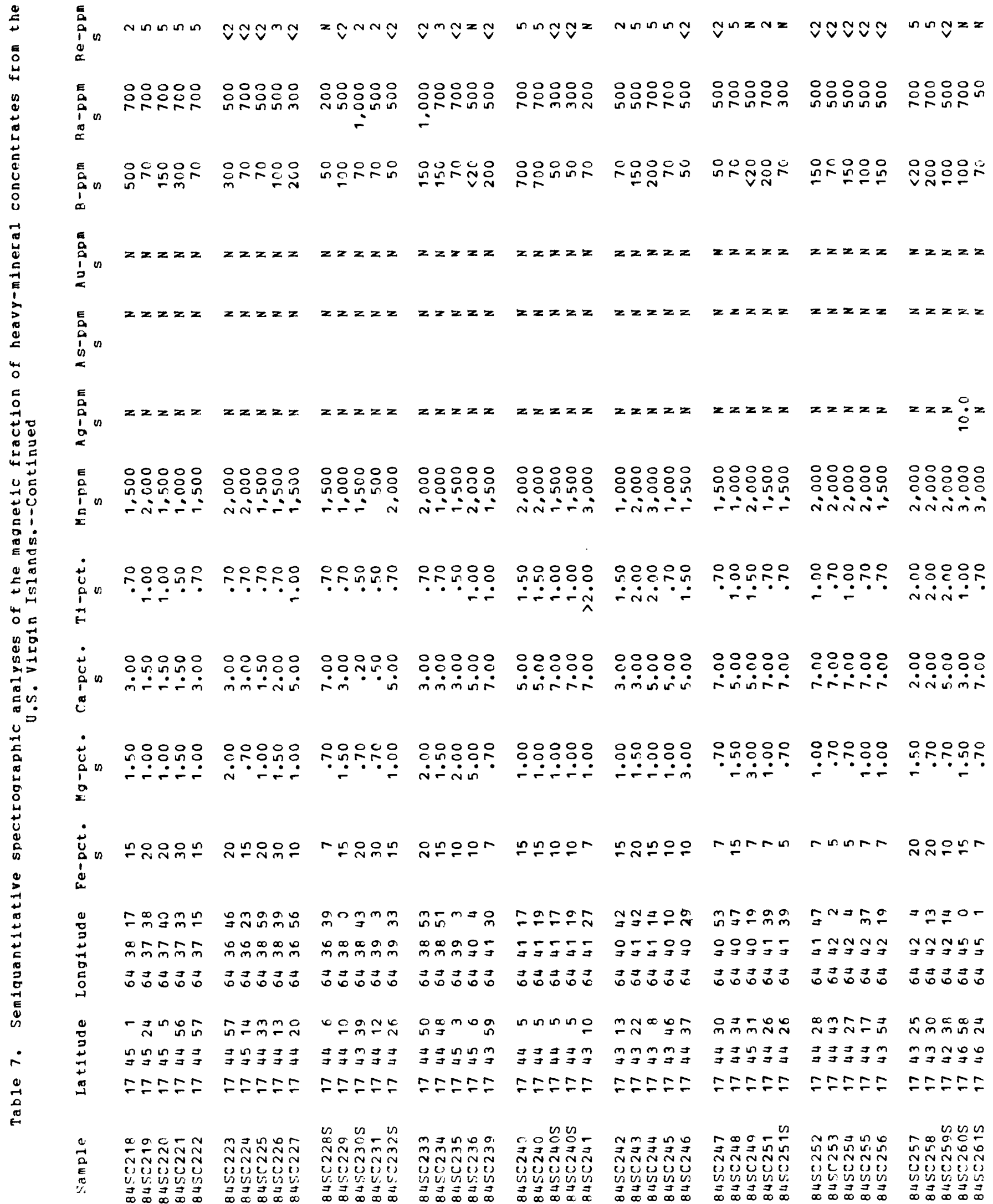




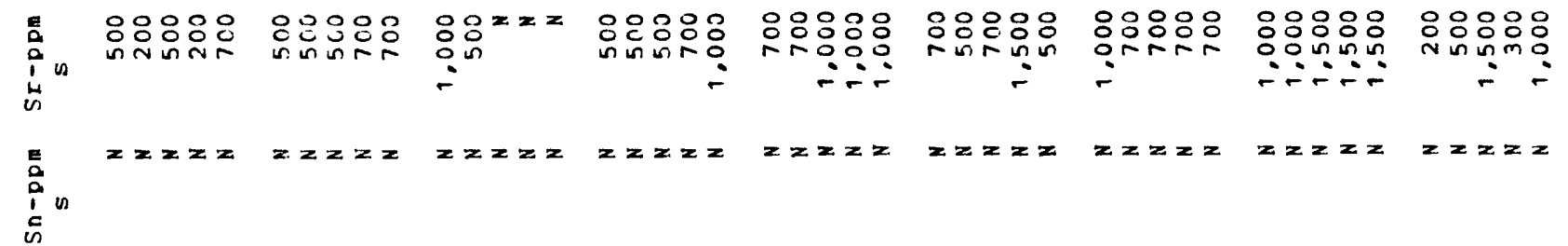

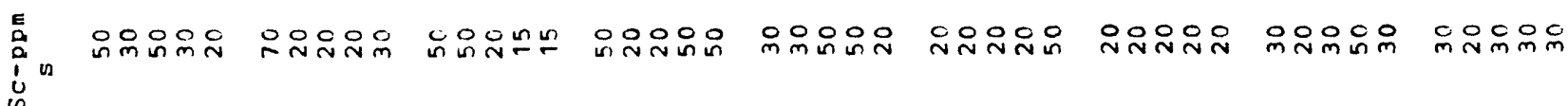

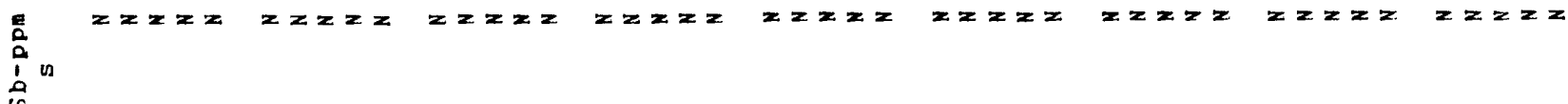

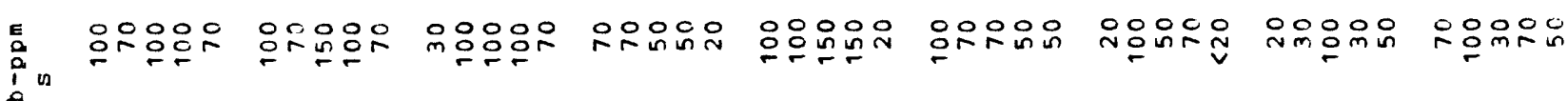
a

E⿸厂⿱二⿺卜丿口 $\underset{z}{z-1}$

E

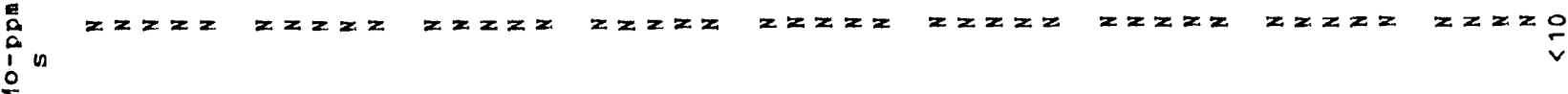

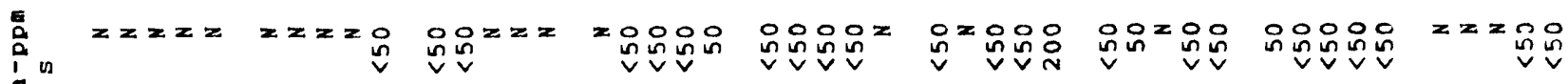
$\stackrel{0}{\rightarrow}$

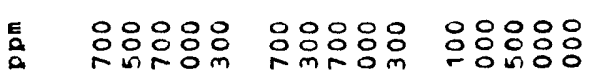
en

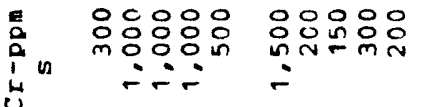

은응ㅇㅇㅇㅇㅡ 응응웅우

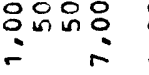

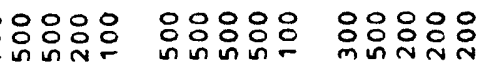

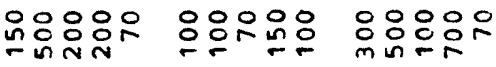

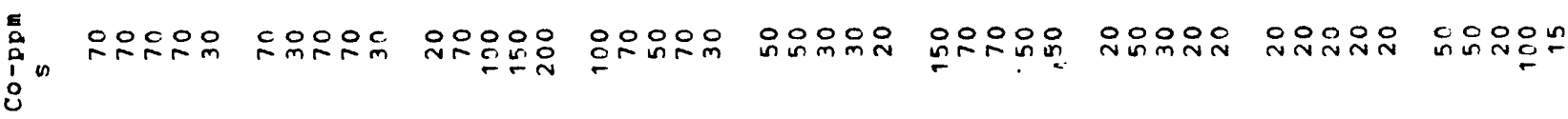

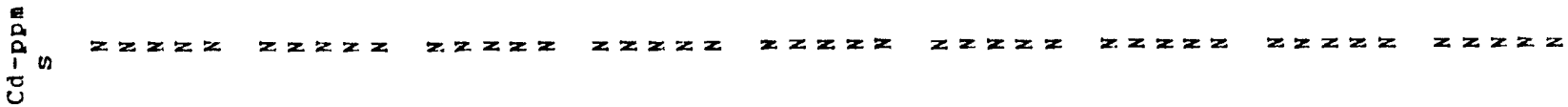

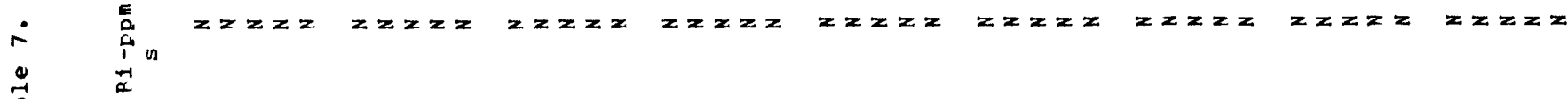
(1)

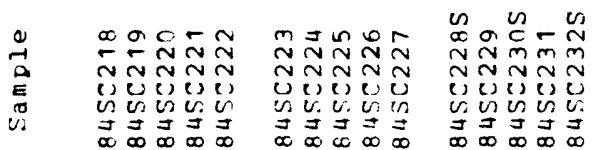

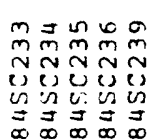

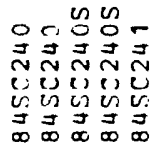

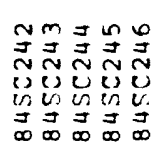

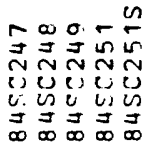

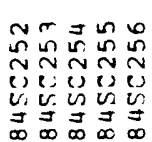

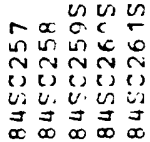




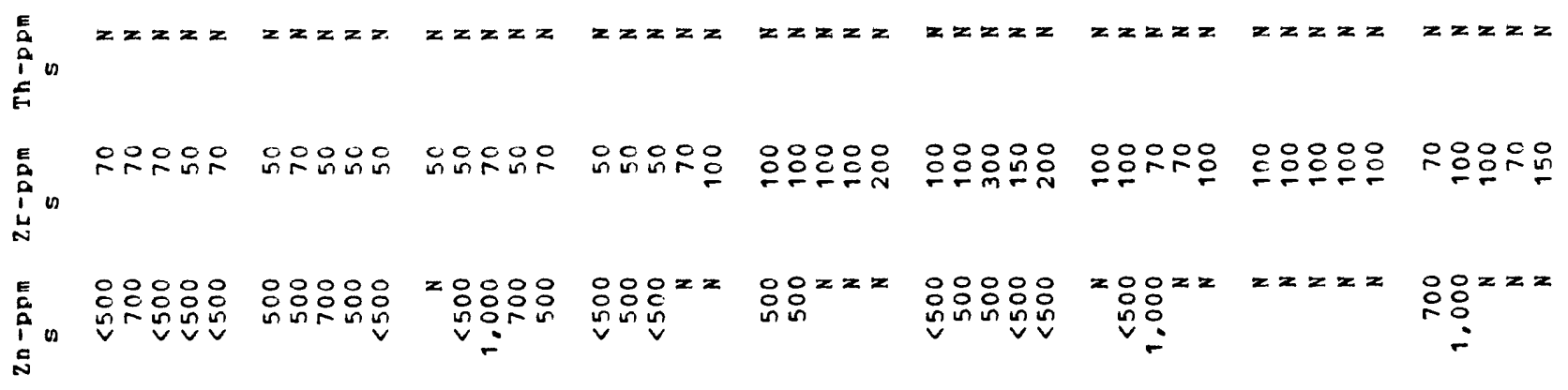

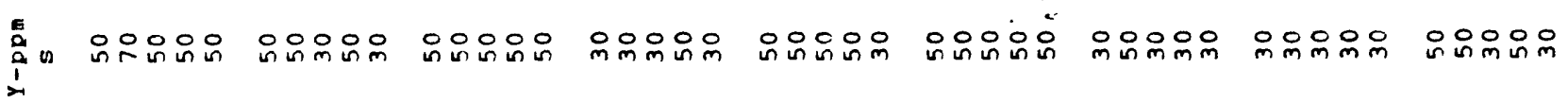

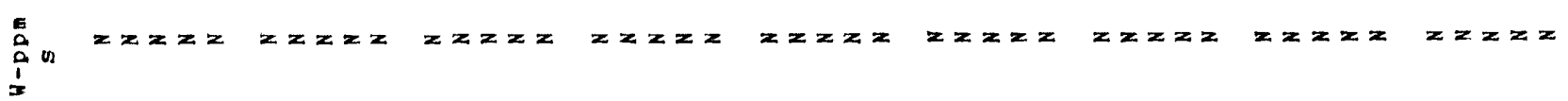

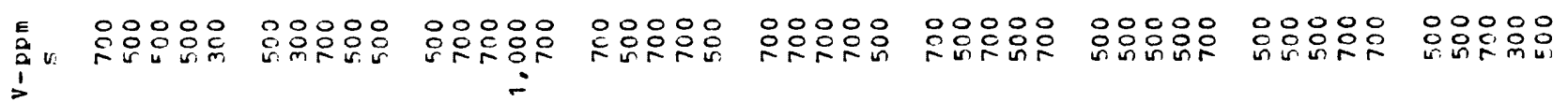

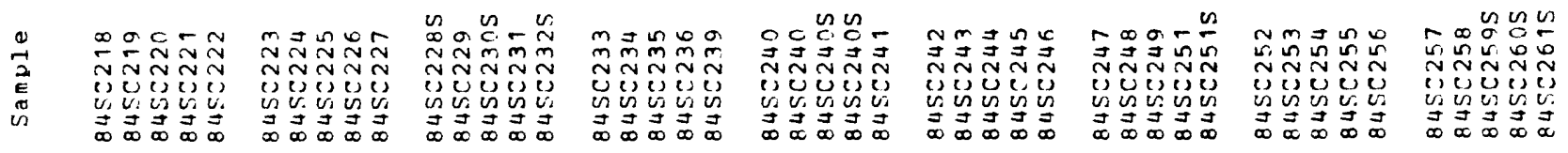




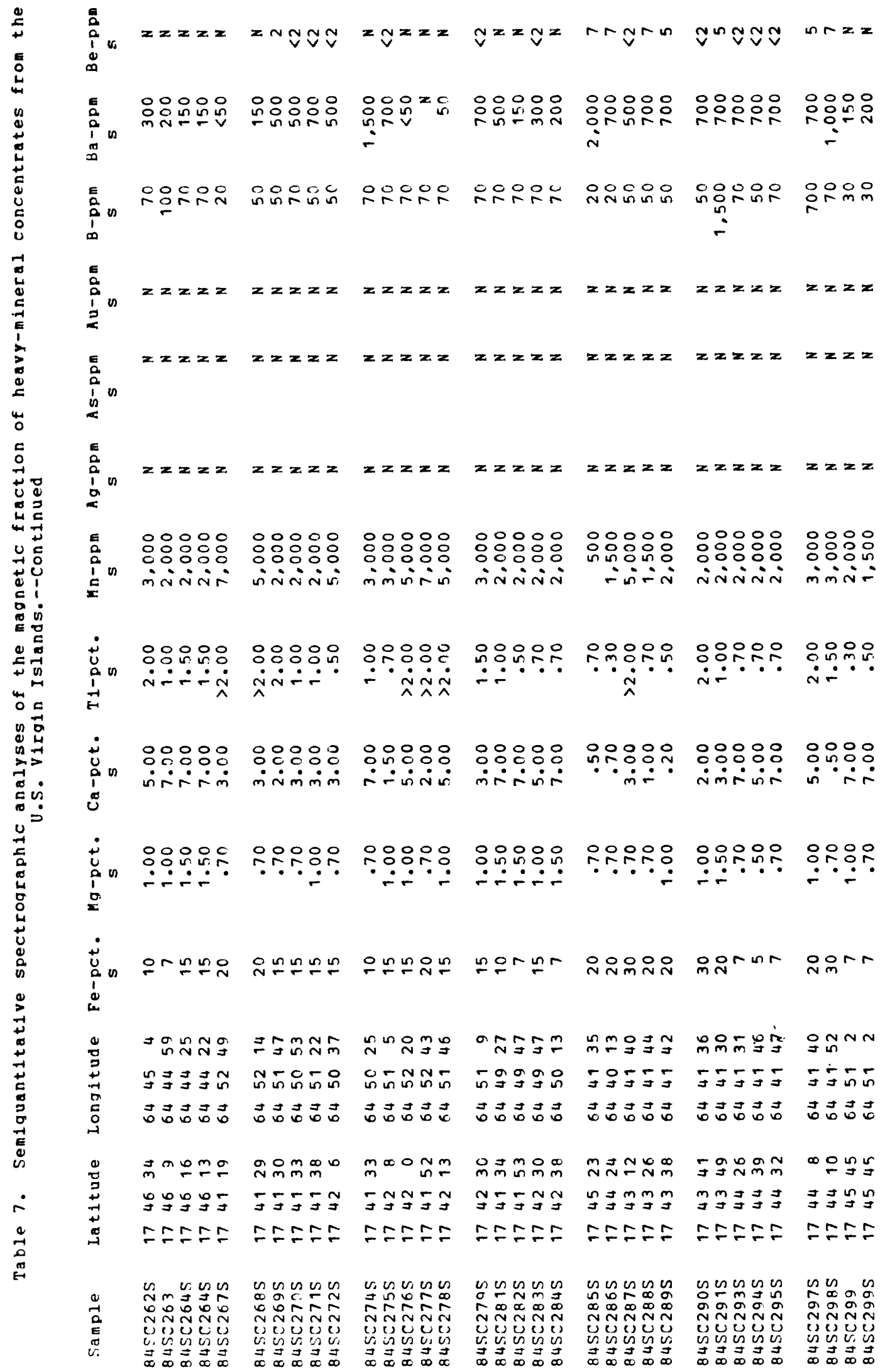




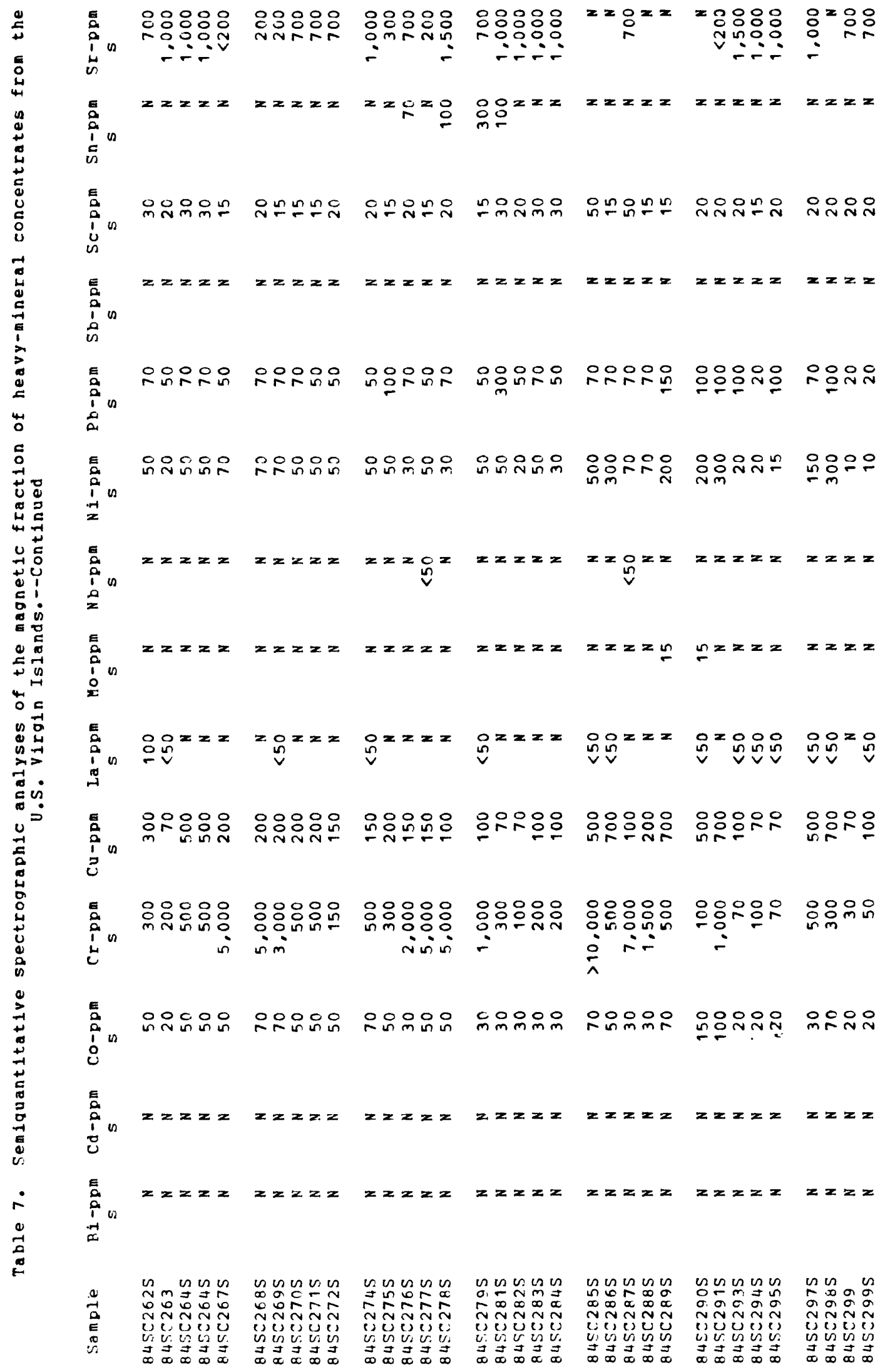




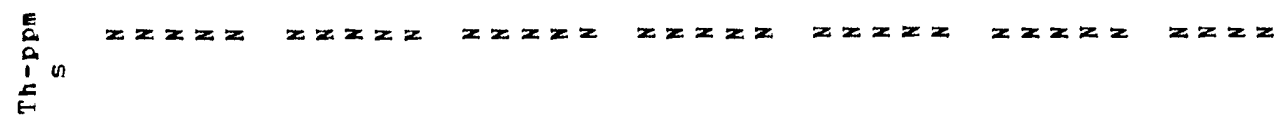

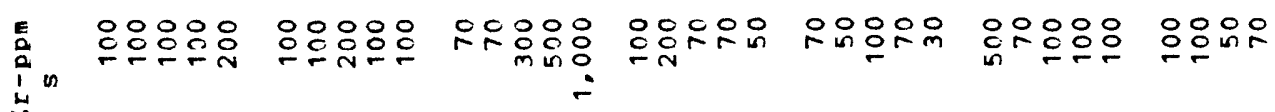

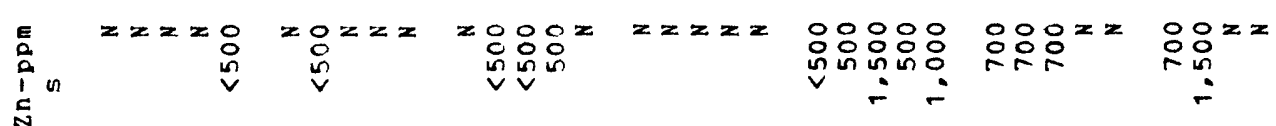

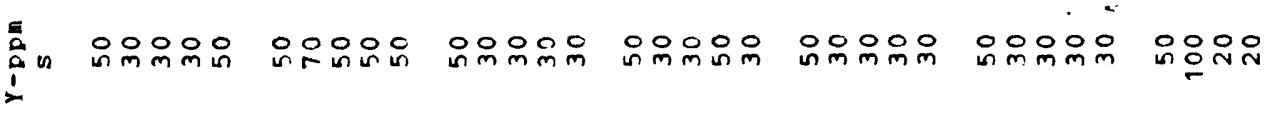

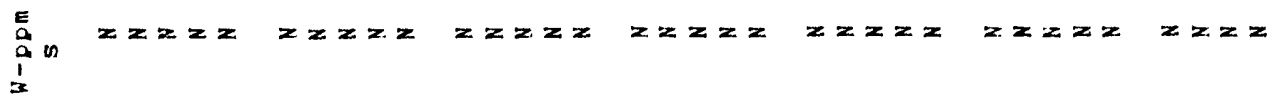

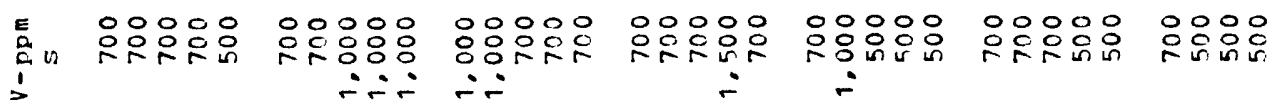

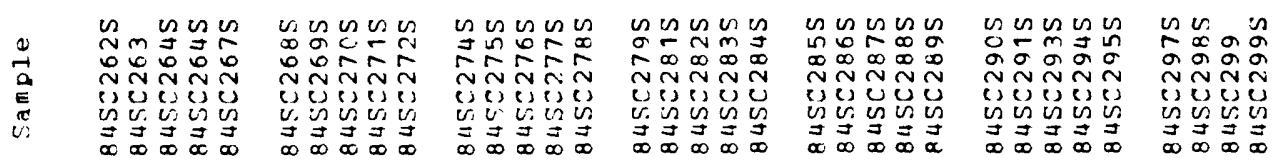


 $\therefore \because \quad \dot{0}=$
$\therefore \dot{m}$
in
¿テ:
$\therefore i$
i

¿

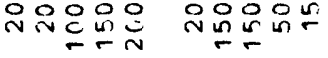

- OOOOS

n000

요용

00000

\section{0}

onoon

윤유유은

$z z z z y z z z z$

$z z z$

$z z z z z \quad z z z z z$

$z z z z$

$z z=z$

$z v z=$

$z z z z$

$N z z z=N z z z N$

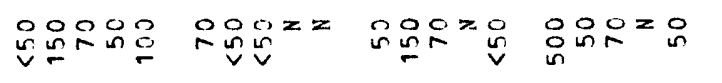

웅

$z=z$

$z z z z z$

$z<z z z$

o

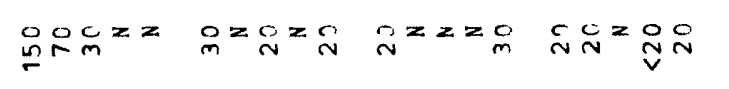

ocoso

$z z z z$

$z z z z$

$z z z z$

$z z z z=$

(1)

$z z z z$

$z z=2$

$z z z z$

$z z z z$

$z z z z$

$z z z z z z z z z$

$z z z z$

$z z z z z y z z z \quad z z z z z$

$z z z z$

$z z z z z z z z z$

$z z z z$

$z z z z z z z z$

\section{응ㅇㅇ 응ㅇㅇ응}

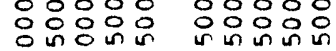

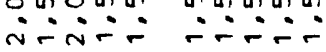

영응응

ming

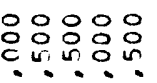

응응응

inifi

응응용요

in

응응응응

i-imin

응응영영

inini=

(20)

웅융유

영융응

응응응

웅응ㅇㅇ

응응요

$\pi-N \pi N$

nN-nN

$\therefore \therefore \dot{n}$

응응응

orimin

영영응

옹유능ㅇㅇㅇ

نं $\dot{\wedge} \dot{\sim} \dot{N}$

$\dot{\sim} \dot{\wedge} \dot{x} \dot{\wedge}$

on

000000

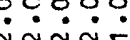

응웅으웅

$\dot{n} \dot{n} \dot{n}$

N⿻n从ग

응용ㅇㅇㅇ음

응응ㅇㅇㅇ응

minmin

vini் $\dot{0}$

응ㅇㅇㅇ

응응용ㅇㅇ

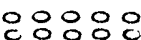

जinisin

$\dot{n} \ddot{i} \dot{m}$

с

00000

00000

00000

nunmin

우응ㅇㅇㅇㅇ

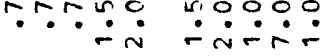

ำ.ㄴำ

$\because \because \frac{1}{2}$

i.

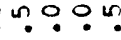

000

cooo

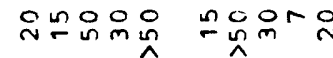

뚠요

으은요응

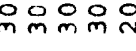

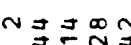

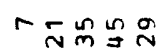

ㅋํำำ

负药的的

颛误寻昌

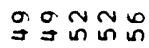

的的解范

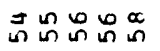

00000

ำ

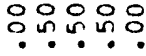

arta

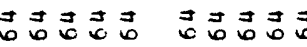

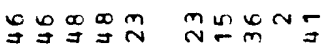

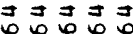

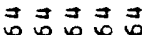

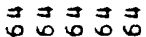

ํํㅇํํ로

gNNN每$$
\text { ( }
$$

$-\bar{m} \underset{m}{g} \stackrel{\infty}{N} 工$

$\infty-\infty \dot{m}$

은유윰유

으ํํํํำ

ofrog

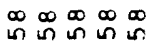

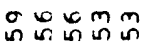

in

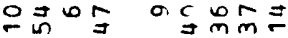

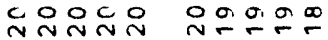

$=\stackrel{\infty}{\sim} \stackrel{\infty}{\sim}$

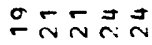

กลก

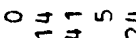

$\bar{n}=\sin$

\section{m}

(1)

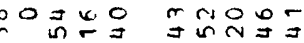

$\stackrel{\infty}{\sim} \stackrel{\infty}{\sim} \stackrel{\infty}{\sim} \underset{\infty}{\sim} \stackrel{\infty}{\sim}$

$\infty \propto \infty \propto \infty ⿻$

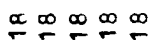

$\stackrel{\infty}{\infty} \stackrel{\infty}{\sim} \stackrel{\infty}{-}$

$\infty \infty \infty$

$\infty \infty$

ㄸำกㄴ.

$\stackrel{\infty}{\sim} \stackrel{\infty}{\sim} \stackrel{\infty}{-}$

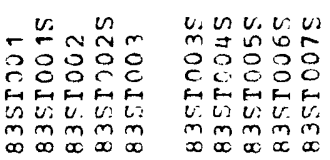

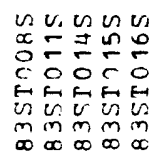

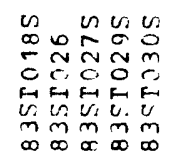

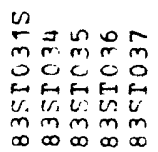

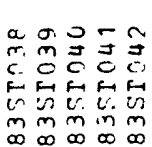

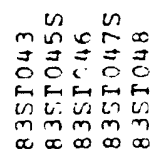

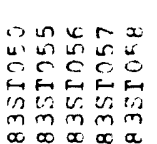

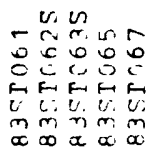


응응응 애는유

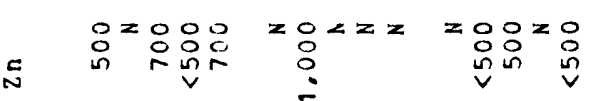

$0000=$

以in

4

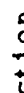

ư

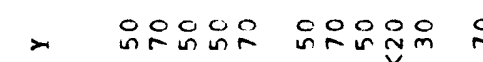

$z z z z z z z z z$

은유을

은유우은

$z z z z$

$z z z z z$

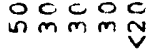

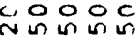

응응응ㅇㅇㅇㅇㅇ응

ondo

웅요

응응용응

응용으

$z z z z$

$z z z z$

mroos rogon

옹ㅇㅇㅇㅇㅇㅇ

옹ㅇㅇㅇㅇㅇ

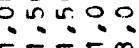

웅ํํ

응영응

요의?

응웅ㅇㅇㅇㅇㅛ

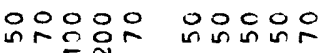

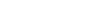

虫

08
$\therefore$
0

응ㅇㅇㅇㅇㅇㅇ응

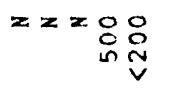

$\circ=0$
$\circ$
$\circ$

응응등유

응응유융유

$\stackrel{i}{v}$

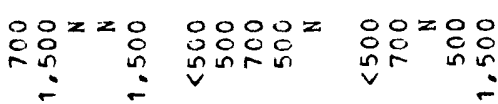

$z=0 z z$

$\therefore \because$

in

$z z z z z \quad z z z z$

옹우

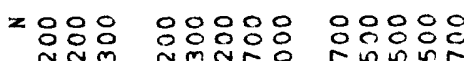

$\lambda$ n

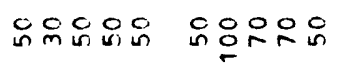

엔ㄷㄴㅇㅠ 유윤유

잉유요

$z z 0_{i} z$ in

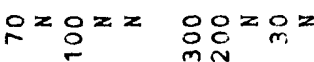

$z \quad z z z z$

$z z z$

$z z z z$

$z z z z$

$z z z z$

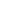

$z z z$

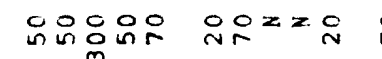

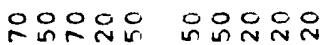

응윤도

논옹윰워

윳ํํ유요

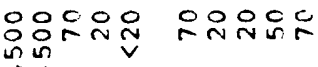

竞

$\bar{z}$

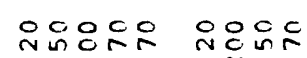

oo oco

cooon

0000

o000n

z

$z z z z \quad z z z z z$

$\checkmark$

$z z z z$

$z z z z$

$\operatorname{rng}$

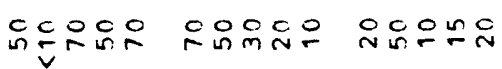

$z z z z z \quad z z z z$

운요율

$z z z z$

$n z z z z$

$z z z z$

$z z z z$

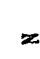

$z z z$

$z \quad z z z z$

ㄷํㅇ요의

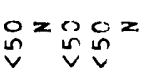

$z z=0 z \quad \circ z z \circ z$

$z$ 요요 $=x$

กิำ

$z$

윰융일요용

은응ㅇㅇㅇㅇㅇ

동ㅇㅇ응

웅ㅇㅇ은

언은ㅇㅇㅇㅇㅇㅇ

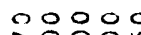

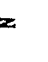

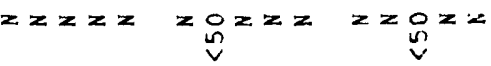

$\stackrel{0}{a}$

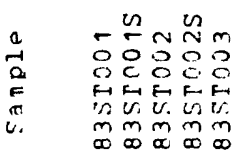

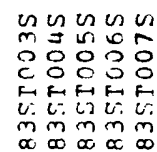

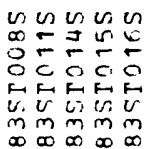

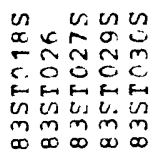

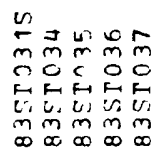

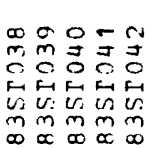

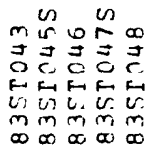

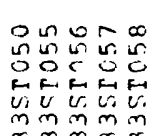

$-\stackrel{n}{n} \min$

c.

tht

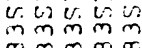




\section{ü \\ 응응ㅇㅇㅇㅇㅇ 응응응응 \\ ind in}

ن

¿

$\overrightarrow{0}$

$\approx$

$\stackrel{\infty}{\infty}$

㟧

落

U.

5

응용요

$\because \because n \dot{n}$ ninis

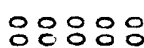

तi $\dot{N} \dot{N} \dot{N}$

응응응

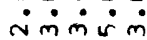

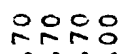

$\stackrel{0}{2}$

$\stackrel{0}{2}$

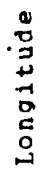

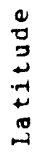

$\stackrel{2}{2}$

$z \geq z 2 z$

$z z z=$

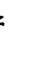

응응용응

نं $\dot{\sim} \dot{\sim}$

응ㅇㅇㅇ음

mirisi

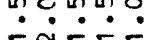

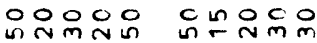

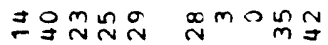

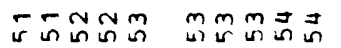

可苟苛

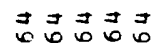

\section{ตํํํำ \\ $\therefore$ 皮}

의의

aㅇoㅇ

$\stackrel{\infty}{\infty} \stackrel{\infty}{\infty}$

$\stackrel{\infty}{\infty} \stackrel{\infty}{\sim}$

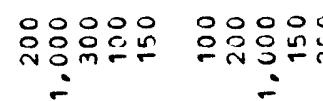

당응요

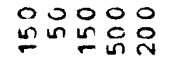

응응요웅

inmo $\therefore \circ$

in

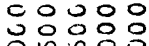

inn $\operatorname{lin}$ $00 z 00 \quad 00 z 00$

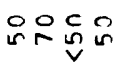

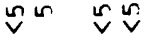
in

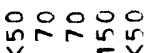

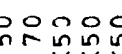
ข้ำ

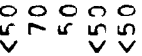

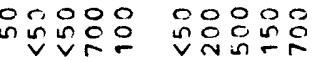

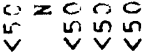

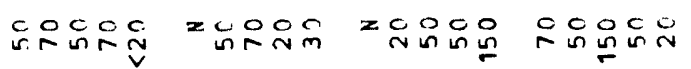

$z z z$

$z$

$z z z$

$z$

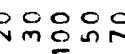

$z z z z$

$z z z z$

$z z z z z$

$z z z z z \quad z z z z z$

․․요

응웅응

i் $\dot{N} \dot{N} \dot{N}$

e.0.0.0

نini

$\dot{\sim} \dot{n} \dot{n}-$

응응응

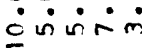

응ㅇㅇㅇ응

$\dot{m} \dot{\sim} \dot{m} \dot{m}$

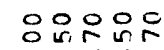

응웅요은

은우용ㅇㅇㅇ

$\therefore \dot{-1}$

- -

$\ddot{1} \div \dot{-1}$

은든듀엉

กำ

응ㅇㅇㅇㅛ

\section{oooon}

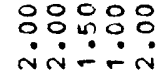

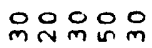

- 두용

읃응영응응

$\dot{n} \dot{m} \dot{m}$

\section{.}

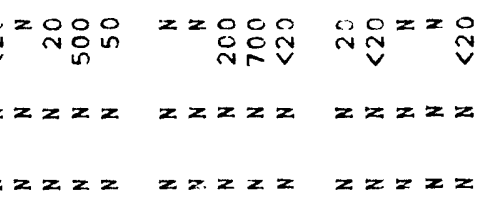

$z z z z z \quad z z z z z \quad z z z z z$

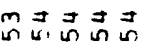

응의

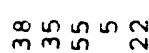

ํํำ

in

-orvin

n

ㅇํำก

융ㅇㅇㅇㅇㅇㅇㅛ

은응은응

둔?

00000 00000

กูก

in

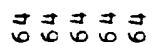

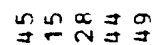

$\stackrel{\infty}{n} \stackrel{\infty}{n} m$

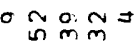

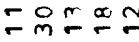

กำ

Nละกำ

윧ํํ유

유묻ㄴ

$\dddot{\infty} \stackrel{\infty}{\infty} \stackrel{\infty}{\sim}$

$\stackrel{\infty}{\infty} \stackrel{\infty}{\infty}$

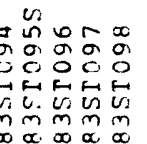

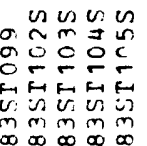

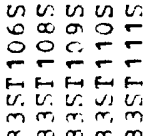

Nํ용ำ

응응

in vun

응용ㅇㅇㅇㅇㅇ $\because \because n N$ in

음응융 섯N서

웅융ㅇㅇㅇ

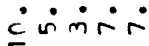

동응요요 $\because \because \because$

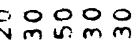

두요요 战坒昌昌

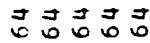
$\infty \propto \infty \infty$ 
$E$

$$
\text { N }
$$

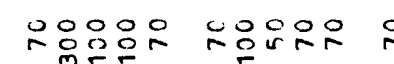
용ㅇ 80780

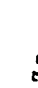

$\stackrel{\sim}{\sim}$ in $\because=$

은은은요

$z z z=2$

응ㅇㅇㅇ

$$
\text { r }
$$

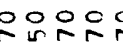

응ㅇㅇㅇㅇㅇ

은오은은

으용으은

은으동요

든요응요

응ㅇㅇㅇㅇㅇ

영 $z=0$
in in in

พับ

응운옹응

4

음응응

응응응응응

으으으은

옹으두은

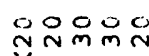

윰ํㅇํํ

유ำ ํㅝㄴ

z옹유이

은으은은

$z x z z=$

$z z z z$

$z z z z$

$z z z z$

$z=2$

$z=2 x z$

$z x z z$

응유유

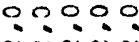

응ㅇㅇㅇㅇㅠ

응ㅇㅇㅇㅇㅇㅇㅇㅇ

요는?

ก!?ำ?

응ㅇㅇㅇㅇㅇㅇㅇ
004

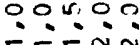

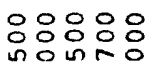

응응ㅇㅇㅇㅇㅇㅇ

응ㅇㅇㅇ응

non?

n?

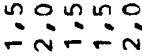

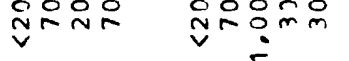

응응ㅇㅇㄷ

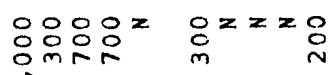

요용

in $x=0$

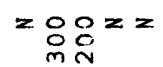

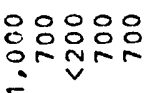

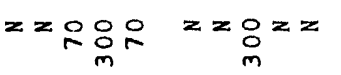

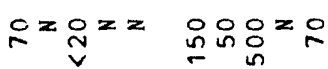

응 $z=z$

응 $x=0$

$\therefore \geq 0$

$z=80 z$

un

0000

우웅으은

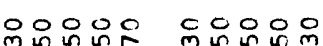

잉ㅇㅇㅇ

엉듕요

cood

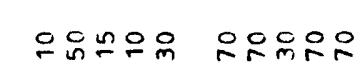

$z z z=$

$z z z$

$z z z z$

$z z z z$

$z z z z$ $z$

윰윰유

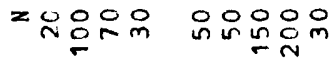

coooc O0OCO

00000

$\pi s 000$

ococo

\section{ococo}

\section{0}

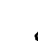

$x z z x y \quad z x z z$

$z=2 x$

z: $z x_{2}$

$z z z z z$

$z z z z$

$z z z z$

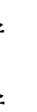

$z=2$

$z z z z$

$z$

$x \geq z z$

$z x z$ 응

$x=$

$\frac{0}{2}=$

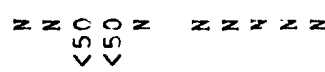

$z z z \circ z=z=0 x$

$z z z x z$

$z z z z$

$z z z z z \quad z=0 z$ in

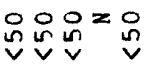

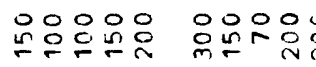

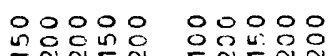

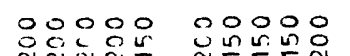

00000

00000

n-

은은음웅웅

$\stackrel{a}{a}$

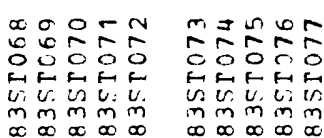

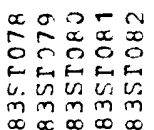

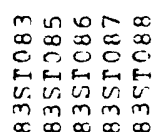

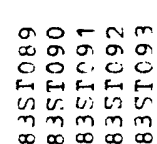

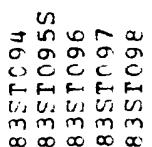

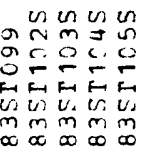

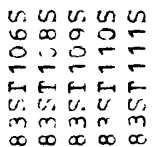

-NMJ

응응용ㅇㅇ

ज柁鸟记 

iनi mrin

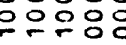

영ㅇㅇㅇ $\therefore$ i

niner $\therefore$ in

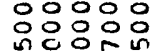
in:

영유

$ㅇ ㅡ ㅇ ㅇ ㅇ ㅇ ㅇ$

00000

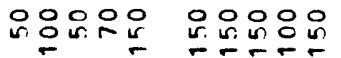

옹운융으

c0000

00000

오융ㅇㅇㅇㅇㅇ in $\therefore$ i: in

8

$z z z z$

은영영영 응영영영 जivimim 的㑊 응요웅

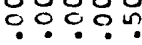
nNiñ응은

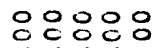
तंतiñ 응ㅇㅇㅇㅛ mंर्षिं

응윰응

옹융ㅇㅇㅇ $\therefore \dot{\sim} \dot{m} \dot{m}$ írin

있윰유유

유슛드용

กำ $=00 N 0$

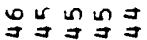
节芯吉吉吉 亲寻寻孚 苛范菏

nNNon $\bar{\sim} \bar{\sim} \bar{N} \bar{N}$

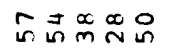
กักักัก $\stackrel{\infty}{-} \stackrel{\infty}{\sim} \stackrel{\infty}{\leftarrow}$ $\stackrel{\infty}{\infty} \stackrel{\infty}{\sim} \stackrel{\infty}{\sim}$

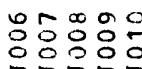

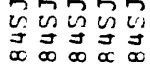

$-\sim m=n$ б드으

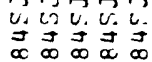

영영응 영웅융응

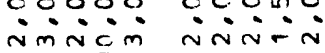

응응용응 $\dot{-i} \dot{\sim} \dot{x}$

용ㅇㅇ -

영웅응ㅇㅇㅇ

웅융응 $\therefore \dot{m} \dot{m}$

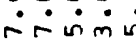

응용ㅇㅇㅇㅇㅇ

ㅇㅇㅇㅇㅇㅇㅇㅇ

in $\dot{m} \dot{\alpha}-$

$\dot{m} \dot{m} \dot{\sim} \dot{\sim}$

단음요소

구ㅇㅠㅠ융

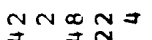

ํㅗำกัก

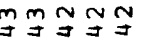

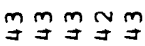

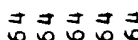

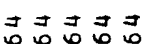

กㄴㅇำ

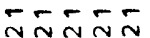

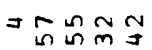
꾸슛유

$\infty \propto \propto \infty$

$\infty \infty \propto \infty \propto$

누두웅옹

的絮

u. u. vic

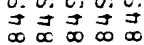

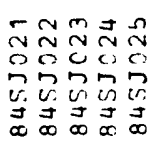

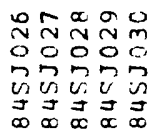

영융유

는둔 m-nim

응응응

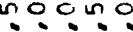

秐向

유윰읃응 $\because \dot{\sim} \dot{\sim}$

융응용요 -

응응ㅇㅇㅇㅇㅛ

mixi்

응ㅇㅇㅇㅇㅠ

$\because \dot{\sim} \dot{m} \dot{n}$

웅응ㅇㅇ

웅ㅇㅇㅇㅜ

$\dot{m} \because \dot{\sim}$

문

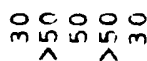

은은요음ㅇ

บํํำกำ

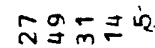
푀엄엉

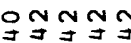

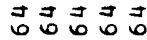

司吉吉吉吉

욤욨 추중요

$\stackrel{\infty}{\infty} \stackrel{\infty}{\infty}$

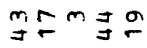
웃도의

$\infty \infty \infty \infty \infty$

응ㅇㅇㅇㅇㅇㅇㅇㅇ

r.

-niñ

응응영영 은드. ininim

응융ㅇㅇㅇ응

웅융응 $-\dot{N} \dot{x}-\dot{x}$

웅웅응 NNNNN

읃응응응

o00용

min

ㅇoㅇ응 NกNล mm nn

응ㅇㅇㅇ 웅ㅇㅇㅇㅇ $\because \frac{0}{0}: \dot{0}$

응응응

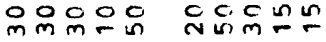

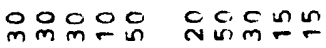

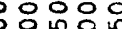

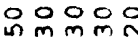

mูag

$=$ 요뭉

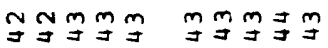

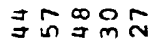

诂司可

m气ูำ

00000

Om n⿺辶

뚜욜

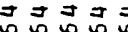

aga

a9929

윰ำ용

$\infty \infty \infty \infty \infty$

$\infty \infty \infty \infty \infty$

음의의

$\stackrel{\infty}{\infty} \stackrel{\infty}{-} \stackrel{\infty}{-}$

-

लिखिंm

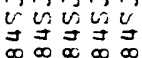

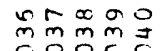

든

GUv

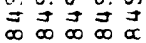

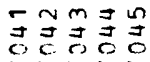

एवृen

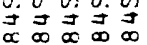

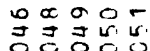

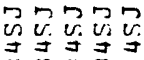


E

N

ร

:

영영웅응

손?

응ㅇㅇㅇㅇㅇㅇ응

3.?.:0

Ninin

응응응=

$z=O^{z}=$

응으운

읃응ㅇㅇㅇㅇㅇㅇ

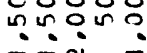

응ㅇㅇㅇㅇㅇㅇㅇㅇㅇ

in:

응응ㅇㅇㅇㅇㅇㅇ

ㄴ?

잉ㅇㅇㅇㅇㅇㅇㅇ

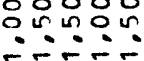

응ㅇㅇㅇㅇㅇㅇ

$\because \because \because 9 !$

$\circ z=z z$

응윰윰윰

$z z z=$

$z$

$z=O^{2}$
$\stackrel{\circ}{\mathrm{O}}$

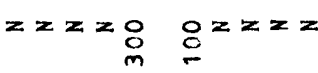

$z z z=2$

$z=28$

$z z z$

$z$ 용요

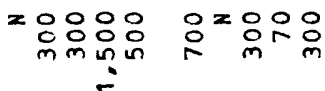

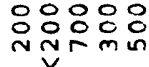

은옫ㅇㅇㅇㅜ 은은응

$z z z=$

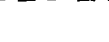

$z z z z$

\section{$z$}

은융유

은유늠ㅇ

on on

oodon

윳유

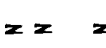
언엉ㅇㅇ 응잉요욤

ㅇmㅇ유운 은도윰요

Ocooo

음음듀웅

을옹으웅

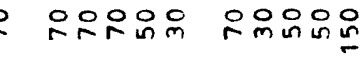

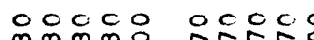

00000

00000

00000

o0000

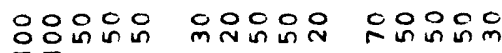

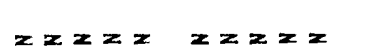

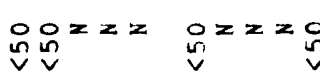

$z z=0$

$z \underset{\cap}{0}=x=$

$z z z z$

$z=0, \underset{n}{n}=2$

z 은은

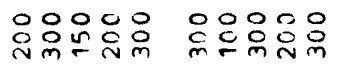

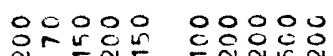

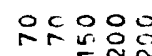

웅ㅇㅇㅇㅇㅇㅇㅇㅇ

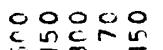

응유융요

$\frac{0}{0}$

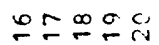

응․

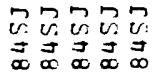

$\stackrel{\sim}{N} \underset{N}{N} \stackrel{N}{n}$

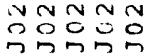

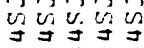

ํํำ 월 뜽ํㅇำ

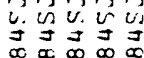

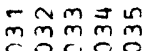

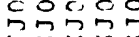

U. U.

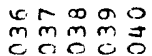

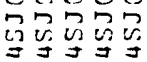

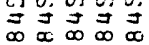

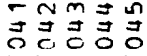

근근 U. U⿺辶寸

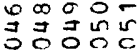
근근

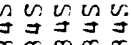




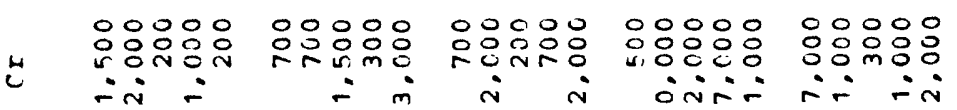

운

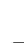

i

$\infty$

$\nsubseteq$

$\infty$ $\circ$

:

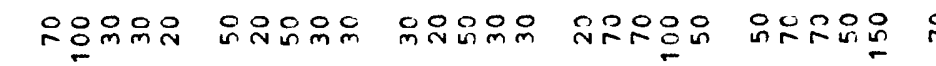

$z z z z z z z z z$

$z z z z$

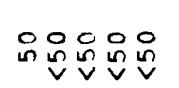

$z=z$

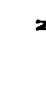

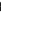

$\infty$

$z 2 z=2$

$z z z z$

$z z z z$

2

2

$z x z z=$

$z z z=$

$z$

$2 z 2=$

응응응

용유

응융융유

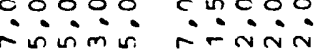

영영응

융유

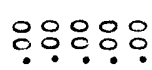

NกN

i

i $\operatorname{Ni}^{\alpha} \dot{N}$

옹응ㅇㅇㅇ

응ㅇㅇㅇ

부운

rí용ㅇㅇ

응응응

부용

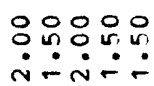

응용응

응유

$\dot{\sim} \dot{N} \dot{\sim} \dot{\sim}$

的的立-

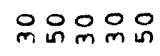

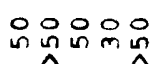

웃ㅇㅅㅅ유음

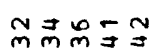

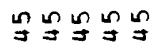

的背品

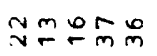

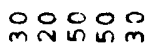

जै

농웜워

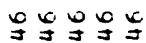

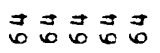

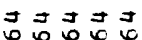

กลำ

운유융ㅇ

INON

에나

I

윰ㄷN융요

유유슈유

$\stackrel{\infty}{\sim} \stackrel{\infty}{\sim} \simeq$

$\stackrel{\infty}{\infty} \stackrel{\infty}{\sim} \underset{-}{-}$

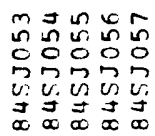

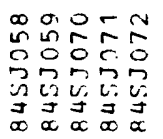

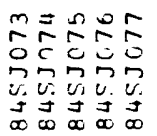
을요용

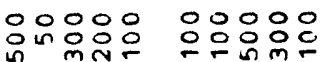

응ㅇㅇㅇ iั่

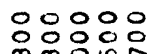

$\therefore$

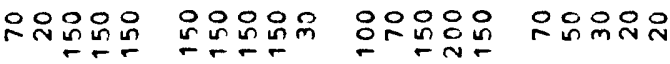

$z z z z z \quad z z z z$

$z z z z$

$z z z z$

$z z z z$

$z=2 z 2$

$z z z z z$

$\mathbb{N} \geq z \geq z$

응응ㅇㅇㅇ

$\therefore: 0: 0$

$z z z z$

$z z z z$ n nก-

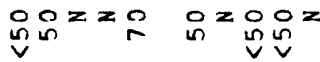

$z z z z$

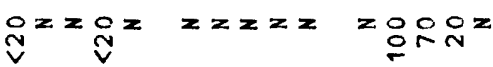

$z z z z z \quad z z z z z \quad z z z z z=z z z$

$z z x z$

$z z z z$

$z z z z$

$z z z z$

$z z z z$

$\because z z z z$

$z z z z$

$z z z z$

응융융

ínini

윰웅유.

수숫ㅊ

응ㅇㅇㅇㅇㅁ

जiñinin

응융ㅇㅇㅇ

$\because \because \dot{\sim} \dot{ }$

눈용요

등요음동

융ㅇㅇㅇㅛ तinini

웅응응

imin

오ำำก

欲寻寻寻

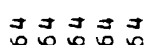

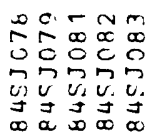

응융ㅇㅇㅇ $\because$ ․․․

응융ㅇㅇㅇ응 iniviní

응융융유 $\because \because \cdots$

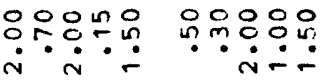

응요요 ini:-

운윤융유 응용요 용유 $\dot{\circ} \dot{\circ} \dot{\sim} \dot{\circ}$

$\dot{n} \dot{i} \operatorname{in}$

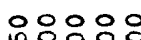
பn்ंत.

ㅇㅇㅇㅇㅇㅇ

응윰요 웅요융

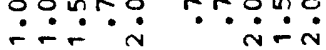

옹유용 ن்

00000

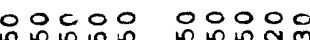

응ㅇㅇㅇ응

뚜두뭉

的的知

ํำกำกั

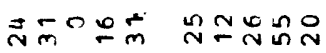

$\operatorname{m}=-\infty$

으수숭으

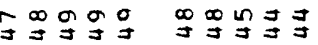

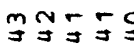

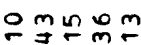

寻寻寻寻守

可可者

可苛萿

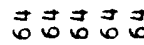

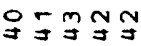
हैं

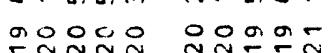

$\bar{\pi} \bar{N} \bar{N}$

m

$m=\infty 0 x$

芯志吉芯吉

$\stackrel{\infty}{\leftarrow} \underset{\infty}{\infty}$

กลกกล

둥유유

J舟的舟事

$\infty \infty \propto \infty \infty$

$\stackrel{\infty}{\infty} \stackrel{\infty}{\infty}$

$\infty \infty \infty \propto \infty$

ํํำ

$\stackrel{\infty}{-\infty} \underset{\infty}{\infty}$

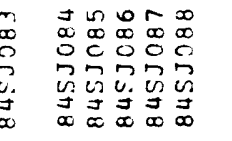

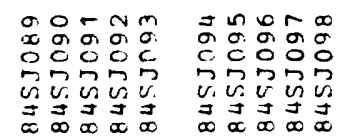

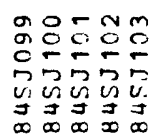

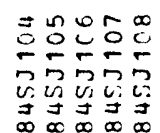


으응 $x=0$

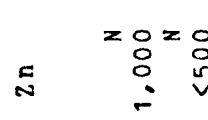$$
\begin{aligned}
& 0=0 \\
& 0 \\
& 0
\end{aligned}
$$

융 $z=0$ ㅇํㅇ

20
in ${ }^{2}=$

V눈요

오응응

은드음요음

응으은요

ocooc

00000

Un

in $x$

$000=0$

$z z_{z x}$

$z z z z$

$z x z z$

$z z z=$

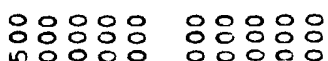

?min

$\because \sin$

응ㅇㅇㅇㅇㅇㅇㅇ

은ํำ

응ㅇㅇㅇㅇㅇ응

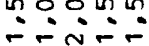

응응ㅇㅇ음

$-i n$
0

응응ㅇㅇㅇ응

in:

응응응ㅇㅇㅇ

$\because \div$ i

응융ㅇㅇㅇㅇㅇ

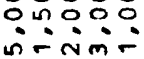

응요윰

응융ㅇㅇㅇㅇㅠ $z=$ 응융유

은응응응요

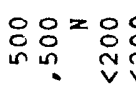

응을용요

$\begin{array}{ll}0 & x=2 \\ 0 & 0\end{array}$

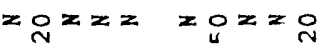

응유 $=2$ 응

일 $z x z y z x z$

$z=z \circ \circ$ ì

$u$

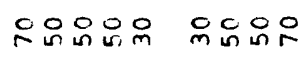

$z z_{1} z$

$z x=x$

음우음요

도응유융

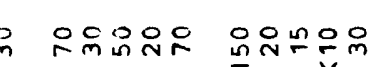

$x \geq 2 z x$

$z z z z$

$z z z z$

$z z z z z$

$z=0$

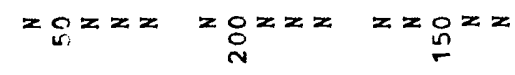
v.

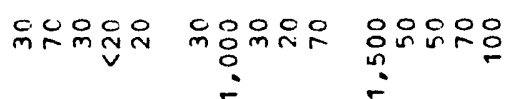

응요응윰

응은다요

든응ㅇㅇㅇ

$\because$

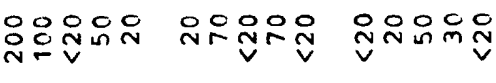

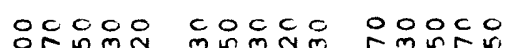

응ㅇㅇㅇㅇ

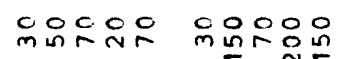

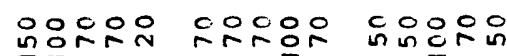

$z=2 z$

$z=\geq \geq$

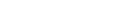

$z x_{1} z z$

$z z z z$

$z z z z$

$z=z z$

$z x z z$

$x z z z$

$x \geq 2 z$

$z z z z z \quad z z z z$

$\underset{\pi}{\pi}$

율 $z$ 㖞 $z$

$z=2 z z$

$z=\stackrel{g}{v}=0$

$z$ 윰 $z=$

$z x \geq z=$

$z z z z$

$z x z z$

$z x z z z y z z$

을융유융유

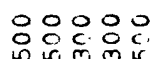

응ㅇㅇㅇㅇㅇㅇ

은ㅇㅇㅇ운

$z z=2 z$

$z z x \geq z$

$x z x z$

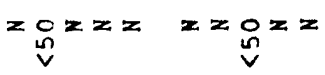

$\stackrel{\infty}{\infty}$

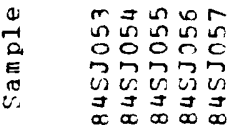

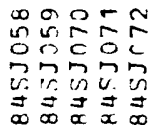

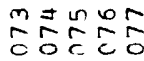

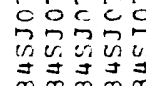

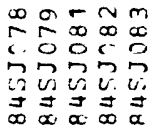

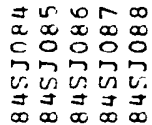

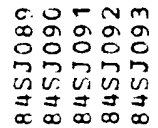

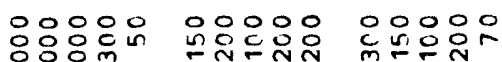

잉잉요 응융 $\because \div$

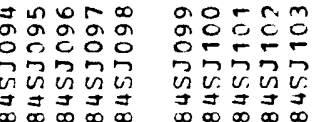

ㄹ. 농ㅇㅇㅇ

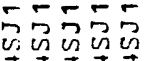

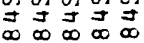




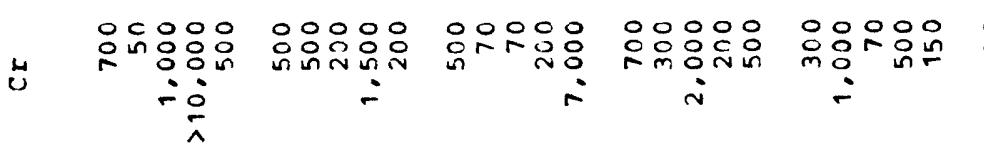

o

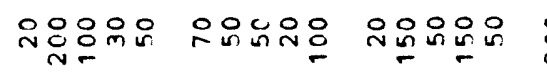

0

$+1$

๓

$\infty$

0

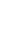

莒

$\infty$

$=$

2

$z z z z$

$z x z \stackrel{\sim}{\mathcal{V}} \underset{V}{\mathcal{V}}$

$z \geq z z z$

(1)

$z z z z$

$z z z z$

$z \underset{N}{O} z=$

응유은옹

웅응요음

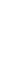

$z z z z$

$z z \mathrm{O}^{2}$

$z z z z$

$z$

$z \mathfrak{z} z=$

$z z z z$

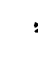

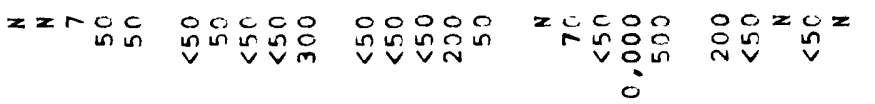

$$
\text { ㅇ }
$$

$z x z=$

$z z z$

$z z z$

$z z=\frac{0}{i} z \quad z=z z z$

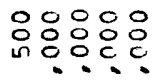

응읃유

둔ㄷㄴ

응웅융

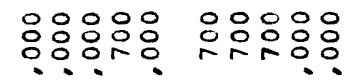

i $\because \because \because i$

$\therefore$

응요

선

nnn

둥ㅇㅇㅇㅇㅇ

웅ㅇㅇㅇ

๙

웅응ㅇㅇㅇ NNNN

i

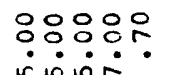

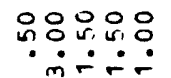

응웅웅

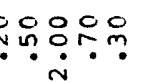

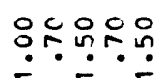

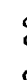

응응으

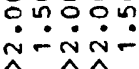

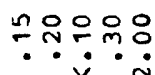

80808

inimin:

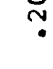

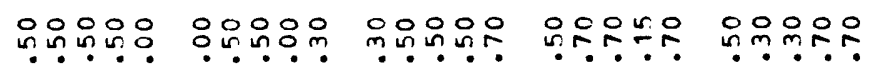

$\stackrel{0}{2}$

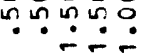

ํㅜㅁำ

mํำ

․․․․

응음웅ㅇㅇㅇ

$\therefore \because \because$

\section{운}

ำำ

ㄴํํํํำ

응융유웅

iन

옹웅용응응

$\therefore \therefore$

응응응

늠으.

:

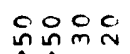

등응용ㅇㅇ

웅ㅇㅇㅇ

은둥요

드임잉요

늠우융

응오잉

00000

-naun

요요

กำำำำ

品一品前

可星寻寻寻

可寻寻寻昌

约狩寻学可

年年企占

mํำ

งธำกำ

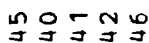

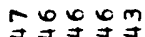

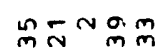

\section{$\exists$}

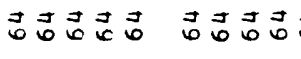

㞋者古古

可古考古

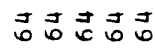

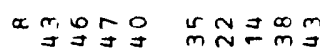

ระกัน

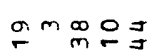

ッコีコ

可寻吉可

욱은

두엄도

으웃ㅇㅇ

웅ㅇㅁㅇㅢ

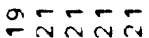

윷의

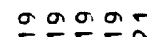

$\stackrel{\infty}{\infty} \stackrel{\infty}{=} \stackrel{\infty}{=}$

$\stackrel{\infty}{\infty} \propto \infty$

$\not \propto \infty \propto ⿻ 上 丨$

$\propto \infty \infty \infty \infty$

$\stackrel{\infty}{\infty} \stackrel{\infty}{\leftarrow} \stackrel{\infty}{\leftarrow}$

$\infty \propto \infty \infty$

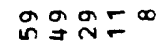

웅우운

$\infty \infty \infty \infty \infty$

minm

ㅇํำํำ

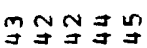

西

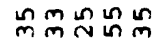

a oor

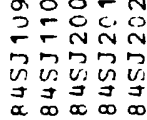

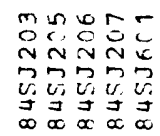

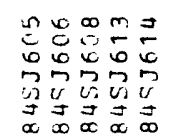

수ㅇㅝㅛ

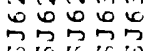

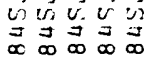

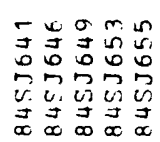

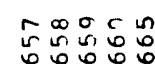

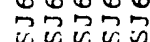

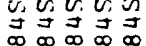

어눈

象包包

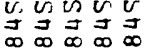

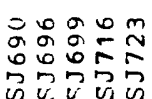

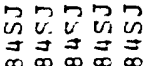

웅ㅇㅇ응ㅇㅇㅇ 무

은응응응 $\therefore \dot{4} \div$

웅응ㅇㅇㅇ 눈

은드응응

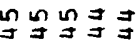

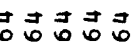

오를월은 유윳N유 $\because \infty \stackrel{\infty}{\sim} \stackrel{\infty}{\sim}$

Nomm

N-NA

额鸟

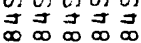


E

$\stackrel{H}{N}$

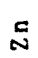

¿

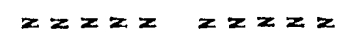

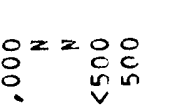$$
=0=0
$$$$
\text { z }=080
$$$$
\begin{aligned}
& 0 \\
& 080 \\
& 0 \\
& 0
\end{aligned}
$$

운유유요

운응응

응요

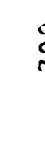

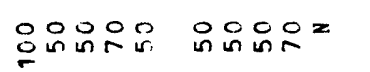

$z z z z z \quad z z z z$

윰유유유

$\geq 0 \geq 0$

$z=x z$

융ㅇㅇ 융유

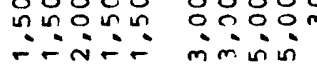

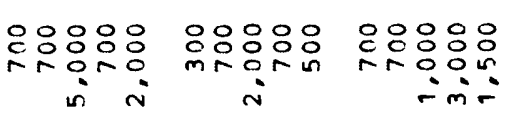

i

$\therefore$ 我

응ㅇㅇㅇ

inㅇㅇㅇㅇㅇㅇㅇㅇ

z $x$ 웅용

응유유

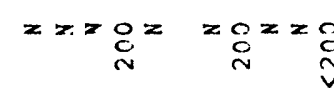

$z z z z$

$z z z z$

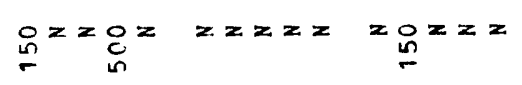

$z z \underset{m}{0}=z$

$z=z$ 品

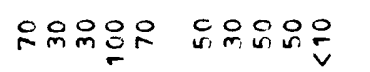

$z x z z$

$z z z z z$

$z$

든댕웅요

00000

$$
\text { 욤 }
$$

c

두융윤ㅁ

운유은

으뇨엔ㄷㄴ

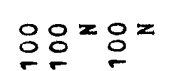

$z=$ in $x=$

(1)

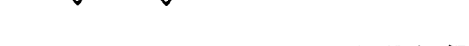

$z z z z$

$z z z z z$

$z z z z$

$z z z z$

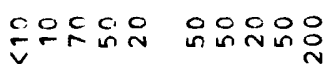

은오용요

ㅇํㄴ은

웁원음은

다이 $=2=$

$=$

$z z x z \quad z z z z z$

$z z z z$

$z z z z$

$z=z z$

응용요

\section{웅}

$\sin 100$

$z z z z$

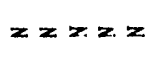

$=$

$z z z$

$z z z \stackrel{n}{v} z=z z z$

$z=z z$

$z=z{ }_{m} z$

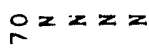

$z z z z$

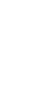

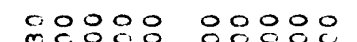

음동응

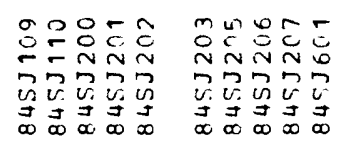

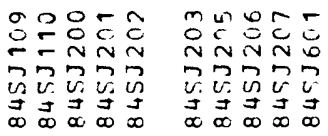

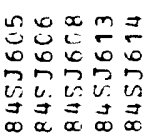

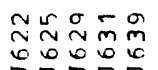

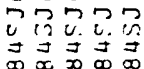

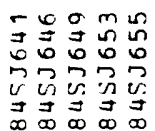

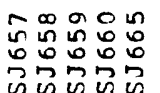

记解

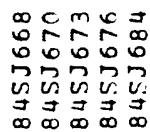

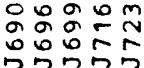

纪村

ำำ

Nmmm

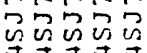

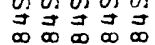


Ü

i

¿

$\vec{\infty}$

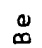

$\infty$

$\infty$

$z$

2

2

5

$\vec{E}$

ษ

$z x z$

z

$=\stackrel{0}{\dot{\square} \frac{0}{v}}=$

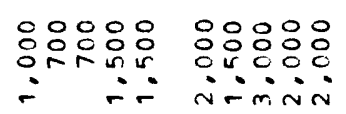

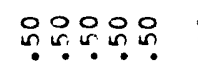

응융유

$\because \because \because \dot{\sim} \dot{\sim} \dot{\Lambda} \dot{N}$

응는용ㅇㅇ

용요

$\because \because \dot{m}$

Nंن்ंm

웅ㅇㅇ응

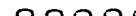

$\stackrel{0}{2}$

$\stackrel{8}{2}$

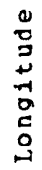

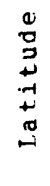

$m m m-n$

ลกลก

$\stackrel{\infty}{\sim} \stackrel{\infty}{\sim} \stackrel{\infty}{=}$

$\operatorname{nan}$

ลำ

뜬ㄷㄴ

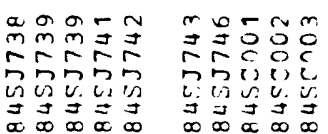

응ㅇㅇㅇㅇㅠ

mंñति

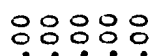

NㅅNㅅN

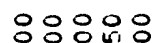

$\dot{m} \dot{m} \dot{N} \dot{\sim}$

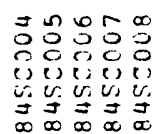

응용ㅇㅇㅇ

$\therefore \because \because 9$

$\therefore \circ 800$

숫ㅊㅅㅅㅅ

옹용ㅇㅇㅇ

$\because \because \dot{\sim} \dot{\sim}$

운유웅응

웅ㅇㅇㅇㅇㅇㅇㅛ

$\therefore \therefore-\therefore$

융윳읏요

고ำำำ

욱웝의

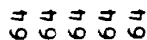

$\overrightarrow{3} \mathfrak{=}=\infty$

$\cong$

ㄷำ

ำ的两

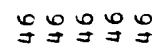

ニะIF

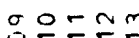

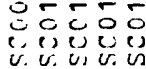

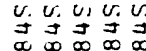

응응응응

的补

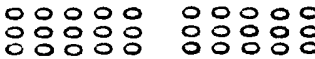
nivivin ínimin
응응응

oin

ज泣:
응응용 $\therefore$

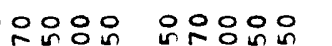

$z z z$

은도온은

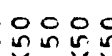

ทำ zazz

$z z z=$

$z z z z$
2

$z$ $z=z z$
$z z z z$
$z z z z$
$z z z z$

영융응

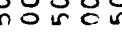

$\because \because n$ in

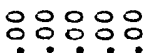

응요움

ㅅNㅅN섯

솟N수

응응응

ஸंतini

은융웅요

$\therefore \dot{\sim} \div \dot{\circ}$

웁웅ㅇㅇㅇㅇㅇㅇㅇ

-

\section{(1)}

옷용ํㅅㅇㅛ

으숫음요

in

m $\approx$ m

ำกำ

ower

ษュง

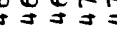

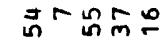

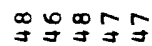

ืี

$\vec{\nabla} \vec{a}$

जै $\overrightarrow{0} \overrightarrow{0} \overrightarrow{0} \overrightarrow{0}$

ํํำํํำ

o요요

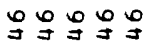

un

エะニニ

도는

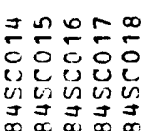

윳NNN

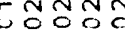

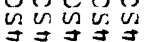

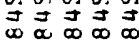

응응영응

Nंimm

$\therefore:: 8:$

섯N서

응응음

Nंن்-:

운웅응

\section{oo}

$\vec{\infty} \underset{\infty}{\infty} \vec{\infty} \underset{\infty}{ }$ $\therefore \therefore i$

응응우우

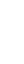

$\therefore \circ: \circ: \circ$

$\because \because 904$

minim -

응응 $\because 2$ 는

융ㅇㅇ

ixं $\dot{x}$

응요웅

inin

윰용요 웅용요 $\because \because \because \therefore ・ \because ・ ・$

응ㅇㅇㅇ

온은유온

\section{숫}

กำำกำ

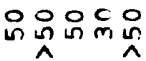

이욤요

ำงกำ

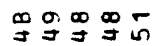

응요은

芯芯芯苛 $\stackrel{\infty}{\rightarrow}$ 只

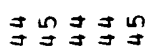

กะะระ
둣둉응

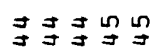

든드

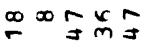

ป

ะะะะร

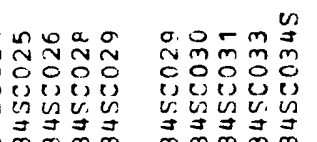

ines

min

i) oc o o

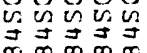


E

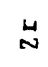

$\stackrel{5}{5}$

$>$

3

$>$

虫

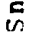

$\ddot{u}$

is

2

$-1$

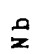

ㅇ․

$\stackrel{0}{\oplus}$

己.

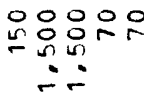

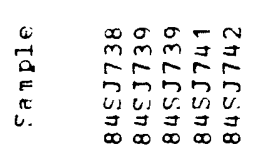

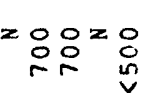

음유믄

응융ㅇㅇ

율 $z=$

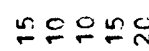

$z O O$
유
$V V$

응욘돈도

z:유 $z z z=$

$z z z$

$z x z z z$

$z z z z z$

$z z z z$

$z z z z$

유유유

m

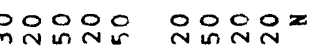

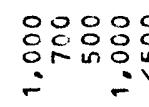

웅융윰요

응응융음

\section{응ㅇㅇㅇㅇㅇ}

ㄴ.

\section{ind}

음워ㄴㅠㅠ

은윤

$\mathbb{N}_{z=z}$

$z z z z$

\section{응ㅇㅇㅇㅇㅛ}

in:용ㅇㅇ

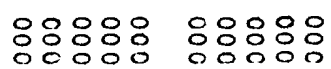

inimin?

응융유

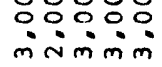

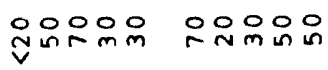

¿ㅇ

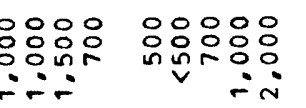

용ㅇㅇㅇㅇㅇ

i:

윰유유

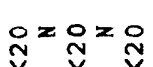

윤윤유

กิ

유 $z$ 윰유

$z x z=$

$z z z z z$

$z z z=$

$z z z z$

$z z z z$

$2 z 2 z=$

뜌뜨융웅

$z z z z z$

$z \underset{r}{0}=2$

c 2

$z z z z$

$2 x z 2 z$

$z z z z z$

융용요

minmin

응응ㅇㅇㅇ음

군웅

$z z z z z \quad z z z z z$

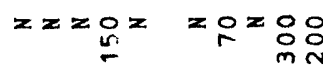

응

$n: 0$
0
0

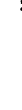

$z z z=0$

융유

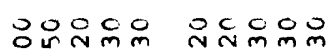

대있우있요

으웄옹요

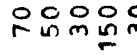

응은우응

$-$

응윤응

우숨원응

oococ

암

$z z z z$

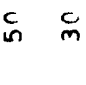

coco

00000

in

응ㅇㅇㅇㅇㅇ

웅응요

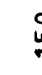

욷응ㅇㅇㅇ

은

욹윤윤윤욘

옹은요옹

$z z z z$

$z z z z$

$z z z=$

$z=2 z$

$z z z=$

$z z z=2$

$z=z z$

$z=2 z$

$z z z z$

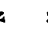

$z z z z \quad z z z z z$

$z z z z$

$z z z z$

$z z z z$

$z z z 2$

$z z z z$

$z x \geq z$

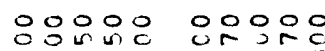

\section{0}

\section{0}

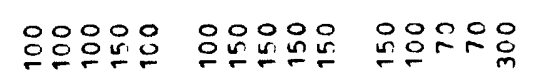

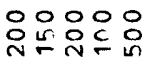

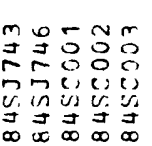

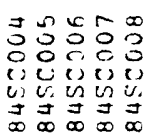

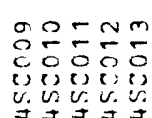

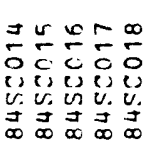

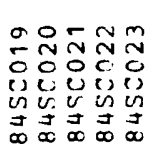

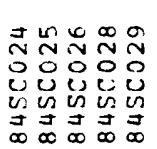

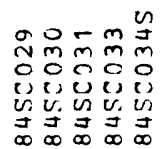

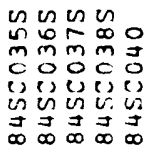




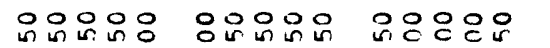

잉ㅇ 웅ㅇㅇ

出

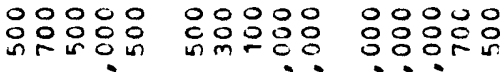

in

ion

응용ㅇㅇㅇ

iñ

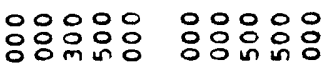

im :-

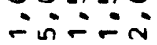

응ㅇㅇㅇ응

$\therefore \because \because i$

응응응

$\therefore \circ: \circ 0$

$\therefore \because$

in i

¿

$\vec{\infty}$

$\stackrel{\oplus}{\infty}$

$\infty$

$\infty$

2

2

2

$\underline{\Sigma}$

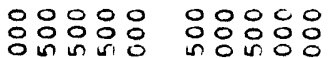

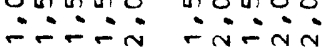

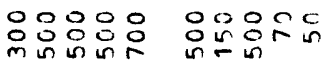

西

$z z z z$

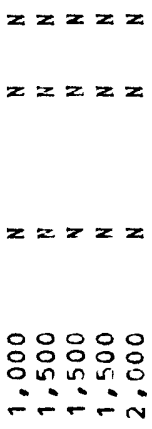

융용ㅇㅇ응

응오옹응

$\vec{H}$

$\because \div$

$\because \because \div$

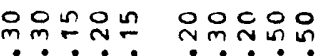

…

…ㄴ

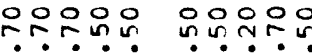

\section{:}

\&

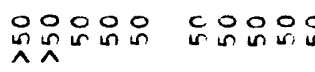

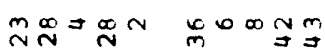

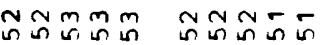

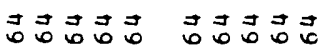

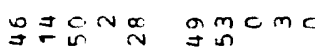

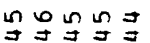

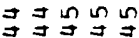

ヒะะะ

ะ⿱上ละ

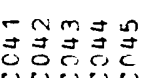

एक

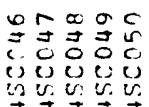

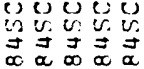

응응용요

은옹ㅇㅇ옹

$\therefore$

윤오눈온

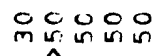

的的的

เด็

m.m $m \underset{\exists}{\exists} \vec{\exists}$

fะ์ะ์

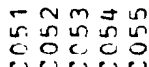

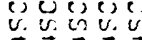

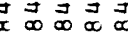

윤동ํํ용

$z \stackrel{0}{m} z=$

$\therefore \sqrt{10.5}$

응유음

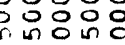

$\because \because n$

영응ㅇㅇㅇㅇㅇㅇ

inin

응응ㅇㅇㅇ

nn:

$\because$ inim

응ㅇㅇㅇㅇㅇㅇ응

숭

응응유

읃응ㅇㅇㅇ응

نं $\dot{i} \dot{\wedge}$

NNN서

웅유웅

NลNกN

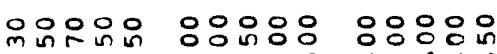

m.ำ.ㄴำ

뭉뭉

수수

웅오용요

ำ

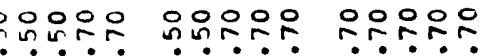

ํำ

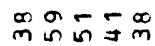

\section{的的}

\begin{abstract}
응요
\end{abstract}
in

0000

政

0000

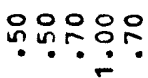

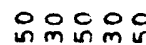

r.

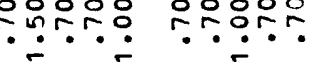

$\sim_{m}^{\infty} 00 \prod_{m}^{\infty}$

공ำำ

กำลำกี

ำ

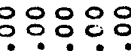
กNำก

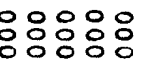

$\because \because 0: 9$ 응응용ㅇㅇ용 $\because \because \because$

응용ㅇㅇ

․․ $\dot{\sim} \dot{\sim} \dot{-} \dot{\sim} \dot{\sim} \dot{\circ}$

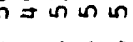

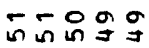

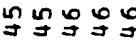

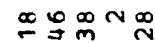

응요유

กNำ

$\sin \left(\frac{\pi}{2}\right.$

苛苛苛

जै $\overrightarrow{0} \overrightarrow{0} \overrightarrow{0} \overrightarrow{0}$

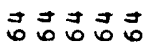

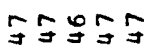

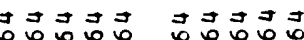

mon

in $\operatorname{Nin}$

rmomin

हn $=0$ 绳

妇寻寻寻寻

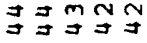

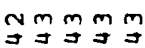

$\vec{m} \backsim=\overrightarrow{0}$

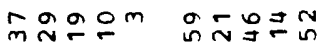

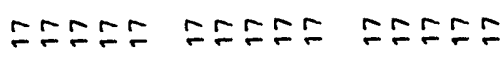

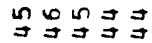

可寻寻寻寻

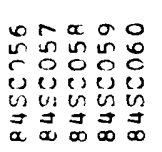

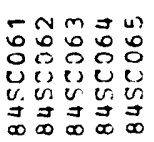

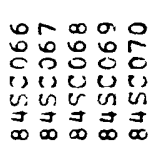

IFIFF FEFF

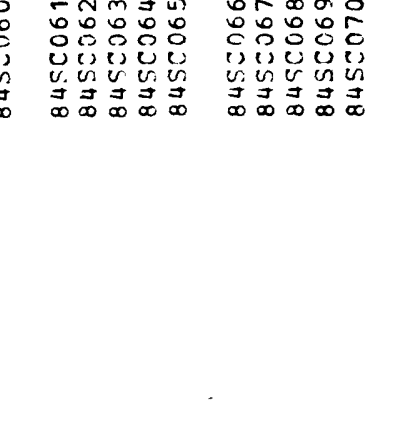




\begin{tabular}{|c|c|c|c|c|c|c|c|c|c|}
\hline 5 & $z z z z z$ & $z z z z$ & $z z z z z$ & $z z z z z$ & $z z z z z$ & $z z z z z$ & $z z z z z$ & $z z z z z$ & $z z z z z$ \\
\hline$\stackrel{H}{N}$ & $\stackrel{\stackrel{N}{V}}{v} z z z$ & 윰 & 윰유 $\underset{V}{C}$ & = ONㅠㅇㅠ & z z욧ㅇㅇ & $z$ in in in & 응요용요 & 웃앙요움 & 웅으용요 \\
\hline & 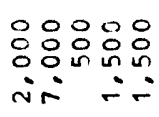 & 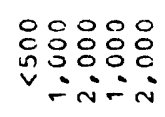 & 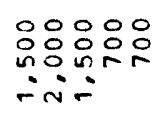 & 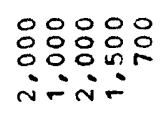 & 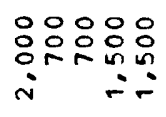 & 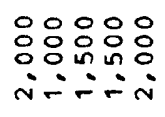 & 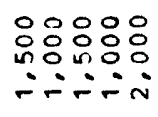 & 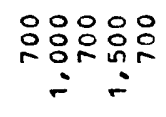 & 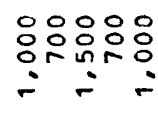 \\
\hline 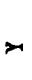 & 잉임용유 & $\stackrel{C}{{ }_{M}} \underset{V}{ } z z z$ & 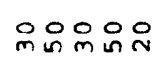 & 윰유 윳 & 윰유임요 & 유ㅁㅠㅠ유유 & 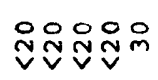 & 윰율이 & 윰윰요 \\
\hline & $z z z z z$ & $z z z z z$ & $z=z=$ & $z z z z z$ & $z z z z z$ & $z z z z z$ & $z z z z z$ & $z z z z z$ & $z z z z z$ \\
\hline & 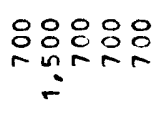 & 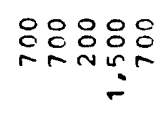 & 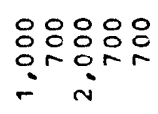 & 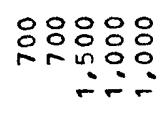 & 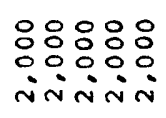 & 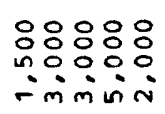 & 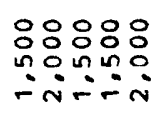 & 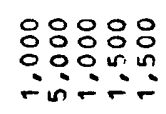 & 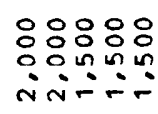 \\
\hline & $z x=z$ & $z z z z z$ & $z z z z z$ & $z z z z$ & $z=0_{0} z z$ & $z$ : & $z z z z z$ & $z z z z z$ & \\
\hline
\end{tabular}

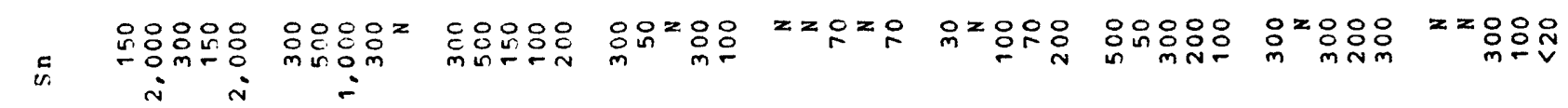

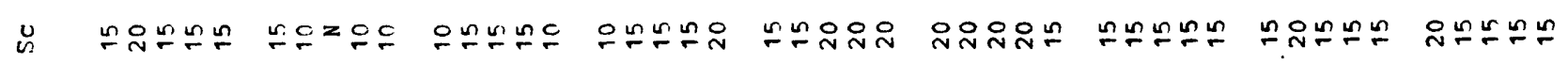

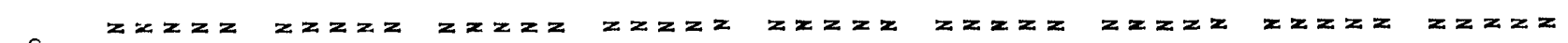
is

00000 :0000 00000

00000

$\sin 0$

\section{(1)}

int

$\vec{z}$

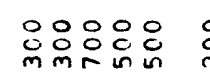

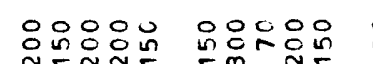

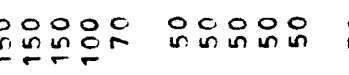

운은으응

응응ㅇㅇㅇㅡ

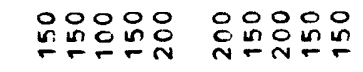

$\hat{z}$

$z z z z=$

$z z z z=\quad Z z z z$

$z z \geq z=$

$z \geq z z$

$z z z=$

$z z z z z$

$z=z z z$

$z z z z$

$z z z z \quad z z z z z$

$z z z z$

$z \geq z z z$

$z=z$

$z z z z$

$z z z z$

$z z z z$

$z z z z z$

$z z z z$

$z z z z$

$z z z z z$

$z z z z z \quad z z z z z$

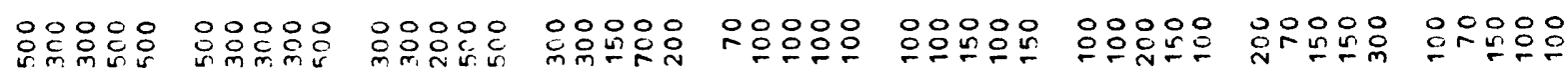




\section{0

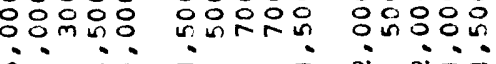 in $\therefore$}

¿

¿

$\vec{x}$

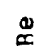

$\infty$

$\infty$

$z$

2

$\stackrel{0}{2}$

5

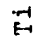

응응응

숫ㅊㅅㅜ

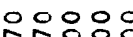

눙

운ㅇㅇㅇㅇㅇㅇㅇ

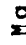

$\therefore$

음윳응응

ะำก

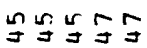

可考范苛

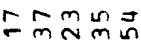

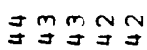

ระะ

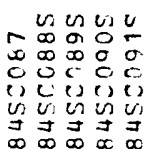

응ㅇㅇㅇ응

cccus

ninin

응용요

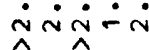

응응

的芒

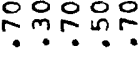

응요용

inisin

응응응

iत்ंவ

Niñ

응응웅유웅

- ……

우움우요

on 000

00000

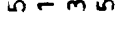

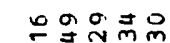

일요

곸웜워

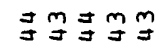

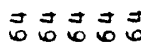

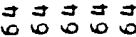

s $=0$ in

mmm

는

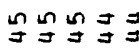

ニะニะ

든

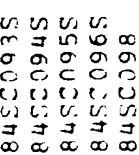

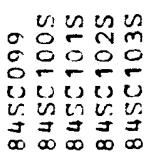

웅융ㅇㅇㅇㅇㅇ

$\therefore \therefore$ 的
융유융요

i:
응ㅇㅇㅇ

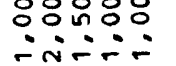

$\therefore: 00: 00$ $i \quad i$
응ㅇㅇ 응유 indi.

옹옹요

\section{응ㅇㅇㅇㅇ}

읃유윰용

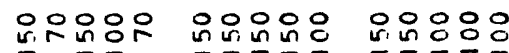

$z z z z z \quad z z z z z \quad z z y z z$

$z z z z z \quad z z z z z \quad z z z z z$

$z z z z$

$z z z z z z z z$

$x \geq z x$

$z z z z z \quad x z z z$

$z z z z z=z z z$

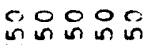

$z z=00$

$V^{z} z=z$

$z v^{\prime}=$

$z z z z z \quad z z z z z$

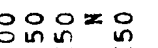

O) 000

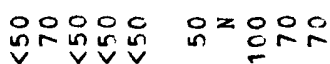

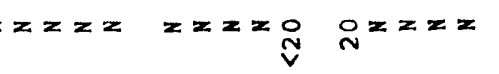

$z x=0$

$z z z z z=z z z$

$z z z z z \quad z z z z z \quad y z z z z$

$z z z z z \quad z z z z z$

$z z z z z$

$z z z z z$

$z z z z \quad z z z z z$

$z z z z z \quad z z y z z$

$z z z z z=z z z$

$z x z z$

$z z z z$

$z z z z$

$z z z z$

응응응ㅇㅇㅇㅇㅇㅇ

nแก แn⿺

rnin

응ㅇㅇㅇ응

수서수

$\therefore \circ: 00$

ن수수숫

응융응

$\therefore \because \because \therefore$

웅융ㅇㅇ

$\ddot{n} \because \dot{n}$

운유우눈․․

우순유은

0000

in in

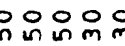

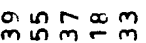

กิธก

急㞥寻寻寻

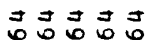

寻寻寻寻年

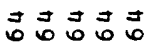

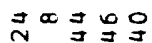

$\underset{\sim}{ } \pm \infty{ }^{\circ} g$

寻寻寻寻孚

$\underset{\exists}{\exists} \underset{\exists}{\exists} \exists$

FF:

ニะニะ

皮为为

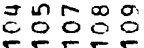

(1) 200

0
$\infty$
응유유

inini

응유유

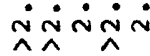

응요운은

$\therefore \therefore ?$

ํํํํำ

응응웅

ஸेंति

$\wedge \wedge \wedge$

우융ㅇㅇㅇ

00000

ㄴ.?ㄴ.?

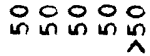

은

ตำกำำก

鱼舟孚孚寻

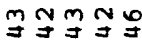

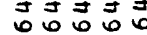

可

ำกำํำำ

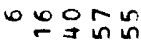

$\mathcal{\exists} \exists \mathcal{\exists} \mathcal{\exists}$

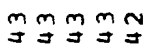

ニㅗ

오는

约组的里

$\underline{\underline{z}}=\frac{\infty}{=} \frac{0}{=}$

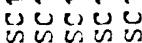

约结记

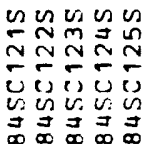

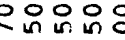

ํํำำำ

은유음요

$\hat{N}=\infty$ O $^{m}$

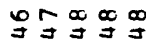

융융융

तinmón

응융융 miñm

영응응

응융응

กNกNำ

inini

응응ㅇㅇㅇ

우융ㅇㅇㅇㅇㅇ

$\therefore \dot{\sim} \div$

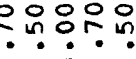

윳옷요숫

ํํํำำ

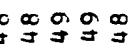

苛苛芯

añ

$\sim \underset{m}{\sim} \stackrel{\sim}{\sim} \vec{m}$

m®mm

$m \sim m m$

ํㅗㄴ

ニニ

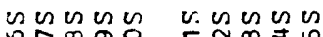

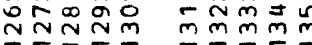

正

(i) U⿺辶一兀

()

(1) isu

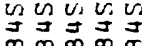


E. $z z z \dot{z} \quad z z z z=$

$\stackrel{4}{N}$

ล

으으으요

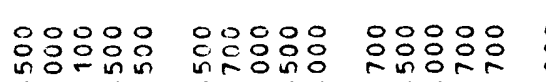

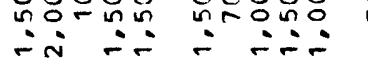

ind

$\stackrel{O}{V} \mathbb{V}^{z z z} \quad \operatorname{OO}_{m} z z$

$z z z z z z z z z$

$z=2$ O N

$z z z z$

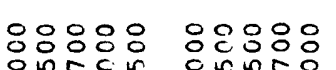

onisum ons?

\title{
옹ㅇㅇㅇㅇㅡ
}

nn

웅용

in

응용요

nn:ㅇำ

$z z z z z$ in $z=x$

$z z z z$

$z z z z$

$z x z z z$

응유 윰 윰유

웄웅웅 $=$

zo용요

응응

웅유유

nnำ웅

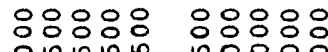

ㄴ.ㄴำ

$z z z z$

$=$

$z z=$

임잉유

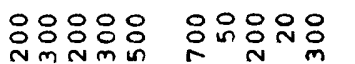

은응유응

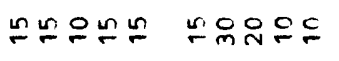

$\sin 2$

u.

is

$z z z z$

$z z z z$

$z$

$z z z=$

\begin{abstract}
nomon
\end{abstract}
nก $\operatorname{lng}$

nnom

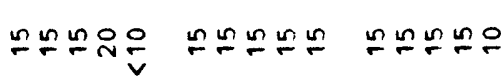

$\stackrel{2}{2}$

$\ddot{z}$

a

울

$\stackrel{\pi}{\sim}$

2

웅ㅇㅇ요요

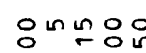

으웅요

00000

in

웅요으응

$z z z z$

$z z z z$

$x z z z$

웃요울을

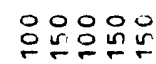

웅유읃요

옹웃우운

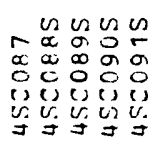

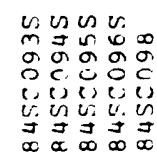

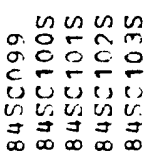

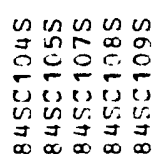

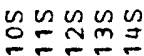

こニ

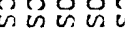

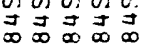

\section{$z z z z$}

$x x z z$

$z z z z z \quad z z z z z$

응ㅇㅇㅇ

$x z z z$ 


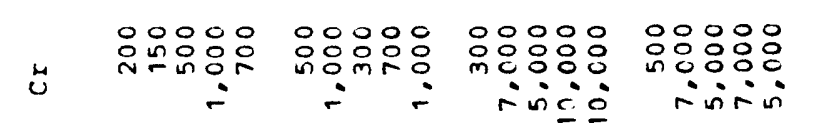

요

ర

का

$\stackrel{0}{\infty}$

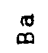

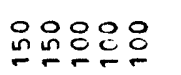

$z z z z$

$z z z z$

$z z z z \quad z z z z$

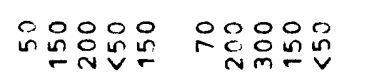

$z \mathbb{z} z=$

있응융응

$n z z z z$

응ㅇㅇㅇ

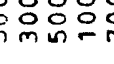

$x \geq z=2$

에 $z \geq z z$

운

$z z z z$

$z z z z$

2

2

$z z z z z$

$z z z z$

$z z z z$

$z z z z$

0000

$\Sigma$

$\because \because \because 9$

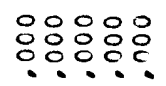

$\circ 0000$

-ini:

웅융ㅇㅇㅇ

inimin

$\because \because \dot{N}$

음웅웅응

Nं$-\dot{N} \sim$

영유

iniñ

욱응응용

응응웅

- $\dot{\sim} \dot{N} \dot{ }$

$\therefore \dot{\sim} \dot{\alpha}-$

욱우웅ㅇㅇㅇ

둥옹용

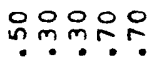

00000

$\therefore$ …

$\because \dot{m}$

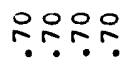

웅웅ㅇㅇ

응ㅇㅇㅇ응

m.

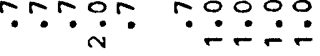

운오용요

읏으숭요용

듯응요웅

윤윤용요

ํำกับ

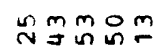

N우엠

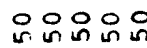

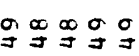

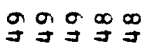

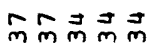

$\underset{m}{0} \underset{7}{\infty}-m$

옹요웅요

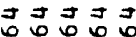

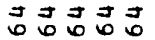

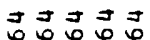

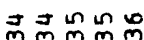

召苛苟吉

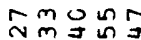

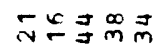

으눙ำ

止嵒品

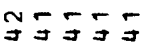

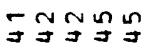

战约约

กำำำ

FระFล

FะFะ

エะニะ

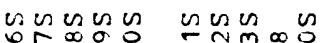

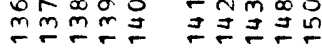

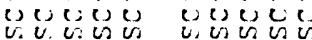

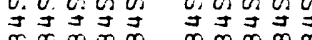

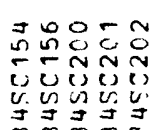

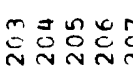

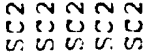

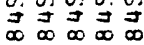

영영영웅

$\because \because \because$

응응용유

$\therefore$

음응응ㅇㅁ은

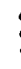

00000

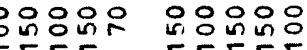

$z z z 2$

$z z z z$

$z z z z$ zzzzz

$\mathcal{V} \approx \mathcal{V} \mathcal{V} \mathcal{V} \quad \mathcal{V} \mathcal{V} \mathcal{V}$

응응응 응응영

价们

00000 00000

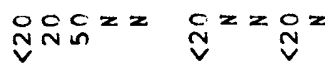

$z z z z y \quad z z z z$

$z=2 z$

$z z z z$
웅응용

$\because \because \because \because \cdot$

유ำñ

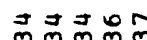

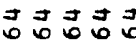

응응응영

응ㅇㅇㅇ Ni் 응음우우운 कांतें

영융융

i二iñ niniñ

00000 응요

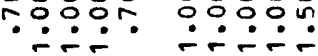

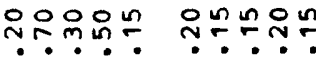

웅ㅇㅇㅇ

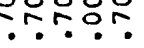

00000

으눈우누․

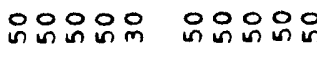

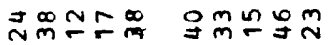
nrama

ज节苛寻

o-

ca- $-\vec{n}$

設㙁记寻寻

घु

シュニュニ

ระะニ

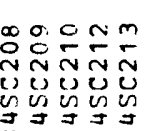

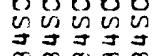

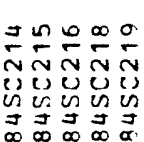

$\exists$

ก品的

敏疑品

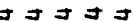

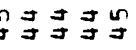

Aะกะ

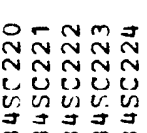

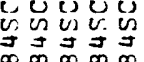

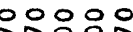

ㄴ.ㅇ․․

운오웅

응응웅응 inin

응응응 $\because$ ini

응ㅇㅇㅇ응

움우웅용 ํํํํำ

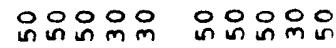

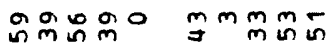

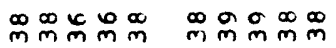

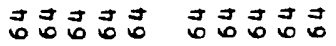
mํํ윰ำ 寻寻寻寻寻

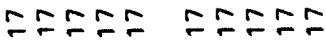

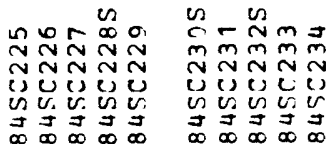

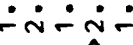




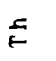

N

N

4

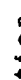

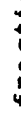

4. N유윰

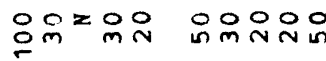

응웅응요유

$\therefore=$

웅융융응

$\therefore \because \because$

유융ํㅇㅇ

응유을

$z z z z$

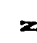

$z z z z$

옹융융응

웅융융유

응

응응ㅇㅇㅇㅇ

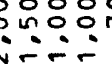

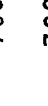

응ㅇㅇㅇㅇㅇㅇ

웅웅요

$\therefore \div$

$z z z=$

$z=0 z=$

$z x z z=$

$z z z z$

$O_{0}=x=$

융유

$z x=$

오욜

$z z x z=$

$12 \times 2$

x용으

은

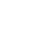

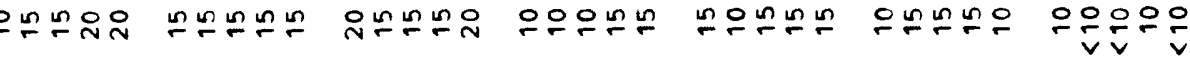
$x z z x \quad z x z z z$ $z z z z$

\section{$z=$}

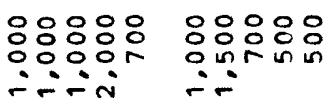

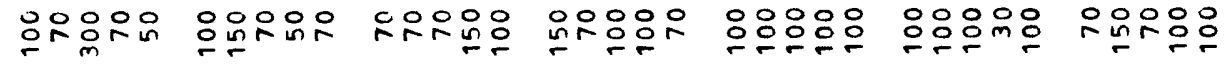

\section{0}

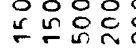

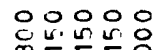 $\therefore$}

융융유요 $\sin \min ^{\infty}$

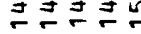

() () 0,0

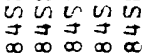

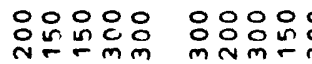 \\ 응응응

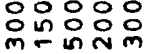

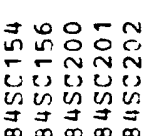

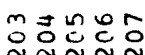

i)

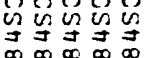

$z \geq z$

$z z z=2$

$z \geq z$

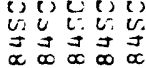

moㅇำ는

Niñ

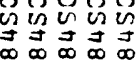

$\exists \stackrel{2}{2} \div$

ก⿻่ง

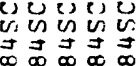

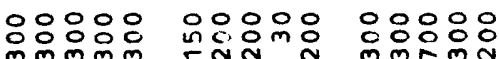

$z z x z y z z z y \quad z z z z$

$z z z z z \quad z z z z y \quad z z z z$

$z z z z z \quad z z x z z \quad z z z z z$

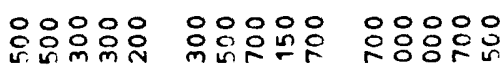
$\therefore$

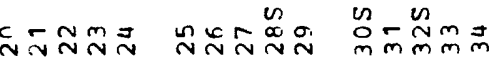
NNNNN NNNNN

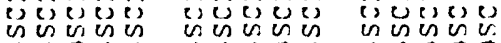

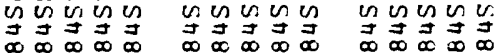




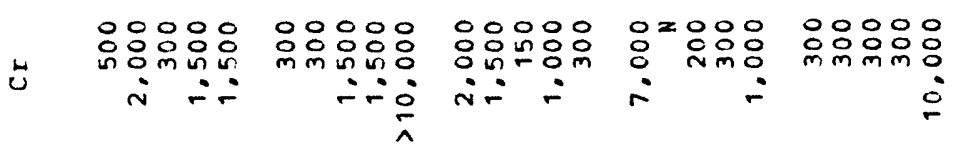

¿

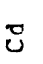

$-1$

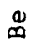

$\infty$

$\stackrel{4}{\circ}$

돈

U

$\infty$

$z$

$\stackrel{n}{2}$

2

,

41



is

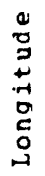

ב⿱

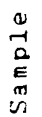

$z z z z$

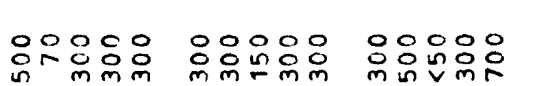

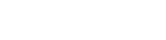

z

윤

$z z z z$

$z z z z$

$z z z z$

,

$z=2$

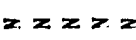

$z z z z$

$z z z z$

\footnotetext{
$z=2 z$
}

$z z z z$

$z z z z$

$z z x=$

$2 z 2 x=$

응ㅇㅇㅇㅇㅇ

옹응용

응응ㅇㅇㅇ

옹ㅇㅇㅇㅇ

응응응

กㄴํำ

는으.

ㅇํㅇ응

00000

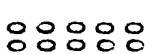

00000

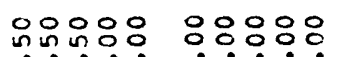
$\dot{\sim} \dot{\sim} \dot{\sim}$

$\dot{m} \dot{\sim} \dot{\sim} \dot{\sim} \dot{x}$

뚜뭉

$-\underset{\wedge}{\wedge}$

กNN

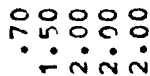

응응영융요

웅옹요

영융요

m的 ?

i

응윰우눈

웃은옹응

옹오웅ㅇ

응우우웅

옹유웅ㅇ

은응으요

$\because \div \div$

$\because \div \cdot$

․․․․

당ㅇㅇㅇㅇㅇ

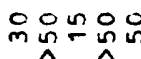

오엉요

든으음욧

$m=0$

으노ำ

크유ำ

Nㅜำ

Nang

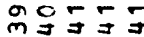

五尔

ㄷㅇㅇㅇㅇㅇㅇ

ㄷㅍㅍ

Nㅗ

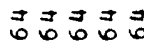

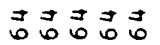

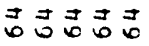

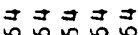

$\vec{B} \vec{\exists} \overrightarrow{\overrightarrow{0}}$

mogñ

แกํำNㅜㄴ

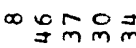

m气 ํㅜㄴ

m도응

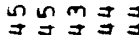

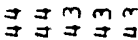

m品寻寻寻

纪寻寻寻寻

寻寻寻荘孚

ㄷํㄴㄷㅡ

ะะระ

드는

Fะะะะ

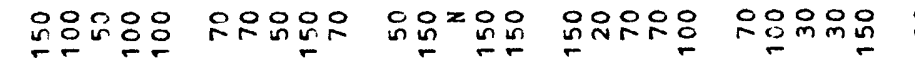

$z x z z=$

$\sin 0$

$x$

$z x z$

$z$

응융유용

응응ㅇㅇ

영용유

웅ㅇㅇㅇㅇㅇ $\because \because \frac{1}{2}$

$\therefore$

noto

옹융응

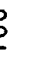

응유용

운욘요응

$x z x z$

$x z z z$

$z z z=$

$z z z z$

$z z z x z \quad z z z z z$

$z=2 z z$

$z x=2$

$z z z z$

$z z 2 z$

$v \geq z z=$

$z z z=2$

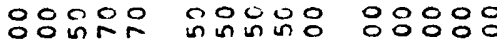

00000 ñv vve m

$z z \geq z=$

$z x z=$

$z z z z$

$z z z z z$

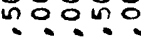

응융융유 영응융

옹응ㅇㅇㅇ

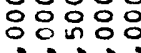

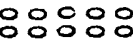

inin inimim

和的

inis

응융유

08000

웅용ㅇㅇㅇ

8080유요

$\dot{\pi} \dot{\pi} \dot{n} \dot{2}$

$\dot{\sim} \dot{\sim} \dot{N} \dot{N}$

$\dot{n} \dot{\sim} \dot{n} \dot{n}$

ininin

응응유운

응으융응

으응ㅇㅇ

읐웅용ㅇㅇ

옹응요

$\because \because \div$

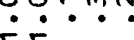

$\because \because \because$

$\because \because \because$

응ㅇㅇㅇㅇㅇㅇㅇ

웃웅ㅇㅇㅇㅇㅁ

으웅ㅇㅇㅇㅇㅜ

응응운운

$\therefore$

$\because \div$

누

$\therefore$

읐응요 은

등요융ㄷㅇ

운융요웅

읐유은응

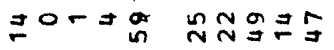

กับกณ

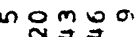

네

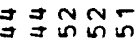

은드뉴요

ถูกููกับ

$\overrightarrow{\vec{B}} \overrightarrow{\overrightarrow{0}} \overrightarrow{\overrightarrow{0}} \overrightarrow{0}$

قै

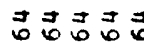

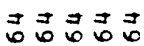

min

$m \infty \infty m \infty$

DONMO

웤워

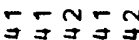

ag $⿻ \underset{n}{2}$

ヘニュニニ

NANEN

nニニニ

Nニニニ

ทะะะร

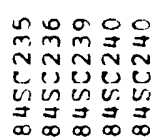

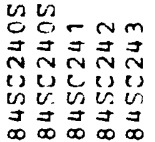

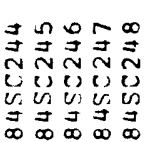

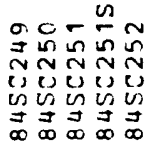

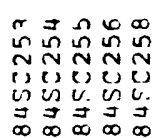

ํ. 녀ㅇㅔㅠ

esescos cos

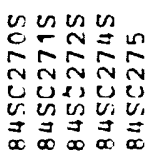

U. $\operatorname{lig}_{0} \sin \alpha$

웅요

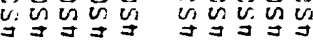

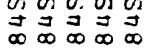

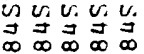




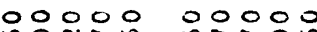

엉ㅇㅇㅇ

윙ㅇํㅇㅇㅇㅇ

은유운우

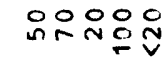

응ㅇㅇㅇㅇㅇ 응응ㅇㅇㅇ응 응응ㅇㅇㅇㅇㅠ

\section{응ㅇㅇㅇ음}

ㅇㅇㅇㅇㅇㅇ

응웅ㅇㅇㅇㅇㅇ

$\therefore i \div$ $\therefore$

$\therefore$ in

$\because 0$

in

$\operatorname{rinds}$

웅웅ㅇㅇㅇㅇㅇ

n- :

z응ㅇㅇㅇㅇㅛ

00000

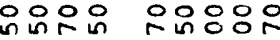

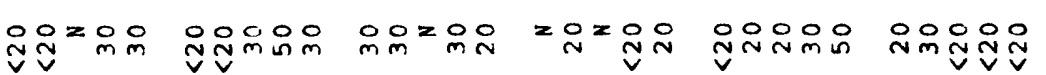

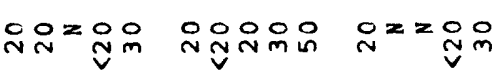

$z z z z$

$z z z z$

$z z z z$

$z z z z z$

$z=2 z$

$z=2 x=$

$z z z z$

$z z z z z_{1} z_{2} z$

응ㅇㅇㅇㅇㅇㅇㅇㅇㅇㅇㅇ

noo in in ooo in

응ㅇㅇㅇㅇㅇ 욷ㅇㅇㅇㅇㅇㅇ

응ㅇㅇㅇ음

웅ㅇㅇㅇㅇㅇ

응ㅇㅇㅇㅇㅇㅇ응

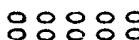

응응요

nir niñ

nin:

in

$\therefore$ iñ

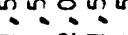

00 in in

in 00 in in

000 in in

$z z z z=2 z z$

융

$z{ }^{2}=2$
0
$i$

$z z z z$

$x z 2 z z$

$z z z z$

$=2 \underset{\sim}{\stackrel{\circ}{\circ}}=$

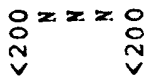

동ㅇㅇㅇㅇㅇ용

$z$ 융ㅇㅇㅇㅇ

운 $=0$

음윤용은

$z=\underset{m}{z} z$

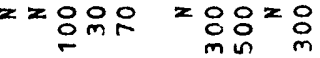

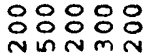

응ㅇㅇ은

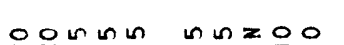

으웅으는

ำกำ

느웅은

는ำ은

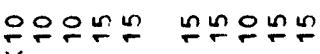
v. $z z z z \quad z z z z$ $z z z y=z z z x$

$z z 2 z$

$z z z z z$

$z z z z=$

$z z x_{1} z$

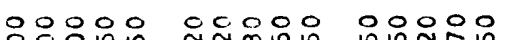

00000

응웅우운

으음유우

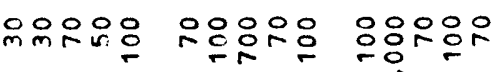
(1)

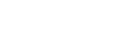

$\vec{z}$

응은용ㅇㅇㅇ

응응응응

0000

00000

웅ㅇㅇㅇ

coono

0000000000000

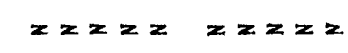

음음응옹요

응응유용유

응응ㅇㅇㅇ

웃ㅇㅇㅇㅇㅛ

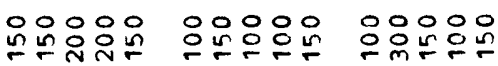

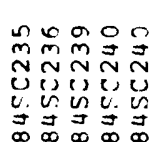

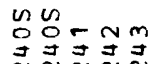

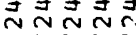

约约记

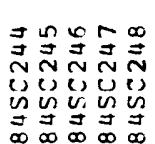
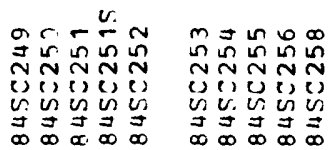

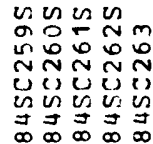

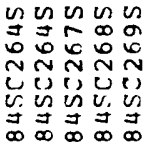

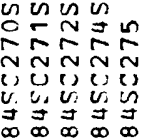

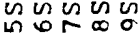

5.5.5

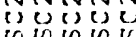

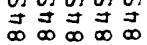




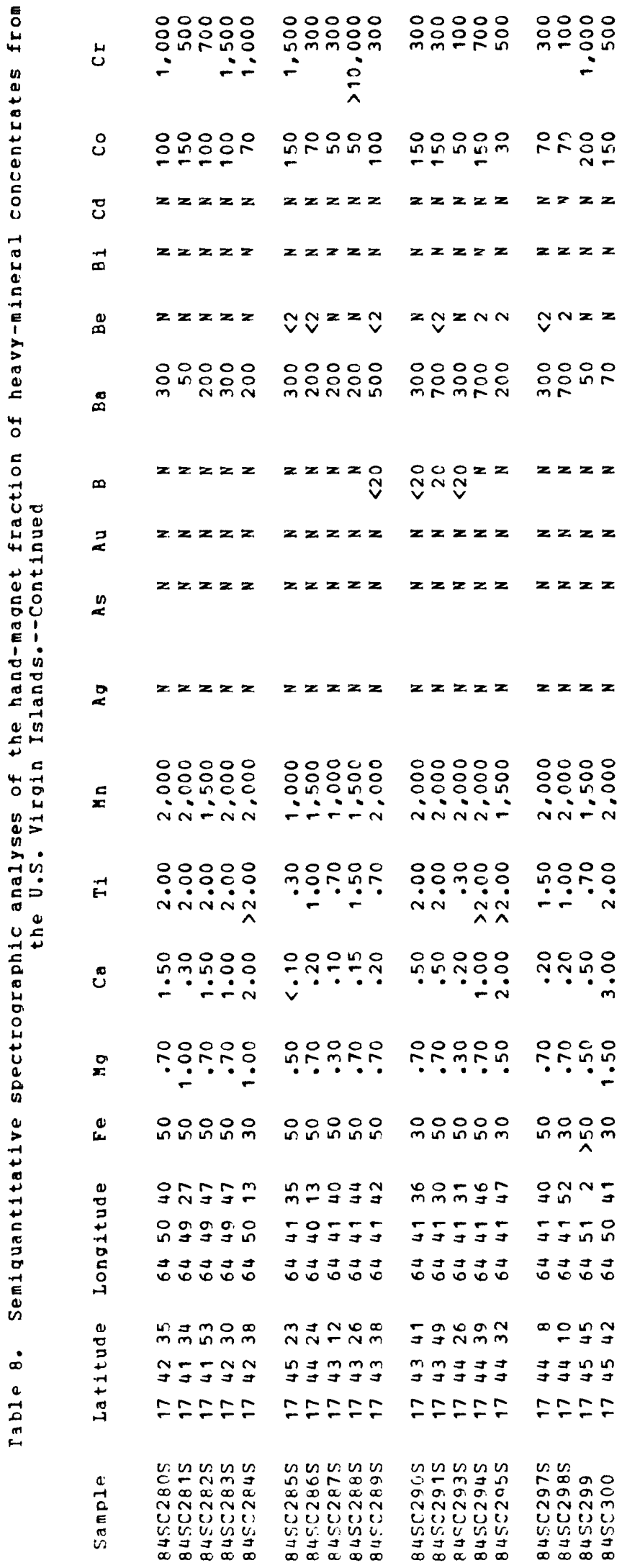




\begin{tabular}{|c|c|c|c|c|}
\hline$\underset{H}{E}$ & $z z z z z$ & $z z z z$ & $z \geq z z z$ & $z z z z$ \\
\hline$\stackrel{M}{N}$ & 을 & 융유 & 응을ㅇㅇㅇㅇㅇ & 등요용요 \\
\hline 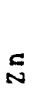 & 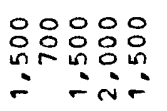 & $\begin{array}{l}\circ 8000 \\
\circ 8000 \\
\circ 00 \\
m-m i n\end{array}$ & 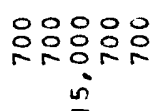 & 음음 \\
\hline 2 & $\stackrel{O}{N}=\stackrel{O}{V} \stackrel{O}{\mathrm{~N}}$ & $\stackrel{\circ}{V} z z z z$ & 을 $z$ 윰 & $\stackrel{O O O}{N} \underset{V}{ }$ \\
\hline$x$ & $z z z z z$ & $z z z z z$ & $z z z z z$ & $z z z z$ \\
\hline$>$ & 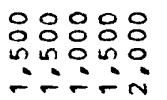 & 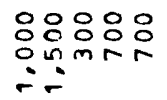 & 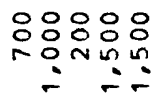 & 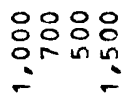 \\
\hline in & $z z z z \stackrel{O}{O}$ & $z z z z z$ & $z z z z z$ & $z z z$ O \\
\hline in & 은융용요 & $z=\underset{m}{0} z=$ & $z=\underset{\text { in }}{g} z z$ & $z O{ }_{1} z z$ \\
\hline$\dot{n}$ & 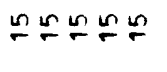 & 융이은은 & 윤욘ำ & 으웅요묘 \\
\hline है & $z z z z z$ & $z z z z z$ & $z z z z z$ & $z z z z$ \\
\hline 룰 & 응웅윤은은 & 응응ㅇㅇㅇㅇ음 & 옷융요 & 응으윰 \\
\hline$\vec{z}$ & 은은은욤음 & 은운용용 & 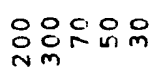 & 은은윤으 \\
\hline$\frac{2}{2}$ & $z z z z z$ & $z z z z z$ & $z z z z z$ & $z z z z$ \\
\hline 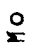 & $z z z z z$ & $z z z z z$ & $z z z z z$ & $z z z z$ \\
\hline$\stackrel{0}{\oplus}$ & $z z z z z$ & $z z z z z$ & $z z z z z$ & $z z z z$ \\
\hline 己 & 윤융ㅇㅇㅇㅇㅇㅇ & 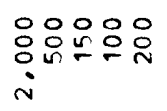 & 응융융유 & 웅웅음요 \\
\hline 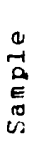 & 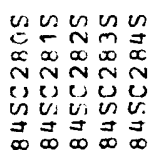 & 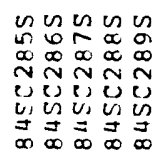 & 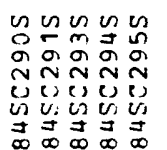 & 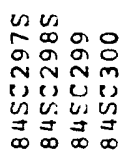 \\
\hline
\end{tabular}




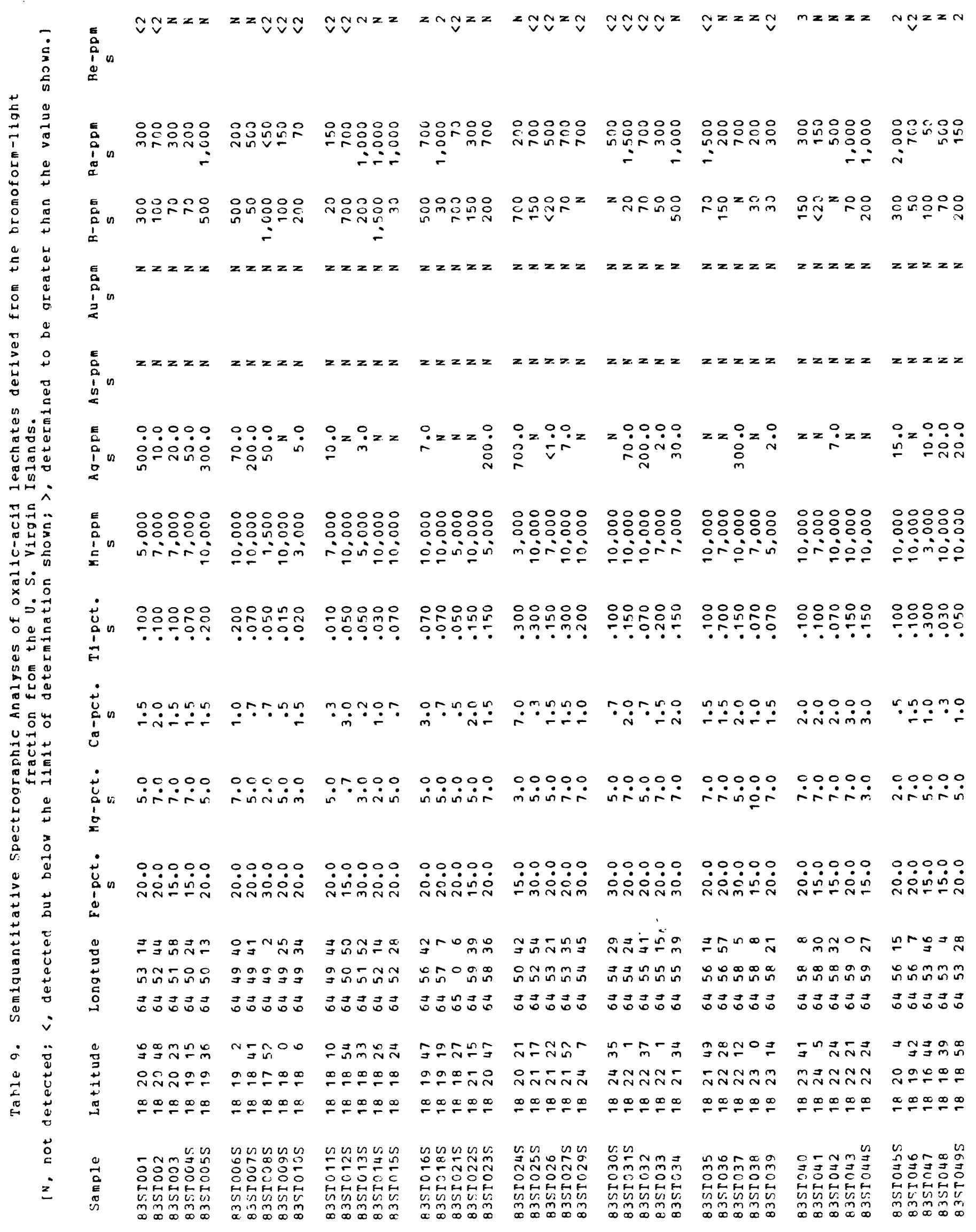




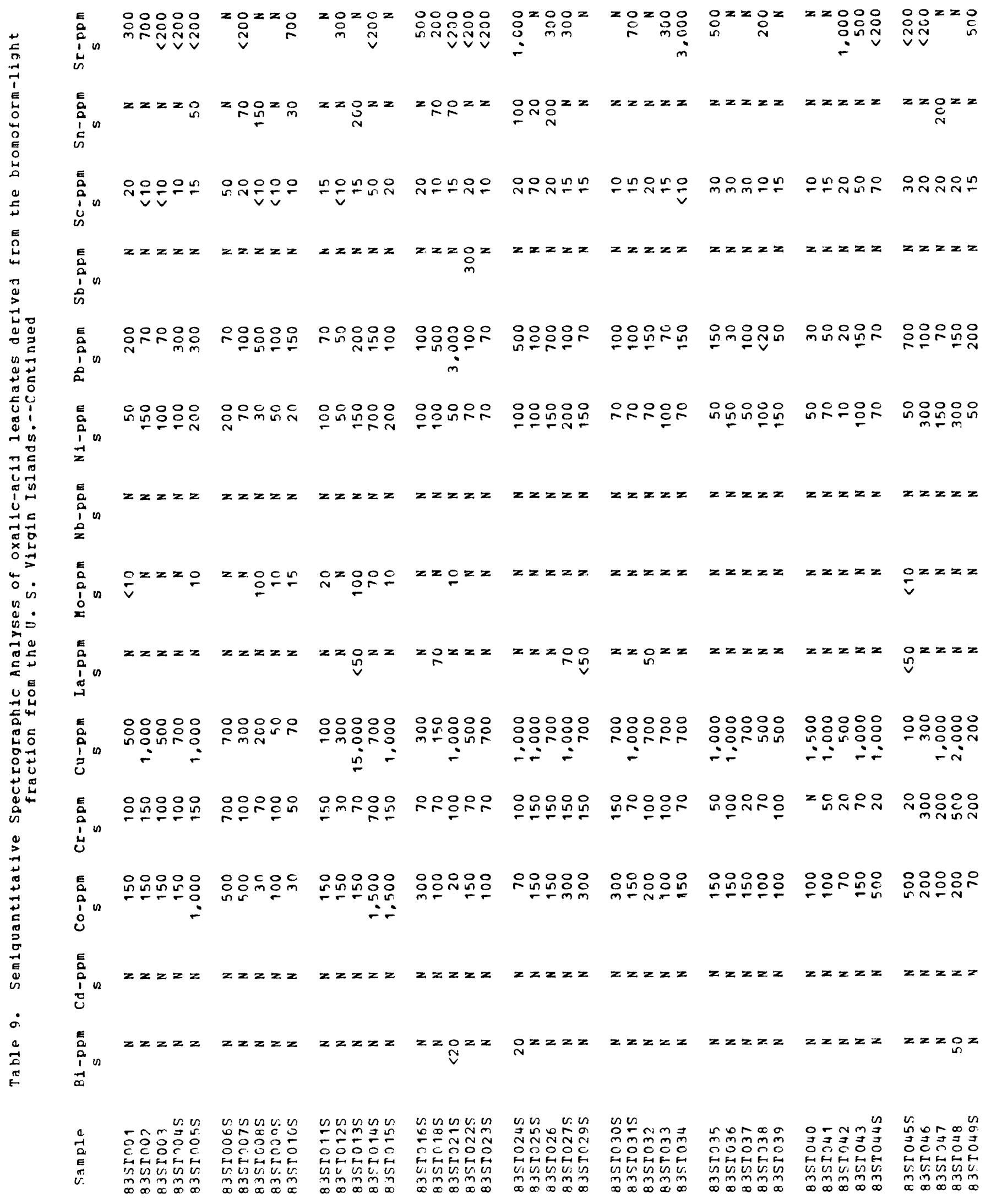




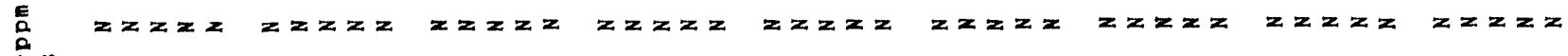

$$
\begin{aligned}
& i^{n}
\end{aligned}
$$

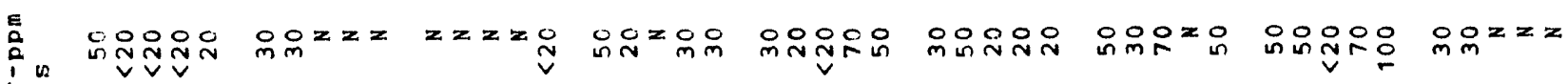

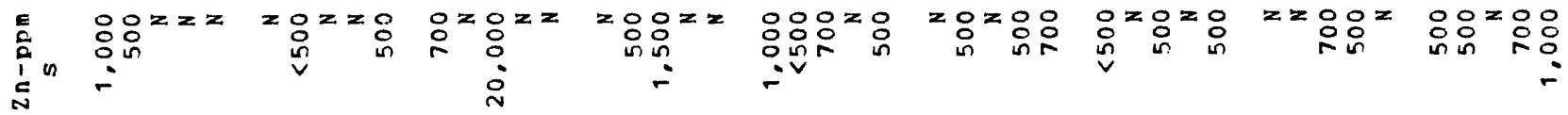

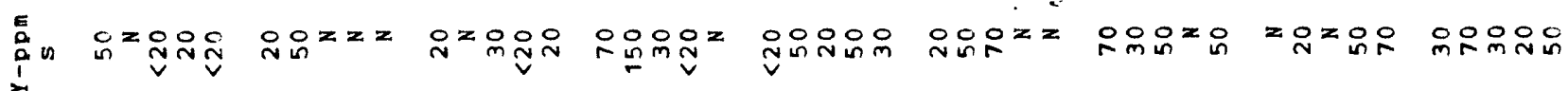

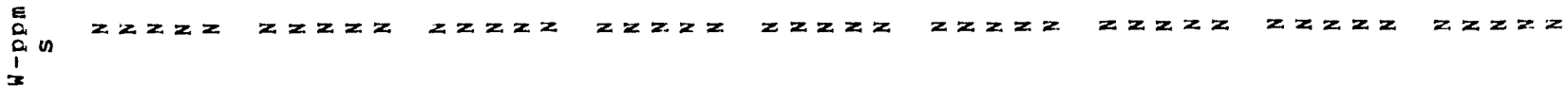

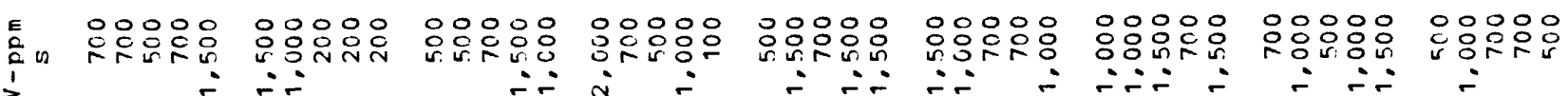

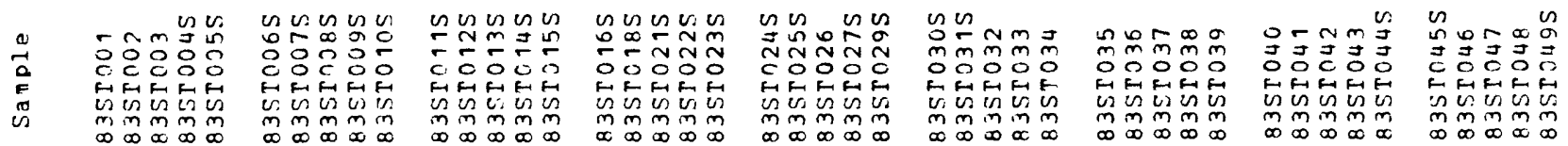




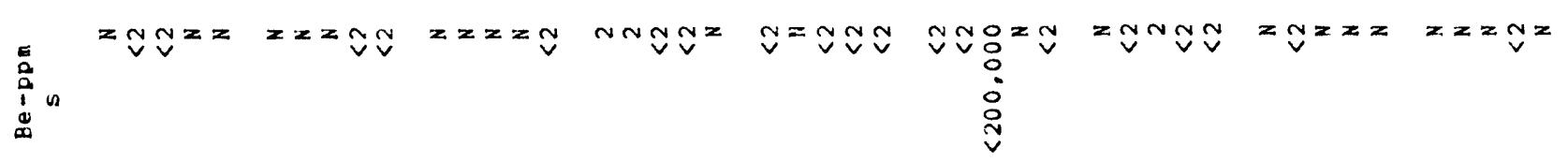

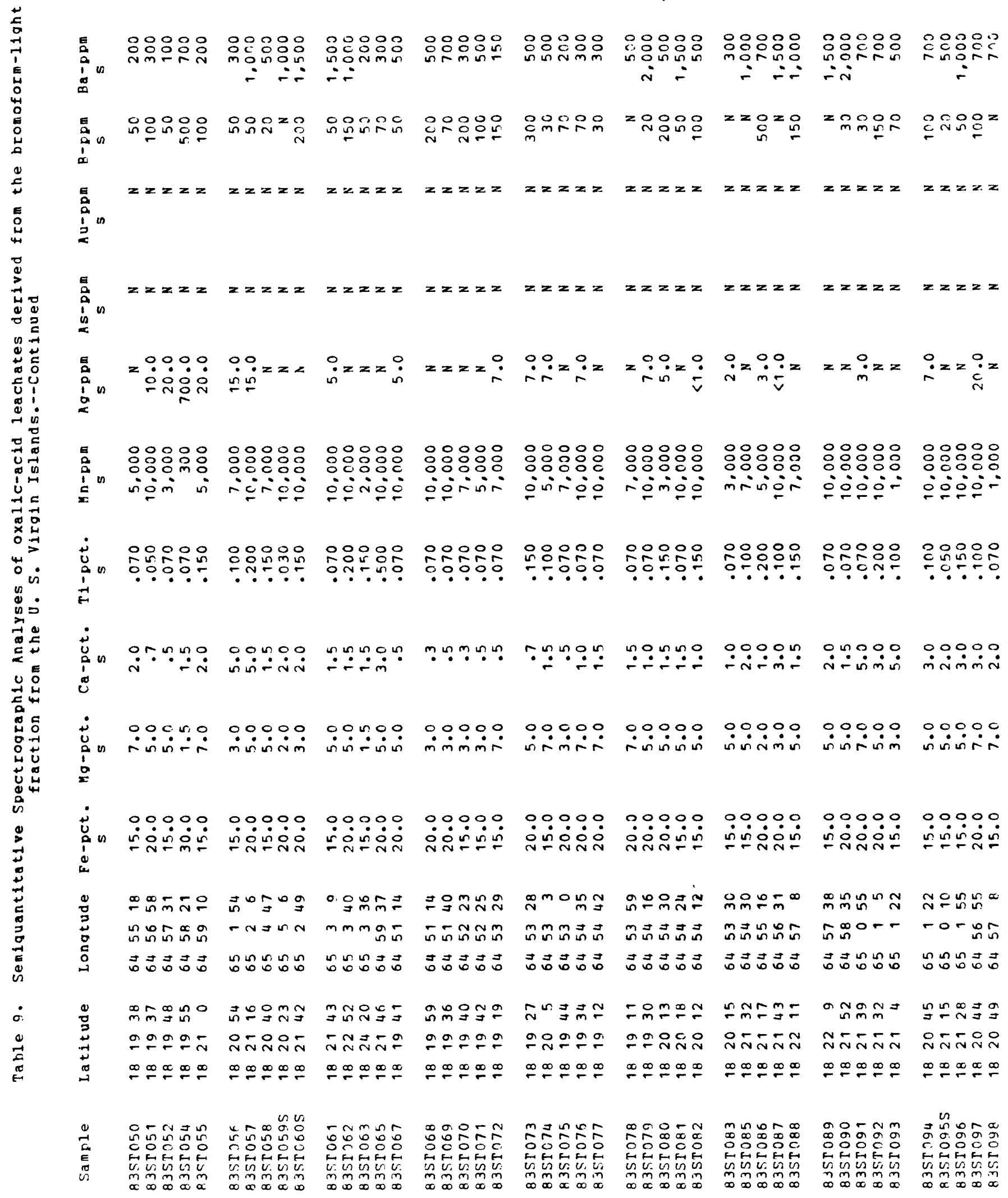




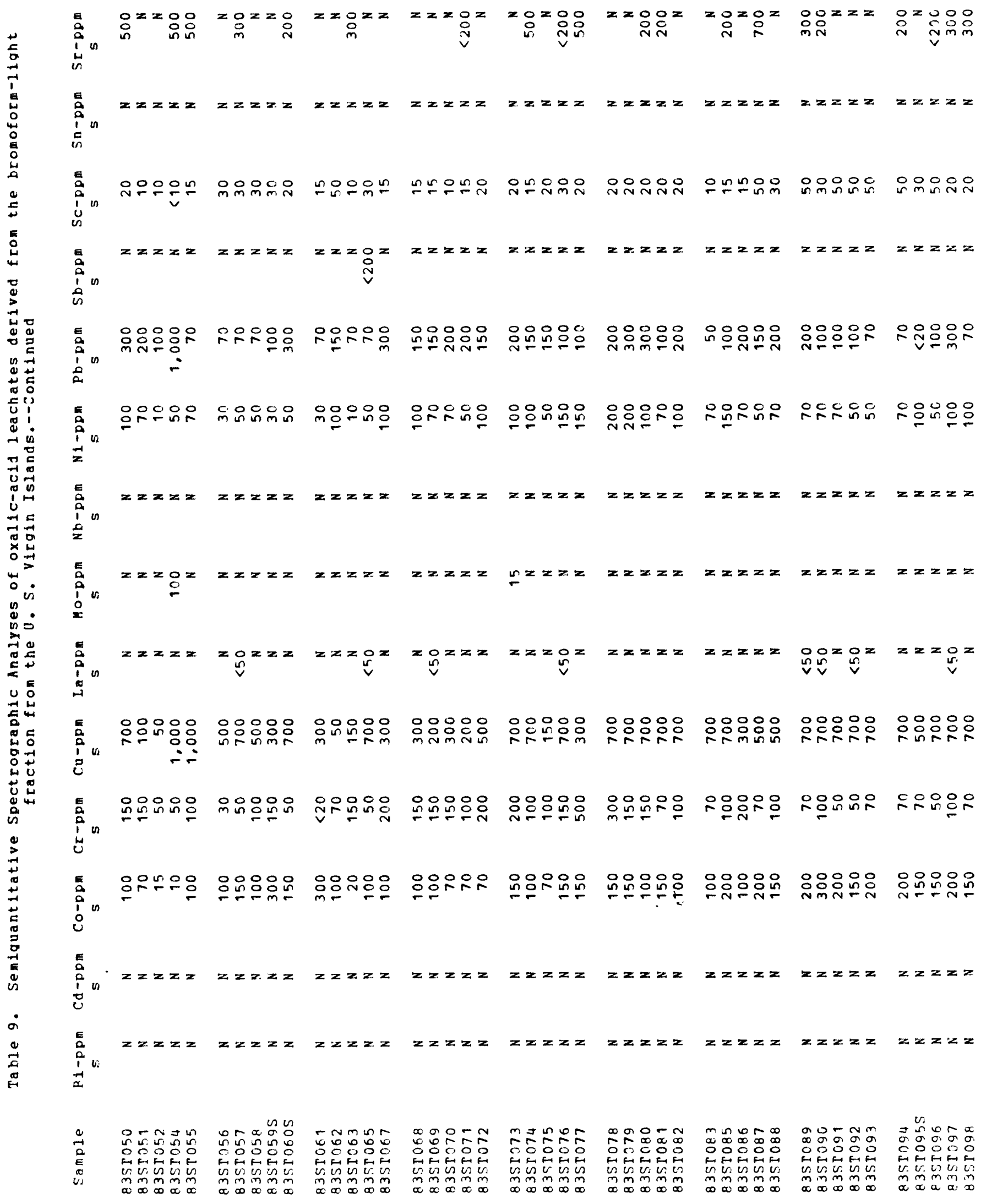




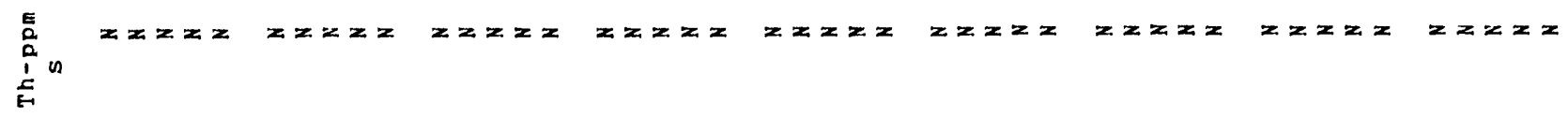
真 $z=z z$ N

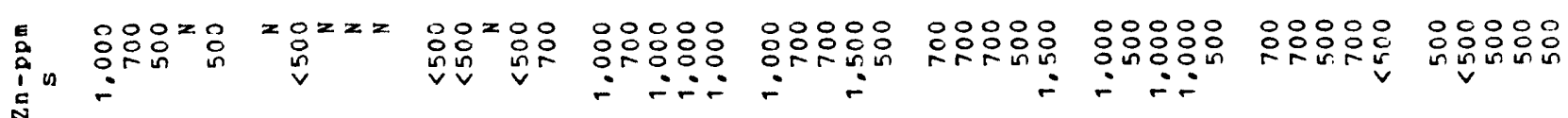

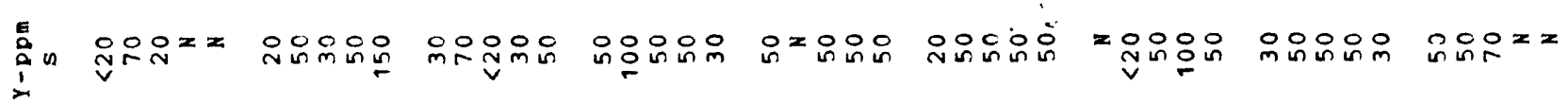

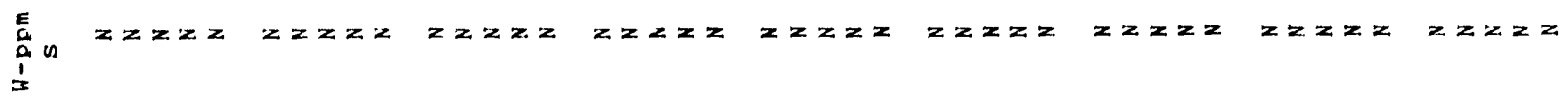

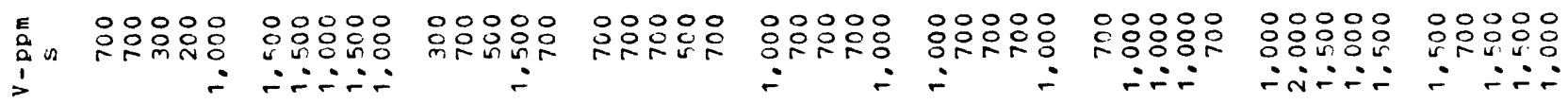

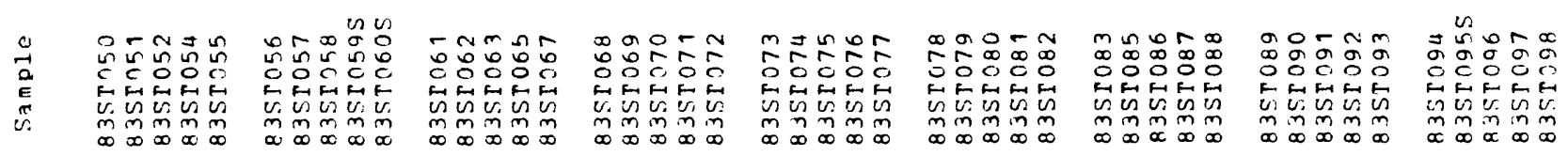




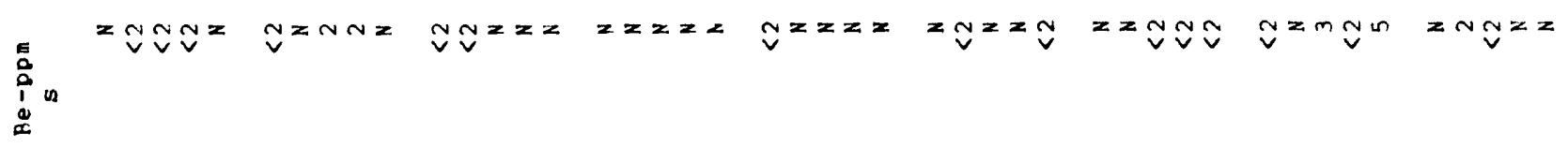

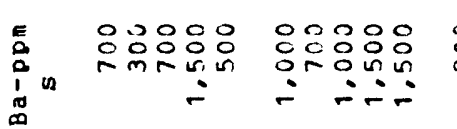

웅영 웅ㅇㅇㅇ

영용웅

옹ㅇㅇ

00000

응요용

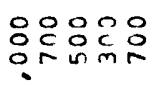

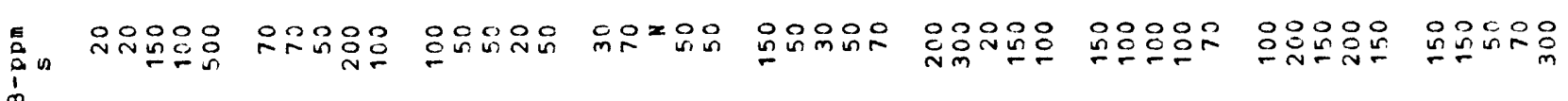

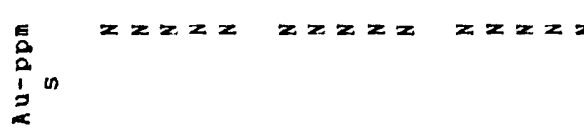

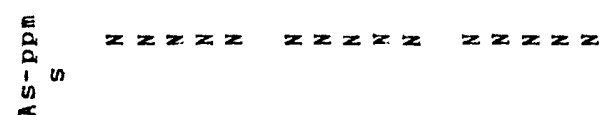

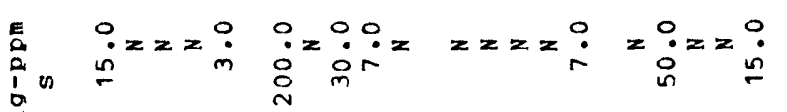

00000
요용

$0000 \%$

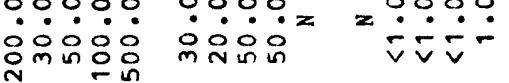

00.00

Ning

in

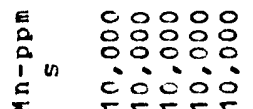

응ㅇㅇㅇㅇㅇㅇㅇㅇㅇㅇㅇㅇㅇㅇㅇㅇ

웅웅ㅇㅇㅇ

응ㅇㅇㅇㅇ

웅ㅇㅇㅇㅇㅇ

응응ㅇㅇㅇㅇㅇ

요요

응ㅇㅇ응

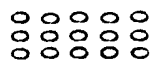

응 -

용요융

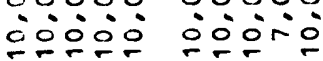

수숫

\section{$\wedge$}

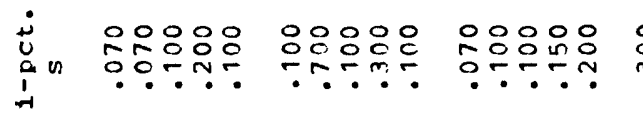

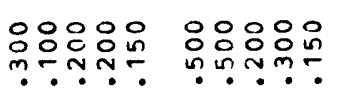

응응옹ㅇㅇ음

00000

웅ㅇㅇ

n!?

ํํㄴำ

․․․․․․․

응응용ㅇㅇㅇ

․․․․․․․

$\stackrel{+}{0}$

orring orcoo obmoos

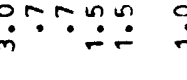

نே.

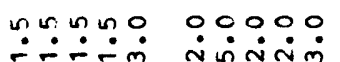

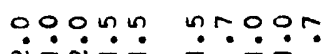

$\operatorname{10}: 0.0$

c.: in

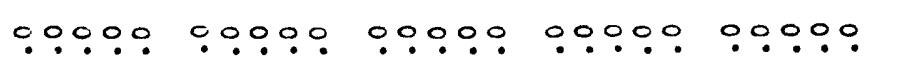

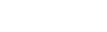

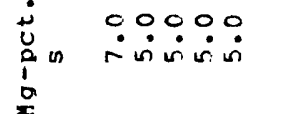

immin miri:

rírí

ம்

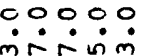

0.0000

CM000

00000 $x$

:00:0

0.040000000

0.000

0.000

0.000.

0.000

0.0 .00

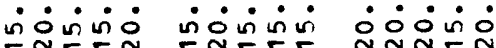

00000

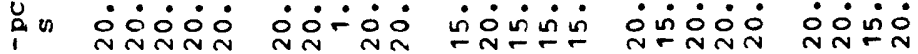
¿̀

$\operatorname{lon} 0$

พำ

तั

$\ln a \bar{\pi} a$

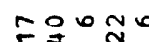

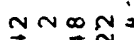

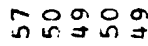

gin $\operatorname{nin}$

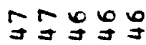

ชำ

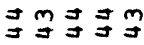

m $m \underset{\exists}{\mathbb{N}} \mathbb{N}$

ลีำลกกั

ת

mmm $\mathfrak{m} \mathbb{m} \mathfrak{g}$

กำ

กัฐต

茄苟寻苟

जु قै $\overrightarrow{0} \vec{b} \overrightarrow{0}$

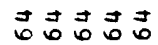

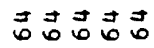

궁ํํ

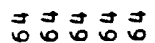

जै

于5웍

CNN

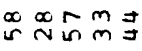

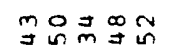

กิ에 $m$

N $า \simeq$

in $z^{\infty} \infty$

กำㅇํำ

= กิก

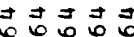

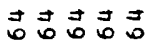

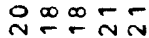

둥ํㅇ

웅유유

กักลัก

กักลัก

กักลัก

푸운유

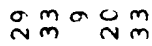

$m=m \exists \sigma$

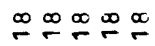

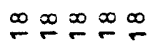

$\stackrel{\infty}{\infty} \propto \infty$

$\stackrel{\infty}{-\infty} \stackrel{\infty}{\leftarrow}$

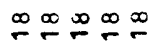

$\infty \dddot{\infty} \infty \propto$

$\stackrel{\infty}{\infty} \cong \infty$

ลกักํํำ

융유용

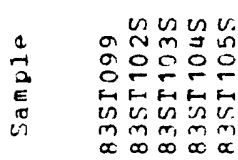

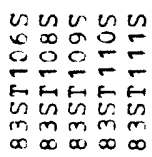

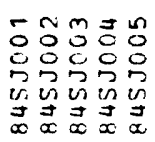

농용요

ㄱㅇㅇ뭉

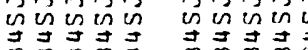

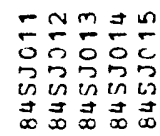

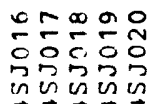

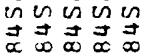

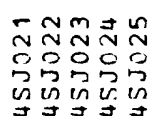

$\stackrel{\infty}{\infty} \stackrel{\infty}{\longleftarrow}$

$\stackrel{\infty}{\infty} \stackrel{\infty}{\leftarrow}$

눈용

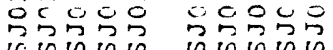
U: 


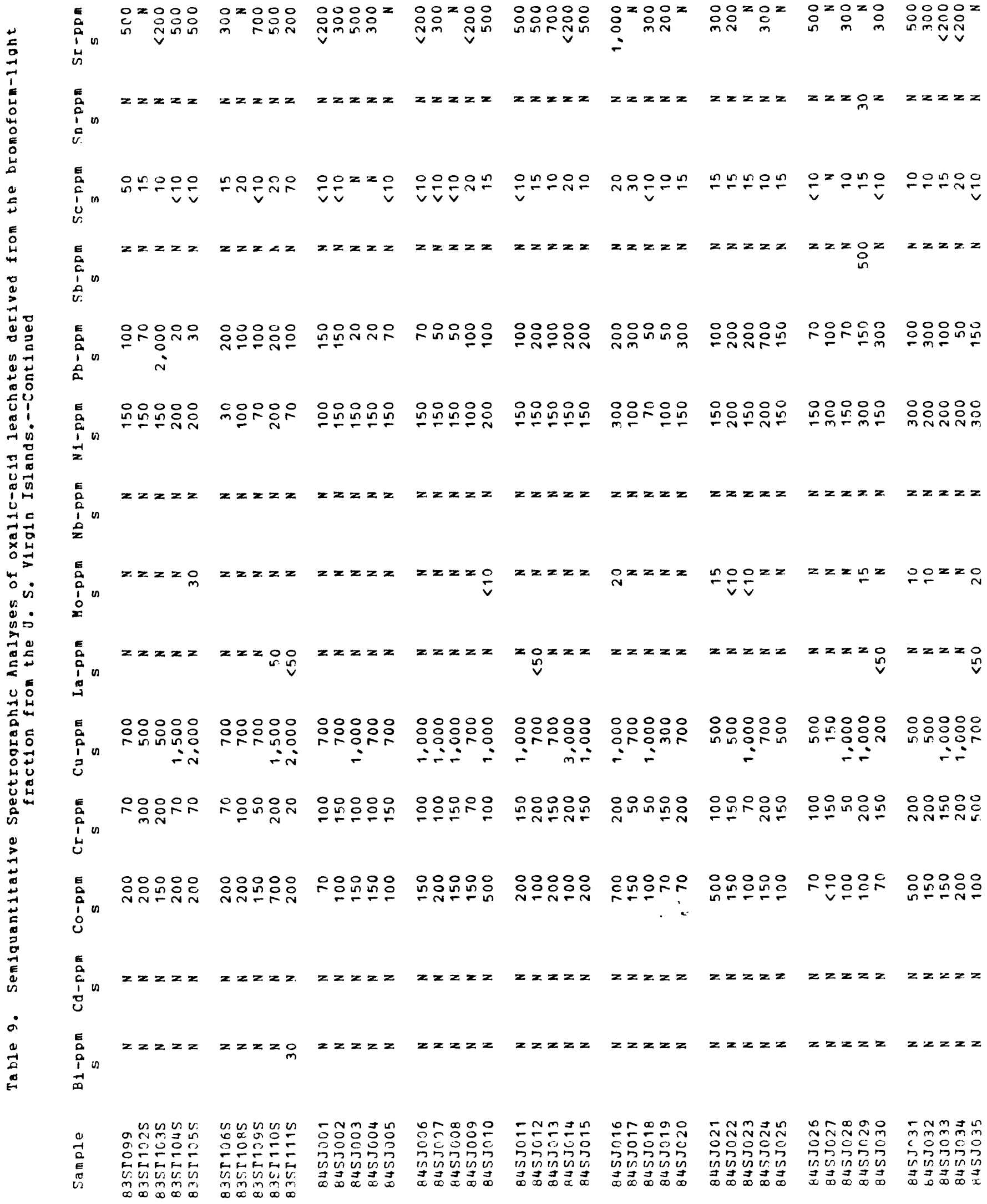


E⿱

$z z z z z \quad z z z z$ $z z z z$

$z z z z z \quad z z z z z \quad z z z z z$ E

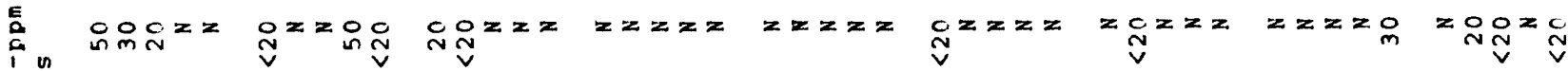

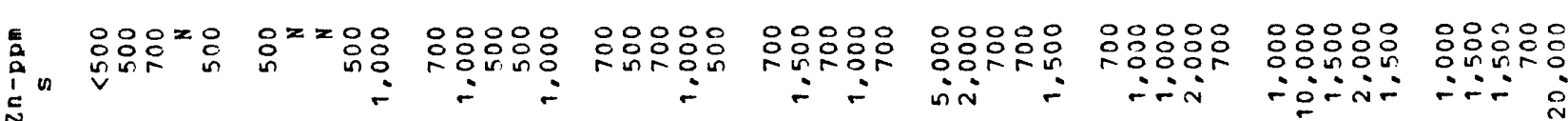

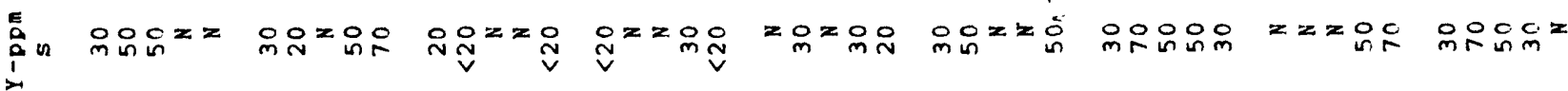

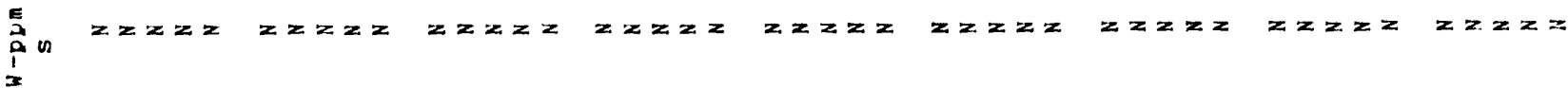
틍ㅇㅇㅇㅇㅇㅇㅇㅇㅇㅇㅇㅇㅇㅇㅇㅇㅇㅇㅇㅇㅇㅇㅇㅇㅇㅇㅇㅇㅇㅇㅇㅇㅇㅇㅇㅇㅇㅇㅇ a n in $\because \because \because \because \because \because \because \because i$ iñin

응읃ㅇㅇㅇㅇㅇㅇㅇ

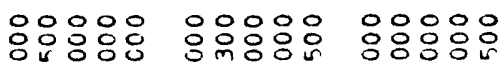
$>$

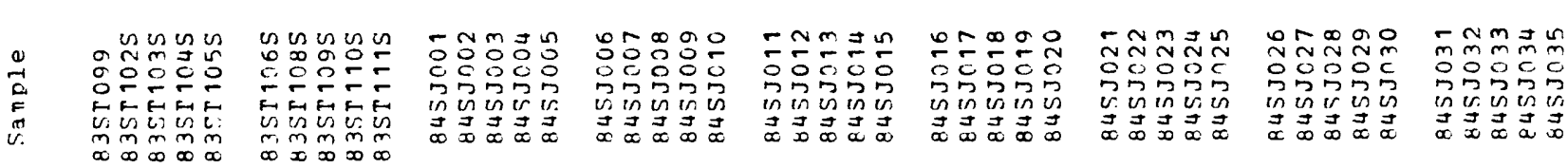



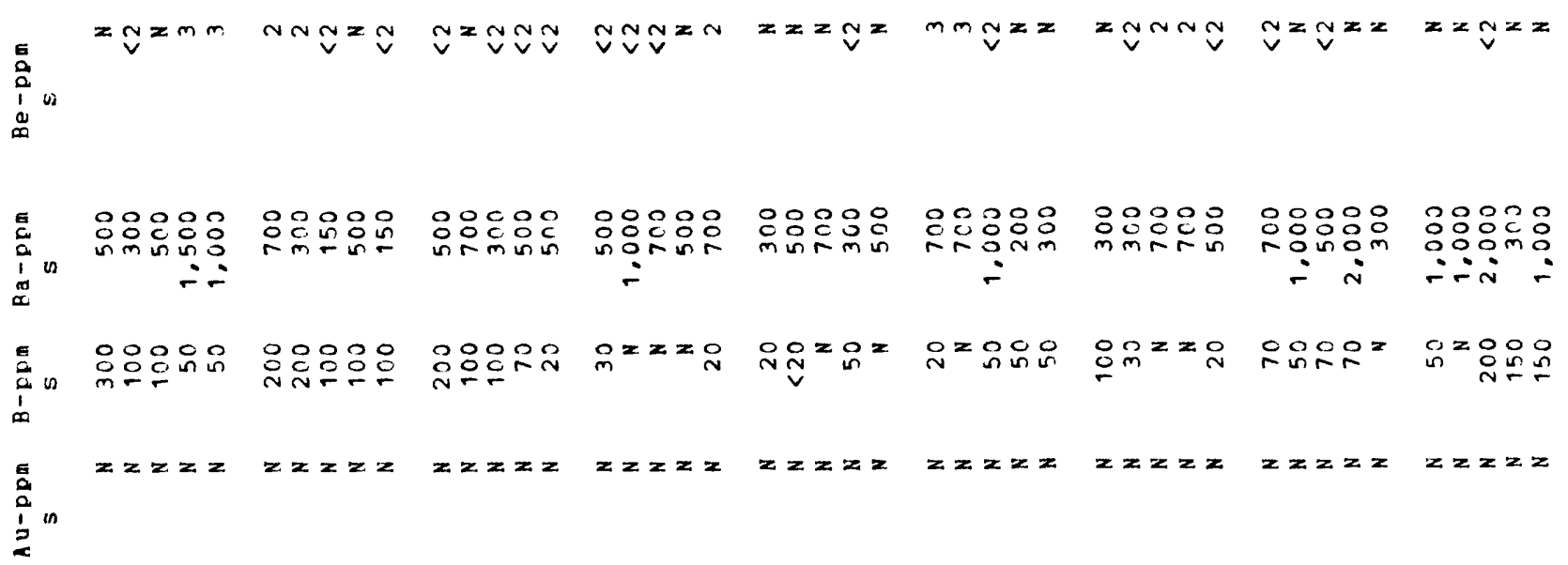

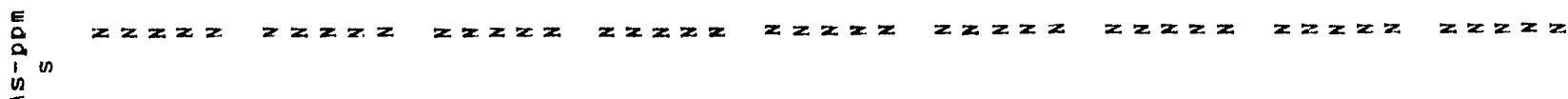

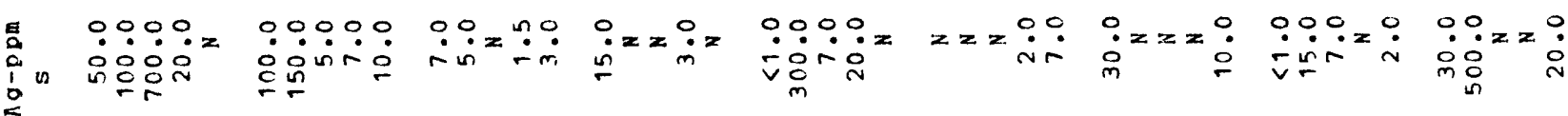

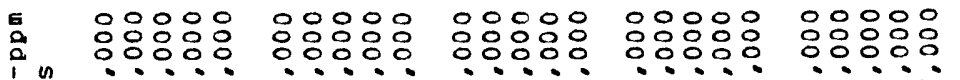

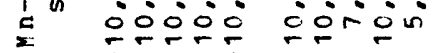

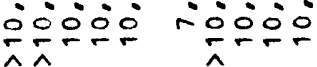

iónis

응응ㅇㅇㅇㅇㅇㅇㅇㅇㅇㅇㅇㅇㅇㅇㅇㅇㅇㅇ

cónir ricó

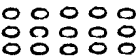

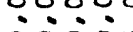

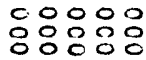
응ㅎำ

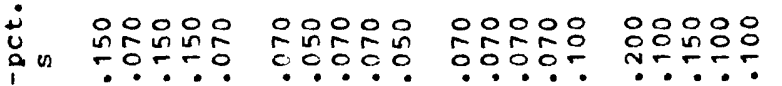

응용ㅇㅇ응

00000

응ㅇㅇㅇㅇㅇㅇㅇ

웅은은

$\hat{\wedge} \wedge$

$\therefore \rightarrow \div$

$\cdot \cdot$

.

$\cdots$

・.?

..:.

$\div \div \div$

옹웅응응 옹응응음

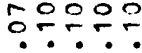

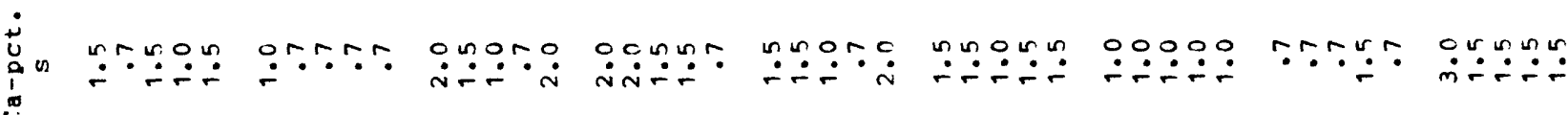

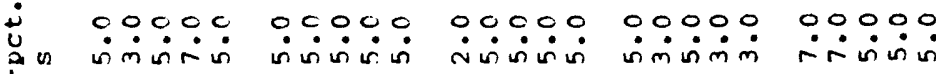
o

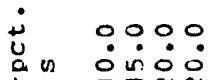
i

0
0
0
0
0
0
0

$\stackrel{m}{\sim} a=n$

$\stackrel{m}{\exists} \underset{g}{g} \stackrel{m}{g}$

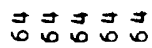

으는우요 어요의

$\stackrel{\infty}{\sim} \stackrel{\infty}{\sim} \stackrel{\infty}{\sim}$

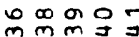

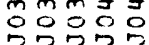

in $0 \begin{aligned} & \text { in } \\ & \text { in }\end{aligned}$
웅요
ตำ 곤 영응

$\because \propto \infty \infty$

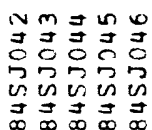

\section{윰욤ㄱ \\ ํํํํำ}

n

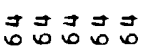

确与步

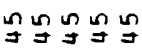

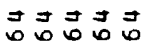

보ำกั

ำำ

웜ㅇㅇ

위융유유

$\stackrel{\infty}{\infty} \stackrel{\infty}{\infty} \stackrel{\infty}{\sim}$

$\stackrel{\infty}{\infty} \stackrel{\infty}{\sim}$

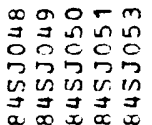

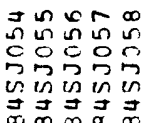

00090 유윰

$\stackrel{9}{=} \div$ ำ 웅의

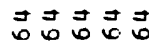

Na $\stackrel{n}{m} \stackrel{0}{=}$ 뜽ㅇㅇㅇㅇㅇ

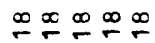

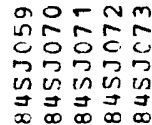

ம

0.000

00000

$\dot{n} \dot{\sin } \dot{0}$

00000 $\dot{m} \dot{\sim} \dot{m} \dot{m} \dot{m}$
웅요용

00000 용ㅇㅇ

0.000 io in

00000 送它完

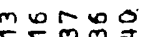
甲 000

กิกักลัก 弯寻寻寻

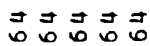

$\vec{\nabla} \vec{\exists}=$

a. $n=$ y 은

응유윰

유융유유

$\stackrel{\infty}{\infty} \stackrel{\infty}{\leftarrow}$

$\infty \propto \infty \infty \infty$

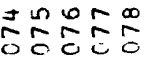

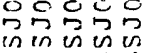

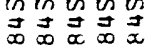

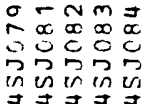

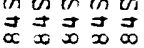

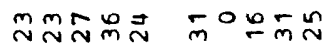

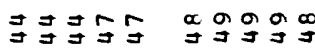

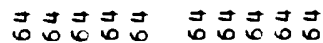

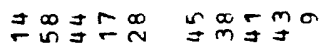

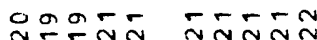

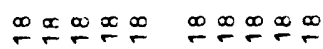

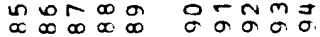

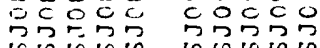

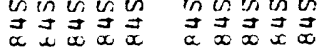




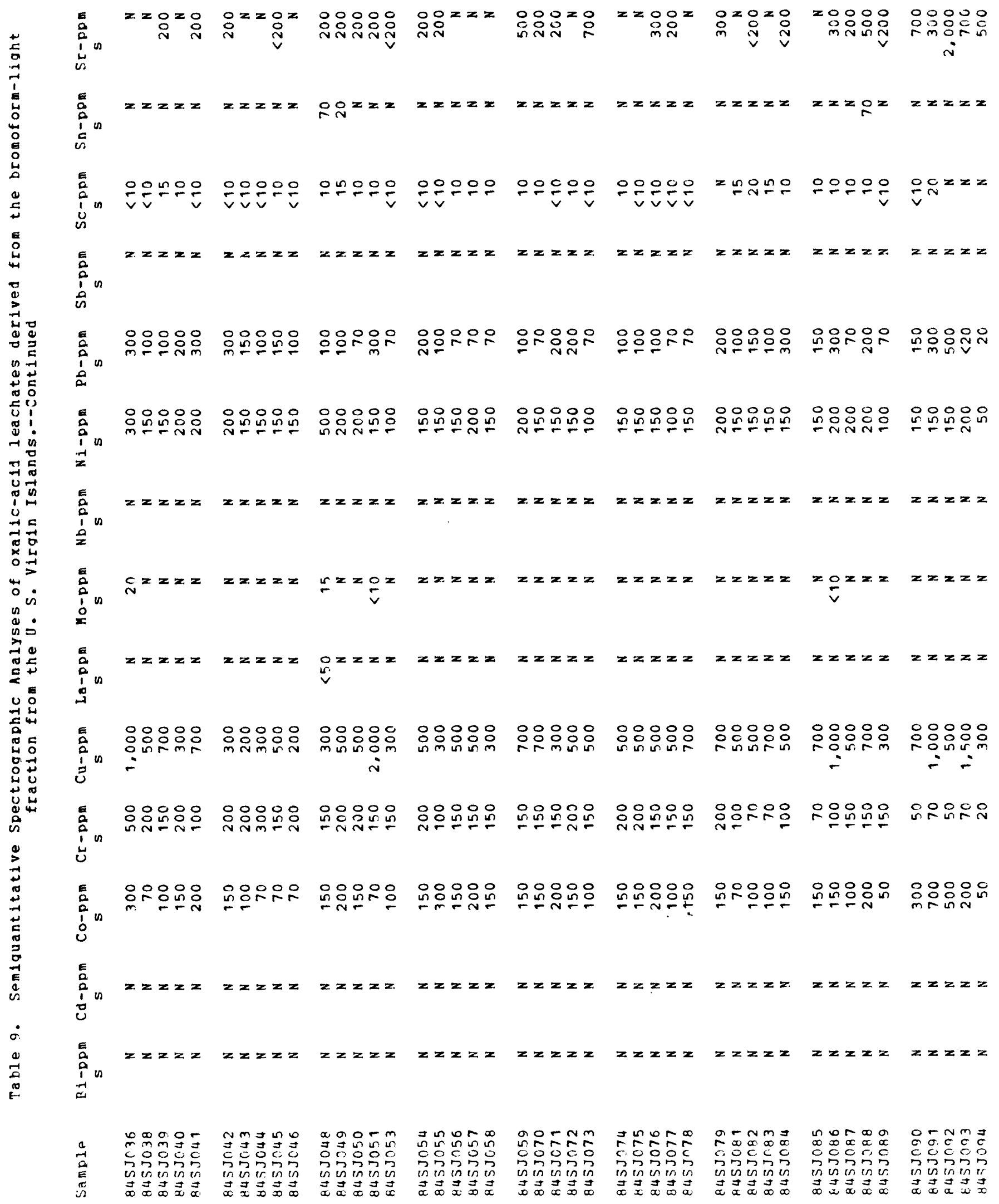




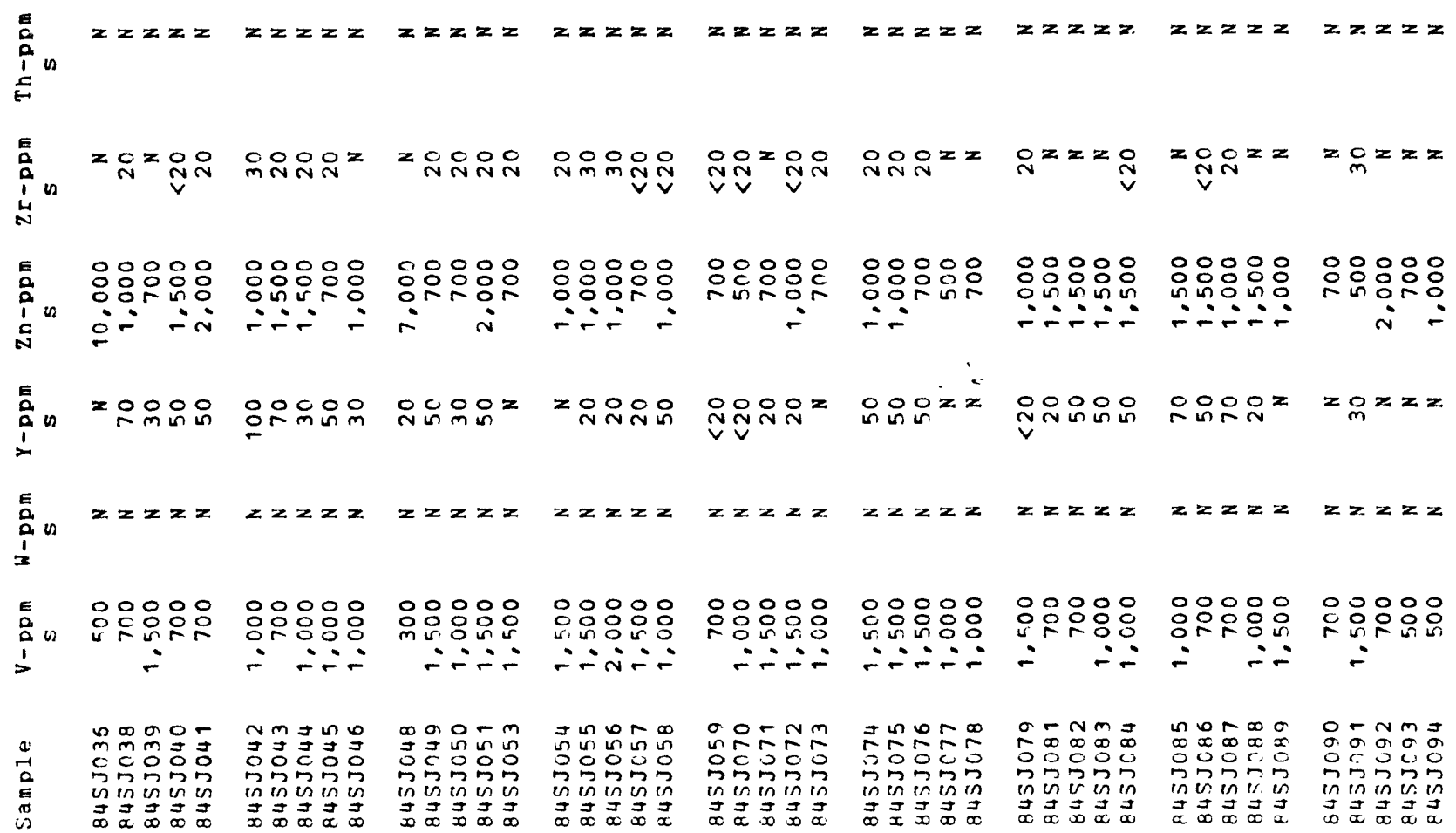


E⿱

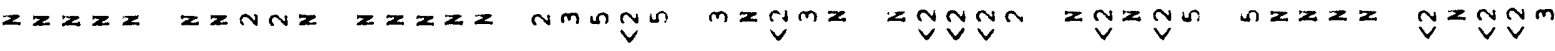

\section{- 0000}

हn

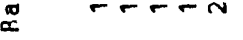

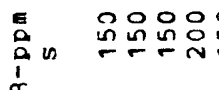

${ }_{2}^{5}$

$z z z z$

웅ㅇㅇㅇ응

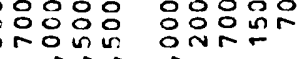
$\because \div$
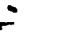

80000

응응ㅇㅇㅇ

ㄴํㄴㅇㅠ

$z z x z$

$2 x z$

E

E 00

c

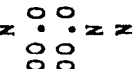

8

5
2
1
0
2

c0000

응응응

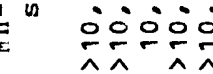

응영응

nio.

융유

$\dot{0}: 0 .=$

z $\frac{0.0}{\dot{v}}=\stackrel{0}{i}$

: $=$

$z z z z$

$=\because \dot{m}=\stackrel{0}{\bar{v}}$

는 웅융요

ㄴ $0 \div \div \frac{1}{1}$ $\rightarrow$

范

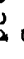

n. 000

mo0no

응ำ

in in s. Co

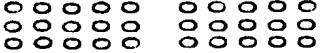
的唡 웅응

응응ㅇㅇㅇ응 ㅇoㅇ

응응응응

mison

A

응용응요

웅웅응응

응은에은옹

rर

은?

옹응ㅇㅇㅇㅇㅇㅇ

는드.

응웅응요

ov으.

․․․․․․․

rari

no

:

0.00

$0000 \%$

00000

c.0.0. nin

نें山िं

c:000 minim

¿ 0000

0.:00:

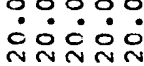

0.000

0.000

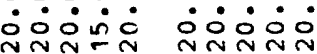

0.000

원ㄷㄴ

:

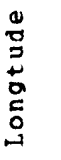

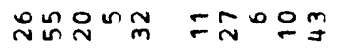

ํำ

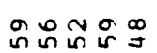

n $\exists m ?$

돌월

$m \sim ⿻ a$

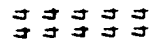

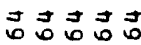

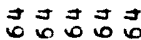

जै जै जु चु

$\overrightarrow{0} \overrightarrow{0} \overrightarrow{0} \overrightarrow{0} \overrightarrow{0} \overrightarrow{0}$

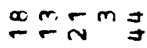

$\infty a \infty=\infty$

ㅇำ $\underset{n}{\infty}$

ำㅇำㄴำ

กNำ

$\stackrel{\infty}{\infty} \stackrel{\infty}{\div} \stackrel{\infty}{\infty}$

유유유ำ

$\stackrel{\infty}{\sim} \stackrel{\infty}{2} \stackrel{\infty}{\infty}$

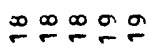

엉ㅇㅇㅇㅇ

$\because \infty \stackrel{\infty}{\infty}$

$\stackrel{\infty}{\sim} \cong \stackrel{\infty}{\sim}$

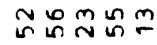

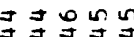

$\overrightarrow{0} \overrightarrow{0}$ जै $\overrightarrow{0} \overrightarrow{0}$

$\exists \underset{m}{m} \Xi \Xi$

유의

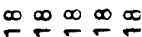

Ning

푿유

$\infty \infty \infty \propto \infty$

웅ㅇㅇㅇㅇㅇ

$\exists \cong \div$

学可可

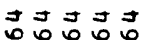

눙ㅇㅇㅇ

-

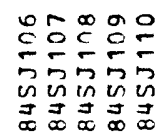

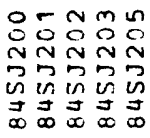

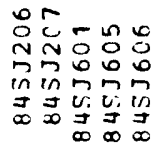

wining in

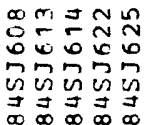

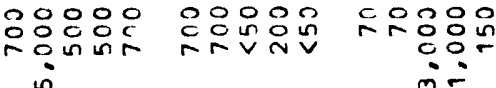

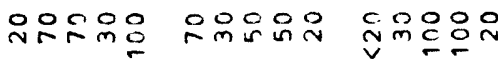

$z z z z z \quad z z z z y z z z$

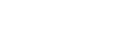

\section{0}

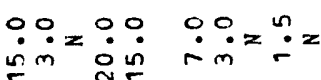

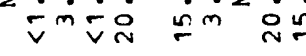

응영ㅇㅇㅇ 응응응응응

응ㅇㅇㅇㅜ in onvin vivimin

ingón

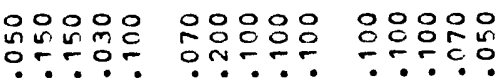

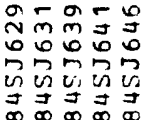

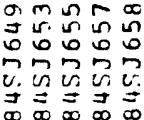

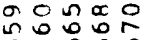

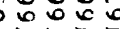
ज电包的

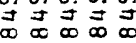




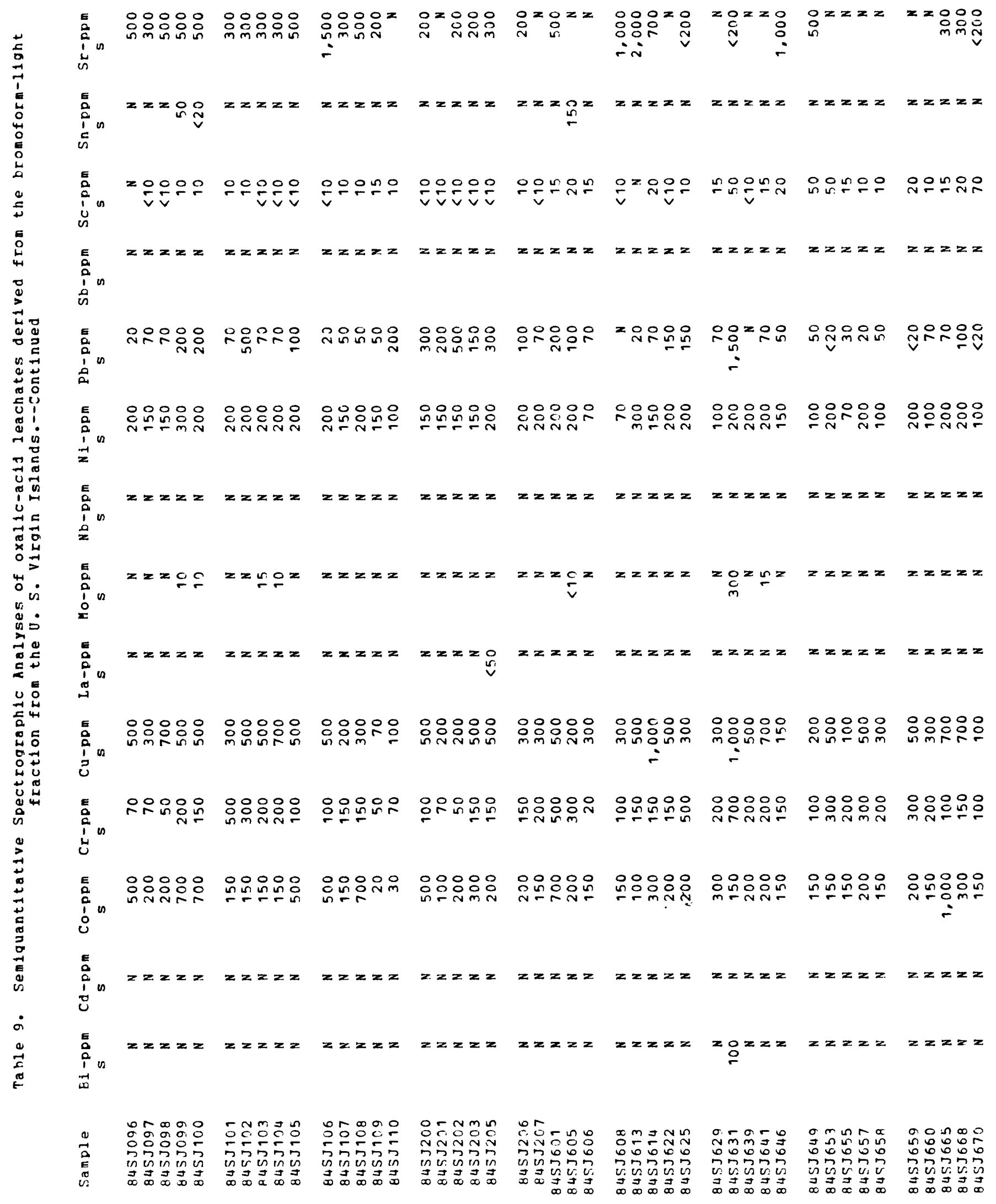




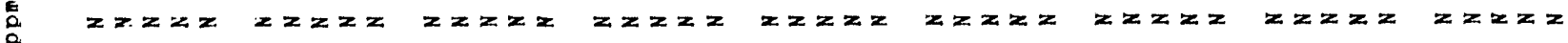

$$
\begin{aligned}
& \text { in }
\end{aligned}
$$

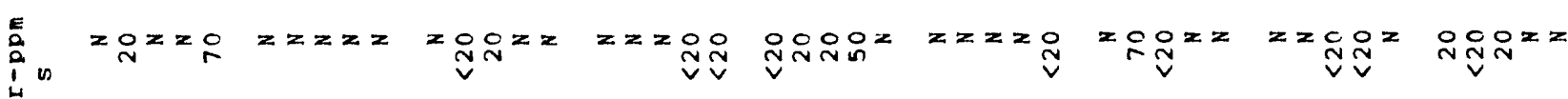

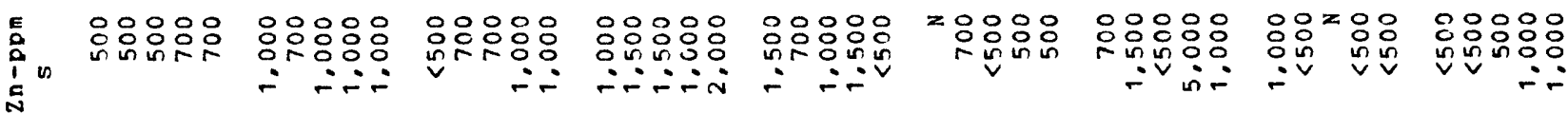

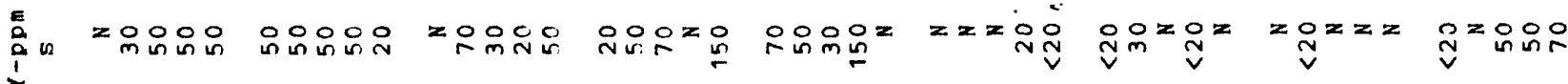

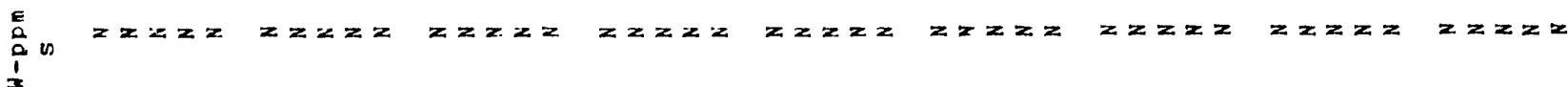

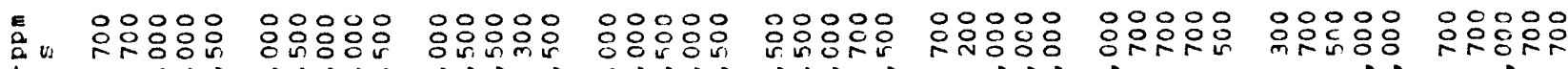

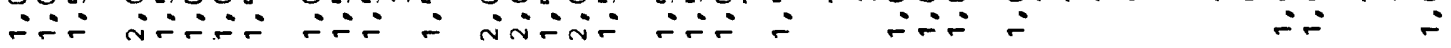

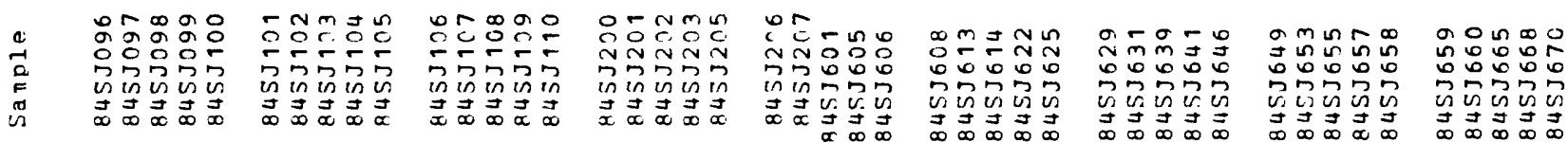



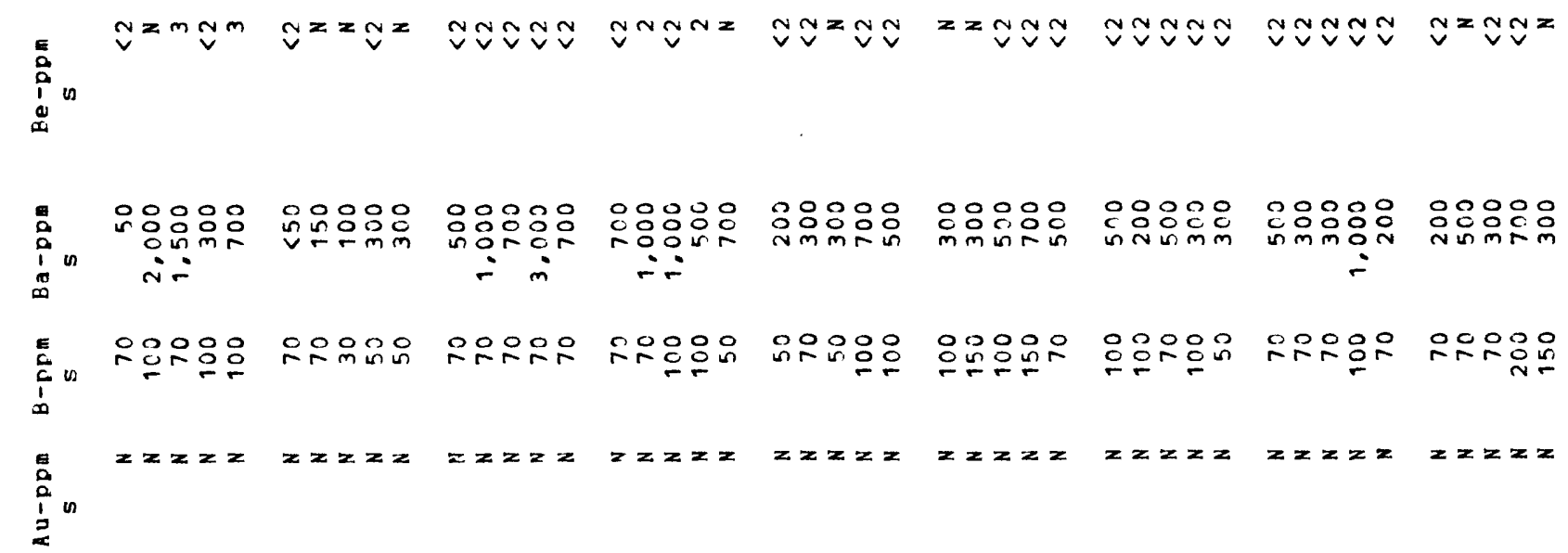

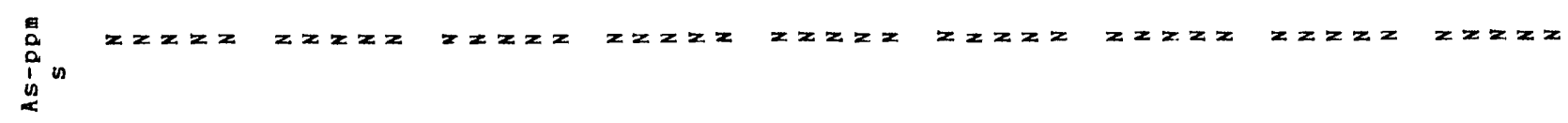

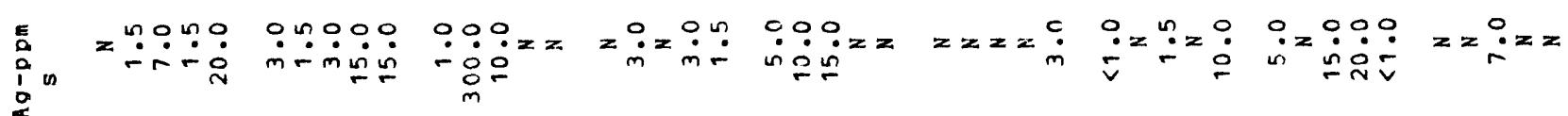

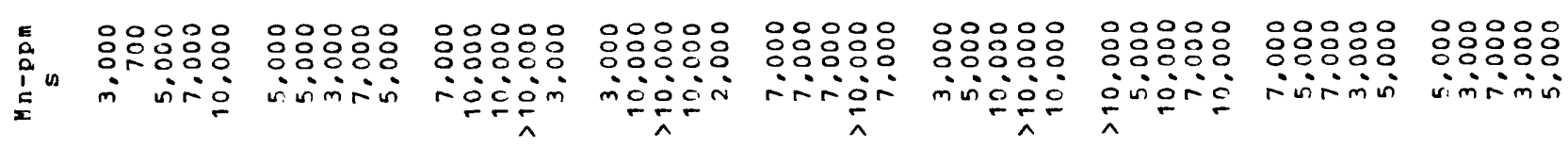

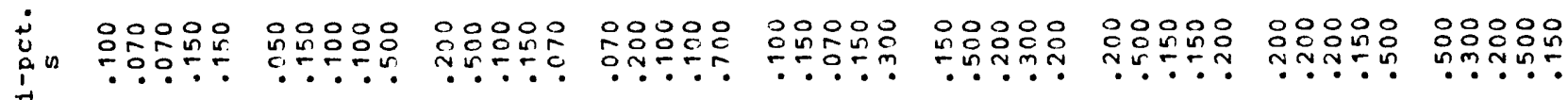

范

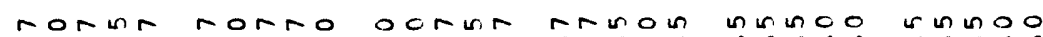

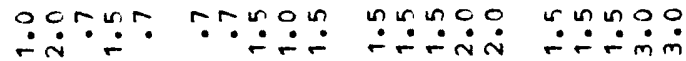

0.000

noo in un noo in in

i 0 no 0000000

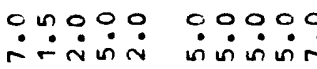

$0: 0 \%:$

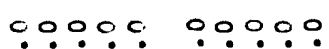

$0000 \%$

0.000

\section{$r$}

c:0.:0 0.00: 1.

+ 0000000000

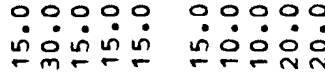

00000

00000

00000

00000

00000

0000000000 i

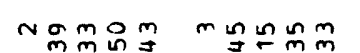

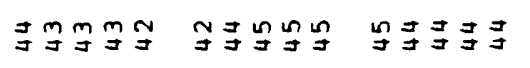

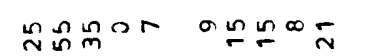
角寻宛

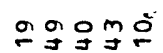

西

윰N요

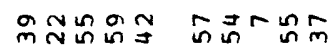
可可弯昌 $\begin{array}{lll}\infty & 0 & 0\end{array}$

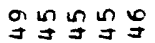

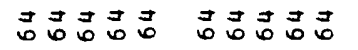

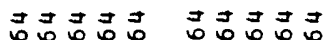

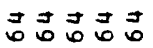
올

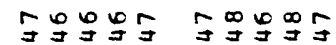

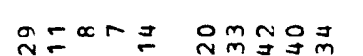
엄ㅇㅇㅁㅜ $m m-n r$

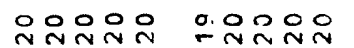
윰ำ

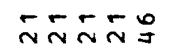
I $-n=5 a$

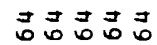

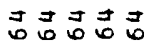

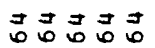
뭄ำ

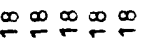

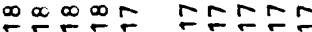
$\begin{array}{llll}\pi & 0 & 0 & 0\end{array}$

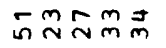

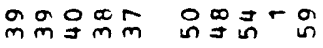
$\begin{array}{llll}0 & 0 & 0 \\ 0 & 0 & 0 & 0\end{array}$ $\begin{array}{llll}0 & 0 & 0 & 0 \\ 7 & 0 & 0 & 0\end{array}$ $0 \cap 0 \ln n$ 约寻寻寻

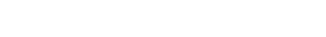

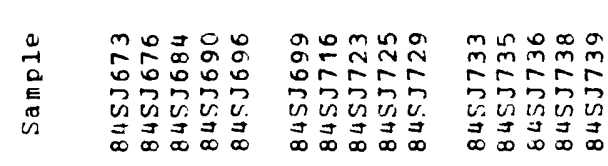

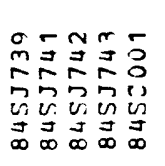

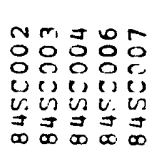
ำะี ㄷำ

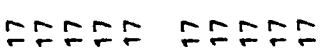

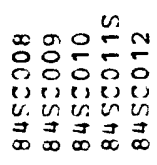

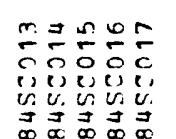

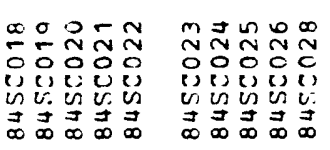




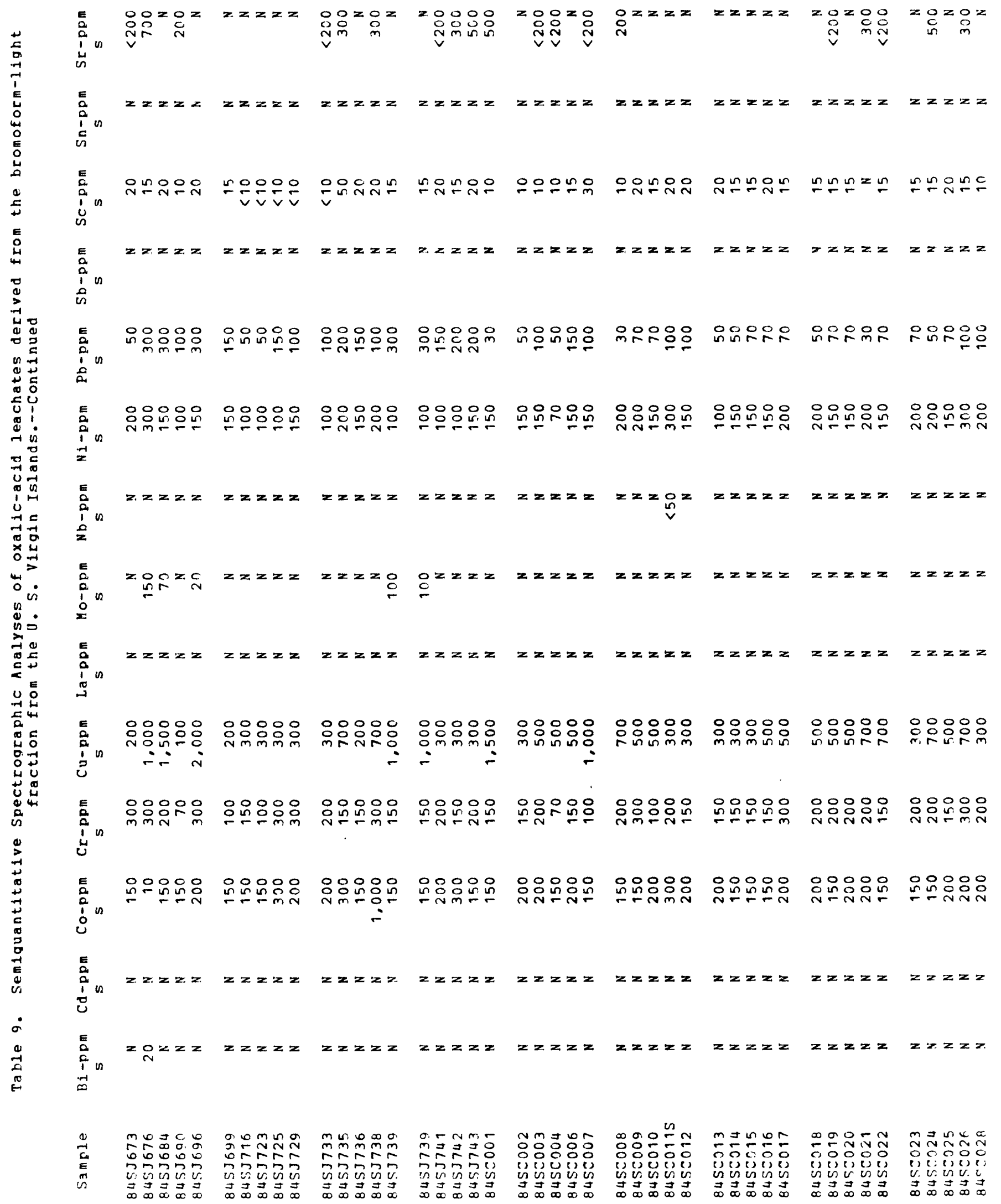




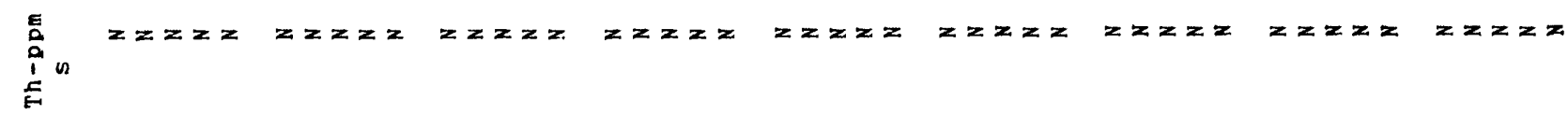

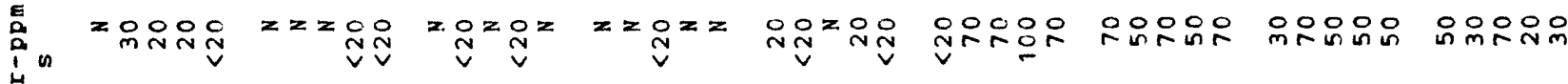

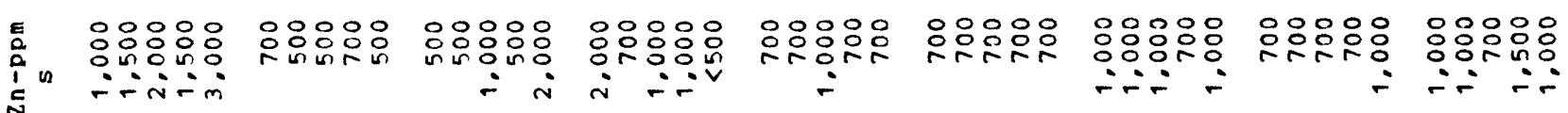

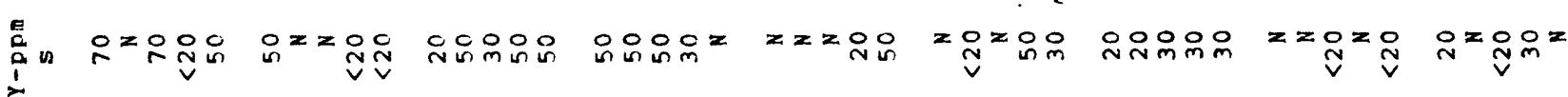

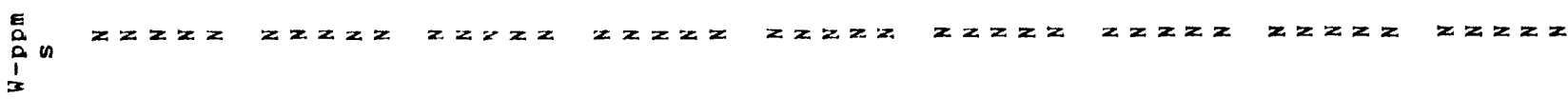

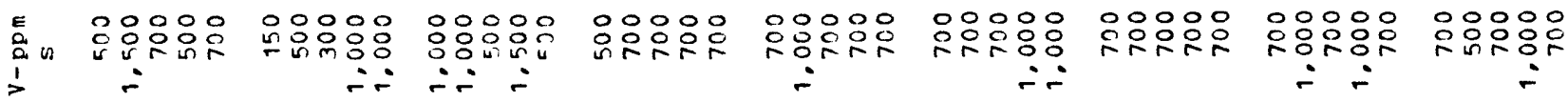

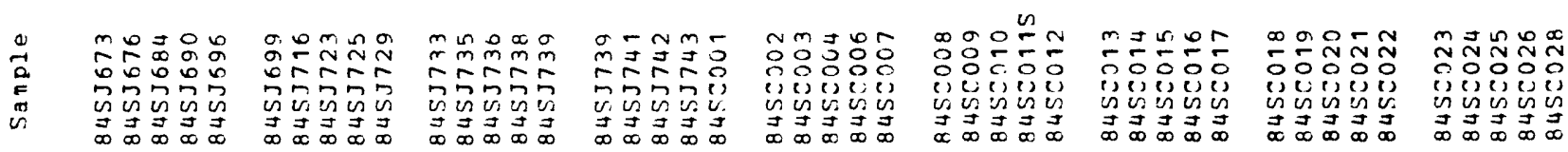




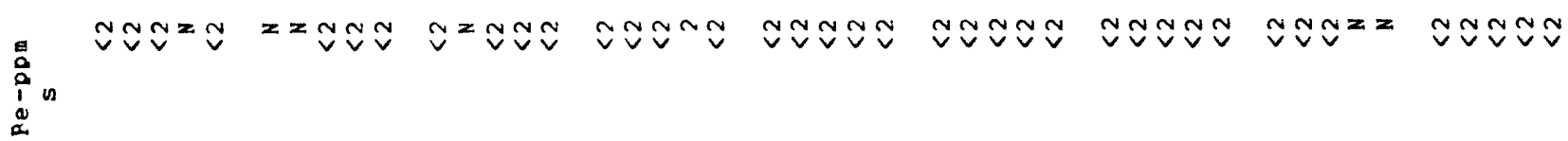

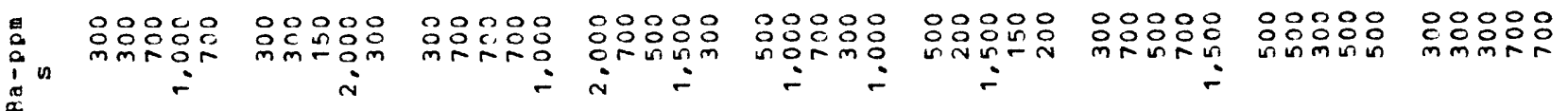

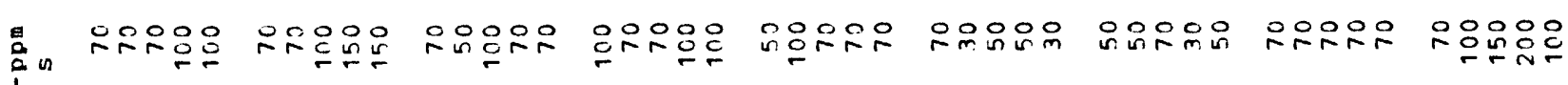
i

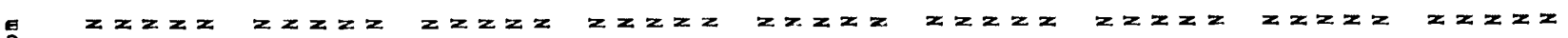
$i_{0}^{\circ}$

:

$z z z z z=2 z z$

$z z z z \quad z z z z z \quad z z z z$

$z z z z$

$z z z z z \quad z z z z z \quad z z z z z$

是

$z z=\stackrel{0}{m}=$

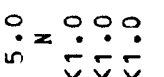

$\ddot{r} z=\ddot{0}_{m}^{0} z=\ddot{i}^{0}$

$z=\stackrel{0}{r}=\frac{0}{i}$

$z z \stackrel{0}{0}: \stackrel{0}{\text { in }}=$

$z z z=\stackrel{0}{\circ}$

$\ddot{0}$

ro:00

\section{E $\quad 000000$}

응응ㅇㅇㅇㅇㅇ

ronoin

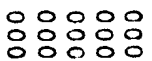

등ㅇㅇㅇ응

irisio

0.0000

응융유

o요요

응ㅇㅇㅇㅇㅇㅇㅇㅇ

orionis

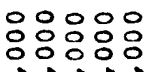

웅ㅇㅇㅇ

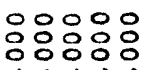

00000

社的

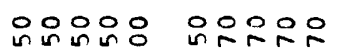

00000

00000

응용용ㅇㅇ

웅요옹응

운온은운

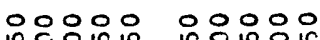

ㄷำ

$\div \div \div$

……

..?

?.?

ㄷ․․․․

둔..ㄴ..

苔。

nnoog un no no

o no no

$00 \ln 00$

in mo의

on nom

n. ำ 1500

ำำำ \%

$\stackrel{+}{\dot{U}}$

c:0.

0.000

$00 \% 0000900$

$0000 \%$

00000

00000

00000

00000 :

+ 0000

0000000000

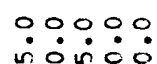

แ $\sin$

Tn nivi

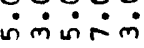

유용 ษ

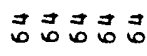

노응

承寻寻

ะะะ

mogn 드응용

$\stackrel{\sim}{\sim} \stackrel{\infty}{\sim} \stackrel{\infty}{\sim}$ กำกำ

$\sim \operatorname{mp}_{m} \infty \propto$

ก้กำกำก

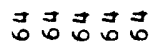

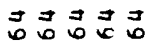

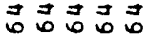

요요

북유

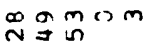

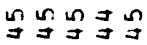

ว

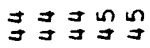

엉ํำ

⿰纟mm $m$ J

ำะร

픈드

든드

ำะะ

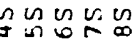

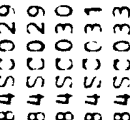

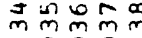

ivisu

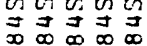

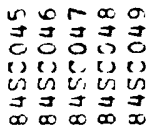

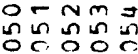

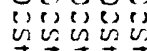

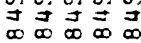

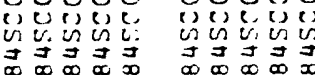

00000

00000 00000

0000000000

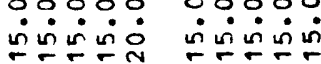

00000 ํํㅇํํㅇํㅇ

00000 ำำํำ

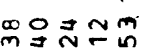

的的的品

可可

$\because \sim m_{n}^{\infty} 00$

ㅇํํㅇํำำ

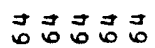

ㄹำ

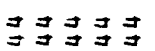

in

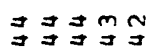

in

ヘะะキ:

F:FF

กำ

i) i is

$\vec{\infty} \vec{\exists} \vec{\infty} \vec{\infty}$

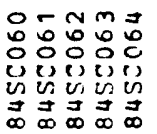

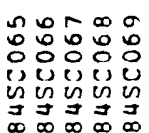




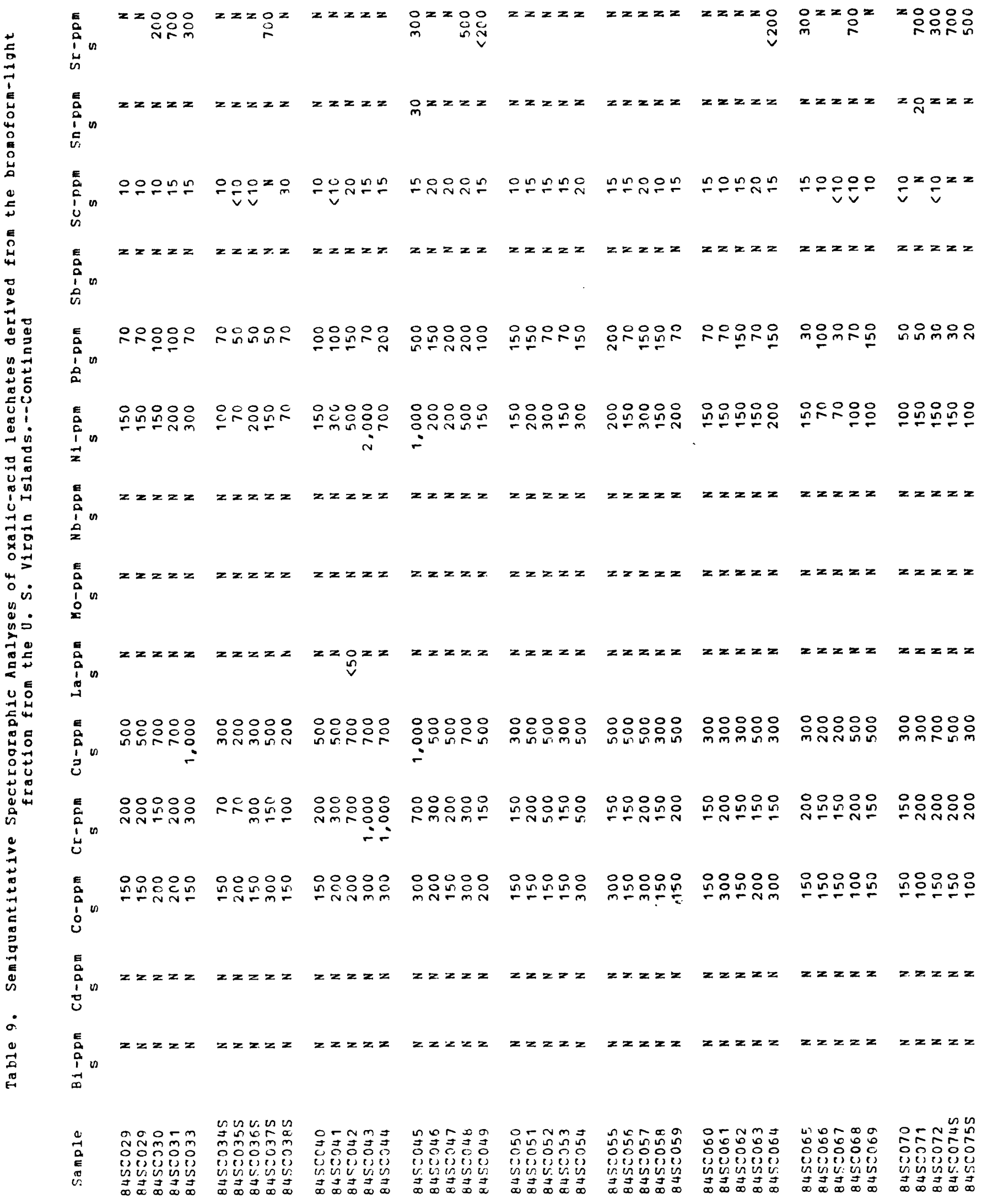




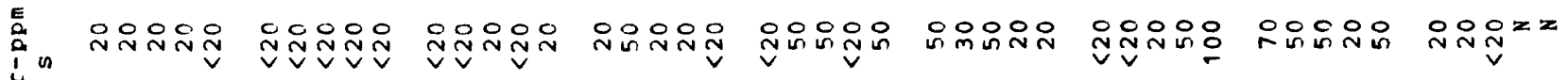

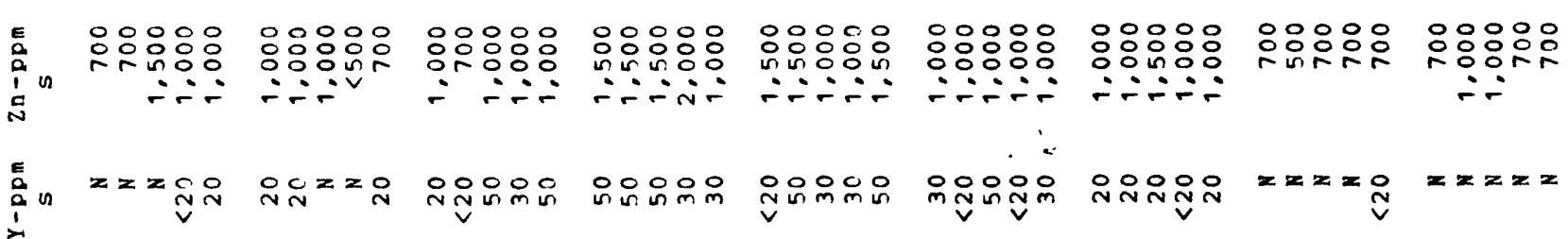

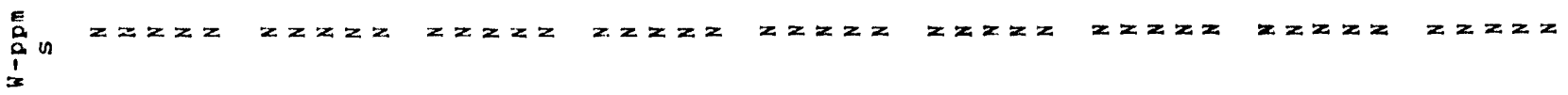

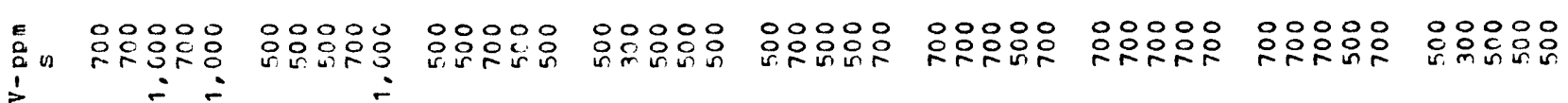

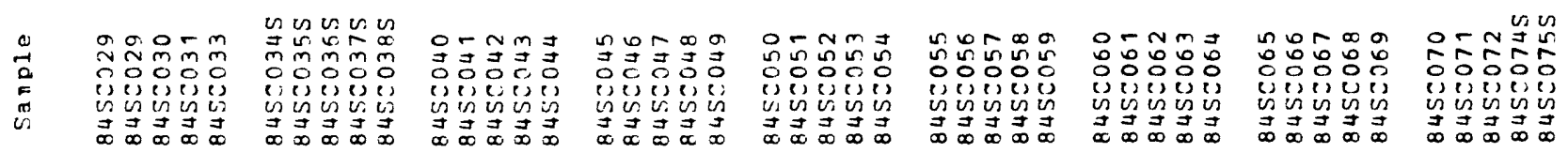




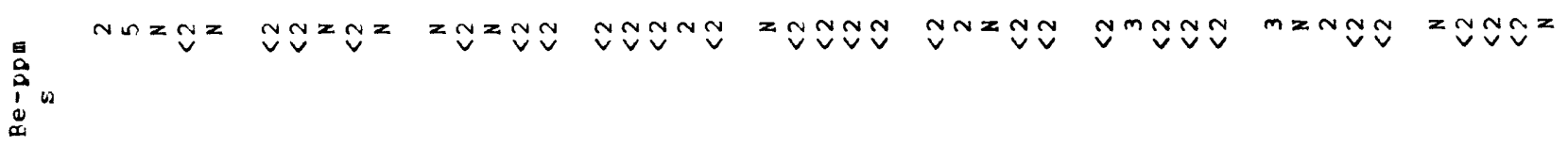

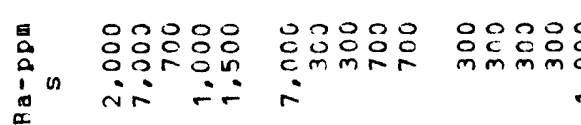

E

$\underbrace{1}_{\substack{0 \\ 2}} \quad z z z z$

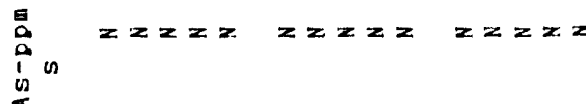

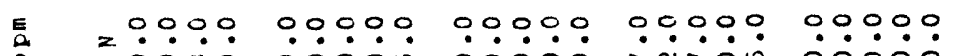

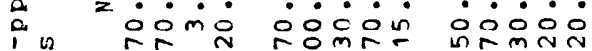

2
0

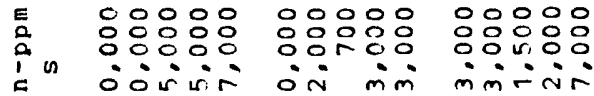

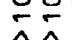

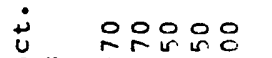

10

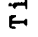

$\stackrel{+}{i}$

onoor

$\dot{i} \dot{\sim} \dot{m} \dot{\circ}$

$\stackrel{\substack{u \\ i}}{i}$ :

$\dot{4}$

ă

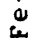

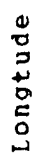

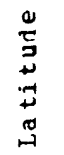

:ำ:ㄴ? กํำ

$\dot{\sim} \dot{0} \dot{m} \dot{0}$

$\therefore \dot{0} \dot{0} \dot{0}$ i

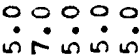

in

응응ㅇㅇㅇㅇㅇㅇㅇㅇ

$\because$ in mi

응응용ㅇㅇ

$\therefore$ inis

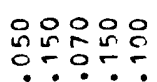

웅응용ํㄴ은

응은은은

옹응용유

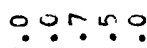

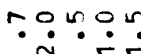

$\because 0900$

ก:ㅇำ

$\because \div \div ? ?$

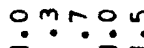

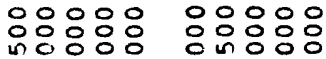
$\therefore$ inim

$00000 \quad 0.000$ orinin

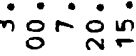

0.0 .00 숭-

00000 $r$ r

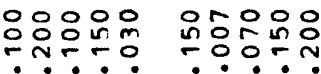

응응영영웅 inmi i

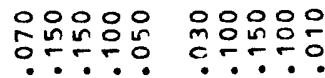

00000

0000000000

0.000

음ํㅛ

무요뭉

virir

둥음

iñi்:

iि용

$\because \dot{0} \dot{0} \dot{0}: 0$

in:요요

00000

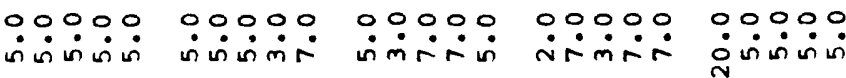

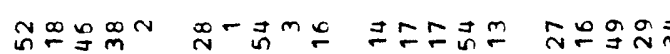

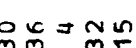

ตำกำ

กิก

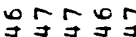

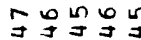

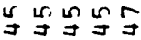

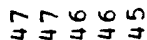

可魚寻孚

鱼曽寻寻寻

可寻寻

음워

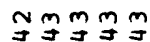

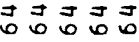

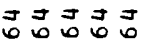

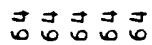

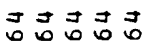

जै

ज्ञ $\overrightarrow{3} \overrightarrow{0}$

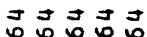

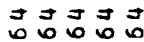

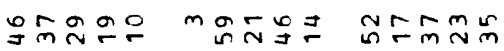

寻寻寻寻寻

寻留寻寻号

च止寻寻孚

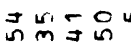

amm nूm

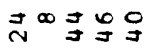

N๋⿻ำ

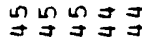

寻寻寻寻学

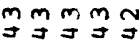

hatia

fing

든

n=NーR

RENニ

Fะะระ

a

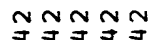

ニะกニ

约㧒瓷

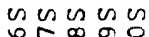

는 $\stackrel{\operatorname{cn}}{\mathrm{m}}=\mathrm{O}$

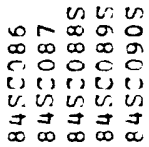

vines $\cos$

б.

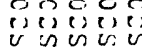

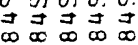

응응응

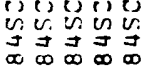

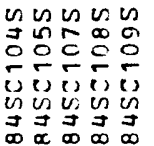

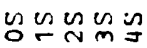

둔

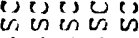

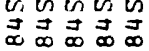

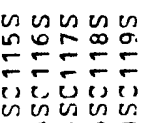

出记
ํํํํํำ

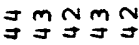

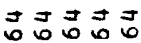

mong Nmmm $m$ エะะะร

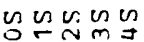
ํํำกี () एक एक

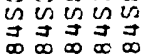




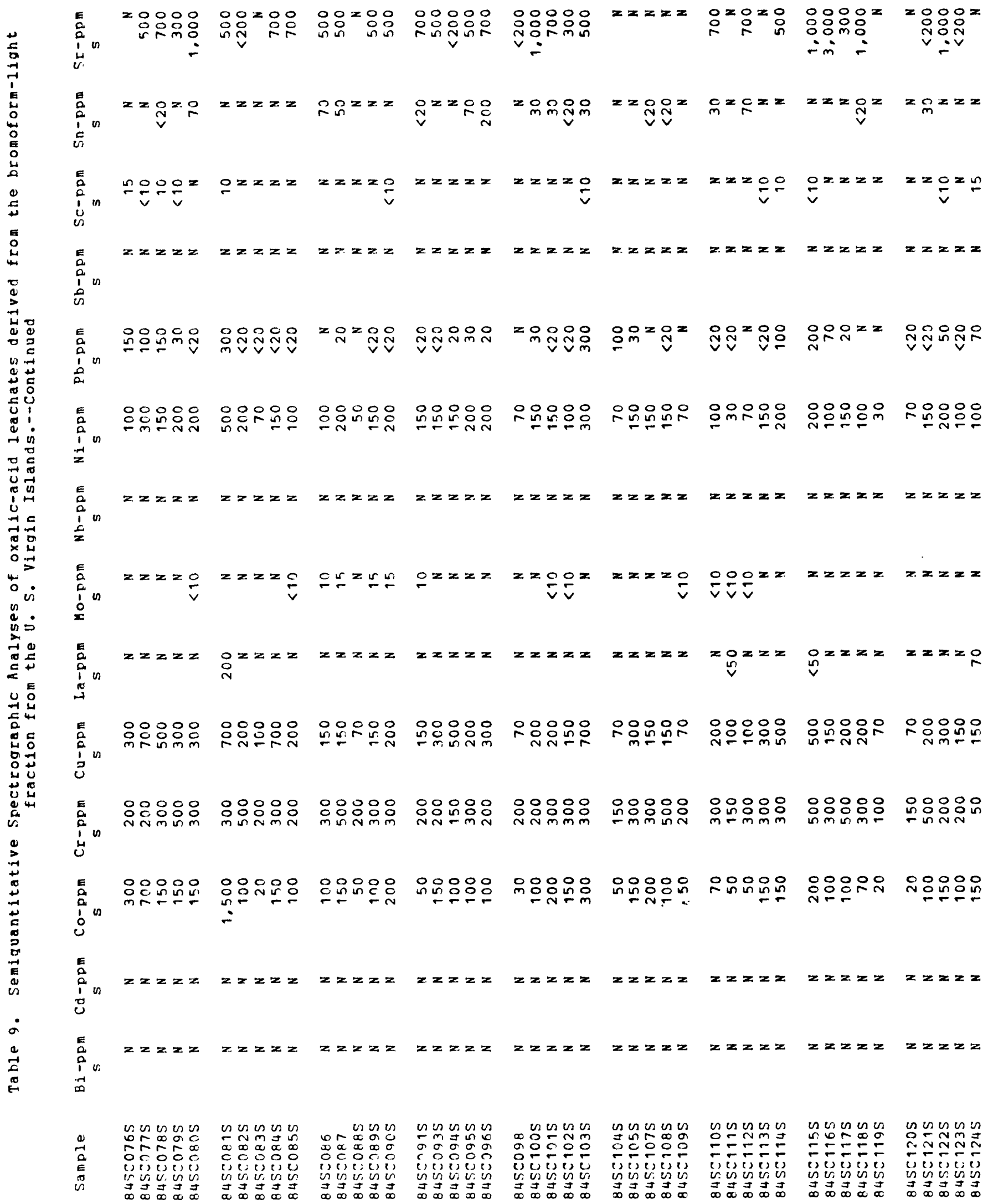




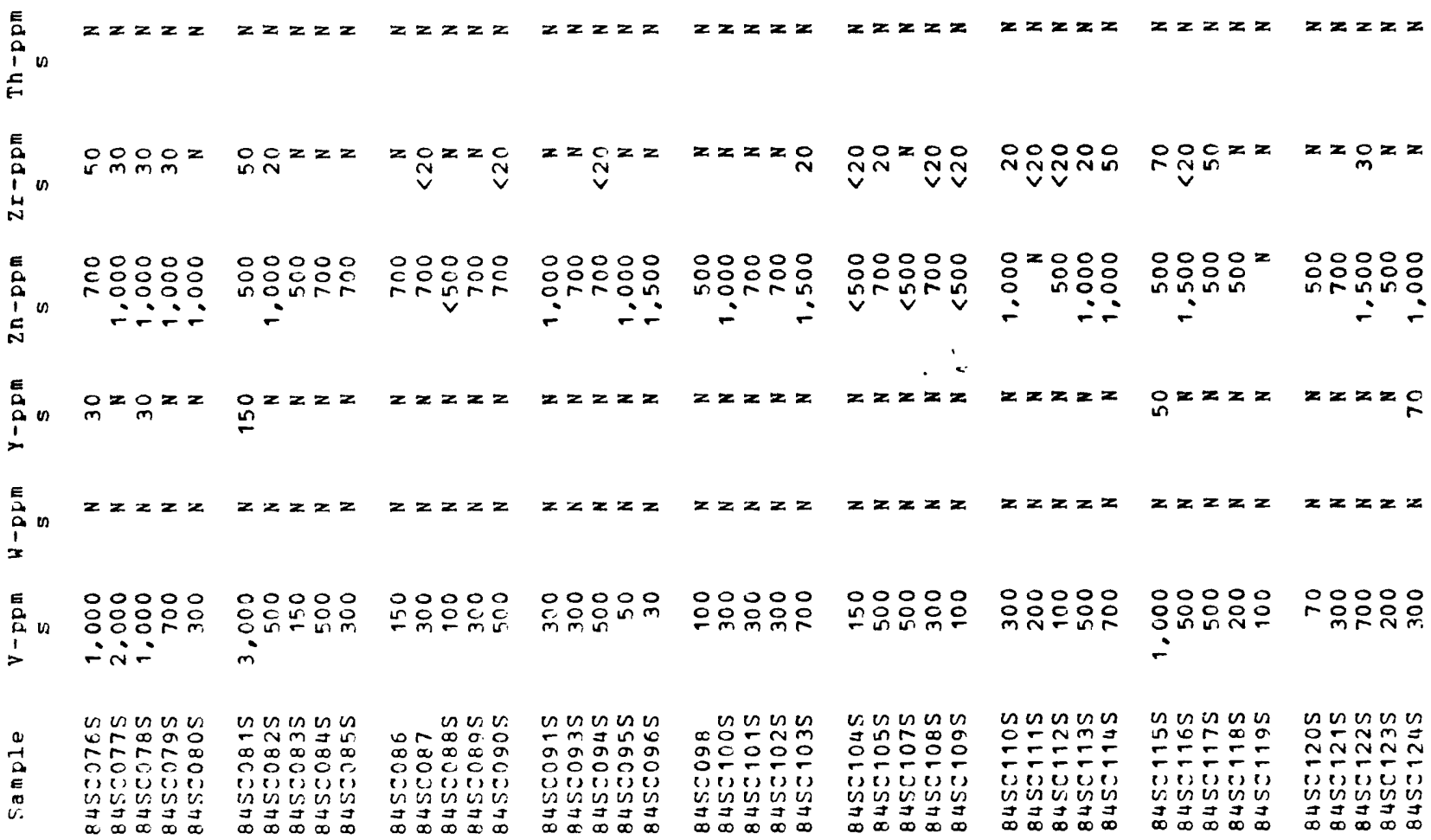



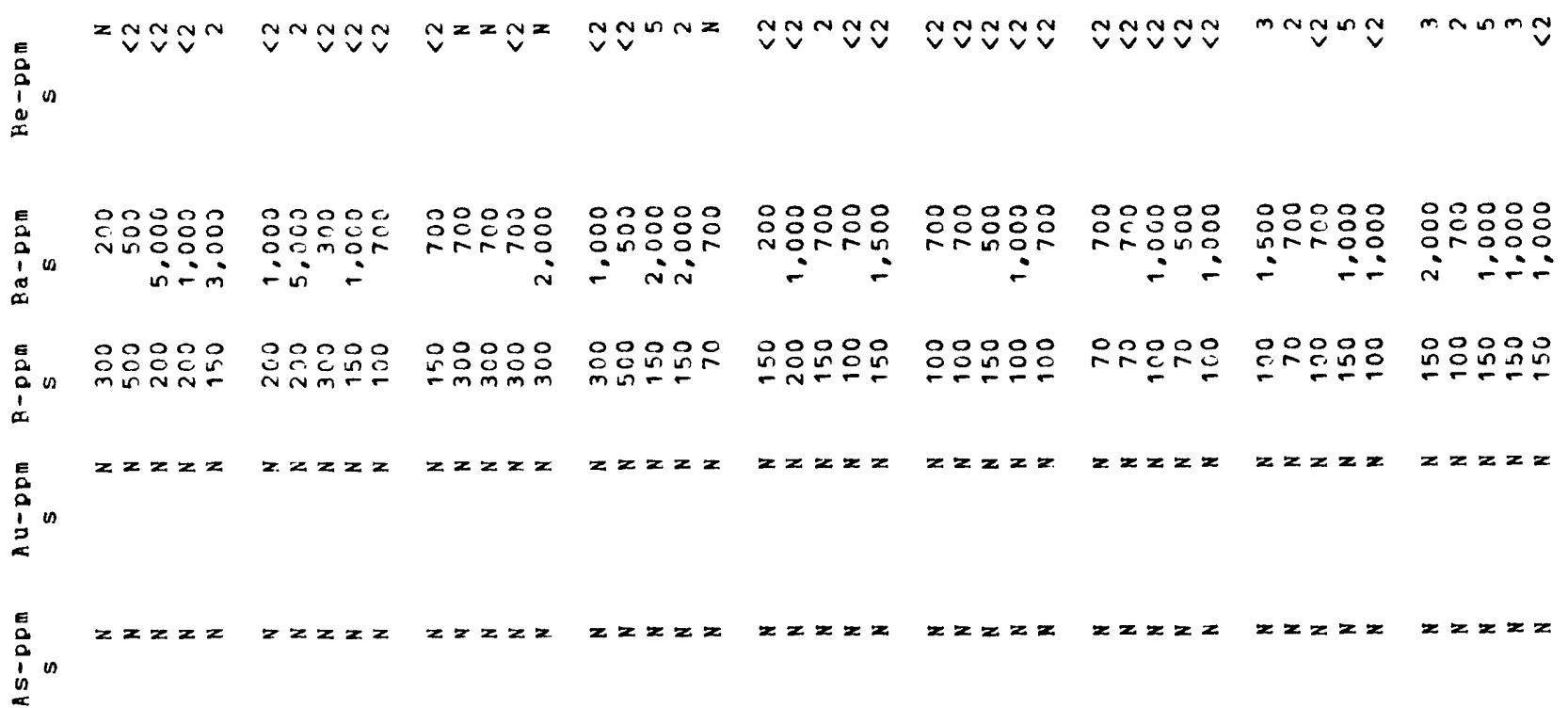

E

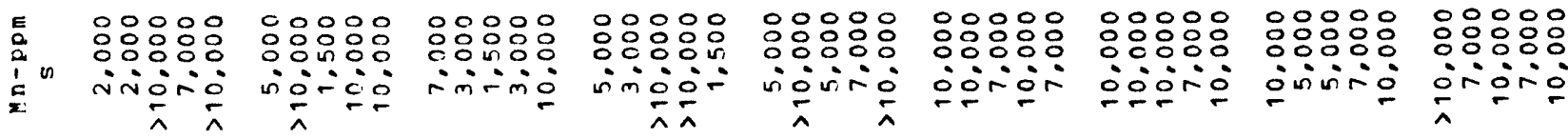

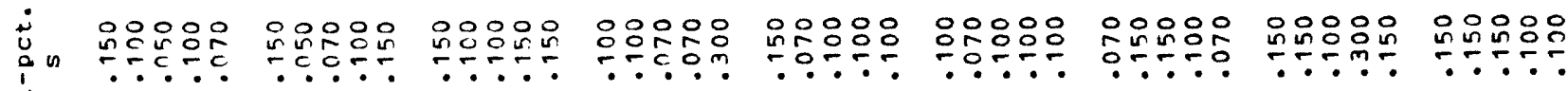
$\stackrel{1}{6}$ is

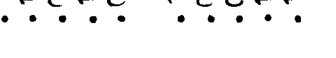

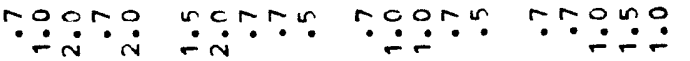

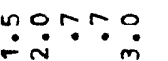

nonoo roogn

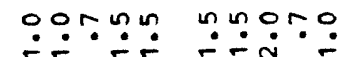
i

过

$0,000 \pi \quad c 0000$

$00000 \quad 00$ in ino

00000

00000

00000

00000

noooc :

ن 0000

뭉웅

00000 minrím

in inir

กิن $\sin$ in

invinim

Nminim

-mंím

กูก๊ก

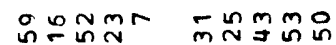

뜬음

$\infty+\infty$

$\begin{array}{lll}\infty & \infty & 9 \\ \exists & = & 0\end{array}$

कom $\infty$

ô 9090

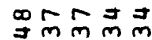

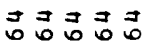

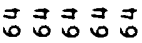

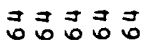

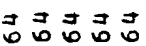

जै $\overrightarrow{0} \overrightarrow{0} \overrightarrow{0} \overrightarrow{0}$

m

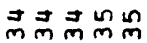

ํํㅇํำ

กำ

mom $m \stackrel{m}{m} \stackrel{0}{=}$

in an:

กN

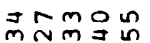

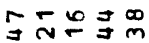

른워음

$\exists \vec{\exists}$

品菂菂品

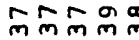

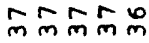

$N m \sim m m$
$\exists=g 9$

NNmm

mas:

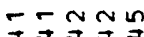

nิ

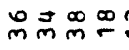

हैं

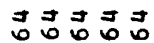

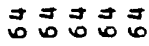

IEะE

ㄷN

든

드는

든

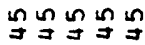

$\infty \simeq 0-\infty$

₹

ํำ ถูกิ

senese.

usengen

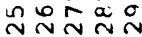

穴鸟分分

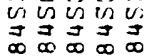

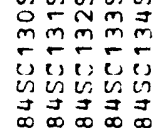

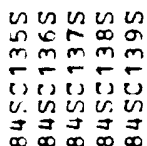

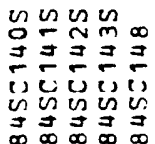

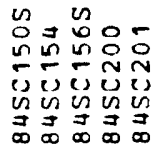

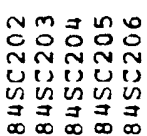

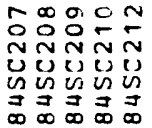

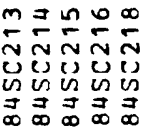

g유Nำ

$-\pi N N N$

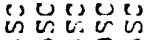

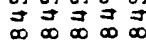




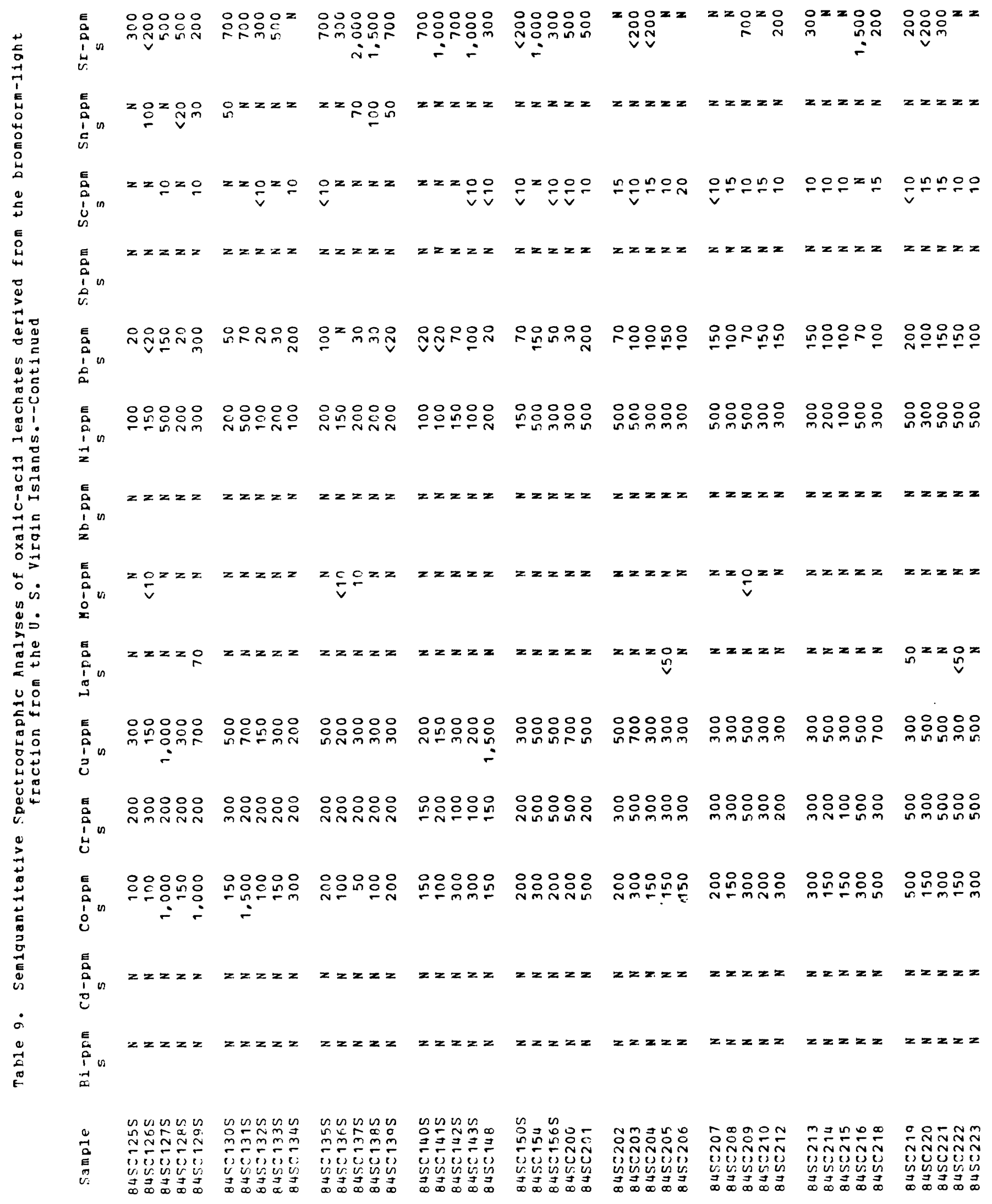


镸 $\stackrel{1}{=}$

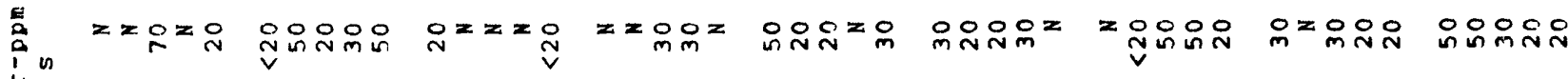
岕

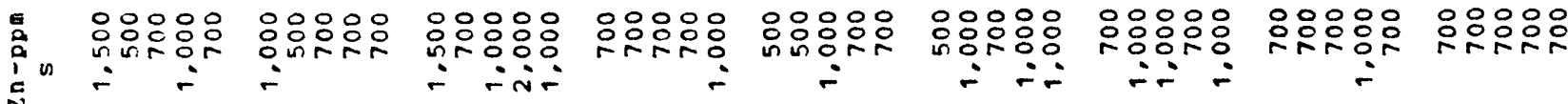

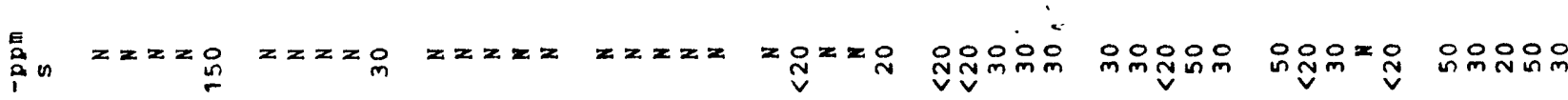

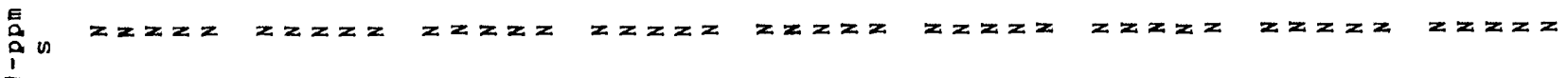

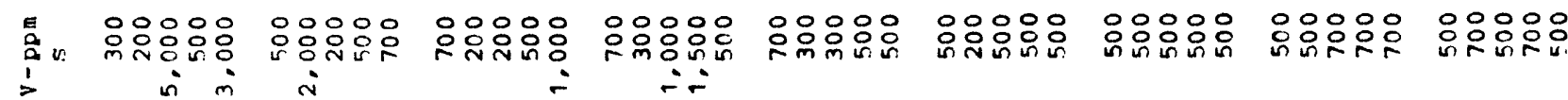

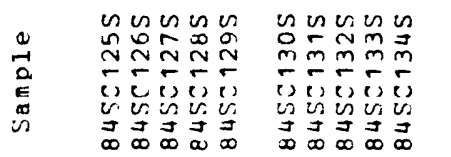

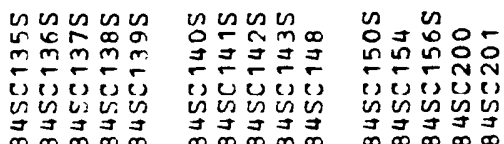

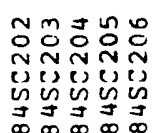

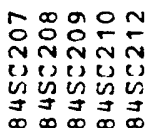

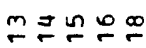
-กNำ ivin

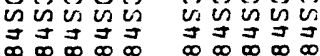




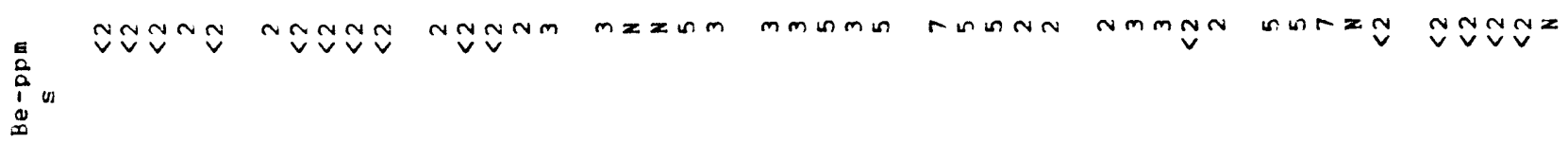

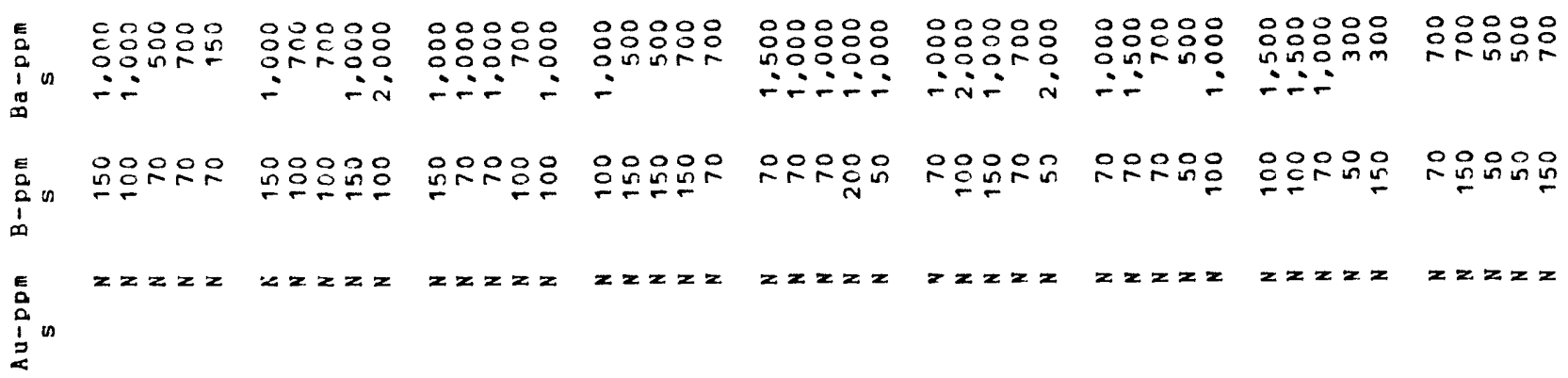

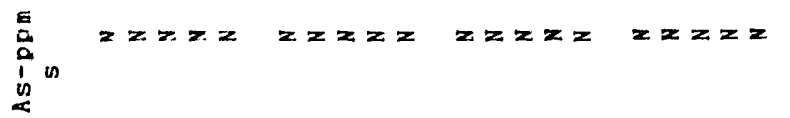

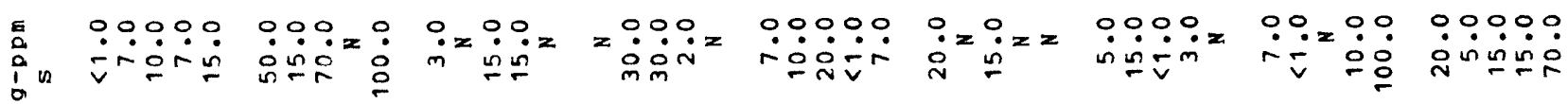

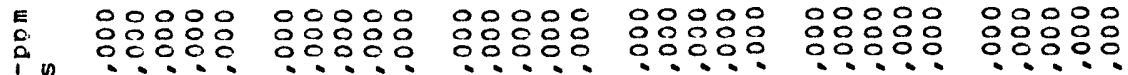
in óosin

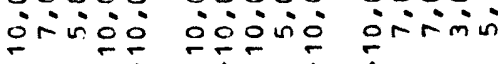
orinis 웅요

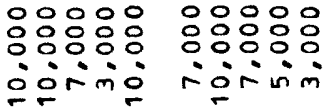

응응응웅응 $z \geq z \geq z$ $x z z z$ $z x z z=$ $z z z z z$ $z z z z z$

$\dot{5}$

$\stackrel{+}{0}$

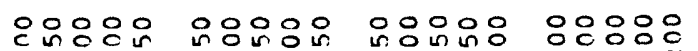

는은은 $\because \frac{1}{2} \div$

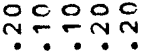

응ㅇㅇㅇㅇㅇㅇㅇ

응응ㅇㅇㅇㅠ

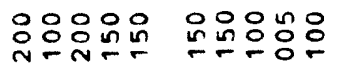

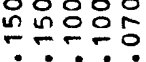

E-

过

$1.0 .00^{2}$

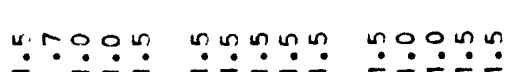

$\operatorname{nin} 0.00$

ก? กา?

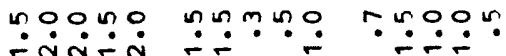
药

苔

00000

00000

00000

$00 r 0000000$ :

00000

蒙

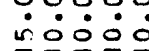

00000

0000000000

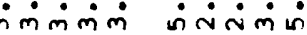

$\dot{\min } \dot{\sin }$

$\dot{\theta} \dot{0} \dot{0} \dot{m}$

in $\dot{m} \operatorname{in} \sin$

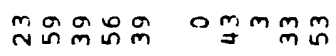

J $m$ n

in

บี๋ำ

00000

00000

00000

00000

00000

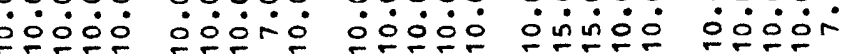

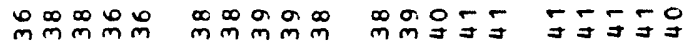

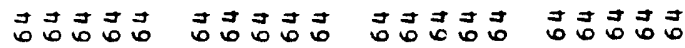

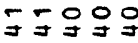

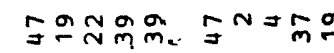
Im

$=\operatorname{inn} \frac{\pi}{\pi}$

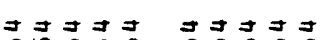

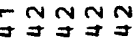
ำ 可寻寻出 (a)

(a)

monom nun nom

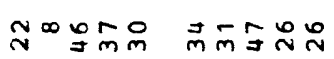

$\vec{B} \vec{\exists} \overrightarrow{0} \overrightarrow{0}$

ज可可

$\overrightarrow{0} \overrightarrow{0} \overrightarrow{0} \overrightarrow{0} \overrightarrow{0}$

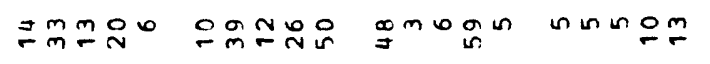
可寻寻寻 寻学寻寻

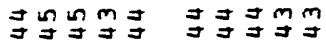
mmm $m \vec{m}$

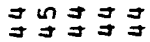

$\stackrel{\infty}{\Rightarrow} \underset{n}{*}=$

ヘึํำm

$\vec{m} \sigma 0 m a$ エะニะ IIIF IFニะF NF

IEFEF EะIE

寻寻寻手

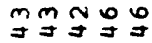

월ำ - nun a n

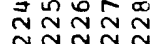

i) is us

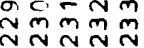

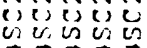

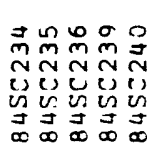

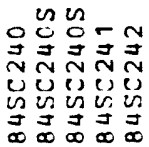

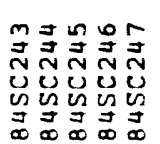

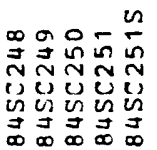

ะะ

든

든

$\infty \propto \infty \infty \vec{\infty} \quad \vec{\infty} \vec{\infty} \vec{\infty} \vec{\infty}$

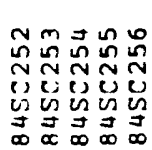

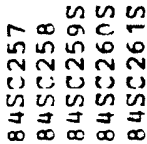

N $\operatorname{lng} 2 \cos$

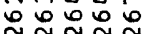

论化

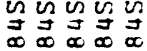




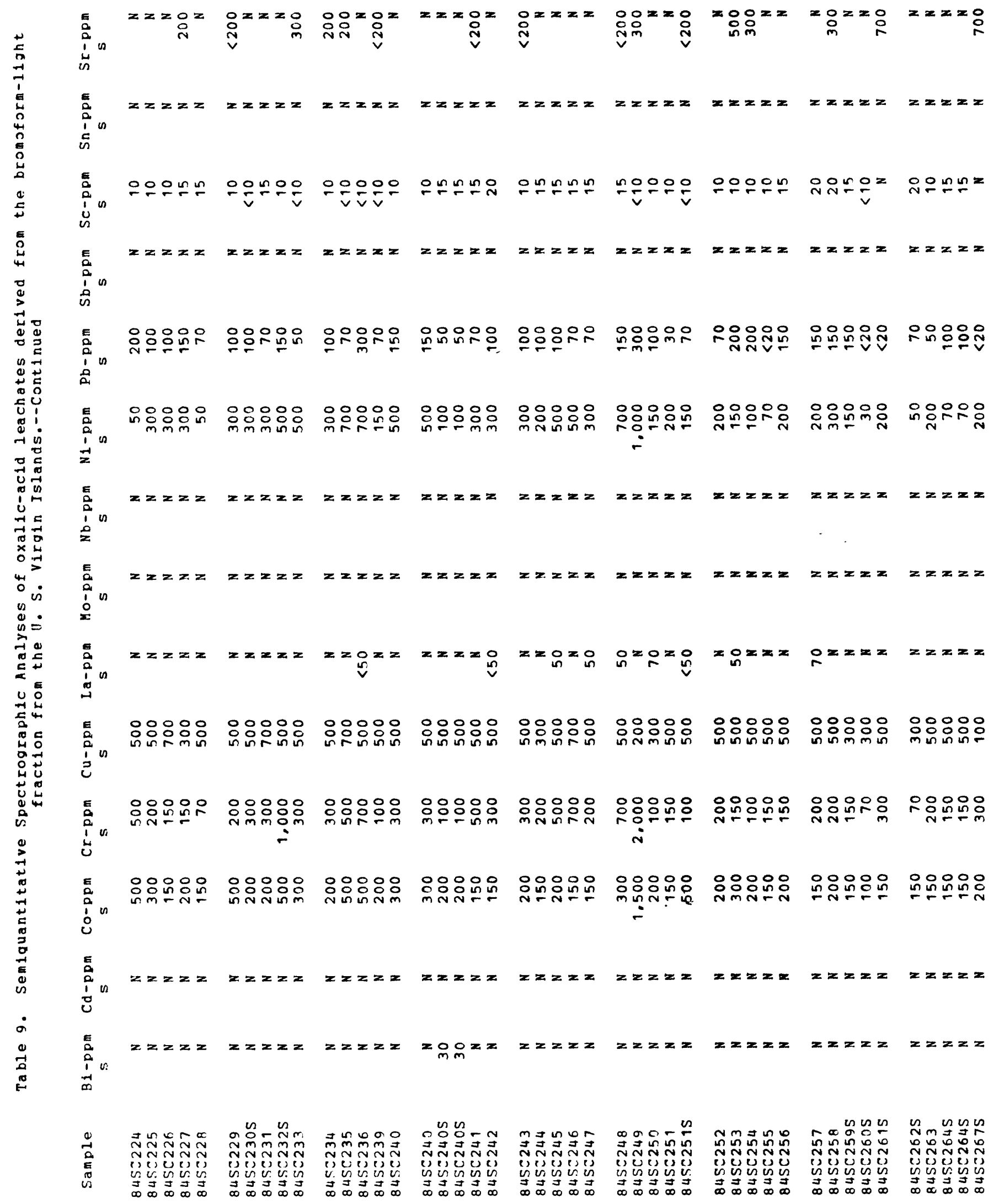




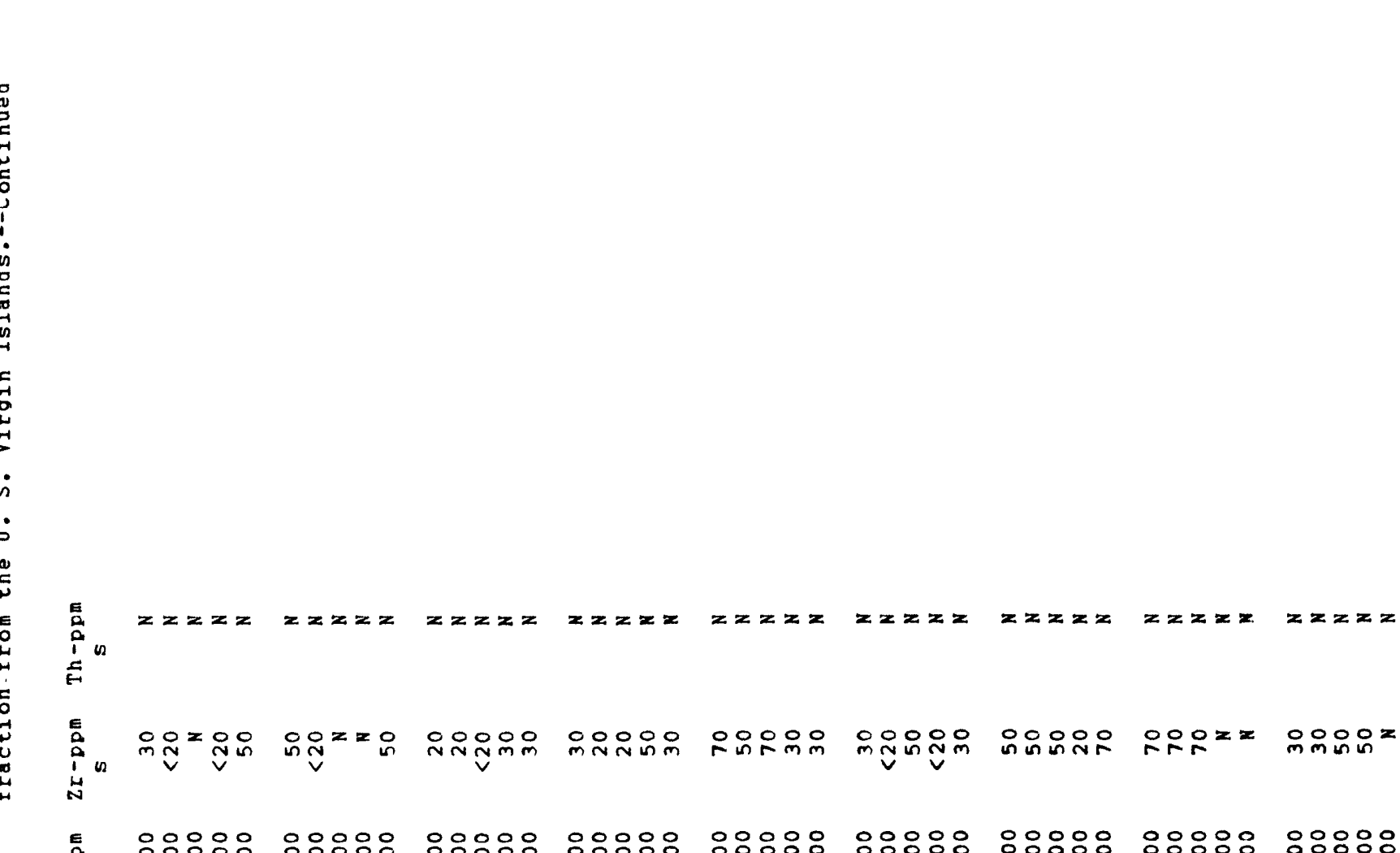

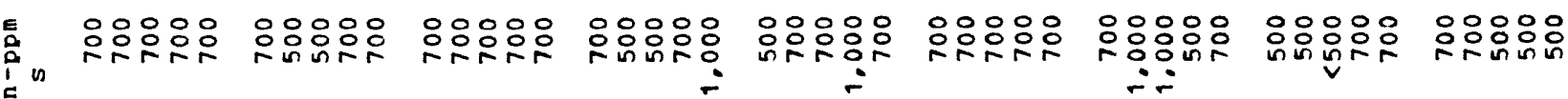
N

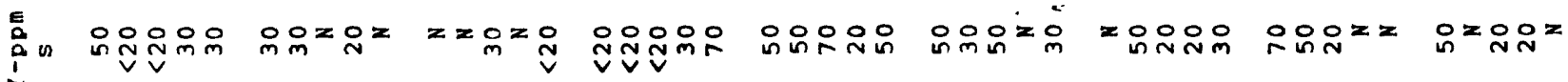

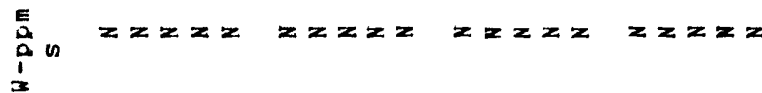

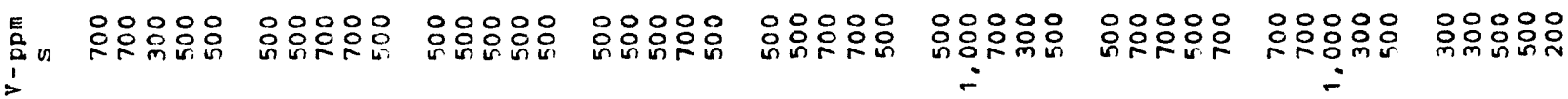

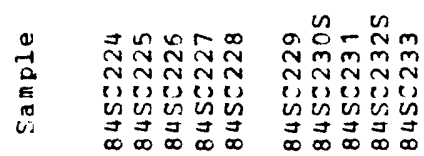

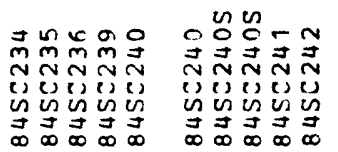

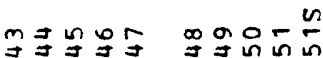
곤료

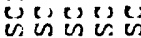

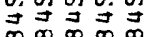

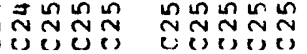

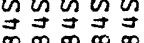

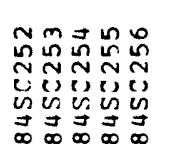




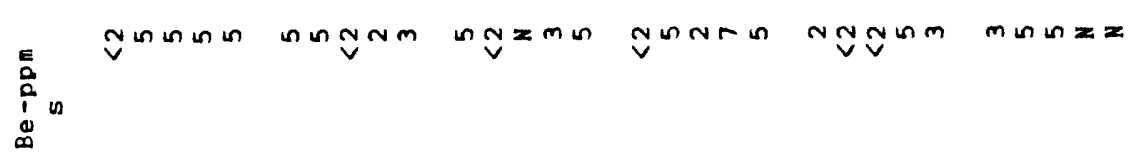

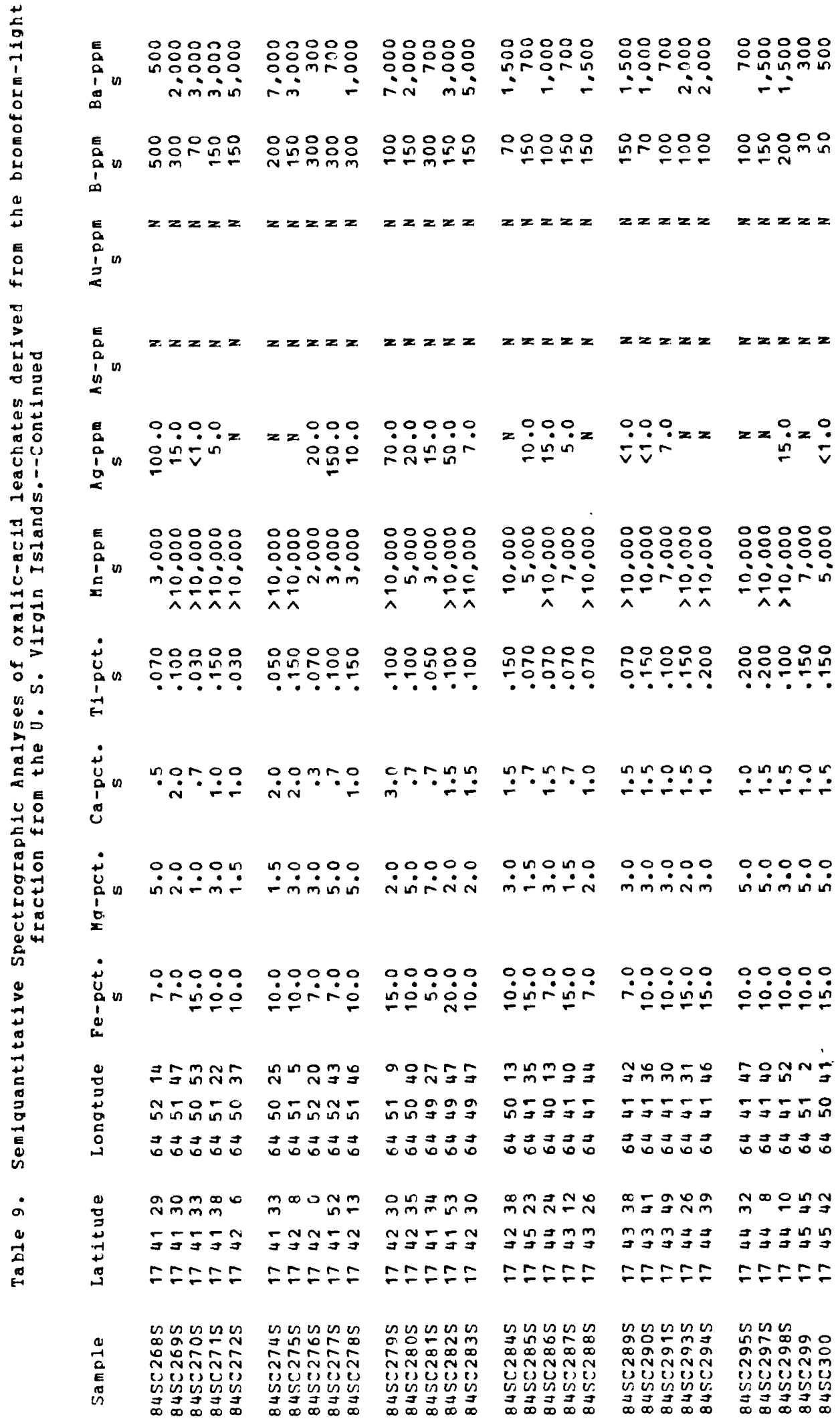




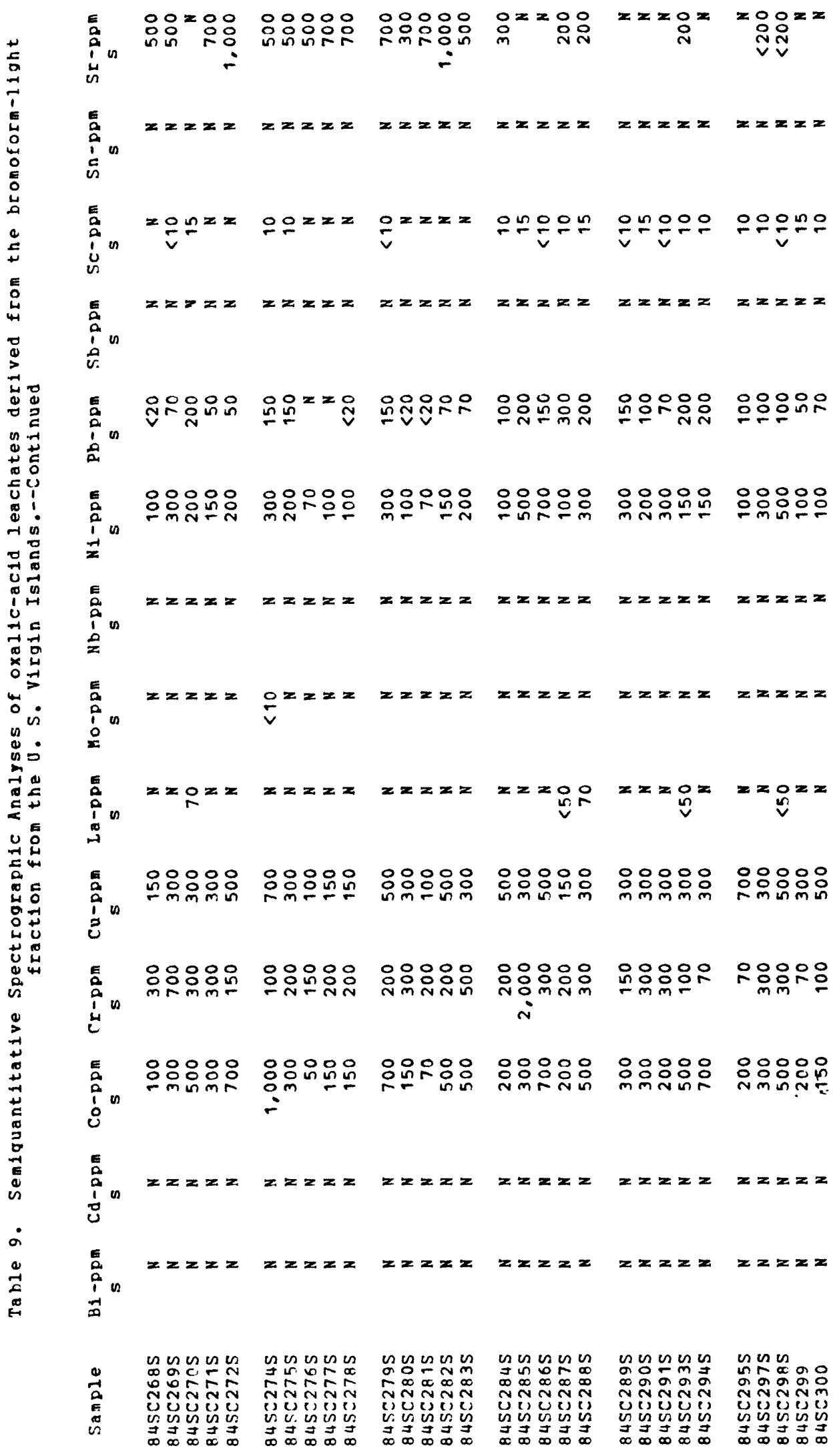




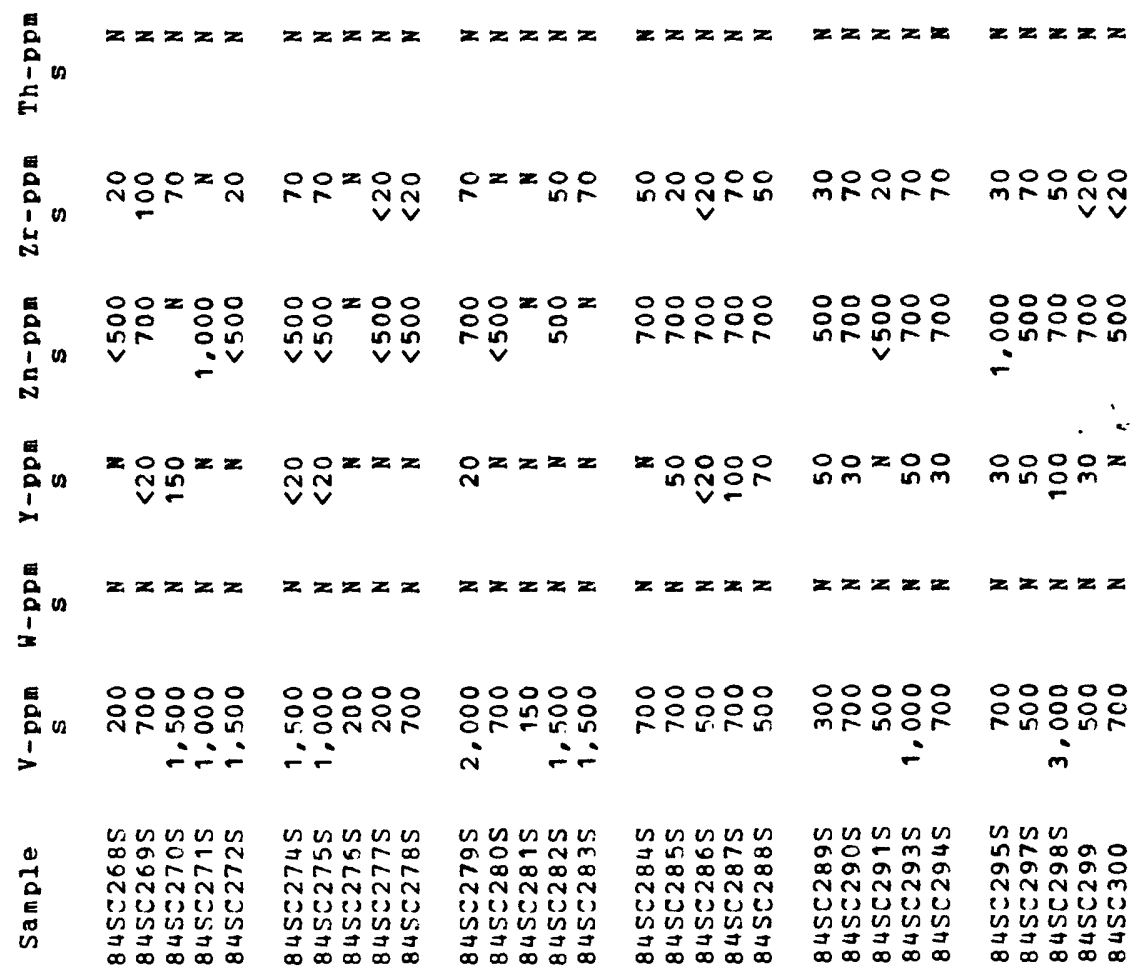

